
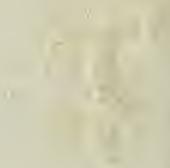
$11^{6}$

$q$ kes: 

LES

\section{COLONIES FRANCAISES}

GÉOGRAPHIE, HISTOIRE, PRODUGTIONS

ADMINISTRATION ET COMMERCE 
Tout exemplaire de cet ouvrage non revêtu de notre griffe sera réputé contrefait.

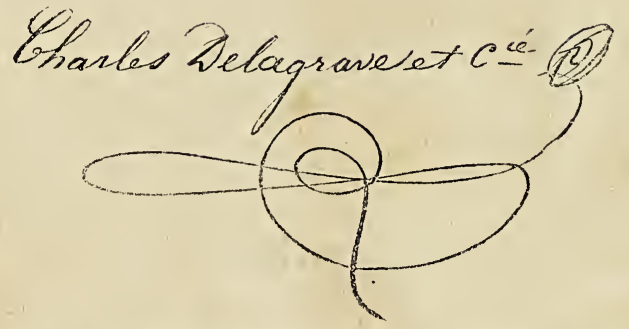

\section{PRINCIPAUX OUVRAGES DU MEME AUTEUR}

Histoire et légendes des plantes utiles et curieuses (gr. in-8, illustré).

LE LANGAGE MIMIQUE COMME LANGAGE UNIVERSEL (ouvrage couronné).

LA SCIENCE POPUlatRE, OU REVUE DU PROGRÈs DEs CONNAISSANCES ET DE LEURS APPI_ICATIONS (ouvrage à sa $6^{\mathrm{e}}$ année).

LFS ASTRES OI NOTIONS D'ASTRONOMIE POUR TOUS (ouvrage couronné). 


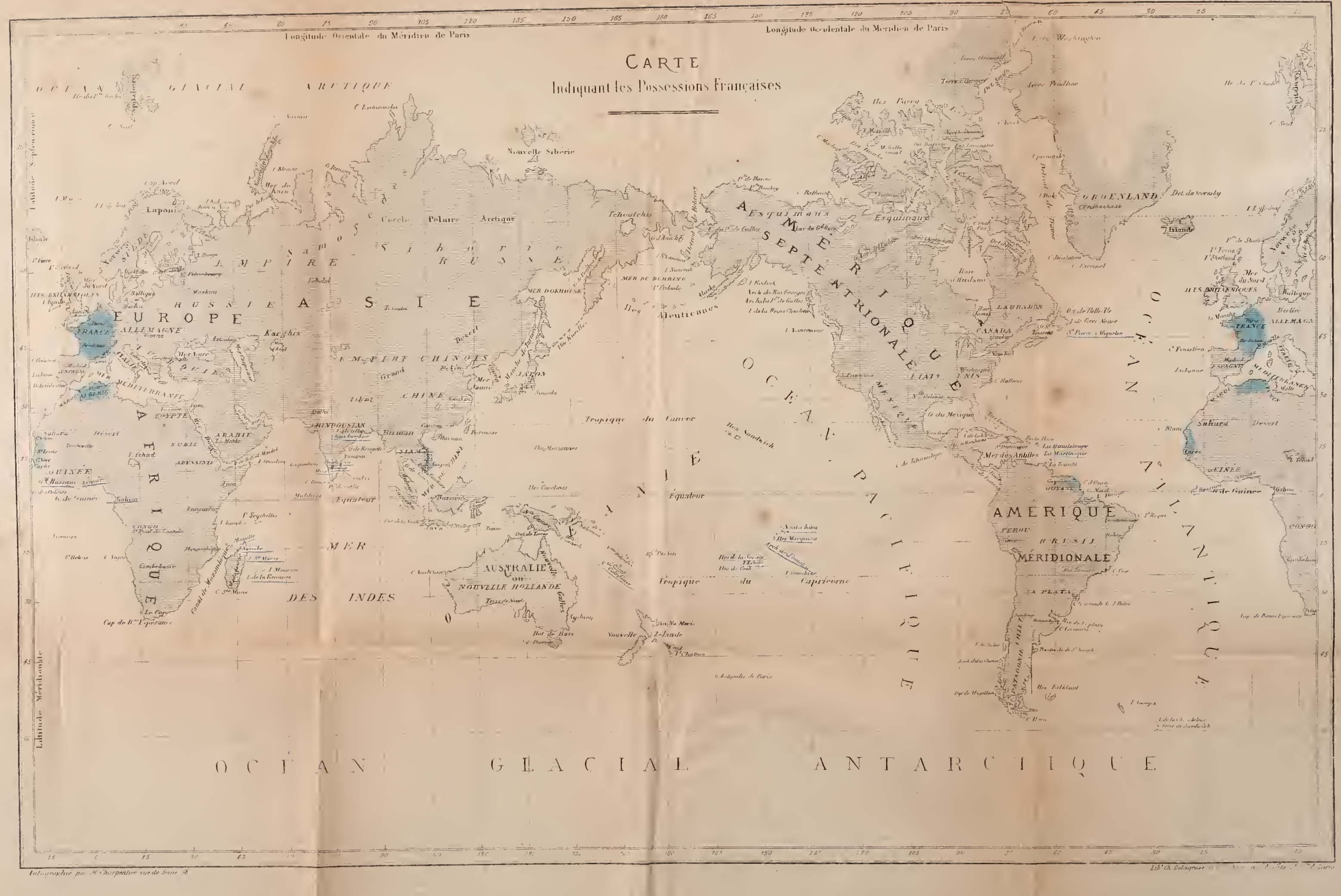






\section{ES}

\section{Ril}

\section{C0L0NIES \\ FRANCAISES}

AFA

GÉOGRAPHIE， HISTOIRE， PRODUCTIONS

ADMINISTRATION ET GOMMERCE

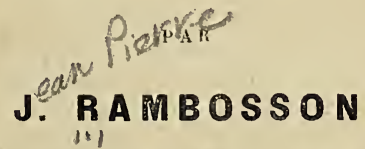

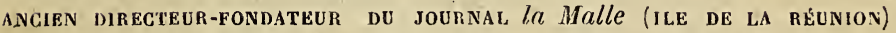
ANGIEN RÉDAGTEUR EN GHEF DE la Science pour tous

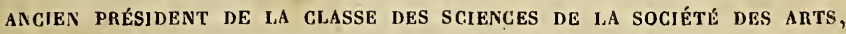
SCIENCES ET BELLES-LETTRES DE PARIS.

Avec une Carte générale et six Cartes particulières.

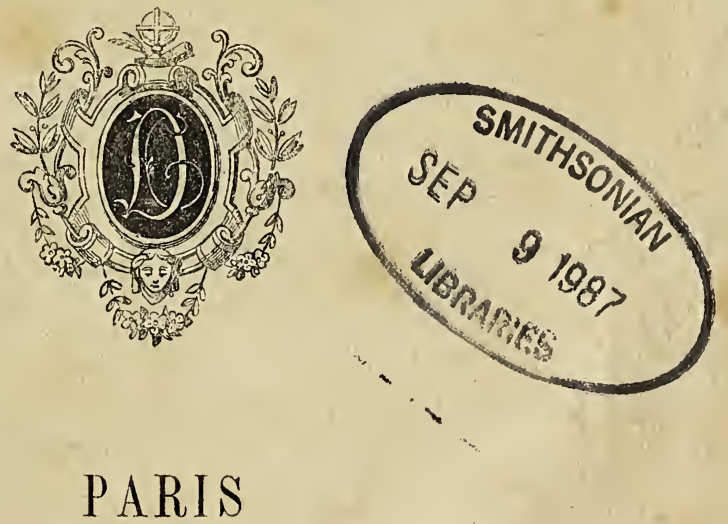

CH. DELAGRAVE ET Cie, LIBRAIRES-ÉdTEURS

78 , RUE DES ÉCOLES 

MONSIEUR LE BARON OSGAR DE WATIEVILLE.

Monsieur le Baron,

En faisant un ouvrage sur les Colonies francaises, je n'ai fait que suivre votre inspiration ; en vous l'offrant, je le restitue donc à son véritable auteur.

Je ne puis, cher Monsieur, en écrivant votre nom sur cette page, me défendre d'un touchant et triste souvenir.

Monsieur le baron de Watteville, votre vénérable père, que sa haute intelligence et ses rares qualités ont élevé au rang de législateur dans sa carrière administrative, m'honorait d'une amitié qu'il vous a transmise à mon égard.

Si cette amitié est pour moi la plus flatteuse des louanges, ma plus douce satisfaction est de la reconnaître en vous dédiant cet ouvrage qui, d'ailleurs, ne pourrait paraitre sous de meilleurs auspices.

Daignez agréer, cher Monsieur, cette expression de mon profond attachement et de ma vive sympathie.

J. RAMBOSSON. 



\section{UN MOT AU LEGTEUR}

Les Colonies françaises sont presque inconnues en France!

Si l'on demandait seulement: Quel est le nombre de nos Colonies? il y a bien peu de personnes qui pourraient répondre à cette simple question.

Que serait-ce si l'on entrait dans le détail de leur géographie, de leur histoire, de leurs productions, de leur commerce, de leur administration? Questions qui présentent cependant un si haut intérêt à tous les points de vue, et qui mériteraient d'avoir une large part dans les études classiques de nos colléges.

Bien plus ! - Si le voyageur, le commerçant, le colon velllent avoir quelques détails sur le pays qu'ils désirent visiter ou qui les intéresse, ils sont presque dans l'impossibilité de se les procurer. Il faut alors avoir recours à de gros volumes ou à de nombreuses brochures qui ne sont pas à la portée de tous, et qui souvent ne contiennent pas les documents que l'on y cherche.

Une monographie complète sur les Colonies françaises est donc d'une urgence extrême, d'une nécessité absolue, et nous croyons avoir fait un livre utile au pays, avoir comblé une lacune en y travaillant.

Les quelques années que nous sommes demeuré à l'île de 
la Réunion, nous les avons passées dans l'intimité de M. Charles Desbassayns, alors président du Conseil général. - C'est à l'école de ce vénérable créole qui avait vieilli dans l'étude et dans l'administration des colonies, et au regard perspicace duquel rien n'échappait, que nous nous sommes principalement initié aux connaissances qui nous occupent, et d'un autre côté, dirigeant la Malle, un des grands journaux de l'île de la Réunion, nous avons été obligé de nous mettre au courant de tout ce qui intéresse nos contrées lointaines; nous avons également été à même depuis dix ans, de rassembler nombre de matériaux qui nous ont servi dans cet ouvrage. - Nous avons largement puisé dans les publications des Ministères de la Marine, de la Guerre et du Commerce, spécialement dans les Notices publiées par ordre du Ministre de la marine et des colonies, qui ont paru en volume lorsquenotre travail était déjà fort avancé, mais assez tôt cependant pour nous être grandement utiles. Nous avons profité également des nombreux et excellents travaux dus aux plumes les plus compétentes, entre autres de MM. Jules Duval, le savant directeur de l'Économiste Français, de Coincy, Taillefer, Fillias, général Daumas, Nettement, de Baudicour, docteur Perron, Clément Duvernois, C. Devaux, baron H. Aucapitaine, etc., etc., etc...

Géographie, histoire, productions, administration et commerce, telles sont les grandes divisions auxquelles toutes les notions ont pu se rattacher : - Superficie, sol, climat, histoire naturelle, races, mœurs, population, statistiques officielles de toutes sortes; divisions administratives, importance industrielle et commerciale des diverses localités ; organisation coloniale et agricole, routes, poste, télégraphie ; cultures diverses; organisation financière, budgets divers, impôts, octrois ; importation, exportation, mouvement de la naviga- 
tion, cabotage, pêche, assistance publique, hôpitaux, sociétés diverses ; institutions de crédit; instruction publique, culte, agriculture, etc., etc.

Sur chacun de ces sujets nous avons donné les statistiques les plus exactes, les documents les plus récents, les plus sûrs. Cet ouvrage présente donc toutes les garanties d'un ouvrage officiel. Il peut servir aussi bien au législateur, au magistrat, aux personnes appelées à administrer les càlonies qu'au voyageur, au commerçant, au colon ou au simple amateur.

Nous a vons tâché d'être aussi complet que possible dans l'espace le moins long, afin de faire un ourrage commode et portatif, dont le prix ne soit pas trop élevé et qui puisse en même temps, dans les circonstances ordinaires, donner tous les renseignements dont on peut avoir besoin pour une de nos colonies quelconque.

Ce n'est certainement pas un ouvrage de poésie ou de prose amusante, mais c'est le guide, le vade-mecum de tous ceux qui, de près ou de loin, s'occupent des colonies. Nous nous sommes, en un mot, placé au point de vue de la pratique et de l'utile, et nous n'avons rien négligé pour atteindre ce but.

Voici l'ordre que nous avons suivi :

\section{Afrique :}

$1^{\circ}$ Algérie.

$2^{\circ}$ Sénégal et dépendances. - Établissement de la Côted’Or (Grand-Bassam, Assinie, Dabou). — Gabon.

$3^{\circ}$ La Réunion. - Mayotte. - Nossi-Bé. - Sainte-Marie de Madagascar.

II. Amérique :

$1^{\circ}$ Iles Saint-Pierre et Miquelon.

$2^{\circ}$ Martinique. 
$3^{\circ}$ Guadeloupe et dépendances (Grande-Terre, Basse-Terre, les Saintes, Marie-Galante, la Désirade, Saint-Martin).

$4^{\circ}$ Guyane.

III. ASIE :

$1^{\circ}$ Établissements de l'Inde(Pondichéry, Karikal, Yanaon, Chandernagor, Mahé).

$2^{\circ}$ Cochinchine.

IV. OCÉANIE :

$1^{\circ}$ Établissements de l'Océanie (Iles de la Société, IlesBasses, Archipel Tubuaï et Marquises).

$2^{\circ}$ Nouvelle-Calédonie.

Nous nous faisons un devoir de remercier ici publiquement et bien sincèrement notre savant ami, M. Ach. Genty, pour l'aide intelligente qu'il nous a donnée dans l'exécution de ce long et pénible travail. 



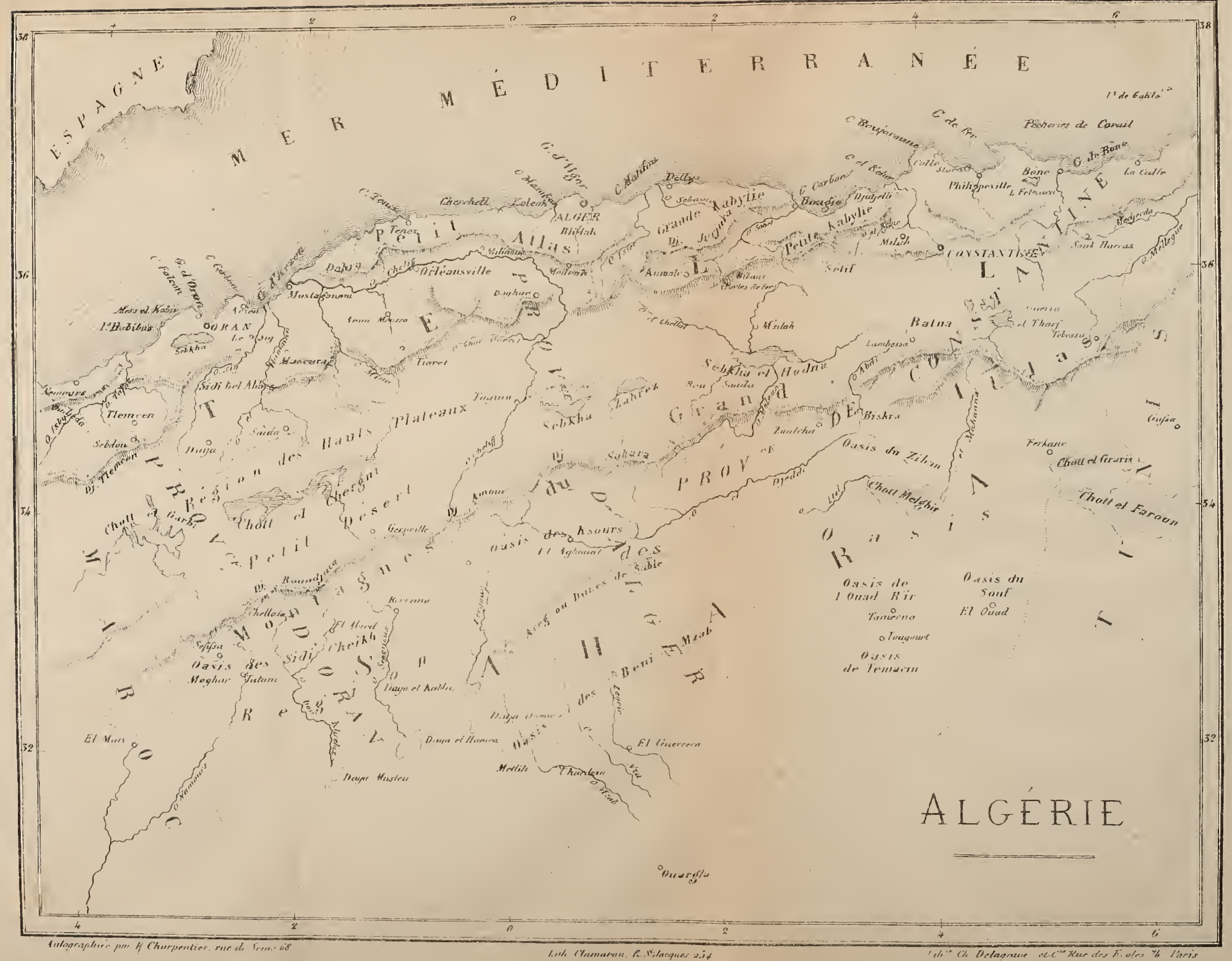

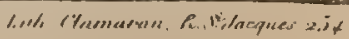




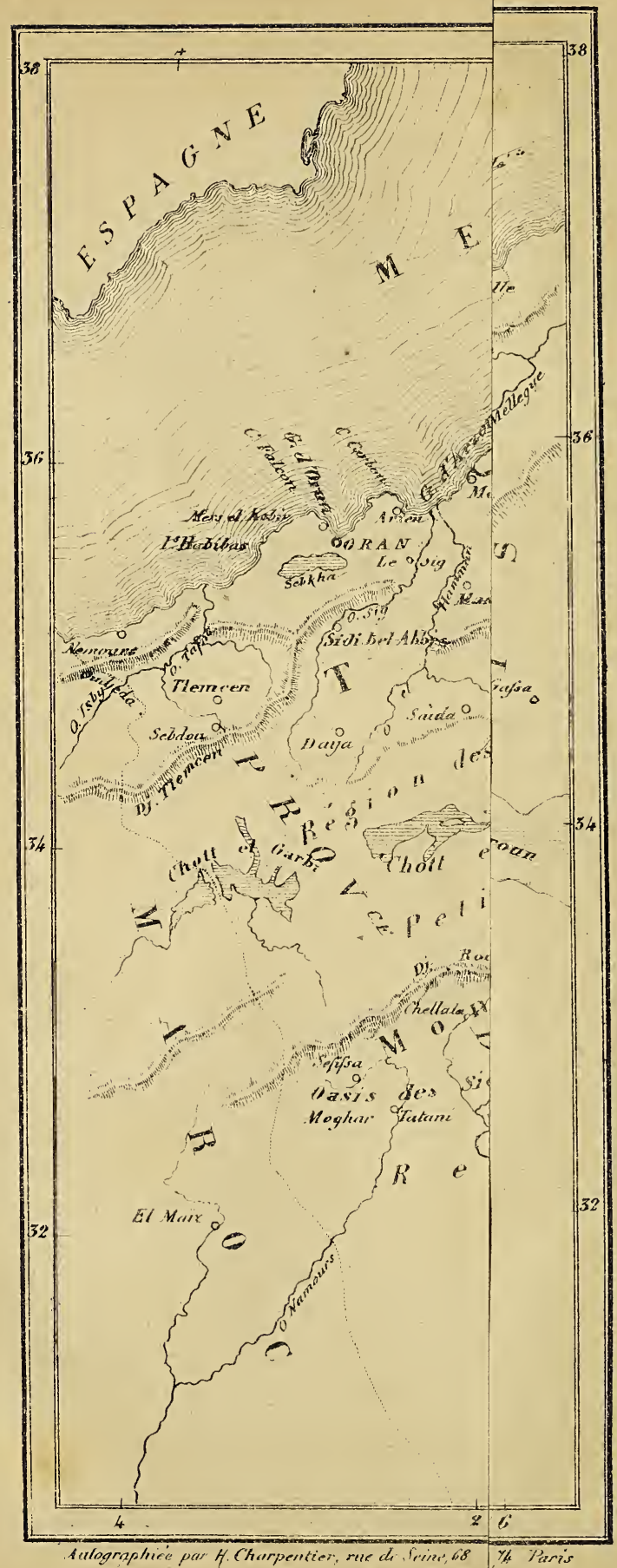




\section{A L G É R I E}

\section{CHAPITRE PREMIER}

Limites, - Divisions naturelles. - Caps, golfes et baies. - Montagnes. - Cours d'eau. - Lacs. - Eaux minérales et thermales. - Climat. - Flore. Faune. - Minéralogie. - Races de l'Algérie : MM. de Casabianca et Charles Dupin. - Henri Martin. - Jules Gérard. - Berbers ou Kabyles. - Arabes. - Mœurs. - Mariage musulman.

L'Algérie, située au nord du continent africain, est comprise entre le $6^{\text {e }}$ degré de longitude 0 . et le $7^{\mathrm{e}}$ degré de longitude $\mathbf{E}$. - Le Kis et la Moulouïa la séparent, à l'O., du Maroc, et l'Oned.el-Zaïne la sépare, à l'E., de la régence de Tunis. Au N., elle est bornée par la Méditerranée et au S. par le Sahara proprement dit, ou Grand.Désert.

Du nord au sud, elle a 600 kilomètres, et, de l'est à l'ouest, elle en compte de 850 à 900 . En superficie, elle égale environ les $4 / 5$ de la France : elle n'a pas moins de 390,000 kilomètres carrés.

L'Algérie présente trois grandes divisions naturelles : la région du Tell, la région des plateaux, et le Sahara algérien.

Le Tell commence au littoral de la Méditerranée, et s'étend des frontières de Tunis à celles du Maroc, région fertile où les céréales prospèrent.

Les plateaux sont la région formée par la double chaine de montagnes dont se compose l'Atlas.

Enfin, le Sahara algérien est la région des oasis, sorte de transition entre le sol des plateaux et du Tell, et le sol désolé du Grand-Sahara.

L'État actuel de l'Algérie, publié en 1864, n'admet que deux 
grandes divisions territoriales pour l'Algérie. On peut, en effet, rattacher la région des plateaux soit au Sahara algérien, soit surtout à la région du Tell.

L'Algérie, au point de vue territorial, peut aussi se répartir en deux grandes divisions : au N., le Tell, et au S., le Sahara.

Le Tell, qui commence au littoral de la Médilerranée, s'étend des frontières de Tunis à celles du Maroc, jusqu'au Sahára.

Il embrasse toute la Kabylie.

La population musulmane se composait, au dernier recensement quinquennal (1861), de :

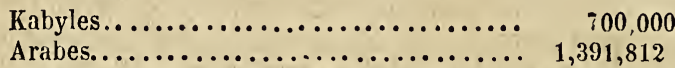

(ceux-ci divisés en 1,200 tribus fractionnées en 10,000 douars).

Le Sahara comprend d'immenses pâturages, quelques cultures voisines du Tell, et quelques rares oasis dans les plaines sablonneuses qui le terminent au sud. En 1861, sa population était évaluée à 600,000 Arabes formant 200 tribus.

Les principaux caps de l'Algérie sont ceux de Sidi-Ferruch, Tenez, Colombi, Ivi, Carbon, Falcon, Figalo, Matifou, Fer, Rosa; les principaux golfes sont ceux de Bône, de Stora, d'Alger, d'Arzew, d'Oran ; Bougie possède une magnifique baie : c'est le port naturel le plus vaste et le plus sûr de l'Algérie (Moniteur, 10 juin 1863̈).

L'Algérie est sillonnée, de l'O. à l'E., par une immense chaine de montagnes, l'Atlas, divisé en deux chaînes secondaires : le Grand et le Petit Atlas.

Celui-ci longe la Méditerranée ; celui-là sépare les États barbaresques (berbéresques) du Sahara.

Le plus haut sommet de l'Atlas est le Miltsin (3,470 mètres). Ses branches les plus remarquables sont le Djurjura (2,400 mètres), au S.-E. d'Alger, le Mouzaïa, l'Ouanseris, le Djebel-Amour, le Djébel-Aurès, etc.

La plupart des cours d'eau algériens se jettent dans la Méditerrarée. On distingue : la Moulouïa ou Moloçath ou Mulucha (autrefois Malva), la Tafna (ảutrefois Siga), le Chéliff, l’Oued-elKébir ou Rummel, la Seibouse, le Goadilbarbar, le Medjerdah, etc. L'Oued-el-Djeddi est du nombre des cours d'eau qui vont se rendre aux lacs salés ou aux sables du désert.

Les trois provinces de l'Algérie possèdent des lacs (sebkas), 
que la saison pluvieuse remplit d'eau, mais qui se dessèchent pendant l'été. Les principaux de ces lacs sont le Zagris (prov. d'Alger), le Chott, le Fezara, le Sebka (prov. de Constantine), le Melah, le Chergui, le Charbi, le Sebka (prov. d'Oran).

Les sources d'eaux minérales et thermales sont nombreuses. Quelques-unes ont $96^{\circ} \mathrm{C}$.

Le climat du littoral est à peu près celui de l'Espagne, du Portugal, de l'Italie, de la Provence, de la Grèce. Celui du Sahara est presque tropical.

Sur les plateaux du Tell, on subit quatre saisons, comme au centre de l'Europe; mais, sur le littoral et dans les plaines du sud, l'automne et le printemps n'existent pas à proprement parler. Le thermomètre, en général, ne descend pas au-dessous de $+8^{\circ}$ cent. La période des chaleurs commence en juin et finit en octobre; la période tempérée embrasse novembre à mai.

Le climat d'Alger est recommandé par la plupart des médecins aux phthisiques (D ${ }^{\text {rs }}$ Pietra-Santa, Moreau, C. Broussais, Baudin, etc.). On le considère comme plus propice que celui meme de Nice. La température, à Alger, demeure, au minimum, à $+4^{\circ}$ cent.

Les maladies les plus communes, en 1863, ont été, dans les hôpitaux civils de l'Algérie : les fièvres, les rhumatismes et les ophthalmies purulentes.

Partout où le sol algérien peut être arrosé, la fertilité est, pour ainsi dire, prodigieuse. Un triple épi était jadis l'emblème de la Nauritanie.

La Flore algérienne est riche et pourrait s'enrichir de la plupart des végétaux qui croissent ailleurs. Signalons ici les céréales (le blé dur, entre autres, qui manque à la France), le maïs, le millet, le riz, l'olivier, le chêne-vert, le chêne-liége, le palmier nain, le dattier, le coton, le tabac, la canne à sucre, le mûrier, l'amandier, le grenadier, l'oranger, la vigne, le cyprès, le lentisque, tous les arbres, toutes les plantes potagères du midi de l'Europe.

La Faune ne le cède pas à la Flore. Si, à l'état sauvage, on remarque, parmi les animaux de l'Algérie, le lion, la panthère, le chacal, l'hy'ène, etc., on trouve, parmi les animaux domestiques, le cheval, le mulet, le chameau, le dromadaire, le bœuf, le mouton, la chèvre, etc.

Le règne minéral présente d'abondantes mines de fer, de 
mines de plomb, de cuivre, de cinabre, peut-être même des mines argenti-aurifères assez riches pour être exploitées.

La population non européenne de l'Algérie ne forme point un ensemble homogène.

"Il existe des différences essentielles, au point de vue de l'organisation sociale, entre les Arabes et les Kabyles. Ces derniers ont d'autres lois, d'autres mœurs, et leur culte même n'est pas identique. Les Kabyles sont les anciens chrétiens réfugiés dans les montagnes pour y défendre leur liberté. Ils ont sauvé leur indépendance; ils ont gardé les anciennes lois municipales de l'Afrique romaine, lois auxquelles ils ont conservé le nom gréco-latin de canons. Au point de vue civil, leur organisation se rapproche de nos municipalités. Leur mahométisme est mitigé; le Coran n'est point pour eux la loi civile; ils n'ont pas accepté la polygamie, et, par conséquent, leurs familles sont restées semblables à nos familles d'Europe: tout s'y rapproche de nous. " (Sénat, 24 mars et 8 avril 1863. Discours de MM. Casabianca et baron Dupin.)

"Il n'y a pas, dit Henri Martin, quinze millions d'Arabes en Afrique; il n'y a pas trois millions d'Arabes en Algérie. La trèsgrande majorité des indigènes du nord de l'Afrique en général, et de l'Algérie en particulier, ne sont point Arabes. Il y a ici un grand et dangereux malentendu. On a confondu l'unité de religion avec l'unité de race, et, partout où l'on voyait des musulmans, on a cru voir des Arabes, ou tout au moins des populations fondues, absurbées dans l'élément arabe. Il n'en est rien pourtant. Les Arabes ne sont en Afrique que des étrangers, une minorité ccnquérante qui n'a jamais légitimé sa conquête, car elle n'a jamais rebâti les villes ni replanté les forêts qu'elle a brûlées, jamais rendu à la fertilité les sillons qu'elle a stérilisés, jamais remplacé, en un mot, la civilisation qu'elle a détruite.... ")

Les vrais indigènes de l'Algérie et de l'Afrique septentrionale paraissent etre les Berbères, qui occupent toute la grande région de l'Atlas. On appelle Kabyles (mot qui signifie tribus ou communes), les Berbères algériens qui occupent le massif du Djurjura. C'est une race très-mêlée, mais elle possède un fonds commun de mœurs, de traditions, de tendances, et une langue différente de l'arabe.

D'après le docteur Warnier, les Berbères purs, ceux du moins qui ont conservé leur organisation et leur langue, le tamachek, 
atteindraient, en Algérie, le chiffre d'un million. Il y aurait environ 1,200,000 Berbères plus ou moins arabisés, c'est-à-dire dont la langue serait un mélange d'arabe et de berber, mais qui auraient gardé, maigré l'influence de leurs conquérants, les tendances et même les habitudes de leur race. Les premiers sont concentrés dans les massifs des montagnes. Les autres sont mêlés aux Arabes des plaines, des landes et des plateaux; leur vie est à peu près pastorale, tandis que celle des Berbères purs est agricole.

Le nombre des Arabes purs n'excéderait pas 500,000 .

Le principal noyau des Berbères purs, les Kabyles du Djurjura, comprend 43دั,000 âmes. Ils n'ont été conquis par la France qu'en 1857.

Ils sont organisés en communes (kabyla). Une sorte de maire (amin) et un conseil municipal (djemaa), élus au suffrage universel, administrent chaque commune. Il est rendu compte tous les ans de l'administration à l'assemblée générale.

En 1862, un traité de commerce a été conclu avec les Touaregs, grande tribu berbère du Sahara. MM. de Polignac et Henri Duveyrier ont montré tout le parti qu'on peut tirer de cette tribu, dont l'influence est grande dans le Soudan.

Dans un article du Moniteur (21 février 18วั), Jules Gérard, dont la fin tragique et prématurée vient d'attrister ses nombreux amis de France et d'Algérie, répartissait la population algérienne en trois races distinctes:

$1^{\circ}$ Les Kabyles, établis dans les montagnes situées sur le littoral, et dont les demeures sont fixes ;

$2^{\circ}$ Les Chaonia (anciens Numides), qui forment plus de la moitié de la population dans la province de Constantine, et dont les tentes et les troupeaux occupent tout le pays compris entre la Kabylie et le désert;

$3^{\circ}$ Enfin, les Arabes proprement dits, qui sont maîtres des oasis, qui passent la saison d'été sur les hauts plateaux et celle d'hiver dans le Sahara ou sur ses limites.

On voit, par ce qui précède, combien différentes sont les opinions relatives à la composition des populations indigènes du sol algérien. Il est, en effet, bien difficile de discerner, au milieu du mélange que les siècles ont opéré, quels sont les éléments appartenarit à telle race et quels sont ceux appartenant à telle autre. Peut-être la seule distinction à laquelle on devrait s'arrêter, 
serait-elle celle qui répartirait les indigènes en partisans de la polygamie et en partisans de la monogamie. Les Arabes ont plusieurs femmes; les Berbères ou Kabyles, en général, quoique musulmans, n'en ont qu'une.

Les mœurs des Kabyles et des Arabes ont été tant de fois décriles que nous considérons comme inutile d'en présenter ici tout le détail. Nous nous contenterons de reproduire ce qui a été dit au Sénat par MM. Charles Dupin et de la Rue sur le mariage musulman.

"Je me suis enquis, dit le général comte de la Rue, dans un des pays où le mahométisme est resté le plus fervent, au Maroc, de la façon dont les chefs musulmans pratiquaient la polygamie dans l'intérieur de leur ménage, et voici ce que j'ai appris :

a Ils ont le droit d'avoir quatre femmes, quatre femmes légitimes, indépendamment des esclaves, bien entendu. Eh bien! et c'est là que se trouve la distinction, les chefs ne prennent pas leurs quatre femmes à la fois.

" C'est ainsi, je pense, qu'on a pu remarquer à Constantinople un certain affaiblissement de la polygamie. Les chefs mulsumans épousent d'abord une jeune tille de douze à treize ans; quand quclques années se sont écoulées, qu'elle a atteint vingt-sept ou vingt huit ans, ils n'y ont plus goût, et ils la mettent au cadre de réserve.

"Ils prennent alors une nouvelle femme; et c'est peut-être parce qu'il n'y a qu'une épouse en exercice, qu'on a vu là un affaiblissement de la polygamie.

a Du reste, il n'y a que les gens riches qui puissent pratiquer la polygamie; car on doit assurer l'existence de la femme qui a été misc de côlé.

" Je crois que nos chefs musulmans, en Algérie, agissent comme je viens de l'indiquer...) (Sénat, らّ juillet 186ว.)

"Lá durée, dit M. le baron Charles Dupin, d’un mariage musulman à Alger ne dépasse pas deux ans. Remarquez qu'il ne s'agit pas ici de concubines, mais de mariages régulièrement contractés devant le cadi.

"Quand on peut avoir quatre femmes, et que l'on ne supporte le mariage que deux ans, on fait certainement preuve d'un singulier amour de la variété. -) (Sénat, 5ّ juillet 186̆.) 


\section{CHAPITRE II}

Résumé historique de l'Algérie.

La partie de l'Afrique occupée aujourd'hui par la France comprenait, sous la domination romaine, savoir : A l’E., la province de Numidie; à l'O., celles de Mauritanie Césarienne et Sitifienne, entre la Mauritanie Tingitane (Maroc) et la province d'Afrique proprement dite (Tunis) où se trouvait Carthage. Trente-trois colonies, romaines y propagèrent l'agriculture.

Au cinquième siècle, les Vandales s'en emparèrent; au sixième, ce fut le tour des Grecs. Les Arabes s'y étahlirent vers la fin du septième, et se mêlèrent aux anciennes populations du pays, Numides, Maures, Berbères.

Alger (Al-Djezaïr, ou les Ilôts) fut fondée par eux, en 935, sur les ruines d'Icosium. Les Arabes Zéïrites, puis les Almohades (1269), puis une foule de dynasties ou de tribus indépendantes dominèrent successivement en Algérie.

Chassés d'Espagne, les Maures s'y réfugient (1492), et dès lors Alger devient la capitale de tous ces pirates qui, pendant si longtemps, devaient infester les mers.

En 1วั06, Ferdinand le Catholique prend Oran et Bougie. En 1509 , il s'empare d'Alger.

Arroudj-Barberousse, appelé par les émirs d'Afrique, fonde, en 1516, la domination ottomane et se fait sultan d'Alger, de Ténès et de Tlemcen.

Des prisonniers chrétiens construisent, en 1518, la digue qui réunit Alger à l'île située vis-à-vis.

En 1535, Charles-Quint, dont les possessions d'Italie étaient menacées par les pirates, débarque près des ruines de Carthage avec une armée de 27,000 hommes. Le 14 juillet, la Goulette, la flotte et l'arsenal sont pris par les Espagnols, qui, six jours après, marchent sur Tunis. Cette ville, qui renfermait 10,000 esclaves chrétiens, ne put tenir contre les assiégeants et fut mise au pillage.

Les corsaires n'en montrèrent que plus d'audace. Leurs vaisseaux parurent plus nombreux dans la Méditerranée. Le pape Paul III se vit obligé de publier contre eux une croisade. CharlesQuint en eut le commandement. Mais le puissant empereur et 
roi d'Espagne, malgré le courage personnel qu'il déploya dans la bataille' livrée sous les murs d'Alger, malgré l’héroïsme des chevaliers de Rhodes, fut contraint à une retraite précipitée. 6,000 prisonniers, un matériel immense, durent être abandonnés à l'ennemi.

La France ne fut pas plus heureuse dans son entreprise contre les pirates algériens en 166\%. Mais, l'année suivante, elle prit une revanche éclatante. A la hauteur de Tunis, où le duc de Beaufort, qui commandait les navires français, rencontra les pirates, ceux-ci furent complétement battus; devant Alger où le duc se rendit aussitôt après, la flotte algérienne fut presque anéantie. Le dey demanda la paix.

Elle dura peu. A peine remis de lcur défaite, les corsaires reprirent le cours de leurs déprédations. Ils osèrent venir pirater jusque sur les côtes de Provence. Duquesne et Tourville, pendant les années 1682, 1683, 1685, le maréchal d'Estrées en 1688, dirigèrent, par ordre de Louis XIV, plusieurs expéditions contre les villes barbaresques du littoral, firent subir aux pirates des pertes immenses, mais ne purent les anéantir.

Les expéditions entreprises par les Espagnols en 1774 et années suivantes contre Alger n'aboutirent pas, et, jusqu'à l'intervention de la France en 1827, l'histoire de la régence n'offre guère qu'une série d'affronts subis par les diverses puissances européennes de la part des Barbaresques.

La France devait enfin mettre un terme à cet état de choses. Voici, en quelques mots, l'origine de l'intervention française.

De 1793 à 1798, des fournitures de céréales avaient été faites à la France par la régence d'Alger. Les premières livraisons avaient été soldées en monnaie métallique; les autres ne le furent qu'en assignats. Réclamation des fournisseurs, les juifs Busnach et Bacri; ils demandèrent avec raison une indemnité. Mais, dans les mémoires qu'ils produisirent, ils ajoutèrent des intérêts usuraires, et les négociateurs français, chargés de la liquidątion, demandèrent une réduction importante, en se fondant principalement sur ce que les dernières fournitures se composaient entièrement de blés avariés.

La liquidation eut lieu en 1819. La dette de la France fut portée à sept millions. Mais des négociants de Marseille, qui avaient fait de fortes avances aux Juifs Busnach et Bacri, mirent opposition au payement de la somme et produisirent contre eux une 
créance de 2,500,000 francs. Il ne fut donc payé aux juifs algériens que 4;500,000 francs. Le reste fut versé à la caisse des dépôts et consignations.

Le dey dépêcha alors un envoyé à Paris. Il se prétendait créancier de Bacri et réclamait les 2,500,000 francs non versés. On lui répondit que les tribunaux étant saisis de l'affaire, le gouvernement ne pouvait intervenir.

Hussein-dey s'emporta, écrivit au roi, au président du conseil, au ministre des affaires étrangères, dans des termes si peu convenables qu'on jugea bon de n'y pas répondre officiellement.

On chargea le consul de France à Alger, M. Deval, d'avoir une explication verbale avec le dey.

La colère de celai-ci n'eut bientôt plus de bornes. Plusieurs fois, M. Deval eut à subir ses emportements et ses injures.

Enfin, à l'époque des fêtes du Beyram, M. Deval, s’étant rendu au palais avec les consuls des autres nations pour complimenter le dey, Hussein l'interpelle et lui demande s'il a une lettre à lui remettre de la part du roi.

- Votre Altesse sait bien, répond M. Deval, que le roi de France ne peut correspondre avec le dey d'Alger.

Hussein, fürieux, se lève, injurie le consul et le frappe au visage avec son chasse-mouches.

Tous rapports officiels durent cesser.

En juin 1827, une division navale se présentait devant Alger, notre consul et nos nationaux quittaient la ville, après le refus du dey de réparer l'outrage fait à la France, et un blocus rigoureux était établi.

Le 2 août 1829, une nouvelle insulte rendit la France et le dey ennemis irréconciliables. Un raisseau parlementaire fut accueilli à coups de canon par l'artillerie algérienne et criblé de boulets.

Aussi, le 25 mai 1830, une expédition sous les ordres du comte de Bourmont, après avoir pris passage sur la flotte commandée par le vice-amiral Duperré, se dirigea-t-elle sur Alger. Le débarquement eut lieu le 14 juin, près du cap de Sidi-Ferruch (à 26 kilomètres d’Alger), sans coup férir. Les Arabes s'étaient retirés à 1 kilomẹ̀tre du littoral derrière deux redoutes.

L'infanterie française se forma en colonnes et se porta en avant. Accueillie par l'artillerie arabe, que servaient d'habiles pointeurs, elle montra un instant d'hésitation. Mais bientôt la première divi- 
sion, sous le commandement du général Berthezène, enlève les redoutes, et les Arabes culbutés s'enfuient vers le plateau de Staonéli. On leur prend onze canons et deux mortiers. Nos pertes ne s'élèvent qu'à trente-cinq hommes tués ou blessés.

Le 29 juin, le quartier général de l'armée française était assis sur le plateau qui domine le fort l'Empereur.

" Après un bombardement de plusieurs jours, dit M. Kleine, dans ses excellents Récits d'histoire contemporaine, l'assaut va être donné. Les Arabes ne l'attendent pas : ils font sauter le château et une explosion terrible nous annonce notre victoire. Le dey Hussein demande à capituler, et, le 5 juillet, le drapeau de la France flottait sur les murs d'Alger d'où il ne devait plus être arraché. ")

Sans tarder, trois expéditions sont lancées sur Blidah, sur Oran é sur Bone.

Le général Clauzel, nommé commandant en chef, réforme l'administration, crée le corps des zouaves, et jette les bases de la colonisation dans les plaines de la Mitidja.

Le 17 novembre, la seconde expédition de Blidah est commencée. On occupe, dans l'Atlas, le col de Ténia, et le bey de Titterie voit sa capitale, Médéah, subir une garnison française le 22.

Le général Berthezène, nommé commandant en chef, entreprend, en juin 1831, une expédition contre Médéah, où les Arabes et les Kabyles ont réuni leurs forces.

En 1832, Savary, duc de Rovigo, est nommé commandant en chef. - Sous ce commandement, on remarque : la prise de Bone (mars); la défense d'Oran (mai). - Des travaux protégent Alger contre les pillages des Arabes (sept.-oct.).

En 1833, Abd-el-Kader, émir de Mascara (au S.-E. d'Oran), commence à se montrer. On le considère comme un libérateur envoyé de Dieu. - Néanmoins, l'armée française prend Arzew, position maritime ( $ّ$ juin), et s'établit définitivement à Mostaganem (juill.-août).

Lutte, dans la division de Bone, avec le bey de Constantine; prise du port de Bougie (octobre).

Au commencement de 183\%, le général Desmichels entame des négociations avec Abd-el-Kader; on établit une nouvelle organisation de l'Algérie; désormais elle aura un gouverneur général, un intendant civil, un commandant de la marine. 
Des magistrats indigènes, maures et israélites, sont maintenus.

Parmi les autres événements des années suivantes, nous signalerons : la victoire remportée sur six mille Kabyles par les Français venant de Bougie; la défaite d'Abd-el Kader par le général Trezel, près de la Sig, entre Mascara et Oran (26 juin 1835); la victoire d'Abd-el-Kader à la Macta (28 juin); l'heureuse expédition du maréchal Clauzel contre Mascara, avec le duc d'Orléans (novembre); l'expédition contre Tlemcen, province d'Oran (13 janvier 1836); la victoire du général Bugeaud sur Abd-el-Kader à la Sickack, petit fleuve voisin de la Tafna (6 juillet). Il ravitaille Tlemcen.

Lutte, dans la province d'Alger, contre les tribus des Hadjoutes et des Mouzaïas, et contre les Kabyles.

Le maréchal Clauzel est repoussé de Constantine (novembre); l'armée ést ramenée à Bone, au milieu de grands dangers; le duc de Nemours faisait partie de cette campagne.

Tarif des douanes remanié, moins prohibitif.

Le 30 mai 1837, intervient le traité de la Tafna entre le général Bugeaud et Abd-el-Kader.

Le général Damrémont, nommé gouverneur général, attaqué, avec le duc de Nemours, le bey de Constantine, Achmet ( $1^{\text {er }}$ vetobre). Il est tué. Le général Vallée emporte la ville d'assaut (13 octobre).

L'année 1839 se passe en explorations mililaires, en tentatives pour rattacher les Arabes à la domination française. Le général Vallée, nommé maréchal et gourerneur, accompagne le duc d'Orléans à travers la contréc d'entre Alger et Constantine. Mais notre bonne volonté vient échouer contre l'hostilité d'Abd-el-Kader. Il écrit au gouverneur général que tous les musulmans ont délibéré et arrêté de recommencer la guerre sainte. On n'en pouvait douter', puisque, antérieurement à cette déclaration, plusieurs de nos colonnes ou de nos postes avaient déjà subi le choc de l'ennemi. Cette tentative n'eut aucun succès. A la fin de 1839, Abd-elKader ne pouvait plus guère compter que sur les fanatiques du Maroc. Toutefois, les trois provinces, d'Alger, d'Oran et de Constantine étaient en fermentation.

On résolut d'en finir. Le gouverneur général soumit au gouvernement un nouveau plan de campagne. En janvier 1840, les hostilités commencent sur tous les points. Mustapha-Ben-Tami, lieutetenant d'Abd-el-Kader, à la tête de 12,000 hommes, attaque 
le poste de Mazagran (province d'Oran). Ce poste, occupé par 123 hommes de la $10^{\mathrm{e}}$ compagnie du $1^{\text {er }}$ bataillon d'infanterie légère, et commandé par l'intrépide capitaine Lelièvre, oppose aux assaillants une résistance si énergique pendant quatre jours entiers, que Mustapha est contraint à donner le signal de la retraite. Les Arabes eurent environ six cents tues ou blessés; les Français trois tués et seize blessés. Une colonne monumentale s'élève aujourd'hıi sur le petit fort où tant d'intrépidité, tant d'héroïsme fut déployé (2-6 février 1840).

Le passage du col de Mouzaïa, l'occupation par le duc d'Orléans d'un piton élevé qui dominait au loin la position et que défendirent vaillamment les Kabyles, la prise de Médéah, celle de Milianah, etc., sont encore des événements qui se rattachent à l'année 1840. L'année se termine par la nomination du général Bugeaud aux fonctions de gouverneur gẻnéral. L'heure est venue d'agir avec énergie et ténacité.

L'effectif de l'armée est porté à 73,500 hommes et 13,500 chevaux (1841). Dans les trois provinces, quelques succès notables inaugurentl'année qui commence. Tagdempt, où $\mathrm{Abd}$-el-Kader a établi son principal dépôt d'armes et de munitions, est prise, ainsi que Mascara (mai). Lamoricière établit son quartier général dans cette dernière ville, c'est-à-dire au centre du pays ennemi. Baraguey-d'Hilliers, pendant ce temps, parcourt tous le bas Chélif et remporte des avantages signalés. Bedeau soumet, sur le haut Habra, l'importante tribu des Bordja. La défection se met parmi les partisans d'Abd-el-Kader.

Au commencement de 1842, l'émir en était réduit à la défensive. Bugeaud, avec 3,000 caraliers arabes, se rend dans l'Atlas et soumel toute la chaîne depuis Cherchell jusqu'à l'Arrack. Le colonel Korte, au combat d'Aïn-Tlemsil, fait aux Kabyles 3,000 prisonniers, et leur prend 1,300 chameaux, 300 chevaux ou mulets et 15,000 têtes de bétail. Changarnier enlère la Smala du Khalifat Ben-Allah, lui fait 3,000 prisonniers et lui enlève plus de 30,000 têtes de bétail. Abd-el-Kader, réduit à se jeler dans les montagnes de l'Ouarcnserris pour y recruter ses troupes régulières, y est suivi par trois colonnes que commandent le duc d'Aumale et les généraux Geıtil et Lamoricière. La soumission de toutes les tribus de la chaîne de ces montagnes et de la rive gauche du Chélif ne tarde pas à s'ensuivre.

Vaincu, mais non découragé, Abd-el-Kader reparaît, en jan- 
vier 1843, au milieu des tribus de la vallée du Chélif et recrute 3,000 Kabyles. Bientôt l'émir est refoulé par nos colonnes. L'une d'elles, commandée par le duc d'Aumale, s'empare de la Smala, composée de la famille, des principaux lieutenants, des marabouts dévoués et d'une partie des réguliers d'Abd-el-Kader. Ce fait d'armes mérite une mention particulière.

Après une marche de vingt-cing heures à travers un pays inculte, le jeune duc d'Aumale se trouve, le 14 mai, en présence de la Smala. Il n'avait que 500 cavaliers; les zouaves, l'ambulance et l'artillerie étaient restés en arrière avec le lieutenant-colonel Chasseloup; ceux-ci ne pouvaient rejoindre le duc que deux heures plustard. Pendant ce temps, la Smala pouvait disparaître d'un autre côlé, l'ennemi n'avait pas moins de $ّ, 000$ combattants; il eût eu le temps de se reconnaître; le succès devenait douteux.

- Monseigneur, dit au prince le général Yusuf; que faut-il faire?

- Entrer là dedans, pardieu!

Le brave Yusuf croit avoir mal entendu et répète au prince sa question.

- Entrer là dedans, répète le prince.

- Nous sommes tous flambés, se dit Yusuf. - Et tous s'élancent.

On tua aux Arabes 300 hommes, on leur prit 4 drapeaux, 1 canon, un immense butin et 4,000 prisonniers. - Nous eùmes 9 hommes tués et 12 blessés. "Pour entrer, disait le vaillant colonel Charras, pour entrer, cornme l'a fait le duc d'Aumale, avec 500 hommes au milieu d'une pareille population, il fallait avoir vingt-deux ans, ne pas savoir ce que c'est que le danger, ou bien avoir le diable dans le ventre. Les femmes seules n'avaient qu'à tendre les cordes des tentes sur le chemin des chevaux pour les culbuter, et qu'à jeter leurs pantoufles à la tête des soldats pour les exterminer tous, depuis le premier jusqu'au dernier. "

Le brillant combat du 11 novembre, livré près de l'Oued-Malah par le général Tempoure à Sidi-Embarek, l'un des plus puissants Khalifas d'Abd-el-Kader, combat où périt ce lieutenant de l'émir, les succès obtenus par Bedeau et Tempoure vers la Tafna et le Ghott, terminent cetle campagne qui réduit Abd-el-Kader à errer avec les débris de sa Smala sur la frontière du Maroc ou dans le désert. - Notre colonisation prend des développements sensibles. 
Un nouvel ennemi se présente au commencement de 1844 : C'est Muley-Abd-er-Rhaman, empereur du Maroc. La prise d'Ouchda, à l'entrée de cet empire, le bombardement de Tanger par le prince de Joinville, enfin la brillante victoire d'Isly (14 août), où 8,500 soldats français dispersent une armée innombrable, contraignent l'allié d'Abd-el-Kader à signer la convention de Tanger et à répudier pour toujours l'alliance de l'émir.

Celui-ci appelle les Kabyles à l'insurrection (1845), et sa voix est entendue. 11 trouve un allié ou plutôt un rival dans le fanatique Bou-Maza. L'année s'écoule dans une alternative de succès importants et de revers sans grande portée. Rien de définitif.

Les années 1846 à 1848 sont remplies par les événements qui suivent :

Réapparition d'Abd-el-Kader en Algérie; sa déira, qui contient toutes les réserves de l'émir en argent, en provisions et ses prisonniers, est poursuivie par le général Caraignac jusque sur le territoire marocain. Trois cents des prisonniers faits par les Arabes dans l'embuscade de Sidi-Brahim en 1845, sont massacrés; onze officiers et soldats sont épargnés; quelques-uns parviennent à se sauver et se réfugient dans les douars des Beni-Tenasen, tribu marocaine. Abd-el-Kader, assure-t-on, est demeuré étranger à ce massacre. Bou-Maza, croyant Abd-el-Kader jaloux de son influence, quitte la déira de l'émir avec 40 cavaliers; scission entre les deux chefs. Ordonnance royale, en date du $\mathbf{2 1}$ juillet, sur la propriété des colons.

Le schérif Bou-Maza se rend à nous le 12 avril 1847. Abd-elKader gagne le Maroc. Le maréchal Bugeaud entreprend une heureuse expédition contre la grande Kabylie. Le duc d'Aumale est nommé gouverneur général de l'Algérie.

L'année 184.7 se termine par la reddition d'Abd-el-Kader. Traqué par nos troupes, l'émir avait dû se réfugier au Maroc. Il profite de la division qui y régnait pour intriguer contre l'empereur Muley-Abd-er-Rhaman. L'empereur envoie un corps de cavaliers pour surreiller l'émir; celui-ci taille en pièces ces cavaliers. La rérolte est flagrante. Cerné bientôt par trois colcnnes de troupes marocaines, pendant que le général de la Moricière se tient sur notre frontière avec 3,000 hommes et 1,000 chevaux, l'émir n'a plus d'autre ressource que de se rendre aux Français. On le conduit à Djema-Ghazaouat, au duc d'Aumale, gouverneur général, qui vient de débarquer en cet endroit. Introduit près du 
gouverneur, le vaincu dépose ses sandales sur le seuil et attend pour s'asseoir l'invitation du prince. Après un moment de silence, il dit en arabe :

" J'aurais voulu faire plus tôt ce que je fais aujourd'hui ; j'ai attendu l'heure marquée par Dieu. Je demande l'aman du roi des Français pour ma famille et pour moi."

Abd-el-Kader ne s'était rendu qu'à la condition d'être transporté avec tout son monde, soit en Arabie, soit sur un autre point de l'Asie. On ne lui tint point parole. Embarqué pour Oran le 24 décembre, il fut de là dirigé immédiatement sur Toulon avec sa mère, ses femmes, ses enfants, des membres de sa famille, quelques serviteurs fidèles, en tout 97 personnes.

La révolution de février $\mathbf{1 8 4 8}$ donne le gouvernement de l'Algérie au général Cavaignac. Les principaux faits de cette année sont, outre quelques expéditions militaires bien conduites, un décret électoral qui confèreà l'Algérie le droit d'élire des représentants et une loi sur la colonisation.

On peut résumer ainsi les faits qui se produisent pendant les années suivantes :

Apparition d'un faux Bou-Maza parmi les' tribus du Djurjura ; il est tué le 2 octobre 1849. La prise de Zaatcha le 26 novembre de la même année; le siége de cette ville a duré oัl jours. Expédition du général Saint-Arnaud contre la petite Kabylie. Loi dı 17 juin 18 I I réglementant les propriétés des indigènes et des Européens. - Bombardement par l'amiral Dubourdieu de Rabat et de Salé, repaires des pirates marocains. - Mise en liberté d'Abd-el-Kader, retenu prisonnier à Amboise (octobre 18ว2); on lui assigne Brousse en Asie, pour résidence. - Soumission des Zouaouas, dans la grande Kabylie. - Percement de routes dans la Kabylie centrale.

Prise de Laghouat, sur le Schérif d'Ouargla, à 120 lieues S. d'Alger (4 décembre 18วั2).

Culture du coton encouragée (18ว3).

Le général Randon, gouverneur général, et les généraux MacMahon et Bosquet frappent les Kabyles des monts Babors, entre Sétif, Bougie et Djidjelli.

Exécution de nouvelles routes.

Excursions militaires aux oasis d'Ouargla, de Metlili et chez les Beni-Mzab. Le khalifat Si-Hamza prête son concours (janvier-février 180ั4). 
On travaille à la route carrossable de Boghar à Laghouat, par Djalfa.

Expédition contre les Kabyles. Zouaouas du haut Djurjura, et surtout contre les Beni-Hidjer, qu'excite le faux Schérif Bou-Bargla (juin-juillet).

Prise de Tuggurt, où s'était réfugié l'ancien Schérif d’Ouargla (2 décembre).

Bou-Bargla tué par un caïd qu'il avait attaqué (26 décembre).

Exposition universelle à Paris (15 mai au 15 novembre 1850). L'Algérie y envoie ses produits.

Tremblement de terre en Algérie, ressenti surtout à Philippeville (2I août 1856).

Les divisions Renault et Yusuf opèrent contre les Kabyles Guetchoulas, du Djurjura (sept.). Lc maréchal Randon se joint à l'expédition (oct.).

Vente des terres, à titre définitif. Jusque-là, le système des concessions temporaires et conditionnelles avait prévalu.

Décret du 4 janvier 1857, étendant Jes attributions du gouverneur général, des préfets et des chefs militaires.

Décret du 14 mars, établissant un collége arabe-français à Alger.

La culture du coton encouragée. Prix impérial de 20,000 fr. proposé.

Lignes de chemins de fer décrétées ( 8 avril).

Campagnes du gouverneur général, des généraux Renault, Yusuf et Mac-Mahon, contre les Zounouas, dans la grande Kabylie du Djurjura (mai-juillet). - Route de 25 kilomètres ouverte en dix-sept jours au milieu des montagnes; elle relie Tizi-Ouzou à Souk-el-Arbâ, point culminant ; fort Napoiéon.

Décret du 4 août, établissant à Alger une école préparatoire de médecine ct de pharmacie.

Population européenne de l'Algérie : 167,670 Ames.

Ministère de l'Algérie et des colonies créé.

Le prix de 20,000 fr. institué pour la campagne cotonnière de 185ั7, attribué à M. Colonna de Cinarca (prov. d’Oran).

Décret du 31 août 18ñ8, supprimant les fonctions de gouverneur général de l'Algérie, etc.

Décret du 31 août, nommant le général de Mac-Mahon commandant supérieur des forces de terre et de mer employées en Algérie. 
Sur le rapport du prince chargé du ministère de l'Algérie, décret du 21 nov.-5 déc. créant un conseil supérieur de l'Algérie et des colonies.

Expédition du général Desvaux dans l'Oued-Souf et l'Oued-Rif (février-mars).

Forages artésiens dans le Sahara.

Travaux du chemin de fer d'Alger à Blidah.

Caravane de Laghouat revenue de Ghat.

Culture prospère de la vigne, du coton, du sorgho, du tabac, du henné.

On remarquera parmi les événements plus rapprochés de nous: les relations nouées par le gouvernement de l'Algérie avec les prircipaux chefs des Touaregs; un traité de commerce a été signé à Ghadamès par leurs représentants et ceux de la France (1862).

Pour conserver leur indépendance contre les Arabes envahisseurs, les Touaregs se sont créé une existence exccptionnelle. Ils forment, d'après le tableau de la situation 1862 , une race unique dans le monde. L'aridité de leur pays (du Sahara au Soudan), ne leur permettant de devenir ni pasteurs, ni agriculteurs, ni industriels, ils se sont faits les convoyeurs du désert; ils se chargent de protéger et de conduire, à travers l'océan de sable, les caravanes qui, des marchés du Sahara, se rendent dans le Soudan. Les coutumes ou redevances qu'on leur paye constituent leur seule richesse.

Voyage du Cheick Targni Si-Othman et de deux de ses neveux à Paris. Leur lettre enthousiaste à l'Empereur (juin 1862). Leurs rapports aux Touaregs.

Mission de Ghadamès, et rapport par le commandant Mircher (oct.-nov. 1862).

Lettre de l'Empereur au duc de Malakoff, gouverneur général, (6 février 1863; Tableau de la situation, Paris, Impr. impér., 1865, p. 丂), sur la conduite à tenir vis-à-vis des Arabes.

On lit dans cette lettre :

"La terre d'Afrique est assez vaste, les ressources à y développer sont assez nombreuses pour que chacun puisse y trouver place et donner un libre essor à scn activilé, suivant sá rature, ses mœurs et ses besoins.

"Aux indigènes, l'élevage des chevaux et du bétail; les cultures naturelles au sol.

"A l'activité et à l'intelligence européennes, l'exploitation des 
forêts et des mines, les desséchements, les irrigations, l'introduclion des cultures perfectionnées, l’importation de ces industries qui précèdent ou accompagnent toujours les progrès de l'agriculture.

"Au gouvernement local, le soin des intérêts généraux, le développement du bien-être moral par l'éducation, du bien-être matériel par les travaux publics. A lui le devoir de supprimer les réglementations inutiles et de laisser aux transactions la plus entière liberté. En outre, il favorisera les grandes associations de capitaux européens, en évitant désormais de se faire entrepreneur d'émigration et de colonisation, comme de soutenir péniblement des individus sans ressources, attirés par des concessions gratuites.

"Voilà, Monsieur le Maréchal, la voie à suivre résolûment; car, je le répète, l'Algérie n'est pas une colonie proprement dite, mais un royaume arabe...."

Rapport de M. le comte de Casabianca sur le sénatus-consulte relatif à la constitution de la propriété algérienne dans les territoires occupés par les Arabes (Sénat, 8 avril). Sénatus.consulte y relatif (13-22 avril).

Rapport à l'Empereur, par le maréchal Randon, ministre de la guerre, sur le régime administratif de l'Algérie ( 7 juiliet). Décret impérial y relatif (7 juillet 1864).

Les terres domaniales vendues à prix fixe et à bureau ouvert (décret, 10 déc.).

Défection de Si-Seliman-ben-Hamza, bach-agha des Ouled-SidiCheikh (fin février). Massacre du colonel Beauprêtre et de son détachement (8 avril).

Combat de Saïn-Legta (général Martineau).

Combat de Chaab-el-Ameur (général Deligny).

Soulèvement des Flittas (mai).

Mort du gouverneur général, le maréchal Pélissier, duc de Malakoff (22 mai).

Combat du général Rose à Dar-ben-Abdallah et mort du marabout insurgé Si-Lazereg (ॐ juin).

Défection des Larbaas et des Harar, avec Si-Lala à leur tête août).

Le maréchal de Mac-Mahon, gouverneur général (décret, $1^{\text {er }}$ sept.), et le général Desvaux, sous-gouverneur. 
Combats de Teniet-el-Rihh, d'Aïn-Dermel, d'Aïn-Malakoff (sept.-octob.).

Défecticn des Ouled-Nayl (octob.).

Combats d'El-Beїda, de Touten-Yaya (sept.-oct.).

Combat de Sahh-Ahmed-Annoual (général Legrand), 29 nov.

La plupart des tribus révoltées sont soumises, sauf les OuledSidi-Cheikh et les Trafis.

Voyage de l'Empereur Napoléon III en Algérie (mai-7 juin 1865̋).

Sénatus-consulte du ऽ juillet; il détermine l'état des personnes et les conditions de naturalisation en Algérie.

Lettre de l'Empereur au maréchal de Mac-Mahon, duc de Magenta. Datée du 20 juin 186วั, cette lettre a parule 4 novembre, et a produit la plus vive sensation. On en trouvera un extrait important dans l'appendice qui termine ce travail sur l'Algérie.

Combat de Ben-Hattab, et défaite de Si-Hamed (15 mars 1866). Mort du général Yusuf, à Cannes.

Le dernier événement, le plus important de tous au point de vue de l'avenir de la colonie, est la constitution définitive de la société Frémy et Talabot.

Elle a émis 100,000 actions de $500 \mathrm{fr}$. La souscription ouverte le 6 août 1866 a été fermée le 8 août.

Quelles que soient les critiques de détail auxquelles ait pu donner lieu le mode de procéder adopté par la société, il est hors de conteste que l'Algérie retirera de sa constitution, trop longtemps ajournée, des avantages considérables.

\section{CHAPITRE III}

Population. - Européens. - Israélites indigènes. - Musulmans. - Répartition des Européens entre les trois provinces algériennes. - Population en 1861, 1862,1863 et 1864 . - État civil des Européens. - Mariages. - Naissances. Décès. - Etat civil des indigènes. - Les Djemmaâs.

Le mouvemenl de la population varie peu d'une année à l'autre. 
En 1861, on comptait, en Algérie, 2,990,583 habitants, se répartissant ainsi :

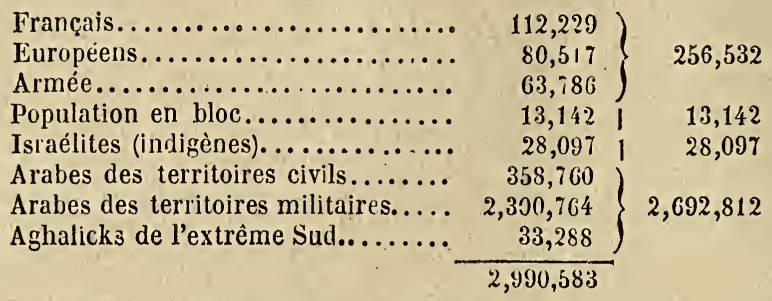

Sous le nom de population en bloc, on comprend : le personnel des hôpitaux, des orphelinats, des lycées, des colléges, des pensionnats, séminaires, couvents, prisons, etc., parmi les Européens; et, parmi les indigènes, tous les Berranis (artisans et manœuvres) formant la population flottante.

L'État de l'Algérie en 1863 répartissait ainsi, entre les trois provinces, l'élément européen de la population, pour 1861 :

\begin{tabular}{|c|c|c|c|}
\hline & $\begin{array}{l}\text { Province } \\
\text { d'Alger. }\end{array}$ & $\begin{array}{l}\text { Province } \\
\text { d'Oran. }\end{array}$ & $\begin{array}{c}\text { Province } \\
\text { de Constatitine }\end{array}$ \\
\hline Français .... & 49,731 & 32,055 & 30,443 \\
\hline Espagnols........... & 23,105 & 24,835 & 2,081 \\
\hline Italiens............. & - 4,031 & 2,261 & 4,964 \\
\hline 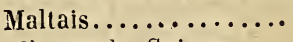 & 2,502 & 192 & 6,016 \\
\hline Allemands, Suisses.... & 3,432 & 1,627 & 3,273 \\
\hline \multirow{2}{*}{ Nationalités diverses.. } & 906 & 294 & 998 \\
\hline & 83,707 & 61,264 & 47,775 \\
\hline
\end{tabular}

En tout : 192,746 Européens.

A la fin de 1863, la population européenne était évaluée à 213,061. Soit, en deux ans, une augmentation, en population fixe, de 20,315 Européens. - Dans ce chiffre, on ne comprend pas la population en bloc. (État de l'Algérie en 1863.)

Au 31 décembre 1864, le nombre des Européens était, en Algérie, d'après le Tableau de la situation publié en 1866, de 235,570 individus.

Le chiffre adopté par M. le ministre d'Etat dans un discours au Corps législatif du 5 mars $\$ 866$ est inférieur au précédent. Suivant lui, la population algérienne présentait les chiffres suivants :

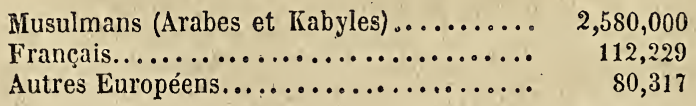


La lettre de l'Empereur au maréchal, duc de Magenta, offrait aussi à peu près les mêmes chiffres :

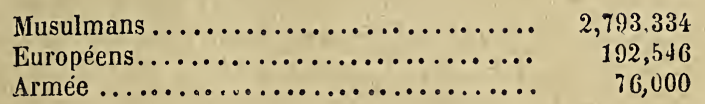

Le désaccnrd n'est qu'apparent. Le chiffre adopté par M. Rouher et dans la lettre impériale est celui de 1861, au lieu d'être celui de 1864, inconnu alors.

La population européenne est disséminée diversement dans les trois provinces.

La province de Constantine possède surtout, en étrangers, des Italiens et des Maltais. "Ce sont, dit le général de la Rue, des hommes pleins d'ardeur au travail; ils ont formé à Bône, à Constantine et à Philippeville, des établissements importants, dont les chefs exercent sur la colonisation une influence considérable. Ils sont producteurs, commerçants, armateurs même...

“ Dans la province d'Alger, les établissements industriels et agricoles ont été fondés surtout par des Français et par des Juifs indigènes. L'élément étranger est représenté par des Espagnols des îles Baléares et de la huerta de Valence. Ces hommes sont commerçants en ville et jardiniers à la campagne...

"La province d'Oran renferme comme élément étranger des Espagnols des côtes de Malaga et de Carthagène; quelques-uns s'y sont constitué de l'aisance, mais peu y ont fondé des établissernents commerciaux. Ce sont des hommes actifs, mais difficiles à conduire, et qui souvent ont des antécédents fâcheux... C'est là, dans le voisinage du Maroc, que le fanatisme religieux est le plus vivace. Il est entretenu par les chefs de corporations religicuses marocaines qui, dans ce pays, font quelquefois échec à l'empereur lui-même. " (Sénat, š juillet 1865.)

L'état civil des Européens et des Israélites indigènes fournit les résultats qui suivent :

\section{Européens.}

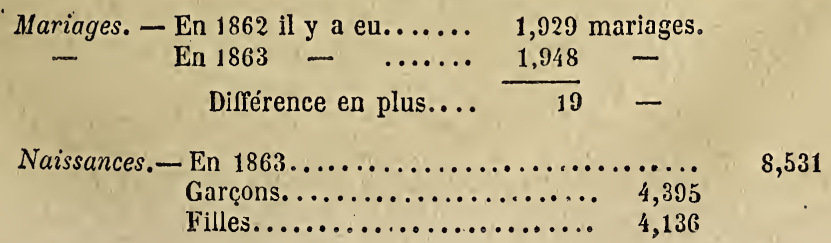


Décès. - En

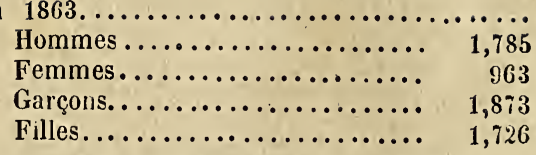

La différence au profit des naissances a donc été de.....

20 Israélites indigènes.

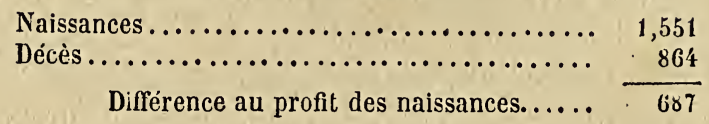

Le nombre des naissances a été, en 1864, de 8,408 (Européens). Le nombre des décès, de 5,497 .

En prenant pour moyenne de la population européenne 214,158 habitants, on a 2.76 pour 100 pour rapport des naissances aux décès.

Or, en 1862 , ce rapport a été, en France :

De 2.48 dans le département de la Seine;

De 2.53 dans les villes au-rlessus de 2,000 habitants.

De 2.02 dans les campagnes.

D'où cette conséquence que, parmi les Européens de l'Algérie, la mortalité serait supérieure de 0.23 pour 100 à la mortalité dans les villes de plus de 2,000 habitants en France, c'estàdire que, pendant qu'il meurt 300 personnes dans ces villes, il en meurt un peu moins de 301 en Algérie.

Mais ce chiffre est trop élevé; car, en Algérie, la statistique embrasse les morts-nés, et on ne les compte pas en France.

Par le seul fait de l'excédant des naissances sur les décès, la population européenne de l'Algérie devrait doubler en 56 ans environ, tandis que la population de la France ne le peut qu'en 141 ans.

La moyenne des mariages est de 1,828 ou 0.85 par 100 habitants. - En France, elle n'a été, en 18692 , que de 0.81 pour 100.

Depuis la conquête jusqu'au 31 décembre 186^, il y a eu, en Algérie, 62,768 décès contre 44,900 naissances; soit un excédant de décès de 17,868. - En 185̋3, l'excédant des décès a cessé de se manifester.

La population israélite indigène a donné, en 1864, des résultats plus satisfaisants encore. 


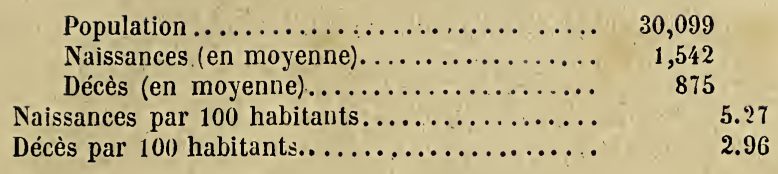

Les Israélites indigènes meurent un peu plus que les Européens. Différence : 0.20 pour 100. Mais ils se multiplient dans une proportion plus grande; différence : 1.30 pour 100 .

De 1862 à 1864, la population israélite s'est élevée de 28,097 à 30,099 , c'est-à-dire 7 pour 100 . Par ses seules forces de reproduction, elle peut donc doubler en 31 ans et 9 mois.

Tous les chiffres ci-dessus sont extraits, soit de l'État de l'Algérie en 1863, soit du tableau de la situation des établissements français (1864), publié en 1866.

L'ětat civil des Musulmans présente des difficultés presque insurmontables.

Chez les populations du Tell, il est possible de le constituer; mais chez les populations sahariennes, il n'y faut pas compter.

Dans la province d'Oran, la tenue des registres de l'état civil a été confiée aux cadis et à leurs adouls. Ces magistrats y font figurer, sur les renseignements qui leur sont donnés par les caïds et les chefs de douar, les naissances, les décès, les mariages et les divorces. "Lies déclarations des mariages, divorces et décès ont lieu assez exactement, parce que des intérêts matériels sont attachés à ces actes ; mais il n'en est pas de meme des naissances, dont les déclarations ne sont pas faites le plus souvent par les familles. Ces constatations, tout incomplètes qu'elles soient, n'ont lieu que dans le Tell. Les exiger chez les populations sahariennes serait demander l'impossible, à raison du genre de vie de ces populations. ") (Tableau de la situation des établissements français dans l'Algérie en 1864. - Paris, Imprimerie impériale, 1866).

En 1864, dans le ressort administratif des centres européens, la population musulmane était de 358,760 individus. C'est d'après ce chifire de population que les calculs suivants ont été faits :

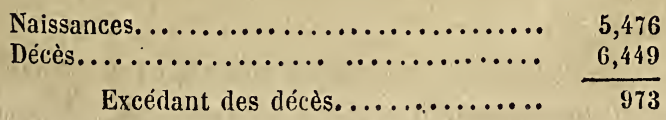


Mais il est probable que la proportion des décès renferme une certaine exagération.

Depuis le sénatus-consulte de 1863, les registres de l'état civil sont confiés aux djemmaâs. "Celles-ci, disait le général Allard au Corps législatif, séance du 5 mars 1866, vaincront facilement les résistances que l'établissement de l'état civil a rencontrées jusqu'à ce jour chez les Arabes. »)

\section{GHAPITRE IV}

Divisions administratives. - L'Algérie sous la domination ottomane. - L'Algérie sous la domination française. - Gouverneur général. - Territoire civil ; territoire militaire. - Bureaux arabes. - Organisation indigène. - Chefs indigènes. - Vallée du Chélif ajoutée au territoire civil (1865).

Sous la domination ottomane, c'était un Dey (du persan Dei, Dieu, ou plutôt de l'arabe Dä, conducteur) qui gouvernait l'Algerie. Divisée en quatre provinces - Alger, Oran, Constantine, Titeri, - elle avait chacune d'elles administrée par un Bey (colonel ou seigneur).

L'Algérie, sous la domination française et depuis 1843 , forme trois provinces : les provinces d'Oran, d'Alger el de Constantine, subdivisées en arrondissements, cantons et communes. Les anciennes subdivisions musulmanes ont aussi dû être respectées jusqu'à un certain point; on y voit commander des Khalifats, des Aghas, des Kaïds, des Cheikhs.

Une autre division ou plutôt une distinction a été faite entre le pays civil, le pays intermédiaire et le pays arabe. Le premier est celui où l'administration européenné a pu facilement s'imposer; dans le second, la protection du pouvoir militaire est encore nécessaire; enfin, dans le troisième, le pouvoir militaire règne exclusivement.

Les pouvoirs civil et militaire sont concentrés entre les mains du gouverneur général.

Chaque province se compose de deux territoires : le Territoire civil et le Territoire militaire.

Le territoire civil forme le département. Il comprend : la préfecture, les arrondissements, les commissariats civils ou districts, 
les communes de plein exercice et leurs annexes, enfin les localités non érigées en communes.

Un préfet, assisté d'un conseil de préfecture, administre le département. - Un șous-préfet administre l'arrondissement; celuici comprend les communes proprement dites, et, en outre, un certain nombre de districts administrés par des commissaires civils qui sont soumis aux sous-préfets. - Un maire, assisté d'un conseil municipal, administre la commune.

Des chefs indigènes, sous la surveillance du maire, administrent les indigènes fixés sur le territoire civil. - A chaque préfecture est attaché un Bureau arabe départemental; à chaque arrondissement est attaché un Bureau arabe civil, que gèrent des adjoints au bureau arabe départemental, sous les ordres des souspréfets.

Le territoire militaire comprend : la Division militaire, les Subdivisions, les Cercles, qui sont à la subdirision ce que le district ou la commune sont à l'arrondissement.

Le commandant de la division, assisté d'un Conseil des affaires civiles, administre le territoire militaire. Il statue sur les matières attribuées aux préfets en conseil de préfecture. Son administration s'étend sur les Européens et les indigènes établis en territoire militaire.

Les fonctions de commissaires civils sont remplis par les commandants supérieurs de cercles.

A défaut de fonctionnaires civils, les commandants de place, en territoire militaire, remplissent les fonctions municipales et celles d'officiers de l'état civil et de juges de paix. Ils connaissent des contraventions de simple police.

Des Bureaux arabes, spécialement chargés de l'administration des populations indigènes, sont établis dans toutes les subdivisions et dans chaque cercle. Ils sont dirigés par des officiers français, sous l'autorité du commandement militaire.

Une Direction divisionnaire des affaires arabes centralise, dans chaque division, les affaires arabes auprès du général. - Le Bureau politique, placé sous la direction du général de division, sous-gouverneur de l'Algérie, centralise, à Alger, l'administration générale des indigènes en territoire militaire.

La fixation des circonscriptions militaires a déterminé l'organisation des tribus. On distingue chez celles-ci : le Douar ou réunion de tentes rangées en cercle, qui correspond à un de nos 
hameaux; la Ferka, on réunion de plusieurs douars, sous un Cheikh; la Tribu, qui réunit plusieurs ferkas et obéit à un Kaïd; l'Aghalik, ou grand Kaïdat, réunion de plusieurs tribus, sous un Agha ou un Kaïd-el-Khiâla (général de la cavalerie). Plusieurs aghaliks réunis ont pour chef un Bach-Agha ou un Khalifat.

Le Cercle embrasse plusieurs Khaïdats.

Les Aghas sont nommés par le ministre de la guerre. Leur rôle consiste à surveiller les kaïds et les khalifats. Ils disposent d'une troupe indigène soldée par la France. Leur autorité est politique.

Les Kaïds sont nommés par le commandant de la division. Ils veillent à l'exécution des ordres du commandant et lèvent les impôts dans leur tribu.

Les Cheikhs ont un rôle analogue à celui des maires. Ils sont assistés par un conseil des notables.

L'institution des bureaux arabes a été généralisée par une or-

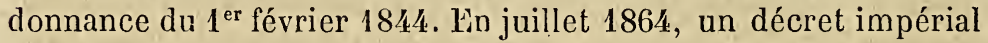
les a réorganisés et en a augmenté le nombre. Dans sa lettre au duc de Magenta (1865), l'empereur veut que le rôle des bureaux arabes soit à l'avenir plutôt politique qu'administratif.

Tous les nouveaux centres de population qui ont acquis un certain développernent sont érigés en communes par décret impérial.

En 1865, toule la vallée du Chélif a été ajoutée au territoire civil.

Il comprend actuellement :

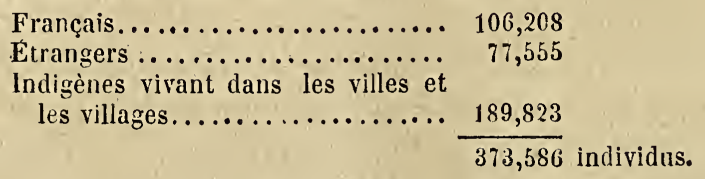

" C'est à peu près, dit le général Allard, la population d'un dé. partement français, mais la superficie de ce même territoire civil est quinze ou vingt fois plus grande que celle d'un département. ") 


\section{CHAPITRE V}

Désignation des principales localités des trois provinces. - Leur population. Leur industrie.

\section{PROVINCE D'ALGER.}

4 arrondissements : Alger, Blidah, Médéah et Milianah.

\section{1 cantons.}

1 division militaire.

7 subdivisions militaires : Alger, Aumale, Blidah, Dellys, Médéah, Milianah et Orléansville.

6 cercles militaires.

\section{Hondissement d'Alger.}

Achour (EL), commune de Déli-Ibrahim.

AfFreville, commune de Milianah. 118 Européens, 918 indigènes.

Aïn-BË̀d et Ain-Taĩa. 580 Européens, 65ı) indigènes.

Aïn-BÉnian (Guyotville). 249 Européens. AïN-MadHl.

Aï-Taïa et Aïn-BeïdA. 580 Européens, 650 indigènes.

Aïn'TASTA.

Aïoun-Sebaa.

ALGER, ville, chef-lieu du département de ce nom - A 1553 kil. de Paris. 34,000 Européens, 20,000 Musulmans, 10,000 Juifs. - 13 cantons. Poste. - Télégraphe. - Port militaire. - Archevèché. - Grand et petit séminaires. - Temples protestants. - Mosquées. - Synagogues. École de médecine et de pharmacie. - Lycée. - Collége impérial français-arabe. - La Casbah, ancien palais du dey.

Industrie : Osière, absinthe; broderies en or ; carton, ardoise, toile bitumée; chandelles; chapeaux de paille; charrues ; tanneries, corroieries, corderies, crin végétal de palmier, tabac, conserves alimentaires, semoule, eaux gazeuses, distilleries, huilerie, fonderies de métaux, minoterie, scieries à vapeur, etc.
Commerce : Spirilueux, vins, huile d'olive, droguerie, équipements militaires, fournitures pour la marine, bois de construction, etc.

ALGER (département d').

4 arrondissements : Alger, Blidah, Médéah et Milianah.

$91,(100$ Européens; 118,000 indigènes.

Aichevèché. Cour impériale. Académie universitaire.

Division militaire à Alger et sept subdivisions : Alger, Aumale, Blidah, Dellys, Méléah, Milianah, Orléansville; six cercles militaires.

Topographie : Le département d'Alger occupe le centre de l'Algérie ; il s'étend $\epsilon$ trteles provinces d'Oran et de Constantine. Il a 160 kilomètres de côtes, et sa superficie est de 423,990 hectares.

Faune : Chameaux, dromadaires, chèvrés, brebis, bœufs, ânes, etc., parmi les auimaux domestiques; autruches, chacals, hyènes, panthères, lions (rares), antilopes, singes, etc.

Flore : Céréales, œillette, pavots, sésame, vignes, tabacs, cotonniers, orangers, citronniers, amandiers, etc.; cèdre, pin d'Alep, chêne à glands doux, chène-liége.

Minéralogie: Mines de cuivre, fer, zinc; grès à paver, porphyre, pierre 
de taille, marbre, plâtre; eaux minérales ferrugineuses.

Industrie: Papeteries, minoteries, essences odoriférantes, magnaneries.

Commerce: Coton, soie, cochenille, laine. miel, safran, vins, tabacs, huile d'olive, d'amande, de ricin, gingembre, grain, essences, etc.

Alma: Annexe du Fondouck.

ARBA (L') et ses annexes : Rivet, Rovigo et Sidi-Moussa.

1,157 Européens; 2,920 indigènes.

Industrie: Coton, tabac, garance.

Commerce: Garance, coton, tabac, longue laire, chardons à foulon.

Acmale, chef-lieu de canton. $-1,020$

Européens, 500 indigènes.

Bureau de poste. - Télégraphe.

Chef-lieu de la 3 e subdivision militaire et de cercle.

Commissariat civil.

Industrie : Pierres à bâtir, porphyre feldspathique, chênes-verts, cliènesliége, pins, lentisques ; minoteries.

Commerce : Vius, quincaillerie.

BAB el-Ourd, faubourg d'Alger. 1,800 Européens.

Industrie : Chandelles, poteries, briques, chaux; usines pour la mouture des céréales, huileries, glacières, fonderies de fer.

BABA-IIASSEN. 150 Européens.

Industrie : Oliviers, nopals (le mûrier de la cochenille).

Ben.N'choud, annexe de Dellis.

Béni-Mançour, annexe d'Aumale.

BÉnI-Moussa. Culture de la garance.

$B \operatorname{Br}{ }^{\circ}(\mathrm{EL})$. 1,100 Européens, 350 indigènes.

Les sources alimentant les fontaines d'Alger viennent du coteau d'El Biar. Orphelinat. Couvent du Bon-Pasteur.

Industrie et commerce: Céréales, coton, soie, chardons à foulon, oliviers, tabac, vignobles; huile d'olive, fabriques de couleurs végétales.

Bir-DJaïch, l'un des quatre groupes de Guelt-Zerga.

Bir-Kadem. 600 Européens, 550 indigènes.

Indus/rie : Coton longue soie, tabac, vin, carthame (plante).

Birmandreis. 600 Européens, 350 indigènes.
Industrie et commerce : Essences, huile d'olive, cochenille.

Borzaréa, avec Pointe-Pexade et SaIntEugène. 1,520 Européens, 1,050 indigènes.

Industrie et commerce : Céréales, tabac, garance, coton, huile d'olive.

Chéragas. 1,000 Européens, 400 indigènes.

Industrie et commerse : Coton, chanvre, canne à sucre, tabac, toiles de palmier, fil brut et écru, filasse, tapis de toile de palmier, essences.

Crescia. 210 Européens. 20 indigènes.

Coton, tabac.

Dellis ou Deluys, chef-lieu de canton.

- 800 Europeens, 1,400 indigènes.

Burean de poste. - Télégraphe.

Ville maritime.

Chef-lieu de la $1^{\text {re }}$ subdivision militaire et de cercle.

Commissariat civil.

Industrie et commerce : Grès à paver, raisins renommés, buile, grain, figues, abricots, miel, céréales.

Paquebots pour Alger et Bugie.

Deli-Ibrahin. 480 Européens, 164 indigènes.

Industrie et commerce : Céréales, mais, olivier, soie, coton, tabac, vin, laine, huile.

Douéna, chef-lieu de canton. 1,330 Européens, 1,302 indigènes.

Bureau de poste.

De création française, cette ville est sur la route d'Alger à Blidah, par le Sahel.

Industrie et commerce : Céréales, coton, tabac, garance, vin, grains. Transit.

DraA-El-Mizan. 95 Européens. - Annexe du cercle militaire de TiziOuzou.

Drariah. 425 Européens, 430 indigènes. FondoucK (LE). 515 Européens, 3,800 indigènes.

Industrie et commerce : Coton, carrières de marbre. Grande ferme.

Fort-de-L'Eau. 410 Européens, 105 indigènes.

Grandes cultures.

GúlT-Zerga, à 7 kil. d'Aumale, comprend quatre groupes : Ain-Tasta, Ailoun-Sebaa, Bir-Ljaich et GueltZerga. 
Guyotrille. 250 Européens.

Halma (LE). Pépinière centrale du gouvernement.

\section{HAMEDI.}

Husseri-Dey. 1,150 Européens, 250 indigènes.

Industrie et commerce : Vers à soie, cochenille, tabac, laines, essences, fromages, huiles d'amande, d'olive, de ricin.

Kaddous et Drariair.

Kouba. 750 Européens, 280 indigènes.

Grand séminaire. - Maison de la Sainte.Enfance.

Industrie et commerce : Coton, soie, tabac, vétiver, gingembre, olives, miel, safran.

Laghovat. 2i0 Européens, 2,000 indigènes.

Bureau de poste.

Chef-lieu de cercle militaire; sise à $400 \mathrm{kil}$. d'Alger, prise en 184 ' par le général Marey, Laghuuat, par sa position dans l'oasis des Krour (Sahara), met l'Algérie en rapport avec les tribus de l'intérieur, les Touaregs entre autres.

Matifoux et Rouiba: 150 Européens, 130 indigènes.

Mines (Les) et Montenotte.

Montenotte et Les Mines. 450 Européens.

Musta pha (banlieue d'Alger).

Hôpital civil. - Orphelinat.

Bains de mer.

Industrie et commerce : Coton, chanvre, garance, vers à soie, cochenille, tabac, vignes, essences, machines agricoles.

Oued-Allflah (L'). Mines de cuivre.

Oued-Corso (L') et Le Fondouck.

Oued-Taffilet. Mines de cuivre.

Ouled-Faïet. 275 Européens.
Ouled-Mendil et Douéra.

Pointe-Pescade, avec Bouzanéa et SAINT-Eugène. 1,525 Européens, 1,030 indigènes.

Rassauta (LA). 4,700 luabitants.

Industrie et commerce : Céréales, coton, soie, tabac, cultures maraîchères.

RÉGhaïa. 160 Européens, 150 indigènes. Bureau de poste.

RIVET.

Rovïba et Matifoux.

Rovigo et Sidi-Moussa. 300 Européens, 1,120 indigènes.

Inclustrie et commerce : Céréales, coton, garance, tabac, essences, plâtres, orangers.

Saoula. 175 Européens, 250 indigènes.

SıDı-Bou-Aïssı. Mines de cuivre.

Sidi-Ferruch. 90 Européens, 80 indigènes.

Industrie et commerce : Cire, miel, coton.

Sidi-Moussa et Rovigo.

Staouéli. 50 Européens.

Bureau de poste.

Établissement de trappistes.

SaINTE-AmÉlie. 210 Européens.

Saint-Eugènf et Pointe-Pescade.

Saint-Ferdinand et BuUkandoura. 130 Européens, 110 indigènes.

Saint-Jules et Doujéra.

TÉxÈs. 1,750 Européens, 550 indigènes.

Port.

Chef-lieu de canton.

Bureau de poste. - Télégraphe.

Chef-lieu de cercle militaire.

Commissariat civil.

Industri, et commerce : Grains, mines de cuivre.

TŕnÈs (V'IEUX). 670 indigènes.

Tizi-0uzov. 160 Européens.

Chef-lieu de cercle militaire.

\section{0 rondissement de Hlidah.}

BÉsi-Mered. C02 Européens.

Industrie : Céréales, tabac.

Commerce : Céréales, vins, soie.

Berbessa.

Birtouta. 400 Européens, 1,200 indigènes.

BLIDAH, chef-lieu d'arrondissement.

A 48 kil. d'Alger. 7,000 habitants.

Bureau de poste. - Télégraphe.
Chef-lieu de subdivision militaire et de cercle. - Conseil de guerre. Haras.

Blidah, la ville des fleurs, dont SidAhmed-ben-Youssef a dit : "Les hommes t'ont nommée petite ville; moi, je t'appelle petite rose, " est située au pied du petit Atlas, au bord de la Mitidja. Elle est émaillée et en- 
tourée d'orangers, de citronniers, etc. , sur une étendue de 20 hectares.

Industrie et commerce: Essences, liqueurs, bière, minoterie, bouchons, mines de cuivre; coton, farine, maïs, vins, fruits, laine, garance, quincaillerie, noureautés, etc.

Bouffarick, chef-lieı de canton. 3,300 Européens, 800 indigènes.

Bureau de poste.

Comice agricole (présidé par l'empereur le 6 mai 1865 ).

De création française, située dans la plaine de la Mitidja, Bouffarick est aujourd'hui la ville agricole la plus prospère de toute l'Algérie.

Industrie et commerce : Céréales, fourrages, tabac, soie, coton, minoteries, bestiaux (grand marché); commerce d'entrepôt pour toute la $\mathrm{Mi}^{-}$ tidja.

Bouinan.' 155 Européens.

Boukandoura et Saint-Ferdinand. 130 Européens, 100 indigènes.

Castiglione. 3i0 Européens.

Industrie et commerce: Tabac, coton,

blé tendre, arachides.

Chaїв, annexe de Coléah.

Chfbli. 270 Européens, 20 indigènes.

Cherchell, chef-lieu de canton; 1,270

Européens, 1,900 indigènes.

Petite vilie maritime.

Bureau de poste. - Télégraphe.

Chef-lieu de cercle militaire.

Commissariat civil.

Industrie et commerce : Minoterie; carrières de plâtre ; mines de fer exploitées par les Kabyles; comestibles, coton, laines, nouveautés, grains, cochenille, vins et liqueurs.

Coléa H, chef-lieu de canton ; 1,400 Européens, 1,450 indigènes.

Bureau de poste.
Chef-lieu de cercle militaire.

Industrie et commerce: Citronniers, oliviers, tabac, minoteries, carrières de pierres de taille. Grandes exploitations dans les bois de Mázafran, sur lesquels la ville est assise.

Dalmatie. 265 Européens.

Industrie et commerce : Céréales, coton, vin, tabac, olives, minoteries; carridres de marbre et de porphyre, minerais de cuivre, zinc, fer, plomb. Dovaouda. 310 Européens, 95 indigènes. Fолкан. 365 Européens, 50 indigènes. JoINVILLE. 300 Européens.

Industrie et commerce : Cérẻales, tabac, coton, soie, distilleries d'asphodèles.

MaZafran. Vastes forêts. - Importantes exploitations.

Messaud.

Montpens:er. 200 Européens.

Movzaïaville. 650 Européens.

Bureau de poste.

OUED-EL-HALLEG (L'). 460 habitants.

Industrie et commerce : Coton, tabac.

OUED-EL-KÉbir. Mines de cuivre.

Oued-el-Menja. Mines de cuivre.

Quatre-Cheminś. 80 Européens, 40 Indigènes.

Saighr.

Sovna. Colonie agricole européenne (280 Européens).

Tefeschoun. Colonie agricole de $250 \mathrm{Eu}-$ ropéens.

Teniet-el-HaAd, 240 Européens, 80 indigènes.

Bureau de poste.

Chef-lieu de cercle militaire.

Bureau arabe.

ZÉr ALDA. 170 Européens, 65 indigènes. ZOUDJ-EL-ABBÈS.

\section{Bo rondissement de Plédéah.}

Affroun (EL) et Bon-Roumi. 311 Européens.

Loghar. 220 Européens, 60 indigènes.

Bureau de poste. - Télégraplie.

Bureau arabe.

Clief-lieu de cercle.

Bon-Ruumi et AfFroun.

Chıffa. Colonie française. - 260 Européens.
DamietTe. 350 Européens.

DJALFA, annexe du cercle militaire de Laghouat.

Djemma-Ghazaouah ou Nemours.

C'est-à Sidi-Brahim, à 15 kil. de Nemours, qu'Abd-el-Kader fit égorger un corps de prisonniers français, en 1846. In monument leur a été élevé à Nemours. V. Nemours. 
Lod1 . 350 Européens.

NIAHELIia, 2:30 Européens.

Maison-Blanche (La). 160 Européens, 1,200 indigènes.

Maison-Carrée (La). 360 Européens, 800 indigènes.

Bureau de poste.

Prison arabe.

Industrie: Papeterie.
MÉDÉAH. 3,08ก Européens, 5,400 indigènes.

Industrie et commerce : Céréales, houblon, raisin, pommes de terre, pins d'Alep, minoterie, pépinière.

Mouz IÏA-LES-Mines. 370 Européens.

Industrie et commerce : Chènesliége, chênes à glands doux, mines de cuivre et de fer.

\section{0 rrondissenent de Drilianah.}

Ain-Sultan, annexe de Milianah. -200 Européens, 18 indigènes.

Ameur-el-Aïn, annexe de Marengo.

Bou-M E DEA. 220 Européens, 20 indigènes.

BoukıkA. 170 Européens, 80 indigènes. J) UPERKÉ.

Ferme (LA). 255 Européens, 55 indigènes.

Lavarande. 110 Européens, 170 indigènes.

Marengo. 710 Européens, 80 indigènes. Chef-lieu de canton.

Bureau de poste.

Commissariat civil.

Colonie agricole.

Industrie et commerce : Céréales, tabac.

MILIANAH. 2,200 Europeiens, 4,000 indigènes.

Chef-lieu d'arrondissement.

Bureau de poste. - Télégraphe. $5^{\mathrm{e}}$ subdivision militaire.

Industrie et commerce : Céréales, vins, fruits, minerais de cuivre.

Novi. 210 Européens, 70 indigènes.

Orléansville. 1,070 Européens, 550 indigènes.

Chef-lieu de canton.

Bureau de poste. - Télégraphe.

Chef-lieu de subdivision milltaire.

Commissariat civil.

Industrie et commerce : Coton, safran, cochenille.

Pontr BA. 260 Européens, 95 indigènes.

Industrie et commerce : Coton, safran, cochenille.

Tipaza. 90 Européens, 185 indigènes. Petit port.

Tesoul-Benian. 250 Européens.

Zurich. 190 Européens, 30 indigènes.

\section{PROVINCE D'ORAN.}

4 arrondissements : Oran, Mascara, Mostaganem et Tlemcen. 8 cantons.

1 division militaire.

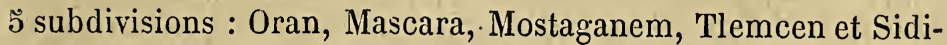
Bel-Abbès.

6 cercles militaires.

\section{Arrondissement d'Oran.}

Aîs-BEida, annexe de Misserghin.

Poste aux lettres.

Industrie : Garance, tabac, céréales.

AïN-EL-Turk et Bou-Sefer. 150 Européens, 300 indigènes.
Commerce : Céréales. Aiv. Khial. 46 Européens.

Aïn-Temouchent. 745 Européens, 100 indigènes.

Arcole, annexe de Sidi-Chami. - 90 Européens, 23 indigènes. 
Grande culture.

A RzEw. 1,030 Européens, 133 indigènes.

Bureau de poste.

Port offrant un excellent mouillage.

$\mathrm{Au}$ sud de la villo, forêt de Muley. Ismail.

Industrie : Bois et charbon; sel du Inc d'Arzew ; coton, millet, arachides, tabac, pois chiches.

Commerce : Céréales, coton, vin muscat, amandes, caroubes, anis.

Assi-Ameur, annexe de Fleurus.

Assi ben.FÉrÉaH, annexe de SaintLouis.

Assi BEN-0кнвA, annexe de Fleurus.

Assi-Bou-Niff, annexe de Fleurus.

Assi el-Biod, annexe de Sidi-Chami.

Bou-Strar. 150 Européens, 300 indigènes.

Industrie el commerce : Céréales.

Boy-TLELIS. 555 Européens.

Chimetil et Sainte-LÉoniz.

Céréales.

Dsïs, annexe du cercle militairo de Sidi-bel-Aubès.

DAмÊme. 135 Européens, 15 indigènes. ÉToile (L'). 55 Européens, 15 indigènes.

Figuier (Le) ou Valmy-le-Figuier. 410

Europ ells.

Bureau de poste.

Industrie et commerce : Céréales.

Fururus. Colonie agricole. - $275 \mathrm{Eu}$ ropéens.

Frenda. 30 Européens, 180 indigènes.

GÉrivilze, chef-lieu de cercle militaire.

Gudel. Bureau de poste.

KLÉben. 250 Européens.

Colonie agricole. - Céréales, lin et moutarde.

Lalla-Macrnia. Bureau de poste.

Chef-lieu de cercle.

Mines de plomb argentifère.

LOURMEL.

Mangin. 185 Européens.

MrFessciur. 250 Européens.

Mers-el-Kéb'r. 1,4110 Européens.

Ville maritime; bon port à 8 kil. d'Oran.

Misserghiv. 1,050 Européens.

Bureau de poste.

Orpheinat. - Maison du Bon-Pasteur.

Industrie et commerce : Céréales, pavots, tabac, opium, oranges, citrons, grenades, miel, bambous, coton, patates.
Muley-ABd-EL-Kader. 150 Européens.

Muley-Magoun et Saint-Leu.

ORAN, ville. 17,000 Européens, 7,900

indigènes.

Bureau de poste. - Télégraphe.

Port.

Ville de guerre de $1^{\text {re }}$ classe. - Direction d'artillerie.

Préfecture.

Tribunal de première instance ; tribunal et chambre de commerce.

Chambre d'agriculture.

Industrie et commerce : Céréales, pâtes alimentaires; bières, vins, alcool d'asphodèles et de figues; produits chimiques; comestibles, bijouterie, bonneterie, fromages, parfumerie, laines, étoffes, quincaillerie, métaux, etc.

ORAN (département d').

4 arrondissements : Oran, Tlemcen, Mascara, Mnstaganem.

Division militaire.

5 subdivisions et 6 cercles militaires.

Le département d'Oran couvre une superficie de 10,200 hectares $(3,500$ dans le Tell, 6,700 dans le Sahara).

Faune: Vaches, brebis, chèvres.

Flore: Oliviers, orangers, mùriers, figuiers, grenadiers, citronniers, amandiers, caroubiers, vignes, tabac, pavots, plantes oléagineuses, patates, orges, céréales, maïs, lin, miliet, moutarde blanche, garance, anis ; chènesverts, chènes blancs, pins, thuyas.

Minéralogie: Mines d'argent, de plomb, de zinc, lignite, pouzzolane ; marbre, onix translucide, pierres à aiguiser; lac salin d'Arzew, etc.

Industrie et commerce : Coton, soie, céréales, bestiaux, anis, arachides, burnous, corail, cire, garance, fruits, huile d'olive, tabac, sorgho blanc, kermès, pistaches, miel, etc. Petit-Parc.

Rocher (Le). 50 Européens.

Salnt-Aimé, dépendance de La Sénia. Sainte-Banbe-du Tlélat et Sido belKhair. 340 Européens, 35 indigènes. Saint-Cloud. 780 Européens, 70 indigènes.

Chef lieu de canton.

Bureau de poste.

Industrie et commerce : Céréales, 
coton, lin, moutarde blanche, olives, raisin, tabac, garance. Transit.

SAINT-DENIS-DU-SIG, et UNION-DU-Sig. 2,000 Européens, 150 indigènes.

Chef-lieu de canton.

Bureau de poste.

Commissariat civil.

Industrie et commerce : Coton, raisin, patates, tabac. Transit.

Saint-Hubent, dépendance de La Sénia.

Saint-Joseph, dépendance de La Sénia.

Sainte-Léonie et Christel. 240 européens.

Saint-Leu et Muley-Magoun. 180 Européens, 510 indigènes.

Saint-Lovis. 400 Européens.

SÉNiA (LA). 560 Européens, 70 indigènes. Industrie : Vigne.

SIDı-Alı. Colonie agricole.

Industrie et commerce : Céréales, fromages, beurre, laine.

Sidi-AmadodGK.

SIDI-AMIN.

SIDI-BEL-ABbÈs. 3,550 Européens, 650 indigènes.

chef-lieu de canton.
Bureau de poste. - Télégraphe.

Chef-lieu de la $3^{\text {e }}$ subdivision mi-

litaire. - Ville de guerre de 2 e classe.

Commissariat civil.

Industrie et commerce : Vins, spiritueux, grains, étofles, quincaillerie, thuyas, etc.

Sidi-BEL-Khair et SAINTE-BARBE.

Sidi-Brahim. 120 Européens.

Sidr-Chami. fleurs.

Industrie et commerce : Vigne,

Sid I-KhaLed. 200 Européens.

SIDI-L'H HSSEN. 410 Europćens, 30 indigènes.

Takadenpt ou Tekedempt (La capitale d'Abd-el-Kader après la prise de Mascara par les Français).

Texsalmet et Missenghin.

TLÉlat, Janlieue d'Oran.

Trembles (Les . 100 habitants.

UNiON-DU-Sig et SAINT DENIS-DU-Sig.

Valmy le-Figuier. 420 Européens.

Bureau de poste.

Industrie et commerce : Céréales.

\section{Arondissement de Mascara.}

MASCARA. 2,330 Européens, 5,055 indigènes.

Bureau de poste. - Télégraphe.

Chef-lieu d'arrondissement et de la $4^{e}$ subdivision militaire.

Industrie et commerce : Céréales, olives, raisin, garance, alcool de figues de Barbarie; pépinière; articles de Paris.

OUed-el-Hamman 190 Européens.

SAÏDA, chef-lieu de cercle militaire. 230 Européens, 200 indigènes.

Bureau de poste.
Industrie et commerce : Cèreales. Saint-Andné. Colonie agricole de 290 Européens.

Industrie et commerce : Laines, fromages.

Saint-Hippolyte. 70 Européens.

Tranet. 410 Européens, 390 indigènes.

Bureau de poste.

Chef-lieu de cercle militaire.

Industrie et commerce : Liége, bois, tabac, garance, gomme d'amiandiers sauvages, pierres à aiguiser.

\section{Arrondissement dile Mtaganem.}

Aвoukrr. 237 habitants (Européens).

Colonie agricole.

Intustrie : Colonnier, mûrier. Commerce: Coton, laine, heurre.

Aïn-BOU-Dinar et VALiéli-LLS-JaRdiNs.

Colonie agricole.

Ain-Noussi. 242 Européens.

Colonie agricole.

Industrie : Cotonnier.
Commerce: Coton, céréales.

Aïs-Si-Cherif. 183 Européens.

Colonie agricole.

Intustrie : Céréales.

AïN TÉnÉLĖs. 418 Européens.

Colonie agricole.

Industrie: Soie grége, tabac, garance, huile d'olives sauvages, coton de Géorgie, etc. 
Commerce : Sorgho, miel, kermès, thuya (bois), cire, etc.

Amm-Moussa. Chef-lieu de cercle militaire. 49 Européens, 26 indigènes.

Bled-Touaria. 300 Européens.

Colonie agricole. - Garance, lin.

Kharouba. 40 Européens.

LiBÉRĖS OU l'ÉLISSIER.

Mazagran. 370 Européens, 550 indigènes.

yillage fameux par le siége qu'y soutinrent le capitaine Lelièvre et 123 Français contre 12,000 Arabes (2-6 février 1840).

Industrie et commerce : Coton, confitures, fromages, tabac, vins, figues.

MOSTAGANEM. 4,250 Européens, 4,300 iudigènes.

Chef-lieu d'arrondissement.

Port.

Bureau de poste. - Télégraphe.

Chef-lieu de la $2^{\mathbf{e}}$ subdivision mili- taire. - Place de guerre de deuxième classe.

Industrie et commerce : Céréales, fourrages, laines, lissus, bonneterie, quincallerie, bestiaux, broderies de bonnets pour les Arabes; entrepót.

Mouley-Ismaï. Exploitation forestière. OURÉa. 40 Européens.

PÉlissier ou Libérés. 1,880 Européens.

Colonie agricole.

Pont-du-Chelif. 190 Européens.

Industrie et commerce : Céréales, arachides, pistaches, coton.

Rivolı. Colonie agricole européenne.

Sourk-EL-Mitou. Colonie agricole $(320$ Européens).

Inilustrie et commerce: Garance.

Stidia (LA). 470 Européens.

In'lustrie et commerce: Céréales, lentilles, haricots, garance.

Tounin. Colonie agricole de 200 Européens.

VALlÉE-Les-Jardins et Aïn-Bou-Dinar.

\section{Arrondissement de Tlemcen.}

Aï-TABbaleK.

Industrie : Carrières d'agate antique (onyx translucide).

BṘ̇a. 180 Européens.

Industrie et commerce: Garance, céréales.

Gar-Roubban. Mines de plomb argentifère.

Hennaïa. 240 Européens.

LeLLA-MaghrNia. 135 Européens, 420 indigènes.

Mansourah. 130 Européens.

NÉGRIER. 130 Européens.

Industrie et commerce : Vigne, moulin à farine.

Nemouns. 740 Européens, 280 indigènes.

Bureau de poste.

Chef-lieu de canton et de cercle militaire. Place de guerre de troisième classe.

Industrie et commerce : Abeilles, lin, céréales, cire, miel.
Oued-Chouli.

Ouled-Mazig. Mines de plomb argentifère.

OULED.Nimoun.

PONT-DE-L'ISER.

Rachgoun.

Sebdou, chef-lieu de cercle militaire. 180 kuropéens.

SEISAF. 0 Européens.

TLEMCEN. 2,300 Européens, 11,500 indigènes.

Chef-lieu d'arrondissement.

Chef-lieu de la $5^{\mathrm{e}}$ subdivision militaire. Place de guerre de troisième classe.

Bureau de poste. - Télégraphe.

Industrie et commerce : Céréales, garance, huile d'olive, semoule, farines, bestiaux, laine, vin, terre à pipe.

Marché indigène pour le trafic avec le Maroc. 


\section{PROVINCE DE CONSTANTINE.}

$\breve{5}$ arrondissements : Constantine, Bône, Philippeville, Sétif et Guelma.

8 cantons.

1 division militaire.

4 subdivisions militaires : Constantine, Batna, Bône et Sétif.

7 cercles militaires.

\section{1' Arrondissement de Constantine.}

Aïn-BeïdA. 218 Européens, 294 indigènes.

Aïn-Guerfa.

Ain. NAHS.

Aïn-Smara.

Aria (EL).

Batna. 1,400 Européens, 500 indigènes. Chef-lieu de canton.

Bureau de poste. - Télégraphe.

Chef-lieu de la $3^{e}$ subdivision militaire et de cercle.

Commissariat civil.

Batna est place de guerre de deuxième classe. Elle est située dans les inonts Aurès. De grandes forèts de cèdres la couvrent au N. 0 .

Industrie : Scieries mécaniques. - Pépinière du gouvernement. Exploitation dans les forêts. - Grandes cultures.

Commerce: Vins, quincaillerie, épicerie.

BÉNi-Morra. Oasis située à un demikilomètre de Biskra.

Jardin d'acclimatation.

Biskra ou Biscara, chef-lieu de cercle, capitale des oasis du Ziban, située au versant méridional des mouts Aurès.

Industrie et commerce : Salpêtrerie

" du gouvernement, pépinière, minoterie; caravanes; transit entre le Tell et le Sahara.

Bizot.

Bou-Merzoug (Vallée du). 350 Européens, 6,500 indigènes.

Moulins à farine. - Fermes.

CondÉ. 164 Européens, 55 indigènes.

Bureau de poste.
CONSTANTINE, ville. 16,000 Européens, 30,000 indigènes.

Bureau de poste. - Télégraphe.

Piace de guerre de $1^{\text {re }}$ classe.

Siége de la $2^{\mathrm{e}}$ division militaire. Direction d'artillerie.

Chambre d'agriculture.

Tribunal de première instance.

Pléfecture.

Construite sur une table de rochers, séparée du plateau de Mansourah par un ravin de 228 mètres; Constantine occupe une superficie de 42 hectares.

- A 280 kilomètres d'Alger.

Industrie et commerce : Céréales, farine, chanvre, antimoine, essences, cocons, laine, fruits, vins, mercerie, quincaillerie, nouveautés ; distilleries, brasseries, minoteries, tanneries, vermicelleries. Pépinière du gouvernement.

CONST ANTINE (département de).

Superficie : 175,900 kilom. carrés. Population : 1,300,000 habitants.

5 arrondissements : Constantine, Bône, Sétif, Guelma, Philippeville.

$2^{\mathrm{e}}$ division militaire; 4 subdivisions, 7 cercles.

Faune: Chevaux, chèvres, mulets, bestiaux, lions.

Flo'e : Céréales, chanvre, garance, vignes, tal)ac, lin; culture maraî chère ; citronniers, orangers, oliviers, cédrats, amandiers, cotonniers, cèdres, chênes-liéges, chênes-zéens.

Minéralogie: Fer, antimoine, marbres blanc, rose et noir, plomb argentifère et aurifère, mercure. Eaux thermales sulfureuses. 
Industrie et commerce : Vers à soie, distilleries de betteraves, alcool de figues de Barbarie, huile d'olive, pêche du corail, minoteries, scieries, liége, usines métallurgiques, chevaux, mulets, chèvres, coton, laine, soie, corail, cire, grain, fruits, tobac, miel, vin, bois, cuir. Articles de marine. Transit, par Philippeville, du commerce avec le Sahara.

Rivières : Le Mafrag, la Mansourah, la Serra, le Rummel ou Ouedel-Kébir.

Fermaton. Colonie française. 110 Européens.

Fornier.

GuelaA-bou-Sba. 155 Européens, 10 indigènes.

Haminate (EL). Mines d'antimoine.

Hama (Le). Minoteries, distilleries de betteraves.

Kalfoun. 70 Européens.

Fermes.
IKrovbs. 40 Européens.

LAMBESSA. 400 Européens, 50 indigènes. Bureau de poste.

Colonie agricole.

Industric et commerce: Moulins à eau. Pépinière.

En 1850, il y fut envoyé une colonie d'insurgés de juin 1848 .

LAMBLÈCHE.

LaUasser. 70 Européens.

Meridj.

Colonies agricoles.

Mesloug. Colonie agricole.

NiLAH. Bureau de poste.

Oued-Berda.

OUED-DECKRI.

OUEd-Massine.

OUED-TARFE.

Ouled-Ramoun. 50 Européens.

Outaïa (EL). Sel gemme.

Ras-bOU-MEBzoUg.

Suendou ou Condé.

Ziban. Oasis.

\section{$2^{\circ}$ Homalissement de Hône.}

Ain-Morka.

Industrie: Mines de fer.

ALÉLIK (L'). Dépôt d'étalons.

Industric: Mines de fer de la Méboudja; usine pour le traitement du minerai.

Barral. 300 Européens, 15 indigènes.

Colonie agricole. - Fermes.

Industri?: Tubac.

Commerce : Céréales.

BONE, chef-lieu d'arrondissement. 6,300

Européens, 5.000 indigènes. - Près des ruines d'Hippone.

Bureau de poste. - Télégraphe.

Chef-lieu de cercle militaire. -

Ville de guerre de 2 e classe.

Collége.

Chambre de commerce.

Industrie et commerce : Exploitation des forêts de l'Edough (chênesliéges et chènes.zéens), fabriques de sàvon, distilleries, pèche du corail; mines de fer, carrières de marbre; vins, huile, nouveautés, quincaillerie, grains, farines, fourrages, cire, épicerie, cuirs, bestiaux.

Bugeaud. 125 Européens, 70 indigènes. Calle (LA), chef-lieu de canton. 930 Européens, 200 indigènes.
Bureau de poste.

Place de guerre de 3 e classe et chef-lieu de cercle militaire.

Commissariat civil.

Port sur la Méditerranée.

Industrie et commerce: Pèche du corail; exploitation des vastes forêts de chênes-liéges voisines de la ville.

Mines de plomb aurifère et argentifère.

Collo ou Calla. 2,000 habitants.

Port sur la Méditerranée.

Inciustrie et commerce : Pêche du corail ; fabrique de faïence.

DIjzerville. 65 Européens, 30 indigènes. Guebar-BoU-Aoun.

HADJAR-EL-BED. 55 Européens.

Carrières de marbre.

Hamman-Meskoutin. Eaux thermales. Kif-oum-Theboul (EL). 195 Européens.

Mines de p'omb argentifère.

Meboudja (La). Mine de fer.

Mondovi. 450 Européens.

Colonie agricole.

Industrie et commerce : Céréales, tabac.

Nechueya. 160 Européens.

Penthièvre. 150 Européens.

Bureau de poste. 
Sнекота. Carrières de marbre.

TAGILT. Patrie présumée de saint Augustin.

Tebessa ou Tipsa. 100 Européens, 1,100 indigènes.
Bureau de poste.

Annèxe du chef-lieu de cercle mi litaire (Constantine).

TIFFECH.

Tipsa. V. Tebessa。

\section{0 rrondissement de Sétif.}

Aïn-Arnat (avec Bouhira, Mahouan, Misoud et Ouricia). 427 Européens, 75 indigènes.

Aï-SfiaA (annexe de Sétif). 38 Européens.

Bo:iDJ-BOU-ARERIDJ. 240 Européens, 200 indigènes.

Chef-lieu de cercle militaire.

Bougie, chef-lieu de canton. 1,700 Européens, 1,500 indigènes.

Bureau de poste. - Télégraphe.

Ville de guerre de $2^{e}$ classe et cheflieu de cercle militaire.

Bon port.

Industrie et commerce : Huiles, miel, cire, grain, oranges; entrepôt des produits de la Kabylie centrale.

Boumira.

Bou-SAADA. 50 Européens, 50 indigènes.

Annexe du cercle militaire de
Bordj-bou-Areridj.

MaHOUAN.

M'silla, ville arabe.

Industrie : Sellerie.

M'soud.

Ouricia (EL). 80 Européens.

SÉTIF, chef-lieu d'arrondissement. 2,700 européens, 1,200 indigènes.

Bureau de poste. - Télégraphe.

Place de guerre de $2^{e}$ classe. -

Chef-lieu de cercle militaire.

Sétif, située sur un plateau de 1,400 mètres, est renommée pour sa salubrité.

Industrie et commerce : Chevaux, mulets, chèvres, fruits, comestibles, sel, vins, distilleries, brasseries, minoteries, quincaillerie.

TeMellovcka. 340 indigènes.

Tinnar. $2: 0$ indigènes.

\section{Arondissement de hilippeville.}

Ahmed-brN-Alt. 112 Européens.

Arrouch (EL). 594 Européens, 25 indigènes.

Bureau de poste.

DAMRÉMONT. 95 Euronéens.

DJIDJELLI, chef-lieu de canton. 2,120 habitants.

Ville maritime.

Bureau de poste. - Télégraphe.

Chef-lieu de cercle militaire.

Commissariat civil.

Industrie et commerce : Fruits, huile, bestiaux, volailles grains.

Filfica. 200 Européens, 10 indigènes. Industrie et commerce: Marbres blanc, noir et rose.

Gastonville. Colonie agricole. 505 Européens.

Industrie et commerce : Lin.

HANEd-BEN-A t.r. 125 Européens.

Jemuapes. 1,045 Européens, 25 indi-. gènes.

Bureau de poste.

Commissariat civil.
Industrie et commerce : Céréales.

KaNTOUR (EL).

PHILIPPEVILLE. 11,300 habitants.

Port à Stora.

Chef-lieu d'arrondissement.

Bureau de poste. - Télégraphe.

Place de guerre de $2^{e}$ classe.

Tribunal de $1^{\text {re }}$ instance. - Chambre de commerce.

Industrie et commerce : Marbre, charbon de terre, fer et acier, chênes liége, fournitures pour la marine, nouveautés, quincaillerie, distilleries d'asphorlèles.

Robertuille. 4 i 0 Européens.

Sidi-Nassar. 190 Européens.

Stora. 610 Européens.

A 4 kilomètres de Philippeville, dont il est le port.

Saint-ANToine. 250 Européens.

Saint - Charles. 140 Européens, 430 indigènes.

Vallie. 250 Européens. 


\section{Arouhissement de Guelma.}

GUELMA. 1,520 Européens, 2,100 indigènes.

Bureau de poste. - Télégraphe.

Chef-lieu de cercle militaire.

HÉLIOpolis. 330 Européens, 450 indigènes.

Céréales, tabac, minoteries.

Les colonies agricoles de Petit, Héliopolis, Millésimo, dépendent de Guelma.

Industrie et commerce : Usines à huile et à farine, culture de l'olivier, commerce de produits agricoles, mines d'antimoine, fabriques de pâtes
d'Italie, tuilerie, briqueterie.

Medjez-Amar. 10 Europeens.

MLLLÉSIMO. 28 Éulopéens.

Oued-Touta. 85 Européens.

P'ETIT. 215 Européens, 180 indigènes.

Industrie et commerce: Céréales, tabac.

Souk Arras. 450 Européens, 340 indigènes.

Ghef-lieu de canton.

Bureau de poste.

Chef-lieu de cercle militaire.

Commissariat civil.

\section{CHAPITRE VI}

Organisation coloniale et agricole. - Nouveaux centres de population. - Villes, villages et périmètres de colonisation. - Terres disponibles. - Concessions. - Terres affectées à la colonisation (décr. 25 juillet 1860 ). - Population agricole. - Propriétés européennes. - Propriétés indigènes. - Prix des terres. Voies de communication. - Chemins de fer. - Cultures diverses : céréales, coton, soie, tabac, vigne et vins, oranger, citronnier, cédratier, lin. - Forêts. - Pépinières. - Jardin d'acclimatation de Hamma (comnune d'Alger). Mines. - Forages artésiens. - Expositions agricoles en 1864 et 1865. - Lacs salés. - Décisions du ministre des finauces facilitant les transactions.

Sept nouveaux centres de population ont été créés en 1863.

\section{PROVINCE D'O'RAN.}

hect. ares.

Sidi-Khaled, 60 feux, superficie de....... $1,993 \quad 16$

Les Trembles, 60 feux, - $\quad \ldots \ldots \ldots \ldots \quad 2,278 \quad 97$

La Djemmaâ, 10 feux, - $\quad \ldots \ldots \ldots \ldots .6536$

Oued-Imbert, 8 feux, $\quad-\quad \ldots \ldots \ldots .61,701 \quad 27$

Mekedra, 9 feux, $\quad$ - ........ 1,071 40

Province de constantine.

Oued-Dehab; f4 feux, superficie de....... hect.

Sidi-Tamtam, 65 feux, $\quad$. ....... 600

Au 31 décembre 1864, on comptait en Algérie 240 villes, villages ou autres agglomérations européennes, dites périmètres de colonisation.

En 1863, il y avait 900,000 hectares de terre disponibles (azels). 
Dans la province d'Oran, il y en avait 3500,000 hectares; 24,000 ont été concédés à l'adjudicataire du barrage de l'Habra. Le reste a été rendu aux tribus en toute propriété, depuis le voyage de l'empereur.

Dans la province d'Alger, 110,000 hectares de terres domaniales ont été concédés ou vendus.

Dans la provinçe de Constantine, on a loué à des indigènes sur baux renouvelés par adjudication. On loue les terres $10 \mathrm{fr}$. l'hectare.

Les concessions, délivrées ou régularisées en 1863, se sont élevées à 1,676, embrassant une superficie de 19,240 hectares 14 ares 25 centiares.

Le nombre des concessionnaires frappés de déchéance s'est élevé à 71, savoir : 30 dans la province d'Alger; 39 dans la province d'Oran; 2 dans celle de Constantine. - Les terres reprises forment un total de 1,752 hectares.

D’après le décret du $2 ð$ juillet 1860 , les terres affectées à la colonisation sont aliénables, ou parventes à prix fixe, ou par ventes aux enchères publiques.

\section{3}

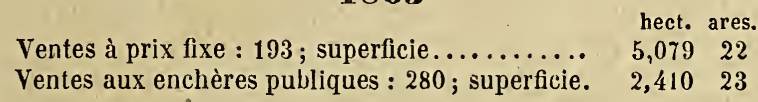

Le chiffre atteint par les ventes aux enchères publiques s'est élevé à 1,007,241 fr.

Population agricole. Elle était, en 1864, dans le ressort administratif des divers centres colonisés, de 110,̋ั53 Européens, et de 318,309 indigènes.

Propriétés européennes : 567,277 hectares; 188,521 hectares ont été ensemencés en 1864.

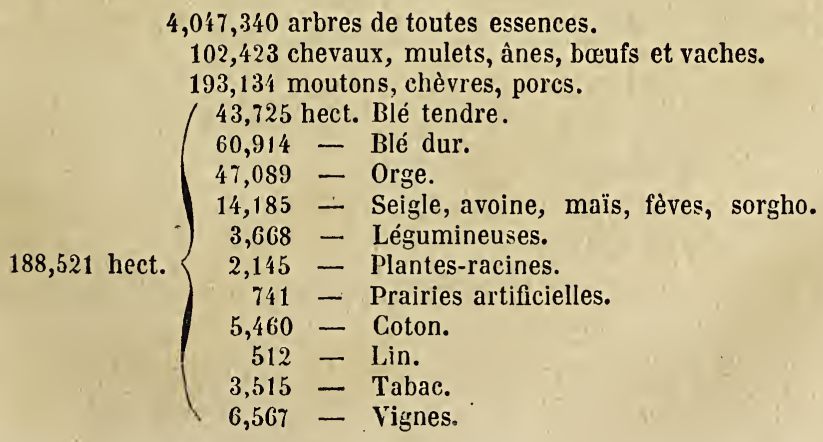


Propriétés indigènes : 951,174 hectares; 418,157 ont été ense. mencés en 1864.

1,778 hect. Blé tendre.

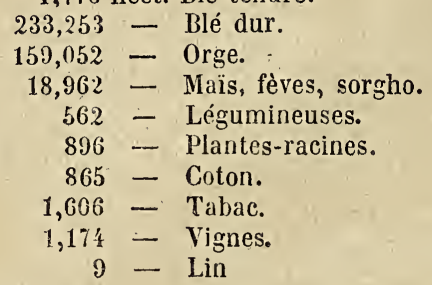

Arbres........................... $636,0,00$

Chevaux, mulets, ânes, bœufs ou vaches...... 259,033

Moutons, chèvres ou porcs .............. 701,362

Gourbis ou tentes...................... 56,194

Maisons............................ 5,682

a Dans les environs d'Alger, l'hectare de terre produit anjourd'hui plus de 1,000 fr. de revenu. Et dans la Mitidja, ces anciens marais Pontins de l'Algérie, qui se sont assainis grâce au dévouement et à l'héroïsme des colons, l'empereur a eu un spectacle qui a excité son admiration. - En d'autres localités encore, on a fait des miracles. M: Ferdinand Barrot a pu cultiver 100 hectares de lin en une scule pièce, et il a établi près de celte culture une manufactureà vapeur d'après les modèles qui réussissent le mieux dans le département du Nord... ) (Sénal, ร juillet 186ə̃ ; discours de M. Charles Dupin.)

Au Corps législatif, séance du 3 juillet 1865, M. le baron. Jérôme David, rapporteur de la loi relative à la convention Frémy et Talabot, convention qui doit introduire en Algérie d'importantes améliorations, disait en parlant des voies de communication: "L'un des points régulièrement desservis en Algérie est Aumale, à environ 30 lieues d'Alger. Le transport d'une tonne de marchandises d'Alger à Aumale coûte $60 \mathrm{fr}$. Le même transport coûterait en France 6 ou 8 fr. ")

Cette situation ne saurait durer longtemps, en présence de l'activité des ponts et chaussées.

Les travaux entrepris comprennent: Voies de communication (routes, chemins, etc.), cours d'eau (desséchements et irrigations), voirie urbaine, service des eaux (aqueducs, fontaines, égouts), ports et fanaux, créations de centres, usines, travaux neufs.

De 1861 à 1863, les travaux neufs et d'entretien se sont élevés à : 


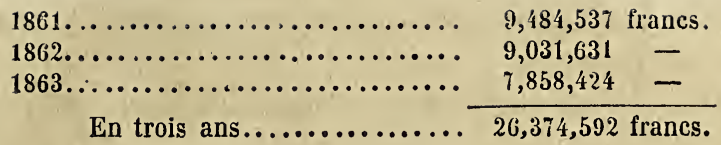

$\mathrm{Au} 31$ décembre 1864 , on comptait 7 routes impériales, 38 routes provinciales et 430 chemins de grande communication. Après achèvement complet, ces routes et chemins embrasseront un parcours de 6,661 kilomètres.

\begin{tabular}{|c|c|c|c|c|}
\hline Rou & npé & no $^{1}$, d'Alger à Laghouat..... & 425,303 & mètre \\
\hline & 一 & $\mathrm{n}^{\circ} 4$, d'Alger à Oran.......... & 170,856 & - \\
\hline & - & no $^{\circ}$ 5, d'Alger à Constantine... & 99,423 & - \\
\hline & - & $n^{0} 2$, d'Oran à Tlemcen...... & 138,000 & 一 \\
\hline - & - & de Stora à Biskara .......... & $3 \approx 8,000$ & - \\
\hline
\end{tabular}

En 18วั6, l'Algérie ne possédait pas 1 kilomètre de chemin de fer.

A la session du Corps législatif (1866), M. le général Allard a résumé ainsi tout ce qui a été fait sous ce rapport :

"Le chemin de fer de Philippeville à Oran sera livré à la circulation en 1869.

"Celui d'Alger à Oran est entamé (1866) par ses deux extrémi tés. Ia section d'Alger à Blidah est déjà livrée au public; celle d'Oran ̀̀ Relizane le sera en 1867. - Cette grande ligne suit la vallée du Chélif; le Gouvernement a décidé la création de dix nouveaux centres de population sur cette voic ferrée.

"Le gouvernement affecte, par an, aux travaux publics autres que les chemins de fer, une somme de 2 millions.

" Une impulsion plus grande encore va être donnée par la Société générale Algérienne fondée au capital de 220 millions. "

Le Tableau de la situation pour 1864 donne les détails suivants sur la section ouverte :

Une scule section est ouverte : celle d'Alger à Blidah, sur la ligne d'Oran. Elle a été livrée à l'exploitation en septembre 1862. Voici son mouvement en 1864.

Longueur exploitée..............

Nombre des voyageurs transportés...

Tonnage (grande vitesse)...........

Produit total

(petite vite:se)............

Produit kilométrique
196,670

49 kilomètres.

870 tonneaux.

$50,769-$
630,15 francs.

13,043 - 
L'intérêt de l'agriculture algérienne exige que ces voies de communication soient promptement achevées.

Quelques chiffres encore pour donner une idée plus complète du mouvement agricole de la colonie.

On a vu déjà l'extension prise par les céréales. Les autres cultures ne sont pas demeurées en arrière.

COTON.

Année 1861-1862........ 524,060 kilog. (poids brut).

- 1862-1863......... 530,115 -

Primes d'encouragement payées par l'administration :

\begin{tabular}{|c|c|}
\hline-1862. & 314,315 \\
\hline $1862-1863 \ldots \ldots \ldots \ldots \ldots \ldots \ldots \ldots \ldots$ & 314,712 \\
\hline 1863-1864 (approximativement)....... & $2,500,000$ \\
\hline
\end{tabular}

Une prime de $1 \mathrm{fr}$. par are est offerte dans la province d'Alger, pour les cotonnières de 20 ares au moins et de 1 hectare au plus.

En 1862, dans l'arrondissement de Bône (province de Constantine), un Européen a cultivé, de compte à demi avec les indigènes de 11 douars, 8 hectares de cotonniers. Il a été récolté 24,861 kilogr. de cotons bruts, représentant une valeur de 62,241 fr., c'est-à-dire une moyenne à l'hectare de 292 kilogr. et de $726 \mathrm{fr}$. La récolte cependant s'était faite dans de mauvaises conditions.

En 1864, la production cotonnière a présenté les résultats qui suivent :

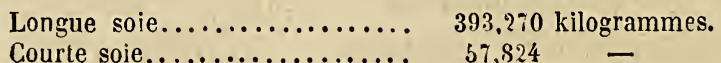

On a calculé que, depuis 18309 , l'accroissement de production avait été de $3330 / 0$.

SÉRICICUITURE.

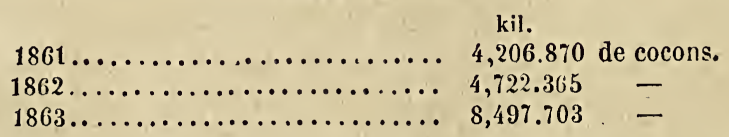

En 1864, la production s'est élevée à 15,534 kilogrammes 7 ๖ั0 grammes de cocons.

TABAC.

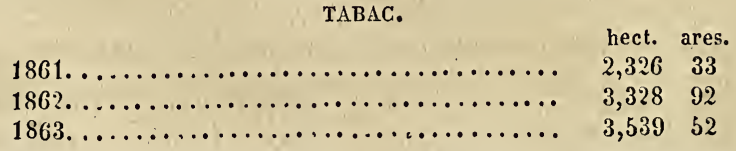


ALGÉRIE.

La situation, en 1864, a été comme suit :

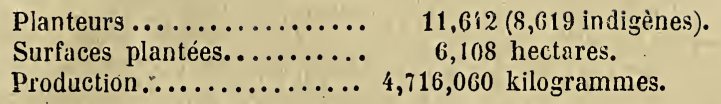

VIGNE.

hect. ares.

1863. Étendue cultivée............. 8,5:3 5

1864. $\quad-\quad \ldots \ldots \ldots \ldots \ldots \ldots \ldots .6 \%$ 9,715 25

Les raisins provenant des cultures indigènes sont tous consommés en grappes.

Les Européens ont produit, en 1864: 63,832 hectolitres de vin :

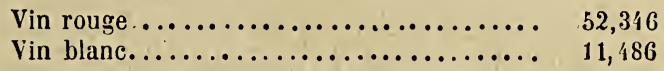

La culture de l'oranger, du citronnier, du cédratier, a présenté cette situation :

Nombre des planteurs................ 3,096

- des arbres en rapport........... 130,411

_ des arbres ne produisant pas encore. . $\quad 72,447$

Quantité de fruits exporiés........... 14,285,580

Nombre des planteurs européens.......... $\quad 728$

- $\quad-\quad$ indigènes.......... 2,368

LIN.

Le lin croît à l'état sauvage dans toutes les prairies algériennes.

1863. Nombre des plantations...... 187

- Étendue totale ........... 316 hect. 53 ares.

1864. Étendue cultivée.......... 765 hect.

Les planteurs appartiennent pour plus d'un tiers à la race indigène.

FORETS.

Concessions temporaires de forêts (état au 31 décembre 1864).

Chênes-liége................. 155,118 hectares.

Chênes-zéens.............. 28,724

Chênes verts ............... $\quad 755$

Cèdres 3,000

Oliviers (avant d'être soustraits au régime forestier) $\ldots \ldots \ldots \ldots \ldots \ldots \ldots \ldots \ldots \ldots \ldots \ldots \ldots \ldots \ldots$

Pins......................

Le sol forestier de l'Algérie est évalué approximativement à 1,361,192 hectares. On ne peut guère compter que sur 284,000 hectares. 
PÉPINIÈRES.

On les supprime aujourd'hui. Elles n'ont plus leur raison d'être. Ont été supprimées celles de :

Bone, Batna, Sétif, Aumale, Milianah, Orléansville, Philippeville, Mostaganem, Mascara, Tlemcen, Nemours.

Ces établissements sont transformés en promenades publiques ou vendus par lots, aux enchères, et deviennent ainsi des pépinières particulières.

JARDIN D'ACCLIMATATION DE HAMMA.

(Situation en 1864.)

Division fruitière.

Arbres en pépinière, en école et à demeure....... 86,281

Plants en pépinière................... 54,306

Division forestière.

Arbres en pépinière................. 103,722

Plants pour pépinière.................. 121,826

Semis et boutures en planches.............. 335,799

Division des serres.

Arbres en pépinière, d'acclimatation, en école et à de-

meure .......................... 34,496

Végétaux en pots...................... $\mathbf{6 6 , 6 3 2}$

Plantes grasses en pots................... 4,441

Plantes en école et à demeure.............. 8,431

Animaux d'acclimatation.

Quadrupèdes........................... 10

Bipèdes............................ 39

Produit des ventes en 1864 (végétaux, fruits, plumes d'autruche $. \ldots \ldots \ldots \ldots \ldots \ldots \ldots \ldots \ldots \ldots \ldots, 51,035 \mathrm{fr}$.

MINES.

En 1863, quatre mines étaient en exploitation.

\section{PROVINCE D'ORAN.}

Mine de Gar-Rouban (plomb sulfuré, cuivre sulfuré et carbonaté). - Elle a donné, dans la dernière campagne, 20,302 quintaux de plomb, valant 369,516 francs. - On y emploie 288 ouvriers.

\section{PROVINCE DE CONSTANTINE.}

Mine de Karésas (minerais de fer). - Elle a donné, en 1863, 219,33 s quintaux, valant 211,658 francs. - On y emploie 70 ouvriers.

Mine de Raz-el-Mah (sulfure de mercure). - On en a ex- 
trait 7,500 quintaux, valant 3,900 francs. - On emploie 29 ouvriers.

Mine de Kef-Oun-Teboul (plomb). - On en a extrait 17,763 quintaux, valant 2Ј̌4,738 francs. - Ouvriers employés : 178.

\section{Mines en exploitation (1864).}

Province d'Alger : Mouzaïa (cuivre gris).

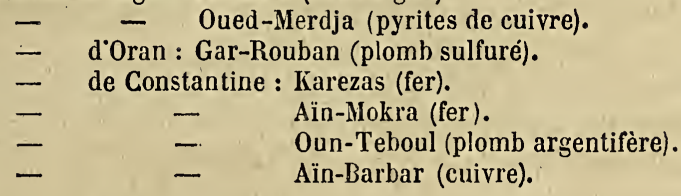

Ces 7 mines, en 1864, ont présenté la situation suivante :

Ouvriers employés

Quantités extraites.......... 176,453 quint. métr.

Valeur des minerais......... 1,286,213 francs.

Un certain nombre de permis d'exploration on été accordés.

FORAGES ARTÉSIENS.

Province de Constantine (1864).

Un certain nombre de sondages, pratiqués dans la province de Constantine, ont donné les résultats suivants :

A Dayet-el-Habara, on a obtenu, à 68 mètres, 1,40ั0 litres d'eau par minute.

A El-Griat, à 138 mètres de profondeur, on a rencontré trois nappes ascendantes dont le niveau s'est tonjours maintenu à 8 mìtres au-dessous du sol.

A Ourir $\left(79^{\mathrm{m}}, 29\right)$, on a obtenu 2,746 litres par minute.

A Tinedla $\left(82^{\mathrm{m}}, 00\right), 2,000$ litres par minute.

A Zaouiat-Rihab $\left(72^{\mathrm{m}}, 80\right)$, 72 s litres par minute.

A Sidi-Yahia $\left(41^{\mathrm{m}}, 83\right), 1,140$ litres par minute.

Ces résultats ont été obtenus par M. l'ingénieur Jus et le capitaine Zikkel.

\section{EXPOSITIONS AGRICOLES DE 1864.}

A l'exposition interuationale de Bayonne (France), l'Algérie, représentée par 460 exposants, a obtenu 81 récompenses, pour ses farines, semoules, pâtes, cotons, lins, soies; tabacs, huiles, vins, essences et parfums, minerais divers.

A l'exposition d'Oran, le rapport de la commission a signalć les fermes suivantes : 
Ferme Martel, à Pélissier.

Ferme Guyonnet, à Assi-bou-Nif.

Ferme Calmels, à Sidi-Marouf.

Ferme Daudrieu, près d'Arcole.

Fermes Ricard, à Saint-André-de-Mascara et dans la plaine d'Eghris.

Ferme Lenfroy, à Sidi-bel-Abbès.

Ferme Bastide, à Sidi-bel-Abbès .

Ferme Bardet, à Sidi-Khaled.

Ferme Boulet, à Sidi-Khaled.

Des médailles d'or ont été décernées à MM. Boulet, Calmels et Bastide; des médailles d'argent, à MM. Lenfroy, Martel, Ricard et Guyonnet.

L'exposition agricole de Bouffarick (mai 1865̈), a eu un visiteur auguste et inattendu : l'Empereur.

LACS SALÉS.

En 1863, les cinq lacs salés mis en adjudication l'année précédente dans la province de Constantine, ont été exploités. Le prix d'adjudication a été de $\mathbf{4 , 8 8 0}$ francs, avec une redevance annuelle de 1,700 francs.

Pour faciliter les transactions, le ministre des finances a, en août 186ว̆, autorisé les trésoriers payeurs des trois provinces à recevoir désormais les fonds des négociants et à délivrer en échange des mandats sur leurs préposés. Les entraves résultant pour le commerce de la difficulté des transports de fonds et du nombre encore très-restreint des maisons de banque dans les places de l'Algérie, seront ainsi considérablement atténuées.

\section{CHAPITRE VII}

Organisation financière. - Budget du gouvernement général. - Budgets provinciaux. - Budgets communaux. - Budgets locaux. - Budgets des centimes additionnels à l'impôt arabe. - Impôts. - Impôts arabes. - Amendes. - Octroi de mer. - Produits réalisés au profit du Trésor en 1864. - Télégraphie. - Postes. - Enregistrement et domaines. - Impôt foncier.

L'organisation financière de l'Algérie comprend les budgets suivants : 
10 Hudget du gouvernement général.

Il est préparé, chaque année, par le gouverneur général, en conseil supérieur du gouvernement; il est voté par le Corps législatif.

En 1861 il a été de........... 21,764,456 fr. 41 c.

En $1862-\ldots \ldots \ldots \ldots \ldots . .19,391,743 \quad 31$

En $1863-\ldots \ldots \ldots \ldots \ldots 18,693,533 \quad 00$

¿o Hudgets provinciaux.

Préparé par le préfet et le général de division commandant le territoire militaire, puis présenté par le préfet au conseil général, le budget de chaque province est délibéré par le conseil général et réglé définitivement par décret impérial.

Budget provincial d'Alger.

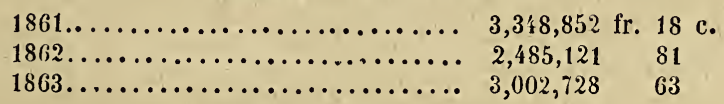

Budget provincial d'Orun.

$1861 \ldots \ldots \ldots \ldots \ldots \ldots \ldots \ldots \ldots .2,054,627$ fr. 71 c.

$1862 \ldots \ldots \ldots \ldots \ldots \ldots \ldots \ldots \ldots \ldots, 1,879,731 \quad 9,3$

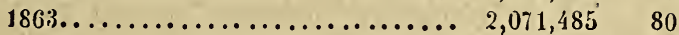

Budget provincial de Constantine.

$1861 \ldots \ldots \ldots \ldots \ldots \ldots \ldots \ldots \ldots \ldots . . . . .216,070$ fr. 14 c.

$1862 \ldots \ldots \ldots \ldots \ldots \ldots \ldots \ldots \ldots \ldots, 3,929,481 \quad 99$

$1863 \ldots \ldots \ldots \ldots \ldots \ldots \ldots \ldots \ldots \ldots \ldots \ldots \ldots \ldots, 3,2,766 \quad 46$

La recette la plus importante des budgets provinciaux est fournie par l'impôt arabe.

\section{Hudgets communaux.}

Les recettes ordinaires et extraordinaires des communes constiluées se sont élevées, en 1862, à $8,415,233$ francs.

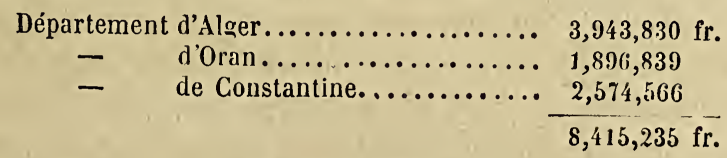

40 Hudgets locaux.

Ils sont spéciaux aux localités non érigées encore en communes.

Ils se sont élevés pour les trois provinces :

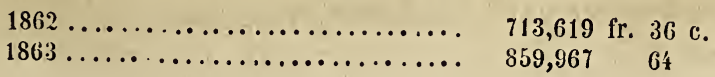




\section{Hudgets des centimes additionnels à l'impôt arabe.}

La quotité de ces centimes est de 18 centimes par franc d'impôt achour et zelikat (impôt sur la récolte et sur les bestiaux).

1862

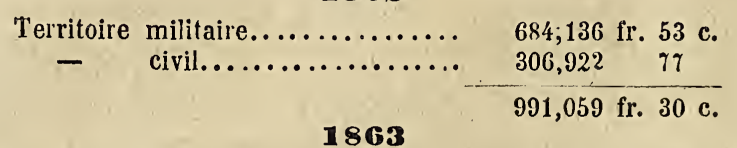

Territoire militaire........... 632,600 fr. 99 c.

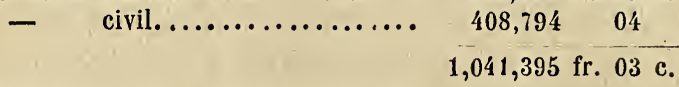

Impôts. On distingue, parmi les taxes établies, celles qui le sont au profit de l'État et celles qui le sont au profit des communes.

Les premières comprennent:

Les impôts arabes ;

La contribution des patentes;

Les droits d'enregistrement, de timbre, de greffe et d'hypothèques ;

Les droits de licence;

Le produit de la vente des poudres et des tabacs de la régie de France; les droits de garantie des matières d'or et d'argent;

Les droits de vérification des poids et mesures ;

Les droits de douane.

Les secondes comprennent :

La taxe des loyers;

Les prestations en nature;

La taxe sur les chiens;

L'octroi de mer.

Impôts arabes. En territoire civil, les indigènes, outre les taxes qu'ont à subir les Européens, supportent les impôts achour et zekkat, représentant à peu près l'impôt foncier dont les Européens sont exempts.

En territoire militaire, les indigènes payent l'achour, le hokor, la zekkat ct la lezma.

L'achour, dîme sur les récoltes, payé d'abord en nature, est aujourd'hui payé en argent. Il est fixé, dans les provinces d'Alger et d'Oran, tous les ans d'après l'importance des moissons et le prix des denrées; dans la province de Constantine, il est fixé à 2 francs. 
Le hokor est une sorte de loyer fixé à 20 francs. Il est spécial à la province de Constantine. Réuni à l'achour, il s'élève à 400 francs par charrue.

La zelkat, impôt sur les bestiaux, est arrêtée, chaque année, par le gouverneur général. En 1863, le tarif était ainsi arrêté :

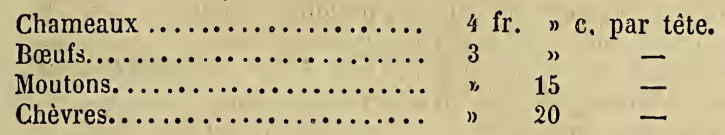

La lezma est une redevance fixe, qui porte sur des tribus non soumises à notre domination, mais reconnaissant notre souveraineté. Chez les Kabyles, c'est un impôt de capitation; dans quelques oasis, c'est une taxe sur les palmiers.

Le produit des impôts arabes s'est élevé :

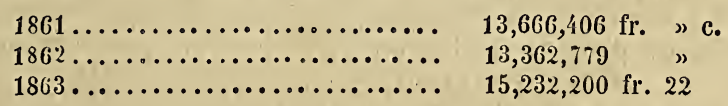

Amendes. Les amendes, dont les tribus ou fractions de tribus sont frappées, sont recucillies par les chefs indigènes et versées à la caisse du receveur des contributions diverses.

Elles se sont élevées :

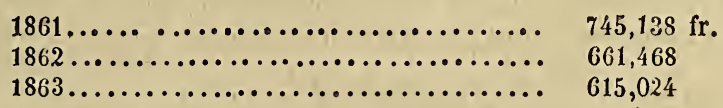

OctroI DE MER. Il est perçu sur les denrées qui arrivent par mer, et sur tous les produits tunisiens et marocains susceptibles d'un droit à l'entrée par mer.

Il s'est élevé :

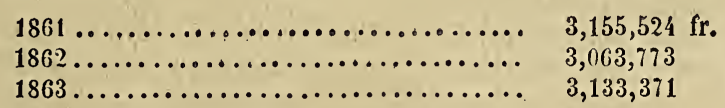

Aux documents qui précèdent, extraits de l'État de l'Algérie, publié en 1864, nous ajouterons ceux qui suivent et que nous extrayons du Tableau de la situation, publié en 1866.

Produits et revenus réalisés au profit du Trésor pendant l'exercice 1864.

Le chiffre de ces produits s'est élevé à 20,093,814 fr. 29 c., se décomposant ainsi : 
Contributions directes............. 706,659 fr. 45 c.

Enregistrement, timbre et domaines..... 5,205,692 77

Forêts..................... 143,317 22

Douanes.................... 2,406,637 68

Contributions indirectes............ 1,488,706 30

Postes...................... 894,631 65

Contributions arabes $(5 / 10) \ldots \ldots \ldots \ldots \ldots 6,154,131 \quad 67$

Produits divers (redevances, produits des

mines, télégraphie privée, brevets d'in-

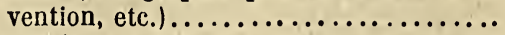

Recettes de différentes origines (prises sur

$582,744 \quad 82$

l'ennemi, contributions extraordinaires

de guerre, etc.)............... 2,511,892

Télégraphie.

Réseau télégraphique des trois provinces..... 3,983 kilom.

de la régence de Tunis... $\quad 517$

Ils se répartissent ainsi :

4,500 kilom.

Province d'Alger.................. 1,355 kilom.

- d'0ran .................... 816

- de Constantine............... 1,812

Régence de Tunis................... 517

Trois lignes nouvelles ont été ouvertes en 1864:

De Mascara à Saïda (province d'Oran)......... 80 kilom.

De Relizane à Tiaret (mème province)......... 100

De Bordj-bou-Aréridj à Bou-Saada (province de

Constantine)..................... 118

En 1864, il y avait 54 bureaux ouverts :

Province d'Alger..................... 17

- d'Oran............................. 13

- de Constantine........................ 18

Régence de Tunis........................ 6

Nombre des dépêches officielles en $1864 \ldots \ldots . \quad 66,548$

Nombre des dépêches privées........... 189,009

Recettes produites par les dépêches privées... 257,318 fr. 63 c.

Postes.

Produit net de la taxe des lettres........ 732,361 fr. 37 c.

Droit sur les articles d'argent $\left(\begin{array}{llll}1 & 0 / 0\end{array}\right) \ldots . \quad 31,637 \quad 14$

Droit de 10 0/0 sur les valeurs déclarées.... $13,523 \quad 94$

Recettes diverses et accidentelles......... $\quad 950 \quad 70$

Produit net des places sur les paquebots... 116,158 50

894,631 fr. $65 \mathrm{c}$.

En 1863, le chiffre des recettes avait été de 890,304 fr. 10 c.

1863. Nombre des lettres rebutées............ 33,619

1864. - $\quad$ - $\quad \ldots \ldots \ldots \ldots \ldots \ldots . .6 \% 32,305$ 
Les lettres indigènes forment environ un dixième de la correspondance. Elles fournissent un tiers des rebuts.

1863. Nombre des timbres-poste vendus........ $3,454,450$

1864. - - - ........ 3,490,074

Ces progrès sont dus à plusieurs améliorations introduites dans le service des postes en 1864, notamment: à la création d'un bureau ảe recette à Relizane, à l'exactitude du service dans les environs des principaux centres et sur le parcours du chemin de fer, au nombre des courriers qui a été doublé entre Alger et les principaux centres de la Kabylie, à l'utilisation, pour le transport des dépêches, des services de navigation à vapeur entre Bone et Stora, d'une part, et Marseille, de l'autre, ce qui permet à la province de Constantine comme à la province d'Alger, d'échanger trois fois par semaine des dépêches avec la France.

\section{Enregistrement et domaines (1864).}

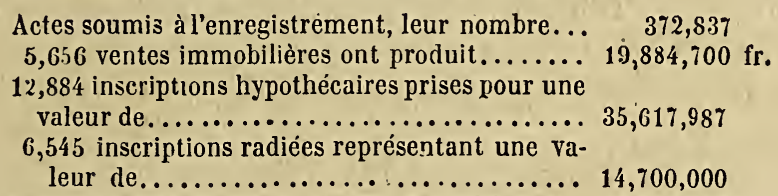

Droits d'enregistrement, greffe, hypothèques.. 2,483,173

Perçu au profit des provinces............ 312,131

Perçu au profit des localités non encore érigées en communes (permis de chasse, cimetières, fourrières publiques, etc.)............ 103,147

\section{Contributions diverses.}

Ce service comprend, entre autres, l'octroi de mer, qui, en 1864 , a produit $3,526,397 \mathrm{fr}$. perçus sur $26,257,211 \mathrm{fr}$. de valeur importée.

$$
\text { Impôt foncier. }
$$

Par décision impériale du 2 juillet 1864, le principe de l'impôt foncier pour les propriétés européennes, s'appliquera désormais à l'Algérie.

Il sera question des Douanes dans le chapitre suivant. 


\section{CHAPITRE VIII}

Commerce. - Importations. - Exportations. - Douanes. - Mouvement de la navigation en 1864 . - Cabotage. - Mouvement des entrepôts réels et fictifs. Pèche du corail. - Pêche du poisson.

Avant la domination française, le commerce algérien se bornait aux plumes d'autruche, aux dents d'éléphant, aux dattes, tapis, parfums, poudre d'or. Depuis lors, les choses ont singulièrement changé de face.

Depuis 18ว0, époque où l'Assemblée constituante a voté le libre commerce entre la France et l'Algérie, c'est-à-dire en treize ans, les importations en Algérie ont doublé; quant aux exportations, elles ont presque septuplé.

"Les États-Unis, disait avec raison M. le baron Charles Dupin, en présentant le rapport de la loi sur la convention Frémy et Talabot (Sénat, 7 juillet 1863ั), les États-Unis, l'Australie et le Canada, dont on fait de si grands et si justes éloges entre les années 1800 et 1863 , sont bien loin de présenter un si merveilleux progrès."

\section{0}

Valeur des marchandises importées..... $\quad 72,692,782 \mathrm{fr}$.

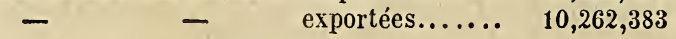

\section{4}

Importations ................. 136,458,793 fr.

Exportations................ 108,067,354

La France entre dans le chiffre des importations, pour $121,410,361 \mathrm{fr}$., ou 89 pour 100, et l'étranger pour 15,048,432 fr. ou 11 pour 100.

La France entre, dans le chiffre des exportations, pour $80,262,225 \mathrm{fr}$. et l'étranger pour 17,80ð,129 fr. différence : 76 à 26 pour 100 .

\section{RECETTES.}

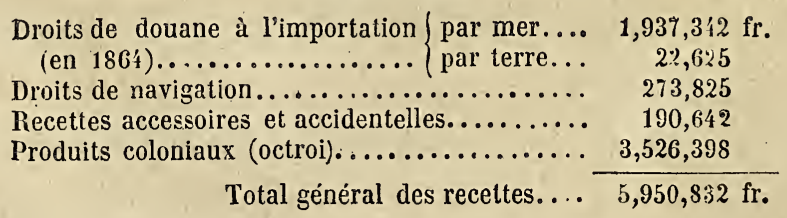




\section{ALGÉRIE.}

Mouvement de la navigation (1864).

E N T R É

(France.)

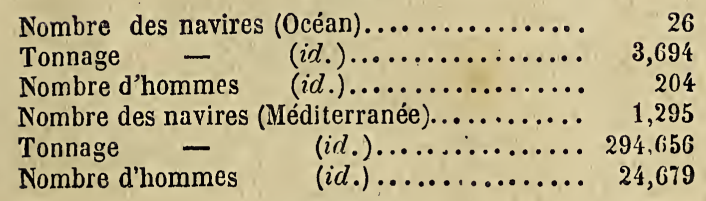

Nombre d'hommes

(id.) $\ldots \ldots \ldots \ldots \ldots$..... 24,679

\section{Étrønger.}

Nombre des navires.................. 2,240

Tonnage .......................... 167,495

Nombre d'hommes d'équipage............ 20,925

Il y a eu, sur 1863, une augmentation de 621 navires, 66,149 tonneaux, et 6,221 hommes.

\section{S O R T I E.}

(France.)

Nombre des navires (Océan) $\ldots \ldots \ldots \ldots \ldots \ldots . .183$

Tonnage $\quad-\quad$ (id.)................. 29,280

Hommes d'équipage (id.)................ 1,453

Nombre des navires (Méditerrauée)......... 1,125

Tonnage - $\quad$ (id.) $\quad$...........272,367

Hommes d'équipage (id.) $\quad \ldots . . . . . .2 \quad 23,583$

(Étranger.)

Nombre des navires.................. 2,193

Tonnage ........................... 160,i,

Hommes d'équipage.................. 20,363

L'augmentation, sur 1863, a été de 605 navires, 60, 222 tonneaux, et 6,457 hommes.

Les pays étrangers avec lesquels la colonie a entretenu le plus de relations maritimes sont: l'Angleterre, l'Italie et l'Espagne.

Sous le rapport du tonnage, la France entre dans le mouvement de la navigation pour $\mathbf{7 8 . 7 6}$ pour 100 ; l'Espagne pour 7.28 ; l'Angleterre, 5.03; l'Italie, 4.84; l'Autriche, 1.0د (V. Tableau de la situation des Établissements français dans Algérie, en 1864. Paris, Imprimerie impériale, 1866 , gr. in $\left.-4^{\circ}\right)$.

Mouvement du cabotage entre les ports de l'Algénie (1864.

Les céréales, les huiles, les boissons, toutes les denrées alimentaires en général, forment les principaux éléments de cette navigation. 
En 1863, le poids total des marchandises mises en circulation par cette voie a été de 507,222 quintaux métriques. En 1864, il a été de 508,738. Différence (augmentation): 1,516 quintaux métriques.

Mouvement des entrepôts réels et fictifs.

Entrepôts réels. - (Entrées.)

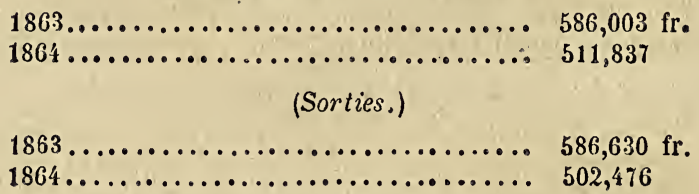

Entrepôts fictifs. - (Entrées.)

$1863 \ldots \ldots \ldots \ldots \ldots \ldots \ldots \ldots \ldots \ldots \ldots, 3,723,247$ fr.

$1864 \ldots \ldots \ldots \ldots \ldots \ldots \ldots \ldots \ldots \ldots .4,627,690$

(Snrties.)

$1863 \ldots \ldots \ldots \ldots \ldots \ldots \ldots \ldots \ldots \ldots \ldots, 3,765,851$ fr.

$1864 \ldots \ldots \ldots \ldots \ldots \ldots \ldots \ldots \ldots \ldots \ldots \ldots \ldots \ldots \ldots, 4,643,460$

Diminution, pour les entrepôts réels, à l'entrée, de 74,166 fr., et, à la sortie, de 84,154 fr.

Augmentation, pour les entrepôts fictifs, à l'entrée, de $904,443 \mathrm{fr}$, et, à la sortie, de $877,609 \mathrm{fr}$.

Pêche du corail (1864).

Nombre des bateaux français............... 186

- $\quad$ - italiens................. 118

- $\quad$ - espagnols............... 23

En 1860, on comptait 26 bateaux français seulement, 152 italiens et 26 espagnols.

Le chiffre des prestations, malgré l'augmentation du mauvement, n'est allé qu'à 100,800 fr. Le décret du $1^{\text {er }}$ juin 1864 a exonéré des prestations beaucoup de barques corallines.

Pêche du poisson (1864).

Nombre des bateaux français.............. 229

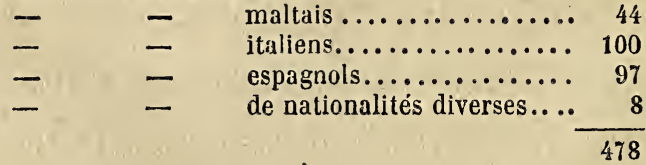




\section{CHAPITRE IX}

\section{ADMINISTRATION PROVINGIALE.}

Communes ; leur nombre en 1864. - Assistance publique : hôpitaux et infirmeries; établissements d'eaux thermales ; établissements d'aliénés ; orphelinats; bureaux de bienfaisance. - Mont-de-pićté d'Alger. - Caisses d'épargne. Sociétés de secours mutuels. - Prisons civiles. - Animaux nuisibles.

\section{$\S 1$. Communes.}

1863. Nombre des communes.............. 71

1864. - $-\quad$ - $\ldots \ldots \ldots \ldots \ldots \ldots$. 74

Les centres de Mers-el-Kébir, Aïn-el-Turck, et Bou-Tlélis (province d'Oran), ont été érigés en communes de plein exercice.

La province ou département d'Alger comprend 29 communes et 64 annexes.

La province ou département d'Oran comprend 21 communes et 38 annexes.

La province ou département de Constantine comprend 24 communes et 27 annexes.

§ 2. Hôpitaux et infirmeries (1863).

Province d'Alger. Hôpitaux militaires............ 17

- - - civils................. 4

Province d'Oran. Hôpitaux militaires............... 12

- $\quad$ - $\quad$ civils.................. 7

Province de Constantine. Hôpitaux militaires........ 12

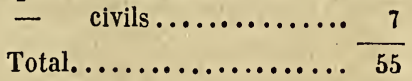

En 1863, il a été traité dans ces divers établissements, 43,260 individus civils ainsi répartis :

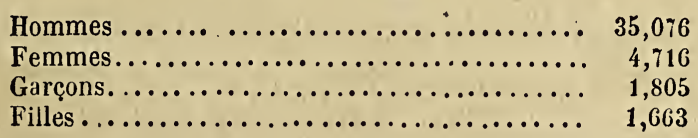

Les décès ont été dans les proportions suivantes :

Femmes............................ 6.40 p. 100

Garçons............................ 5.05

Filles............................... 6.04

Hommes.,......................... 4.94 
La mortalité a été :

$$
\begin{aligned}
& 1862 \ldots \ldots \ldots \ldots \ldots \ldots \\
& 1863 \ldots \ldots \ldots \ldots \ldots \\
& 18,762 \text { malades dont } 2,048 \text { morts. }
\end{aligned}
$$

\section{6是}

Nombre des hôpitaux ou ambulances militaires... 41

llôpitaux civils....................... 14

Nombre des malades civils traités. ........... 39,433

Nombre des malades indigènes traités........ 10,000

Rapport du nombre des malades aux décès: $\mathbf{4 . 8 2}$ pour $\mathbf{1 0 0}$ dans leshôpitaux civils; 5.47 pour 100 dans les hôpitaux militaires. (A Paris, ce rapport est, à la Charité où il meurt le moins de malades, de 9.59 pour 100 ).

§ 3. Etablissements d'eaux thermales.

Un grand nombre de sources thermales existent en Algérie. Trois de ces sources sont surtout exploitées :

Hammam-Rira (province d'Alger);

Bains de la Reine (province d'Oran);

Hammam-Meskoutin (province de Constantine).

Ln 1864, il a été traité dans ces trois établissements 432 malades.

\section{$\S 4$. Établissement d'aliẻnés.}

La plupart des aliénés sont renvoyés en France dans les établissements d'Aix, Marseille, Dijon et Montpellier. L'asile de Milah (province de Constantine) recueille un petit nombre d'aliénés inusulmans.

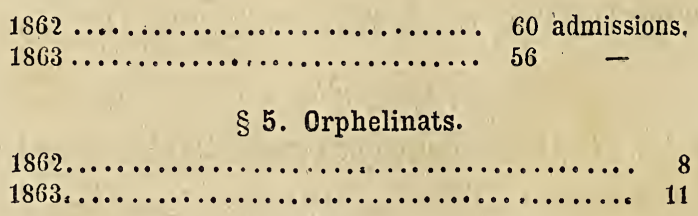

L'orphelinat de Dély-Ibrahim (province d'Alger) est spécial aux protestants.

En 1863, il est entré, dans ces divers orphelinats, 262 enfants des deux sexes.

Orphelinats (1864).

Leur nombre.

Province d'Alger : Mustapha (garçons et filles), Bouffarick (garçons), Dély-Ibrahim (mixte), El-Biar (filles). 
Province d'Oran : Misserghin (garçons et filles).

Province de Constantine: Bone (filles), Soukharas (garçons).

L'orphelinat de Dély-lbrahim est spécial aux protestants.

Ces établissements avaient, en 1864, 1,365 enfants.

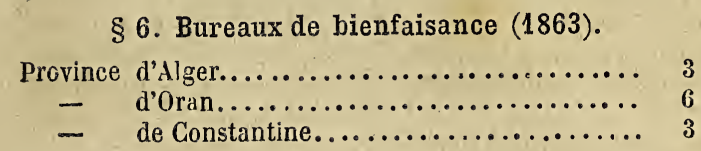

Les recettes se sont élevées à 164,574 fr. Les dépenses en secours à 106,408 fr. On a secouru 10,596 indigents.

Les Musulmans d'Alger ont un bureau spécial, subventionné par le bureau provincial. Cette subvention s'élève à $80,318 \mathrm{fr}$.

\section{4}

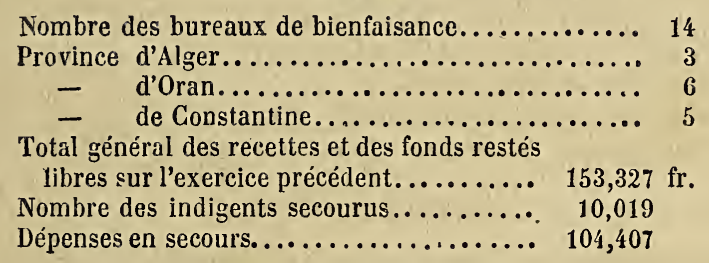

$\S 7$. Mont-de-piété d'Alger.

1864

Nombre d'articles ayant été l'objet d'un prêt, par engagement ou par renouvellement, en $1863: 53,6507$.

Sommes prêtées.................. 1,115,732 fr.

Moyenne des prêts par article : $20 \mathrm{fr} .79 \mathrm{c}$.

Il a été dégagé, en $1863,49,341$ articles, montant à.......................

2,060 articles vendus pour. .............

Ce sont les Israélites qui empruntent les plus fortes sommes el qui abandonnent le plus de nantissements :

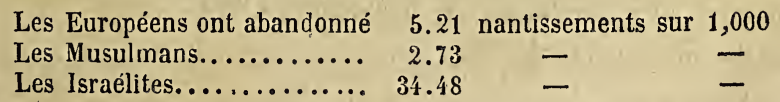

Sur les $\mathbf{5 3 , 6 5 7}$ articles engagés ou renouvelés en $\mathbf{1 8 6 3}$, on en compte 87 seulement qui ont été l'objet d'un prêt de 500 à 1,000 fr., et 27 qui ont été celui d'un prêt de 1,001 fr. et au-des- 
sus. D'où cette conclusion que le commerce en gros emprunte peu au mont-de-piété.

\section{4}

Engagements .......................... 49,515

Renouvellements..................... 2,731

Sommes prètées.............. 1,133,787 fr. " c.

Noyenne du prêt, par article........... $21 \mathrm{fr} .70$

Nombre d'articles dégagés................. 50,312

Moyenne des sommes prêtées :

Aux Européens...................... 21 fr. 31 c."

Aux Arabes....................... 19 n

Aux Juifs........................ $33 \quad 70$

\section{§ 8. Gaisses d'épargne.}

Dans les cinq caisses existant à Alger, Oran, Constantine, Philippeville et Bone, il y avait à la fin de 1863, 5,022 livrets.

Encaisses et crédits divers........... 2,038,045 fr.

Remboursements et versements......... .770,192 -

Solde dù aux déposants............ 1,267,853 -

Caisses d'épargne (1864).

5 caisses d'épargne : Alger, Oran, Constantine, Philippeville et Bone.

Solde dû aux déposants le $1^{\text {er }}$ janvier $1864 . . \quad$ 1,266,671 fr.

Sommes déposées en 1864 (3,727 déposants). $\quad 743,909$

Intérèts et arrérages.............. 42,565

Soit, en masse.......... $\overline{2,053,145 \mathrm{fr}}$

D'où il faut retrancher :

Remboursements en espèces ou rentes achetées......................... 732,629

Soit, pour solde dû aux déposants (31 décembre 1864).................

Sur le nombre des déposants, les militaires et les marins comptent pour plus de 57 pour 100 .

Le nombre des livrets au 31 décembre 1864 , était de 5,078 ; soit 412 de plus qu'en 1863.

$\S$ 9. Sociétés de secours mutuels (1863).

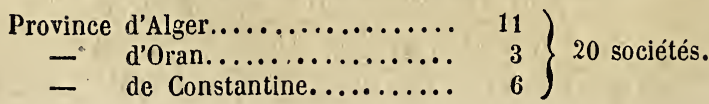


Nombre des sociétaires.................... 5,695

Produit des cotisations.............. 65,000 fr.

Nombre des malades secourus. .............. 1,602

On compte parmi les sociétaires :

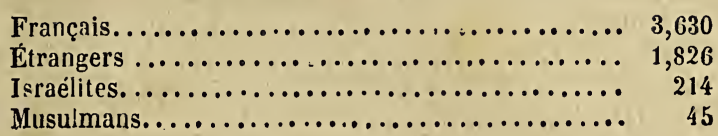

Sociètés de secours mutuels (1864).

35 sociétés de secours mutuels : province d'Alger; 20 ; province d'Oran, 4 ; province de Constantine, 11.

Nombre des sociétaires..................... 5,177

Produit des cotisations et recettes diverses... 69,375 fr.

Nombre des sociétaires secourus................. 1,293

Tutal des dépenses................... $67,541 \mathrm{fr}$.

Dans le chiffre de 5,177, les Français figurent pour 3,466; les Espagnols, 759; les Italiens, 262 ; les Allemands, 141 ; les Israélites, 277; les Musulmans, 86, etc.

\section{$\S 10$. Prisons civiles.}

Département d'Alger......... 4 maisons de détention.

- deran........... $3{ }^{3} \quad$ -

Au 31 décembre 1863, il restait dans ces maisons 2,583 détenus, savoir :

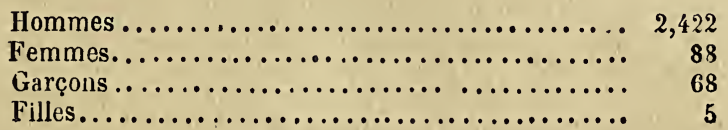

\section{1}

14 prisons civiles : province d'Alger, 4 ; province d'Oran, 3 province de Constantine, 7.

Entrées en 1864

6,222

\section{$\S 11$. Animaux nuisibles.}

\section{Primes accordées :}

Lion ou lionne..................... $40 \mathrm{fr}$.

Lionceau de 1 à 6 mois................ 15

Panthère......................... 40

Jeune panthère..................... 15 
Hyène........................... 5 fr. w $\mathrm{c}$.

Jeune hyène $\ldots \ldots \ldots \ldots \ldots \ldots \ldots \ldots \ldots \ldots \ldots, 1-50$

Chacal............................. $1-50$

En 1863, il a été abattu dans les trois provinces :

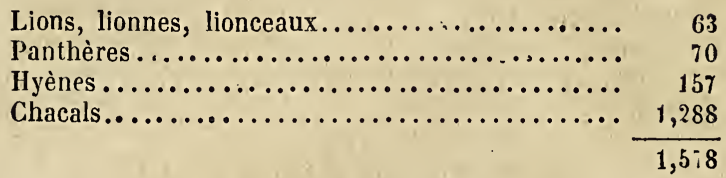

C'est dans la province de Constantine, la plus boisée des trois provinces, que se trouvent le plus grand nombre de betes fauves.

\section{GHAPITRE X \\ INSTITUTJONS DE GRÉDIT.}

Opérations de la Banque d'Algérie en 1863 et 1864. - Crédit foncier de France : ses opérations en 1864. - Société Frémy et Talabot. - Mont-de-piété d'Alger (V. le chap. Ix).

\section{$\S 1$. Banque d'Algérie.}

(1862-1863.)

Escompte (du 1er novembre au 31 octobre 1863).

Les agios de l'escompte ont produit..........
Les effets à l'encaissement se sont élevés à 31,525 effets, et à....................

Les traites du Trésor reçues des correspondants en couverture des encaissements de la Banque, ou prises au Trésor, se sont élevées à 6,262

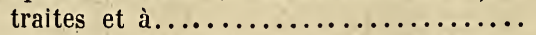

Circulation permanente des billets de la Banque pendant l'exercice $1862-1863 . . . \ldots$.

Banque d'Algérie (1864).

(13e Exercice.)

Escompte

Agios de l'escompte

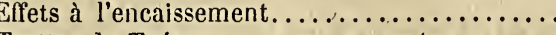

Traites du Trésor reçues en couverture.......

Circulation permanente des billets de la Banque pendant ce $13^{\mathbf{e}}$ exercice.................

Effets en souffrance...................
$72,798,117 \mathrm{fr}$.

623,656

$15,423,039$

$21,471,200$

$5,468,450$

$15,423,039$

$77,894,541 \mathrm{fr}$.

676,354

$25,273,028$

$25,310,000$

$5,036,950$.

7,529 


\section{$\S$ (2. Grédit foncier de France (1864).}

(Succursale de l'Algérie).

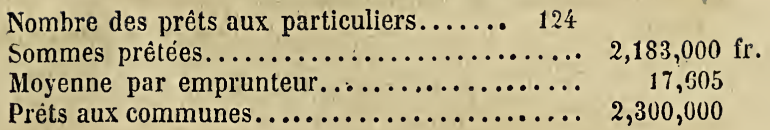

§ 3. Société Frémy et Talabot.

La Convention passée entre S. E. le ministre de la guerre et MM. Frémy, gouverneur du Grédit foncier de France et d'Algérie, Paulin Talabot, directeur général de la Compagnie des chemins de fer de Paris à la Méditerranée et de l'Algérie, et consorts, a été approuvée par le Corps législatif, dans sa séance du 3 juillet 186ว, et par le Sénat, dans sa séance du 7 du même mois.

Aux termes de cette convention, la Compagnie doit procurer des capitaux et ouvrir des crédits pour toutes opérations agricoles, industrielles et commerciales en Algérie, entreprendre ou réaliser ces opérations directement et par elle-même.

Elle est fondée au capital de 200 millions, sur lesquels 100 mil-lions doivent être prêtés à l'État et dépensés en six ans par celuici aux travaux publics de l'Algérie.

\section{§4. Mont-de-piété d'Alger.}

Voir le chapitre IX.

\section{CHAPITRE XI}

\section{INSTRUCTION PUBLIQUE.}

Enseignement supérieur. - Enseignement secondaire. - Enseignement primaire.

\section{3}

10 Enseignement supérieur.

École de médecine et de pharmacie à Alger.

Cours publics d'arabe.

$2^{\circ}$ Enseignement serondaire.

Lycée impérial d'Alger........... 503 élèves (1863).

Collége communal de Bone......... 121

- de Constantine.... 134

de Philippeville.... 77 
Collége communal d'Oran......... 132 élèves )1863).
de Tlemcen..... 25
Institution privée de Notre-Dame, à
Oran.$\ldots \ldots \ldots \ldots \ldots \ldots \ldots \ldots \ldots \ldots$. $139 \quad-$ (inst. ecclés.).

$3^{\circ}$ Enseignement primaire.

1862. Nombre des établissements........... 471

Nombre des élèves reçus.............. 35,999

Européens ................ 31,325

Indigènes israélites.......... 4,376

- musulmans........... 298

Enseignement laique............... 15,257

congréganiste $\ldots \ldots \ldots \ldots \ldots .20,742$

De 1861 à 1863,25 écoles nouvelles ont été créées.

$4^{\circ}$ Instruction publique chez les indigènes.

Collége impérial arabe-français (créé en 18577).

Les 3 médersas (écoles supérieures musulmanes).

Les écoles françaises musulmanes.

Les écoles primaires musulmanes.

\section{4}

L'Académie d'Alger embrasse les trois provinces. Elle comprend tous les établissements destinés aux élèves chrétiens et israélites des deux territoires.

Quant aux établissements destinés aux musulmans, ils relèvent du gouverneur général.

ACADÉMIE D'ALGER.

Recteur........................... 1

Inspecteurs d'académie....................

Secrétaire............................ 1

Commis.......................... 1

Inspecteurs primaires................... 3

École de médecine et de pharmacie............. 1

Cours pubiics d'arabe (Alger, Oran, Constantine)..... 3

Lycée (Alger)...................... 1

Culléges (Bone, Constantine, Oran, Philippeville)... 4

Ecole libre d'Oran (des pères jésuites).

Classes élémentaires, à Tlemcen et à Mascara.

École secondaire ecclésiastique d'Alger.

Maîtrises.

Écoles (enseignement primaire)..$\ldots \ldots \ldots \ldots \ldots .233$

Médersas (écoles supérieures pour les indigènes)... 3

(A Alger, Tlemcen et Constantine).

- Voir pour plus de détails, en ce qui concerne les indigènes, le chapitre XVI: 


\section{GHAPITRE XII}

C ULTES.

Culte catholique. - Culte protestant. - Culte hébraïque. - Culte musulman (V. chap. Xvi). - Situation en 1863 et 1864 .

\section{3}

1 diocèse.

$1^{\circ}$ Culte catholique.

176 paroisses.

44 vicariats.

Province d'Alger : grand séminaire de Kouba.

École secondaire ecclésiastique de Saint-Eugène.

Maîtrise de la cathédrale.

13 aumôniers.

Abbaye de la Trappe (Staouëli : 120 religieux).

Maison des PP. Jésuites et œuvre de Saint-Régis.

Maison des Lazaristes.

2 orphelinats : Bouffarick et Ben-Aknoun. .

Province d'Oran : 7 aumôniers.

Maison des PP. Jésuites.

1 orphelinat (Missergbin).

Province de Constantine: 8 aumôniers.

Maison des PP. Jésuites.

Dans chaque province on compte, en outre, des prêtres auxiliaires et des sœurs de la Doctrine chétienne ou de différents ordres.

$$
2^{\circ} \text { Culte protestant. }
$$

Province d'Alger.......1 consistoire central.

Id. 4 conseils presbytéraux.

Province d'Oran....... 3 conseils presbytéraux.

Province de Constantine.. ã conseils presbytéraux.

$3^{\circ}$ Culte hébraïque.

Province d'Alger........ 1 consistoire, ๖̀ membres.

Province d'Oran........ 1 id. 4 id.

Province deConstantine... 1 id. 4 id.

\section{4}

Culte catholique.

Paroisses............................... 181 
Vicariats............................. 21

Églises............................. 225

Culte protestant.

Consistoire central....................... 1

Conseils presbytéraux...................... 11

Paroisses ................................ 12

Culte hébraïque.

Consistoire central..................... 1

Consistoires provinciaux.................. 2

- Pour le Culte musulman, voir chapitre XVI.

\section{GHAPITRE XIII}

JUSTICE.

Organisation judiciaire. - Statistique judiciaire. - Situation en 1863 et en 1864. - Justice indigène (V. chap. xvi).

\section{3}

1 Cour impériale, à Alger.

9 tribunaux de première instance.

3 tribunaux de commerce.

36 justices de paix.

1863. Chiffre des affaires civiles............. 5,558

- commerciales......... 8,846

Nombre des faillites................. 168

Accusations pour crimes contre les personnes. $\quad 88$

- contreles propriétés. $\quad 199$

Délits correctionnels................. 3,642

Appels entre Musulmans des jugements des cadis en matière civile et commerciale portés devant les tribunaux civils des trois provinces..........................

Nombre des actes reçus par les notaires de l'Algérie et portant conventions entre Musulmans seuls :

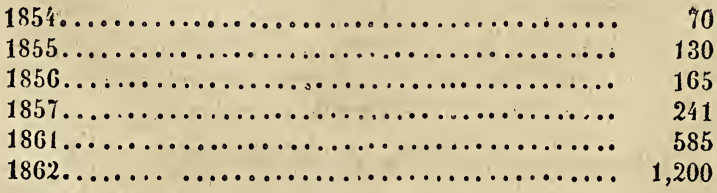




\section{4}

En Algérie, la justice civile est rendue par :

1 Cour impériale (siégeant à Alger);

9 tribunaux de première instance ;

27 justices de paix ;

7 commissair es civils faisant fonctions de juges de paix, et, en territoire militaire, les commandants de place.

Il y a deux ordres de juges de paix : ceux à compétence ordinaire (auxquels sont à peu près assimilés les commissaires civils et les commandants de place) ont la même juridiction que les juges de paix de France; ceux à compétence étendue connaissent de toutes les actions civiles et commerciaies, jusqu'à 500 fr. en dernier ressort, et jusqu'à 1,000 en premier ressort.

Les tribunaux français connaissent, sans distinction de territoire, des contestations entre Français, entre Europécns et indigènes, et même.entre indigènes, lorsque ceux-ci, dans l'acte attaqué, ont déclaré se soumettre à la loi française ou se présentent, d'un commun accord, devant les tribunaux français. - Les indigènes, en outre, peuvent toujours appeler des jugements de leurs cadis devant les tribunaux de $\mathbf{1}^{\text {re }}$ instance, si l'objet du litige excède $200 \mathrm{fr}$. et ne dépasse pas $1,500 \mathrm{fr}$.; devant la Cour impériale, s’il excède 1,500 fr.

$$
\text { COUR IMPÉRIÁLE (1864). }
$$

Nombre des affaires à juger............... 1,388

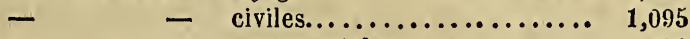

- $\quad$ - commerciales............. 279

TRIBUNAUX CIVILS (1864).

Nombre des affaires à juger pour les 9 tribunaux civils (Alger, Oran, Constantine, Blidah, Bone, Mostaganem, Philippeville, Sétif et Tlemcen)... $\quad 6,938$

Nombre des affaires jugées............... 5,882

Venteș judiciaires...................... 656

Ces ventes ont produit $4,216,104 \mathrm{fr}$.

$$
\text { TRIBUNAUX DE COMMERCE (186'). }
$$

Nombre des affaires à juger............... 8,520

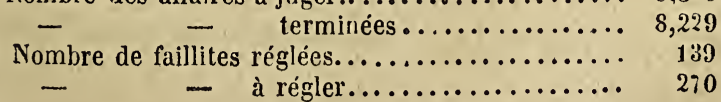

JUSTICES DE PAIX ET COMMISSARIATS CIVILS (1864).

Nombre des billets d'avertissement.......... 44,469 
Conciliations...................... 14,269

Affaires jugées ou à juger................ 13,577

JUGEMENTS RENDUS PAR LES COMMANDANTS DE PLACE FAISANT FONCTIONS DE JUGES DE PAIX EN TERRITOIRE MILITAIRE. .

Affaires jugées.

2,102

JUSTICE CRIMINELLE.

Les Européens et les indigènes sont justiciables des tribunaux criminels ordinaires pour tous les crimes et délits commis par eux en territoire civil (ordonnance 26 septembre 1842).

Les crimes et délits commis par des Européens ou des Israélites en territoire militaire sont déférés aux cours d'assises et aux tribunaux correctionnels (décret 15 mars 1860).

Nombre des justiciables des deux territoires en 1864: Européens, 235,570 ; Musulmans ou Israélites, 386,857.

Les cours d'assises, en Algérie, jugent sans l'assistance du jury.

Grimes contre les personnes................ 104

propriétés................ 127

Les indigènes fournissent les trois quarts des accusés.

Il s'est présenté devant la police correctionnelle 3,639 affaires. - Le nombre des récidivistes a été de 5ั27.

Les tribunaux de simple police ont rendu 11,69ð jugements.

- Voir pour la Justice indigène le chapitre XVI.

\section{CHAPITRE XIV}

\section{A R M É E T M A R I NE.}

Armée : effectif. - Hôpitaux et ambulances militaires. - Justice militaire. Établissements hippiques. - Fortifications. - Marine : effectif.

\section{$\S 1$. Armée.}

En 1864, l'effectif de l'armée d'Afrique s'est élevé à 92,897 hommes et à 18, 486 chevaux; savoir :

Troupes françaises de toutes armes....

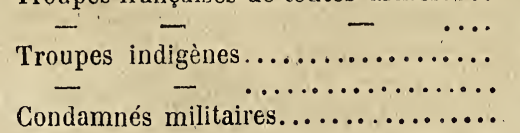

79,921 hommes. 3,5,6 chevaux. 9,763 hommes. 3,546 chevaux. 2,922 hommes. 3 chevaux. 
Sur cet effectif, 300 officiers, 8,432 hommes de troupe, 285 chevaux d'officiers, et 2,229 chevaux de troupe ou de trait, ont été détachés au corps expéditionnaire du Mexique ; - 2 officiers et $\mathbf{4 5}$ hommes de troupe ont été détachés au corps expéditionnaire de la Cochinchine.

Pour les quatre années 1861, 1862, 1863 et 1864, voici quel a été l'effectif des troupes:

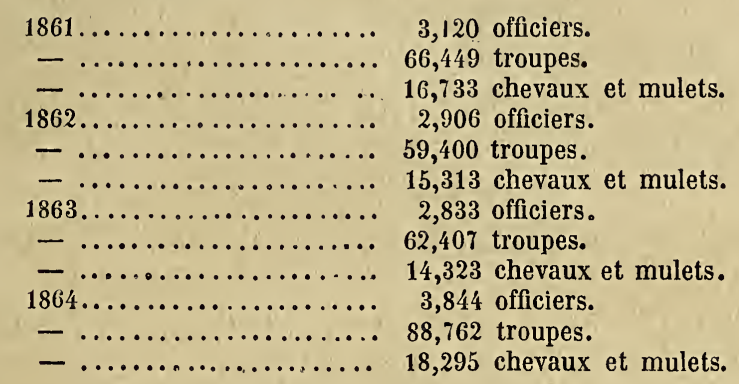

L'effectif plus considérable de 1864 a été nécessité par l'insurrection du sud.

HOPITAUX ET AMBULANCES MILITAIRES.

รัวั,802 militaires ont été admis, en 1864, dans les hôpitaux et ambulances divisionnaires. Il en est mort 866 , ou 1,55 pour 100.

20,468 malades civils ont été admis dans les mêmes établissements. Il en est mort 1,120 ou 5,47 pour 100 . - Il est à noter que les indigènes, Arabes, Kabyles et Juifs, fournissent un nombre considérable de malades civils; ce nombre va chaque année en augmentant.

Maladies les plus fréquentes : fièvres à types quotidiens, trèssouvent accompagnées d'hypertrophie de la rate et d'engorgement du foie ; affections rhumatismales, affections de l'appareil respiratoire. - Ghez les indigènes, maladies syphilitiques et cutanées.

\section{JUSTICE MILITAIRE.}

Conseils de guerre. Ils connaissent à la fois des crimes et délits commis par des militaires, et des crimes et délits comımis en territoire militaire par les Arabes et les Kabyles. 
Nombre des prévenus jugés en $1864 \ldots \ldots \ldots \ldots \ldots \quad 1,805$

SAVOIR :

Militaires de toutes armes................ 1,337

Arahes et Kabyles...................... 464

Condamnés à mort.................... 39

- aux travaux forcés.............. 103

- à la réclusion................. 81

- aux travaux publics............. 181

- à l'emprisonnement.............. 1,040

Nombre des individus acquittés.................

Il y a eu, par conséquent, 19.2 acquittements sur 100 accusations.

\section{ÉTABLISSEMENTS HIPPIQUES.}

Service de la remonte. En 1864, trois dépôts dê remonte existaient en Algéric.

A Blidah (province d'Alger); à Mostaganem (province d'Oran); à Constantine (province de Constantine).

Un officier supérieur est à la tête de chaque dépôt.

Les remontes sont chargées des achats de chevaux pour le service de l'armée, de la surveillance des étalons impériaux entretenus dans les dépôts, de la surveillance des étalons đés tribus.

Remonte........................... 3,474

Prix total des achats....................... 1,439,258 fr.

Moyenne des achats....................... 414

Effectif des étalons impériaux (chevaux, baudets et poulinières)..$\ldots \ldots \ldots \ldots \ldots \ldots \ldots$.

Étalons des tribus.......................

Etalons approuvés et autorisés.............

Montant des primes données aux éleveurs..........

Nombre total des saillies opérées en $1864 \ldots \ldots .25,25,310$

205

425

27

22,945 fr.

\section{FORTIFICATIONS.}

Les travaux neufs et d'entretien, les acquisitions de terrains ou d'immeubles appropriés au service du génie, ont nécessité :

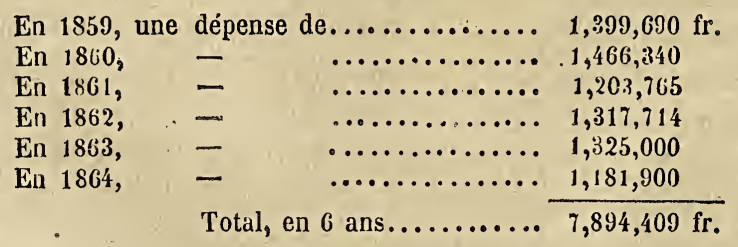

§ 2. Marine.

En 1864, le service de la marine à terre comprenait : 
27 officiers ou officiers de différents grades, attachés à la station;

408 ouvriers et marins, dans es différents ports du littoral.

4,955 patrons, marins et mousses étaient inscrits sur les matricules tenus dans les ports du littoral.

Il avait été attaché à la station : 8 navires à vapeur, 1 corvette à voiles, 1 brick à voiles, 1 balancelle et 1 péniche; en tout: 12 batiments.

62 officiers, chirurgiens et commissaires composaient l'étatmajor de ces navires; ils avaient 1,0:34 hommes d'équipage.

Les bâtiments faisant le service de la côte ont transporté 47,101 passagers (militaires et civils), et 1,892,636 kilogrammes de marchandises.

\section{GHAPITRE XV}

\section{SITUATION DES INDIGÈNES.}

Propriěté du sol. Sénatus-consulte du 22 avril 1863. - Réorganisation des tribus. - Terres domaniales. - Terres Melk, etc. - Justice en pays arabe. - Justice en pays kabyle. - Djemaâs. - Mehakmas. - Pénitenciers agricoles indigènes. - Instruction publique des indigènes. - Écoles des douars. - Zaouïas. Médersas. - Écoles arabes-françaises. - Collége impérial arabe-français. Travaux publics en territoira militaire. - Productions agricoles. - Fermeécole pour les indigènes à A:n-Ouarrât.

PROPRIÉTÉ DU SOL.

Par le sénatus-consulte du 22 avril 1863, on a assuré aux tribus de l'Algérie la propriété incommutable du sol qu'elles occupent.

Les conséquences de ce système doivent être de supprimer la propriété collective là où elle existe aujourd'hui, et de remplacer cette sorte de communisme par l'établissement de la propriété individuelle. Déjà cette propriété individuelle se rencontre sur certains points sous la dénomination de Melk. Il s'agit, avant tout, de la consolider.

Pour arriver à ce résultat si désirable, dit le Tableau de la situation (1864), l'Administration se trouve en face d'une tâche que quelques explications permettront d'apprécier.

Le sol de l'Algérie est partagé entre un grand nombre de tribus, 1,200 environ, qui, considérées au point de vue de l'occu- 
pation et de la jouissance du sol, peuvent se subdiviser en deux grandes catégories :

$1^{\circ}$ Les tribus Arch, à territoire en quelque sorte indivis, dont le nombre est bien moins considérable qu'on ne l'avait d'abord supposé ;

$2^{\circ}$ Les tribus Melk, où la terre est partagée entre propriétaires et détenue régulièrement en vertu de titres authentiques.

Le mode de procéder est le même pour chacune de ces deux catégories ; seulement, pour la première, la série des opérations se subdivise en trois parties bien distinctes, tandis que, pour la seconde, elle se borne à deux.

Lorsqu'une tribu est désignée pour être soumise à l'application du sénatus-consulte, le premier soin doit être naturellement de bien déterminer le territoire sur lequel on aura à opérer. Il faut donc délimiter ce territoire sur tout son pourtour; travail souvent délicat, car il soulève des difficultés graves avec les tribus voisines. Ce premier pas fait, on a dégagé de la masse confuse des terrains arabes le tout sur lequel devront porter les opérations. Cette première partie du travail est connue sous le nom de délimitation de la tribu. Elle est applicable à toutes les tribus, Arch ou Melk.

La délimitation n'est, à vrai dire, qu'une opération préliminaire faisant connaître nettement le territoire où il y aura lieu de concentrer les opérations ultérieures : aussi ne modifie-t-elle en rien l'organisation intérieure de la tribu. Elle n'en est pas moins d'une utilité évidente, par la raison bien simple que, lorsqu'on doit subdiviser un tout, il est nécessaire de le parfaitement connaître.

La deuxième partie consiste à distribuer entre un certain nombre de douars le territoire que la première partie a délimité. Par son importance, par l'influence qu'elle doit exercer sur la transformation de la société arabe, cette partie exige au plus haut degré l'attention des commissions et sous-commissions chargées d'appliquer le sénatus-consulte. De sa bonne et intelligente exécution dépendent, en effet, les résultats qu'on est en droit d'attendre du sénatus-consulte.

Rien dans la tribu, telle qu'elle existe aujourd'hui, ne répond au douar qu'il s'agit de constituer. C'est une création tout à fait nouvelle, qui doit correspondre comme étendue, population, ressources, à nos communes de France. C'est le commencement de 
la désagrégation de la tribu; c'est la suppression, dans un avenir plus ou moins éloigné, de cette unité territoriale dont la population est si difficile à surveiller, à diriger et parfois à contenir; c'est, en un mot, le germe de l'assimilation future des deux races. Ce rapide exposé doit faire comprendre tout l'intérêt qui s'attache à une bonne exécution de cette partie dı sénatus-consulte. Il permettra en même temps d'apprécier avec combien de soins et de prudente réserve on doit procéder à cette délicate innovation. Du reste, l'organisation intérieure des tribus facilitera, dans une certaine limite, l'introduction de ce nouvel élément. Telles que nous les trouvons constituées, les tribus se subdivisent ordinairement en fractions (ferka), et ces fractions en douars. C'est là une base qu'il ne serait pas sage de négliger, et l'expérience acquise permet de penser que, dans bien des cas, le douar à constituer pourra être formé d'un ou plusieurs anciens douars ou d'une fraction. Ce sera même là une combinaison avantageuse lorsqu'elle pourra se réaliser, car elle évitera de froisser les habitudes des indigènes et de jeter la perturbation dans des divisions territoriales qui existent depuis des siècles et qui sont connues de chacun. Mais les agents chargés de ce travail n'en auront pas moins à s'éclairer, par l'étude du terrain, des mœurs, du chiffre de la population, etc., sur l'opportunité de conserver intactes ou de modifier les subdivisions existantes. Ils auront à concilier le respect de la tradition et de la propriëté avec les obligations d'un ordre de choses nouveau pour les indigènes et qui doit exercer une influence immense sur l'avenir de l'Algérie.

Le travail de la Répartition du territoire de la tribu entre les douars présente donc de sérieuses difficultés. Mille exigences s'imposent à l'opérateur, qui est tenu de compter avec chacune d'elles. Rien d'absolu, rien de définitif dans le problème à résoudre. Ainsi telle tribu ne comprendra qu'un douar, telle autre en renfermera plusieurs; des considérations diverses obligeront à réduire la superficie d'un douar à 1,000 hectares, ou même moins; des raisons également graves nécessiteront l'attribution à un autre de 8 ou 10,000 hectares. La population de cette nouvelle unité sera ici de 500 et là de 5,000 âmes. Impossibilité, par suite, d'indiquer des règles absolues, de fixer des chiffres, etc. C'est sur le terrain seulement et par une étude approfondie qu'on peut se rendre compte de la situation et formuler des propositions satisfaisantes. Aussi les instructions données 
laissent-elles la plus grande latitude à cet égard, sans cependant supprimer le contrôle qui existe même à plusieurs degrés.

L'opération qui nous occupe ne se borne pas à la simple répartition du territoire de la tribu entre les différents douars qu'elle doit comporter. Ce classement est accompagné d'une reconnaissance de tous les terrains qui, suivant leur nature, se répartissent dans les quatre catégories suivantes :

10 Terres domaniales;

2' Terres Melk;

$3^{\circ}$ Terres collectives de culture;

$4^{\circ}$ Terres de parcours dites communales;

Les tribus Melk peuvent ne renfermer que des terres de la deuxième catégorie; mais presque toujours elles en contiennent de la première, et fréquemment de la troisième et de la quatrième.

Les tribus Arch, de leur côté, peuvent n'être composécs que de terrains de la troisième et de la quatrième catégorie; mais presque toujours aussi elles en renferment de la première et quelquefois de la deuxième.

Au moment de la reconnaissance faite par une sous-commission, les diverses natures de terres sont revendiquées par qui de droit. L'Administration des domaines, les propriétaires et les djemaâs de tribus et de douars représentent les différents intérêts qui sont en jeu. Un délai de deux mois est accordé pour la présentation des revendications; des affiches, ainsi que l'insertion au Moniteur de l'Algérie et au Mobacher, font connaître la date certaine qui sert'de point de départ à ce délai.

Voici comment on procède : La tribu, représentée par sa djemaâ, n'a pas à formuler de revendications; le domaine et les particuliers seuls sont astreints à cette formalité. Dans ces conditions, lorsqu'une revendication se produit au sujet d'un terrain, elle est communiquée à la djemaâ qui, suivant qu'elle croit avoir ou n'avoir pas de droits sur ledit terrain, forme opposition ou s'abstient. De cette façon, si dans une tribu il ne se produit pas une seule revendication, le territoire appartient en entier et sans conteste à la tribu; si des revendications sont formées et qu'elles ne soient suivies d'aucune opposition, le sol se répartit sans difficultés, sauf celles qui peuvent résulter de la production de plusieurs revendications pour un même terrain, et qui rentrent dans 
la compétence des tribunaux; si enfin certaines revendications sont suivies d'oppositions, les contestations sont résolues : administrativement ou par la voie des tribunaux, s'il s'agit du domaine et de la djemaâ; judiciairement, si au contraire le débat existe entre des particuliers et la djemaá.

On est ainsi arrivé à diviser la tribu en douars; chacun de ces douars est parfaitement déterminé, et toutes les terres qu'il renferme sont classées dans une des quatre catégories précédentes. Sans attendre la constitution de la propriété individuelle, la transformation dont nous avons parlé peut avoir lieu, et le douarcommune se mettant à fonctionner, l'ancienne organisation de la tribu devient inutile et disparaît.

Pour permettre à ce douar-commune de vivre, on s'est attaché à lui assurer dès le premier jour des ressources : il possède des communaux qui, gérés par la djemaâ, peuvent être aliénés par elle dans des cas de besoins bien constatés. La vente et la location de ces communaux, si les besoins de la commune le demandent, sont une des ressources dont s'alimenteront un jour les budgets communaux.

La troisième partie qui doit couronner l'œurre, la constitution de la propriëté individuelle, reste à appliquer. Grâce aux opérations précédentes, bien des renseignements indispensables sont déjà connus. On sait de quelle façon la terre est détenue dans la tribu, si les habitants sont dans l'habitude de labourcr toujours les mêmes parcelles, ou bien si chaque année amène un remaniement territorial et une nouvelle distribution des terres. Les espaces sur lesquels le travail doit porter ont été déterminés par le classement qui a été fait des terrains en quatre catégories, et il n'y a à se préoccuper que de ceux de la troisième dans l'opération à entreprendre. On a aussi des aperçus assez complets sur l'état de la population, les principales familles, les droits et les besoins de chacun. La tâche détinitive se trouve donc sensiblement facilitée; elle n'en constitue jas moins encore un long travail exigeantà lui seul beaucoup plus de temps que la première et la deuxième partie. Jusqu'à présent (1866) ce travail n'a été fait, dans aucune tribu, et l'expérience manque pour fixer sur les moyens les plus efficaces à cmployer dans son exécution.

En résumant la marche qui vient d'être indiquée, on voit que, lorsqu'il s'agit d'appliquer le sénatus-consulte à une tribu, il faut commencer par bien connaître et bien déterminer le tout sur 
lequel on aura à opérer. Ce résultat est obtenu par la délimitation de la tribu.

Une fois ce tout parfaitement dégagé, on le répartit entre plusieurs groupes auxquels on donne le nom de douars. Ils sont destinés à former les communes futures du pays arabe et doivent, par conséquent, réunir les conditions de superficie, de population et de ressources diverses nécessaires à l'existence de cette unité administrative.

Enfin, dans chacun de ces douars aura successivement lieu la constitution de la propriété individuelle, dernière opération dont le résultat sera de fixer et d'attacher au sol la population arabe, de sanctionner ses anciens droits, et cela en lui créant de nouveaux besoins et par suite de nouvelles aspirations, de la transformer en un mot en lui faisant comprendre et apprécier notre organisation sociale.

Tel est le sénatus-consulte du 22 avril 1863... L'Administration a borné prudemment, dans l'origine, le nombre des commissions et sous-commissions à deux par province. Après quelques hésitations bien naturelles, deux arrêtés du gouverneur général, en date du 30 avril 1864, ont paru; ils fixent, l'un, le nombre des commissions à quinze, soit une par subdivision, et celui des souscommissions à vingt et une. En même temps, des remaniements étaient introduits dans le personnel; ils étaient destinés à faciliter le travail et à introduire dans les opérations une notable économie.

Le 12 aov̂t 1863 a paru le premier décret désignant des tribus à l'application du sénatus-consulte. An mois d'octobre suivant, on se mettait partout à l'œuvre... Le 15 juin 1864, le travail des Hassen-ben-Ali, tribu des environs de Médéah, était terminé; il en fut de même dans trois autres tribus avant la fin de cette même année 1864. Ces trois tribus sont les Hachem-ben-Darough, d'Oran, les Ouled-Attia et les Souhalia, de Constantine.

Outre ces quatre tribus terminées à la fin de l'exercice 1864, on en comptait vingt-six autres en cours d'exécution.

Résumé du travail exécuté chez les quatre tribus ci-dessus :

$1^{\circ}$ Hassen-ben-Ali (Alger).

Population de la tribu........... 4,600 individus,

Etendue du territoire........... 22,552 hectares.

Nombre des douars............. 6 
$2^{\circ}$ Hachem-ben-Darough (0ran).

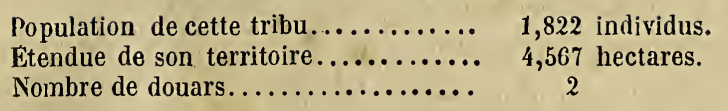

$3^{\circ}$ Ouled-Attia (Constantine).

Population de cette tribu........... 4,440 individus.

Étendue du territoire............. 14,050 hectares.

Nombre de douars............... $\quad 6$

$4^{0}$ Souhalia (Constantine).

Population de cette tribu........... 1,968 individus.

Étendue du territoire............... 7,304 hectares.

Nombre de douars............... 4

JUSTICE.

Sont justiciables des conseils de guerre, ou des commissions disciplinaires établies par l'arrêté ministériel du 20 avril 1860, les indigènes des tribus du territoire militaire coupables de crimes et délits.

Les six conseils de guerre des trois provinces ont été saisis, en 1864, de 329 affaires (concernant les indigènes).

Les commissions disciplinaires des subdivisions ont été saisies de 446 affaires, et les commissions disciplinaires des cercles de 400 .

Les indigènes du territoire militaire peuvent, en outre, être punis directement par les commandants militaires ou leurs délégués, pour contraventions de police, et pour fautes commises dans le service militaire ou administratif. - Les limites dans lesquelles les commandants militaires peuvent punir de prison ou d'amende, ont été fixées par un arrêté ministériel du 20 avril 1860.

En 1864, il a été imposé 27,502 amendes, dont le produit, s'élevant à 488,173 fr. 20 cent., a été versé dans les caisses du service des contributions diverses. - Dans ces amendes sont comprises celles qui ont été infligées à des tribus, fractions de tribus ou douars, par application du principe de la responsabilité collective des tribus, principe maintenu par la circulaire ministérielle du 8 mai 18วั9, lorsqu'il s'agit de faits généraux, de crimes commis avec une sorte de responsabilité collective, et lorsque le châtiment individuel en est tout à fait impossible.

En pays kabyle, ce n'est point aux commandants militaires ou à leurs délégués, comme en pays arabe, qu“incombe le devoir 
de punir directement les individus coupables de contraventions et de fautes commises dans le service militaire et administratif; c'est aux djemaâs, du moins, dans la plupart des cas.

Ces djemaâs n'ont d'autre moyen de répression que l'amende, qui est prononcée d'après les Kanouns. Ces amendes sont versées aux fonds communaux, dont emploi est fait par les djemaâs pour les hesoins divers de l'administration de village et des travaux d’utilité publique, tels que l'aménagement des sources, l'entretien des fontaines, des mosquées, etc.

La justice, cn matière civile, est rendue par les tribunaux musulmans; mais le décret du 31 décembre 18009 a, sous ce rapport, partagé en deux zones le territoire militaire.

Dans la première de ces zones, celle qui est la plus rapprochée de nos centres d'occupation, existent 229 mehakmas, composées d'un cadi, d'un bach-adel et d'un adel. Ces mehakmas sont placées sous la surveillance des commandants de province, du premier président et du procureur général de la Cour impériale d'Alger.

Dans la seconde, qui comprend la Kabylie et le pays situé au delà du Tell, l'action du premier président et du procureur général cesse : les djemaâs kabyles rendent la justice suirant leurs coutumes; les cadis de la région en dehors du Tell appliquent la loi musulmane, sous la surveillance de l'autorité militaire.

En ce qui concerne les populations de la première zone, le décret du 31 décembre 1859 a reconnu que la loi musulmane régissait toutes les conventions et toutes les contestations civiles et commerciales entre indigènes musulmans; mais il a, en même temps, proclamé que les musulmans sont libres de contracter sous la loi française.Il a consacré le droit d'appel devant nos tribunaux, des jugements des cadis, voulant ainsi rétablir le lien entre les magistrats français et les tribunaux musulmans, en faisant rentrer sans froissements ceux-ci dans la voie normale.

Pour les populations de la seconde zone du territoire militaire, comme on l'a dit, la justice est rendue, en pays kabyle, par les djemaâs, et dans la région en dehors du Tell, par des cadis relevant de l'autorité militaire.

Les djemaâs sont composées de l'amin, de l'oukil, d'un dhaman et d'un akeul, par kharouba (fraction). Ces membres sont renouvelés tous les ans au mois de janvier, moment où ont lieu les élections dans toute la Kabylie. 
Les djemaâs sont assistés de kodjas dont elles font choix. L'amin en est le président.

Elles jugent d'après les anciennes coutumes (qui, malheureusement, ne sont pas écrites, en général).

Les décisions des djemaâs sont sans appel (un vice de cette organisation).

Les djemaâs, en 1864, ont fonctionné avec une grande régularité, et dans plus d'une circonstance elles ont su, avec intelligence, modifier certaines coutumes, en ayant égard aux progrès que notre contact fait faire, lentement il est vrai, aux populations kabyles.

Dans ia région en dehors du Tell existent 48 mehakmas, dont la composition est la même que celles de la première zone. La juridiction des cadis est restée telle qu'elle était avant le décret de 1864. - L'appel d'un jugement rendu par un cadi est porté devant un medjelès, dont le rôle n'est peut-être pas assez nettement défini...

Cette organisation de la justice en matière civile dans les tribus du territoire militaire est susceptible, nous le pensons du moins, d'être avantageusement modifiée sur les deux points suirants :

$1^{0}$ Former, en développant l'instruction dans les médersas, des hommes aptes à occuper les emplois de la magistrature musulmane;

$2^{\circ}$ Assurer un traitement aux magistrats musulmans. (Voy. Tableau de la situation en 1864, publié en 1866.)

Pénitenciers agricoles indigènes. - Les indigènes détenus en vertu de décisions des commissions disciplinaires, sont, quand ces décisions ont été rendues exécutoires par le gouverneur général, envoyés dans les établissements dont il s'agit.

On en compte quatre : ceux d'Aumale et d'Orléansville (province d'Alger); celui de Bou-Khanifis, près de Sidi-bel-Abbès (province d'Oran), et celui d'Aïn-el-Bey, près de Constantine.

Mouvement des entrées et des sorties en 1864

PÉNITENCIER D'AUMALE.

Restant au 31 décembre $1863 \ldots \ldots \ldots \ldots \ldots \ldots \ldots . \ldots \ldots$

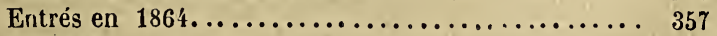

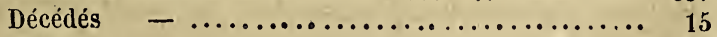

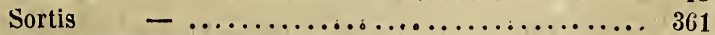

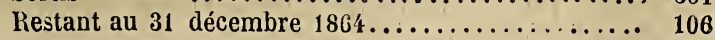




\section{PÉNITENCIER D'ORLÉANSVILLE.}

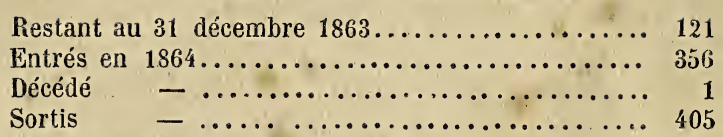

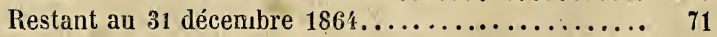

PÉNITENCIER DE BOU-KHANIFIS.

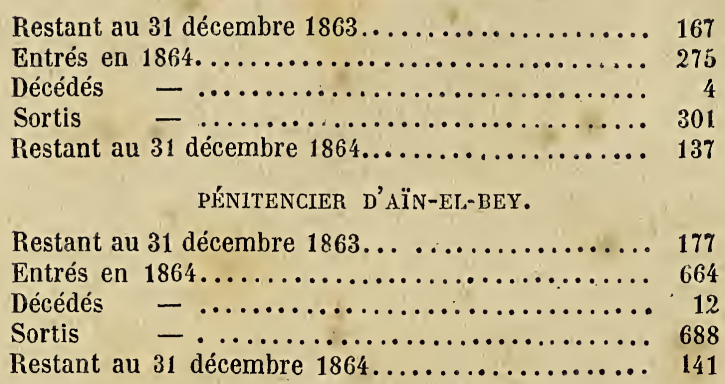

Sur le nombre des individus entrés en 1864, 101 ont été arrêtés par mesure politique.

Sur le nombre des individus sortis, 71 n'avaient pas terminé leur peine; le gouverneur général les a graciés.

Dans ces établissements, les détenus sont employés à des travaux qui ont pour but de les initier à nos procédés de cultures perfectionnées et à certaines professions, telles que celles de maçon, de briquetier, de serrurier, etc. Des chefs et des sous-chefs d'ateliers sont choisis parmi ceux qui se font remarquer par leur conduite et leur intelligence...

Il n'est pas douteux que plusieurs, parmi les détenus, les Kabyles particulièrement, prennent dans les pénitenciers des notions de jardinage et de greffage qu'ils utilisent en rentrant dans leurs tribus.

La mortalité du pénitencier d'Aumale a eu pour cause des fièvres produites par les défrichements. Cet établissement ne date que de quatre ans.

\section{INSTRUCTION PUBLIQUE.}

Les établissements d'instruction publique, d'après le tableau pour 1864, ouverts à la jeunesse des tribus de l'Algérie, sont de deux sortes:

Dans les uns, les écoles des douars ou des villages, les zaoü̈as et les médersas, l'instruction est purement arabe.

Dans les autres, les écoles arabes-françaises et le collége impé- 
rial arabe-français, on se propose d'enseigner aux enfants indigènes la langue française, l'arithmétique, l'histoire, la géographie, etc.

Les écoles des douars et des villages sont au nombre de plus de 2,000. Elles sont fréquentées par 27 à 28,000 enfants auxquels des tolbas, munis d'une autorisation délivrée par les commandants des territoires, apprennent à lire et à écrire; ces tolbas donnent, en outre, à leurs élèves, quelques notions d'arithmétique, et leur font apprendre par cœur et réciter un plus ou moins grand nombre de versets du Coran. C'est par le nombre de ces versets que, la plupart du temps, on juge du degré d'instruction de l'enfant. - Les résultats'obtenus dans ces écoles sont presque nuls.... Les maîtres sont le plus souvent fort ignorants euxmêmes. Ce n'est que dans les douars et villages qu'habitent quelques chefs indigènes, quelques personnages religieux qui veulent faire des sacrifices pour inștruire leurs enfants, qu'on rencontre des tolbas aptes à être à la tête d'une école.

Cette situation fâcheuse est la conséquence obligée du genre de vie des populations arabes. Une école est-elle possible avec ces tentes qui se déplacent, tantôt pour trouver des pâturages, tantôt pour les travaux des semailles el des récoltes? Elle ne l'est guère plus chez les populations qui, habitant la montagne, loin de se réunir en villages, dispersent leurs gourbis, les cachent dans le fond d'un ravin ou les groupent au nombre de quatre à cinq sur des crêtes difficiles, sur des pitons inaccessibles.

Dans les villages de la Grande-Kabylie, les écoles pourraient être mieux installées, plus suivies, et donner de meilleurs résultats qu'en pays arabe. Mais le Kabyle n'a pas de langue écrite; s'il apprend la langue arabe, ce n'est qu'en voyageant comme colporteur, au milieu des tribus arabes, qu'il en fait usage: il n'a pas pour cela besoin d'école. D'un autre côté, il fait assez peu de cas de l'instruction; il laisse les marabouts ou ceux qui prétendent le devenir vivre d'aumônes et de revenus plus ou moins licites dans quelques zaouïas. Satisfaire par l'industrie, le commerce et la culture de quelques parcelles de terrain aux besoins matériels de la vie, telle est la préoccupation de la population de la Kabylie. Un jour viendra certainement où sa vive intelligence, s'éveillant à notre contact, embrassera des horizons nouveaux et appréciera combien est puissante l'instruction comme auxiliaire du travail manuel. 
Les zaoüas sont des établíssements où les jeunes gens qui ont appris à lire et à écrire plus ou moins bien, vont perfectionner leurinstruction, étudier le Coran et ses commentaires, Sidi Khelil et autres auteurs, qui font âlitorité en matière de religion et de législation musulmane. - L'enseignement, dans ces écoles, est presque toujours gratuit. Les zaouïas sont entretenues, les unes par des marabouts influents, les autres au moyen d'aumônes et de quêtes. Il en est qui ont des revenus assez importants, provenant de donations faites à divệrses époques, par des hommes qui en ont été les fondateurs ou qui ont regardé comme une œuvre méritoire de doter des établissements religieux de tout ou partie des biens qu'ils laissaient en mourant. - C'étaient ces zaouïas qui araient autrefois le monopole de former des cadis et autres magistrats indigènes. Il n'en est plus ainsi, et trois médersas sont, à Alger, Tlemcen et Constantine, ouvertes aux jeunes gens qui se préparent à occuper dés emplois dans la magistrature musulmane.

L'enseignement donné dans ces médersas par des professeurs musulmans, comprend : la grammaire, le droit et la théologie. Un cours d'arithmétique est aussi fait aux élèves, et, depuis quelques années, un prợfesseur de langue française a été attaché à ces écoles.

Les médersas ont reçu èn. 1864: celle d'Alger, 42 élèves; celle de Tlemcen, 60 ; celle de ,Constantine, 45 . La durée réglementaire des études est fixée à troís ans.

Les écoles arabes-françaises étaient, en 1864, au nombre de 18, savoir :

$$
\text { PROVINCE D'ALGER. }
$$

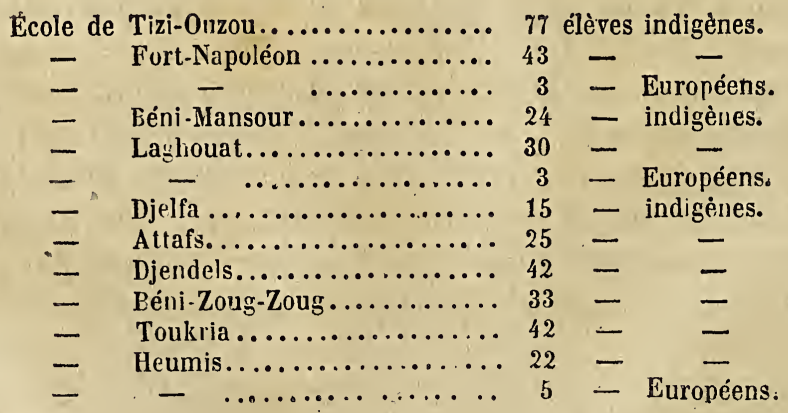


PROVINCE DE CONSTANTINE.

École de Tebessa.............. 10 élèves Européens.

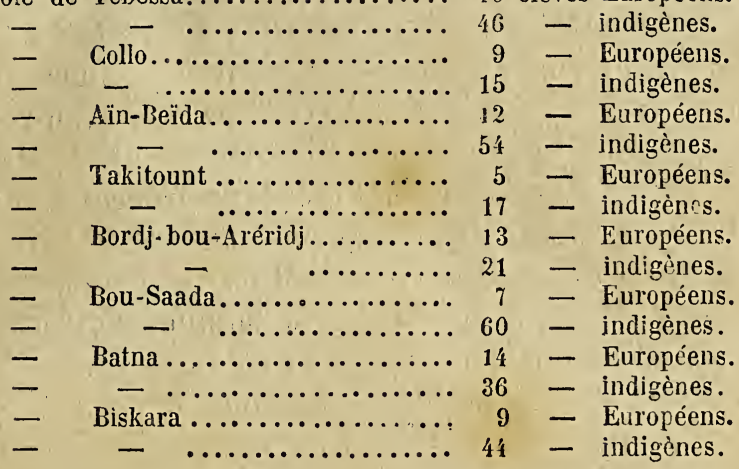

En 1865̆, d'autres écoles arabes-françaises ont dû s'ouvrir dans la province d'Oran, qui jusque-là n'en avait pas eu : à AmmiMoussa, Nédromah, Frendah, Zemmorah et Saïda.

On enseigne dans ces écoles la langue française, l'arithmétique, la géographie, l'histoire. Un maître indigène est chargé, en outre, de l'enseignement de l'arabe et de l'éducation religieuse.

Les écoles arabes-françaises sont, par le fait, dit le Tableau pour 1864, le plus puissant moyen d'action dont dispose le gouvernement pour pousser les indigènes dans la voie du progrès et de la civilisation.

Un inspecteur spécial de ces écoles, de celles des douars et villages, ainsi que des zaouïas et des médersas, a été nommé en 1863... Ce n'est là évidemment qu'un moyen de contrôle; il serait impuissant pour remédier complétement aux inconvénients qui ont pu être signalés dans le recrutement du personnel enseignant. Bientôt ce recrutement sera assuré par une école normale primaire destinée à fournir des instituteurs à l'Algérie, et qui aura pour élèves des Européens et des indigènes. - Là, se formeront des maîtres qui seront spécialement préparés à l'éducation de la jeunesse musulmane, et, soit qu'ils restent dans les villes, soit qu'ils soient envoyés dans les tribus, ils ne seront point complétement étrangers à la langue et aux mœurs de la jeune population sur l'esprit de laquelle ils sont appelés à agir. - D'un autre côté, il entre dans les projets du gouvernement général d'assurer, mieux qu'elle ne l'a été jusqu'ici, la position du personnel enseignant 
des écoles arabes-françaises et de doter largement leurs établissements du matériel de toute sorte dont ils ont besoin. Des

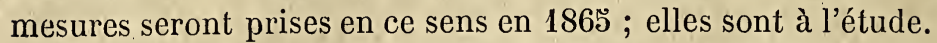

$\mathrm{Au}$-dessus des écoles ci-dessus se trouve le collége impérial arabe-français d'Alger. Fondé en 1857, il a vu le nombre des élèves indigènes internes s'élever progressivement à plus de 100. L'enseignement du collége comprend la langue française, l'histoire, la géographie, l'arithmétique, les éléments de géométrie, l'arabe, le dessin linéaire et le dessin d'imitation, la gymnastique et le chant. - La répugnance de certaines familles indigènes à nous confier l'éducation de leurs enfants va, en diminuant.

Des colléges arabes-français, semblables à celui d'Alger, ont dû s'ouvrir en 1863 , ou le seront très-prochainement, à Oran et à Constantine.

\section{TRAVAUX PUBLICS.}

Les travaux exécutés, en 1864, dans les tribus du territoire militaire ont atteint le chiffre de $714,758 \mathrm{fr} .37 \mathrm{c}$.

\section{PRODUGTIONS AGRIGOLES.}

La statistique agricole des tribus du territoire militaire, malgré toutes les difficultés qu'elle présente, peut se résumer ainsi :

10 Situation des cultures et des récoltes indigènes en territoire militaire.

\section{A. PROVINGE D'ALGER.}

Blé tendre. Superficie cultivée.........

- Quantité récoltée..........

Blé dur. Superficie cultivée.........

- Quantité récoltée............

Orge. Superficie cultivée............

- Quantité récoltée..............

Mais. Superficie cultivée............

- Quantité récoltée..............

Fèves. Superficie cultivée. ...........

- Quantité récoltée.............

Sorgho (Bechna ou dra). Superficie cultivée...................

- Quantité récoltée.............

Légumineuses. Superficie cultivẻe...... Planteś-racines (betteraves, etc.). Superficie cultivée.

B. PROVINCE D'ORAN.

Blé tendre. Superficie cultivée ......... Quantité récoltée........

Blé dur. Superficie cultivée..........
37 hectares.

444 hectolitres. 190,245 hectares. 863,017 hectolitres. 313,867 hectares. 1,976,413 hectolitres. 967 hectares. 5,638 hectolitres. 15,823 hectares. 145,081 hectolitres.

18,390 hectares. 263,637 hectolitres.

2,830 hectares.

115 hectares.

11,986 hectares. 131,381 hectolitres. 164,581 hectares. 
Blé dur. Quantité récoltée.

Seigle. Superficie cultivée............

- Quantité récoltée.............

Orge. Superficie cultivée.

- Quantité récoltée.

Maïs. Superficie cultivée

- Quantité récoltée.

Fèves. Superficie cultivée

- Quantité récoltée.............

Sorgho (Bechna ou dra). Superficie cultivée.................

- Quantité récoltée.............

Légumineuses. Superficie cultivée.....

Plantes-racines. Superficie cultivée....
$1,602,188$ hectolitres.

8,545 hectares.

171,434 hectolitres.

261,446 hectares.

$2,418,323$ hectolitres.

724 hectares.

8,711 hectolitres.

2,946 hectares.

25,075 hectolitres.

606 hectares.

5,420 hectolitres.

331 hectares.

158

C. province de constantine,

Blé tendre

Blẻ dur. Superficie cultivée.................

- Quantité récoltée............

Seigle........................

Orge. Superficie cultivée.......... 461,548 hectares.

- Quantité récoltée...........4,084,031 hectolitres.

Avoine........................

Maïs. Superficie cultivée............

- Quantité récoltée..............

Fèves. Superficie cultivée...........

- Quantité récoltée............

Sorgho. Superficie cultivée.........

- Quantité récoltée............

Légumineuses...................

Plantes-racines..................

411,386 hectares.

$2,311,300$ hectolitres.

3,077 hectares

22,900 hectolitres.

14,337 hectares.

122,672 hectolitres.

20,871 hectares.

147,281 heetolitres.

1,560 hectario.

279 -

Dans les trois provinces, il s'est produit, en 1864, un mouvement agricole, consistant bien plus dans une tendance à l'extension des cultures que dans l'amélioration des procédés employés. Ges procédés sont, à peu d'exceptions près, les mêmes qu'avant la conquête.

Ce n'est que sur un assez petit nombre de points, principale. ment dans les tribus voisines de Bône et de Guelma, que des indigènes ont commencé à abandonner les anciens usages, entrepris des cultures nouvelles, telles que celles du coton, du tabac, de la pomme de terre, et fait des plantations d'arbres fruitiers.

Cependant certains progrès ont été réalisés.

D'ailleurs le sénatus-consulte du 22 avril 1863 a ouvert aux Arabes une ère nouvelle. Ils avaient jusqu'ici pu avcir quelque inquiétude sur l'avenir que leur réservaient les mesures de cantonnement, mesures qui; à diverses époques, les ont vive- 
ment préoccupés. Menacés de se voir retirer une partie des terres sur lesquelles ils avaient vécu jusqu'à ce jour, ils avaient dû peu s'adonner à des travaux pouvant les rendre plus fertiles et plus riches.

Aujourd'hui, la position est changée. L'exécution du sénatusconsulte assure aux membres des douars qu'elle constitue, et dont elle fera plus tard une véritable commune, des droits inviolables sur le sol. Les biens domaniaux, les terrains communaux, se séparent nettement des parcelles de labour, dont chaque membre du douar est en possession. La propriété melk, trop souvent contestée, s'affirme, et c'est là une des premières conditions à satisfaire pour arriver à de réels progrès agricoles.

Une ferme-école pour les indigènes a été installée, en 1864 , à Aïn-Ouarât (province de Constantine). On en attend de bons résultats.

En pays Kabyle, la fabrication des huiles n'est pas demeurée stationnaire. Des indigènes ont vendu leurs olives à des fabricants européens et d'autres ont monté des moulins d'après les méthodes modernes.

\section{GHAPITRE XVI}

\section{RENSEIGNEMENTS UTILES.}

Distances et communications. - Acclimatement.

1. Distances et communications.

- De Marseille à Siora (pour Philippeville), la distance est franchie en 60 heures.

- De Cette à Alger, en 60 heures.

- De Marseille à Alger en 50 heures.

- De Toulon à Alger, en $\mathbf{4 1}$ heures.

On compte d'Alger à Oran: 36 š kilom.

2. Acclimatement.

Le docteur Marit, professeur à l'école de médecine d'Alger, a publié un volume intitulé : Hygiene de l’Algérie. La lecture de ce volume est indispensable à tout Européen qui voudra se rendre sur le sol algérien. Quelques extraits donneront une idée de l'importance de l'ouvrage. 
Vêtements en laine, tenus proprement et séchés après la pluie ou l'humidité; propreté indispensable; ne jamais dormir en plein air. Aliments de bonne qualité, légèrement toniques, substantiels et pris arec modération. Le thé et le café léger auront de bons effets; pas d'excès alcooliques, ni d'indigestion : l'eau des puits et citernes doit etre filtrée. Les passions vives, les émotions violentes, la fatigue, les veilles, doivent être évitées.

L'intérieur des habitations des villages sera propre et légèrement chauffé pendant les nuits des saisons fraîches; les ouvertures, closes avant le crépuscule, ne seront rouvertes qu'après le lever du soleil. On évitera l'humidité et les effets des premières pluies. Les étages supérieurs seront seuls habités, si c'est possible.

Le choix de l'emplacement pour l'habitation est de la plus haute importance. Les localités basses, souvent baignées par des eaux stagnantes, privées des vents frais de la mer, sont dangereuses à habiter, à cause des miasmes et de l'air humide qu'on y respire. Les hautes montagnes présentent beaucoup d'inconvénients: il y fait froid et il règne des vents violents. Les collines rerdoyantes, les points d'une certaine hauteur, tournés vers le nord, pas trop près du rivage, doivent être choisis. Il faudrait pouvoir suivre l'exemple des Arabes, qui, l'hiver, habitent les collines et les plaines, tandis qu'en été, ils gagnent les endroits élevés.

Les demeures doivent être vastes et aérées, avec des murs épais en pierre, peu susceptibles de s'imbiber d'humidité. Avec de la chaux hydraulique, du ciment romain, des pilotis injectés, on atténuera l'état d'un terrain trop humide pour les fondations. L'exposition sera au nord et au midi. On n'habitera pas des maisons nouvellement construites. Les parquets cirés sont les meilleurs; pas de dallage en pierre; des nattes ou des tapis sur les carreaux de faïence. Chambres à coucher vastes; plusieurs personnes ne doivent pas dormir dans la même chambre; les portes et fenêtres doivent être fermées avant le coucher du soleil. Il ne faut habiter ni au rez-de-chaussée ni au grenier. Les caves sont très nécessaires. Corridors et escaliers bien aérés; grande propreté. Les latrines ne s'ouvriront ni sur l'escalier ni près de la cuisine. Éloigner les habitations les unes des autres; éloigner les fumiers et les immondices. Ne pas coucher dans les étables. Les baraques sont très-mauvaises, ainsi que les tentes et les gourbis arabes.... 
Le Tell de l'Algérie comprend des plaines basses renommées pour leur fertilité; malheureusement, ce sont les points les plus insalubres. La faiblesse et l'anémie, par l'excès de chaleur, outre l'insalubrité de l'atmosphère, sont trop souvent le partage des habitants des vallées. Les plaines sont généralement marécageuses ¿ en juger par le teint flétri des colons. Elles sont arrosées par des ccurs d'eau qui usurpent, pendant six mois, le nom de rivières et ne sont jamais navigables, à l'exception de quelques-uns à leur embouchure, à cause du desséchément trop rapide des sources àestinées à les alimenter. En été, leur lit est à peine humecté par un faible courant. En hiver, l'éboulement des berges sous la violence du courant détermine des inondations, ou le rétrécissement du lit par les débris amène des débordements. La nature argileuse du sol empêche l'infiltration et produit des marais. Sur les hauteurs, la terre est légère et le sol aride.

Presque toutes les plaines et les vallées, d'une terre grasse, molle et ductile, présentent des conditions favorables à la formation des marais. Funestes effets des eaux stagnantes : fièvres rémittentes, intermittentes, pernicieuses, dysssenterie, choléra, pendant juillet, août et septembre; affaiblissement des facultés, perturbation de l'économie. L'insalubrité est un obstacle à la colonisation, car le peuplement véritable se fait par la propagation de l'espèce, et non par l'immigration.

La chalcur extrême a des effets bien fâcheux : souvent on est pris de délire et frappé de congestion cérébrale. Elle développe aussi des ophthalmies très-graves. Les mois de juillet, août et septembre, prédisposent aux affections cutanées, aux maladies du tube digestif et de l'encéphale, à cause de la fluxion ou de la langueur dont ces organes sont le siége.

Il faut éviter les fortes chaleurs, les variations brusques de température et l'impression du froid lorsque le corps est en sueur. Il faut, de toute nécessité, ne consacrer au travail que les heures les moins chaudes. On ne négligera ni les bains, ni les affusions d'eau fraîche.

La grande lumière, dont la puissance augmente avec la température, a pour effet de surexciter l'organe de la vue, d'impressionner fortement le cerveau; de là, des lésions nombreuses : ophthalmies, amauroses, congestions cérébrales. Les campagnards sont sujets à des rougeurs inflammatoires de la peau. L'action d'un soleil trop intense fait courir des dangers à l'encéphale. 
Le sirocco, qui varie du S.-S.-E. au S.-S.-0, est un air brûlant qui agit sur toutes les constitutions. Les sanguins sont exposés aux congestions cérébrales; on est sans énergie, sans force, anxieux, somnolent et très-irritable; il frappe d'un coup mortel la plupart des hommes affaiblis. Son règne est de mai en octobre. Malheur à ceux qui se livrent à de longues marches ou à de rudes travaux.

Les nuits, sans sommeil, sont privées de toute fraîcheur. Il donne lieu à la lassitude et à la céphalalgie. Il est particulièrement insupportable en septembre et en octobre. Il règne deux ou trois jours, et quelquefois plus longtemps. Il faut rentrer chez soi et garder le repos.

Qu'importe au cultivateur et au soldat de savoir qu'il y a à l'ombre 30 degrés, quand il est exposé, une partie de la journée, à une température de 45 , de 50 degrés et même plus? La chaleur est étouffante dans les plaines basses et encaissées. Entre le matin et le milieu du jour, les écarts de 10 degrés ne sont pas rares. Sur le littoral, le maximum est de 30 à 32 degrés; dans l'intérieur, sur les plateanx, de 38 degrés; dans les plaines, de 45 degrés; dans le Sahara, de 50 degrés. On a vu le thermomètre, dans la Metidja, à 5̌ degrés au soleil, et à 18 degrés la nuit du même jour.

" De nos jours, dit le. docteur Dutrouleau, l'Afrique tend à redevenir, pour bien des esprits enthousiastes, ce qu'elle a été dans l'antiquité, une terre promise, n'attendant que les bienfaits de la colonisation européenne pour produire des merveilles. La géographie médicale qui met en lumière les conditions de santé et de maladie, de vie et de mort, d'extinction et de propagation de races qu'y rencontre l'Européen, semble bien propre à contenir ces aspirations dans des limites plus raisonnables et à éviter les écoles du passé. ")

D'après le docteur Beaufumé, l'obstacle le plus sérieux à la colonisation de l'Algérie, "celui contre lequel nous aurons à lutter, éternellement peut-être, ") c'est la difficulté de l'acclimatement, surtout pour les Français.

Ainsi, en 1856, on comptait pour chaque élément colonial (par an et par 1000) :

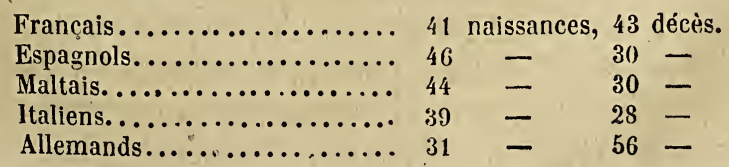


En Afrique, il n'y aurait donc que les Espagnols, les Maltais et les Italiens à prospérer; les Français s'y soutiendraient à peine; quant aux Allemands, l'Afrique serait leur tombeau.

Les années 18303 et 18304 ont été plus désastreuses encore pour les Français :

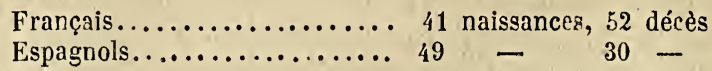

L'Espagnol prospère en Afrique mieux qu'en Espagne même. Le nombre des décès est identique, mais le nombre des naissances n'est que de 37 en Espagne (par 1000 et par an).

"L'Espagnol est avant tout le colon né de notre Algérie. Ce privilége, il est facile de voir qu'il le doit à l'avantage d'être né sous un climat isotherme, ou à peu près, à sa nouvelle patrie. Est-il besoin de rappeler, en outre, que les Maures d'Afrique ayant, dans les temps modernes, possédé l'Espagne pendant une longue suite de siècles, avec une puissance et un éclat favorable aux croisements, on peut affirmer que le sang africain a été largement infusé au sang espagnol et que la température élevée de la péninsule a dî conserver à ce sang sa facile adaptation aux climats tropicaux?"

Partout où les émigrants se sont portés vers des latitudes non isothermes à leur patrie (Guyane, Mexique, etc.), le résultat a été désastreux. Au contraire, en Acadie, c'est-à-dire dans la même bande isotherme que le nord de la Prusse, de l'Écosse et du Danemark, on a vu 4 à こ000 émigrants (1671) former, sous Louis $\mathrm{XV}$, lorsque cette colonie fut abandonnée aux Anglais (Nouvelle-Écosse), une population de 70,000 individus. Au Canada, les 10,000 Français qui gagnèrent cette contrée, de 1663 à 1670, sont aujourd'hui au nombre de 1 million *de Franco-Canadiens, malgré la guerre et l'émigration aux États-Unis.

Aux Etats-Unis du Nord, l'acclimatement de la race anglaise n'est pas moins évident, bien qu'il ait eu pour effet de nolables modifications physiques el morales qui constituent le type yankee. Les traits les plus saillants de ces modifications sont la disparition du système cellulo-adipeux, l'amoindrissement du système glandulaire et notamment de la glande mammaire chez la femme, sa fécondité restant la même, enfin une certaine sécheresse générale qui s'accompagne de l'allongement des formes et d'une singulière et fiévreuse activité. 
Mais lorsqu'on s'approche des États du Sud, alors l'acclimatement devient pour l'organisme chose plus grave; des maladies nouvelles surgissent (fièvre.jaune), 'd'autres s'aggravent (fièvre palustre, dyssenterie)... La fièvre jaune qui parcourt en souveraine les Antilles et le golfe du Mexique, oublie rarement ses nouveauxsujets dont, suivant ses arrêts capricieux, elle moissonne les deux tiers, la moitié, le tiers, et, dans ses plus bénignes visites, un sixième, un septième lui payent leur tribut. Par une heureuse ressemblance avec la variole, elle n'est pas sujette à récidive; mais cette première atteinte à l'organisme, secondée par le climat, ne fait qu'augmenter l'aptitude à toutes les maladies régnantes, fièvre palustre, dyssenterie, hépatite... Est-il rationnel de penser qu'au milieu de ce conflit de causes destructrices ou modificatrices, l'homme puisse conserver la faculté de se reproduire dans une race valide...

En Afrique, ce n'est donc ni dans les fautes de nos colons ni dans les erreurs des gouveruements, s'il y en a eu, que réside lat véritable difficulté de la colonisation; la statistique des décès et des naissances, le peu de progrès que fait l'immigration, la logique des faits anciens et modernes que nous avons cités, démontrent surabondamment que l'obstacle réel est dans les conditions climatériques qui s'opposent à l'adaptation de nos colons. Cet obstacle est l'effet de trois causes inégalement distribuées sur le sol africain :

$1^{\circ}$ La température toujours élevée;

$2^{\circ}$ Les émanations telluriques et palustres ;

$3^{\circ}$ Le sirocco ou vent du désert, le même qui, au. Sénégal, amène les hépatites, moins torride en Afrique, parce qu'il s'est rafraîchi, en passant sur les sommets de l'Atlas, et pourtant assez brûlant encore pour troubler singulièrement l'organisme européen : - Trois causes qui, isolées ou réunies, produisent les fièvres, les dyssenteries, l'hépatite purulente, l'ophthalmie, et minent sourdement la santé, surtout celle des Français...

Ce que nous avons dit des Espagnols, des Maltais, des Italiens, auxquels on peut ajouter le Juif, race propre aux pays chauds, comme on l'a vu par sa rapide propagation en Égypte, porte avec soi un enseignement; c'est à ces peuples qui ont sur nous l'avantage de pouvoir sadapter au climat africain que doit revenir la mission d'être les agents principaux de notre colonișation. Que non-seulement la porte de l'Algérie soit donc toute 
grande ouverte à tout ce qui porte dans ses veines le sang méridional, mais encore qu'on encourage l'immigration de ces auxiliaires utiles par tous les moyens possibles, l'appât des terres, les immunités, etc. (Docteur Beaufumé, Coup d’œil sur les colonies, etc., Paris et Châteauroux, 1865, brochure in- $\left.8^{\circ}\right)$.

\section{CHAPITRE XVII}

\section{APPENDICE.}

Rapport fait, au nom du Jury spécial, par M. Jules Duval, membre du conseil général de la province d'Oran, sur les produits exposés par l'Algérie au concours général et national d'agriculture de Paris, en 1860 (extraits). - Végétaux et produits végétaux. - Textiles. - Cotons. - Matières oléagineuses et savons. - Céréales, etc. - Extrait du discours de M. Lestiboudois, conseiller d'État, président du conseil général de Constantine, à l'ouverture de la session de 1861. - Extraits de la brochure anonyme intitulée : L'Algérie francaise: Indigènes et immigrants, - publiée en 1863, à Paris. - Sénatus-consulte du 5 juillet 1865. - Appréciation de la lettre de l'Empereur au maréchal de MacMahon, duc de Magenta, par le général Allard (Corps législatif, 5 mars 1866). - Résumé de la lettre de l'Empereur (mesures proposées). - Texte du décret du 21 avril 1866 portant règlement du sénatus-consulte sur la naturalisation en Algérie. - Aperçu des communications télégraphiques entre la France et l'Algérie.

Extraits du Rapport fait au nom du jury spécial par M. Jules Duval, membre du conseil général de la province d'Oran, sur les produits exposés par l'Algérie au Concours général et national d'agriculture de Paris, en 1860 (1).

PREMIERE SÉRIE.

VÉGÉTAUX ET ṖRODUITS VÉGÉTAUX.

$1^{\text {re }}$ SEction : Thuya. "Au premier rang brillait, comme on devait s'y attendre, le thuya, qui a acquis en quelques années une vogue dont l'honneur revient, pour une grande part, à l'ébénisterie parisienne, si habile à le mettre en œuvre sous les formes les plus élégantes. Tout a été dit sur ce bois qui semble réunir les qualités les plus recherchées, densité et fermeté du tissu, finesse du grain, éclat des teintes avec de merveil-

(1) On sait que M. Jules Duval, rédacteur en chef de l'Économiste français, est un de nos publicistes les plus distingués et les plus compétents, et qui ont rendu le plus de services aux colonies par leur vaste science et leurs publications spéciales, et pour ainsi dire classiques en leur genre. 
leuses nuances moirées ou semées de mouchetures; travail facile, durẻe pour ainsi dire indéfinie. Quoique les coupes de racines présentent ces qualités avec une perfection particulière, le corps de l'arbre n'en est pas dépourvu, et, quand l'ébénisterie le dédaigne, son incorruptibilité lui assure encore la faveur de la charpente et de la menuiserie. " - Une médaille d'or, des médailles d'argent, etc., ont été décernées. On a remarqué une racine de thuya dont le prix était établi à 30 francs les 100 kilogrammes.

Liége. "A côté du thuya, le liége rappelait le contraste, dans toute sa vérité, de l'utile avec l'agréable. C'est une matière qui devient rare et chère en Europe, à mesure que se répand l'usage $\mathrm{du}$ vin, qui en consomme, pour la fabrication des bouchons, d'énormes quantités. - L'industrie ne peut nanquer de tirer parti, pour ses nouveaux besoins, des 300,000 hectares de forêts de chêne-liége de l'Algérie, lorsque l'exploitation pourra s'en faire dans les conditions normales de succès. Le concours en présentait de nombreux spécimens, depuis l'écorce brute de troncs entiers simulant des colonnes végétales jusqu'aux planches de toutes dimensions et aux bouchons de tout emploi. Ils venaient des provinces d'Alger et surtout de Constantine, qui possèdent, cette dernière surtout, les plus vastes étendues de chênes-liége. Dans la province d'Oran, la subdivision de Mostaganem avait envoyé aussi des spécimens de ses richesses en ce genre, moins connues et encore moins exploitées. "-Médailles d'argent accordées à plusieurs exposants.

Cannes de bois algériens. Celles de myrte et de palmier ont obtenu une médaille de bronze.

Des mentions très-honorables ont été accordées aux services forestiers des trois provinces. Voici l'énumération des objets exposés :

Abricotier, alizier commun, alizier à feuilles d'érable, amandier sauvage, arbousier, aubépine, aune, azerolier.

Blanc de Hollande, bourdaine, bruyère étalée, bruyère arborescente, buis.

Cactus ou figuier de Barbarie, caroubier, cèdre de l'Atlas, châtaignier, chêne ballotte (à glands doux), chêne kermès, chene faux kermès, chêne-liége (mâle et femelle), chêne vert (yeuse), chêne zéen, citronnier, cytise en arbre (faux ébénier), cyprès pyramidal. 
Dattier.

Érable champêtre, érable napolitain.

Figuier, frêne élevé, frêne de l'Aurès à petites feuilles, frêne des marais.

Genévrier oxycèdre, genévrier phénicien, genévrier commun, genévrier cédrille, grenadier, genêt commun, genêt d'Espagne, guimauve en arbre.

Houx commun.

If.

Jujubier cultivé, jujubier sauvage.

Laurier-rose, laurier-sauce, lentisque, lierre.

Mélia azédérach, merisier commun, micocoulier de Provence, myrte, mûrier blanc.

Nerprun alaterne, noyer. .

Oranger, orme champêtre, orme fongueux, orme à petites feuilies, olivier.

Palmier de Briskra, palmier nain, phyllirea, pin d'Alep, pin pignon, pistachier térébinthe, pistachier de l'Atlas, peuplier blanc, peuplier grisard, peuplier noir, platane d'Occident, prunellier saurage.

Ricin.

Saule pédicellé, saule marsault, sumac thézéra, sumac des corroyeur's, sureau.

Tamarix africain, tremble, thuya articulé.

Vigne sauvage, viorne-tin.

En tout : 87 espèces.

A ces produits spontanés ou de longue date cultivés dans l'Afrique du Nord, la pépinière centrale avait ajouté $2 \%$ troncs de phoriix dactylifera ou palmiers-dattiers, et huit variétés de bambous (bambusa arundinacea, Thouarsii, variegata, mitis, verticillata, nigra, spinosa, scriptoria), plus un certain nombre de végétaux vivaces des zones tropicales, réduits aux modestes proportions qu'ils peuvent atteindre sous la zone tempérée.

La flore forestière de l'Algérie se compose d'un beaucoup plus grand nombre d'essences que celles de l'Exposition de 1860 .

$2^{\text {e }}$ SEGTION : Textiles autres que le coton. Parmi les textiles croissant spontanément en Algérie, on remarquait à l'Exposition : le lin, le chanvre commun, l'aloès (agave americana), le palmier nain, l'alfa (sparte), ]e dis (graminée qui, comme l'alfa, est une espèce du genre stipa), le drinn (de la même famille). — Les 
textiles cultivés étaient: l'urtica nivea, l'abutilon indicum, les bananiers, le chanvre géant, le chanvre de Chine, le corète textile, le sanseveria.

Dans les envois de la pépinière centrale, honorés d'une récompense collective, figuraient, entre autres textiles, des écorces de mûrier de la Chine (broussonetia papyrifera), employées dans ce pays pour faire du papier, et des tiges de l'ortie blanche de Chine, les unes à large feuille, les autres à petite feuille, dont les Chinois obtiennent une soie régétale et des tissus, comparables par leur finesse, leur brillant et leur légèreté à tout ce que la soie ou le coton peuvent fournir de plus délicat. Cependant cette plante, cultivée avec persévérance à la pépinière centrale, depuis quelques années, essayée dans plusieurs autres, recommandée par les inspecteurs de la colonisation, n'est point sortie du domaine de l'horticulture. '

En étudiant les produits de cette section, le jury a regretté de ne pas voir appréciés à toute leur valeur les services que pouvaient rendre à la papeterie française l'alfa, le dis et le palmier-nain, répandus à profusion à travers toute l'Algérie. Sur les tables du concours agricole, et encore mieux dans les armoires de l'Exposition permanente, ces matières figuraient sous toutes les formes, en brin, en pâte, en carton, en papier de toute nuance et de toute dimension, avec toutes les apparences d'une bonne et solide fabrication... Quant au prix, il ne pourrait qu'être de beaucoup inférieur à celui des chiffons, si les transports s'effectuaient sur de meilleures routes, ces végétaux étant un don spontané et inépuisable de la nature.

$3^{\circ}$ SEGTION : Les cotons. "... Il n'y a plus rien à dire sur les caractères du coton algérien, maintes fois décrits dans les rapports antérieurs. La longue-soie possède la longueur, la finesse, la nuance à un degré comparable aux plus belles sortes d'Amérique; si le nerf semble souvent faire défaut au lainage, il l'acquiert en mûrissant en balle, car une fois ouvré les fabricants s'en déclarent très-satisfaits. Le défaut de pureté et d'homogénéité qui lui est reproché à plus juste titre provient de la faute seule des cultivateurs, soit dans le choix de la graine, soit dans les soins de la cueillette. En un mot, toutes les promesses des premiers essais ont été confirmées par une expérience qui compte déjà sept à huit années sur une grande échelle, sauf quelques restrictions à faire sur l'étendue des terres qui conviennent au 
coton. Les coteaux élevés et surtout les hauts plateaux et les montagnes cù l'été, quoique brûlant, est court, n'en permettent pas la maturité complète : il doit etre réservé aux plaines basses du Tell et aux oasis sahariennes, où il trouve d'ailleurs, en même temps que la température qui lui convient, les émanations et les imprégnations salines de l'atmosphère et du sol qui en améliorent la qualité. - Les cultures sahariennes sont encore à l'état naissant, et c'est dans les plaines seules du Tell que le jury a trouvé des concurrents à récompenser. »-Une grande médaille d'or, une médaille d'or, des médailles d'argent ont été décernées.

" Le coton courte-soie, le seul qui paraisse bien s'accommoder de la température plus mociérée de la province de Constantine, a valu à des chefs indigènes une médaille d'or... Au point où en est arrivée la culture du coton en Algérie, le jury croit pouvoir dire qu'elle prendra tout l'essor que permettent les convenances naturelles du pays et l'aptitude acquise par les habitants, dès qu'une viabilité perfectionnée et une impulsion décisive donnée à la colonisation auront amélioré les conditions économiques, sous le double rapport des transports et de la main-d’œuvre. ")

$4^{\mathrm{e}}$ SECTION : Matières oléagineuses et savons. "Les huiles ne tiennent pas encore, ni dans l'agriculture ni dans l'industrie algérienne, la place que leur assigne l'aptitude du pays à la production de l'olivier. Cependant, il y a progrès vers une situation meilleure... »

$\breve{5}^{\mathrm{e}}$ SECTION : Matières tinctoriales et tannantes. On doil signaler la garance, le sumac thézéra, le henné, l'écorce de grenade, et, parmi les matières tannantes, la scille maritime.

$6^{\mathrm{e}}$ section : Baumes, gommes et résines. On a remarqué le lot de produits résineux envoyé par $M$. Chaussadis, d'Alger, et provenant de la forêt de Boghar. Il comprenait : $1^{\circ}$ de l'essence de térébenthine non rectifiée; $2^{\circ}$ de la colophane, du goudron et autres résidus provenant de la distillation; $3^{\circ}$ de la cire brute pour cacheter les bouteilles.

$7^{\mathrm{e}}$ SECTION : Matïres médicinales. Exposants peu nombreux.

$8^{\mathrm{e}}$ SEction : Céréales, fourrages, légumes. "Avec les substances alimentaires nous rentrons dans le cœur de l'agriculture algérienne. Céréales dans les champs, fourrages dans les prairies, légumes dans les jardins, telles sont bien, quant à présent, et pour longtemps encore sans doute, ses principales branches de culture. - Le jury n'a pas cru cependant devoir régler ses récom- 
penses sur le nombre et l'importance des lots exposés; il a considéré que, dans la beauté des céréales, la nature a sonvent plus de part que l'homme, qu'un triage grain par grain est d'ailleurs facile, que cette sorte de production est excilée par le besoin et l'intérêt immédiat à un degré suffisant pour en assurer le développement: il a donc réservé ses plus hautes récompenses des céréales à leur mise en œuvre sous forme de farines et de pâtes alimentaires..."

$9^{\text {e }}$ SECTION : Farines, semoules et pâtes alimentaires. "La juste popularité acquise à certaines cultures industrielles ne saurait enlever aux céréales le premier rang dans l'économie rurale de l'Algérie; devant l'impérieuse exigence des besoins, devant les suprêmes convenances du sol et du climat, sont tombées toutes les objections tirées de la prétendue impuissance des Européens à soutenir la concurrence arabe. L'expérience a justifié la théorie affirmant d'avance que le prix des céréales africaines s'élèverait au niveau des cours de France, dès que les marchés français leur seraient ouverts, et que dans ces prix convenablement rehaussés par la demande métropolitaine, le colon européen trouverait une rémunération suffisante quoique inférieure à celle de l'Arabe; le premier gagnerait moins que le second, telle serait toute la différence. Au lieu donc de détourner les Européens d'une culture que nulle autre ne pouvait remplacer, il convenait de réclamer les conditions légales et économiques propres à améliorer les prix qui étaient avilis par l'encombrement, avant que la loi du 11 janvier 18 Iั1 commençât l'assimilation commerciale heureusement développée depuis lors, mais qui attend encore son complément définitif. La minoterie rend à l'agriculture l'éminent service de soutenir le cours des blés par son débouché toujours ouvert, et à la consommation celui non moins précieux de lui fournir une matière alimentaire saine et fraîche, et, sous tous les rapports essentiels, supérieureà celle qui lui arrive de loin, après avoir traversé la mer. Cette industrie pénètre dans les habitudes arabes, et, en rapprochant les populations, elle adoucit le sort de la femme arabe, soulagée, partout où s'installe un moulin français, de la dure corvée de moudre à la main le blé qui doit faire le couscoussou de la famille. - C'est donc avec une véritable satisfaction que le jury, appréciant ces bienfaits, a trouvé, dans les farines et les semoules de qualité supérieure soumises à son examen, l'occasion de placer ses plus hautes récompenses... - 
Les pâtes alimentaires, connues sous le nom de pâtes d'Italie, sont un emploi fort important des blés durs d'Afrique, depuis longtemps pratiqué en Algérie par des. Espagnols et des Maltais, mais qui a eu besoin de la puissance financière et de l'expérience consommée d'industriels français pour révéler toute sa valeur... Le jury croit pouvoir déclarer que le problème de la mouture perfectionnée du blé dur paraît définitivement résolu. Si les farines et les semoules diffèrent au tact et à l'œil des farines de blé tendre, il n'y a dans cette différence aucun signe d'infériorité ce sont les caractères propres de chaque espèce, et c'est entre les produits de même origine et non d'une espèce à l'autre que la comparaison doit s'établir. Par sa saveur très-agréable, par ses propriétés nutritives, par son rendement élevé, le pain de blé dur, si longtemps méconnu en France et en Algérie même, justifie donc la faveur que revendiquait pour lui, il y a dix ans de cela, dans la presse oranaise, un colon dont la voix parvint à se faire entendre du ministre de la guerre; par ordre supérieur des expériences furent entreprises, et leurs résultats entraînèrent l'adoption du pain de blé dur, totalement ou en partie, par les populations civiles et par l'armée... 》

$10^{\mathrm{e}}$ section : Alcools, vins, conserves, confiseries. "... Les conseils donnés à nos colons dans les précédents rapports, et notamment dans celui fait à la suite de l'Exposition de la Société impériale et centrale d'horticulture en 18508 , ont porté leurs fruits. Les vins nouveaux ont paru mieux préparés, plus naturels ; les propriétaires sont deyenus plus sobres dans l'emploi de matières aromatiques. Plusieurs même ont complétement renoncé à l'usage de ces moyens, qui dénaturent et altèrent les vins sanș les améliorer... La qualité supérieure du vin muscat obtenu par M. Dumas, de Médéah, nous engage à insister sur les avantages que la viticulture algérienne pourrait retirer de la préparation de cette espèce de vin... Il est facile de reconnaître que l'Algérie, par son climat, appartient, au point de vue de la culture de la vigne, à cette série de vignobles qui avoisinent les bords de la Méditerranće et qui produisent la majeure partie des vins de liqueur les plus estimés. - Nous obtenons dans le midi de la France des vins de cette nature, mais si leur qualité est supérieure, leur production est restreinte... Ces considérations, jointes à la bonne qualité des vins de cette nature obtenus à Médéah, rendent très-probable le succès des vins à liqueur de l'Algérie, non-seulement sur le 
marché français, mais aussi sur les marchés étrangers, où ils pourront faire une sérieuse concurrence aux produits semblables de l'Tialie, de l'Espagne, de la Grèce et des autres contrées viticoles produisant des vins de liqueur.

"Nous pouvons signaler aussi une autre classe de vins à la production desquels l'Algérie doit se prêter également bien: c'est la classe des vins blancs secs de Xérès, de Madère, de Marsalla, etc.

“En un mot, nous croyons que l’Algérie doit, par la nature de ses produits viticoles, ressembler aux pays méridionaux, à l'Espagne, au Portugal, à l'Italie, à la Grèce...

« Certainement, il sera possible d'obtenir en Algérie des vins ordinaires, rouges et blancs, pouvant former des vins de table. Les faits que nous avons constatés au dernier concours suffisent pour le démontrer. Mais arrivera-t-on à faire de ces vins un article d'exportation pouvant faire concurrence à nos vins fins et communs du centre et du S.-O. de la France, et se mêler avantageusement avec eux sur nos marchés? Nous ne le croyons pas.

"Que l’Algérie fasse des vins de table pour la consommation de ses habitants, qu'elle s'affranchisse pour les produits de son sol de l'importation des vins ordinaires, cela est possible, et l'on parviendra, en perfectionnant les méthodes suivies pour la fermentation, à faire des vins agréables et légers, mais c'est plutôt dans les vins dont nous parlions tout à l'heure qu'elle trouvera des articles sérieux d'exportation...

"La préparation des produits d'imitation offrira un large débouché aux vins de l'Algérie. Nos colons pourront produire en grande abondance des vins semblables à ceux que fournissent l'Hérault, le Gard et les déparlements voisins, et qui servent de base au commerce si important dont Ciette est le centre.

"Ainsi nous croyons que l'extension de la culture de la vigne en Algérie ne peut donner lieu à aucune crainte au point de vue de l'écoulement des produits.

"Les vins de liqueur, les grands vins blanes secs nous paraissent etre les produits de qualité supérieure que l'Algérie pourra nous offrir.

" Elle fournira également des vins ordinaires pour suffire à la consommation de ses habitants, et en dehors elle nous donnera des vins rouges précieux pour le commerce et des vins blancs que Cette utilisera avec avantage. 
"La fabrication des vinaigres, la distillation, pourront encore, dans certaines circonstances, donner aux vins.communs de précieux débouchés...

"Peu de plantes sont mieux appropriées que la vigne au climat algérien; là, comme ailleurs, elle se plaît dans des terrains maigres, légers et rocailleux, impropres à toute autre culture; elle peut se passer d'irrigation, avantage inappréciable dans un pays aussi exposé à la sécheresse; elle réussit à toutes les altitudes, depuis le littoral jusqu'aux plateaux élevés de Médéah et de Milianah; sa culture demande moins de main-d'œurre que les plantes annuelles; une fois que le plant est bien enraciné, les récoltes sont à l'abri de tout risque atmosphérique; les raisins, d'un goût exquis, sont d'une vente facile et peuvent aisément se préparer pour la conservation; le vin bien fait a des qualités que le Concours de $\mathbf{1 8 6 0}$ met hors de doute...

"On peut donc espérer un brillant avenir pour la viticulture algérienne, et cet espoir se fortifie si l'on considère que, née exclusivement de l'initiative des colons, elle a grandi par leurs seuls efforts, sans aucun concours de l'Administration. ")

$11^{\mathrm{e}}$ SEGTION : Essences, huiles, parfums. Les environs d'Alger, et surtout l'arrondissement de Blidah, ont mérité, comme par le passé, les justes éloges du jury.

$12^{\circ}$ section: Tabacs. "Les tabacs occupent le premier rang parmi les récoltes de l'Algérie qualifiées d'industrielles ou de commerciales. Leurs mérites sont constatés par les achats qu'en fait la Régie, à concurrence de 6 millions de kilogrammes. »

Prix des bons tabacs de la province d'Oran : 130 à 150 francs les 100 kilogr.

Prix du tabac virginie, du territoire de Tlemcen : 70 à 110 francs les 50 kilogr.

Les tabacs du territoire de Sidi-bel-Abbès, excellents pour robes et sous-enveloppes de cigare, pourraient lutter avec les tabacs du Palatinat que toute l'Europe emploie aujourd'hui et qui se vendent à Oran de 200 à 300 francs les 100 kilogr.

Les terrains gras, comme il s'en trouve dans toutes les plaines de la province, conviennent pour le tabac en poudre ou à priser, très-fort, tel que l'aiment les indigènes. Prix : de 25 à 140 francs les 100 kilogr.

$13^{\mathrm{e}}$ SEGTION : Divers végétaux industriels ou alimenlaires. La 
poudre de caroube desséchée, torréfiée, a été trouvée supérieure à la chicorée, mais inférieure au café et au chocolat.

$14^{\mathrm{e}}$ SEGTION : Herbiers. Une médaille d'argent a été décernée à M. Durąndo, le doyen des botanistes algériens.

$15^{\mathrm{e}}$ SEGTION : Fruits et tubercules. Les envois de M. Hardy, directeur de la pépinière centrale d'Alger, lui ont mérité une grande médaille d'or.

\section{DEUXIËME SÉRIE.}

ANIMAUX ET PRODUITS ANIMAUX.

$1^{\mathrm{re}}$ SEGTION : Laines et poils. Spécimens très-remarquables.

$2^{\mathrm{e}}$ SEction : Soies. Une médaille d'or, des médailles d'argent, des médailles de bronze, des mentions honorables ont été décernées.

$3^{\mathrm{e}}$ Segtion : Cuirs et peaux. Il a été reconnu que l'application de la scille maritime au tannage des cuirs était une découverte importante. L'auteur de cette découverte, M. Coopmann, a obtenu une médaille d'or.

$4^{\mathrm{e}}$ SECTION : Cires et miels. "Un seul exposant a présenté des produits assez remarquables pour mériter une distinction; c'est M. Bœnsch, de Kouba... L'immense étendue de terres incultes, couverte de plantes aromatiques, a naturalisé la production de la cire et du miel chez les Arabes et les Kabyles : il appartient aux Européens de la perfectionner en l'adoptant. "

$5^{\mathrm{e}}$ SEGTION : Produits tirés des eaux. Mention honorable à MM. Redier et $\mathrm{C}^{\mathrm{ie}}$, de Philippeville, pour leurs conserves de sardines et d'anchois.

\section{SÉRIE DES INSTRUMENTS ARATOIRES.}

Une charrue, exposée par M. Massardier, d'Oran, n'a pu être examinée par le jury spécial des instruments aratoires.

\section{SÉRIE DES ANIMAUX.}

Un prix unique a été décerné à M. de La Motte pour un cheval de race arabe.

Les spécimens présentés n'ont pu donner qu'une idée trèsinsuffisante des animaux de l'Algérie. Le temps a manqué pour préparer dignement cette partie du concours. 
SÉRIE MINÉRALE.

MM. Laurent et Degousée, de Paris, ont obtenu une médaille d'or pour leurs collections de roches sahariennes (recueillies dans leurs sondages artésiens). - MM. Pallu et $\mathrm{C}^{\mathrm{ie}}$, de Paris, ont remporté une médaille d'or pour leurs collections d'albâtre, ou o nyx translucide. - Des marbres, des salpêtres, les collections géologiques de l'exposition pérmanente, ont aussi été l'objet de distinctions diverses.

\section{HORS SÉRIE.}

Médaille d'or à M. Ben-Sadoun, de Paris, pour la fabrication en Algérie, l'importation et l'imitation en France de produits algériens.

Médaille d'argent à M. Noirot, directeur de l'Algérie agricole (recueil mensuel), pour l'aide qu'il n'a cessé de prêter à l'organisation des concours algériens.

Nous n'avons pu reproduire tous les détails du rapport si instructif de M. Duval. Nous renvoyons ceux de nos lecteurs à qui ne suffirait pas l'extrait ci-dessus, à ce document important.

Extrait du discours de M. Lestiboudois, conseiller d'État, président du Conseil général de Constantine, à l'ouverture de la session de 1861.

Pour moi, dès que j'ai eu mis le pied sur la terre d'Afrique, deux idées principales m'ont dominé, et, après douze années d'études assidues, je ne trouve rien de meilleur, dans mes convictions, sur les moyens de peupler cette terre et d'en oḅtenir d'abondants produits.

Pour tirer de ce sol une grande richesse, il est inutile, à l'origine, d'y implanter, à grands frais et risques, des végétaux étrangers; il suffit de lui demander ce qu'il a produit de tout temps et pour ainsi dire spontanément.

Il donne des céréales de première valeur, la soie, le lin, la laine, le coton peut-être, l'huile et le tabac, et tous les fruits qui entrent comme un élément considérable dans le grand com- 
merce; enfin les vins, dont les qualités ne sont plus contestées. Ne demandons pas davantage pour les premiers temps. Bien des nations sont opulentes qui n'ont pas de pàreils trésors.

La seconde pensée qui m'a saisi, c'est que, si on peut assurer la prospérité de l'Algérie au moyen des végétaux qui lui sont propres, on ne peut assurer leur culture qu'au moyen des hommes qui l'habitent, en les éclairant, en les dirigeant, en les associant aux races européennes:

L'Arabe est d'une intelligence rare; il a de la dignité, et aspire conséquemment à une haute civilisation; il est pasteur; il est propre à certaines cultures; il est commerçant habile; il peut donc rendre de grands services.

Le Kabyle sédentaire, pratiquant l'horticulture avec amour, démascleur émérite, ouvrier incomparable pour ces contrées, a déjà prouvé qu'il viendra de grand cœur prendre part à nos travaux.

Mais on a peu de souci des résultats que pourrait amener l'association de pareils éléments avec les pionniers de la civilisation européenne.

On / colonise une terre déserte, un pays dont on veut refouler la population, ou dont, à la honte de l'humanité, on projette d'exterminer les habitants; on colonise une contrée à laquelle on veut demander des produits qui exigent des travailleurs tout à fait spéciaux. Mais ici une population nombreuse est répandue sur toute la surface du pays; des races distinctes, pourvues d'aptitudes précicuses, sont disposées à entreprendre toutes les cultures; le sol donne naturellement les plus riches éléments d'échange. Que parle-t-on donc de coloniser l'Algérie, et d'y appeler des émigrants de toutes les parties du monde, pour y constituer une race subordonnée à l'intelligence européenne? Cette race couvre le sol; il ne faut que l'utiliser.

(Extrait de la brochure anonyme intitulée: l'Algérie française. Indigènes et immigrants. Paris, Challamel, 1863, broch.in-8.)

Tant que les indigènes n'auront pas opéré une séparation radicale entre le spirituel et le temporel, tant que leur culte et leurs dogmes religieux seront en contradiction avec nos Codes, ils ne pourront être investis du titre de citoyens français. Il faut que le Koran devienne pour eux un livre purement religieux, 
sans action sur la législation civile. Ce progrès n'est pas impossible. D'autres peuples sont sortis de l'organisation théocratique et se sont rangés sous un gouvernement séculier, sans abdiquer leurs croyances. (Brochure anonyme, 1863.)

A cette opinion nous en devons joindre quelques autres.

"Rien dans le Koran, dit M. Pellissier de Reynaud, ne s'oppose formellement aux investigations scientifiques, ni au libre développement de l'intelligence... La brutale réponse d'Omar, fort contestable d'ailleurs, s'efface devant la fondation de milliers de bibliothèques créées par les Arabes an temps de leur puissance.

a Les transgressions particulières.à la loi religieuse ne sont que de la licence, et ne sauraient constituer un principe de progrès. Le Musulman qui viole le jeûne et boit du vin n'est pas plus près de la civilisation qu'un autre. Une nation ne progresse pas par de petits actes de révolte individuelle contre ses usages et ses croyances, actes qui sant presque toujours lè résultat de passions mauvaises, et que très-solivent le repentir fait tourner, un peu plus tard, au profit de la superstition.

"Le despotisme et l'anarchie marchaient déjà de pair avant le Koran. Chez tous les peuples orientaux, le principe d'immobilité existait avant lui dans les sociétés orientales.

“ Au résumé, à l'exception de la Trinité, que le Koran repousse en termes formels, les musulmans et les chrétiens ont sur Dieu les mêmes idées. La doctrine de l'amour divin est également la même dans les deux religions.

"L'islamisme exalte l'excellence de Marie, mère de Jésus, autant que le christianisme lui-même. Le Koran dit qu'elle conserve sa virginité intacte et qu'elle naquit purifiée. Beaucoup de commentateurs ont cru voir dans ce passage la proclamation formelle de l'immaculée conception, qui est un dogme tout récent du catholicisme.

" Il est certain que Mohammed est un des hommes les plus extraordinaires qui aient paru.

"Les dogmes du Koran sont simples et inattaquables, à moins qu'on ne pousse l'incrédulité jusqu'à l'athéisme. Les chrétiens peuvent trouver qu'il n'en dit pas assez, mais non que ce qu'il dit est faux. ") (Pellissier de Reynaud, De l'islamisme et de son action sur les mœurs de ceux qui le professent.)

aDe tous les peuples conquérants, dit Viardot, les Arabes furent, 
sans contredit, le moins exigeant comme le moins cruel. Ilsimitèrent la tolérance religieuse et civile des Romains de l'empire, sans avoir imité les excès militaires des Romains de la République. Toute leur histoire rend témoignage de cette grande modération... La conquête de l'Esspagne par les Arabes, bien différente de celle par les peuples du Nord, se fit sans ravages, sans effusion de sang, comme une simple prise de possession. ")(Viardot, Hist. des Arabes tt des mœurs d'Espagne, t. II.)

Le renom de fertilité de l'Algérie, vit sur le vieux mot latin : l'Afrique, grenier de Rome. On se garde bien de rechercher si la province d'Afrique n'était pas située beaucoup plus à l'est, répondant à la Tunisie, et non à l'Algérie; si, le temps écoulé, les changements apportés dans les coutumes, dans les mœurs, dans l'existence politique et sociale de la population, dans la densité du peuplement, dans l'assiette des centres habités, dans le boisement des montagnes, dans le débit des sources et des cours d'eau, n'ont pas créé une situation tout autre. Parce qué le mot latin disait grenier de Rome, c'est-à-dire pays des céréąles, on a voulu trouver une zone tropicale propre aux cultures des climats chauds. (Broch. anonyme, 1863.)

Le caractère général des terrains algériens est argileux, marneux ou calcaire; il ne comportera pas, de longtemps, un mode d'exploitation plus farorable que la culture pastorale. Les cultures sarclées ne pourront être entreprises que lorsque la culture pastorale aura été perfectionnée. C'est aussi l'avis du savant M. Moll. On avait tenté la colonisation par l'introduction des plantes tropicales, avant de savoir si les conditions agricoles et économiques du pays permettaient d'espérer la réussite. On persévéra dans les mêmes efforts par routine et par préjugé, à travers tous les changements de situation apportés par le temps. On exagérait les résultats partiels obtenus, comme on avait fait pour la fertilité universelle du sol. On passa les échecs sous silence pour n'avoir pas à reconnaître des erreurs et à renoncer à des illusions. (Broch. anonyme, 1863.) - On lit, d'un autre côté, dans la brochure de M. Albert de Broglie, Une Réforme administrative en Algérie : "L'Algérie, telle qu'elle nous est tombée en partage, n'était pas un pays inhabité, mais un pays mal habité. Une terre mal cultivée est une terre à laquelle le possesseur a beaucoup demandé et beaucoup pris sans lui rien rendre. L'Algérie 
est cette terre-là. Pour être rétablies dans leur abondance et dans leur vigueur primitives, les richesses naturelles exigent un travail presque aussi considérable et aussi coûteux que celui qui est nécessaire à nos vieilles terres fatiguées par tant de siècles de culture... »

L'Européen garde son énergie sous toutes les latitudes, mais à la condition expresse de ne pas appliquer sous une trop haute température cette énergie aux travaux manuels qui le conduiraient infailliblement à sa perte.

Pendant la saison sèche, en Algérie, non-seulement les Européens, mais les indigènes, travaillent la terre avec fantaisie, c'està-dire sans continuité ni permanence. Voilà pourquoi il serait si désirable de pouvoir consacrer aux rudes travaux d'été de la campagne des ouvriers d'une autre couleur et d'une autre complexion, en réservant les blancs pour la direction des travaux. Le travail de surveillance, quelque pénible qu'il paraisse, donne aux individus qui l'exercent une occupation et une activité favorables à`leur santé.

L'avenir de la colonisation agricole en Algérie est incontestablement lié au développement des cultures industrielles, surtout de ces grandes cultures du coton et de la canne à sucre, qui ont fait, de tout temps, la fortune de nos autres colonies. Ces cultures ne sauraient donner de grands résultats en Algérie, qu'à la grande exploitation, puisque cette exploitation est la seule qui offre des garanties suffisantes au capital. (Bulletin de la Soc. d'agriculture d'Alger, 1861, p. 68 et suiv.)

Le caractère général de la propriété, dans les villes, était individuel; dans les tribus, il était collectif.

C'est la grande culture et l'éducation des bestiaux que le sol et le climat de l'Algérie favorisent le plus généralement; l'une et l'autre exigent des déplacements continuels, car il faut, dans certains moments, fuir des lieux malsains, inoṇdés ou desséchés, qui, dans d'autres moments, sont très-productifs et très-habitables. Les conditions hygiéniques pourront s'améliorer avec le temps et par d'immenses travaux, de même que notre conquête a amélioré les conditions politiques; mais jusque-là la nature des choses sera difficile, sinon impossible, à changer d'une manière générale. (Enfantin, De la colonisation de l’Algérie.) 
Des esprits superficiels, en voyant le fâcheux état de l'agriculture indigène dans ces plaines brûlées, accusent la barbarie des habitants. Cette qualification n'est pas justifiée. Les agriculteurs français les plus compétents établis depuis longtemps en Algérie rendent à l'intelligence agricole des indigènes une justice plus impartiale. N'avons-nous pas entendu confesser qu'après avoir fait pour l'ensemencement l'essai des qualités diverses des céréales, on avait reconnu le blé dur des indigènes comme donnant les meilleurs résultats ? Le même aveu a été fait pour le maïs, pour les fèves; nous pouvons ajouter pour le tabac aussi, puisque les plants indigènes sont d'une qualité incontestablement supérieure et se vendent à un prix beaucoup plus élevé. En présence des capricieuses péripéties du climat, les cultivateurs sagaces se demandent si l'indigène, labourant légèrement de grands espaces, n'est pas mieux avisé que l'Européen, qui concentre ses efforts sur un point limité, jouant, chaque année, une partie de ruine ou de succès avec la sécheresse, les pluies torrentielles, la grêle, les brouillards du matin et le vent du désert. Si l'on examinait la situation agricole avec attention, peut-être découvrirait-on que les faits donnent souvent raison à ce que nous appelons la routine indigène contre la science exotique. Il n'y a rien d'universel ni d'absolu en fait d'expérience.

Les personnes qui ont exploré les parties montagneuses du pays ont pu constater que la culture, protégée par la sécurité, élait aussi avancée que dans la moyenne de nos départements français. Les montagnards tirent le meilleur parti des eaux, du fumier même. La propriété est très-divisée, complantée d'arbres fruitiers et close par des murs en pierres sèches ou par des haies. La population, plus dense et fixée au sol, a fait appel à l'industrie pour parfaire les ressources trop faibles de la culture.La Kabylie du Djurjura ne mesure que 63 arès de terre à chacun de ses habitants, et le Tell de l'Algérie (14 millions d'hectares, y compris les montagnes, lacs et rivières) est aussi peuplé que la moyenne des 57 départements français les moins populeux. On a relevé récemment que, sur $2,500,000$ charrues qui labourent en France, 1,600,000 (plus des $3 / 5$ ) ne sont encore que l'araire sans roues, peu supérieur à la charrue employée par les Arabes. Il y a lieu d'espérer que nos tentatives en faveur de l'amélioration de l'agriculture indigène seront couronnées de succès. Il sera plus praticable de perfectionner la main-d'œuvre algérienne, en la 
maintenant à bon marché, que d'introduire des cultivateurs étrangers en les faisant vivre dans de bonnes conditions de production.

En résumé, le vrai paysan de l'Algérie, l'ouvrier agricole, la base la plus rationnelle et la plus solide de la propriété, c'est l'indigène. (Brochure anonyme de 1863 : L'Algérie francaise, Indigènes et immigrants.)

Il ne serait pas prudent de renoncer trop tôt au concours de l'aristocratie indigène pour commander les régions où nous ne pouvons agir directement. Il n'y aurait aucun avantage, ni pour la paix, ni pour l'ordre public, ni pour la civilisation, à décapiter la société indigène, en enlevant aux plus instruits, aux plus nobles, aux plus riches, les moyens de se rattacher honorablementà notre gouvernement... D'ailleurs, frapper ceux que l'opinion n'a pas encore condamnés, c'est préparer des chefs pour les agitations et pour les troubles. (Brochure anonyme de 1863.) "L'aristocratie arabe, dit d'Escayrac de Lauture (le Désert et le Soudan), est essentiellement nationale. Le noble est toujours le parent du prolétaire, qui ne le reconnaît pour son chef qu'en vertu du droit d'aînesse, et parce que le type primitif semble moins altéré chez le noble."

"L'étendue des côtes algériennes (0. Mac-Garthy, Géographie de l'Algérie) dépasse 1,000 kilom. (250 lieues), et ses autres limites en ont une de 1,600 kilom. (400 lieues), ce qui donne un périmètre de 2,600 kilom. (650 lieues).

"La superficie, l'étendue de la surface que cette double ligne enveloppe, est d'environ 60 millions d'hectares, c'est-à-dire qu'elle est égale à celle de la France, plus 1/8 environ.

"Quant à l'étendue respective de nos deux grandes divisions naturelles, elle a :

"Pour le Tell, 14 millions d'hectares;

"Pour le Sahara, 46 millions d'hectares."

Ces 60 millions d'hectares sont occupés par environ 3 millions d'indigènes.

On évalue à 1,801,803 hectares la superficie occupée par les bois et forêts dans les trois provinces de l'Algérie, savoir :

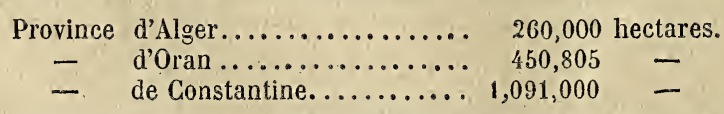

(Éiat actuel de l'Algérie, 1862, p. 30.) 
Une expérience de vingt années, dit M. de Launoy, ingénieur à Constantine, semble avoir démontré que, dans la province de Constantine, le cultivateur européen ne saurait subsister en dehors de la région de l'olivier et de la vigne, laquelle occupe, le long du littoral, une bande de 4 à כ̌ myriamètres de largeur. Les concessions faites en dehors de cette zone ont donné le triste spectacle d'un honteux gaspillage de la fortune publique en constructions et en plantations destinées seulement à apparaître un jour, dans l'unique but de servir au libellé d'un titre, et n'ont abouti qu'à enrichir l'obsession et la faveur. (Broch. anonyme de 1863 : Indigènes et Immigrants, p. 66.)

L'auteur de la brochure anonyme de 1863 : L'Algérie française, Indigènes et Immigrants, - résume ainsi ses idées :

" $1^{\circ}$ Indépendance très-large laissée au pouvoir local, sous la seule garantie du contrôle et de l'inspection, indispensables dans un gouvernement représentatif;

" $2^{\circ}$ Sages ménagements envers l’état social des indigènes; offrir à ceux-ci les moyens de se rallier à nous honorablement et avec profit;

" $3^{\circ}$ Abandonner l'agriculture aux natifs, sauf à étudier les meilleures mesures pour les faire progresser;

" $4^{\circ}$ Création de l'industrie par les immigrants; encouragements sérieux pour aider le développement industriel;

" $5^{\circ}$ Enfin tirer des indigènes un concours militaire qui allége pour la France les charges de la conscription. »)

\section{Sénatus-Consulte du 5 juillet 1865.}

Art. $1^{\text {er }}$. L'indigène musulman est un Français; néanmoins, il continue à être régi par la loi musulmane.

Il peut être admis à servir dans les armées de terre et de mer. Il peut être appelé à des fonctions et emplois civils en Algérie.

Il peut, sur sa demande, etre admis à jouir des droits de citoyen français : dans ce cas, il est régi par les lois civiles et politiques de la France.

ART. 2. L'indigène israélite est Français; néanmoins, il continue à être régi par son statut personnel.

ll peut être admis à servir dans les armées de terre et de mer. Il peut etre appelé à des fonctions et emplois civils en Algérie.

Il peut, sur sa demande, etre admis à jouir des droits de citoyen francais : dans ce cas, il est régi par la loi française. 
Art. 3. L'étranger qui justifie de trois années de résidence en Algérie peul être admis à jouir de tous les droits de citoyen français.

ART. 4. La qualité de citoyen français ne peut être obtenue, conformément aux art. 1, 2 et 3 du présent sénatus-consulte, qu'à l'âge de vingt et un ans accomplis; elle est conférée par décret impérial rendu en conseil d'État.

ART. 5. Un règlement d'administration déterminera :

$1^{\circ}$ Les'conditions d'admission, de service et d'avancement des indigènes musulmans et des indigènesisraélites, dans les armées de terre et de mer;

$2^{\circ}$ Les fonctions et emplois civils auxquels les indigènes musulmans et les indigènes israélites peuvent être nommés en Algérie;

$3^{\circ}$ Les formes dans lesquelles seront instruites les demandes prévues par les art. 1, 2 et 3 du présent sénatus-consulte.

\section{Appréciation de la lettre de l'Empereur, par le général Allard.}

La lettre de l'Empereur au maréchal de Mac-Mahon, duc de Magenta, parut le 4 novembre 1863 (elle est datée du 20 juin 1865).

" Elle causa, dit le général Allard, une vive émotion en France et en Algérie; mais on en a singulièrement exagéré la portée; on s'est mépris sur ses conséquences.

"Elle contient deux choses distinctes: d'abord un programme général, puis des mesures de détail inspirées par une étude faite sur les lieux et propres à le réaliser après examen sérieux par les hommes compétents.

"Il y a, en Algérie, deux grands intérêts dont l'antagonisme est ancien et constant, et que l'Empereur s'est proposé de réconcilier. Il y a l'intérêt français et européen représenté par 200,000 individus disséminés sur le littoral et dans le Sahel; et il y a l'intérêt arabe représenté par 2,500,000 indigènes, vivant, sous la tente, des produits de la terre, formant des tribus indépendantes, propriétaires, depuis un temps immémorial, des territoires qu'elles occupent.

"Fallait-il, après la conquête, pour faire de la place à la colonisation, refouler un peuple fier dans le Sahara, lui infliger le sort des Indiens dans l'Amérique du Nord? Fallait-il même adopter le système mitigé qu'on a appelé le cantonnement indigène et dont l'application a suscité la guerre sainte? L'humanité, la politique, l'intérêt bien entendu de la France, ne permettaient pas une telle conduite. L'Empereur ne l'a pas pensé. Le système qui a été formulé dans la lettre impériale n’est pas un système nouveau; elle trace des règles de conduite pour les administrateurs.... " (Corps législatif, séance du 5 mars 1866.) 


\section{LETTRE DE L'EMPEREUR}

\section{SUR L'ALGÉRIE.}

La Lettre sur la politique de la France en Algérie, adressée par l'empereur au maréchal de Mac-Mahon, gouverneur de l'Algérie, est divisée en quatre chapitres qui ont pour titres: les Arabes, - la Colonisation, - l'Ogcupation militaire, RÉSUMÉ.

Le chapitre les Arabes se subdivise ainsi : Position des Arabes, Conduite envers les indigènes, Terres azels, l'Impôt, l'Usure et la tribu, Justice, et enfin les MesuRes proposées dont voici le texte:

1. Déclarer que les Arabes sont Français, puisque l'Algérie est territoire français, mais qu'ils continueront d'être régis par leurs statuts civils, conformément à la loi musulmane; que, cependant, les Arabes qui voudront être admis au bénéfice de la loi civile française seront, sur leur demande, sans conditions de stage, investis des droits de citoyens français.

2. Proclamer l'admissibilité des Arabes à tous les emplois militaires de l'empire et à tous les emplois civils en Algérie.

3. Exécuter loyalement le sénatus-consulte en respectant les droits acquis des Arabes.

4. Dans les tribus qui n'ont cédé aucune partie de leur territoire aux Européens, la commission chargée d'appliquer le sénatus-consulte ne devra admettre les droits du domaine que sur les portions du territoire reconnues par la tribu elle-même comme appartenant à l'État à un titre quelconque, c'est-à-dire comme terres de beylick, biens habbous, ou immeubles provenant des successions vacantes.

Dans les tribus dont une portion de territoire a été livrée à la colonisation à un titre autre que ceux ci-dessus indiqués, on devra chercher a rendre aux tribus, s'il est possible, une quantité de terre équivalente à celle qui leur a été enlevée, et, dans tous les cas, suffisante pour leurs besoins.

Dans les tribus établies sur le territoire azel, on devra distinguer entre les tentes qui l'occupent, à titre définitif depuis un temps immémorial, et celles qui ne l'occupent qu'à titre provisoire, depuis le temps, par exemple, que ces terres ont été louées à leur chef, étranger à l'azel.

Les premières devront être considérées comme propriétaires des terres cultivées par elles, et, s'il est reconnu que ces terres ne sont pas suffisantes, il devra leur etre concédé, sur l'azel, des lots assez considérables pour leur permettre de vivre dans de bonnes conditions. 
Quant aux tentes étrangères à l'azel, la commission nommée ad hoc devra constater à quelles tribus elles appartiennent et les renvoyer à ces tribus, si celles-ci peuvent les recevoir. Si, au contraire, les tribus n'ont pas assez de terre pour recevoir ces tentes, la commission devra donner à ces dernières, sur l'azel, les terrains qui leur sont nécessaires.

5. Disposer que la propriété personnelle, lorsqu'elle sera créée en exécution du sénatus-consulte du 22 avril 1863 , sera insaisissable aux créanciers, pour les dettes antérieures à la constitution de la propriété.

6. Comme à la fin de l'année prochaine presque tous les territoires azels auront été soumis à l'application du sénatus-consulte, dégréver en attendant, d'une partie de l'impot, les douars qui ont affermé des azels anciennement cultivés par eux.

7. Déclarer que l'expropriation pour cause d'utilité publique ne pourra être faite qu'en vertu d'un décret de l'empereur, ainsi que cela se pratique en France.

8. Etablir des registres de l'état civil aussitot que les douars auront été constilués en communes et que les djemmaâs seront organisées.

9. D'après le décret du 7 avril $186 \%$, toutes les tribus organisées ont été replacées en territoire militaire, à l'exception d'une fraction de la tribu des Gharabas; il serait désirable de faire disparaître cette exception.

10. Restreindre les réserves forestières; les reviser de manière que les Arabes ne soient pas privés du seul moyen qu'ils aient de faire paître leurs troupeaux.

11. Faire un partage d'attributions et de compétence entre les juridictions musulmanes, de telle sorte que ces dernières ne connaissent que des affaires ressortissant à la loi religieuse, et que les autres procès soient déférés aux tribunaux français. Pour l'étude de cette grave question, former une commission où seront appelés des tolbas et légistes musulmans.

Déclarer que le délai d'appel fixé par l'art. 30 du décret de 1859 devra partir du jour de la notification du jugement prononcé par le cadi.

Les concussions des adouls sont un des maux de la justice arabe. Afin d'y mettre un terme, peut-être y aurait-il lieu d'assigner à ces officiers ministériels un traitement fixe en ne leur accordant des vacations que pour les transports. Lè coût des actes serait rersé au domaine, ce qui compenserait et au delà le nouveau sacrifice imposé au Trésor.

Suspendre pendant la guerre tous les délais de la procédure civile à l'égard des Arabes qui combattent sous nos drapeaux.

L'assistance judiciaire pour les Arabes indigents existe, mais ils n'en profitent pas. Leur faire comprendre les bienfaits de l'institution.

12. Organiser un consistoire musulman par province, et nommer un conseil de fabrique pour chaque mosquée de première classe. Le consistoire musulman remplirait pour le culte le même office que les consistoires protestant et israélite. Il serait, en outre, consulté sur les œuvres de bienfaisance et d'assistance publique intéressant les musulmans. 
Instituer également une Commission, composée des mêmes éléments que la premiere, avec adjonclion de quelques personnages religieux, et lui demander son avis sur le projet d'organisation des consistoires.

Entourer de quelque solennité officielle la célébration des grandes fêtes musulmanes.

13. Établir un medjlès par subdivision; en même temps étendre les ressorts des cadis; apporter une plus grande surveillance dans le choix de ces magistrats; régler l'administration et l'avancement dans la magistrature indigène.

14. Désigner un tribunal de première instance par province, auquel sera dévolu exceptionnellement le droit de prononcer souverainement sur les appels, dans les affaires qui ne présenteront pas le caractère religieux défini plus haut, jusqu'à concurrence de 10,000 francs au moins, en attendant que chaque province puisse être dotée d'une Cour impériale.

15. Les zaouz̈a sont en général des écoles, des réurions de tolbas ou de gens prenant ce titre, qui se groupent autour d'une mosquée, vivant d'aumones, des revenus des biens appartenant à l'établissement, des redevances que payent certaines tribus. Afin d'éviter les écarts possibles des direcleurs de zaouïa, former dans chaque zaouïa une sorte de conseil d'administration sur lequel on essayerait d'agir pour donner à l'enseignement une bonne direction.

16. Ne déférer aux conseils de guerre que la connaissance des faits réputés crimes; attribuer aux commissions disciplinaires, établies dans chaque cercle, le jugement des délits. Aujourd'hui les délits commis à Tuggurt, c'est-à-dire dans le désert, sont jugés à Constantine, et l'on oblige ainsi les inculpés et les témoins à un voyage de près de 400 lieues pour aller et revenir.

17. Constituer le plus vite possible et sans attendre les opérations prescrites en exécution du sénatus-consulte, la djemmad des tribus, conseil municipal non électif qui surveillera et contiendra le chef indigène, en l'assistant dans toules les affaires intéressant la commune.

18. Autoriser les douars constitués à contracter des emprunls, en offrant leurs communaux comme gage,jusqu'à ce que leurs ressources budgétaires soient régularisées.

19. Prendre en territoire militaire, pour l'assiette de l'impôt, la moyenne descontributions pendant les dix dernières années, en dégager un impot unique, invariable pourdix ans, le répartir partribu et par fraction de tribu bien délimitée (1) et le faire percevoir par les djemmaàs.

(1) Cette fraction pourrait être la ferka, fraction parfaitement connue de chaque tribu; elle se compose, en moyenne, d'une centaine de tentes réparties entre six ou huit douars, lesquels sont de création tout administrative et française. II ne conviendrait pas de descendre au-dessous de la ferka, le douar n'offre pas au Trésor assez d'éléments de solidité et de garantie. Chaque ferka, connaissant son impôt fixe pour dix ans, désignerait le chef des douar's qui formerait en même temps et la djemmad et le conseil des répartiteurs. Cette manière d'agir n'est pas nouvelle chez les Arabes : du temps des Turcs, l'impôt était fixe. Les ferradine ou répartiteurs choisis par les contribuables établissaient le compte de chacun avec une exactitude remarquable. 
20. Dans le territoire civil, convertir en un impot unique, et fixé une fois pour toutes, les diverses contributions dues à la commune par l'Arabe admis dans un centre européen.

21. En territoire civil, élever le nombre des membres musulmans des conseils municipaux en proportion de la population.

Nommer un adjoint indigène dans les communes où les indigènes sont en nombre suffisant.

22. Augmenter le nombre des membres indigènes pour les conseils des Monts-de-piété, des Caisses d'épargne, des prisons, de l'Académie, etc.

Choisir ces membres de préférence parmi les notables n'occupant pas d'emplois salariés, afin d'augmenter les rapports et les contrats entre les populations française et indigène.

23. Créer à Alger une École supérieure pour les études de législation musulmane.

24. Développer l'instruction publique musulmane dans les communes du territoire civil comme dans les villes. Suivre l'exemple de Cherchel, où les enfants des deux cultes fréquentent les mêmes écoles.

Réorganiser les écoles supérieures musulmanes, de façon à y recruter les agents de la justice musulmane et les secrétáires pour la langue arabe. Créer une École d'arts et métiers par province. (A l'instar de celle du Fort-Napoléon, qui sera ouverte dans quelques mois.)

Fonder des orphelinats musulmans pour les garçons et pour les filles dans chaque province.

25. Etablir des salles spéciales pour les indigènes dans les hopitaux, et assurer le service du culte pour les morts.

Propager la vaccine; donner des consultations gratuites; créer des infirmeries indigènes dans les cercles où il n'existe pas d'hopital; attacher à chaque bureau arabe un médecin pour donner des soins aux tribus.

26. Transformer les prisons centrales affectées aux indigènes en pénitenciers agricoles, un par province; assurer le service du culte et respecter autant que possible, les tombes musulmanes.

Réunir en un lieu distinct les indigènes condamnés aux travaux forcéz, le contact des condamnés européens achevant de les pervertir.

27. Ordonner que dans les villes ce qui reste entre les mains du domáine, de maisons provenant de habbous (communautés religieuses), soit respecté, et qu'elles soient louées àu indigents musulmans à bas prix, d'après l'intention des fondateurs qui ont constitué originairement ces habbous.

28. Proposer tous les ans, au 15 août, un état des condamnés auxquels il est possible de faire grâce. Y comprendre principalement ceux qui, frappés sévèrement par notre Code, n'auraient encouru qu'une peine légère si on leur avait appliqué la loi musulmane.

29. Recommander à toutes les administrations de se défaire des formes brusques et 'souvent méprisantes avec lesquelles on accueille les indigènes qu'un intérêt amène dans les bureaux. 
Le deuxième chapitre la CoLonisation est subdivisé ainsi : Règles gérérales, Liberté commerciale, Emplacement de la colonisation, Centres européens, Concessions, Difficultésde l'immigration, Développement des villes, Simplification de l'administration, Affranchissement de la commune, et enfin les MEsures proposéEs sont formulées ainsi :

1. Déclarer la franchise de tous les ports de l'Algérie; supprimer ainsi toutes les douanes, et ne conserver l'octroi de mer que comme ressource pour les villes. Admettre en même temps dans la métropole, sans droits, tous les produits de l'Algérie.

Déjà, d'après l'avis du gouverneur général, j'ai décidé la suppression de la douane établie sur les frontières du Maroc : elle coûtait plus de 100,000 francs et n'en rapportait que 8,000 .

2. Créer dans chaque province un comptoir d'escompte, pouvant prêteraux colons, comme aux Arabes, à un taux modéré.

3. Tracer un périmètre à la colonisation autour des chefs-lieux des trois provinces.

Ainsi, dans la province d'Oran, le périmètre du territoire dan lequel les Européens pourront développer leur's intérêts sera circonscrit par une ligne qui, à l'ouest, partant de l'embouchure du RioSalado, remontera ce cours d'eau jusqu'au territoire de Bou-Tlelis, et de là, se dirigera vers le sud en laissant intérieurement tous les élablissements eur'opéens dans la direction d'Oran à Tlemcen, y compris le territoire d'Hennaya. Dans le sud, cette ligne, partant de Tlemcen, gagnera le territoire d'Hadjar-Roum, en suivant le pied des montagnes, puis celui de Sidi-Ali-ben-Youb, et ira jusqu'à Tenira pour revenir à Sidi-bel-Abbès. De là, elle descendra le Sig jusqu'à Saint-Denis, embrassera Perregaux sur l'Habra, Bouguirat, l'Hilil, Relizane et les centres de population qui seront créés sur la ligne des chemins de fer dans la vallée de Chćliff, jusqu'à la limite des divisions d'Oran et d'Alger. Enfin la limite nord comprendrait le territoire de Mostaganem et remonterait la vallée du Chéliff.

Dans la province d'Alger, cette ligne renfermera les crêtes du petit Atlas qui entourent la Mlitidja, laissant au nord tous les territoires euro péens qui s'étendent depuis Novi et Cherclell jusqu'ì Dellys; de plu une zone comprenant tous les centres déjà créés sur la route de Blidah à Orléansville et tous ceux à fonder dans la partie sud de la vallée du Chéliff, depuis Milianah jusqu'à la province d'Oran; enfin les établissements de Tenez et d'Orléansville.

Dans la province de Constantine, la limite nord devra comprendre, $\grave{a}$ parlir de Sétif, les territoires déjà occupés ou à occuper sur la route de Sétif à Constantine jusqu'à l'Oued-Decri; de là, gagner Milah pour redescendre dans la vallée de l'Oued-Kehi jusqu'au territoire de Smendou, d'où elle atteindra Collo en suivart la vallée de l'Oued-Guebbi. La limite sud laissera en dedans les centres de population établis entre Sélif et Hammam-Grouss; elle joindra, le terriloire d'Aïn-Mlila, d'où elle se 
dirigera sur Aïn-Ghoul; puis, laissant intérieurement le territoirø de Guelma, elle décrira une courbe pour venir se relier avec Souk-Ahras, et remontera vers le nord jusqu'à Mondovi, d'où elle arrivera à la Calle.

Dans la province d'Oran, les territoires de Nemours, de Mascara et de Tiaret ne pourront prendre de nouveaux développements que lorsque les populations deviendront plus denses. Il en sera de même, dans la province d'Alger, pour le territoire d'Aumale; dans la province de Constantine, pour les postes de Bougie, Djidjelli, Collo et Batna. Quant aux postes de Maghnia, Sebdou, Daya, Saïda, Ammi-Moussa, dans la province d'Oran; les postes de Teniet-el-Haâd, Boghar, Tizi-Ouzou, Fort-Napoléon, dans la province d'Alger ; enfin, les postes de Bordj-bouAréridj, Biskra, Aïn-Béida et de Tebessa, dans la province de Constantine, ils devront rester dans l'état actuel, sans que leurs territoires puissent etre augmentés. Toutefois, on viendra en aide par des subsides aux colons qui demanderont à rentrer dans les zones de colonisation.

4. Employer aux travaux suivants les 100 millions que le gouvernement de l'Algérie recevra en six ans: 30 millions pour. les routes; 20 millions pour les ports; 30 millions pour les barrages, les canaux, les desséchements de marais, les puits artésiens; 15 millions pour le reboisement des montagnes; 5 millions pour réintégrer dans les zones de colonisation les Européens qui végètent loin des côles.

5. Confier le service de correspondance et de transport à l'industrie privée. Elle remplacerait avec avantaze les bateaux de l'État qui, n'étant pas emménagés pour ce service spécial, n'embarquent aucune, espèr:e de marchandise, tandis que l'insuffisance des six places réservées aux passagers oblige tous les autres voyageurs à endurer sur le pont 1 intempérie des saisons.

6. Dans l'exécution des travaux publics introduire la plus stricte économie. Il ne s'agit pas dans un pays nouveau de faire des œuvres d'art, mais de satisfaire de la manière la plus simple aux besoins impérieux de la colonisation. Recommander aux provinces de mettre la plus grande réserve dans la construction de leurs édifices. Suivre la même règle pour les constructions qui sont à la charge de l'État. Les établissements civils et militaires créés à Oran, à Tlemcen, à Batna, etc., sont hors de proportion avec les besoirs et les ressources du pays.

7. Renoncer à toute espèce de concessions, même pour les forêts, ainsi que le prescrit le décret du 31 décembre 1864, et changer les concessions en propriétés définitives, sauf à en réduire l'étendue.

8. Renoncer à la création de centres de population factices. Néanmoins réserver, sur le parcours des chemins de fer, des emplacements pour des villages, en adoptant un plan définitif.

9. En territoire civil, établir, le plus tol possible, l'impot sur les terres, en prenant pour base la qualité du sol, qu'il soit cultivé ou non, comme cela a lieu en France. Cette mesure, réclamée par les colons eux-memes, obligera les propriétaires à défricher ou à vendre.

10. Emanciper la commune en lui permettant de nommer les mem. 
bres des conseils municipaux, de s'imposer pour ses besoins comme elle l'entendra et de contracter des emprunts.

11. Affranchir les colons du service militaire en France, l'alléger en Algérie, ainsi que cela sera expliqué dans le chapitre suivant.

12. Crécr un évêché par province; élever l'évêché d'Alger au rang d'archevêché.

13. Réduire considérablement le personnel, et par suite les frais d'administration civile, lesquels montent chaque année à 3 millions et demi. Supprimer les seize bureaux arabes civils.

14. Désigner des auditeurs au conseil d’État pour les attacher au conseil du Gouvernement. Les auditeurs, après cinq années passées à Alger, auraient la faculté de rentrer au conseil d'État comme maîtres des requêtes.

15. Assurer la sincérité des délibérations des conseils généraux, en exigeant dans ces assemblées l'introduction d'interprètes. Jusqu'à présent, à Oran, le conseil général n'a pas permis aux indigènes d’avoir un interprète, de sorte qu'ils restent étrangers à ce qui se passe dans le conseil. Il n'y a dans les conseils généraux que des indigènes rétribués par l'Étal (sauf peut-être une exception pour Alger). Il serait important d'y placer des notables indépendants et riches.

16. Publier un vocabulaire des noms arabes, dans le territoire civil, car ces noms sont d'une transcription difficile en caractères français; en les écrivant comme on croit les entendre prononcer, tout le monde ne les orthographie pas de la meme manière; chacun suit un système différent de transcription. Ainsi, le meme nom figure tantôt d'une façon, tanlot d'une autre, sur les registres de l'élat civil, sur les matricules de l'impôt ou sur les sommiers du domaine, ou dans les dossiers du tribunal, ou sur les registres des greffes et des municipalités. Une orthographe uniforme et rigoureuse des noms est cependant indispensable pour les actes de l'élat civil.

17. Chercher si l'on ne pourrait pas simplifier les procédures en matière civile, car une des choses qui lèsent le plus les Arabes, comme les colons, c'est la longueur des formes judiciaires et administratives. Il serait bon, d'ailleurs, de faire, en Afrique, l'essai de réformes qui pourraient plus tard être appliquées en France.

18. Veiller à ce que les journaux ne sèment pas la méfiance et la désaffection entre les indigènes ct les Européens par des attaques exagérées ou sans fondernent.

19. Examiner si le conseil du gouvernement ne pourrait pas, pour beaucoup d'affaires urgentes, se dispenser du renvoi au conseil d'Etat, cause de bien des longueurs.

Le troisième chapitre l'OGGupation MILITAIRE est ainsi subdivisé : Emplacement des troupes, Makhzen, Colonnes mobiles, bureaux arabes, milice européenne, les turcos, les spahis, fortifications, et il se termine commeles précédents, par les MESURES PROROsÉES dont voici le texte : 
1. Réduire le nombre des centres militaires.

2. Porter la plus grande partie des forces près de la lisière da Tell.

3. Diminuer insensiblement l'importance politique et militaire des postes de Géryville, de Laghouat, de Djelfa. Rattacher les tribus de ces cercles à celles de la lisière du Tell, chez lesquelles ces tribus viennent s'approvisionner. Rappeler de ces lieux tous les colons.

4. Créer sur la lisière du Tell des tribus makhzen.

5. Réduire peu à peu l'effectif de l'armée à 50,000 hommes et créer des colonnes mobiles montées de 1,800 hommes.

6. Apporter la plus grande attention dans le choix des chefs des divisions militaires et des bureaux arabes. Eviter les mutations fréquentes parmi les chefs de ces bureaux, et les maintenir au poste aussi longtemps que le permet l'intérêt de leur carrière militaire. N'appeler comme chefs de bureau que des capitaines; admettre dans ce service les officiers des armes spéciales; les réduire à n’être que les officiers d'état-major des commandants de subdivision. Recommander expressément de ménager en toute circonstance l'amour-propre des chefs arabes, et laisser à ces derniers les commandements lor'squ'on réunit les gou ms.

7. Organiser la milice européenne en exemptant les jeunes gens tombés au sort, du service en France, et les placer dans la réserve en Algérie, suivant les règles établies pour la constitution de la réserve dans la métropole.

8. Augmenter l'effectif et le nombre des bataillons de turcos, et retrancher, en France, une compagnie par régiment d'infanterie. Chaque rengagement de turcos compenserait une exonération en France.

9. Améliorer les smalas de spahis, créer un régiment de marche et former un corps spécial pour les bureaux arabes.

10. Simplifier le système des fortifications et des servitudes.

Enfin, le quatrième chapitre, qui a pour titre : RÉsumé, est ainsi conçu :

D’après ce qui précède, j'aime mieux, vous le voyez, utiliser la bravoure des Arabes que de pressurer leur pauvreté, - rendire les colons riches et prospères, que d'importer à grands frais des émigrants étrangers, - maintenir nos soldats dans des positions salubres, que de les cxposer au climat dévorant du déseri. En réalisant ce programme, nous obtiendrons, je l'espère, l'apaisement des passions et la satisfaction des inlérêts. L’Algérie ne sera plus pour nous, comme je l'ai dit en commençant, un fardeau, mais un nouvel élément de force. Les Arabes, contenus et réconciliés, nous donneront ce qu'ils peuvent nous donner de mieux, des soldals; et la colonie, devenue florissante par le développement de ses richesses territoriales, créera un mouvement commercial éminemment favorable à la métropole.

Votre expérience et vos lumières, monsieur le maréchal, me sont un sûr garant du zèle que vous mettrez à réaliser tout ce qui peut concourir au bien de l’ślgúrie. 
Sur ce, je prie Dieu, monsieur le maréchal, qu'il vous ait en sa sainte garde.

\section{NAPOLÉON.}

Fait au palais des Tuileries, le 20 juin 1865.

Décret du 21 avril 1866, portant règlement d'administration publique pour l'exécution du sénatus-consulte sur la naturalisation en Algérie.

\section{TITRE PREMIER}

ADMiSSION, SERVICE ET AVANCEMENT DES INDIGÈnES DE L'ALGÉRIE DANS L'ARMÉE DE TERRE.

Art. $1^{\mathrm{er}}$. Les troupes indigènes de l'Algérie font partie de l'armée française.

Elles comptent dans l'effectif général.

Ant. 2. Elles se recrutent par des engagements volontaires.

ArT. 3. Tout indigène peut être admis à contracter un engagement pour un corps indigène, s'il satisfait aux conditions suivantes.

Il doit :

$1^{0}$ Être âgé de dix-sept ans au moins et de trente-cinq ans au plus, et avoir la laille de $1^{\mathrm{m}}, 56$ au moins ;

$2^{\circ}$ Être reconnu apte physiquement au service militaire;

$3^{\circ}$ Être jugé digne, par sa conduite et sa moralité, de servir dans l'armée française.

Art. 4. L’âge est constaté dans les formes usitées en Algérie.

L'aptitude physique est reconnue par un des médecins militaires du corps.

La conduite et la moralité sont appréciées, sur le rapport du chef du bureau arabe de la circonscription, par le chef de corps, lequel donne son avis et envoie la demande et les pièces à l'appui au commandant de la subdivision, qui prononce.

ART. 5. L'engagement est d'une durée de quatre ans.

Il est reçu par le sous-intendant militaire de la circonscription, en présence d'un interprète et de deux témoins pris parmi les officiers, sous-officiers, caporaux et brigadiers indigènes.

Il donne droit à une prime dont le montant est fixé, chaque année, par un arrêté du ministre de la guerre, rendu sur la proposition du gouverneur général de l'Algérie, et qui est payable une moitié le jour de l'engagement, et l'autre moitié deux ans après.

L'interprète explique les conditions de l'engagement au contractant, qui déclare s'y soumettre et prête serment sur le Koran.

ART. 6. Dans le dernier trimestre de la quatrième année de service, l'indigène peut être admis par le conseil d'administration du corps à contracter un rengagement, soit pour un corps indigène, soit pour un corps français.

Ce rengagement est contracté dans les conditions prévues par les art. $11,12,13,14,16,17$ et 18 de la loi du 26 avril 1855 , relative à la dotation de l'armée. 
Toutefois, une prime spéciale est attribuée à ce rengagement; elle est fixée chaque année par un arrêté du ministre de la guerre, rendu sur la proposition de la commission supérieure de la dotation.

ART. 7. L'avancement des indigènes dans l'armée a lieu exclusivement au choix, en se conformant aux dispositions de la loi du 14 avril 1832, concernant la durée de service exigée dans chaque grade pour pouvoir être promu au grade immédiatement supérieur.

ART. 8. Sont applicables aux militaires indigènes :

Le Code de justice militaire pour l'armée de terre, et généralement tous les règlements relatifs au service et à la discipline militaire;

La loi du 19 mai 1834, sur l'état des officiers ;

La loi sur les pensions de l'armée de terre, à la condition toutefois, en ce qui concerne les veuves et les orphelins, que le mariage aura été contracté sous la loi civile française.

TITRE II.

AdMission, SERvice et AVANCEMENT dANS L'ARMÉE DE MER.

Art. 9. Les conditions d'admission, de service et d'avancement des indigènes dans les troupes de lá marine et dans les équipages de la flotte sont les mémes que celles qui sont formulées au titre $1^{\text {er }}$ ci-dessus pour l'armée de terre.

La décision impériale du 20 juin 1864, qui dispense des levées et considere comme en cours de voyage les marins indigènes qui se livrent à la pêche el au cabotage sur les côtes de l'Algérie, est maintenue.

Ceux de ces marins indigènes qui veulent servir au titre d'inscrits maritimes doivent se faire inmatriculer au port de Toulon.

TITRE III.

ADMISSION DANS LES FONCTIONS ET EMPLOIS CIVILS.

ART. 10. L’indigène musulman ou israélite; s'il réunit les conditions d'âge et d'aptitude déterminées par les règlemients français spéciaux à chaque service, peut être appelé, en Algérie, aux fonctions et emplois de l'ordre civil désignés au tableau annexé au présent décret.

Il n'est admis à des fonctions et enplois autres que ceux prévus à ce tableau, qu'à la condition d'avoir obtenu les droits de citoyen français.

Les indigènes titulaires de fonctions et emplois civils ont droit à la pension de retraite aux conditions, dans les formes et suivant les tarifs qui régissent les fonctionnaires et employés civils en France.

Toutefois, leurs veuves ne sont admises à la pension que si le mariage a été accompli sous la loi civile française.

TITRE IV.

DISPOSITIONS CONCERNANT LA NATURALISATION DES INDIGÈNES.

ART. 11. L'indigène musulman ou israélite qui veut être admis à jouir des droits de citoyen français, conformément au $\S 3$ des art. 1 et 2 
dı sénatus-consulte du 14 juillet 1865 , doit se présenter en personne, soit devant le maire de la commune de son domicile, soit devant le chef du bureau arabe de la circonscription dans laquelle il réside, à l'effet de former sa demande et de déclarer qu'il entend être régi par les lois civiles et politiques de la France.

Il est dressé procès-verbal desdites demande et déclaration.

ART. 12. Le maire ou le chef du bureau arabe procèdent d'office à une enquête sur les antécédents et la moralité du demandeur. Le résultat de cette enquête est transmis, avec le procès-verbal contenant la demande, au général commandant la province, qui envoie toutes les - pièces, avec son avis, au gouverneur général de l'Algérie.

ART. 13. Le gouverneur général transmet la demande à notre garde des sceaux, ministre de la justice et des cultes sur le rapport duquel il est statué par nous, le conseil d'État entendu.

ART. 14. Si le demandeur est sous les drapeaux, le procès-rerbal prescrit par l'art. 11 est dressé par le chef du corps ou par l'officier supérieur commandant le détachement auquel il appartient et transmis au général commandant la province, avec: $1^{0}$ l'état des services du demandeur; $2^{\circ}$ un certificat relatif à sa moralité et à sa conduite.

Les pièces sont adressées par le général commandant la province, avec son avis, au gouverneur général de l'Algérie, pour être ensuite procédé conformément à l'art. 13 du présent décret.

\section{TITRE $\vee$.}

DISPOSITIONS CONCERNANT LA NATURALISATION DES ÉTRANGERS RÉSIDANT EN ALGÉRIE.

ART. 15. L'étranger résidant en Algérie, qui veut obtenir la qualité de citoyen français, doit former sa demande derant le maire de la commune de son domicile, ou la personne qui en remplit les fonctions dans le lieu de sa résidence. Il lui en est donné acte dans un procès-verbal dressé à cet effet.

- ART. 16. L'étranger dépose, pour etre joints à sa déclaration, les documents propres à établir qu'il réside actuellement en Algérie et depuis trois années au moins.

Cette preuve est faite par des actes officiels et publics ou ayant date certaine, et, à défaut, par un acte de notoriété dressé, sur l'alfirmation de quatre témoins, par le juge de paix du lieu.

ART. 17. Le temps passé par l'étranger en Algérie sous les drapeaux est compté dans la durée de la résidence légale exigée par l'article précédent.

Arт. 18. Il est procédé, pour l'instruction de la demande, conformément aux dispositions des art. 12, 13 et 14 du présent décret.

\section{TITRE VI. \\ DISPOSITIONS GÉNÉRAL.ES.}

ART. 19. Les indigènes musulmans et israélites et les étrangers résidant en Algérie ne sont admis à former les demandes énoncées 
aux art. 11 et 15 du présent décret qu'à l'âge de vingt et un ans accomplis.

Ils doivent justifier de cette condition par un acte de naissance, et, à défaut, par un acte de notoriété dressé, sur l'attestation de quatre témoins, par le juge de paix ou par le cadi du lieu de la résidence, s'il s'agit d'un indigène, et par. le juge de paix s'il s'agit d'un étranger.

Apr. 20. Est fixé à un franc le droit de sceau et d'enregistrement dû par les indigènes et les étrangers admis à jouir des droits de citoyen français, en exécution du sénatus-consulte du 14 juillet 1865.

ART. 21. Nos ministres secrétaires d'État de la guerre, de la marine et des colonies, des finances, de la juslice et des cultes, et de l'instruction publique, et notre gouverneur général de l'Algérie sont chargés, chacun en ce qui le concerne, de l'exécution du présent décret, qui sera inséré au Bulletin des lois et au Bulletin officiel du gouvernement de l'Algérie.

Tableau des fonctions et emplois civils auxquels l'indigène musulman ou israélite, qui ne jouit pas des droits de citoyen français, peut être appelé en Algérie.

(Annexé au décret du 21 avril 1866.)

SERVICE DE LA JUSTICE.

Commis greffier et greffier de la cour et des tribunaux.

Interprète judiciaire et traducteur.

Notaire.

Défenseur.

Huissier.

Commissaire-priseur.

ADMINISTRATION GÉNÉRALE ET MUNiGipaLE.

Membre d'un conseil général.

Commis, sous-chef et: chef de bureau de toute classe de préfecture, de souspréfecture et de commissariat civil.

Emplois de tout grade dans le personnel administratif des maisons d'arrêt, des prisons départementales et des pénitenciers.

Membre de la commission de surveillance des prisons.

Emplois de tout grade dans le personnel administratif des hôpitaux, asiles, orphelinats, dépôts d'ouvriers et autres établissements de bienfaisance.

Membre de la commission administrative des hôpitaux.

Conseiller municipal.

Receveur municipal.

Inspecteur, secrétaire.de commissariat de police.

Administrateur de la Caisse d'épargne.

Administrateur du Mont-de-piété.

Administrateur du Bureaude bienfaisance.

Milicien, sous-officier et officier des milices, jusqu'au grade de capitaine exclusivement.

Préposé des octrois.

Garde champêtre.

Garde des eaux.

Et généralement tous les emplois de l'administration générale et de l'administration communale auxquels les préfets et les maires sont autorisés à nommer directement. 
Surveillant et stationnaire.

TELÉGRAPHIE.

Directeur de station.

INSTRUCTION PUBLIQUE.

Membre du conseil académique.

Maître, diresteur et inspecteur des écoles arabes-françaises.

Titulaire d'une chaire publique d'arahe.

Maître d'études, maître répétiteur et professeur de lycée.

SERVICE DES TRAVAUX PUBLICS.

Commis de toute classe, dessinateur et garde-magasin dans les services des ponts et chaussées, des mines et des bâtiments civils.

Piqueur et conducteur des ponts et chaussées.

Garde-mine.

Inspecteur ordinaire des bâtiments civils.

SERVICES FINANCIERS.

Commis de tout grade dans les bureaux des services:

De l'enregistrement et des domaines,

Des contributions,

Des douanes,

Des postes,

Des forêts,

De l'administration des tabacs.

Distributeur,

Postes:

Facteur et brigadier,

Facteur-boîtier,

Préposé, brigadier et officier de service des douanes, jusqu'au 'grade de capitaine exclusivement.

Garde et brigadier forestier.

Géomètre de toute classe dans le service des opérations topographiques.

Garde-pêche.

SERVICE DES PORTS ET DE LA SANTÉ.

Pilote.

Inspecteur des quais.

Garde et secrëtaire de la santé.

Historique des communications télégraphiques entre la France et l'Algérie.

En 1853, le premier câble télégraphique destiné à relier la France et l'Algérie, fut posé par la Compagnie Brett. Il passait par la Spezzia, la Gorse et la Sardaigne. Après avoir fonctionné pendant dix-huit mois, il fut abandonné par l'entrepreneur.

En avril 1860, on conclut avec la Compagnie Glass-Elliott un traité, en vertu duquel les communications télégraphiques, au lieu de s'effectuer par l'Italie (ce qui avait eu des inconvénients), se feraient plus directement. Un câble direct fut posé de PortVendre à Alger, par Minorque. Il ne fonctionna que vingt-six 
mois (du 20 sept. 1860 au 27 nov. 1862). A la suite d'une tempête, une avarie s'y déclara à 180 kilomètres d'Alger, par une profondeur de 2,600 mètres.

Les deux tentatives de M. Siemens, un autre entrepreneur, en décembre 1863 et en janvier 1864, échouèrent plus complétement encore. Il s'agissait de rattacher Oran à Carthagène seulement. Dans le premier essai, le câble se brisa à 17 kilomètres du point de départ; dans le second, à 72 kilomètres. - En septembre 1864, nouvelle tentative. Le câble se rompit en touchant à Carthagène.

En novembre 18,64, un autre traité a été passé avec M. Siemens. Le câble devait être jeté entre la pointe de Carthage et la Sicile. Il partait de la Calle, suivait -le littoral jusqu'à Bizerte, et traversait la mer pour aller se rattacher à Marsala, au réseau italien. (V. Corps législatif, 7 juin 186̋.) 
4

$+2$

- $=2$ 



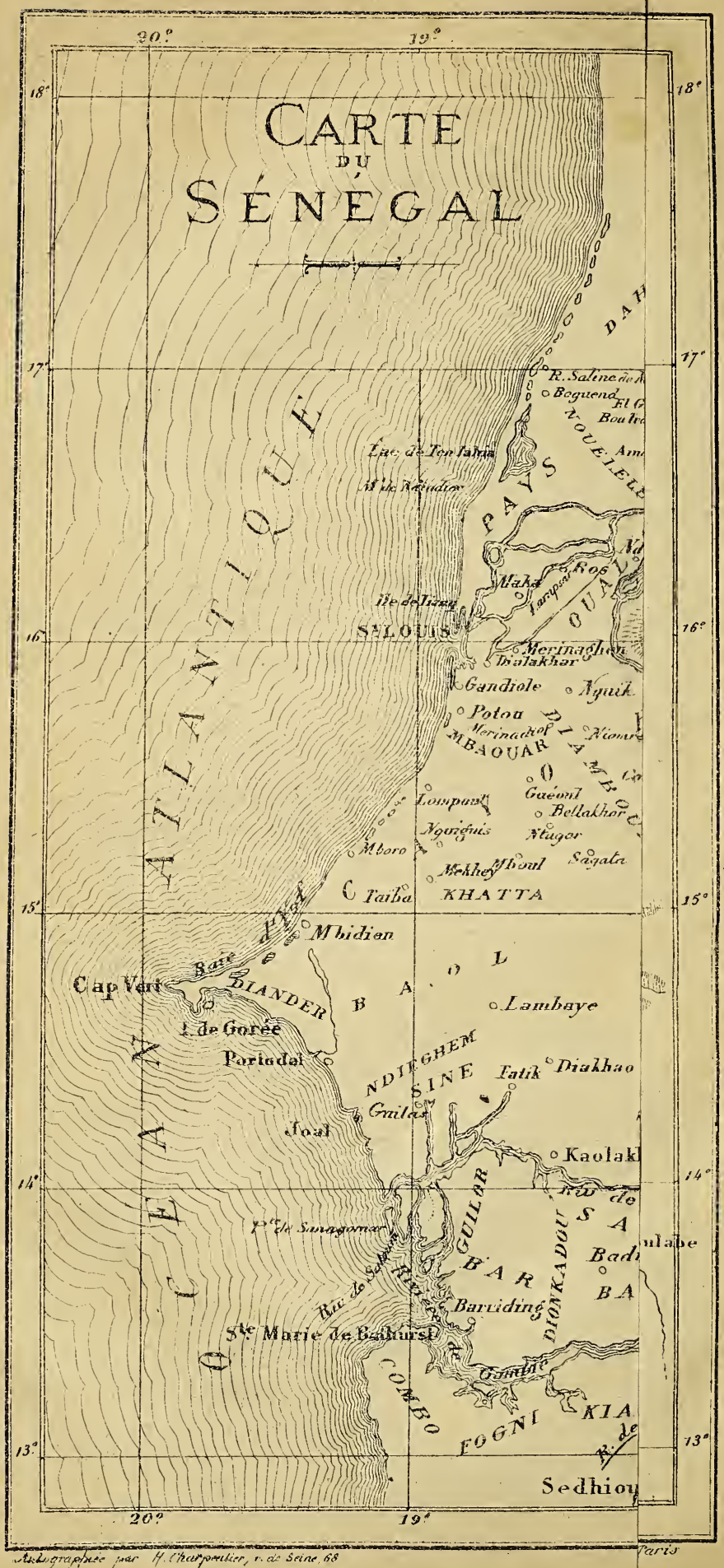




\section{LE SÉNÉGAL}

\section{CHAPITRE PREMIER}

\section{Résumé historique.}

La Sénégambie, contrée dont dépend notre colonie du Sénégal, est située à la partie occidentale du continent africain.

Le Sahara la limite au N., l'océan Atlantique à l'O., la Guinée au S., et le Soudan à l'E.

Elle est comprise entre le $10^{\mathrm{e}}$ et le $18^{\mathrm{e}}$ degré de latitude $\mathrm{N}$, et le $7^{\mathrm{e}}-20^{\mathrm{e}}$ degré longitude 0 .

Le nom, primitivement donné au Sénégal, est celui de Zénaga. Ainsi s'appelait une peuplade berbère qui habitait la rive droite du fleuve.

L'origine de cette colonie française (la plus ancienne de toutes) remonte au quatorzième siècle. En 136ı, des navigateurs normands fondèrent plusieurs établissements commerciaux sur la côte occidentale d'Afrique, depuis l'embouchure du Sénégal jusqu'à l'extrémité du golfe de Guinée.

En 1664, l'association des marchands de Dieppe et de Rouen qui, depuis 1620, exploitait des comptoirs au Sénégal, céda ses établissements, moyennant 150,000 livres tournois, à la Compagnie des Indes-Occidentales, créée en mai (1664).

Quelques années après (1672), une nouvelle Compagnie fut crééc et substituée à la Compagnie des Indes-Occidentales.

En 1677, l'île de Gorée, les comptoirs de Rufisque, Portudal et Joal, sont enlevés aux Hollandaiis par la France. Cette conquête est ratifiée par le traité de Nimègu'e (1678).

La Compagnie, créée en 1672, prend, en 1679, le titre de C̣om- 
pagnie du Sénégal. - Cette Compagnie cède, en 1681, tous ses droits et priviléges, moyennant une indemnité de 1,010,015 livres tournois, à une société nouvelle, la Compagnie du Sénégal, côle de Guinée et d'Afrique.

L'étendue de la concession est établie, par arrêt du roi, entre le cap Blanc et Sierra-Leone (1684-1685).

En 1694, nouvelle Compagnie: la Compagnie royale du Sénégal, cap Nord et côte d'Afrique. - Elle élève, en 1699, le fort SaintJoseph, près de Dramané.

En 1702, révolte des indigènes. Le fort Saint-Joseph est brûlé. Dissolution de la Compagnie (1709). Constitution d'une nouvelle société qui acquiert les priviléges de la précédente pour 240,000 livres.

Le fort Saint-Joseph est reconstruit à Makana (1713).

Construction du fort Saint-Pierre de Kaïnoura sur la rive gauche de la Falémé (1715).

En 1717, les Maures du Sénégal cèdent Portendick à la France.

La prise de l'île d’Arguin (1724), la cession de Portendick sont confirmées à la France par la convention de La Haye (1727).

Construction du fort de Podor (17733).

Les Anglais s'emparent du Sénégal et de Gorée en 1758, mais en 1763 , Gorée est restituée à la France, et en 1779, le Sénégal est reconquis par le duc de Lauzun.

Le traité entre la France et l'Angleterre (1783) reconnaît les droits de la première de ces puissances au Sénégal et à Gorée.

La colonie est administrée par des gouverneurs que nomme le roi.

Le privilége de la traite de la gomme accordé à la Compagnie de la Guyane (1784), est cédé par elle, en 1785, à une association de négociants qui s'intitule tour à tour Compagnie de la Gomme et Compagnie du Sénégal.

Les cessions successivement faites à la France par le damel (roi) de Cayor, embrassaient, en 1787, le cap Vert et les terres voisines, depuis la pointe des Mamelles jusqu'au cap Bernard, avec le village de Dakar.

L'Assemblée nationale constituante (1791) décrète la dissolution de la Compagnie du Sénégal ; le commerce est déclaré libre au Sénégal pour tous les citoyens français.

L'île de Gorée est, en 1800, prise par les Anglais. Saint-Louis leur résiste et leur échappe. - L'île de Gorée qui, d'après le 
traité d'Amiens (1802), eût dû être rendue à la France, et ne le fut pas, est enlevée aux Anglais par des corsaires français réunis. à un détachement de la garnison du Sénégal (1804).

En 1809, Gorée et le Sénégal furent repris par les Anglais, mais en 1817, conformément au traité de 1814, qui restituait à la France tous les établissements qu'elle possédait au $1^{\text {er }}$ janv. 1792 à la côte occidentale d'Afrique, les Anglais rendirent le Sénégal. - Naufrage de la Méduse, qui portait les fonctionnaires et les troupes chargés de reprendre possession de la colonie.

A partir de 1819, le territoire colonial qui, jusque-là, n'avait en réalité embrassé que l'îlot de Saint-Louis et l'île de Gorée, prend de l'extension. - Les traités passés avec les chef́s du Oualo cèdent à la France en toute propriété les îles et terres de cette contrée qu'on voudra cultiver. Dès 1820 , on construit dans le Oualo, sur la rive gauche du Sénégal, les forts de Richard-Toll et de Dagana; peu après, on élève celui de Bakel. - En 1824, l'exploitation du commerce de la haute Sénégambie est concédée à la Compagnie commerciale et agricole de Galam et du Oualo.

De 1826 à 1848, aucun résultat utile ne fut atteint dans la colonie. La culture du coton et celle de l'indigo n'aboutirent qu'à un insuccès notoire. Les chefs maures de la rive droite du fleuve voulant atteindre la rive gauche et y asseoir leur domination, il fallut plusieurs fois les réprimer (1826, 1830, 1832, 1843). Les populations noires, trop éloignées de la main protectrice de la France, plièrent sous le joug des Maures. - En 1848, le privilége de la Compagnie fut supprimé.

Depuis 18:1, l'attention du gouvernement français s'est portée sur la situation du Sénégal d'une manière toute particulièré. Il était temps. En 183̋', un noir, El-Hadj-Ornar, fanatique musulman, affichait sa prétention de détruire les établissements curopécns et de fonder un vaste empire indigène et mahométan. Dans șon intéressant ouvrage sur le Sénégal, M. J. Mavidal a montré combien il était urgent de veiller sur les tendançes et les menées des Músulmans voisins de la colonie.

C'est aussi en 1854 que M. Faidherbe, alors commandant du génie, aujourd'hui général, fut envoyé comme gouverneur au Sénégal. On sait tous les services qu'il y a rendus à la France, soit comme diplomate, soit comme homme de guerre, soit comme savant. 
Les années suivantes ont été remplies par de nombreux événements dont voici, en résumé, les principaux :

Fondation de la Banque di Sénégal, de l'imprimerie du gouvernement et du jcurnal officiel de la colonie (185̌5).

Traité avec les Maures Trarzas et leur roi. Le Oualo, les villages de Dagana, de Bakel, de Sénoudebou, des îles de Thiong et de Ndiago, annexés aux possessions (1856).

Défénse du fort de.Médine par Paul Holl, métis sénégalais. Délivrance des assiégés, après trois mois de siége, par le gouverneur (1857).

Renonciation des Anglais au droit de commerce sous voiles, depuis l'embouchure de la rivière Saint-Jean jusqu'à Portendick, en échange de la factorerie d'Albréda sur la Gambie (1857).

Annexion des villages de Gaé, Réfo, Bokol, etc., aux environs de Saint-Louis (18כ̌8).

Traité de paix consacrant l'annexion de la rive gauche du fleuve, depuis Bakel jusqu’à la Falémé (Guoy), celle du Dimar, et le droit de créer des établissements sur tout le cours de la Falémé (1858).

Prise, par le lieutenant-colonel Faron, du village fortifié de Guémou (18วั9).

Démembrement du Fouta en trois États indépendants: Damga, Fouta central et Toro (18ðั9).

Annexion du Damga; soumission du Toro (18气9).

Voyages d'exploration dans les contrées voisines par MM. Mage, Vincent, Pascal, Lambert, Bourel, Azan, Alioun-Sal, Bou-elMoghdad et Braouézec (1860).

Le mouvement de réaction qui s'opéra à Saint-Louis, à partir de 18כ̌ 4 , s'étendit à Gorée, dont les dépendances ne comprenaient à cette époque que le comptoir d'Albréda, en Gambie, cédé depuis à l'Angleterre, - les îles de Djogué et de Carabane dans la basse Caramance, et le territoire de Sedhiou dans la haute Caramance, achetés en 1828, 1836 et 1837 aux indigènes de cette rivière.

Depuis 18วั4, revendiquant des titres anciens, nous avons repris sur la presqu'île du Cap-Vert les droits que nous conféraient trois traités passés en 1763,176 et 1787 , avec le roi de Cayor. Ce pays, parcouru en 1861 et 1862 par diverses colonnes commandées successivement par les gouverneurs Faidherbe et Jauréguiberry, est 
devenu accessible à notre influence et a fini par accepter notre suzeraineté.

Un traité du $1^{\text {er }}$ février 1861 nous a cédé toute la côte entre Saint-Louis et Gorée, sur une profondeur de trois lieues; la province $d u$ Gandiole, voisine de Saint-Louis, et celle du Diander, en face de Gorée, ont été également annexées à nos possessions.

En 180̈9, les royaumes de Baol, Sine et Saloum ont été visités par nos colonnes; trois traités ont été passés avec les rois de ces pays, et nous nous sommes établis à Rufisque, Portudal, Joal et Kaolakh.

Dans la Casamance, plusieurs expéditions heureuses de M. lechef de division Pénaud en 185ั1, à Cagnut sur les îles Aïamats; đe M. le chef de division Protet en 18509, sur les Jigonches et les Banjiars de Kamabel; du commandant Laprade en 1860, sur les Karônes, à Hilor et Courba, et à Thionk sur les Jigonches; enfin du même officier supérieur en 1861, sur le Souna et les Balantes de Couniara, ont soumis à la France la plupart des terrains arrosés par ce fleuve. (Traités des 7 nov. 18øั5, 9 janv. 1859, 14 fév. 1861 et 17 mars 1863.)

Depuis lors, les coutumes arbitraires imposées à nos traitants, ont été supprimées; Sedhiou est devenu le centre d'un commerce florissant, la rivière de Songrougou, affluent de la Casamance, a été explorée et ouverte à nos nationaux.

Enfin, dans le courant de 1862, des troubles ayant éclaté dans le Fouta central, des populations amies ayant été pillées par les Toucouleurs, trois expéditions furent successivement entreprises contre ces fanatiques en juillet et sept. 1862 et janv. 1863. Vaincues et dispersées dans ces trois circonstances, les populations du Fouta-Toro ont demandé et obtenu la paix. (V. les excellentes Notices sur les colonies francaises, publiées par ordre du ministre de la marine, - par E. Avalle, biblioth. du ministère de la marine. - Paris, 1866, in-8.)

Depuis 1831, la colonie du Sénégal a compté parmi ses gouverneurs :

MM. Renault de Saint-Germain, chef de bataillon d'infanterie de marine (1831).

Cadéot, sous-commissaire de la marinę, intérimaire (1833).

Quernel, capitaine de frégate, intérimáire (1833).

Pujol, capitaine de frégate (1834).

Malavois, lieutenant de raisseau (1836). 
Guillet, sous-commissaire de la marine, intérimaire (1836). Soret, capitaine de corvette (1837).

Charmasson, capitaine de vaisseau (1839).

Montagniès de la Roque, capitaine de vaisseau (1841).

Pageot des Noutières, commissaire de la marine, intérimaire (1842).

Bouet-Willaumez, capitaine de corvette (1843).

Laborel, chef de bataillon d'infanterie de marine, intérimaire (1844).

Thomas, commissaire de la marine, intérimaire (1844).

Ollivier, capitaine de vaisseau (1840ั).

Houbé, chef de bataillon d'infanterie de marine, intérimaire (1846).

Comte Bourdon de Gramont, capitaine de corvette (1846).

Caille, lieutenant-colonel, intérimaire (1847).

Bertin du Château, chef de bataillon, intérimaire (1847).

Baudin, capitaine de vaisseau (1847).

Bertin du Château, chef de bataillon d'infanterie de marine, intérimaire (1848).

Baudin, capitaine de vaisseau, commissaire de la République (1848).

Aumont, capitaine de frégate, gouverneur intérimaire (1850).

Protet, capitaine de vaisseau (1850).

Aumont, capitaine de frégate, intérimaire (1852).

Vérand, commissaire de la marine, intérimaire (1854).

Protet, capitaine de vaisseau (1834).

Faidherbe, chef de bataillon du génie (1834).

Morel, chef de bataillon d'infanterie de marine, intérimaire (1856).

Faidherbe, lieutenant-colonel du génie (1856).

Robin, capitaine de frégate, commandant supérieur de la marine, intérimaire (18כ8).

Faidherbe, colonel du génie (1859).

Stéphan, commissaire ordonnateur, intérimaire (1861).

Jauréguiberry, capitaine de vaisseau (1861).

Pinet-Laprade, lieutenant-colonel du génie, intérimaire (1863).

Faidherbe, général de brigade (1863). 


\section{CHAPITRE II}

Possessions françaises. - États voisìns. - Cercle d'action de la France.

La colonie sénégalaise comprend :

$1^{\circ}$ Le bassin du Sénégal, fleuve qui a 1,600 kilomètres de cours, depuis les monts du Fouta-Djalon jusqu'à son embouchure;

$2^{\circ}$ Les forts et comptoirs situés sur la côte, depuis le cap Blanc jusqu'au cap de Sierra-Leone.

Le chef-lieu de la colonie, Saint-Louis, est bâti sur un îlot de sable formé par le Sénégal. L'île a 2,500 mètres de long sur une largeur moyenne de 180 mètres. Sa superficie est de 34 hectares.

On remarque, le long de la rive gauche du Sénégal, les contrées suivantes :

Le Oualo, annexé en $183 ̈ 5$. Deux forts y ont été construits : celui de Richard-Toll et celui de Mérinaghen;

Le Dimar, annexé en 18ə̃8. Le fort de Dagana domine le pays.

Le Toro, soumis en 18วั9, où s'élève le fort du Podor.

Le Fouta, qu'habitent des fanatiques hostiles, Peuls et Toucouleurs, qui toutefois, en 1859 , n'ont osé s'opposer à la construction d'un poste fortifié à Saldé (ou Tébékout);

Le Damga, annexé en 1850 , où Matam, centre commercial plein d'avenir, est protégé par un fort ;

Le Gadiaga (ou pays de Galam), divisé en deux États, le Gouy (en deçà de la Falémé) et le Kamera (au delà de cette rivière); c'est là que se trouve l'important comptoir et le poste fortifié de Bakel;

Le Bondon, État poul et musulman, dominé par le fort de Sénoudébou;

Le Bambouck, pays malinké, non musulman, sis à l'angle oriental que forment la Falémé et le Sénégal.

Le Khasso, occupé par les Yeuls, s'étend depuis Diakhabel jusqu'au confluent du Bafing et du Baoulè, sur chaque rive du Sénégal. Le plus éloigné de nos postes, le fort de Médine, se trouve dans le Khasso.- - Ce pays a subi l'influence de la France.

Le Kaarta, sur la rive droite du Sénégal, a une superficie de 2,ð00 à 3,000 lieues carrées. Les Bambarras l'occupent.

Trois grandes tribus maures du désert, les Trarzas, les Braknas et les Douaïchs, occupent ou plutôt parcourent la rive droite du 
Sénégal, depuis Saint-Louis jusqu'à Bakel. "Les Trarzas, les plus rapprochés de Saint-Louis, habitent le pays qui s'étend des bords du fleuve jusqu'au marigot de Morghen vis-à-vis de Gaé et sur une profondeur de plus de 100 lieues. Les Braknas occupent la contrée qui longe la rive droite du fleuve, depuis le marigot de Morghen jusqu'à El-Modinalla, vis-à-vis du Fouta-Toro. Enfin, le territoire des Douaïchs commence à El-Modinalla et se prolonge jusque derrière les Guidimakka dans l'intérieur et du côté du Tagant. Ces Maures se mettent en contact avec nous pour l'échange de la gomme qu'ils récoltent sur leur territoire." (Notices sur les colonies françaises, publiées par ordre du ministre de la marine.)

Les Trarzas, les Braknas et les Douaïchs, naguère insolents et pillards, respectent aujourd'hui le nom français.

Au sud de l'embouchure du Sénégal, on remarque les contrées suivantes :

Le Gandiole, sis à 8 kilomètres de l'embouchure du fleuve, a été séparé du Cayor et appartient à la France depuis 1861. Il se compose de trois villages.

Le Cayor, sis au sud de Saint-Louis, se prolonge sur la côte jusqu'à la presqu'île du Cap-Yert. Sa longueur est de 40 lieues; il a une largeur de 20 à 30 lieues. La France possède toute la côte sur une profondeur de trois lieues. En 1861, trois postes, servant de stations télégraphiques de Saint-Louis à Gorée, ont été élevés; ce sont ceux de Lompoul, M'boro et M'bidgen.

L'île de Gorée, sise sur la côte à 180 kilomètres de Saint-Louis, est un rocher de 880 mètres dans sa plus grande largeur et de 215 dans sa largeur moyenne: elle a 2,250 mètres de circonférence et 17 hectares de superficie.

La rade de Gorée est très-vaste, et assez sûre pendant la saison sèche.

Le Diander, distrait du Gayor en 1861 et placé sous notre autorité, est situé en face de Gorée; Rufisque, 'son principal port, communique par un fil électrique avec nos autres établissements.

Vakar, la pointe extrême de la presqu'île du Cap-Vert, où l'on construit un port qui doit servir au ravitaillement des paquebots transatlantiques français de la ligne du Brésil, n'est séparé de. Gorée que par un canal de 2 kilomètres.

Les pays de Baol et de Sine, qui viennent ensuite, reconnaissent l'un et l'autre notre suzeraineté. 
La France a, dans le Baol, le comptair de Portudal, et, dans le Sine, celui de Joal.

Le Saloum, sis au sud du Sine, s'étend sur les bords du fleuve Saloum à 120 kilomètres de son embouchure. Nous y avons construit, en 1860, une tour à Kaolakh, principal lieu de traite situé à 6 kilomètres de Cahone, village-capitale du royaume.

A 235 kilomètres de Gorée, à l'entrée du fleuve Casamance et sur sa rive droite, la France possède l'île de Djogué; sur la rive gauche, elle possède les îles de Carabane et de Guimbéring. Dans le haut du fleuve, nous avons le Boudhié (où l'on a établi le comptoir de Sédhiou), le Paliao, le Yassi, sur la rive droite de la Casamance; sur la rive gauche, nous avons le Souna et le Kerakounda.

Le Rio-Nuñez (à 440 kilomètres de la Casamance, en suivant la côte), et le Rio-Pongo (à 130 kilomètres plus bas que le RioNuñez), sont exploités par le commerce français.

\section{GHAPITRE III}

Fleuves et rivières. - Rades. - Lacs. - Étangs salins. - Température. Saisons. - Opinion de Buffon sur le climat sénégalais. - Vents. - Ras de marée. - Marées.

Les principaux fleuves et rivières du Sénégal français et dépendances sont, entre autres :

Le Sénégal ;

La Falémé, son principal affluent;

Le Saloum;

La Gambie;

La Casamance ;

Le Rio-Cachéo;

Le Rio-Geba;

Le Rio-Grande;

Le Rio-Nuñez;

Le Rio-Pongo;

La Mallecory.

Deux rivières forment le Sénégal. Ce sont le Ba-Fing et le Ba-Khoy. Ils descendent des montagnes du Fonta-Djalon et se réunissent à Bafoulabé.

Le Sénégal, à la suite de certains ras de marée, voit son em- 
bouchure déplacée parfois de plusieurs milles; toutefois elle se maintient toujours dans un espace de dix milles, entre la pointe du sud de Guet-N'dar et Mousse-Guiob au sud de Gandiole. La barre, à la date du $1^{\text {er }}$ avril 1863 , se trouvait à 9,300 mètres au sud de l'hôtel du gouvernement à Saint-Louis.

A son embouchure, le Sénégal a de 1,500 à 1,800 mètres de largeur; quinze ou vingt lieues plus haut, elle est de 400 à 600 mètres. Elle n'est que de 150 mètres le long de l'île à Morfil et çà et là, au-dessus de Saldé, de 800 mètres.

La longueur du fleuve est de 400 lieues. Sa profondeur, en deçà de l'embouchure, est de 10 à 12 mètres. A 90 lieues plus loin, à Mafou, premier haut-fond, elle n'est plus, pendant les basses eaux, que de $1^{\mathrm{m}}, 25$.

Pendant les hautes eaux, le Sénégal déborde sur presque toute l'étendue de son parcours. C'est une sorte de flot de marée qui, au commencement de septembre, passe à Bakel et, cinq semaines après, gagne Saint-Louis.

Le débordement dure le plus souvent un mois.

Les eaux alors ont une crue de 16 mètres à Bakel, de 6 mètres à Podor, de 3 mètres à Dagana, de $\mathbf{1}^{\mathrm{m}}, 20$ à Saint-Louis. L'inondation s'étend souvent à plusieurs lieues.

Le mois de juin est l'époque des plus basses eaux. En juillet, elles recommencent à monter jusque vers la fin de septembre où elles sont entièrement répandues sur les terres voisines.

La barre ne permet pas l'entrée du Sénégal aux très-grands bâtiments. Ceux qui calent 12 pieds d'eau peuvent, en toute saison, la franchir et remonter jusqu'à Richard-Toll (à 30 lieues de l'embouchure du fleuve) du mois d'août au mois de novembre.

Les bâtiments calant 8 pieds d'eau peuvent remonter, en toute saison, jusqu'à Mafou, à 90 lieues de l'embouchure.

Enfin, les bâtiments à vapeur peuvent remonter jusqu'à Médine, à 250 lieues de l'embouchure.

On appelle marigots les petits affluents du Sénégal. lls sont nombreux. Ils forment, près de Saint-Louis, plusieurs grandes îles inondées, pour la plupart, pendant les hautes eaux. La plus grande île du Sénégal, l'île à Morfil, est formée par un marigot ou plutôt par un bras du fleuve, qui, se détachant du bras principal sur la rive gauche, ne va retrouver le Sénégal qu'un peu au-dessous de Podor. 
Le Sénégal est abondamment pourvu de poissons. On y remarque un poisson électrique et une huitre non comestible.

La Falémé prend aussi sa source dans le Fouta-Djalon.

Pendant les hautes eaux, les bâtiments calant 6 pieds, peuvent y naviguer sur une longueur de 40 lieues depuis Arondore, point où elle se jette dans le Sénégal, c'est-à-dire après un parcours de 100 lieues.

Le Saloum, après avoir traversé le royaume du même nom, va se jeter à 65 milles de l'île de Gorée. A 30 lieues de son embouchure, à Kaolakh, on a établi un poste, que le bâtiment faisant le service entre Gorée et la Casamance ravitaille chaque mois.

Il se divise en deux branches à 15 lieues de son embouchure. L'une se porte vers l'est, et garde le nom de Saloum; l'autre se dirige vers le nord et porte le nom de rivière de Sine.

Le Sine et le Saloum sont navigables, à marée haute, sur presque toute leur longueur, par les bâtiments qui calent de 6 à 8 pieds.

La Casamance prend sa source dans les montagnes du Kabou. Son embouchure se trouve à 12 lieues de la Gambie, à 40 lieues S. de Gorée. Son parcours est de 250 kilomètres.

L'entrée en est obstruée par des bancs de sable. De ses trois passes, celle du milieu a 1,200 mètres de largeur; c'est la seule praticable pour les bâtiments calant au plus 4 mètres.

Les principaux lieux de traite du fleuve sont Sédhiou, Garabane et Zighinchor (poste portugais non fortifié).

"Le Rio-Nuñez, dontl'embouchure est située par $10^{\circ} 32^{\prime}$ de latitude $\mathrm{N}$. et $17^{\circ} \mathrm{5}^{\prime}$ de longitude 0 , est l'un des fleuves les plus importants par son commerce et l'un des plus fréquentés de la côte occidentale d'Afrique.

“ On y pénètre par une passe, qui a un mille de large et $\mathbf{5}$ à 6 mètres de fond.

G'est à Wakaria que commence le territoire désigné sous le nom de Karcandy, qui s'étend jusqu'à la source du Rio-Nuñez, partie la plus riche et la plus commerçante du fleuve. Le grand village de Boké (d'où partit Caillé, en 1824, pour visiter l'Afrique centrale), est situé à 8 milles environ de l'endroit où le fleuve prend sa source.

"Les bâtiments calant 2 mètres peuvent amortir à Boké, qui . est le point central du commerce du fleuve et le rendez-vous des 
caravanes qui viennent de l'intérieur par le Fouta-Djalon. " (Notices, etc.)

Le Rio-Pongo a deux branches principales, celles de Mud-Bar et de Sand-Bar; ce sont les seules que fréquentent les navires.

L'embouchure est au sud du Rio-Nuñez, à 130 kilomètres de ce fleuve.

La côte occidentale d'Afrique a peu de rades sûres.

"A 15 lieues au sud du cap Blanc et à 90 lieues au nord de l'embouchure du Sénégal, se trouve la rade d'Arguin, peu connue et qu'on considère même dans le pays comme impraticable.

" La baie de Portendick est un peu plus au sud; l'accès du mouillage et l'atterrage en sont très-difficiles.

"La rade foraine de Guet-N'dar, en face de Saint-Louis, est le meilleur mouillage pour communiquer avec cette ville; on $y$ trouve de 13 à 18 mètres de fond, sable et vase.

"La rade de la barre du Sénégal est située en pleine côte; en dehors de la barre, la tenue de la rade est bonne, et offre un fond de vase de 7 à 13 brasses, selon que l'on se place à 2 ou à 5 milles de cette barre. En dedans, la rade est très-sûre, et offre une profondeur de 7 à 8 brasses.

"La rade de Gorée est au N.-E. de l'île, et est abritée de tous les vents depuis le S.-S.-0.jusqu'à l'E.-N.-E. Elle est parfaitement sûre pendant huit mois de l'année, de novembre à juillet. Pendant la mauvaise saison, il faut prendre le mouillage de l'hivernage qui donne la chasse.

"A 3/4 de lieue environ de la pointe N. de Gorée, sur le continent, entre les pointes de Dakar et de Bel-Air, se trouve l'anse de Dakar, où l'on termine en ce moment (1863) une jetée de 250 mètres de long pour former un port qui servira d'escale aux paquebots français de la ligne du Brésil. ") (Notices, etc.)

Le lac de Cayor et celui de Guier sont les seuls auxquels on puisse donner ce titre.

Ils se remplissent, pendant l'hivernage, des eaux du Sénégal, et, lors de la saison sèche, lui rendent leur superflu.

Les bateaux ne peuvent pénétrer dans le lac de Cayor; ses affluents sont engorgés par les herbes.

Ce lac est situé dans le pays des Trarzas, sur la rive droite du Sénégal. Le lac de Guier s'étend dans le Oualo. 
Les étangs salins de Gandiole, près de l'embouchure du Sénégal, jouissent d'une réputation méritée. D’une longueur de 400 à 600 mètres, ils ont une largeur de 200 à 400 mètres. L'eau rend en sel le tiers de son volume.

La quantité produite est supérieure, non-seulement aux besoins de la colonie, mais même à ceux du' commerce avec l'intérieur de l'Afrique.

Les marais salants de N'Guirer, dans le Oualo, sont peu exploités.

La température est fort variable au Sénégal.

A Saint-Louis, pendant la saison sèche, par des vents d'est, on constate souvent $20^{\circ}$ de différence entre la température du matin et celle de l'après-midi.

Pendant le mois de janvier, qui est le plus froid, la température est rarement inférieure à $11^{\circ}$ au-dessus de zéro (à SaintLouis). Elle commence à s'élever dès le mois de février, et parvient à son maximum $33^{\circ}$, en juillet, août et septembre. Néanmoins, pendant la saison sèche, lorsque souffle le vent d'est, le thermomètre monte quelquefois jusqu'à $36^{\circ}$ à l'ombre et $63^{\circ}$ au soleil.

Dans les postes $d u$ haut du fleuve, la température est en moyenne de 4 à らّ degrés plus élevée qu'à Saint-Louis. A Podor, on voit monter fréquemment le thermomètre jusqu'à $65^{\circ}$ à l'ombre. Si les mois de juillet, avril et septembre sont les plus chauds à Saint-Louis, à l'embouchure du fleuve, il n'en est pas de même dans les localités situées à son cours supérieur. Ainsi, à Bakel, on a constaté en 1860 que la température, qui avait atteint le chiffre de $42^{\circ}$ en avril, a commencé à baisser avec les premières pluies en mai, juin, juillet, et est arrivée à $32^{\circ}$ en septembre, pour remonter ensuite en octobre à la cessation des pluies. (Notices, etc.)

Deux saisons : une saison sèche et une saison pluvieuse.

Du milieu de juin à la fin de septembre, les pluies sont abondantes et accompagnées d'orages.

Du mois d'octobre au mois de juin, la sécheresse est extrême. A Saint-Louis, l'hygromètre de Saussure marque souvent $0^{\circ}$. Les rosées et les brumes de décembre en mai atténuent à peine la situation.

Le vent d'est (harmattan) souffle de novembre à la fin de mars. En novembre, il alterne avec le yent du N.-N.-O., mais en janvier 
il règne sans partage. A la fin de ce mois, il diminue insensiblement et disparait en mars.

La chaleur brûlante occasionnée par ce vent est ainsi expliquée: "Au Sénégal, dit Buffon, t. II, p. 211 et suiv., le vent d'est ne peut arriver qu'après avoir parcouru toutes les terres de l'Afrique dans leur plus grande largeur, ce qui doit le rendre d'une chaleur insoutenable. Si l'on prend donc en général toute la partie de l'Afrique qui est comprise entre les tropiques où le vent d'est souffle plus constamment qu'aucun autre, on concevra aisément que toutes les côtes orientales de cette partie du monde doivent éprouver et éprouvent en effet une chaleur bien plus grande que les côtes orientales, parce que le vent d'est arrive sur les côtes orientales avec la fraîcheur qu'il a prise en parcourant une vaste mer, au lieu qu'il prend une ardeur brûlante en traversant les terres d'Afrique avant que d'arriver aux côtes occidentales de cette partie: ainsi les côtes du Sénégal, de Sierra-Leone, de la Guinée, en un mot, toutes les terres occidentales de l'Afrique, qui sont situées sous la zone torride, sont les climats les plus chauds de la terre. ")

Le vent d'ouest paraît en avril et règne jusqu'à la fin de mai. En juin, la brise devient moins régulière. En juillet, août, septembre, elle est tour à tour 0.-N.-O., O.-S.-O.; en octobre, elle revient au N.-N.-O.

De janvier à avril, les ras de marée sont très-forts; ils persistent parfois dix ou douze jours et le plus souvent cessent aux époques de la nouvelle et de la pleine lune.

A Saint-Louis, la pleine mer atteint une hauteur de 1 mètre (11 heures); elle est de $\mathbf{1}^{\mathrm{m}}, 20$ dans la rade de Gorée ( 7 heures $\left.3 / 4\right)$.

\section{GHAPITRE IV}

Population. - Extrait de la Notice du colonel (général) Faidherbe. Blancs : race arabe et race berbère. - Noirs : race poul ou peul; race malinké ou bambara ; race wolof ou ouolof.

Outre les Européens, deux autres races blanches distinctes se trouvent au Sénégal. Ce sont les races arabe et berbère qui occupent la rive droite du fleuve.

La race berbère, d'après les Notices du ministère de la marine 
et des colonies, occupail déjà l'Afrique septentrionale avant les Phéniciens et les Égyptiens. L'une de leurs nations les plus célèbres, les Zénaga s'étaient étendus du Maroc jusqu'au Sénégal ; ils y régnèrent en maitres jusqu'à l'invasion de l'Afrique par les Arabes, au septième siècle de notre ère, et depuis lors leur puissance commença à décroître.

Au treizième siècle, une puissante tribu arabe, les Béni-Hassan, subjuguèrent les Zénaga, les soumirent à l'impôt et dominèrent à leur place sur les bords du Sénégal. Ils achevèrent, contre les noirs, l'œuvre de conversion à l'islamisme et de refoulement vers le centre de l'Afrique commencée par les Berbères.

Aujourd'hui les Maures de la rive droite forment trois grandes tribus : les Trarzas, les Braknas et les Douaïchs, qui se divisent elles-mêmes en une foule de tribus.

L'élément arabe et l'élément berbère sont à peu près égaux dans ces trois grandes tribus; dans les deux premières, les familles d'origine berbère sont tributaires des Arabes-Hassan ou guerriers; au contraire, la race berbère ou zénaga, primitivement subjuguée par les Arabes-Hassan, a repris la prééminence sur ces derniers chez les Maures-Douaïchs.

Enfin, comme les uns et les autres se sont mêlés depuis des siècles aux noirs, et qu'il se trouve parmi eux la moitié de noirs purs, captifs ou affranchis, qui ont adopté les mœurs de leurs maitres on patrons, on doit dire que ces Maures se composent, par tiers environ, de mulâtres arabes, de mulâtres berbères et de noirs affranchis ou esclaves, tous nomades.

Comme les blancs, les noirs du bassin du Sénégal se divisent en plusieurs races. Les principales sont :

La race poul;

La race malinké ou bambara;

La race wolof ou ouolof qui, comme les Sérer et les Soninké, se rattache à la précédente.

Ces différentes races se distinguent par la teinte plus ou moins foncée de leur peau, leurs formes physiques, leur degré d'intelligence.

Les Poul ou Peuls sont des individus d'un brun rougeâtre, aux cheveux à peine laineux, aux traits presque européens. S'étant trouvés les plus rapprochés des populations blanches musulmanes qui ont envahi le Soudan, ils ont les premiers embrassé l'islamisme et jouent vis-à-vis des autres peuples noirs, le rôle de con- 
vertisseurs à main armée. Ils ont fondé des États puissants, tels que le Raoussa, le Macina, le Fouta, le Toro, le Damga, le FoutaDjalon. Ils se sont mélangés avec leurs captifs ou voisins de race noire, et lorsque, dans une de leurs peuplades, l'élément noir entre dans une proportion notable, la race mélangée est désignée, au Sénégal, par le nom de Toucouleur ou Toukrour. Les Poul sont généralement pasteurs; ils ont une langue spéciale, douce et harmonieuse.

Les Malinké et les Soninké, connus au Sénégal sous l'e nom de Mandingues et de Sarakhollé, sont des noirs de haute taille et aux cheveux crépus; ils ont les traits du nègre, mais non pas au même point que ceux des régions équatoriales et du Congo. Ils habitent principalement le versant septentrional des pays. montagneux où le Niger, le Sénégal et la Gambie, prennent leur source. Ces populations parlent divers dialectes dérivant d'une même langue. Les Malinké sont assez guerriers par tempérament; les Soninké sont les noirs les plus commerçants de la côte occidentale d'Afrique.

Les Ouolof et les Sérer sont les plus beaux, les plus grands et les plus noirs de tous les nègres de l'Afrique; ils ont pour berceau les vastes plaines d'alluvion comprises entre le Sénégal, la Falémé et la Gambie. Ils habitent principalement le Oualo, le Cayor, le Baol et le Sine. La race Serer Ouolof parle deux langues à peu près monosyllabiques, qui ont entre elles les affinités les plus complètes. Ces peuples sont doux, puérilement vains, imprévoyants, apathiques, mais très-braves. Ils sont cultivateurs et pêcheurs. On doit leur reprocher une tendance déplorable à l'ivrognerie.

Les Ouolof, au milieu desquels se trouvent nos principaux établissements du Sénégal, vivent généralement avec nous en bonne intelligence. Il est sorti de ce contact une race mélangée, assez nombreuse, qui a fait des progrès bien remarquables depuis le commencement de ce siècle. 


\section{CHAPITRE V}

Ancienne division administrative. - Nouvelle division en trois arrondissements.

- Chiffre de la population. - Sa répartition. - Gouvernement et administration. - Services divers.

Par un arrêté local du 16 juillet 1863, le Sénégal et dépendances ont été ainsi divisés :

1. Arrondissement de Saint-Louis.

Il s'étend, en remontant le fleuve, jusqu'à Aleybé et Aéré inclusivement, et, vers le sud, jusqu'à la Tanma.

Il forme quatre cercles :

Celui de Saint-Louis (jusqu'à la Taouey dans le Sénégal; jusqu'à la Tanma au sud);

Celui de Podor (jusqu'au Toro):

Celui de Dagana (Dimar et partie du Oualo à l'est de la Taouey);

Celui de Mérinaghen (partie intérieure du Oualo, ou canton de N'der, de Foss et de Ross).

\section{Arrondissement de Gorie.}

Il comprend toutes les possessions au sud de la Tanma.

Il forme quatre cercles :

Celui de Gorée (depuis Dakar jusqu'à la pointe de Sangomar);

Celui de M'bidjem (le Diander et les Serrères);

Celui de Kaolakh (dans le Saloum);

Celui de Sédhiou (dans la Casamance).

3. Arrondissement de Bakel.

Il embrasse tous les pays en amont d'Aleybé et d'Aéré.

Il forme quatre cercles :

Celui de Bakel;

Celui de Médine;

Celui de Matam;

Celui de Saldé.

Avant l'arrêté du $\mathbf{1 6}$ juillet, la colonie était divisée en sept arrondissements :

$1^{\circ}$ Arrondissement de Saint-Louis, comprenant Saint-Louis et faubourgs, et la banlieue; 
$2^{\circ}$ Arrondissement de Richard-Toll, comprenant Richard-Toll et Oualo;

$3^{\circ}$ Arrondissement de Dagana, comprenant Dagana et banlieue, et Dimar;

$4^{\circ}$ Arrondissement de Podor, comprenant Podor et banlieue, Saldé, Toro;

$5^{\circ}$ Arrondissement de Bakel, comprenant Bakel et banlieue, Médine, Sénoudébou, Ndangan, Matam, Damga;

$6^{\bullet}$ Arrondissement de Gorée, comprenant : île de Gorée, cercles de Dakar, du Ndiander, des Serrères et de Joal;

$7^{\circ}$ Arrondissement de Sedhiou, comprenant les comptoirs de Sedhiou et de Carabane (Casamance).

En 1863, on évaluait la population immédiatemement soumise à la France à 116,000 âmes, et, en y comprenant la population vivant sous notre dépendance, on la portait à 150,000 . Le chiffre des individus commerçant avec nous dépassait 1 million.

La population était ainsi répartie :

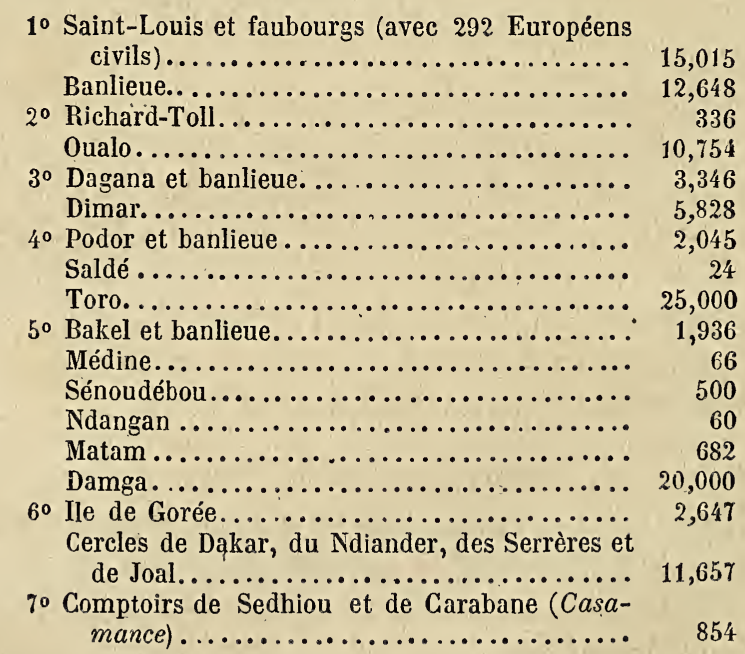

Les troupes indigènes dans les divers postes montaient à 643 hommes.

Les marins et employés indigènes dans les divers postes formaient un total de 433 personnes.

Les militaires, marins et employés européens avec leurs familles s'élevaient à 1,462 . 
Une ordonnance royale du 7 septembre 1840 et un décret du 27 avril 1848 ont réglé le gouvernement et l'administration du Sénégal.

Un gouverneur, résidant à Saint-Louis, est chargé de l'administration supérieure de la colonie.

Chacun des arrondissements de Gorée et de Bakel a un commandant supérieur. Ces commandants relèvent du gouverneur et lui rendent compte de leurs actes.

Les commandants ont sous leurs ordres des chefs de cercle, des chefs de poste, des chefs de village.

Les différentes parties du service public sont dirigées à SaintLouis, sous les ordres du gouverneur, par deux chefs d'administration, l'ordonnateur et le chef de service judiciaire.

La régularité du service administratif est surveillée par un contrốleur.

Un conseil d'administration assiste le gouverneur par qui il est présidé.

Ge conseil, composé des chefs administratif et judiciaire, du contrôleur et de deux notables habitants, a pour mission d'éclairer les décisions du chef de la colonie; il vote le budget local et statue, en certains cas, comme tribunal administratif.

- Une commission administrative est établie dans chacun des trois arrondissements de la colonie. Elle se réunit deux fois par an.

Le chef de l'arrondissement la préside.

Elle se compose du maire (à Saint-Louis et à Gorée), des principaux fonctionnaires, de deux notables, de deux négociants, d'un marchand et de deux chefs de village.

Elle exprime son avis, ainsi que les vœux des populations européenne et indigène, sur l'agriculture, le commerce, les plantations, l'élève des bestiaux, l’instruction publique, le service des milices, la police, les travaux d'utilité publique.

Un directeur, relevant du gouverneur, et assisté de deux adjoints, traite les affaires politiques, c'est-à-dire les affaires relatives aux populations de l'intérieur.

Le personnel administratif de la colonie comprend : un commissaire de la marine, ordonnateur, deux commissaires adjoints, quatre commissaires, sept aides-commissaires et dix commis de marine.

Le service du culte catholique est dirigé par un préfet apostolique. 
Service du Trésor.

Un trésorier, à Saint-Louis.

Un préposé, à Gorée.

Service de santé.

Un médecin en chet.

Trois chirurgiens de première classe.

Dix-huit chirurgiens de seconde classe.

Cinq chirurgiens de troisième classe.

Quatre pharmaciens de la marine.

Service des douanes.

Un sous-inspecteur.

Deux commis.

Service des ports.

Deux capitaines de port ( 1 à Saint-Louis, 1 à Gorée).

Deux maîtres de port.

Un capitaine du poste de la barre du Sénégal.

Quatre pilotes et aspirants pilotes.

Service des ponts et chaussées.

Il est réuni au service du génie. Un çef de bataillon de cette arme le dirige.

Service de la police.

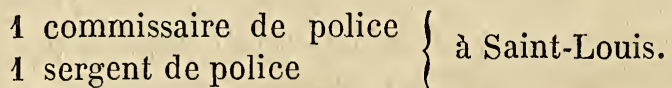

1 commissaire de police, à Gorée.

1 corps indigène de gardes de sûreté à cheval, comprenant 3 brigadiers et 30 gardes.

Service de l'enregistrement et des domaines.

1 receveur, à Saint-Louis.

1 receveur, à Gorée.

Ces receveurs sont aussi chargés de la curatelle aux biens vacants et de la conservation des hypothèques.

Service de la poste.

1 bureau, à Saint-Louis.

1 bureau, à Gorée. 
Service du télégraphe.

Le personnel télégraphique se compose de trois agents détachés du service métropolitain.

L'un d'eux, résidant à Saint-Louis, est chargé de la direction de la ligne, sous les ordres du chef de service des ponts et chaussées; les deux autres sont chargés de la transmission des dépêches aux deux extrémités, Saint-Louis et Dakar; les postes intermédiaires, Gandiole, Lompoul, M'boro, M'bidjem, sont desservis par des sous-officiers. (Notices, etc.)

Service des interprètes.

1 interprète principal.

19 interprètes titulaires divisés en quatre classes.

Interprètes auxiliaires en nombre indéterminé.

Administration municipale.

Un maire et deux adjoints sont établis dans chacune des villes de Saint-Louis et de Gorée.

\section{CHAPITRE VI}

Armée et marine. - Effectif des troupes. - Flottille du Sénégal.

- Effectif des équipages.

L'effectif des troupes militaires, tant européennes qu'indigènes, du Sénégal et dépendances, comprend 93 officiers et 2,162 hommes.

Au $1^{\text {er }}$ mai 1863, il se répartissait ainsi :

État-major général et des places.

8 officiers (1 lieutenant-colonel, commandant de Gorée, 2 lieutenants, 1 enseigne de vaisseau).

Génie.

Sous-direction : 1 chef de bataillon et 10 officiers ou assimilés.

Troupes : une compagnie d'ouvriers indigènes de 130 hommes dont 3 officiers. 


\section{Artillerie.}

Direction : 1 chef d'escadron, directeur et commandant des troupes.

こ officiers ou assimilés.

Troupes : 1 batterie et demie d'artillerie de marine $(6$ officiers et 219 hommes).

1 détachement de 48 ouvriers d'artillerie et de 2 officiers.

1 détachement de 38 indigènes, pour le service des transports.

Gendarmerie.

1 détachement (1 officier et2つ̀ sous-officiers et gendarmes).

Spahis sénégalais.

1 escadron du $2^{\mathrm{e}}$ régiment ( 9 officiers, 141 cavaliers).

Infanteric de marine.

1 bataillon de 6 compagnies (23 officiers, 678 soldats).

Tirailleurs sénégalais.

1 bataillon de 6 compagnies ( 1 lieutenant-colonel, 23 officiers français; 797 hommes).

Disciplinaires des colonies.

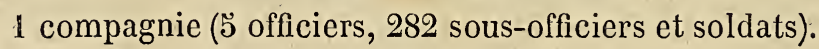

\section{Milices.}

3 compagnies de milice sédentaire ( 1 chef de bataillon).

כ̌ compagnies de milice mobile.

Un arrêté local du 31 janvier 1833 a organisé cette milice, qui est placée sous les ordres du gouverneur.

\section{Volontaires.}

Ils sont au nombre de 3,000 .

Le tiers d'entre eux prend part à nos expéditions.

\section{Station locale.}

a La station maritime locale est placée sous les ordres du gouverneur; quand ce haut fonctionnaire n'appartient pas au corps de la marine, un capitaine de frégate remplit, sous son autorité, les fonctions de commandant supérieur de la marine. 
"La flottille du Sénégal comprend actuellement treize navires de la marine impériale dont voici les noms :

L'Archimède, aviso à vapeur de 80 chevaux et de 4 obusiers de 12.

L'A fricain, aviso à vapeur, de 60 chevaux et de 4 obusiers de 12.

Le Podor, aviso à vapeur de 60 chevaux et de 4 obusiers de 12.

Le Grand Bassam, aviso à vapeur de 40 chevaux et de 2 obusier's.

Le Serpent, aviso à vapeur de 30 chevaux et de 2 obusiers.

Le Basilic, aviso à vapeur de 30 chevaux et de 2 obusiers.

Le $C$ rocodile, aviso à vapeur de 20 chevaux et de 2 obusiers.

Le Griffon, aviso à vapeur de 20 cheraux et de 2 obusiers.

La Couleuvrine, canonnière à hélice de 20 chevaux et de 4. caronades.

La Bourrasque, canonnière à hélice de 2 chevaux et de 4 caronades.

L'Écureuil, côtre à voiles, de 2 pierriers.

La Sénégaluise, citerne flottante.

La Trombe, citerne flottante.

"Ces bâtiments représentent une force de 390 chevaux et de 32 pièces.

"L'état-major se compose de 11 lieutenants de vaisseau, 3 enseignes, 7 chirurgiens et 2 premiers maîtres de timonerie. o (Notices, etc.)

L'effectif des équipages, composé surtout de laptots (matelots noirs), comprend environ 500 hommes.

\section{CHAPITRE VII}

Justice française : Cour impériale ; tribunaux de première instance ; Cour d'assises; conseils de conciliation. - Statistique judiciaire de 1861. - Justice musulmane.

\section{§1. Justice française.}

Le service de la justice a été successivement organisé par l'ordonnance du 7 janvier 1822, celles des 24 mai 1837, 19 novémbre 1840,27 mars 1844 , et 4 décembre 1834 , enfin par le décret du 9 août 1854 . 
Cour impériale.

Elle siége à Saint-Louis.

Elle est ainsi composée:

1 président, chef du service judiciaire de la colonie ;

1 conseiller;

1 conseiller auditeur;

1 greffier.

Le procureur impérial près le tribunal remplit près de la Cour les fonctions du ministère public.

Tous les étabiissements français sur la côte occidentale d'Afrique sont du ressort de la Cour.

Elle connaît des appels en matière civile, commerciale, de douane, correctionnelle et même de simple police.

Tous les arrêts de la Cour, ceux rendus en matière de simple police exceptés, peuvent être déférés à la Gour de cassation.

\section{Iribunaux de première instance.}

Il y en a deux : l'un à Saint-Louis, l'autre à Gorée.

Gelui de Saint-Louis est ainsi composé :

1 juge impérial ;

1 procureur impérial;

1 greffier.

La composition du tribunal de Gorée est identique; seulement; au lieu d'un prócureur impérial, il y a un substitut.

La juridiction du tribunal de Saint-Louis embrasse l'île de Saint-Louis et les établissements français (sauf celui de Bakel) établis sur les rives du Sénégal.

Celle du tribunal de Gorée embrasse, outre cette île, tous les établissements situés au sud.

Ces tribunaux connaissent à la fois des affaires civiles, commerciales, correctionnelles, de simple police et de justice de paix.

Au civil et au commercial, ils jugent, en dernier ressort, jusqu'à concurrence de 1,000 francs en principal ou de 60 francs de revenu déterminé, soit en rente, soit par prix de bail. - Audessus de ces sommes, ils ne jugent qu'en premier ressort.

Au correctionnel et en simple police, ils connaissent de tous les délits et de toutes les contraventions. - En simple police, leurs jugements sont en dernier ressort, s'ils portent moins de cinq jours d'emprisonnement, ou si les amendes, restitutions, 
réparations civiles prononcées, n'excèdent pas 100 francs, dépens non compris.

En matière de justice de paix, ils prononcent d'après les dispositions de l'art. 2 de la loi du $\mathbf{1 1}$ avril 1838 (sur les tribunaux de première instance).

Les maires de Saint-Louis et de Gorée remplissent, dans les affaires soumises au préliminaire de la conciliation, le le rôle de magistrats conciliateurs.

Les fonctions de juge d'instruction sont remplies, en dehors de Saint-Louis et de Gorée, par les commandants des divers arrondissements du Sénégal. (Décr. $1^{\text {er }}$ avril 1863.)

Bakel, par lé même décret, est le siége d'un tribúnal dé police correctionńlle et de simple police. Ce tribunal, présidé par le commandant de l'arrondissement, a en outre pour juges deux notablés nommés pour un an par le gouverneur. - L'officier d'administration en résidence au fort de Bakel remplit les fonctions du ministère public.

Cour d'assises.

Elle siége à Saint-Louis.

Elle est ainsi ccmposée :

Le président de la Cour impériale;

Le conseiller et 'le conseiller auditeur de ladite Cour ;

Quatre assesseurs choisis parmi les notables;

Le procureur impérial;

Le greffier de la Cour.

Lorsqu'un arrêt est cassé, la Cour de cassation peut renvoyer le procès devant la même Cour d'assises du Sénégal, mais alors celle-ci doit être autrement composée.

Le gouverneur de la colonie préside. Il a pour assesseurs deux magistrats qui n'ont pas connu "de l'affaire ou deux notables choisis par luị entre ceux que désigne chaque annéc le gouverneur pour suppléer les mágistrats momentanément empêchés.

\section{Conseils' de conciliation.}

Des arrêtés locaux, en date du 20 janvier 1862 et du 20 juillet 1863, ont établi des conseils de conciliation pour lès établissements de l'inlérieur trop distants de Saint-Louis.

Dans l'arrondissement de Bakel et dans chaque chef-lieu de cercle, il y a un conseil de conciliation destiné à régler ${ }^{j}$ à 
l'amiable les différends entre les résidents qui y commercent.

Le conseil se compose du commandant de l'arrondissement ou du cercle, président; de deux notables et de deux suppléants nommés au commencement de chaque année par le gouverneur.

\section{Conseils commissionnés.}

C'est le titre que portent les avoués, au nombre de quatre, institués par l'arrêté ministériel du 5 mars 1859 , dans le ressort de la Cour impériale.

Commissaire-priseur. Huissiers.

Les ventes volontaires de marchandises, effets mobiliers, navires, etc., ont lieu par le ministère du commissaire-priseur encanteur de Saint-Louis.

Les ventes mobilières après saisie se font par le ministère des huissiers.

\section{Statistique judiciaire de 1861.}

Nombre des affaires portées en conciliation, à Saint Louis, devant le conseiller auditeur................ 861

Affaires conciliées.......................... 393

- non conciliées..................... 197

$\neg$ jugées par défaut.................. 271

Nombre des affarres portées en conciliation, à Gorée, devant le juge impérial...................... 76

Affaires conciliees........................ 18

- non conciliées...................... 58

Nombre des affaires jugées par le tribunal civil et commercial de Saint-Louis.................... 556

Nombre des aff.ires jugées par le tribunal civil et commercial de Gorée....................... 82

Nombre des affaires correctionnelles jugées par le tribunal de Saint-Lonis.......................... 145

Nombre des affaires de simple police jugées par le tıibunal de Sant Louis........................... 283

Nombre des affaires correctionnelies (Gorée).......... 102

- $\quad$ - de simple police (Gorée). ........ 280

Nombre des arrêts reıdus par la Cuur imueriale....... 70

- - - - - d'assise......... 16

Pourrois en cassation (en matière correctionnelle)...... 2

Attentats contre les personnes : $200 / 0$.

Allentats contre les propriéiés : $800 / 0$.

$\S 2$. Justice musulmane.

Par décret du 20 mai 18ว̃7, un tribunal musulman a été établi à Saint-Louis.

Il est ainsi composé :

Un cadi; 
Un assesseur;

Un greffier.

Il statue exclusivement, entre indigènes musulmans, sur les affaires d'état civil, mariagєs, successions, donations, testaments, etc.

L'appel des jugements rendus par ce tribunal est porté devant un conseil composé de la manière suivante :

Le gouverneur, président;

Un conseiller de la Cour impériale;

Le chef de bureau des affaires indigènes;

Le Tamsir (chef de la religion musulmane).

Il est facultatif aux parties intéressées de porter leur cause devant les tribunaux français qui, dans ce cas, statuent d'après la loi française. Toutefois un assesseur musulman est nommé par le gouverneur; il a voix délibérative.

\section{CHAPITRE VIII}

Instruction publique et cultes. - É‘oles primaires. - École primaire supérieure. - Inspection des écoles. - Culte musulman. - Prosélytisme de l'islamisme au Sénégal.

Une mission catholique est établie au Sénégal depuis 1843. Elle fait partie du vicariat apostolique de la Guinée et de la Sénégambie, dont le personnel est alimenté par la congrégation du Saint-Esprit et dı Saint-Cœur de Marie.

Le point central de cette mission (v. les Notices) est à Dakar, sur la presqu'île du cap Vert; c'est la résidence d'un évêque, le lieu d'acclimatement des missionnaires venant de France et l'établissement principal cù l'on enseigne aux enfants les éléments des connaissances littéraires et industrielles adaptées à leur position et à leur avenir.

Get établissement comprend :

Une école primaire supérieure;

Une école primaire élémentaire;

Une école professionnelle.

Les arts et métiers enseignés par les frères de la mission sont ceux de cordonnier, de tailleur, de menuisier, de relieur, d'imprimeur, de cuisinier, etc.

- On organise en ce moment près de Joal un vaste établisse- 
ment agricole qui doit être spécialement affecté à la culture du coton.

4. 'A côté de l'établissement des missionnaires s'élève celui des şurs de l'Immaculée-Conception pour les jeunes filles.

La mission possède aussi une chapelle et une école à Joal.

- Indépendamment de la mission de Dakar, le Sénégal forme une préfecture apostolique dont le clergé est fourni, comme celui de la mission de Dakar, par la congrégation du Saint-Esprit.

Le préfet apostolique, chef du service du culte catholique au Sénégal, est assisté de six prêtres répartis entre les deux paroisses de Saint-Louis et de Gorée.

- En outre des trois écoles tenues à Dakar et à Joal par les missionnaires et les sœurs, on compte dans la colonie douze établissements d'instruction publique, savoir :

A Saint-Louis, pour les garçons, une école primaire supérieure tenue gratuiternent par neuf frères de Ploërmel, et une école primaire laïque; pour les filles, une école gratuite tenue par huit sœurs de Saint-Joseph, et une école primaire laïque.

A Gorée, deux écoles gratuites pour les garçons et pour les filles, tenues, la première par cinq frères de Ploërmel, la seconde par'six sœurs de Saint-Joseph.

A Dakar, Dagana, Podor, Bakel et Sédhiou, une école primaire laïque.

Lies sœurs de Saint-Joseph tiennent en outre un asile à SaintLouis et à Gorée.

Enfin, il existe au chef-lieu une école des otages où le gouverpement entretient et instruit environ trente fils de chefs indigènes qui lui ont été confiés en garantie del'exécution des traités.

- Une commission, composée du chef du service judiciaire, dú préfet apostolique, du maire et d'un habitant notable, est chargée de l'inspection des écoles de Saint-Louis.

Dans l'ouvrage de M. J. Mavidal, Le Sénégal, on trouvera de curieux et importants renseignements sur l'islamisme et: son esprit de prosélytisme.

La plupart des nègres du bassin du Sénégal sont Musulmans, tout en ayant gardé beaucoup de leurs anciennes superstitions et de leurs anciennes pratiques idolâtres:

-! i La raison, dit M: Mavidal, p. 122 et suivantes, la politique; l'humanité, notre intérêt bien entendu, tcut nous invite à prendre fait èt cause pour les idolâtres (Yolofs, etc.), car les idées mo- 
dernes se grefferont plus facilement sur la barbarie que sur le mahométisme... Il ne saurait être permis au mahométisme de s'imposer par la force à des races placées sous notre tutelle, et qui le repoussent avec une extrême énergie. "

Saint-Louis est la résidence du chef de la religion musulmane (Tamsir), au Sénégal. Il y existe une grande mosquée.

\section{GHAPITRE IX}

\section{AGRIGULTURE ET INDUSTRIE.}

Gomme. - Arachide. - Béref. - Riz. - Mil. - Maïs. - Coton. - Indigofère. - Bœuf, âne, chameau. - Cheval. - Ghèvres, moutons, cochons. - Essences principales. - Gonakié, etc. - Professions manuelles des indigènes. - Fer.

- Or. - Pèche. - Constructions maritimes. - Service du remorquage.

La gomme, l'arachide, le béref ou graine de melon, le sésame et autres plantes oléagineuses, l'amande et l'huile de palme, le riz, le mil, le coton; tels sont les principaux produits du sol sénégalais et dépendances.

L’agriculture, au Sénégal, est complétement aux mains des noirs.

La gomme est le produit d'un arbre de la famille des acacias. Les indigènes le nomment vereck, lorsqu'il donne de la gomme blanche, et nebueb, lorsqu'il en donne de la rouge.-La plus estimée et la plus blanche est celle de Galam, que.l'on traite à Bakel. - La gomme de la rive droite du Sénégal est la plus recherchée. On traite pendant les mois de janvier à août.

L'arachide (arachis hypogea) produit une amande de la grosseur d'une petite aveline. On en extrait une huile supérieure, suivant certains connaisseurs, à l'huile d'olive.

Ce n'est pas le seul usage de l'arachide. L'amande sert aussi de nourriture aux habitants; les tiges, de fourrage aux bestiaux, enfin de combustible et d'engrais.

Le Cayor et la Casamance fournissent les quantités les plus considérables; le pays de Galam, les qualités les plus estimées.

Le Béref ou Beraff est une graine que produisent le Cucumis melo et le Cucurbita miroor, deux plantes de la famille des cucurbitacées, que les indigènes consomment crues, mais dont ils gardent la graine pour la vendre. Cette graine, qui contient 30 p. 100 d'huile, est à la fois bonne pour la saponification et l'alimentation. Son huile se rapproche de l'huile d'olive. 
La Casamance donne d'autres oléagineux : la graine de sésame, de pignon d'Inde, la noix de palme, celle de touloucouna, dont la savonnerie surtout peut tirer parti.

Le riz du Kaarta n'est pas inférieur à celui de l'Inde.

Le mil, base de la nourriture des noirs, est cultivé sur les deux rives du Sénégal, mais spécialement sur la rive gauche.

Le maïs, les haricots-niébés font aussi partie de la nourriture des indigènes.

Le coton vient naturellement au Sénégal. Beaucoup plus court que les cotens américains, il ne peut rivaliser qu'avec les sortes moyennes des États-Unis. - Les noirs l'emploient pour tisser leurs vêtements.

L'indigofère vient naturellement aussi. Il est l'objet d'un commerce des plus actifs, surtout en Gambie. On obtient jusqu'à vingt récoltes par an de la plante.

Le bœuf, l'âne et le chameau sont employés à l'agriculture. On élève des chèvres, des moutons et des cochons. Les chevaux, d'origine arabe, sont très-sobres, résistent bien à la fatigue, mais ne sont pas employés comme betes de somme ou de trait.

Les principales essences sont : le gonakié (acacia Adansonii), le caïlcedra (klaya senegalensis). le detarr (detarium senegalense), le vène (pterocarpus erinaceus), le n'dimb (sterculia cordifolia), le solum (dia'ium nitidum), etc.

L'industrie a contre elle les préjugés des indigènes. Noirs et surtout mulâtres se croiraient déshonorés de s'y livrer. Les seules fabriques sont des briqueteries et des chaufourneries.

"Les principales professions manuelles sont celles de charpentier, de menuisier, de maçon, de tisserand, de calfat, de forgeron et d'orfévre; de ces professions, celles de charpentier de marine, de tisserand et d'orfévre, sont les seules qui offrent quelque degré de perfectionnement.

"Indépendamment des forgerons ordinaires, il existe dans la colonie des forgerons nègres ou maures qui ne se bornent pas au travail du fer, et qui fordent, forgent et travaillent tous les métaux indistinclement. Ils fabriquent les outils de culture les plus grossiers et les bijoux en or les plus délicats.

"Les tisserands nègres du Sénégal tissent avec le coton indigène des bandelettes d'éloffe de 15 centimètres de largeur en moyenne. La réunion de plusieurs de ces bandelettes, longues de 2 à 3 mètres environ, forme un morceau d'étoffe, nommé 
pagne, qui constitue le principal vetement des indigènes des deux sexes. Les plus beaux de ces pagres sont mêlés de fils de couleurs qui forment des dessins très-réguliers et même assez compliqués. Le nombre des tisserands excède à lui seul celui de tous les autres ouvriers réunis. „) (Notices, etc.)

C'est dans le Bambouck et le Tambaoura, que se trouve en grande partie l'or qu'on traite au Sénégal; il se rencontre dans des terrains d'alluvion formés de sable, de cailloux quartzeux et d'argile schisteuse. L'imperfection des moyens employés ne permet pas à ce travail d'être aussi lucratif qu'il devrait l'être.

Quoique le Sénégal et la mer qui borde les côtes abondent en poissors, Saint-Louis, non plus que Gorée, ne possède aucun établissement de pêche. Ce sont les nègres qui se livrent à cette industrie. Ils font sécher les quantités considérables de poisson qu'ils prennent et le vendent à l'intérieur. Les procédés trèsprimitifs qu'ils ont employés jusqu'ici commencent à faire place à la seine et à l'épervier.

On compte environ 1,500 marins noirs ou laptols se livrant à la pêche et à la navigation locale.

Saint-Louis et Gorée possèdent quelques chantiers de construction maritime. La colonie a 48 navires de commerce (non compris les embarcations) : 23 long-courriers et 23 caboleurs. Ils sortent de ses chantiers pour la plupart.

Le service du remorquage sur la barre du Sénégal est fait par une Compagnie de Saint-Louis. Deux bateaux à vapeur sont affectés à ce service.

\section{GHAPITRE $\mathrm{X}$}

\section{COMMERCE.}

Commerce de Saint-Louis. - Marchandises d'importation et d'exportation. Commerce de Gorée. - Comptoir de Joal (Sine). - Comptoir de Kaolakh (Saloum). - Co r ptoir de Carabane (Casamance). - Comptuir de Sédhiou (Casamance). - Rio-Nuñez et Rio-l'ongo. - Régime commercial du Sénégal. Coinmerce spécial du Sénégal avec la France. - Commerce général.

\section{SAINT-LOUIS (1861).}

\section{Imporlation.}

Marchandises venant de France .......... 4,554,613 fr.

_ $\quad$ - _ des colonies françaises... 72,169 
Marchandises étrangères venant des entrepôts français ........................... Marchandises étrangères venant des colonies françaises..........................

Marchandises étrangères venant de l'étranger..

Total.

$2,914,392$

89,517

280,226

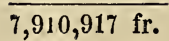

Exportation.

Pour la France.......................

- les colonies françaises................

- l'étranger .........................

Total.

$2,885,692 \mathrm{fr}$.

39,434

$\frac{9,165}{2,934,291 \mathrm{fr} \text {. }}$

Rexportation.

Pour la France.........................

- les colonies françaises.................

- l'étranger .........................

Total.

$181,296 \mathrm{fr}$.

164,285

205,610

$551,191 \mathrm{fr}$.

Les principales. marchandises et denrées qui ont donné lieu aux importations sont les suivantes :

Produits animaux (viandes salées)..........

Farines ............................

Riz . .............................

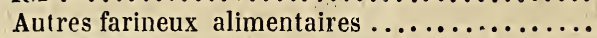

Arachides en coques.....................

Fruits et graines divers. ................

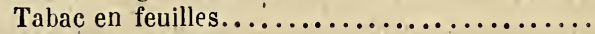

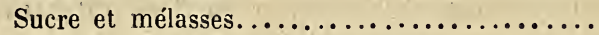

Huile d'olive et de graines grasses............

- de palme.........................

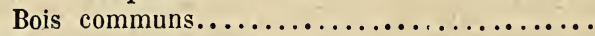

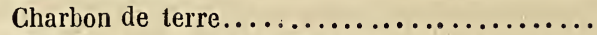

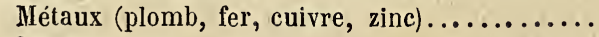

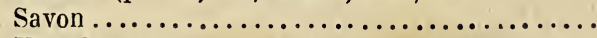

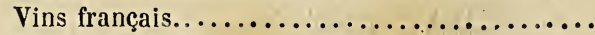

Eaux-de-vie, liqueurs, autres boissons.........

Fils de coton et fils à voiles.................

Guinées et autres tissus de l'Inde..............

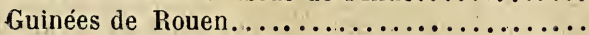

Autres tissus de coton. ....................

Tissus de laine ou de soie.................

- de lin ou de chanvre................

Ouvrages en fer et quincaillerie..............

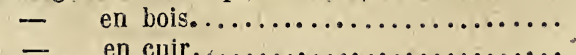

$126,528 \mathrm{fr}$.

295,751

183,210

294,029

105,573

58,613

336,062

267,808

72,865

37,193

148,138

231,352

92,594

57,704

501,345

324,760

84,538

$2,340,963$

72,764

647,735

51,410

78,065

97,159

109,673

57.303

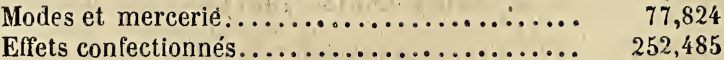

Articles de Paris.................... $\quad 52,787$

Sacs vides......................... 71,776

Apparaux de navires, ancres et cordages...... $\quad 55,953$ 
Poudre de chasse et de traite...............

Armes à feu............................. 68,674

Articles divers.......................... 604,399

Les principales denrées et marchandises d'exportation sont les suivantes :

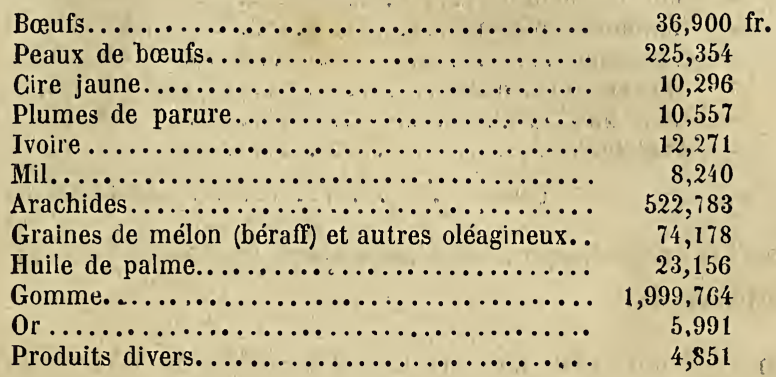

Les denrées et marchandises provenant de l'importation et exportées sont les suivantes :

Farinenx alimentaires. $37,158 \mathrm{fr}$.

Tabac en feuilles.................... 54,301

Huile de palme....................... 11,820

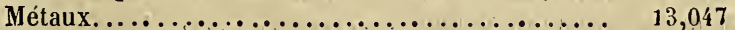

Vins, spiritueux, autres boissons............ $70,7.57$

Guinées de l'Inde et autres.............. 106,179

Ouvrages en matières diverses............. 73,238

Marchandises et produits divers........... 184,641

$\mathrm{Au}$ nombre des objets que la colonie tire de l'étranger on remarque : les guinées et le riz (qui viennent de l'Inde), les tabacs et sucres non raffinés (d'Amérique), la cire, les peaux de bœufs, arachides, amandes, huile de paime (du Cayor et autres contrées limitrophes). - Tous ces objets sont réexportés.

\section{GORÉE (1861).}

\section{Importation.}

Marchandises venant de France.

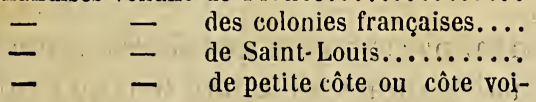

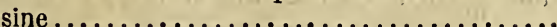

Marchandises venant de Sine et Saloum........

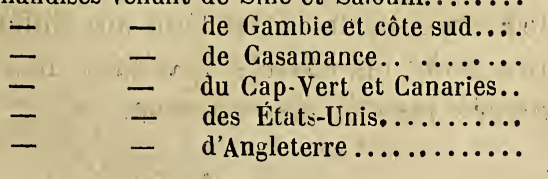

$3,557,268 \mathrm{fr}$.

82,759

58,481

185,659

83,930

329,673

602,524

2,959

414,281

155,269

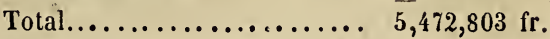


Exportation.

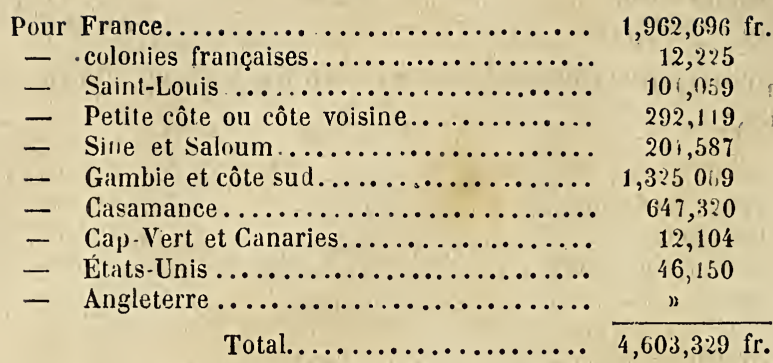

Gorée ne produit rien. Elle réexporte seulement les marchandises importées.

Parmi celles qu'elle tire de la petite côte ou côte'roisine, de Sine et de Saloum, de la Gasamance et de la Gambie, on remarque la cire, l'arachide, etc., qui, en 1861, ont donné :

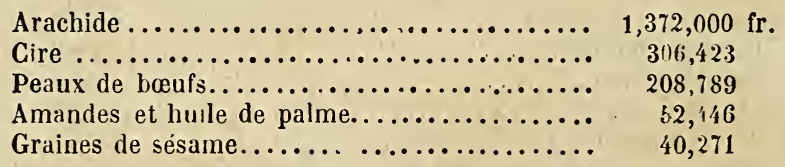

Gorée tire surtout de France : vins, eaux-de-vie, tissus de coton, charbon de terre, farines, sucre raffiné, armes à feu, confections, articles de Paris; des entrepôts français : tabac, tafia, guinées de l'Inde; des États-Unis : tabac, tafia; de l'Angleterre: tissus de coton, ourrages en fer, poudre de traite (ce dernier objet semble devoir être prochainement supplanté par son similaire français).

Elle revend à la côte d'Afrique : les tissus de coton, guinées de l'Inde, tabac, vins, tafia, eaux-de-vie, liqueurs fortes, charbon de terre, farines, sucre raffiné, savon, bougies, armes à feu, verroteries, etc.

C'est principalement par son port que Gorée a quelque importance. Sa consommation locale ne donne lieu qu'à un commerce insignifiant. Son port est un point de relâche et d'échange pour les navires allant de France ou des États-Unis aux différents points de la côte d'Afrique, pour les navires revenant de cette côte et les caboteurs du littoral jusqu'à Sierra-Leone. 
III. COMPTOIR DE JOAL (SINE).

Importation (1861).

Eaux-de-vie et liqueurs...................

Tissus ..............................

Vins................................

Tabac................................

Farines, lard, bière, sucre.

$22,090 \mathrm{fr}$.

3,680

$1,(180$

1,295

691

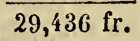

\section{Exportation.}

Peaux de bœufs.

$30,851 \mathrm{fr}$.

Bœufs vivants...

3,890

Chaux et coquilles

19,600

M 1

Charbon de bois.

16,554

Riz

2,609

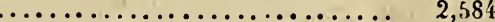

Cire............................ 1,924

Arachides ......................... 1,813

Bois............................... ${ }_{820}$

Moutons, chèvres, pores.................. 130

Total................. $\overline{80,775 \mathrm{fr} .}$

Le commerce extérieur de Joal se fait exclusivement avec Gorée et Sainte-Marie-de-Bathurst (Gambie).

IV. GOMPTOIR DE KAOLAKI (SALOUM).

Importation.

Tabac............................ $31,021 \mathrm{fr}$

Guinées et tissus divers. ............... 29,660

Eaux-de-vie ...................... 26,714

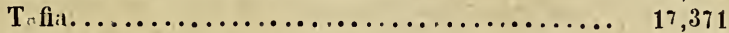

Liqueurs et boissons.................. 5,010

Fusils et pouilre de traite............... 3,275

Articles divers...................... 5,803

Total.

118,854 fr.

Exportation.

Peaux de bœufs

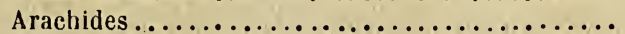

Mil ..............................

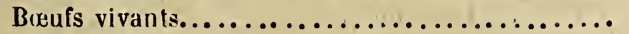

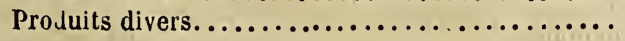

Total.

$25,061 \mathrm{fr}$.

14, 011

5,560

800

610

$46,042 \mathrm{fr}$.

Le commerce extérieur de Kaolakh se fait comme ceiui de Joal, avec Sainte-Marie-de-Bathurst el Gorée. 


\section{v. Gomptoir de Garabane (GASAMANGE).}

Importation.

Marchandises venant de Gorée ou d'Europe.

Tabac

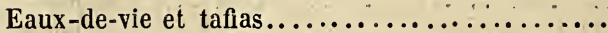

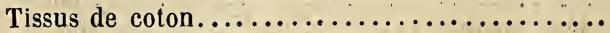

Poudre de traite........................

Verroteries ............................

Fer en barres..........................

Articles divers d'Europe..................

$9,467 \mathrm{fr}$.

8,234

49,292

8,925

4,694

1,767

5,485

Produits venant du haut du fleuve.

Arachides

Aire.

Cire.............................

Peaux de bøufs........................

Riz ..............................

Gomme copal.

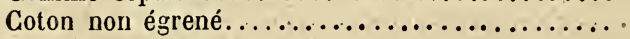

Produits divers.......................

Total.

237,873

4,774

3,975

3,113

3,079

1,680

2,776

$345,134 \mathrm{fr}$.

Exportation.

Produits du sol expédiés à Gorée ou en Europe.

Arachides 320,353 fr.

Riz 36,072

Cire.

15,540

Peaux de bœufs.

10,846

Chaux........................... ${ }_{2,311}$

Amandes de palme................... 1,345

Marchandises provenant de l'importation par mer et expédièes dans le fleuve.

Tissus

30,632

Tabac

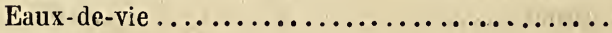

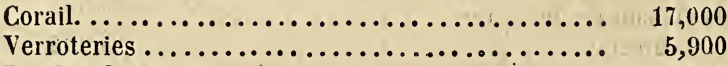

Poudre de traite...................... 1,811

Bijouterie.......................... 5,700

Articles divers.................... 21,516

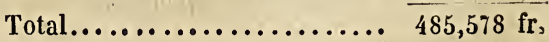

VI. COMPTOIR DE SÉDHIOU (CASAMANCE).

\section{Importation.}

Farineux alimentaires.................... 31,626

Tabac........................... 38,001

Bois ........................... $\quad 3,050$

Barres et plaques de fer.................. 9,101

Zinc........................... 4,131

Sucre raffiné......................... 2,213 


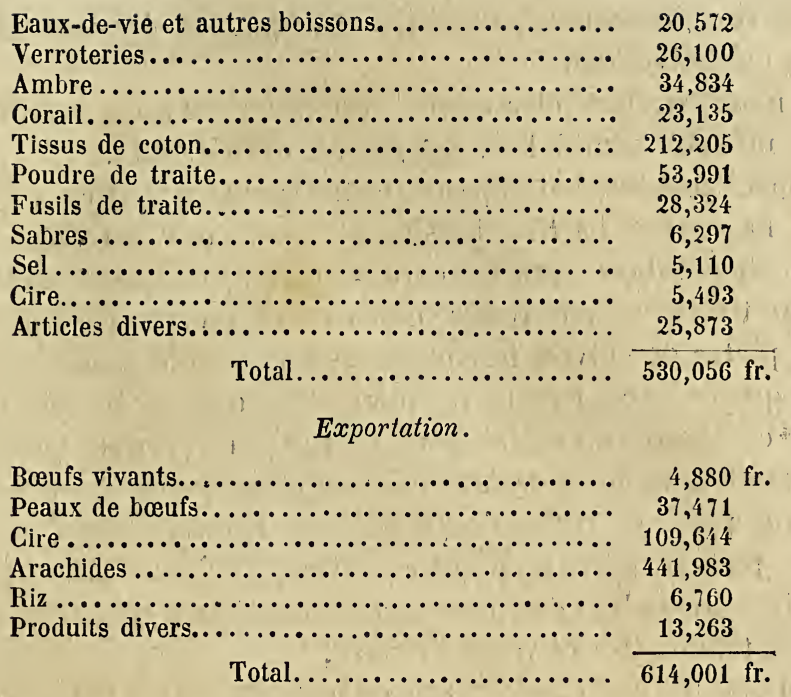

Ces chiffres, concernant le comptoir de Sédhiou, appartiennent à la statistique de 1860. Depuis lors, l'importance de ce comptoir a augmenté; en 1862 , la récolte a été de 380,000 boisseaux (environ $5,130,000$ kilogr.), valant 1,333,000 francs.

\section{RIO-NUÑEZ ET RIO-PONGO.}

Le Rio-Nuñez possède cinq factoreries françaises, trois anglaises, une américaine, une indigène.

Le commerce qu'elles font est de plus de 4 millions.

Principaux articles d'importation : Poudre, armes, cotonnades, verroterie, sel.

Principaux articles d'exportation : Riz, café, cire, arachides, cuirs, ivoire, or:

Le mouvement.commercial de cette zone des dépendances du Sénégal est considérablement accru par le Rio-Pongo et la Mallécory.

Le régime commercial du Sénégal a été tour à tour réglé par l'acte de navigation du 21 septembre 1793, l'arrêté consulaire du 6 décembre 1801, enfin par le décret du 8 février 1852.

Principales dispositions de ce décret :

Les marchandises françaises de toute nature sont admises danst le port de Saint-Louis au droit de 2 p. 100 de la valeur, lors-; 
qu'elles sont importées par navires français, ou des entrepôts de France exclusivement.

Les marchandises étrangères, qui satisfont à ces conditions, payent un droit semblable. Ces marchandises sont :

Ambre, guinées, bajulapaıx, néganépaux et autres toiles de l'Inde, bagueltes, barbus, bassins et chaudrons, bayettes, bonnets de laine, bois, cauris, coraux ouvrés, couteaux, sabres et fusils de traite, cuivre rouge, clous de cuivre, verges rondes et barres plates de cuivre, fers et aciers non ouvrés, fusils de chasse autres que de luxe, flacons de verre, féveroles de Hollande, grelots et clochettes en métal, gros carton brun, grosse quincaillerie, manilles, moques de faïence, neptunes, petits miroirs d'Allemagne, pipes de Hollande, plotilles de Breslau, plomb de deux points, poterie d'étain, poudre à lirer, produits des colonies françaises, rassades et autres verroteries, tabacs en feuilles et fabriqués, trompettes et vases de Saxe.

Les bois, les fers et aciers non ouvrés, les tabacs et les poudres pcurent être introduits au port de Saint-Louis, par extraction de l'entrepôt de Gorée et par navires français, moyennant le même droil de 2 p. 100.

Sont admis en franchise de droits : les poutrelles en fer et les autres fers laminés, propres à la construction des édifices, quand ils arrivent, sous pavillon français, soit des ports ou entrepôts de la métropole, soit de Gorée; les fruits, les légumes frais, les pierres des Canaries importées directement par navires français.

Les toiles bleues de l'Inde (guinées), qui forment le principal élément des échanges, ne peuvent être admises sous le payement du droit de 2 p. 100 de la valeur, qu'après avoir fait escale dans les entrepôts de France.

Les vins étrangers de toute espèce, importés directement sous pavillon français, payent $0,2 \check{c} \mathrm{c}$. par hectolitre.

Les produits du Sénégal ne peuvent être exportés de SaintLouis que par navires français, ni pour d'autre destination que les ports de France et les colonies. Ils payent un droit de sortie de 2 p. 100. - La gomme, toutefois, peut s'expédier par navires français, soit pour Gorée, soit directement pour l'étranger.

Liberté entière pour le commerce de Gorée, de Joal, de Kaolakh, de Carabane te de Sédhiou, sauf en ce qui concerne les guinées. 
Un décret impérial du 24 décembre 1864 a modifié ainsi le régime commercial du Sénégal :

$1^{\circ}$ Importation autorisée par tout pavillon à Saint-Louis et à Gorée des marchandises de toute nature et de toute provenance ;

A Saint-Louis, taxe de 4 p. 100 de la valeur;

A Gorée, franchise de tout droit de douane et de navigation;

$2^{\circ}$ L'accès du fleuve (Sénégal), au-dessus de Saint-Louis, interdit, coinme par le passé, aux bâtiments étrangers;

$3^{\circ}$ Les marchandises importées à Saint-Louis jouissent, pendant un an, du bénéfice de l'entrepôt fictif. A l'expiration de ce délai, les droits sont liquidés d'office.

$4^{\circ}$ Les produits chargés dans le port de Saint-Louis et de Gorée peuvent être exportés pour toute destination et par tout pavillon.

$5^{\circ}$ Les produits chargés dans le port de Saint-Louis et de Gorée sur des navires étrangers sont, à leur importation en France, assujettis à une taxe de pavillon de 20 francs par tonneau d'affrétement.

$6^{\circ}$ Toutes dispositions contraires à ce décret du 24 décembre 1864 sont abrogées.

Depuis 18כ24, les coutumes ou droits que le commerce payait aux Maures, aux différentes escales du fleuve, ont été supprimés. Les traités, toutefois, obligent à n'acheter les gommes qu'à Médine, Bakel, Matam, Saldé, Podor et Dagana; un droit de sortie remplace les coutumes; il est versé aux chef́s des Maures.

Le commerce spécial du Sénégal avec la France est en pleine voie de prospérité depuis 1834 .

En 1818, il n'atteignait (importation et exportation réunies) que le chiffre de $5,120,451$ francs; en $1850: 9,831,110$ francs. Depuis $\mathbf{1 8 5 4}$, il a successivement atteint les chiffres de 16,061,061 (185ั4); 19,503,596 (185ั5); 19,225,844 (1856); 20,763,336 (1857); $25,283,811$ (18כ̋); 25,491,828 (1859); 23,384,807 (1860); $22,118,103$ (1861).

Quant au commerce général de la colonie (France, colonies françaises, étranger), il n'a pas été, en 1861, inférieur à 25 millions. 


\section{GHAPITRE XI}

NAVIGATION.

Saint-Louis. - Gorée. - Joal. - Kaolakh. - Casamance. Droits de tunnage, etc.

I. SAINT-LOUIS.

\section{Entrée}

Nombre des navires..................... $\quad 90$

Tonnage $\ldots \ldots \ldots \ldots \ldots \ldots \ldots \ldots \ldots \ldots \ldots \ldots \ldots, 15,007$

Hommes d'équipage.................. 890

Sortie.

Nombre des navires................... 95

Tonnage .......................... 16,016

Équipage........................ 1,032

II. GORÉE.

Entrée.

Nombre des navires................... $\quad \mathbf{5 9 0}$

Tounage $\ldots \ldots \ldots \ldots \ldots \ldots \ldots \ldots \ldots \ldots \ldots \ldots \ldots \ldots, 40,343$

Équipage........................ $4,00^{\prime}$

Sortie.

Nombre des navires................... 583

Tonnage......................... 38,572

Équipage....................... 3,943

III. COMPTOIR DE JOAL (SINE).

Entrée.

Caboteurs ............................. 41

Tonnage........................... 633

Sortie.

Caboteurs ............................ 38

Tonnage........................ 622

IV. COMPTOIR DE KAOLAKH (SALOUM).

Entrée.

Caboteurs ............................ 184

T'onnage ......................... 1,826

Sortie.

Caboteurs............................. 178

Tonnage......................... 1,732 
V. CASAMANCE.

Entrée.

Nombre des navires................... 232

Tonnage......................... 11,483

Sortie.

Nombre des navires.................. 250

Tonnage ........................ 12,123

Pour son commerce local, la Casamance a une flottille de 37 navires dont le tonnage est de 720 tonneaux. Des chalands, pirogues, canots, grandes goëlettes faisant le cabotage entre Gorée et le fleuve, navires long-courriers allant en France, viennent s'ajouter à cette flottille.

"La navigation entre la France et le Sénégal, y compris l'île de Gorée, et les rapports de la colonie avec les autres possessions françaises d'Asie, d'Afrique et d'Amérique, est réservée au pavillon national.

"Non-seulement les navires français sont seuls admis à faire le commerce dans le Sénégal, mais les navires étrangers venant de l'étranger ne peuvent entrer dans le Sénégal, même pour y introduire les marchardises promises. Les navires étrangers qui touchent à Saint-Louis payent un droit de tonnage de 4 francs par tonneau, sauf le cas de relâche forcée.

"A Gorée, où les navires étrangers sont admis à faire le commerce, le droit de tonnage n'est que de 0, 50 par tonneau (Décrets 8 férrier 18522 et 6 janvier 18505$)$.

"Les taxes accessoires de navigation perçues à Saint-I_ouis consistent en droit de tonnage, de congé, d'ancrage, de francisation et de pilotage, qui sont fixés par des arrêtés locaux.

"Les droits de francisation et de congé sont les mêmes à Gorée qu'à Saint-Louis.

"Dans les comptoirs français de Joal et de Kaolakh et dans ceux de la Casamance, les navires de commerce, quelle que soit leur nationalité, ne sonl assujettis à aucun droit de navigation. " (Notices, etc.) 


\section{GHAPITRE XII}

\section{FINANGES.}

Budget de l'État. - Budget local. - Banque. - Ses opérations en 1861 et 1862.

Pendant l'exercice 1863, le Sénégal et ses dépendances ont figuré au budget de l'Etat pour la somme de 3,804,970 francs.

\section{BUDGET DE L'ÉTAT (1863).}

10 Gouvernement colonial.

\begin{tabular}{|c|c|c|}
\hline Administration générale........... & 132,735 & " \\
\hline Justice............ & 61,800 & $n$ \\
\hline$\ldots \ldots \ldots \ldots \ldots$ & 29,800 & 》 \\
\hline État-major général et des places..... & 54,660 & $n$ \\
\hline État-major de l'artillerie............ & 38,535 & $n$ \\
\hline État-major du génie............. & 70,420 & $n$ \\
\hline Inscription maritime............ & 4,600 & $n$ \\
\hline Gendarmerie coloniale............ & 47,992 & " \\
\hline Équipages du train.............. & 56,490 & 50 \\
\hline Spahis...$\ldots \ldots \ldots \ldots \ldots \ldots \ldots \ldots$ & 216,111 & " \\
\hline Compagnies disciplinaires.......... & 117,906 & 78 \\
\hline Troupès indigènes.............. & 434,776 & 69 \\
\hline Accessoires de la solde............ & 62,000 & " \\
\hline Traitement dans les hopitaux........ & 633,190 & 60 \\
\hline ................. & 781,229 & 90 \\
\hline n............. & 2,712 & $n$ \\
\hline
\end{tabular}

Total, pour le personnel civil et militaire, déduction faite d'un trentième pour incomplets......... 2,735,917 fr. $49 \mathrm{c}$.

20 Ports et rades...................... 14,000 fr.

Édifices publics.................... 40,000

Casernement et campement............. $\quad 5,300$

Artillerie et transports............... 119,200

Génie......................... 281,100

Loyers et ameublements.............. 10,000

Impressions et publications............. 4,000

Frais de justice et de procédure.......... 2,950

Encouragement aux cultures........... 2,500

Total, pour le matériel civil et militaire.. $\overline{479,050 \mathrm{fr}}$ $3^{0}$ Subvention au Sénégal.............. 400,000 fr. - . à Gorée et dépendances......... 190,000

Total, pour subvention............ $\overline{590,000 \mathrm{fr}}$

Ce qui donne, en chiffres ronds, un total général de francs $3,804,970$.

Dans ce total ne sont pas comprises les dépenses effectuées au 
compte du service marine. Elles ont été, en 1861, de 1,541,380 francs.

\author{
II. BUDGET LOCAL (1863).
}

10 Recettes.

Droits sur les loyers des maisons.......

Contribution personnelle.............

Patentes industrielles...............

Droits de tonnage..................

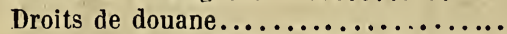

Droits de greffe, enregistrement et timbre.

Produits des domaines...............

Recettes diverses.................

Subvention métropolitaine

16,683 fr. 88 c.

43,000

104,060

6,000

232,550

30,500

19,000

67,400

590,000

Total

$1,109,193$ fr. 88 c.

20 Dépenses.

Administration municipale............

Comité consultatif des colonies (part contributive).

Agents des services financiers..........

Instruction publique................

Personnel des ponts et chaussées.......

Service de la police................

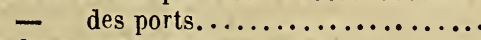

Culte et tribunal musulmans..........

Imprimerie...................

Prisons ........................

Hospice civil. ...................

Télégraphie électrique..............

Direction des affaires indigènes.........

Agents subalternes du culte catholique..

- du service judiciaire...........

- du gouvernement colonial.......

- du service intérieur............

Pensions et secours.................

Postes . ........................

Accessoires de la solde..............

Bourses dans les colléges de France.....

Hòpitaux militaires................

Vivres..........................

Total du personnel, déduction faite du

$45^{\circ}$ pour retenues et incomplets...

10,720 fr. . c.

$\begin{array}{rr}400 & \text { " } \\ 54,420 & " \\ 88,927 & 60 \\ 26,070 & " \\ 24,618 & 10 \\ 32,156 & 38 \\ 10,565 & \prime \prime \\ 18,445 & \text { " } \\ 4,880 & \text { " } \\ 3,800 & " \\ 21,640 & " \\ 43,174 & 50 \\ 2,740 & " \\ 7,120 & " \\ 1,920 & n \\ 12,220 & " \\ 6,197 & 40 \\ 34,290 & " \\ 15,000 & " \\ 6,200 & " \\ 16,357 & 59 \\ 62,311 & 67\end{array}$

495,010 fr. 93 c.

Entretien des bâtiments publics, routes et ponts......................

Approvisionnements généraux.........

Loyers d'établissements et de maisons...

Transports par terre et par eau........

Subventions à divers établissements....

Dépenses de l'hospice civil............

Exposition permanente..............

École des otages et fils de chefs.........

$\begin{array}{rr}356,000 & \text { " } \\ 72,000 & " \\ 23,985 & 83 \\ 6,000 & " \\ 13,500 & \text { " } \\ 8,500 & \text { " } \\ 4,000 & \text { " } \\ 14,000 & \text { " }\end{array}$




\begin{tabular}{|c|c|c|}
\hline Direction des affaires indigènes. & 25,000 & ” \\
\hline 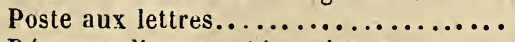 & 6,500 & " \\
\hline Dépenses diver:es et imprérues........ & 70,197 & 12 \\
\hline Éclairage des étabissements publics.... & 14,500 & 口 \\
\hline Total du matériel. & 614,182 & 95 \\
\hline
\end{tabular}

Ce qui donne un total général de 1,109,195fr. 88 c.

\section{B A N Q U E.}

\section{$1860-1861$}

Ensemble des opérations. $2,295,971$ fr. 03 c.

Dividendes, par action............. i $34 \quad 31$

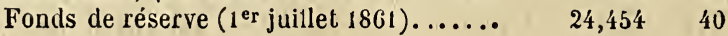

\section{1-1862.}

$\begin{array}{ccc}\text { Ensemble des opérations................ } & 2,381,496 & \mathrm{fr} .47 \mathrm{c} . \\ \text { Difference en plus surl'exercice précédent. } & 88,525 & 44\end{array}$

Dividendes par action. ............ $34 \quad 85$

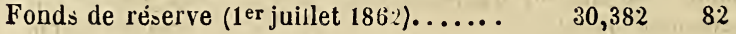

\section{GHAPITRE XIII}

\section{SERVICE POSTAL.}

Bureaux de poste. - Correspondance avec l'Europe. - Frais de port. Frais de passage.

\section{Bureaux de poste.}

\section{Saint-Louis;}

Gorée;

Bakel;

Sur les autres points de l'intérieur, le service est fait par les soins des conımandants militaires.

\section{Correspondance avec l'Europe.}

Deux lignes de paquebots-poste : ligne anglaise et ligne française.

Les paquebots de la ligne anglaise partent de Liverpool le 24 de chaque mois, touchant à Sainte-Marie-de Bathurst (chef-lieu des établissements anglais de la Gambie), le 8 du mois suivant, et arrivent à Fernando-Po le 28. 
Départ de Fernando-Po pour Liverpool, le 28 de chaque mois. On arrive à Sainte-Marie de-Bathurst le $\mathbf{2 4}$ du mois d'après, et à Liverpool, le 10 du mois suivant.

Les correspondances d'Europe pour le Sénégal, ou du Sénégal pour l'Europe, sont déposées à Sainte-Marie-de-Bathurst.

Les lettres, expédiées de Paris le 22, sont distribuées ả SaintLouis et à Gorée vers le 11 ou le 12 du mois suivant. - Celles du Sénégal pour Paris, expédiées vers le 22 ou le 23 , sont distribuées à Paris le 11 on le 12 suivant.

Les paquebots de la ligne française partent de Bordeaux le $\mathbf{2 5}$ de chaque mois, touchent à Lisbonne le 28 , à Saint-Vincent (îles du Cap-Vert), le 6 suivant, arrivent à Rio-Janeiro le 20, et à Buénos-Ayres le $1^{\text {er }}$ du mois suivant.

Les correspondances d'Europe sont prises à Saint-Vincent par un bateau annexe de la Compagnie qui fait le service entre cette ville et Gorée. Elles parviennent à Gorée le 11, et à Saint-Louis, le 12 de chaque mois.

Celles du Sénégal, pour la France, sont expédiées de Gorée le 2 de chaque mois, remises le 10 au paquebot de la ligne du Brésil touchant à Saint-Vincent, et parviennent le 20 à Bordeaux.

Le prix du passage de Bordeaux à Gorée est ainsi établi :

$1^{\text {re }}$ classe : 1,125 francs $;-2^{\mathrm{e}}$ classe : 750 francs $;-3^{\mathrm{e}}$ classe : 625 francs.

Entre-pont : 250 francs.

Les passagers de l'administration bénéficient d'un rabais de 30 p. 100 sur les frais autres que ceux de nourriture.

Frais de port des lettres (de Bordeaux à Gorée).

Lettre affranchie, au-dessous de 7 gr. 1/2. . . . . $0^{\mathrm{f}, 50}$ Lettre non affranchie, id. $0^{\mathrm{f}}, 60$

Les lettres chargées payent double taxe.

Les lettres expédiées de France pour le Sénégal ou du Sénégal pour la France par la voie des navires du commerce, payent 30 centimes par 10 grammes, si elles sont affranchies; sinon, 40 centimes.

Les navires du commerce sont nombreux, principalement entrè Marseille et Bordeaux, d'une part, et le Sénégal de l'autre. Ils meltent ordinairement 18 jours à l'aller et 30 jours au retour. - 
Le prix du passage (aller) est en moyenne de 400 francs et de 500 francs (retour).

Transport des lettres à l'intérieur.

Le service se fait, à l'intérieur, au moyen de courriers expédiés par terre, et par les bateaux à vapeur qui desservent les postes établis sur les bords du fleuve, ainsi que nos établissements de la côte occidentale d'Afrique.

Jusqu'à $7 \mathrm{gr} .1 / 2$, la taxe est de 50 centirnes; au-dessus, elle est de 1 franc.

Les bâtiments des stations locales peuvent aussi recevoir des passagers civils. Le gouvernement fixe le prix du passage, prix généralement modéré. 


\title{
DEUXIEME PARTIE
}

\section{ÉTABLISSEMENTS FRANÇAIS DE LA COTE D'OR}

\author{
GRAND-BASSAM - ASSINIE - DABOU
}

\section{CHAPITRE PREMIER}

Résumé historique.

La côte d'Or ou d'Ivoire, où se trouvent les établissements français dont il va être parlé, est cette partie de l'Afrique occidentale que baignent les eaux du golfe de Guinée.

Elle s'étend vers le $5^{\text {e }}$ degré de latitude $N$. et le $2^{\text {e }}$ degré de longitude E. et 0 .

Voici les principaux faits historiques concernant cette partie du territoire colonial de la France.

1364. Des Dieppois établissent des comptoirs sur la côte occidentale d'Afrique, depuis l'embouchure du Sénégal jusqu'à la rivière de Sierra-Leone.

1382. Les commerçants dieppois, après avoir poussé leurs explorations jusqu'à la côte d'Or, y élèvent le fort de la Mine. De tous les établissements fondés par eux, il ne restait plus à la fin, du seizième siècle, que ceux du Sénégal.

1700. Pour relever le commerce de la côte d'Or, la Compagnie d'Afrique fonde un comptoir à l'entrée de la rivière d'Assinie.

1707. Abandon de ce comptoir.

1797. Le fort élevé à Whydal (côte des Esclaves) vers 1707, est abandonné.

1838. Expédition de la Malouine, commandée par le lieutenant de vaisseau, E. Bouet-Willaumez. A la suite de cette exploration, on décide la création des établissements d'Assinie, du GrandBassam et du Gabon. 
1842. Traités conclus entre les rois indigènes et le capitaine ce corvette E. Bouet-Willaumez; par ces traités, la souveraineté de ces contrées est cédée à la France.

1813. Expédition d'Assinie. Nouveau traité conclu avec Amatifoux, neveu et gendre d'Attacla, roi d'Assinie. La presqu'île où l'établissement est fondé nous est concédée en toute propriété; le pays d'Assinie est, en outre, mis en totalité sous notre protection.

Expédition du Grand-Bassam. Prise de possession.le 28 septembre 1843.

1849. Rébellion des populations de la province d'Aker (entre la rive gauche de la rivière de Grand-Bassam et la rive droite de celle d'Assinie). Le capitaine de vaisseau Bouet-Wiliaumez, contraint à sévir, incendie leur village principal, Yahou, et les oblige à indemniser nos commerçants.

1852. Expédition du capitaine d'infanterie de marine, M. Martin des Pallières, contre les gens de l'Ébrié. Le pavillon français flotte sur tous les villages bordant la lagune et la mer, entre Petit-Bassam et la rivière de Lahou; sa suzeraineté est reconnue. Piter, roi du village du Grand-Bassam, qui avait aidé la révolte, est retenu en otage.

180ั3. Les révoltés de l'Ébrié entraînent ies gens de l'Akba, du Potou, du Dabou el du Bouboury. Amatifoux, jusque là notre allié, fait cause commune avec les rebelles et veut ruincr notre comptoir d'Assinie. - Expédition commandée par le capitaine de vaisseau Baudin. - Destruction des villages d'A bata, d'Éboué et de Dabou: soumission des rebelles. Construction d'un nouveau blockhaus à Dabou (point qui commande la lagune et plusieurs villages).

Le lieutenant d'infanterie Coquet ramène par la persuasion le roi Amatifoux, et la pacification du Potou est accomplie.

"Depuis lors, la tranquillité n'a pas cessé de régner dans nos établissements de Grand-Bassam et d'Assinie. Des travaux d'assainissement ont été entrepris par le commandant Bruyas et poursuivis par ses successeurs ; des chaussées ont été ouvertes, des marais comblés. Dans le premier de ces établissements, le blockhaus a été remplacé par une habitation dite Maison modèle; un hôpilal en briques, une poudrière, ont été construits en 1850 ; l'enceinte fortifiée a été agrandie ct refaite en haie vive par le chef de division Protet, en 1837.

"A Assinie, le blockhaus, construit sur la plage, sur l'emplace- 
ment de l'ancien poste du dix.huitième siècle, a été abandonné pour la Maison modèle et les établissements élevés en face de l'autre côté de la rivière. Le pays environnant, habité par les Assiniens, a défiuitivement reconnu la suzeraineté de la France. ") (Notices, etc.)

A la place du blockhaus de Dabou, on asubstitué un établissement régulier en maçonnerie, qu'entourent des murs bastionnés et armés de quatre obusiers de $12 \mathrm{c} / \mathrm{m}$.

Commandants du Grand-Bassam.

1843-1844. Besson, enseigne de vaisseau.

1840ั-1847. Conjard, sous-lieutenant d'infanterie de marine.

1848 - Pijeon, lieutenant d'infanterie de marine.

1849-1850. Boulay, lieutenant d'infanterie de marine.

1851-1853. Martin des Pallières, lieutenant, puis capitaine d'infanterie de marine.

185:3-185\%. Chirat, capitaine d'infanterie de marine.

1855 - Mailhetard, lieutenant d'infanterie de marine, commandant les trois comptoirs.

1856 - Bruyas, capitaine d'infanterie de marine.

18 zั7 - Brossard de Corbigny, lieutenant de vaisseau.

185̃8-1860. Mailhetard, capitaine d'artillerie de marine.

1860-1862. Liebault, chef de bataillon d'artillerie de marine en retraite.

1862-1863. Alem, capitaine d'infanterie de marine.

1863 - Noyer, chef de bataillon d'infanterie de marine.

\section{Commandants d'Assinie.}

1843. Dufour de Mont-Louis, enseigne de vaisseau.

1844. Boyer, lieutenant de vaisseau.

1862. Darré, capitaine d'infanterie de marine.

1863. Viard, capitaine d'infanterie de marine.

\section{Commandants de Dabou.}

1861. Bruyas, capitaine d'infanterie de marine. 


\section{CHAPITRE II}

Le Grand-Bassam. - Assinie. - Dabou. - Saisons. - Ras de marée. Indigènes.

L'établissement français du Grand-Bassam, disent les Notices, s'élève sur une langue de sable marécageuse située par $0^{\circ} 11^{\prime} 40^{\prime \prime}$ de latitude $N$. et $6^{\circ} 3^{\prime} 4^{\prime \prime}$ de longitude 0 , à la pointe. occidentale d'entrée de la rivière Costa ou de Grand-Bassam.

La rivière a une largeur variable de 200 à 250 mèt. à son embouchure; elle est barrée par des fonds qui oscillent entre 10 et 15 pieds. La barre est dangereuse, surtout en juin, juillet, août et septembre. Des bâtiments à voiles, calant 3 mèt. à $3^{\mathrm{m}}, 50$, peuvent la franchir, mais avec précaution, en décembre et janvier.

Une fois la barre passée, la rivière devient profonde, et l'on y trouve depuis 8 mèt. jusqu'à 10 mèt. de fond ; elle s'élargit aussi considérablement et à 1 mille de son embouchure, on trouve une petite île, l'île Boët, qui la divise en deux.

Un peu au delà de cette île, une vaste lagune sans courant remonte vers le N.-N.-O. pour s'étendre ensuite à l'0. jusqu'à la rivière de Lahou. Quant à la rivière de Grand-Bassam, elle se dirige vers l'est, prend alors le nom d'Akba, et traverse le pays d'Aka qu'elle sépare du Potou et du territoire d'Alepé plus au nord, direction générale que prend l'Akba devant les villages de Yalou et d'Impérié.

Le village de Grand-Bassam se trouve en face de l'Akba, sur la rive droite de la lagune, à 2 milles environ de la barre; c'est la résidence du roi des Bassamans.

En dépassant ce village, fort étendu sur la rive, la lagune se partage en deux bras dont le principal remonte au nord et sépare le pays de Potou de celui d'Ébrié; l'autre bras va rejoindre la lagune plus à l'ouest, formant de grandes îles habitées qui dépendent de Grand-Bassam.

Le bras de Potou, ainși que la lagune et la rivière Akbajusqu'au barrage d'Alépé, est navigable d'un bout à l'autre pour des bâtiments calant au plus 8 pieds chargés. La langue de terre qui sépare la lagune de la mer est habitée par les courtiers indigènes connus sous le nom de Jack-Jacks.

Dabou se trouve à 50 milles environ à l'ouest de Grand-Bassam. 
Le poste français s'élève sur la rive septentrionale de la lagune, au fond de la baie qu'il commande, ainsi que plusieurs villages voisins.

Assinie est séparé du pays de Grand-Bassam par le pays d'Aka. Il est à 27 milles à l'est de Grand-Bassam, à 8 kilomètres de l'embouchure de la rivière d'Assinie, sorte de canal par où les lagunes d'Ahy et d'Ehy versent à la mer les eaux qu'elles reçoivent des rivières de Krinjabo (Bia) et de Tansé.

Le comptoir actuel d'Assinie s'élève sur la rive droite, à 9 milles de l'embouchure et à 1 mille du village d'Assinie. Le fort commande la rivière. - L'embouchure de l'Assinie présente une barre tournante fort dangereuse, impraticable aux bâtiments à voiles. Les avisos à vapeur de 20 à 30 chevaux ont pu seuls y pénétrer jusqu'ici.

La résidence du roi d'Assinie ou d'Amatifoux, le grand village de Krinjabo, est à $\mathbf{2 4}$ milles, sur la rive gauche de l'Assinie.

Le territoire de Grand-Bassam et d'Assinie avec ses lagunes aux eaux stagnantes est extrêmement malsain, surtout à l'intérieur. Nos postes, rapprochés de la mer, dont ils reçoivent les brises, subissent moins l'influence funeste de cet état de choses.

La marée a lieu à 4 heures 20 minutes. Elle se fait sentir peu régulièrement, et à 2 ou 3 milles de terre.

On compte deux saisons pluvieuses. La première se prolonge de la fin d'octobre aux premiers jours de décembre; c'est la saison des tièvres. La seconde commence à la fin de mars et dure jusqu'à la fin de juin; c'est l'époque des tornades et des ras de marée. La belle saison règne du milieu de décembre à la mi-mars. A l'ombre, on a 30 à $32^{\circ}$ centigrades, et au soleil $66^{\circ}$. - De juillet à octobre, la température descend à $25^{\circ}$. Des pluies fines et rares distinguent cette saison.

Les indigènes de Grand-Bassam et d'Assinie, peu nombreux, -ont le teint généralement noir, parfois cuivré comme les Peuls du Sénégal; leurs traits grossiers, leur nez épaté, sont rachetés par leur taille qui est grande et bien prise, par leur peau qui est fine, mais ils seraient rendus plus disgracieux encore, s'il était possible, par la manière dont ils se tressent les cheveux en carrés ou en losanges. Astucieux, pillards, paresseux, féroces jusqu'à l'anthropophagie, dont notre contact les a pourtant à peu près corrigés, ils vivent de pêche, de larcins, d'ignames et de manioc.

Ils sont fétichistes. Dans leurs cases, se trouve un réduit où 
trône le monstre fantastique, en bois peint et grossièrement sculpté, sous la protection duquel est placée la famille. Ce culte leur suffit; ils sont, paraît-il, réfractaires à tout autre.

\section{CHAPITRE III}

Agriculture. - Huile de palme. - Or. - Ivoire. - Commerce. Navization intérieure. - Pècheries.

Le bananier, l'oranger, l'ananas, le manioc, l'igname, le riz, le palmier, le teck, le sandal, le gonalhier, le coton, l'indigofère, etc.; tels sont les principaux régétaux de Grand-Bassam, d'Assinie et de Dabou.

L'agriculture, néanmoins, est fort loin d'être dans un état florissant. La paresse des indigènes en est la principale cause.

Les rivières des rives du lac Appolonie (à l'est du lac d'Ahy), produisent un riz superbe et d'une blancheur remarquable. On plante en février et mars; on récolte en octobre. Les ignames, plantées en même temps que le riz, se récoltent en juillet et août.

Le palmier fournit l'huile de palme, objet principal du commerce de ces contrées. Les régimes (grappes de fruits du palmier) se récoltent de la mi-février à la mi-mai; c'est la meilleure et la plus importante récolte. Une seconde, plus faible, a lieu en novembre.

Les femmes des tribus de l'intérieur préparent celte huile et l'apportent aux marchés des villages de la lagune. C'est là que viennent l'acheter les riverains de l'Océan, sorte de courtiers connus sous le nom de Jack-Jacks.

La plupart de ces riverains négligent le travail de la terre. Ils s'approvisionnent des choses indispensables à Agra, à Potou et dans la lagune. Le palmier, sur la rive opposée, vient sans culture. Le coton, complétement dédaigné par les indigènes, y vient à peu près de même.

La poudre d'or, l'ivoire et. l'huile de palme sont les principaux articles commerciaux des comptoirs de la côte d'Or.

La poudre d'or de ces comptoirs, d'après les Notices, est la plus pure de la côte; elle vaut 45 francs l'once en marchandises (valeur de France); l'ivoire est beau aussi, mais peu abondant; l'huile est 
d'une qualité supérieure; sa valeur moyenne en marchandises (valeur de France) est de 350 francs le tonneau sur place.

Les marchandises les plus propres au commerce d'échange sont : le tabac, l'eau-de-vie, les étoffes et mouchoirs de coton, les verroteries, le corail, la poudre et les armes de traite.

Tout le commerce est entre les mains des Jack-Jacks, qui vont chercher à vil prix, dans leurs pirogues, au delà des lagunes (d'Ébrié et de Potou), les produits qu'ils revendent aux bâtiments européens, échelonnés sur la côte devant les brisants de leurs riches et populeux rivages. On estime à 6 ou 8,000 tonneaux d'huile et à quelques centaines de livres d'or les quantités qui se traitent annuellement par l'intermédiaire des Jack-Jacks.

Le commerce et la navigation intérieurs de nos comptoirs sont réservés à la France.

La navigation et le commerce extérieurs, sauf le cas fort rare de blocus pour cause de guerre, sont entièrement libres devant les villages des courtiers.

En général, les bâtiments troqueurs descendent la côte de l'ouest à l'est, confient aux chefs des villages riverains une partie d'étoffes et d'objets de traite, nouent leurs affaires, et ne reviennent que plusieurs mois après, à une époque convenue, recueillir l'huile qui doit leur être livrée en échange des marchandises déposées.

Les courtier's se montrent ordinairement très-fidèles à leurs engagements. La traite de l'or se fait au comptant. Dans l'intérieur des lagunes les factoreries traitent directement sur des bateaux de 50 à 100 tonneaux. Leurs agents s'établissent souvent dans les villages producteurs en concurrence avec les Jacks Jacks et font descendre leurs produits aux comptoirs, où les navires long-courriers d'Europe viennent charger tonte l'année.

Grand-Bassam possède un grand nombre de pêcheries visitées par une centaine de pirogues que les naturels manœurrent avec la plus grande habileté.

La pirogue du roi, ornée de sculptures, d'une seule pièce, ne mesure pas moins de 20 mètres de long sur 2 de large et $1^{\mathrm{m}}, 50$ de creux; clle porte 200 hommes, dont 100 guerriers et 100 rameurs. Celle d'Amatifoux, roi d'Assinie, est encore plus remarquable. 


\section{GHAPITRE IV}

Administration. - Personnel administratif et judiciaire. - Service des ports.

- Forces militaires.

Autorité supérieure.

Le commandant de la division navale des côtes occidentales d'Afrique.

\section{Personnel administratif et militaire.}

Trois commandants (un pour chaque établissement), nommés par l'Empereur et relevant directement du chef de la division navale.

Trois lieutenants de vaisseau commandant la marine ;

Trois chirurgiens de marine à terre;

Un chirurgien de marine embarqué;

Un lieutenant commandant les troupes ;

Un garde du génie;

Un aide commissaire de marine chargé du service administratif, officier de l'état civil et curateur aux biens vacants;

Un interprète;

Un garde-magasin;

Un agent de police.

Trois pilotes;

Service des ports.

Deux chefs piroguiers;

Huit piroguiers sénégalais ;

Deux chefs kroumen ou kroumanes (hommes de la côte de Krou).

Quarante Kroumen canotiers.

\section{Forces militaires.}

Elles se composent de détachements d'artillerie de marine et de tirailleurs sénégalais.

Grand-Bassam : 2 artilleurs; 48 tirailleurs, dont 1 officier.

Assinie : 1 artilleur; 16 tirailleurs, dont 1 officier.

Dabou : 2 artilleurs; 64 tirailleurs, dont 1 officier.

Le service local des trois établissements est fait par un aviso à yapeur.

On emploie comme dépôt flottant une chaloupe canonnière à hélice hors de service à Grand-Bassam. 


\section{TROISIEMME PARTIE}

\section{GABON}

\section{GHAPITRE PREMIER}

Résumé historique.

Le Gabon, que les indigènes nomment M'Pongo, est un bras de mer ou estuaire pénétrant à 25 milles dans les terres, sur la côte occidentale d'Afrique, par $0^{\circ} 30^{\prime}$ de latitude $N$. et par $7^{\circ}$ de longitude $\mathrm{E}$.

Voici les principaux événements se rattachant à notre établissement sur les rives du Gabon.

1842. Traité du 18 mars, par lequel le chef Louis cède à la France une partie de son territoire sur la rive droite du Gabon. Antérieurement un traité avait été conclu avec le roi Denis, le chef le plus influent de la rive gauche; mais la position assurée $^{-}$ par le nouveau traité est plus avantageuse.

1843. L'expédition partie de Gorée le 16 mai arrive à l'entrée du Gabon le 18 juin.

1844. Nouveaux traités avec les chefs les plus importants des deux rives du Gabon. Ces traités nous assurent la souveraineté sur toutes les terres, îles et presqu'îles baignées par le Gabon et ses affluents.

1849. Fondation du village de Libreville, sur le plateau où étaient les magasins de la station. Pour le peupler, on fait appel aux esclaves enlevés à un négrier et rendus à la liberté. - Exploration des rivières voisines; les droits de souveraineté de la France reconnus par les populations indigènes.

1854. Les établissements de la côte d'Or et du Gabon qui, depuis 1843, dépendaient du gouvernement du Sénégal, sont placés sous l'autorité supérieure du commandant de la division navale des côtes occidentales. 
1862. Traité avec le roi et les principaux chefs du cap Lopez et de la rivière Nazaré. En vertu de ce traité, la souveraineté de la France s'étend, au nord, depuis la pointe Liancé, qui limite le sud des Etats du roi Denis, jusqu'au cap Lopez, au sud.

Etablissement d'un poste à l'embouchure de la rivière Mondah.

\section{Commandants du Gabon.}

1843. Guillemin, capitaine d'infanterie de marine.

1843. De Voisins, enseigne de vaisseau.

1844. Millet, enseigne de vaisseau.

1845. Brisset, lieutenant d'infanterie de marine.

1848. Sourdeau, sous-lieutenant d’infanterie de marine.

1849. Desperles, enseigne de vaisseau.

1849. Deschanel, capitaine d'infanterie de marine.

18ว0. Martin, capitaine d'infanterie de marine.

1852. Vignon, $i d$.

1853-1857. Guillet, id.

18ว6-1859. Vignon, id.

1859. Mailhetard, capitaine d'artillerie de marine.

1860. Pradier, capitaine de frégate.

\section{CHAPITRE II}

Le Gabon. - Situation de notre établissement. - Géologie. - Forêts. - Rivières. - La rivière Como. - L'ìle de Ningué-Ningué. - L'Ogo-Wain-Caps. Température. - Vents. - Marée. - Ras de marée. - Villages de la rive droite et de la rive gauche. - Indigènes : Gabonnais, Bouloux, Bakalais, Pahouins.

"Vis-à-vis de notre établissement, situé sur la rive droite, le Gabon a une largeur de 7 milles; un peu plus loin, il s'élargit et se termine en un vaste bassin, au milieu duquel on distingue quelques îles de moyenne grandeur, dont les principales sont l'île Coniquet, la seule habitée et surmontée d'une hauteur qui sert à se diriger dans les passes d'entrée, et l'île marécageuse des Perroquets.

" Sur la rive droite, au second plan, les monts Bouet et Baudin dominent les nombreuses collines qui se dirigent en pente douce des bords du rivage vers l'intérieur.

"Notre établissement est situé à 12 milles de l'embouchure 
du Gabon; son élévation est de 40 mètres au-dessus du niveau de la mer. Il comprend :

" $1^{\circ}$ Deux pavillons en maçonnerie surmontés d'un étage faisant face à la mer : l'un sert de logement au commandant, aux officiers et employés des divers services; l'autre, d'hôpital et de caserne aux troupes de la garnison.

" $2^{\circ}$ Plusieurs barracons ou planches servant de magasins et d'ateliers.

" $3^{\circ}$ Une poudrière, une batterie.

" $4^{\circ}$ Deux jardins, dont un dit d'essai, fondé par M. AubryLecomte, où l'on cultive le café, le cacao, le coton, les arbres à épices, les fruits intertropicaux et les légumes d'Europe.

" Un.parc et une étable pour le troupeau de bœufs.

"Les pavillons et les magasins sont entourés d'une palissade de 100 mètres de côté. Auprès de notre établissement s'élèvent les factoreries de nos commerçants, la maison des sœurs de la communauté de Castres, les cases du village de Libreville.

a Plusieurs villages indigènes sont disséminés sur le bord de la mer.

"Sur la rive gauche de l'estuaire, s'élève le village Denis, un des plus importants des rives du fleuve.

"Les bâtiments de la mission apostolique française où réside l'évêque, dont le coadjuteur est détaché en Sénégambie, sont construits à quelques kilomètres plus à l'ouest, près du village de Louis, sur le plateau où s'élevait le blockhaus, établi à l'époque de l'occupation en 1842 et aujourd'hui abandonné." (Notices, etc., d'après le Méinoire de M. E. Vignon, ex-commandant du Gabon.)

Le sol sur lequel sont assis nos établissements, et surtout aux environs de ceux-ci, se distingue par une fertilité rare.

Les couches inférieures, formées d'un calcaire coquillier gris à grains fins et réguliers, sont immédiatement surmontées d'une couche de terre jaune argilo-sablonneuse, laquelle, à son tour, est recouverte d'un terreau noir extrêmement abondant et riche.

Le calcaire des couches inférieures peut être converti en chaux, mais après une cuisson d'un mois.

Dans la couche de terre jaune, on trouve des pierres ferrugineuses faciles à tailler et qu'on pourrait employer à bâtir. Les indigènes se servent de cette terre pour former le sol de leurs maisons; à l'aide de l'eau et du damage, on lụi donne une solidité très-grande. 
De nombreuses forêts s'étendent depuis le littoral jusque fort avant dans l'intérieur. Parmi les principales essences dont elles se composent, on doit noter le teck, propre aux constructions navales, l'ébénier, l'oucoumé (sorte de bursera semblable à l'acajou femelle); l'oingo, bois de teinture rouge, le mandgi, beau bois d'ébénisterie, etc. A l'Exposition d'agriculture de $\mathbf{1 8 6 0 ,}$ toutes ces essences ont été fort appréciées. D'autres, en grand nombre, produisent des graines ou amandes oléagineuses.

Entre les rivières qui sillonnent le Gabon, on doit mettre en première ligne celle qui porte ce nom.

Le Gabon est moins un fleuve qu'un magnifique estuaire pouvant offrir un abri sûr à une flotte considérable. Il se trouve naturellement divisé en deux bassins, auxquels on a donné le nom de bassin extérieur et de bassin intérieur.

La longueur de l'estuaire est de 25 milles, et sa largeur moyenne de 8 à 10 milles. La profondeur de l'eau, dans le premier bassin, varie de 8 à 25 mètres, et celle du second, de 5 à 8 mètres. Malheureusement la navigation dans le bassin extérieur et dans les passes qui y conduisent exige la plus grande prudence, à cause des nombreux pâtés de roches à fleur d'eau qui s'élèvent brusquement sur des fonds unis où rien n'annonce leur voisinage.

L'estuaire du Gabon reçoit plusieurs cours d'eau, dont les principaux sont : les rivières Como et Rhamboé.

La rivière Como débouche dans l'estuaire, à une extrémité; elle le continue. Sa source est dans les montagnes de Cristal, non loin des rivières de Bénito, d'Anger, de Mondah, et sur le versant opposé de celle du cap Lopez.

Tous ces cours d'eau s'éloignent de leurs sources en configurant par leur trajet une surface triangulaire dont les montagnes de Cristal forment le sommet, la rivière Bénito le côté nord, celle du cap Lopez le côté sud, en tournant le pâté de montagnes par l'est en arête, enfin la rivière Como à peu près le milieu de la base.

Cette dernière, assez large à son embouchure, ne tarde pas à se rétrécir. Cinquante milles plus loin, elle ne présente plus que 7 à 800 mètres. En cet endroit, elle opère sa jonction avec la rivière Bogoé, son principal affluent, un peu avant d'arriver à un bâtiment de l'Etat qui mouille là et sert d'avant-poste aux commerçants fréquentant la rivière. 
La navigation, facile dans la plus grande partie de ce parcours, n'offre de difficultés réelles que vers les approches du stationnaire où des bancs de sable et de roches forment un chenal assez étroit. Au-dessus de ce point, la rivière n'est plus navigable qu'aux côtres et petites goëlettes. La marée se fait sentir jusqu'à près de 70 milles de l'embouchure, mais on trouve l'eau douce à marée basse.

On observe à l'entrée de la rivière Como quelques îles ayant plusieurs milles d'étendue. La plus importante de ces îles est celle de Ningué-Ningué, placée à l'embouchure du Bogoé, un peu au delà du mouillage du stationnaire.

Cette île sert de point de relâche aux traitants noirs qui parcourent ces rivières.

Une mission protestante américaine a fait de cette île le cheflieu de ses établissements et de son commerce. (Notices, etc.)

Les rivières Rhamboé et Mondah se jettent dans l'estuaire du Gabon, la première près de l'île Ningué-Pongoé; elle forme à son embouchure un bassin de plusieurs milles de longueur sur un mille de largeur; sa profondeur moyenne est de 5 mètres, et son parcours d'environ $\mathbf{4 0}$ milles dans le Sud-Est. La seconde communique avec l'estuaire par une de ses branches, la rivière Cohit; elle a son embouchure dans la baie de Corisco.

L'Ogo-Wai, ou rivière du cap Lopez, se rend à la mer par plusieurs embouchures, au-dessus et au-dessous du cap, à 60 milles environ au sud du Gabon. Cette grande artère, l'une des principales de l'Afrique occidentale, est formée à une soixantaine de lieues de son embouchure par deux rivières considérables, l'Okanda et le N'Gouniay, et reçoit les eaux du lac Ionanga. Dans tout son parcours, il a une largeur moyenne de 2,500 mètres. A marée haute, son eau reste constamment douce.

Les caps à mentionner sont les suivants : le cap Esteiras, à 8 milles au nord de l'entrée de l'estuaire du Gabon, prolongé dans le nord-ouest par des récifs, et où la mission française a un établissement d'instruction primaire; le cap Santa-Clara, pointe nord de l'embouchure du Gabon, qui a 20 mètres de hauteur; la pointe Pongara qui forme l'extrémité sud de l'estuaire; le cap Lopez, à l'extrémité sud de l'île Lopez, à 70 milles au sud du Gabon, à 25 milles de l'embouchure de la rivière Nazaré (une branche de l'Ogo-Wai), où les navigateurs trouvent un abri excellent contre les vents régnant du S.-0. et la houle. 
On a, au Gabon, huit mois de pluie (de janvier à la mi-mai), et quatre mois de saison sèche (de la mi-mai à la mi-septembre).

La température n'èst pas extrême. A l'ombre, on a rarement au delà de $32^{\circ}$. La chaleur est modérée par des nuages qui interceptent les rayons solaires.

Les vents du large varient du N.-0. au S.-S.-0. Pendant la nuit, des brises de terre soufflent du S.-E. à l'E.

Devant le poste, la marée se fait à $5^{\mathrm{h}}, 30^{\mathrm{m}}$. La mer, dans les petites marées, marne de $\mathbf{1}^{\mathrm{m}}, 6$, et, dans les grandes, de $2^{\mathrm{m}}, \mathbf{1}$.

"Les rảs de marée ont lieu principalement lors de la saison des pluies, mais ne sont pas dangereux sur la rade. Une digue en grosses pierres sèches, mais construite avec soin; forme un abri qui protége efficacement les communications de la rade avec le comptoir. Les marées produisent un courant violent qui rend très-pénible le va-et-vient des embarcations. Les grands bâtiments ne peuvent pas mouiller prudemment à moins d'un mille de terre. Les avisos se rapprochent à 500 ou 600 mètres en recherchant avec soin, pour jeter l'ancre, les lits de vase qui séparent les plateaux rocheux embarrassant le monillage devant Libreville. " (Notices, etc.)

Le nombre des Gabonnais, habitant les villages les plus voisins de notre établissement, peut être évalué à 3,000 , esclaves non compris.

Sur la rive droite de l'estuaire, on rencontre les villages suivants :

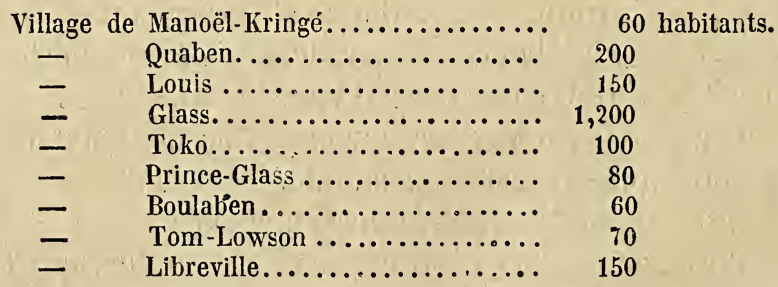

Sur la rive gauche :

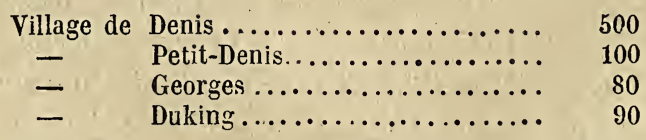

Dans l'île Coniquet, le village français a 100 habitants.

Les Gabonnais ou M'Pongoé, les Bouloux, les Bakalais, les Fans ou Pahouins, tous appartenant à la race nègre, mais aux traits 
plus réguliers, moins disgracieux, à la peau moins foncée, sont les peuplades principales du Gabon et de ses affluents.

"Les Gabonnais servent de courtiers entre les populations de l'intérieur et les capitaines du commerce dont ils reçoivent par avance les marchandises à échanger contre les produits du pays.

"Les Bouloux habitent les premiers villages que l'on rencontre en remontant la rivière Como. Cette peuplade, autrefois toutepuissante, ne possède plus aujourd'hui qu'un petit nombre de villages disséminés sur les deux rives. Elle compte tout au plus 3,000 âmes. Seuls courtiers pendant longtemps des Gabonnais les Bouloux étaient seuls en relation avec les Sauvages de l'intérieur qu'ils tinrent longtemps en échec, mais qui commencent à se rapprocher de nous.

"Les Bakalais ou Akalais, que l'on trouve après les Bouloux, en remontant la rivière Como, appartiennent à une nation comptant environ 60,000 âmes, qui s'étend depuis lès rives de l'OgoWai jusqu'à celles des rivières Bogoé et Como. Cette peuplade, qui sert d'intermédiaire entre les Pahouins et les Bouloux, tend, comme ces derniers, à disparaître devant l'invasion des premiers, de l'est à l'ouest.

«Les Pahouins forment la peuplade la plus nombreuse de ce pays ; leur nombre peut être évalué à 120,000 âmes environ. Ils sont moins noirs que leurs voisins les Bakalais et les Bouloux. G'est un peuple brave, éminemment guerrier et chasseur. Descendus des montagnes de Cristal, ils se sont établis depuis plusieurs années dans le haut de la rivière Como et tendent constamment à se rapprocher du littoral, en exterminant les peuplades qu'ils rencontrent sur leur passage et qui leur ont servi jusqu'à présent d'intermédiaires. Ce sont eux qui poursuivent l'éléphant et qui nous font parvenir, par les Bakalais, les Bouloux et les Gabonnais, l'ivoire que leur fournissent leurs chasses. Ils préparent aussi le caoutchouc, la cire, les billes de bois d'ébène et savent. travailler le fer qui abonde dans leurs montagnes. - Les Pahouins commencent à venir dans notre établissement, à bord de nos navires et dans nos factoreries..." (Notices.)

Ces différentes peuplades ont chacune une langue différente; mais le français, l'anglais, l'espagnol, sont familiers aux Gabonnais, les premiers courtiers de la rivière. 


\section{GHAPITRE III}

Administration. - Forces militaires et maritimes. - Instruction publique.

- Cultes. - Justice.

Un décret du 26 février 1859 a rattaché Gorée à la colonie du Sénégal. Un autre décret, en date du $1^{\text {er }}$ novembre 1854 , avait antérieurement distrait les établissements de la côte d'Or et du Gabon, du gouvernement sénégalais.

Actuellement, chacun de ces établissements est placé sous la direction d'un commandant nommé par l'Empereur, mais qui relève du commandant de la division navale des côtes occidentales d'Afrique.

Le centre administratif des établissements de Grand-Bassam, d'Assinie, de Dabou et du Gabon, est au Gabon.

Service administratif.

Un commissaire-adjoinl de la marine, ordonnateur.

Un agent du commissariat, contrôleur.

Service judiciaire.

Un magistrat chargé du ministère public.

Service des ponts et chaussées.

Un capitaine du génie, directeur des travaux.

Un commissaire ;

Service de la police.

Trois agents.

Service des fonds.

Un trésorier payeur.

Service de santè.

Trois chirurgiens de la marine impériale;

Quatre infirmiers.

Service du port.

Quatre chefs kroumanes ;

Quatre Kroumanes canotiers. 


\section{Forces militaires.}

$1^{\circ}$ Etablissements de la côte d'Or.

133 hommes.

$2^{\circ}$ Etablissement du Gabon.

Un capitaine du génie;

Un garde d'artillerie et trois artilleurs de la marine;

Un capitaine, un lieutenant ou sous-lieutenant et 62 sous-officiers ou soldats du bataillon de tirailleurs sénégalais ;

Trois chirurgiens de marine.

Forces maritimes.

En 1863, la division navale des côtes occidentales d'Afrique, ayant pour centre le Gabon, était commandée par un contreamiral.

Elle se composait de neuf bâtiments représentant une force de 1,020 chevaux, portant 50 canons et montés par 853 hommes.

L'état-major comprenait :

1 contre-amiral;

3 capitaines de frégate;

23 lieutenants ou enseignes de vaisseau;

10 chirurgiens ;

6 officiers d'administration;

13 élèves ou volontaires.

\section{Instruction publique.}

Deux écoles ont été établies par la mission catholique au Gabon.

Quarante enfants des deux sexes y sont entretenus aux frais du budget local. En outre, 60 garçons et 40 filles y reçoivent gratuitement la nourriture, l'instruction religieuse, l'instruction élémentaire, professionnelle ou agricole. - Les missionnaires, pour engager les parents à leur envoyer leurs enfants, donnent tous les deux mois à chacun de ceux-ci une pièce d'étoffe valant 4 ou 5 francs. Au village de Libreville, dont la plupart des habitants sont chrétiens, cet appât n'est pas nécessaire.

\section{Culte.}

La religion des Gabonnais, celle des habitants de l'intérieur n'est autre que le fétichisme. 
Une mission catholique, établie au Gabon en 1844, a obtenu des succès assez notables et pris des développements marqués.

Personnel religieux : 1 évêque, chef de la mission des deux Guinées et de la Sénégambie, résidant au Gabon; 4 prêtres; 4 frères convers; 6 sœurs de la communauté de Castres (l'une d'elles est attachée à l'hôpital).

La mission se livre à la propagation de la foi, à l'instruction de la jeunesse, à l'agriculture.

Une mission protestante américaine s'est aussi établie au Gabon. Elle occupe les hauteurs du village de Glass, à 4 kilomètres de l'établissement français.

\section{Justice.}

Ce sont les tribunaux du Sénégal qui connaissent des affaires civiles, commerciales, criminelles, militaires et maritimes des établissements de la côte d'Or et du Gabon.

Une Commission, instituée par le gouverneur du Sénégal pour chaque établissement, est chargée de régler à l'amiable les différends entre les négociants ou capitaines de navires du commerce et les traitants ou courtiers indigènes.

Elle est composée du commandant de l'établissement, président; du chef du service administratif; d'un commerçant européen, et de deux chefs indigènes.

Deux tribunaux de première instance doivent être prochainement créés, l'un à Grand-Bassam, l'autre au Gabon. L'état de choses actuel offre des inconvénients trop graves pour durer longtemps encore.

\section{CHAPITRE IV}

Agriculture. - Jardin d'essai fondé par M. Aubry-Lecomte. - Bœufs. - Chevaux. - Moutons. - Cabris. - Volaille. - Cire. - Graines oléagineuses. Ivoire. - Bois d'ébène. - Exportation et importation. - Ohjets d'échange. Liberté commerciale. - Mouvement de la navigation à l'entrée.

L'agriculture, très-négligée par les Gabonnais, pouvait facilement prospérer sur le sol de la colonie.

Ces peuples ne cultivent que les produits indispensables à leur nourriture.

Les plantations ont lieu en septembre, disent les Notices pu- 
bliées par ordre du ministre de la marine et des colonies, c'està-dire au commencement des pluies. Elles consistent en patates douces, bananiers, arachides, manioc, maïs et ignames.

La canne à sucre n'est cultivée que comme un objet de luxe, une friandise pour les hommes et les enfants.

En 1850,' un jardin d'essai, fondé par M. Aubry-Lecomte, a prouvé que la plupart des légumes d'Europe pouvaient venir au Gabon. Les expériences tentées dans ce jardin, celles qu'ont tentées dans les leurs les missions française et américaine sur le café, le cacao, le coton, ont été décisives. Malheureusement, il n'a pas encore été possible d'amener les Gabonnais à cultiver ces produits.

Les indigènes n'ont pas de troupeaux de bœufs. Le roi Denis seul en a un; mais il le considère bien plus comme un objet de luxe que comme un objet de spéculation.

Les troupeaux de bœufs du Comptoir et des deux Missions, qui ne comprennent que des sujets nés dans le pays, sont fort beaux. Les bœufs de provenance étrangère vivent difficilement au Gabon.

On peut aussi élever des chevaux, mais ils exigent beaucoup plus de soins que les bœufs.

Les Bouloux et les Bakalais, populations de l'intérieur, possèdent quelques moutons et cabris d'assez bonne qualité, qu'ils vendent aux Européens à des prix modérés.

La volaille est commune; les porcs s'élèvent facilement, mais on en restreint le nombre, à cause des dégâts qu'ils commettent dans les plantations.

La cire qu'on récolte au cap Lopez est de bonne qualité.

Les graines oléagineuses du Gabon donnent une huile analogue à l'huile d'olive; notamment le djavé, le noungou, le dika, l'owal, l'élozy-zégué, les noix de palme, de m'poga et de coula.

Le commerce se fait par l'intermédiaire des capitaines français, anglais, américains et portugais. Les produits qu'ils y traitent, par l'intermédiaire des courtiers indigènes, en échange de leurs marchandises et même quelquefois contre des espèces, sont: l'ivoire (n’pugni), le bois d'ébène (ebila), le sandal (oingo), la gomme copal, le caoutchouc, la cire.

L'ivoire vaut de $1 \mathrm{fr}$. 50 à $20 \mathrm{fr}$. le kilogramme suivant sa grosseur. On sait que l'ivoire du Gabon est le plus beau qui existe; 
c'est surtout dans le haut de la rivière Como que se trouvent les plus beaux spécimens.

Les bois d'ébène coûtent de 15 à 18 francs le tonneau; le sandal, de 15 à 18 francs aussi (chaque bûche doit peser 10 kilogrammes; au-dessous de ce poids, on en peut exiger deux pour une); la cire coûte 2 francs le kilogramme; la gomme copal, ven-

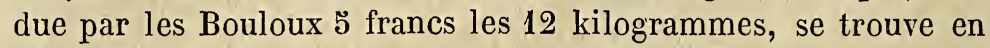
abondance à Cama et au cap Lopez; le caoutchouc, commun dans les rivières Mondel et Danger, se vend, suivant qualité, de 1 à 3 francs.

Il est indispensable que tout capitaine, voulant commercer avec le Gabon, ait un assortiment des marchandises que recherchent le plus les indigènes.

Voici, d'après les Notices de la marine, la nomenclature des objets nécessaires à la traite, avec les prix du pays en regard :

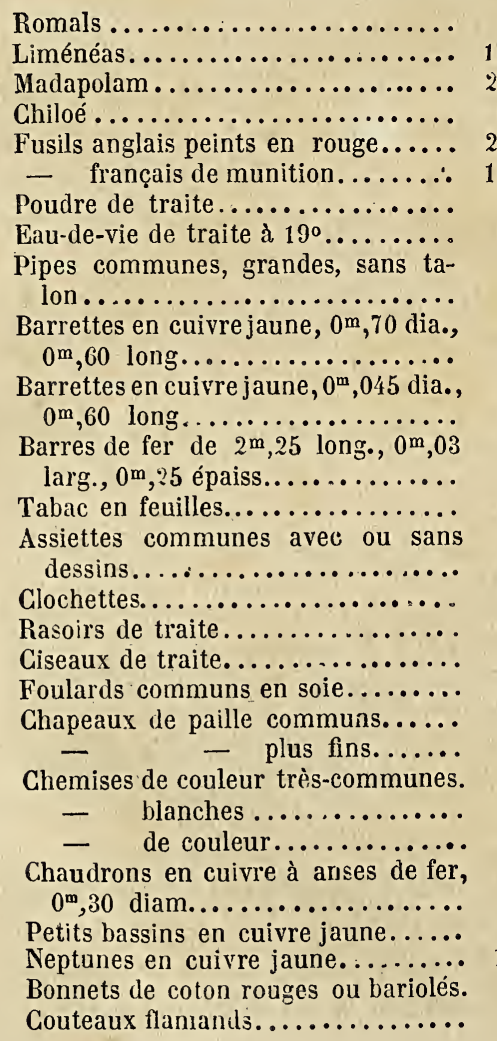

1 fr. "c. la brasse.

15 " la pièce de 9 brasses.

20 \ la pièce de 12 brasses.

5 la pièce de 3 brasses.

20 l'un.

15 D

1 " la livre.

175 le litre.

1 \ les six.

1 n l'une.

la tête de 3 feuilles.

50

50

l'une.

l'un.

50 la paire.

1) l'un.

50) -

50 l'ụne.

5

l'un. 
Coffres en bois blanc léger, planches minces, serrures très-communes, de $0^{\mathrm{m}}, 72$ long., $0^{\mathrm{m}}, 34$ haut., trèsimportants pour la traite; peuvent s'apporter démontés.............

Cuvettes et pot à eau.............

Perles blanches, moyennes mates...

Masses de petites perles mates blanches, roses, bleu clair, rouge-sang, jaune clair .................

Masses de perles rouges moyennes. .

Caisses de vin rouge or dinaire.... 15

Bouteilles de vin blanc.......... 2

- d'anisette commune..... 2

- d'huile d'olive......... 3

- de gin, petites carrées...

Papier peint, de 3 brasses et demi à 4 brasses...................

Casquettes très-communes.........

Gilets de tricot en coton blanc..... - de coton à ramages........ 15

Petits miroirs avec cadres en bois...

Bonnet basque noir commun.......

Chandelles de suif, petites.........

Dames-jeanne de dix litres....... 5

Barbançons en grès............. 1

Verres à boire................,

- de traite............... "

Bols en faïence............... ,

Malles communes grandes........ 15

- - petites.......... 10

Marmites en fonte................

Petites haches.................

Sabres dits manchettes..........

Cadenas de moyenne grandeur.....

Cravates en soie noire, communes..

Parapluies en soie, communs.......

- en coton............ 10

Savon de Marseille..............

5 fr. "c. l'un.

350 les deux.

1 " la livre.

$\begin{array}{llc}1 & \text { " } & \text { la masse. } \\ 1 & \prime \prime & - \\ 5 & \text { "'une. } \\ 2 & \prime \prime & - \\ 2 & 50 & - \\ 3 & 50 & - \\ 5 & \text { " }\end{array}$

\begin{tabular}{|c|c|c|}
\hline 3 & n & le rouleau \\
\hline 2 & 50 & l'une. \\
\hline & ” & l'un. \\
\hline & " & - \\
\hline & $n$ & - \\
\hline & $"$ & - \\
\hline & 25 & l'une. \\
\hline & $"$ & - \\
\hline & 50 & l'un. \\
\hline & 50 & - \\
\hline & 50 & - \\
\hline & 50 & - \\
\hline & $n$ & l'une. \\
\hline & $"$ & - \\
\hline & $n$ & - \\
\hline & $n$ & - \\
\hline & 50 & l'un. \\
\hline & " & - \\
\hline & $"$ & l'une. \\
\hline & $"$ & l'un. \\
\hline & ") & - \\
\hline & 50 & la livre. \\
\hline
\end{tabular}

Boucles d'oreilles de forme tubulaire et creuses en cuivre doré, ayant les dimensions suivantes :

Diam. ext., 48 mil.; diam. int., 35 mil. 15

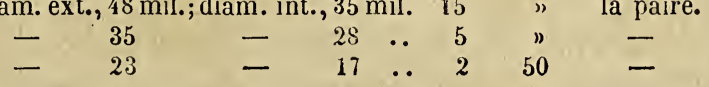

Plus, des effets confectionnés d'été communs, chaussures communes, robes de chambre, couteaux, chaises communes, paniers de bière, sardines à l'huile et parfumerie commune.

"Toutes les saisons sont bonnes pour commercer; mais quand on a à prendre une cargaison de bois rouge, il vaut mieux venir pendant la saison sèche (de mai à septembre); car, à cette époque, les chargements se font beaucoup plus vite, et les équipages res- 
tent moins exposés à l'insalubrité des rivières, dans lesquelles les navires sont tenus de se rendre pour opérer leur chargement.

"Une maison de commerce doit établir le centre de ses opérations sur l'un des points de notre concession ou près du littoral, afin d'éviter une location ou un achat de terrain aux chefs du pays.

"Indépendamment des navires destinés à alimenter la factorerie principale de marchandises d'Europe et à y transporter en retour les produits indigènes, il est indispensable d'avoir une goëlette ou un côtre pour aller dans les rivières voisines alimenter les succursales et y prendre les produits traités dans l’intervalle d'un voyage à l'autre. o (Notices, etc.)

Le commerce du Gabon jouit de la plus entière liberté.

En 1862, les importations ont atteint le chiffre de $655,551 \mathrm{fr}$., et les exportations celui de 1,624,803 francs.

Aux importations on trouve les articles suivants :

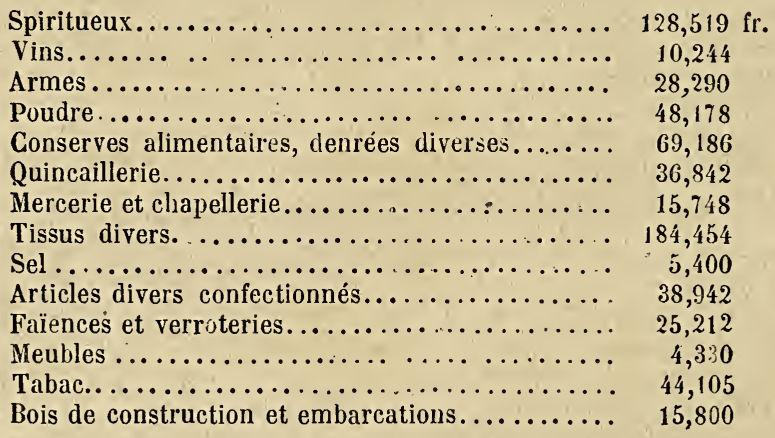

Aux exportations figurent principalement :

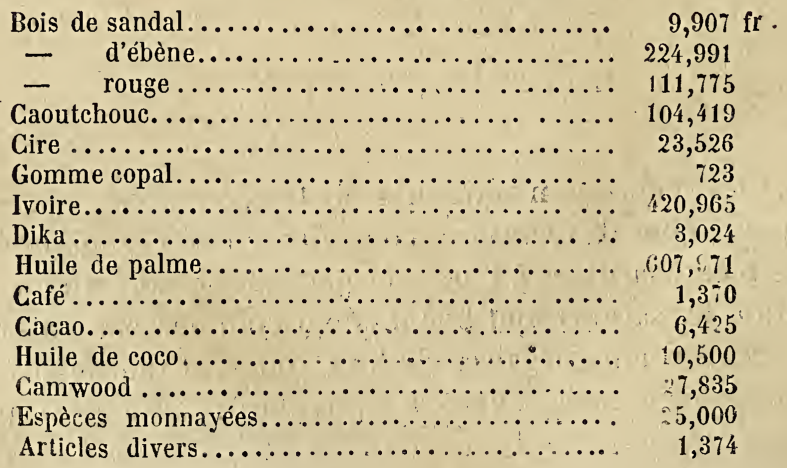


Répartition du commerce extérieur entre les diverses puissances :

\begin{tabular}{|c|c|c|c|}
\hline & & Importations. & Exportations. \\
\hline Navires & français.............. & 198,414 fr. & 330,112 fr. \\
\hline - & anglais ............. & 409,758 & $1,236,682$ \\
\hline - & américains.......... & 32,279 & 58,011 \\
\hline - & portugais ............ & 4,000 & 》" \\
\hline - & hambourgeois........ & 16,000 & w \\
\hline
\end{tabular}

Mouvement de la navigation à l'entrée :

15 navires français, de 3,788 tonneaux, et 173 hommes. 16 navires anglais, de 3,346 tonneaux et 180 hommes. 3 navires américains, jaugeant 646 tonneaux et montés par 39 hommes.

3 navires portugais, de 205 tonneaux et 34 hommes.

1 navire hambourgeois, de 230 tonneaux et 13 hommes.

Le commerce du Gabon est appelé à prendre des proportions autrement importantes.

\section{CHAPITRE V}

Situation financière. - Budget de l'État. - Budget local.

En 1863, la situation financière des établissements de la Côted'Or et du Gabon, a présenté les chiffres suivants :

\section{Budget de l'État.}

10 Personnel civil et militaire.

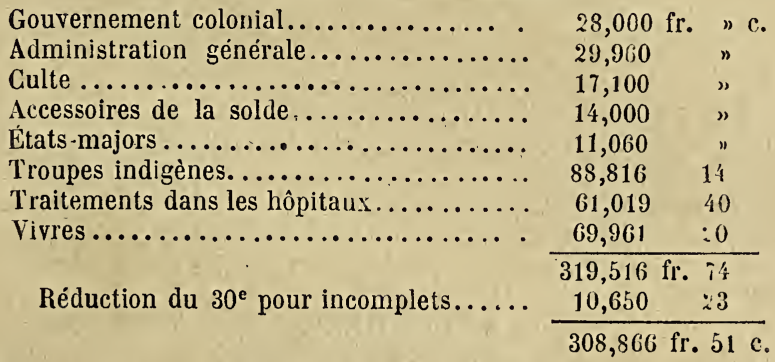

20 Matériel civil et militaire.

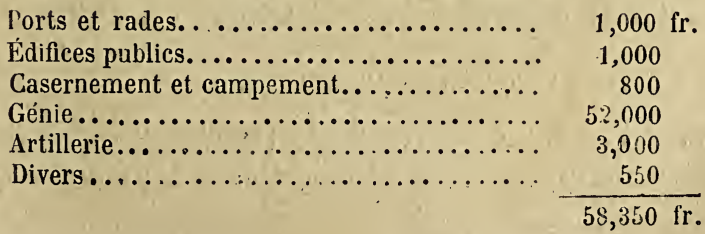


$3^{\circ}$ Subvention de l'État.

Subvention au service local............ 150,000 fr.

Les dépenses de l'Etat s'élèvent donc à 517,216 fr. 51 c., non compris celles du service marine, dont le détail n'est donné que dans les comptes définitifs.

En 1861, les dépenses de ce service se sont élevées à 459,497 fr. $09 \mathrm{c}$.

\section{Budget local.}

10 Recetles.

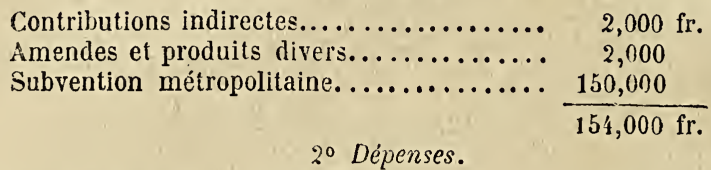

Service des ponts et chaussées......... 3,660 fr. "c.

- des ports.................. 19,895 20

- de la police................ $2,613 \quad 4$

- de l'instruction publique............ 1,200 "

Administration générale (suppléments..... 1,400 "

Agents divers................... $22,869 \quad 72$

Dépenses accessoires................ $\frac{3,000 \quad n}{55,238 \text {. }}$

Déduction du $30^{\mathrm{e}}$ pour retenues à l'hôpital

et incomplets....................

Hôpitaux...................

Vivres..$\ldots \ldots \ldots \ldots \ldots \ldots \ldots \ldots \ldots \ldots$

Travaux et approvisionnements............

Approvisionnements divers.............

Éclairage public...................

Subvention au service du culte........... - $\quad$ - de l'instruction pu-

blique........................

\begin{tabular}{cc}
$\frac{1,831}{28}$ \\
\hline 53,397 fr. & $12 \mathrm{c}$. \\
\hline 10,840 fr. & "c. \\
48,092 & 94 \\
6,500 & $"$ \\
5,200 & $"$ \\
1,000 & $"$ \\
1,000 & $\prime$
\end{tabular}

Frais de correspondance......................

$3,000 \quad$ "

$1,200 \quad$ "

1,500 "

Dépenses diverses et imprévues........ 22,300 "

Total des dépenses,....... $\overline{154,030 \mathrm{fr} .06 \mathrm{c} \text {. }}$

\section{APPENDICE.}

\section{T. Extrait du rapport de $\Pi$. Jules Duval au concours général et national d'agriculture de Paris, en 1860.}

$1^{\circ}$ Essences forestières.

Au concours d'agriculture de Paris (1860), le Sénégal a envoyé un certain nombre d'espèces forestières dont le bois paraît propre aux usages industriels. 
Le rapport présenté au jury par M. Juleș Duval signale les espèces suivantes:

Gonakié (acacia Adansonii). - Constructions navales.

Ghi-ghis (bauhinia reticulata). - Constructions à terre.

Koss (cephalanthus africanus). Menuiserie.

Vene (en yolof ou wolof), Kino (en mandingue), (pterocarpus erinaceus). - Constructions navales.

Detarr (en yolof), Membodo (en mandingue) (Detarium senegalense). - Tabletterie, menuiserie, charpente, constructions navales.

N'dimb (en yolof), D̄anta (en mandingue), sterculia cordifolia). - Constructions navales.

Solum (en yolof), Kocito (en mandingue) (dialum nitidum). Constructions navales.

Benten (en yolof), Bintaforo (en mandingue) (bombax sp.). Pirogues et madriers.

Caïlcedra (khaya senegalensis). - Constructions, menuiserie, tabletterie.

Ces bois proviennent en partie de l'établissement de Sedhiou, dans le bassin de la Casamance, où ils se trouvent en abondance. Les Portugais de Bissao en envoient tous les ans quelques chargements en Europe pour les constructions navales.

\section{$2^{\circ}$ Matières oléagineuses et savonneuses.}

Au Sénégal, l'industrie tire une huile excellente, pour l'éclairage et l'entretien des instruments d'acier, du béraf ou graine de Yombosse (cucurbita miroor).

$\mathrm{Au}$ Gabon, le dika (mangifera gabonensis) offre un extrait dont le goût est analogue au beurre de cacao. La. noix de mpôga, fournissant l'huile la plus fluide qu'on connaisse; peut servir à la confection des bougies, des savons. La noix de pentadesma est une sorte de stéarine végétale; le djavé (bassia gabonensis) est excellent aussi pour la saponification. - Au concours de 1860 , le pain de dika a été l'un des titres de l'administration du Gabon à la mention très-honorable qui lui a été accordée.

Le premier rang d'importance dans les chargements de notre commerce apppartient à l'arachide, à peine connue il y a vingt ans. La rive gauche du Sénégal, autour et en amont de SaintLouis, le Cayor et le Fouta, Dakar, Rufisque, Sainte-Marie dic Bathurst en fournissent annuellement 30 à $3 \check{5}, 000$ tonneaux. 
Le Gabon produit, comme le Sénégal, l'arachide, mais sur une échelle beaucoup moins considérable.

\section{$3^{\circ}$ Gommes.}

Les gommes sont des dons de la nature très-abondants dans leṣ climats tropicaux. La gomme du Sénégal joue un rôle trèsimportant dans l'économie commerciale de cette colonie, dans nos transports maritimes et dans les applications industrielles... $\mathrm{Au}$ Concours de 1860, on a particulièrement remarqué les gommes de l'acajou à fruits et de l'acacia lebbeck (ou bois noir); la gomme copal (guibourtia), une des richesses naturelles de la côte occidentale d'Afrique; le caoutchouc du Gabon, où il peut donner lieu àun commerce des plus considérables...

\section{$4^{\circ}$ Matières tinctoriales et tannantes.}

Pour l'indigo, une médaille d'argent a été accordée à M. Correz, an cienpharmacien militaire au Sénégal, qui avait tenté, dans ces dernières années, de préparer la matière extraite des indigotiers indigènes, d'après des procédés qui lui conservassent toute sa valeur, tandis que les préparations des natifs du pays ne procurent qu'une pâte terne et mélangée. Bien que le succès industriel n'ait pas couronné sa tentative, M. Correz n'en a pas moins établi, par des spécimens qu'il a livrés à l'analyse des juges les plus compétents, les qualités supérieures des indigos du Sénégal, et il a rendu ainsi à la colonie, à la science et peut-être à la métropole, un service que le jury a tenu à honneur de récompenser. M. Correz présentait au Concours de 1860 deux spécimens fort remarquables, dont l'un, fait avec des feuilles vertes, rappelait les meilleures qualités de Java; dont le second, tiré de feuilles sèches, se rapprochait des bonnes sortes du Bengale; tous deux contiennent 60 p. 100 d'indigotine.

Parmi les matières tinctoriales, on a encore remarqué le nebneb, le bablah (gousses tinctoriales et tannantes), le henné commun, le santal rouge qui, au Gabon, est déjà l'objet d'un commerce considérable, etc.

\section{$5^{\circ}$ Cotons.}

Au Concours d'agriculture de Paris (1860), les cotons du Sénégal n'ont obtenu que des mentions honorables; mais, dit M. Jules Duval dans son rapport, c'est parce que ces produits s'éloignaient trop des similaires de la Guadeloupe et même de la 
Guyane, pour rivaliser avec ces types supérieurs. En procédant ainsi, le jury n'a pas entendu déprécier ces types communs qui, dans les colonies de Taïti, du Sénégal et de l'Inde, et aux Antilles mêmes, trouvent leur emploi dans toutes les industries domestiques; au Sénégal et sur la côte d'Afrique, même dans l'intérieur, c'est avec les cotons spontanés ou cultivés que se fabriquent, à défaut de laine, tous les vêtements ; et dans l'Inde, ils sont la matière première des guinées, toiles de coton dont s'habillent les populations d'une grande partie de l'Afrique et de l'Asie. - "Une matière, ajoute le rapport, qui trouve de tels emplois mérite d'être tenue, quelque vulgaire qu'elle paraisse, en une certaine estime, au moins pour sa solidité et pour son bon marché. »

\section{$6^{\circ}$ Farines et fécules.}

Au Concours de 1860, on a remarqué le couscoussou des Sénégalais, farine granulée faite avec des niébés (dolichos lablab), avec le gros et le petit mil sorgho, même le maïs, comme avec le blé dans le nord de l'Afrique.

\section{$7^{\circ}$ Café.}

Au Concours de 1860, le jury a décerné une médaille d'argent à MM. Prom et Maurel, du Sénégal, pour leur café de Rio-Nuñez, espèce d'un arome pénétrant, trouvée à l'état sauvage sur le flanc méridional des montagnes Fouta-Djialon, et faisant l'objet d'un commerce de quelque importance à la côte occidentale d'Afrique.

\section{$8^{\circ}$ Graines alimentaires.}

Parmi les graines alimentaires jouant un rôle de premier ordre, il faut compter les mils de divers genres (sorghum penicellaria), qui, sous les noms de grand et de petit mil, sont la base du régime alimentaire des noirs du Sénégal et de la côte occidentale d'Afrique.

$$
9^{\circ} \text { Cire. }
$$

La cóte occidentale d'Afrique peut fournir de grandes quantités de cire très-propre aux usages industriels.

\section{$10^{\circ}$ Essences forestières du Gäbon.}

Le Gabon a envoyé au Concours d'agriculture de Paris, en 1860, différentes espèces forestières. 
Les suivantes doivent être mentionnées :

Ébène (Diospyros ebenum). - Ébénisterie.

Ceïssendet. - Construction et ébénisterie.

Évino. - Menuiserie, ébénisterie.

Intovo. - Mêmes emplois.

Llonda. - Constructions et meubles.

Oyamba. - Mêmes emplois.

Ojoli. - Id.

Ocoumé (amyris sp.). - Pirogues, ébénisterie.

Pandja. - Mêmes emplois.

Garigari. - Constructions navales.

Combo (myristica sp.). - Bois à crayons.

Ajoutons le sandal rouge et blanc, employé particulièrement pour la teinture.

\section{T. Extrait alu rapport présenté à 19 mpereur, le 4 ant 1865 ,} par la Commission de surveillance des banques coloniales.

SITUATION DE LA BANQUE DU SÉNÉGAL AU 30 JUIN 1864.

Actif.

Numéraire en caisse................... $224,153 \mathrm{fr} .54$ c.

Portefeuille... $\left\{\begin{array}{rrr}\text { Effets escomptés.... } & 173,248 & 33 \\ \text { Avances sur matières } & . & \\ \text { dor et d'argent... } & 239,721 & 37\end{array}\right\} 412,969 \quad 70$

Banque de France (comptes de remises)........... 11,593 08

Caisse des dépots et consignations.............. 152,250 "

Agence centrale........................... 2,017 18

Valeurs mobilières....................... $5,018 \quad 58$

Dépenses d'administration.................... $9,043 \quad 31$

Total de l'actif.............. $\overline{817,045 \mathrm{fr} .39 \mathrm{c} .}$

Passif.

Passif exigible. $\left\{\begin{array}{rrr}\text { Billets de la Banque } & & \\ \text { en circulation.... } & 532,600 & n \\ \text { Récép. payables à vue } & 1,459 & 71\end{array}\right\} \quad 534,059$ fr. 71 c.

Capital ................................ 230,000 "

Primes et intérêts divers......... 16,471 14

Agio de l'escompte............. $4,780 \quad 13$

Intérêts à la caisse des dépôts et con-

signations.................. 2,371 94$\}$

Fonds de réserve........................ 24,441 05

Dividendes à payer......................... $4,921 \quad 42$

Total du passif.............. 817,045 fr. $39 \mathrm{c}$.

H直. 醮posé de la situation de l'Fmpire.

Dans le Sénégal proprement dit, de Saint-Louis à Podor, la sécurité est complète pour notre commerce. 
La production du coton dans nos établissements du Sénégal est toujours l'objet de louables efforts. Le sol convient parfaitement à cette culture, et les cotons des diverses provenances réussissent également bien. Les ensemencements sont même en progrès.

(Moniteur du 2 février 1866.)

En 1864, les importations ont donné, pour le Sénégal: 7,989,563 fr.; les exportations : 6,935,273 francs.

Pour Gorée, importations : 7,437,094 fr.; exportations : 7,974, $\mathbf{4 6 1 \text { francs. }}$

Pour le Gabon, importations : 1,165,430 fr.; exportations : $1,906,048$ francs.

(Tableaux généraux du commerce de la France.)

\section{Service postal de la côte d'Or et du Gabon.}

Assinie.

1 bureau de poste. - Il a pour charge de desservir nos établissements d'Assinie, de Grand-Bassam et de Dabou.

\section{Gabon.}

1 bureau de poste. - Il ne dessert que cet établissement.

Correspondances.

Elles sont transportées de Liverpool le 24 de chaque mois.

Celles qui sont destinées aux établissements de la côte d'Or sont déposées au Cap-Coast-Castle, et de là expédiées à Assinie par la voie de Saint-Georges-d'Elmina (comptoir hollandais de la Guinée supérieure).

Celles qui sont pour le Gabon sont déposées à Fernando-Po (ile du golfe de Guinée aux Espagnols), et expédiées à notre comptoir par un bâtiment de la station locale.

\section{Tarif des lettres}

(par les paquebots-postes anglais).

Lettres affranchies de 7 grammes 1/2 . . . $0^{\mathrm{f}, 50}$

- non affr. ㄴ . . . $0^{f}, 60$

(Par les maisons de Marseille et de Bordeaux.)

Lettres affranchies de 50 grammes. . . . . $0^{\mathfrak{f}, 30}$

- non affr. _ _ ... . $0^{f}, 40$ 
Les correspondances expédiées de la colonie s'affranchissent au moyen de timbres-poste spéciaux (timbres coloniaux).

\section{W. Une station au Gabon.}

Sous ce titre, M. H. Rivière a publié dans le Moniteur du soir (26 avril 1866), un récit curieux qui permet d'apprécier la moyenne intellectuelle des indigènes du Gabon.

L'aviso à vapeur l'Espadon était, il y a deux ans, en station sur la côte d'Afrique, au Gabon. C'était un petit navire de dix chevaux commandé par un lieutenant de vaisseau et n'ayant pour tout équipage qu'un second maître et onze noirs. Ce service de station n'est pas gai. Il s'agit le plus souvent de surveiller la côte à l'embouchure d'une rivière. Or, la côte est nue et sablonneuse, et les rivières sont habitées par les fièvres et les crocodiles. Aussi les moindres incidents de la vie de bord prennent-ils une grande importance. On regarde les caïmans qui s'agitent dans les roseaux ou se traînent dans le limon du fleuve, et, si l'on est en mer, on suit de l'œil l'aileron des requins qui, par les temps calmes, sort de l'eau comme un fer de lance.

Cette existence contemplative s'écoule sans qu'on en ait conscience. On regrette le passé, on désire l'avenir. Attendre, n'est-ce point d'ailleurs le mot éternel de la vie? On s'étonne aussi, les premiers jours du moins, de ces matelots noirs, aux membres luisants, aux dents blanches, dont la vivacité d'impressions et de sensations est extrême. Ce ne sont point des hommes comme d'autres. Ils ont des superstitions robustes et naïves, avec une souplesse et une logique d'argumentation vraiment comiques.

Très-près de la nature, sous un ciel qui leur verse le feu à torrents, en face de l'Océan sans limites, entourés d'animaux bizarres, hideux ou gigantesques, de végétaux presque animés, tant la séve en est exubérante et vivace, ils ont le respect et le culte de la matière. Elle leur apparaît plus grande qu'eux, redoutable dans son immobilité ou dans ses bruits. Ils tressaillent avec elle et la sentent tressaillir dans leur sein. Ils tiennent à elle par de secrètes affinités, et si, passant dans la hiérarchie des êtres, de la matière inerte à la matière animée, ils arrêtent leur pensée enfantine sur les animaux, ils ne sont pas éloignés de se croire avec eux des liens de parenté occulte. Mais les uns leur sont amis, les autres hostiles. Aucun ne leur est indifférent. Ils ont un vague effroi du perroquet. Cette créature digne et falote qui a le plumage éclatant, 
l'œil rond et fixe, la voix humaine, leur apparaît imposante et mystérieuse. Et ils n'ont pas tort.

N'est-ce point en effet pour nous une sinistre dérision que ce don de la parole chez une bête? Voyez-vous cet animal répétant impassible le lendemain, en les scandant, les paroles arrachées la veille à notre désespoir ou à nos terreurs. Quel terrible accusateur que le perroquet d'un assassin qui s'est cru seul et s'est livré à un monologue! On ne sort de là que par un second meurtre, en tordant le cou à la bête, et encore, au dernier moment, doitelle vous regarder d'un œil horriblement dilaté. Les nègres considèrent comme des frères d'une race maudite les orangs-outangs qui les rossent à coups de branche d'arbre et se croient volontiers les cousins germains des autres singes. Ils n'ont point peur des serpents qu'ils apprivoisent avec une extrême facilité et vivent en assez bonre intelligence avec les crocodiles. Mais leur ennemi mortel est le requin. En revanche, le requin adore le nègre, pour le manger.

Or, pour en revenir à l'Espadon, on venait un matin de terminer la propreté du navire. Le pont était lavé de bout en bout, et les noirs passaient de la toilette du bâtiment à la leur. Deux d'entre eux étaient descendus dans la roue de bâbord. L'un, assis sur une des pales, laissait tremper ses pieds à la mer. L'autre nageait à deux ou trois brasses de distance. Tout à coup, un requin vint à passer, flaira le nageur, en fit le tour, ne l'attaqua point, mais, plongeant quelque peu pour se chavirer à l'aise sur le côté, happa par les jambes le noir qui était assis sur la pale. L'eau se rougit de sang, et ce fut tout. Seulement, du bord, les autres noirs avaient tout vu, et quand leur camarade, qui avait si étrangement échappé à la mort, monta sur le pont, on l'entoura et on l'examina avec une défiance extrême. Les soupçons se formulèrent et bientôt les injures les suivirent. Le capitaine sortit au bruit, et le malheureux noir, tout tremblant, se réfugia vers lui. L'officier, s'apprêtant à rendre la justice, se fit expliquer les faits.

- Vois-tu, capitaine, dit en terminant l'orateur de la troupe, li qui nageait près requin, pas avoir été mangé, cela pas naturel, li être de la famille à requin.

— Oui, s'écrièrent les autres en chœur, li être de la famille à requin.

Il fallut mettre aux fers deux ou trois des plus convaincus ou plutôt des plus démonstratifs dans leur conviction. Mais ce ma- 
tin-là, la besogne se fit mal, et la journée fut morne. Le noir, que ses camarades croyaient de la famille à requin, resta à l'index, et une sourde hostilité le menaçait. Il le savait et s'éloignait le moins possible du bord où il était à portée de la protection du capitaine. Une après-midi l'on envoya une pirogue à terre avec deux hommes. Il était désigné, mais il céda son tour. Lie remplaçant n'avait pas étẻ difficile à trouver. Aller à terre, même en service, est à la fois une distraction et un plaisir. Malheureusement la traversée ne fut pas favorable. Il y avait à franchir la barre de la rivière et, à la troisième lame, la pirogue chavira. Un requin se rencontra là encore, qui coupa le remplaçant en deux. L'autre noir fut sauvé.

Ce second incident porta à son comble l'exaspération des nègres. - C'était requin qui avait prévenu son parent de céder son tour ce joúr-là. - Ils ne se bornèrent pas aux injures, et en vinrent aux coups avant que le capitaine fût sorti de sa chambre. Le parent à requin dut etre porté à l'hôpital à terre.

Il en sortit au bout de trois semaines, et, à son retour, on lui, fit moins mauvais visage. Le capitaine, qui l'aimait, car c'était un bon matelot, avait vigoureusement sévi contre les persécuteurs; sentant toutefois que ce n'était pas assez, il voulut lui donner loccasion de se réhabiliter et le chargea de surveiller les lignes à crocs de fer que l'on tendait le long du bord pour prendre les requins. Les noirs riaient d'un petit air capable. - Jamais li prendre requin, capitaine, disaient-ils en se poussant le coude.

Mais voilà qu'un requin avale gloutonnement le morceau de lard passé dans l'hameçon et s'enferre. Parent à requin tire la corde, appelle à l'aide et l'on amène le monstre sur le pont. Aussitôt on lui passe un nœud coulant à la tête, un à la queue et l'on roidit les deux côtés. Puis on lui tranche la queue d'un coup de hache, et, avec un couteau bien affilé, on détache circulairement la tête du tronc. La tête, pleine de vie, mord et tord un balai qu'on lui met entre les dents, et le corps, tout en muscles, s'agite convulsiveme nt.

- Eh bien, dit aux noirs le capitaine triomphant en leur montrant leur camarade, direz-vous encore qu'il est de la famille à requin?

Il y eut un moment d'hésitation, mais de courte curée.

- Oh! reprirent les nègres d'un ton sentencieux et en hochant la tête, li brouillé avec sa famille. 


\section{LA RÉUNION}

\section{ET DÉPENDANCES}






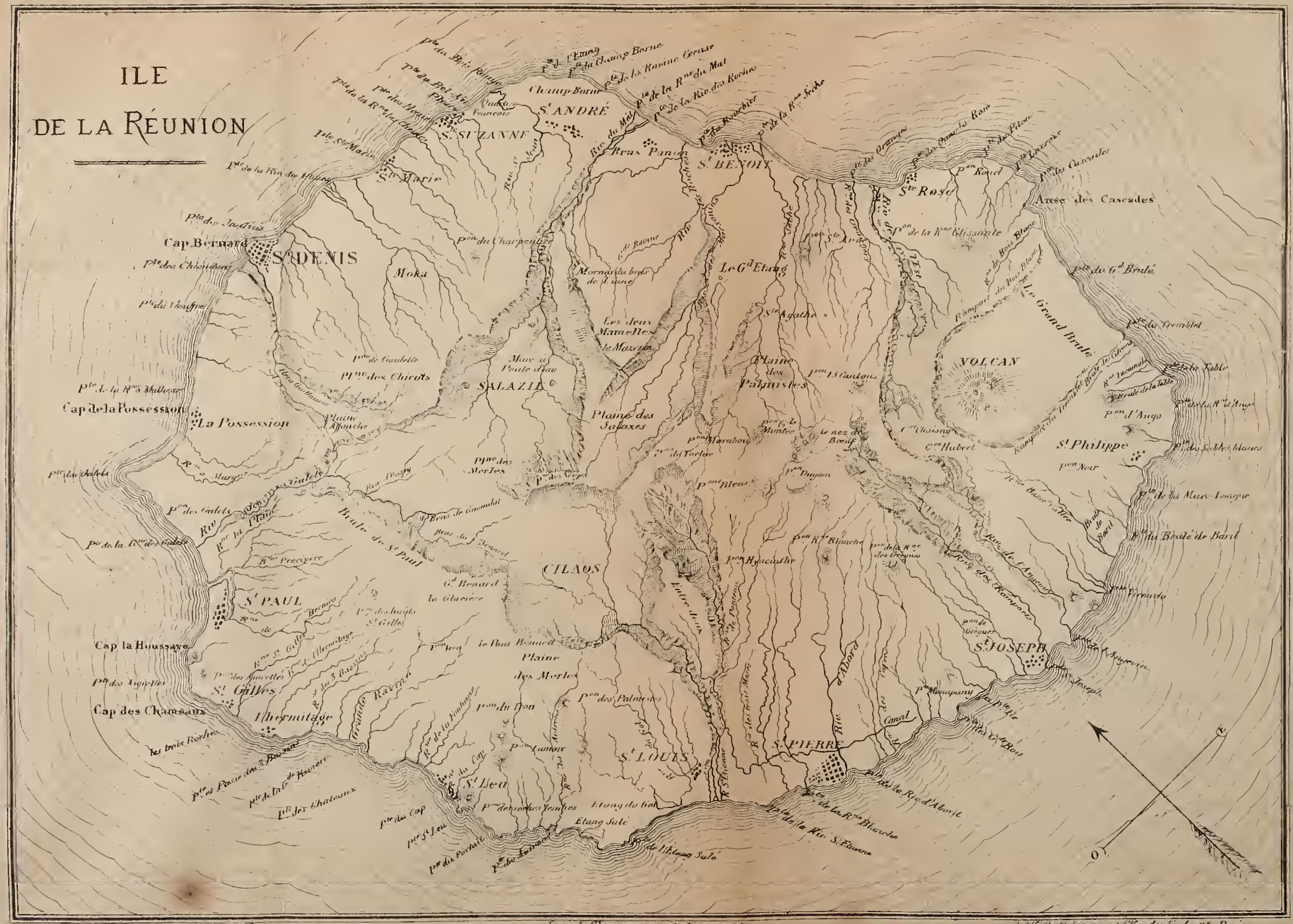

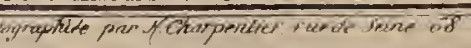





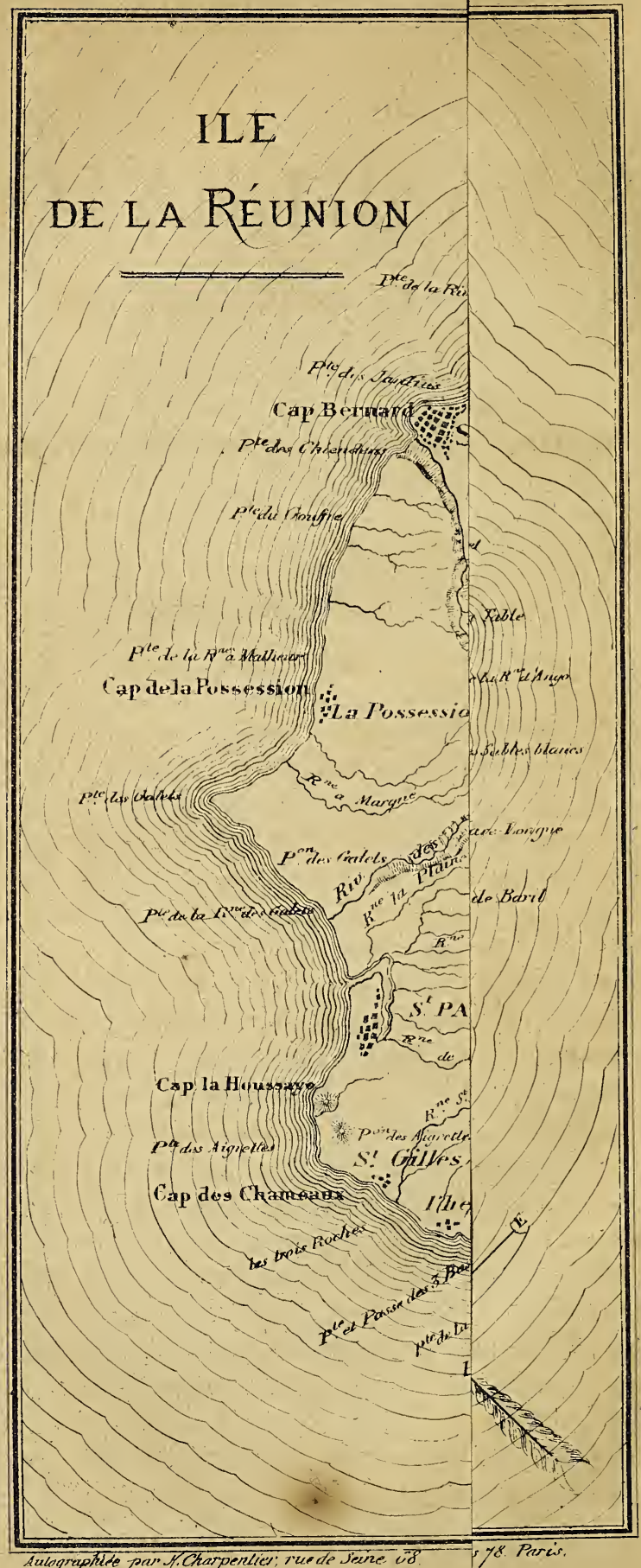




\section{LA RÉUNION}

\section{ET DÉPENDANCES}

\section{MAYOTTE - NOSSI-BÉ - SAINTE-MARIE-DE-MADAGASCAR}

\section{CHAPITRE PREMIER}

Coup d'œil historique.

L'île de la Réunion est située dans l'océan Indien entre $52^{\circ} 56^{\prime}-53^{\circ} 34^{\prime}$ de longitude $\mathrm{E}$. et $20^{\circ} 50^{\prime}-21^{\circ} 23^{\prime}$ de latitude $\mathrm{S}$.

Découverte vers 1503 par le Portugais Mascarenhas, occupée par les Français en 1642 et en 1649, cette île a successivement porté les noms de Mascareigne, de Bourbon (1619); de la Réunion (1793), de Bonaparte (sous l'Empire), de Bourbon (en 1815 lorsque les Anglais qui la détenaient depuis 1810, la rendirent à la Restauration), enfin de la Réunion (1848).

Elle est à 140 kilom. S.-0. de l'île Maurice (autrefois île de France), à 600 kilom. O.-S.-0. de Rodrigue, à 500 E. de Madagascar, à 3,000 N.-E. du cap de Bonne Espérance, et à 16,250 de Brest.

Le drapeau de la France y fut pour la première fois arboré par le capitaine Gobert, de Dieppe, en 1638. Ce fut en 1643 seulement qu'il en fut pris possession au nom de Louis XIII, par le sieur de Pronis, agent de la Compagnie des Indes orientales à Madagascar.

En 1649, cette prise de possession fut renouvelée par M. de Flacourt. L'île perdit alors son nom de Mascareigne et prit celui de Bourbon.

La Compagnie des Indes orientales, à qui elle fut concédée en 1664, comme dépendance de Madagascar, y envoya vingt 
ouvriers qui formèrent le premier noyau de la colonisation.

Une troisième prise de possession, au nom de Louis XIV, eut lieu en 1671.

En 1674, la petite colonie se vit tout à coup augmentée par les Français échappés aux massacres du Fort-Dauphin, à Madagascar. On songea plus sérieusement dès lors à tirer parti de l'île Bourbon.

Voici, en résumé, quels furent les événements subséquents de 1710 à 1793 :

En 1710, une administration régulière fut établie à Bourbon par la Compagnie des Indes : gouverneur, conseil provincial, etc.

En 1724, un conseil supérieur remplaça le conseil provincial, dont il garda les attributions judiciaires.

En 1735, le gouvernement de l'île Bourbon fut réuni à celui de l'île de France (île Maurice). Mahé de la Bourdonnais fut nommé gouverneur général des deux îles.

En 1764, la Compagnie des Indes fut dépossédée par ordonnance royale. Les deux îles rentrèrent sous le gouvernement du roi. Une indemnité de 1,200,000 livres de rente fut donnée à la Compagnie.

En 1766, ordonnance royale confiant l'administration de l'île de France et de Bourbon à un gouverneur et à un intendant. Un commandant particulier et un ordonnateur de la marine, relevant du gouverneur qui siégeait à l'île de France, résidèrent Bourbon. - Impôt de capitation sur les esclaves.

En 1767, organisation des branches du service par l'intendant général Poivre. Il introduisit à Bourbon la culture des épices.

En 1768, conseil électif des notables. Il administre l'emploi des fonds provenant de l'impôt de capitation sur les esclaves (trente sous par tête), destiné à pourvoir aux dépenses communales de la colonie.

En 1774, établissement d'une juridiction autre que le conseil supérieur. Elle est composée d'un juge royal, d'un lieutenant de juge, d'un procureur du roi et d'un greffier.

En 1790, une assemblée coloniale, décrétée par l'Assemblée constituante, et présidée par le général comte de Malartic, gouverneur des îles de France et de Bourbon, qui rendit alors d'immenses services aux colonies (1), s'empara de tous les pouvoirs. Elle pou-

(1) Voir la partie historique consacrée à la Guadeloupe. 
vait se composer de tout indiviau, blanc ou noir libre, et se renouvellerait chaque année. - Institution du jury, des justices de paix, des communes.

En 1793, la République fut proclamée à Bourbon; cette île prit le nom d'île de la Réunion.

Une commission de onze membres fut chargée de surveiller le comité administratif. Le conseil supérieur et de la juridiction royale fut supprimé, et cent huit habitants de la colonie furent déportés.

Le général Decaen, nommé capitaine général des: établissements français au delà du cap de Bonne-Espérance, reçut le gouvernement de l'île, en 1803. - On établit à la Réunion un commandant particulier et un sous-préfet. L'assemblée coloniale cessa ses fonctions.

La situation de l'île fut prospère jusqu'en 1806. A cette date, les habitants demandèrent et obtinrent que l'île de la Réunion fût à l'avenir appelée île Bonaparte. De 1806 à 1810, c'est-à-dire pendant la guerre maritime engagée dans la mer des Indes, entre la France et l'Angleterre, la détresse de la colonie fut des plus grandes.

Les 7 et 8 juillet 1810, les Anglais débarquent 5,000 hommes près de Saint-Denis. En vain la garnison, composée de 260 hommes et de 1,200 gardes nationaux, oppose à l'ennemi une résistance énergique. Le 9 , on fut contraint à capituler. La colonie passa sous la domination britannique et reprit le nom d'ìle Bourbon.

En 1815, l'île fut renulue à la France en vertu du traité de Paris du 30 mai 1814.

Le conseil supérieur de l'île, la juridiction royale, les justices de paix et les communes (sous le nom de Paroisses), furent rétablis.

Un comité consultatif, dit comité d'agriculture et de commerce, fut établi en 1816; le conseil supérieur et la juridiction royale furent remplacés par une Cour royale et un tribunal de première instance. L'organisation municipale de la colonie fut aussi réglée et déterminée.

En 1818, la traite des noirs fut définitivement prohibée.

En 1823, réorganisation du gouvernement colonial. Le comité consultatif est remplacé par un conseil général de douze membres, nommés par la couronne sur une liste de vingt-quatre candidats, présentés par les conseils municipaux de la colonie. Ce conseil général, supprimé à son tour en 1833, fut remplacé par un conseil colonial, composé de trente membres et ayant des attributions 
plus étendues. Un an après, le principe électif fut appliqué à la formation des municipalités.

Lorsque, le 9 juin 1848, la République fut proclamée à Bourbon, l'île reprit son ancien nom d'île de la Réunion.

Le conseil colonial et les fonctions de délégué furent supprimés; - le droit électoral accordé à tout habitant majeur né ou naturalisé français; la Réunion put envoyer trois députés à l'As. semblée nationale constituante.

En 1853, l'Empire fut proclamé. Ėn 1854, un sénatus-consulte, du 3 mai, réglant la nouvelle constitution des colonies, fut promulgué le 26 juillet.

C'est sous l'empire de ce sénatus-consulte que se trouve actuellement la Réunion, ainsi que nos autres colonies.

\section{PRINCIPAUX GOUVERNEURS.}

166らั-1671. Regnault (Étienne), commandant pour le roi et la compagnie des Indes.

1674.

Heure (de la), commandant.

1678.

Orgeret (Henri-Esse d'), gouverneur.

1680. Fleurimont (de), gouverneur.

1686. Bernardin de Quimper, capucin, commandant par intérim (1680-1686).

1689. Drouillard (Jean-Baptiste), gouverneur par intérim (1686-1689).

1689-1690. Vauboulon (de), gouverneur.

1690-1693. Firelin (Michel), commandant.

1694. Prades (de), commandant.

$1696 . \quad$ Lemayeux, directeur pour la Compagnie.

1696-1698. Bastide (Joseph), commandant.

1698-1701. Cour (Jacques de la), gouverneur.

1701-1709. Villers (de), gouverneur.

1710. Gharenville (de), gouverneur.

1710-1715. Parat (de), gouverneur.

1715ั-1718. Justamond (Henry), commandant par intérim.

1718-1723. Beauvollier (Joseph), gouverneur.

1723-1725. Desforges-Boucher, gouverneur.

1725-1727. Dioré (E்lie), commandant, puis gouverneur.

1727-1735. Dumas (Pierre-Benoît), directeur général des îles Bourbon et de France.

1735. Mahé de Labourdonnais, directeur général. 
1735-1739. Lemery-Dumont, commandant.

1739-1743. Heguerty (Pierre-André d'), commandant par intérim.

1743-1745. Didier de Saint-Martin, commandant.

1740ั. Azéma (Jean-Baptiste), commandant.

174ว. Didier de Saint-Martin, commandant.

1740ั-1747. Gérard de Ballade, commandant par intérim.

1747-1748. Didier de Saint-Martin, commandant.

1748-1749. Gérard de Ballade, gouverneur.

1749. Desforges-Boucher, président du conseil et gouverneur par intérim, fils du gouverneur de 1723.

1749-17ว00. Brenier (Joseph), commandant, puis gouverneur par intérim.

1750-1752. Bouvet (J.-B.), gouverneur.

1752-1756. Brenier (Joseph), gouverneur par intérim.

1756-1757. Bouvet (J.-B.), gouverneur.

1757. Desforges-Boucher, gouverneur par intérim.

17วั7 -1763. Bouvet (J.-B.), gouverneur.

1763. Sentuari, commandant par intérim.

1763-1767. Bertin, commandant, puis gouverneur.

1767. Bellier (M.-A.), commandant.

1767-1772. Bellecombe (de), commandant.

1772-1773. Savournin (de), gouverneur par intérim.

1773. Bellecombe (de), gouverneur.

1773-1776. Steynaver (de), commandant.

1776-1779. Souillac (François de), commandant.

1779-1781. Saint-Maurice (de), commandant.

1781-1785. Souville (de), commandant.

178วั-1788. Dioré (Élie), commandant.

1788-1790. Cossigny (de), commandant.

1790-1792. Chermont (de), commandant, sous le gouvernement général du comte de Malartic.

1792-1794. Du Plessis, gouverneur.

1794-1795. Roubaud, gouverneur par intérim.

1795-1803. Jacob, commandant.

1803-1805. Magallon (de), commandant, sous le gouvernement général de Decaen.

1806-1809. Bruslys (des), commandant.

1809-1810. Sainte-Suzanne (de), commandant. - C'est pendant ce commandement que l'île fut prise par les Anglais. 
Gouverneurs Anglais.

1810-1811. Farqhuar, Fraser et Picton, gouvern. par intérim. 1811-1815. Keating.

\section{Gouverneurs français.}

1815-1817. Bouvet de Lozier, maréchal de camp, gouverneur. 1817-1818. Lafitte Courteil (de), maréchal de. camp, commandant.

1818-1821. Milius, capitaine de vaisseau, commandant.

1821-1826. Freycinet (de), capitaine de vaisseau, commandanl. 1826-1830. Cheffontaines (de), capitaine de vaisseau, gouvern.

1830-1832. Duval-Dailly, capitaine de vaisseau, gouverneur.

1832-1838. Cuvillier, contre-amiral, gouverneur.

1838-1841. Hell (de), contre-amiral, gouverneur.

1841-1846. Bazoche, contre-amiral, gouverneur.

1846-1848. Graeb, capitaine de vaisseau, gouverneur.

1848-1850. Sarda-Garriga, commissaire général de la République.

1850. Barolet de Puligny (de), colonel, commandant militaire, gouverneur par intérim.

1850-18こ2. Doret, capitaine de vaisseau, gouverneur.

1852-18วั8. Hubert-Delisle (Henri), gouverneur.

1858. Lefèvre, commissaire de marine, gouverneur par intérim.

1858-1864. Darricau, capitaine de vaisseau, gouverneur.

1864. Dupré, capitaine de vaisșeau, id.

\section{CHAPITRE II}

La Réunion. - Superficie. - Côtes. - Le piton des Neiges. - Le piton de la Fournaise. - Montagnes. - Partie sous le vent. - Plaines. - Forêts. Cours d'eau. - Rivières. - Eaux minérales. - Étangs. - Sol volcanique de l'île. - Eruption du Grand-Brûlé (1860) - - Ports et rades. - Projets de ports nouveaux.

L'île de la Réunion a une superficie de 201,160 hectares .

Sa longueur, de la pointe des Galets à celle d'Ango, est de $7{ }^{\text {kil }}, 20$; et sa largeur, de Saint-Pierre à Sainte-Suzanne, est de $50^{\text {kil }}, 60$.

Ses côtes ont un développement de $207^{\text {kil }}, 30$. 
L'îleest de forme elliptique. Elle s'allonge du N.-O. au S.-E et parait s'exhausser autour de deux centres principaux que marquent d'une part le piton des Neiges (3,069 mètres); de l'autre, le piton de la Fournaise $(2,625$ mètres $)$.

La nature du sol et la disposition des laves dont il est formé attestent que l'île entière est. le produit des éruptions de deux foyers, occupant les deux points que l'on vient de signaler, mais dont le plus considérable, le piton des Neiges, est dès longtemps éteint, tandis que l'autre, le piton de la Fournaise, brûle encore.

Les deux groupes de montagnes de l'île sont réunis par un plateau, appelé la plaine des Cafres, qui est élevé de 1,600 mètres au-dessus du niveau de la mer.

L'île se trouve ainsi partagée en deux divisions naturelles, dont l'une, celle du N.-N.-E., est dénommée Partie du vent, et l'autre, celle du S.-S.-0. : Partie sous le vent.

Le piton des Neiges est le point culminant de l'île.

La partie que domine ce volcan éteint est la plus fertile; c'esí celle sur laquelle se sont principalement développées la culture et l'industrie agricole ; c'est aussi dans cette partie qu'est située la ville de Saint-Denis, chef-lieu de l'île et siége du gouvernement local. (Notices publiées par ordre du ministre de la marine et des colonies.)

A proprement parler, la Réunion n'a pas de plaines; elle n'a guère que des vallées séparant les montagnes entre elles.

Dans la partie moyenne de ces montagnes se trouvent des forêts.

Les cours d'eau sont nombreux. Ils prennent leur source dans la chaîne des montagnes et se rendent impétueusement du centre à la circonférence. Aucun n'est navigable (sauf la rivière SainteSuzanne qui l'est en partie); la plupart se dessèchent en été.

On doit mentionner parmi ces cours d'eau :

La rivière de Saint-Denis, - la rivière des Galets, - la rivière Saint-Etienne, - la rivière d'Abord, - la rivière des Marsouins, - la rivière du Mât, - la rivière des Roches, - la rivière SainteSuzanne, déjà signalée, - la rivière des Pluies.

Les sources d'eaux minérales ne sont pas moins nombreuses que les cours d'eau.

Celle de Salazie, où l'on a établi un hôpital militaire, se trouve à 23 kilomètres de Saint-André et à 872 mètres au-dessus du niveau de la mer. Elle débité 1,372 litres par heure et contient 
$1^{\mathrm{gr}}, 0782$ d'acide carbonique libre par litre. Sa température est de $32^{\circ}$.

La source du Bras-Rouge, peu distante de Cilaos, a une température de $48^{\circ}$.

Les deux sources de Gilaos, dont l'une est froide et possède une température de $20^{\circ}$ à $25^{\circ}$, dont l'autre est chaude et accuse une température de $38^{\circ}$, sont situées à 38 kilomètres de la rivière Saint-Étienne et à 1,114 mètres au-dessus du niveau de la mer. La rivière les sépare. Elles peuvent produire 10,000 litres par heure. L'une et l'autre contiennent de l'acide carbonique libre, mais en quantité différente : la source chaude en renferme $1^{\mathrm{gr}}, 506,475$; la source froide, $0^{\mathrm{gr}}, 92,106$.

La source de Mafat, peu fréquentée jusqu'ici, est située sur la rive droite de la rivière des Galets, à 20 kilomètres de son embouchure et à 682 mètres au-dessus du niveau de la mer. Elle débite 810 litres d'eau par heure. Sa température est de $31^{\circ}$. Elle a fourni à l'analyse, par litre : $0^{\mathrm{gr}}, 00576$ sulfure de sodium, $0^{\mathrm{gr}}, 0011$ sulfure de fer, $0^{\mathrm{gr}}, 0751$ chlorure de sodium, $0^{\mathrm{gr}}, 0235$ sulfate de soude, $0^{\text {gr }}, 0 \check{0} 06$ carbonate de soude.

On compte, dans l'intérieur, un certain nombre d'étangs, dont le principal est le Grand-Étang, sur les hauteurs de Saint-Benoît. Quatre autres, dans la saison des pluies, communiquent avec la mer : l'étang de Saint-Paul, dont la superficie est de $\mathbf{1 6}$ hectares 36 ares, et qui, lorsque les eaux se retirent, donne du natron trèspur; l'étang Salé et l'étang du Gol, à Saint-Louis; l'étang du champ Borne, à Saint-André.

Le sol de l'île est volcanique. C'est un mélange de laves et d'humus. La lave recouverte de mousses et de lichens, puis de fougères, d'arbustes, de grands arbres, enfin le sol cultivé et chargé de récoltes luxuriantes : voilà la Réunion.

$\mathrm{Au}$ mois de mars 1860, l'île de la Réunion a été le théâtre d'un phénomène volcanique extrêmement curieux. Voici ce que nous en avons dit dans notre Science populaire, $\mathbf{1}^{\mathrm{re}}$ année (1863).

L'éruption de mars 1860 a lancé, comme en 1812, des filaments de verre sur les lieux qui l'environnaient; et pendant plusieurs soirs on remarquait de Saint-Denis, en regardant du côté du Grand-Brûlé, un horizon d'un rouge sombre, semblable à celui produit par un vaste incendie. Les promeneurs qui allaient respirer l'air rafraîchi du soir sur le rivage du côté de la place Candide, ont pu parfaitement saisir ce phénomène, qui parais- 
sait plus intense encore lorsque des nuages, faisant l'office de vastes écrans, réfléchissaient la lumière.

La place Candide est dans une situation délicieuse au bord de la mer. Qu'il fait bon, le soir, sur cette place toujours émaillée de verts gazons, où l'on va prendre un bain d'air qui pénètre dans tous les pores, à travers les vêtements de toile blanche du voyageur! C'est là aussi que se trouve le cirque où vont se distraire les élégantes créoles, et où se font le dimanche les danses pittoresques des noirs de toutes les parties du monde. A quelque distance se trouve le cimetière que battent les flots jour et nuit, et qu'ombrage une allée de filaos, arbre le plus élégant du monde, espèce de cèdre qui rappelle le sapin et le saule pleureur; ses feuilles longues, pressées, cylindriques et fines comme des cheveux, penchent vers la terre, et la brise qui les fouette chante mélodieusement d'une voix qu'on recherche toujours dès qu'on l'a entendue une fois. Ce cimetière est une espèce de miniature des champs de repos de toutes les nations; il y a, en effet, des monuments de tous les ordres, de tous les styles, des inscriptions de toutes les langues. Il est difficile de retenir quelques larmes en lisant ces épitaphes qui disent : "Ici repose un tel... Sa mère le pleure à travers l'Océan. "Il est impossible de dire, sur ce point marqué au milieu de la mer des Indes, l'impression que font ces tombeaux qui recèlent les derniers restes de ceux qui appartiennent à notre patrie, et qui sont nés dans cette terre éloignée et chérie où respirent tant d'êtres qui nous sont chers. G'est de ces lieux qn'on allait admirer le superbe phénomène que présentait le volcan en activité.

Notre ami, M. Hugoulin, s'est immédiatement transporté sur le lieu de l'éruption et a pu constater les faits les plus intéressants; nous le suivrons dans le résumé suivant.

Le 19 mars 1860, à 8 heures et demie du soir, un roulement sourd, mais fort bruyant, s'est fait entendre dans toutes les localités voisines du Grand-Brûlé, de Sainte-Rose, et même jusqu'audessus des rampes du nord de la rivière de l’Est. Ce bruit était partout comparable à celui que ferait une charrette pesamment chargée d'objets en fer. C'est là l'impression commune qu'ont éprouvée dès l'abord tous les observateurs. Ce bruit produisait une certaine vibration du sol; il n'y avait pas positivement tremblement de terre, mais la trépidation était assez violente pour produire l'agitation des meubles et des ustensiles qui les recouvraient. 
Une épaisse colonne de fumée grisâtre s'est élancée perpendiculairement dans l'espace, du sommet de la montagne du volcan, dans la partie voisine du piton de Crac. Cette colonne paraissait avoir plus de 100 mètres à la base ; elle a été en s'agrandissant à son sommet, de manière à former un nuage épais, qui s'est étendu en deux sens presque opposés, donnant ainsi naissance à deux nuages distincts : l'un a pris la direction N.-E., vers le bourg de Sainte-Rose; il a empêché les observateurs de cette localité d'apercevoir l'autre nuage qui a marché dans la direction S.-E., vers Saint-Philippe.

Toute la masse de la colonne était illuminée par une masse considérable de points en vive ignition, qui éclataient ensuite en mille gerbes resplendissantes, comme un bouquet de feu d'artifice. Des masses énormes de roches incandescentes la sillonnaient aussi, et éclataient ensuite avec un bruit semblable à des détonations de mousqueterie, en fragments lumineux.

Ce phénomène n'a duré que quelques instants, l'obscurité l'a remplacé, mais les deux nuages formés par l'éruption ont continué leur route en deux sens opposés avec la force d'impulsion première qui leur avait été sans doute communiquée par l'explosion volcanique, car le calme le plus parfait régnait dans l'atmosphère.

Ces deux nuages ont fini par se dissoudre en une pluie de cendres qui a couvert toutes les localités environnantes, à plus de sept lieues du rayon du centre volcanique.

La cendre provenant du nuage qui s'est dirigé vers Saint-Philippe est grise, elle est aussi fine que de la farine de blé; celle de Sainte-Rose est grenue comme de la poudre de chasse; elle ressemble assez au sable de la rivière de l'Est; elle en diffère en ce.qu'elle n'a pas, comme celui-ci, des fragments cristallins et brillants.

Le sol a partout été jonché de ces cendres; les plantes en ont été entièrement couvertes, et cette pluie a été générale, depuis l'extrémité sud de la commune de Saint-Philippe jusqu'à quelques kilomètres de la ville de Saint-Benoît. A 16 milles en mer, le trois-mâts la Marie-ÉElisa, qui venait au mouillage de SainteRose, et dont le capitaine a été l'un des observateurs favorisés, a eu son pont entièrement couvert de cendres.

La plupart des familles ont évacué leurs cases à la hâte, emportant leurs objets les plus précieux. Une heure après l'éruption, 
toute la nature avait repris son calme habituel, et l'on n'apercevait plus que la lueur que répand habituellement le volcan depuis longtemps.

L'île de la Réunion n'a pas de ports proprement dits. Elle n'a que des rades foraines peu commodes pour l'atterrage, sans sûreté pour le mouillage et d'où l'on est obligé d'appareiller aux moindres bourrasques.

Il n'y a guère à tenir compte que des rades de Saint-Denis, de Saint-Paul, de Saint-Pierre et de Sainte-Marie.

En 18ð̌4, la création d'un port a été décidée à Saint-Pierre où un baranchois naturel offrait déjà un refuge aux caboteurs. Les travaux commencés au mois d'août de cette année consistent en : - $1^{\circ}$ une jetée est, ayant 330 mètres de longueur, qui protége l'entrée du port au vent; $2^{\circ}$ un épi de 98 mètres; $3^{\circ}$ une jetée ouest, ayant 293 mètres de longueur, qui forme le côté est du bassin; $4^{\circ}$ deux barrages qui ferment le bassin à l'ouest et au sud.

Le bassin, qui est aujourd'hui complétement fermé, pourra abriter trente navires; on est en train d'en creuser le fond. Il contiendra une forme de radoub et un patent slip.

La construction des jetées et de tous les travaux en général a coûté, d'après les états arrêtés le 31 décembre 1861, une somme de 2,006,628 fr., non compris l'achat du matériel estimé à environ 400,000 fr. Les dépenses de 1862, non encore arrêtées, n'ont pas dû aller au delà de $\aleph_{200,000}$ francs.

Dans la totalité de cette dépense, la métropole a contribué pour un million de francs. D'après une estimation, la dépense totale doit sélever à 7 millions de francs.

En outre du port de Saint-Pierre, il est question depuis quelque temps de la formation d'un port dans lá baie de Saint-Paul. Des études préliminaires ont déià été faites en vue de cette création.

\section{CHAPITRE III}

Climat. - Température moyenne, minimum et maximum. - Moyenne barométrique. - Saisons. - Vents. - Cyclones. - Renvoi à la Science populaire ( $3^{\mathrm{e}}$ année). - Ras de marée. - Etat hygrométrique. - Moyenne de la quantité de pluie tombée. - Marée. - Durée du jour.

Le climat de la Réunion est des plus salubres. Air pur, ciel magnifique, eaux abondantes, fraîches brises, tout s'est réuni 
pour faire de cette île un séjour enchanté. On ne s'y croirait pas sous la zone torride.

La température moyenne atteint $24^{\circ} \mathrm{c.}$; la température rnaximum $36^{\circ}$, et la température minimum $12^{\circ}$.

Au reste, la température et le climat varient, comme dans tous les pays de montagnes, suivant l'altitude.

La moyenne barométrique est de 760 millimètres; le maximum, de $\mathbf{7 7 2}$, et le minimum, de $\mathbf{7 1 9}$.

Deux saisons : l'une, l'hivernage, règne de novembre (du 10 décembre pour la navigation)à mai. Elle se distingue par sa chaleur et l'abondance des pluies. L'autre règne de mai à novembre; les pluies sont rares, les chaleuı́s plus tempérées.

Les vents, sauf d'octobre à la mi-avril, soufflent le plus souvent de l'est-sud-est et du sud-sud-est.

Les cyclones (ouragans) sont épouvantables. Pendant un séjour de plusieurs années à la Réunion, nous avons été trop souvent témoin de leur puissance dévastatrice. Dans l'Appendice qui suit le second volume de la présente étude, nous donnons un extrait de la Science populaire que nous publions chaque année (1). On y verra ce que sont les cyclones, les moyens d'y échapper, etc.

D'avril à novembre, de violents ras de marée se font sentir sur les côtes. Ils se produisent, quand les cyclones passent au sud de l'île, et durent ordinairement vingt-quatre heures.

L'hygromètre accuse une humidité atmosphérique moyenne de $79^{\circ}, 2$ à Saint-Denis, de $83^{\circ}, 3$ à Saint-Benoît, de $77^{\circ}, 9$ à SaintPierre.

Il tombe annuellement en moyenne 1,800 millimètres de pluie. Le minimum a lieu de mai à septembre, et le maximum de décembre à mars. La plus grande quantité de pluie tombe à SaintBenoît, et la moindre à Saint-Paul. Entre les années pluvieuses et les années sèches la différence est d'environ 650 millimètres.

Le maximum de la marée ne dépasse guère $1^{\mathrm{m}}, 10$ au-dessous des plus basses mers, c'est-à-dire $0^{\mathrm{m}}, 55$ au-dessus du niveau moyen.

Le jour le plus long (22 décembre) est de 13 heures 16 minutes 14 secondes. Le plus court (22 juin) est de 10 heures 43 minutes 36 secondes.

(1) On peut voir également un mémoire sur les ouragans, lu par M. Rambosson, à l'Institut (Académie des sciences), le 2 mai 1864. 


\section{CHAPITRE IV}

Division administrative. - Arrondissement du Vent et arrondissement sous le Vent. - Communes et districts. - Superficie de chaque commune ou district. - Villes, bourgs ou villages.

L'île de la Réunion est. divisée en deux arrondissements : Arrondissement du Vent, à l'est : chef-lieu Saint-Denis. - Sous-le-vent, à l'ouest : chef-lieu Saint-Pierre.

Arrondissement du Vent (6 communes et 2 districts).

Gommune de Saint-Denis (superficie : 15,090 hectares).

- de Sainte-Marie $(8,445$ hect.).

- de Sainte-Suzanne (5,580 hect.).

- de Saint-André ( 5,535 hect.).

District de Salazie (10,930 hect.).

Commune de Saint-Benoît (36,558 hect.).

District de la plaine des Palmistes (4,715 hect.).

Commune de Sainte-Rose (17,775 hect.).

\section{Arrondissement Sous-le-vent (6 communes).}

Commune de Saint-Philippe (15,330 hectares).

- de Saint-Joseph (18,817 hect.).

- de Saint-Pierre (36,270 hect.).

- de Saint-Louis (21,380 hect.).

- de Saint-Leu (19,330 hect.).

- de Saint-Paul (35,405 hect.).

La superficie totale de ces communes et districts est de 251,160 hectarès.

La Réunion a 4 villes :

Saint-Denis, chef-lieu de la colonie, siége du gouvernement colonial. Sa population s'est élevée, depuis 1837 , de 12,000 à 36,000 habitants.

Saint-Paul : 25,000 habitants.

Saint-Pierre : 28,000 habitants.

Saint-Benoit : 20,000 habitants.

On y compte 10 bourgs ou villages qui portent les noms des communes mentionnées plus haut. 
$\preceq$ autres villages : ceux de Hell-ville, de Helbourg, dans le district de Salazie; de la Possession, de Saint-Gilles, dans la commune de Saint-Paul; de Sainte-Agathe, dans la plaine des Palmistes.

\section{CHAPITRE V}

Gouvernement local. - Gouvernement colonial. - Services de l'ordonnateur. - Hôpitaux. - Garde-magasin du matériel et des vivres. - Archives colonia les. - Service de santé. - Trésorerie. - Service des ports. - Contrôle coIonial. - Direction de l'intérieur. - Services financiers. - Douanes. - Contributions. - Poste aux lettres. - Organisation municipale, etc.

Le gouvernement de la Réunion a été organisé par une ordonnance royale du 21 août 1825 , moditiée par les ordonnances des 8 mai 1832,22 août 1833 et 15 octobre 1836 , par le sénatus-consulte du 3 mai 1854, et par deux décrets impériaux en date des 26 juillet 1854 et 29 août $185 \% 5$.

\section{Gouvernement local.}

1 gouverneur ;

1 conseil privé;

1 conseil général;

Plusieurs chefs d'administration;

1 contrôle colonial.

Un délégué, élu par le conseil général, représente la colonie auprès du gouvernement métropolitain.

\section{Gouvernement colonial.}

1 gouverneur;

1 secrétaire archiviste;

2 employés attachés au secrétariat du gouverneur.

\section{Services de lordonnateur.}

$1^{\text {or }}$ bureau, secrétariat de l'ordonnateur : 1 chef et 3 employés, chargés de l'enregistrement et de l'analyse des dépêches; des communications de ces dépêches aux services et détails compétents; de la répartition des bulletins officiels, des insertions au Moniteur; des rapports au conseil privé; de lá correspondance et de l'enregistrement de la correspondance; de la répartition des 
ordres de service et de la destination des officiers et employés du service de l'ordonnateur; de la préparation du budget du service colonial.

$2^{\text {e }}$ bureau, fonds : 1 chef et 3 employés chargés du mandement et de l'ordonnancement des dépenses; de la remise des mandats de payement aux parties prenantes; des versements au Trésor; des virements et annulations; du remboursement des avances entre les départements ministériels et les établissements coloniaux; des remboursements par suite de cessions; des dépenses des exercices clos; des rappels sur les exercices courants; des exercices périmés; du compte définitif de l'exercice.

$3^{\text {e }}$ bureau, revues et armements : 1 chef et 3 employés chargés des rapports de service avec les officiers entretenus et autres agents, avec les corps de troupe en ce qui concerne la comptabilité des corps; de la vérification de ces comptabilités; de l'expédition de la solde et des accessoires; de l'examen des réclamations pour solde et accessoires; de la tenue des contrôles; de l'établissement des revues de liquidation; de la préparation des états de service; des délégations; des successions; de l'administration des hôpitaux; des rapports de service arec le personnel embarqué; de l'embarquement et du débarquement du personnel; du contrôle des pièces comptables du bord; du payement de la solde; des accessoires et du traitement de table; des feuilles de journées et revues de liquidation; de la suite à donner aux actes de l'état civil.

$4^{\mathrm{e}}$ bureau, travaux, subsistances: 1 chef et 3 employés chargés du personnel des ouvriers; de la comptabilité du matériel des directions de l'artillerie, du génie et des bâtiments de l'État; des marchés pour entreprise de façons d'ouvrages et de travaux à prix faits; de la location des terrains et maisons ; des acquisitions d'immeubles; des réceptions d'ouvrages; des inventaires; de l'approvisionnement des magasins; de la passation des marchés; des rapports avec le garde-magasin général et les directions de l'artillerie et du génie; de la surveillance administrative sur les comptabilités des matières; du casernement; des commandes aux fournisseurs; des réceptions ou rebuts des matières; de la liquidation des livraisons.

$\check{5}^{\mathrm{e}}$ bureau, inscription maritime: 1 chef et 3 employés à SaintDenis, 1 chef de service à Saint-Paul et 1 à Saint-Pierre.

Classement des gens de mer, des levées, de la police de la navi- 
gation et des pêches maritimes, des bris et naufrages; de l'or ${ }^{-}$ donnancement des dépenses et des recettes de la caisse des Invalides de la marine, du payement des pensions en demi-solde.

\section{Hôpitaux.}

1 hôpital militaire à Saint-Denis;

1 à Saint-Paul ;

1 hôpital thermal à Salazie.

Personnel administratif: Deux directeurs, un agent comptable, deux commis aux entrées. - L'administration est sous les ordres de l'ordonnateur.

Garde-magasin du matériel et des vivres : 3 employés. - Ce garde est chargé du classement et de lạ répartition des approvisionnements; des entrées et sorties; des cessions; des remises faites par les bâtiments en cours de campagne; des recensements et inventaires; de la comptabilité du matériel en service et de l'emploi des matières.

Archives coloniales. - Un commissaire adjoint de la marine chargé de leur conservation.

Service de santé.

1 médecin en chef;

2 chirurgiens principaux;

16 chirurgiens de $1^{\mathrm{re}}, 2^{\mathrm{e}}$ et $3^{\mathrm{e}}$ classe;

4 pharmaciens de $1^{\mathrm{re}}, 2^{\mathrm{e}}$ et $3^{\mathrm{e}}$ classe.

\section{Trésorerie.}

1 trésorier général (en même temps payeur, receveur général des finances, trésorier des Invalides de la marine);

1 trésorier particulier dans la partie Sous-le-vent.

11 percepteurs.

1 capitaine;

Service des ports.

1 lieutenant;

4 maitres de port;

2 pilotes;

4 aides-pilotes;

39 canotiers.

Lobservatoire de Saint-Denis fait, en outre, partie des services de l'ordonnateur. 
CONTRÔLE COLONIAL.

1 contrôleur colonial;

1 chef de bureau;

2 employés.

\section{DIRECTION DE L'INTÉRIEUR.}

Les attributions du directeur de l'intérieur embrassent :

Services financiers.

Enregistrement et domaines, - curatelle aux successions vacantes, - eaux et forêts.

1 inspecteur, chef du service;

21 conservateurs, receveurs et commis;

12 brigadiers;

38 gardes forestiers.

1 directeur;

Douanes.

18 sous-inspecteurs, contrôleurs, vérificateurs et commis ;

1 lieutenant;

76 brigadiers, sous-brigadiers et préposés;

20 agents divers.

1 chef;

\section{Contributions.}

12 contrôleurs et commis;

26 préposés surveillants pour l'inspection des distilleries.

$$
\text { Poste aux lettres. }
$$

1 receveur comptable chef;

1 contrôleur;

4 commis à Saint-Denis;

15 receveurs.

Instruction publique.

1 inspecteur (il est nommé par le ministre);

1 commission centrale (au chef-lieu);

1 commission spéciale (dans chaque commune).

\section{Police.}

1 commissaire central de sûreté, inspecteur; .

1 chef de bureau et 2 commis (pour le service administratif de la police centrale); 
1 commissaire de sûreté;

3 commissaires spéciaux;

5 commissaires de canton;

13 commissaires de police.

Le syndicat des gens de travail, composé de 10 syndics et de 4 commis, l'atelier de discipline divisé en 4 compagnies, rentrent aussi dans les attributions du commissaire central.

Vaccine.

La vaccination est imposée à tous les immigrants.

Un vaccinateur est spécialement chargé de la conservation et de la propagation de la vaccine.

\section{Ponts et chaussées.}

1 ingénieur en chef, chef de service;

4 ingénieurs d'arrondissement;

17 conducteurs; 2 commis;

2 commis à la gérance.

\section{ORGANISATION MUNICIPALE.}

Les 12 communes de la colonie ont, chacune, un maire, des adjoints, des conseillers municipaux, dont le nombre varie de 4 à 14. Ces conseillers ont le droit de nommer la moitié d'entre eux.

L'arrêt local du 12 novembre 1848, modifié par le sénatusconsulte du 3 mai 1854, a organisé l'élection des conseillers municipaux et la nomination des maires et adjoints.

\section{CHAPITRE VI}

Population. - Population maritime. - Travailleurs indiens. - Historique de l'immigration. - Intervention de la Société agricole.

Les derniers mouvements connus de la population ont donné les résultats suivants :

Population (au 1er janvier 1860).

$\left.\begin{array}{l}\text { Hommes................ } 103,290 \\ \text { Femmes............ } 63,268\end{array}\right\} \quad 166,558$ individus.

(Dans ce nombre on comptait 64,733 immigrants de toutes les nations.)

Naissances................. 1 sur 42 indiviılus.

Décès........................ 1 sur 19

Mariages................... 1 170 
Population maritime (1856).

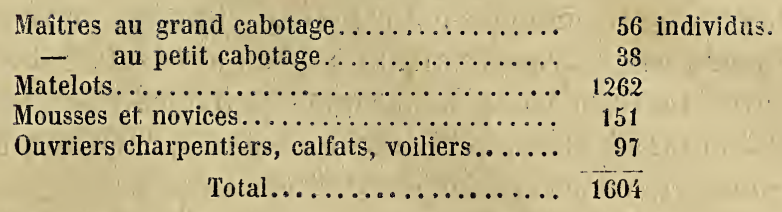

La population est mélangée.

On y trouve :

Européens nés dans le pays ou ailleurs;

petits créoles ou petits blancs;

Africains (Gafres, Iambanes, Maconas, Abyssins, Arabes, de Zanzibar, etc.) ;

Malgaches (Howas et Sakalaves);

Asiatiques (Indiens et Chinois);

Malais ;

Australiens.

L'affranchissement des esclaves rendit l'immigration nécessaire. Les ateliers, désertés par les affranchis, durent être repeuplés avec des travailleurs étrangers. On fit appel aux Indiens dont plusieurs convois furent expédiés de Karikal et de Pondichéry (1848 et 1849). Une société d'immigration fut créée le 18 janvier 1853 , les négociants de l'Inde ayant montré des prétentions exorbitantes; mais cette société ne remplit pas suffisamment son but qui était d'obtenir des travailleurs à meilleur marché; les immigrants qu'elle devait livrer à 158 francs par tête, revenaient souvent à 250 et 300 francs au propriétaire.

Le privilége fut retiré à la société d'immigration en 1855 . Pourtant elle avait rendu des services.

$\mathrm{Au}$ commencement de $\mathbf{1 8 5 3}$, disent les Notices, la Réunion possédait 24,699 Indiens, 499 Chinois, 2,080 Africains. A la fin de 1855, au moment de la dissolution de la société, la colonie comptait, déduction faite des mortalités et des rapatriements pendant ces trois années, 35,201 Indiens, 448 Chinois, et 10,265 Africains. G'était une augmentation de 18,636 immigrants.

Grâce à ces nombreux travailleurs étrangers, la production prenait un rapide accroissement; mais deux causes vinrent $y$ apporter une entrave momentanée. En premier lieu, la Martinique, la Guadeloupe et la Guyane commencèrent à participer largement au recrutement qui s'effectuait dans l'Inde, et dont la 
Réunion avait jusqu'alors profité presque exclusivement; en second lieu, le gouvernement métropolitain, informé des désordres occasionnés par les recrutements à la côte orientale d'Afrique, crut devoir les interdire pendant quelque temps.

La Réunion vit donc subitement diminuer dans une proportion considérable le chiffre des introductions. Dans le courant de l'année 1856 , il ne fut pas introduit plus de 3,000 immigrants dans cette colonie.

La pénurie fut un moment extrême : le prix de cession des contrats atteignit un prix exorbitant. Pour y remédier, le département de la marine et des colonies avait contié les recrutements dans l'Inde à une société dite d'émigration, composée des principales maisons de commerce de Pondichéry et de Karikal, et qui devait livrer les émigrants à la Réunion comme aux Antilles à un prix déterminé (39 roupies pour la Réunion, 42 roupies pour les Antilles). Ces émigrants étaient remis, à leur arrivée à la Réunion, à une société agricole composée de la majeure partie des grands propriétaires de la colonie, et qui, s'interdisant la spéculation, devait céder les contrats d'engagement au prix de revient.

Malgré la surveillance de l'administration locale; cette dernière condition ne fut pas toujours observée; on agiota sur les contrats d'engagement, et certains habitants déboursèrent jusqu'à 1,000 et 1,200 francs pour chaque contrat dont ils obtenaient la cession.

L'année 1857 vit apporter une heureuse amélioration à cette situation. Le gouvernement autorisa les recrutements d'engagés, au moyen du rachat, sur les côtes orientales et occidentales d'Afrique. La Réunion recommença aussitôt, en les environnant des précautions nécessaires, les opérations de recrutement sur les divers points de la côte orientale, à Madagascar et jusque dans la mer Rouge.

Pendant les années 1857,1858 et les premiers mois de 1859 , il fut introduit 13,500 Africains. Le prix de cession des contrats tomba et se maintint à environ 500 francs. Mais lorsqu'au commencement de 1859 , le recrutement des travailleurs fut interdit à la côte orientale d'Afrique, une nouvelle ère de détresse s'ouvrit pour la Réunion, toujours limitée à un faible contingent d'Indiens par suite de la concurrence des Antilles et de la Guyane.

Depuis longtemps les recrutements dans l'Inde ne dépassaient 
pas 5,800 individus par an; la part de la Réunion, dans ce contingent, était de 1,200 à 1,500.

On conçoit que c'était là une bien faible satisfaction pour les besoins pressants de la colonie, et que le prix de cession des contrats dut remonter à un taux fort élevé. Pour faire cesser l'agiotage, le gouvernement métropolitain exigea que les émigrants fussent remis, à leur arrivée, non plus à la Société agricole, mais à l'administration locale elle-même; que des listes tenues à la Direction de l'intérieur servissent à l'inscription des demandes qui lui seraient adressées et que la répartition des immigrants se fît par les soins de l'administration, dans l'ordre des inscriptions et au prix de revient, reconnu et arrêté par l'administration.

Cette mesure maintint le prix de cession des contrats à un taux raisonnable, mais les bras faisaient toujours défaut. Enfin, deux conventions conclues le 25 juillet 1860 et le $1^{\text {er }}$ juillet 1861 entre les gouvernements français et anglais, vinrent mettre un terme aux souffrances que la colonie éprouvait à cet égard.

Parle premier de ces actes, la Réunion put recruter immédiatement 6,000 Indiens à Calcutta. Par le second, elle fut admise, comme nos autres colonies, à recevoir, par l'intermédiaire des agents officiels de recrutement institués par la convention, des travailleurs des diverses parties de l'Inde britannique. Le prix de cession des contrats est depuis lors descendu dans la colonie à $221 \mathrm{fr} .25 \mathrm{c}$., frais de transport compris.

Le chiffre d'émigrants qui existait à la Réunion au mois de novembre 1862 était de 72,594, ainsi répartis :

10 Indiens.

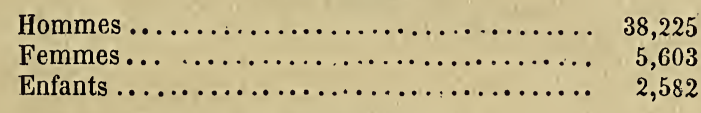

20 Chinois.

Hommes ........................ 413

$3^{\circ}$ Africains.

Hommes..................... 18,875

Femmes $\ldots \ldots \ldots \ldots \ldots \ldots \ldots \ldots \ldots \ldots \ldots \ldots, \quad 5,457$

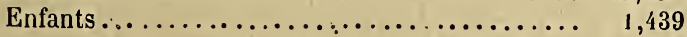

Ces chiffres donnent un total de 72,594 immigrants.

L'introduction des émigrants a toujours eu lieu à la Réunion avec les seules ressources locales, sans subvention de la part de 
l'État. Le gouverneur a récemment autorisé la formation d'une nouvelle société agricole qui sera chargée de fournir les fonds nécessaires aux introductions, d'entretenir des agents dans les divers ports de l'Inde, à l'effet de recevoir les émigrants des mains des agents officiels de recrutement, d'affréter les navires-transports, et de répartir les émigrants parmi les habitants de la Réunion, à un prix de revient contrôlé par l'administration, et d'après les listes d'inscription tenues à la direction de l'intérieur. On espère de bons résultats de cette organisation. (V. Notices, etc.)

\section{GHAPITRE VI}

Instruction publique. - Direction. - Surveillance. - Établissements. - Lycée. - Colléges. - Écoles primaires. - Écoles particulières. - Cours publics et gratuits. - Bibliothèque publique. - Société des sciences et arts. - Presse et ecrits périodiques. - Muséum d'histoire naturelle.

Direction : un inspecteur nommé par le ministre.

Surveillance : une Commission centrale et permanente, ainsi composée :

Le président de la Cour impériale, président;

L'inspecteur;

L'évêque ;

Le maire de Saint-Denis;

Le médecin en chef;

Trois membres au choix du gouverneur.

Établissements : 1 lycée impérial; 3 colléges ecclésiastiques; 99 écoles, asiles, ouvroirs, orphelinats et autres établissements destinés à l'éducation.

Le lycée impérial date de 1818 . Il a 33 professeurs et 9 maîtres répétiteurs. Tout ce qu'on enseigne dans les lycées de France y est également enseigné. - 430 élèves.

Le collége discésain de Sainte-Marie date de 1851. Dirigé par les RR. PP. Jésuites. -180 élèves, 1 recteur, 17 professeurs, 3 surveillants religieux, 9 professeurs laïques.

Le collége Saint-Charles, transféré en 1851 à Saint-Paul, compte 104 élèves. - 1 supérieur, 8 professeurs religieux, כ̌ professeurs laïques.

Le collége communal a été établi en 1856 à Saint-Benoît. Il a 
à sa tête 1 supérieur, 2 professeurs religieux et 3 laïques. 85 élèves.

Écoles primaires gratuites de garçons. Elles sont dirigées par les Frères des Écoles chrétiennes, et entretenues par la colonie. - 72 frères; 2,931 enfants, 2,40כ adultes. L'école agricole et professionnelle de Salazie est également dirigée par les Frères.

Sœurs de Saint-Joseph de Cluny. Elles dirigent 15 établissements d'instruction et plusieurs asiles pour l'enfancè.-2,35ั4 élèves gratuites, $\mathbf{4 7 4}$ élèves payantes.

Filles de Marie. Elles dirigent 5 ouvroirs et 1 orphelinat. 531 enfants.

Établissement de la Providence. Créé, en 1858, à Saint-Denis, par le gouvernement. C'est à la fois une école agricole et professionnelle, et un pénitencier de jeunes détenus. Les religieux du Saint-Esprit et du Saint-Cœur de Marie en ont la direction. 128 enfants à l'école; -100 détenus au pénitencier.

Établissements de Notre-Dame de la Ressource et de Nazareth. Fondés, en 1849, à Sainte-Marie, par les RR. PP. Jésuites pour l'instruction des jeunes Malgaches. - L'établissement de NotreDame est pour les garçons : 70 garçons. - L'établissement de Nazareth, sous la direction des sœurs de Saint-Joseph, est destiné aux filles : 48 filles. - Le but de ces établissements est d'initier les jeunes Malgaches à la connaissance de la religion catholique et de les former aux arts industriels; on les renvoie ensuite dans leur pays pour y propager la foi et la civilisation.

Écoles particulières payantes. - 44 écoles; 1,300 enfants.

Cours publics et gratuits. Ils embrassent sciences exactes, anglais, musique, dessin linéaire. Ils sont faits par des membres de la Société des sciences et arts.

Bibliothèque publique. Établie à l'hôtel de ville en 1859, elle date de 185̋. - 7,000 volumes.

Société des sciences et arts. Fondée en 1855 par M. HubertDelisle. Ghaque année, elle décerne une médaille d'or à l'auteur du meilleur travail sur les questions qu'elle propose. Il est publié un bulletin de ses séances.

Presse et écrits périodiques. - En 1863, la Réunion avait 7 journaux et plusieurs écrits périodiques, savoir :

Le Moniteur, Journal officiel de l'île de la Réunion, publié à SaintDenis et paraissant le mercredi et le samedi ; 
La Malle, publiée à Saint-Denis, et paraissant le jeudi et le dimanche;

Le Journal du commerce, paraissant à Saint-Denis, le mardi et le vendredi;

La Réunion, paraissant à Saint-Denis, le jeudi ;

Le Courrier de Saint-Pierre, publié à Saint-Pierre et paraissant le jeudi;

Le Phare de Saint-Paul, paraissant le jeudi à Saint-Paul;

La Semaine, journal illustré, publié à Saint-Denis et paraissant le jeudi;

L'Album de l'île de la Réunion, mensuel, donnant une feuille de texte et plusieurs lithographies ;

Le Bulletin de la Société des sciences et arts;

Le Bulletin officiel de l'île de la Réunion, mensuel ;

L'Annuaire de la Réunion;

L'Annuaire religieux.

\section{Muséum d'histoire naturelle.}

Fondé en 1854, par M. Hubert-Delisle, gouverneur. Ses collections sont très-riches. On y remarque ses poissons de Madagascar, etc.

\section{GHAPITRE VII}

Justice. - Cour impériale. - Tribunaux de première instance. - Justices de paix. - Cours d'assises. - Cour de cassation. - Statistique judiciaire. Ateliers de discipline. - Prisons. - Maison de correction. - Etablissements pénitentiaires de la Guyane (condamnés aux travaux forcés, etc.).

Cour impériale.

Elle siége à Saint-Denis. Elle est ainsi composée :

1 président;

7 conseillers;

1 conseiller-auditeur;

1 procureur général, chef du service judiciaire;

2 substituts;

1 greffier en chef. 


\section{Tribunaux de première instance.}

Il y en a deux :

Celui de Saint-Denis (arrondissement du Vent) est ainsi composé :

1 président;

2 juges;

1 juge d'instruction;

1 procureur impérial;

2 substituts ;

1 greffier.

Celui de Saint-Pierre (arrondissement Sous-le-vent) se compose de la même manière; toutefois il n'a qu'un juge et un substitut.

$$
\text { Justices de paix. }
$$

Il y en a neuf, c'est-à-dire une dans chaque canton. Les chefslieux sont : Saint-Denis, Sainte-Suzanne, Saint-André, SaintBenoît, Saint-Paul (arrondissement du Vent); Saint-Leu, SaintLouis, Saint-Pierre, Saint-Joseph (arrondissement Sous-le-vent).

\section{Cours d'assises.}

Chaque trimestre, il se tient deux cours d'assises : à SaintDenis et à Saint-Pierre.

Chacune de ces cours est ainsi composée :

3 conseillers de la cour impériale;

4 membres du collége des assesseurs (il se compose de $60 \mathrm{mem}$ bres).

\section{Cour de cassation.}

Le recours en cassation contre les arrêts rendus par les cours d'assises el par la cour impériale, jugeant correctionnellement, a été ouvert par le décret du.7 juin 1862.

L'arrondissement de Saint-Denis a 13 avocats, et celui de Saint-Pierre, 6.

Les avoués sont au nombre de 15 , les notaires au nombre de 16, et les huissiers au nombre de 10.

La statistique judiciaire, pendant la période de 1858 à 1860, donne les chiffres suivants :

Cour impériale. - La moyenne des affaires a été de 139 , chaque année.

Cours d'assises. - Les deux cours ont rendu, pendant les trois 
années (1858, 1859, 1860), 392 arrêts concernant 774 accusés. Il y a eu 5ૅ acquittements. - Le vol domestique a été le crime le plus fréquent. Les attaques contre les personnes et les propriétés ont été commises par des immigrants.

Tribunaux de première instance: Saint-Denis. - Ce tribunal ajugé 992 affaires, tant civiles que commerciales, et, en moyenne, 250 affaires sur appels de simple police.

Saint-Paul. - Ce tribunal a jugé 389 affaires, tant civiles que commerciales, et une moyenne de 141 affaires sur appels de simple police. (Le tribunal a été transféré à SaintPierre en 1862.)

Ateliers de discipline. - La moyenne des détenus a été de 427 individus par an, pendant les trois années 185ั8, 1859, 1860 .

Prisons. - En 1860, le nombre des détenus s'est élevé, dans les deux prisons de Saint-Denis et de Saint-Paul, à 1,122 individus.

Maison de correction. - En 1860, clle a eu 97 jeunes détenus.

Établissements pénitentiaires de la Guyone. - Les condamnés aux travaux forcés doivent y être envoyés. Les condamnés à la réclusion, d'origine asiatique ou africaine, peuvent y être envoyés aussi.

\section{GHAPITRE VIII}

Culte. - Diocèse de Saint-Denis. - Séminaire du Saint-Esprit (à Paris). Mission de Zanzibar. - Mission de Madagascar. - Communautés religieuses. Bureau de bienfaisance. - Société de Saint-Vincent de Paul. - Société de persévérance et de secours mutuels. - Autres sociétés chrétiennes et charitables. Hôpitaux, léproserie, hospice, lazaret, police sanitaìre.

La religion catholique est celle de la presque unanimité des habitants de la Réunion. On n'y compte qu'un petit nombre de protestants, mais les immigrants sont, pour la plupart, idolâtres.

Diocèse de Saint-Denis (suffragant de l'archevêché de Bordeaux).

Évêché (depuis 1860).

Deux archidiaconés (Saint-Denis et Saint-Paul).

Neuf cantons.

Cinquante-quatre paroisses.

Évêque. 
Deux vicaires généraux agréés.

Un certain nombre de vicaires généraux honoraires.

76 prêtres.

7 communautés religieuses.

Séminaire du Saint-Esprit (à Paris).

Le personnel du clergé de la Réunion se recrute des élèves formés au séminaire du Saint-Esprit, à Paris, et des ecclésiastiques appartenant aux diocèses de France qu'agrée l’évêque ou le supérieur général de la congrégation du Saint-Esprit et du Saint-Cœur de Marie.

Le passage est gratuit pour les ecclésiastiques agréés. Les indemnités de trousseau et autres fixées par les règlements leur sont aussi allouées.

\section{Mission de Zanzibar.}

Cette mission, qui s'étend du cap Delgado à l'Équateur, sur une profondeur inconnue, date de quelques années seulement. Placée sous la protection spéciale de Mgr l’évêque de la Réunion, elle a pour directeur un des grands vicaires de celui-ci. Son siége est à Zanzibar. Le monastère, établi dans la ville, renferme un hôpital, un hospice et des ateliers. L'hospice est affecté aux pauvres indigènes ; l'hôpital, aux malades européens. Les enfants apprennent des métiers dans les ateliers.

\section{Mission de Madagascar.}

Elle a son siége à la Réunion, et pour directeur, un préfet apostolique qui d'ordinaire réside à Saint-Denis. En 1860, le préfet était le R. P. Jouen, jésuite, supérieur de la communauté.

\section{Communautés religieuses.}

$1^{\circ}$ Communauté des RR. PP. jésuites, établis dans le diocèse en 1844. Le collége diocésain de Sainte-Marie et l'établissement malgache de Notre-Dame de la Ressource sont sous leur direction. Leur résidence est Saint-Jacques (Saint-Denis), et ils sont au nombre de 30.

$2^{\circ}$ Communauté des religieux du Saint-Esprit et du SaintCœur de Marie, établis en 1843. Ils dirigent à Saint-Denis l'établissement de la Providence, qui comprend une école agricole et professiónnelle, un pénitencier pour les jeunes détenus, un 
hospice de vieillards et d'infirmes. La léproserie est desservie par eux. En 1860, le R. P. Duboin était le supérieur de cette communauté.

$3^{\circ}$ Les RR. PP. Lazaristes, dont l'arrivée dans la colonie date de 1667. Ils l'ont quittée en $\mathbf{1 8 4 1}$ et y sont revenus en $\mathbf{1 8 6 1}$.

$4^{\circ}$ Les Frères des Écoles chrétiennes, établis en 1817. Ils avaient, en 1860, pour visiteur provincial le frère Jean de Matha, et comptent 66 frères et 8 novices. Ils dirigent, 18 établissements. Leurs services pendant le choléra de $\mathbf{1 8 5 9}$, ainsi que ceux des RR. PP. jésuites, leur ont conquis tous les cœurs dans la colonie. On peut, du reste, en dire autant des autres communautés.

$5^{\circ}$ Les sœurs de Saint-Joseph de Cluny, établies en 1816. Supérieure principale : sœur Aimée de Jésus de Poulpiquet (1860); 117 religieuses professes, 15 novices, 21 établissements (pensionnats, écoles gratuites, ouvroirs, salles d'asile). Les hôpitaux de la colonie sont desservis par ces religieuses.

$6^{\circ}$ Les Filles de Marie, congrégation fondée dans le diocèse en 1848 ; 62 religieuses professes, 9 novices et 10 postulantes ; 6 établissements (orphelinats, ouvroirs); l'hospice des vieillards et infirmes, ainsi que la léproserie, sont desservis par ces religieuses et celles du Saint-Esprit.

$7^{\circ}$ Les sœurs de Saint-Vincent de Paul, au nombre de quatre. Elles résident à Sainte-Suzanne. Elles sont attachées aux hôpitaux des exploitations de madame la vicomtesse Jurien de la Gravière. Leur établissement dans la colonie date de 1860.

\section{Bureaü de bienfaisance.}

Sa gestion est entre les mains du maire de Saint-Denis. Ses revenus sont exclusivement affectés à l'entretien de l'hospice de la Providence (vieillards et infirmes). Un projet de réorganisation est à l'étude.

Les autres institutions de bienfaisance sont les suivantes :

Société de Saint-Vincent de Paul.

Fondée en 1834 . - 1 conseil supérieur et 1 conseil particulier à Saint-Denis, 16 conférences; - 200 membres titulaires et honoraires.

Société de persévérance et de secours mutuels.

Son but est de venir en aide à la classe ouvrière. Pour les hommes, elle est sous le patronage de saint Fançois-Xavier, et 
compte 4,000 membres. Pour les femmes, elle est sous celui de Notre-Dame de Bon-Secours, et compte environ 3,000 membres .

Socièté des dames de charité.

Son but est l'entretien d'une maison de refuge à Saint-Denis pour les jeunès filles paurres. Elle doit son origine à madame Cuvillier.

Société des Mères chrétiennes.

Elle a son siége à Saint-Denis.

Société ouvrière et industrielle.

Elle est sous le patronage de Saint-François d'Assise. Elle a été fondée en 1848 par les ouvriers de Saint-Denis. Son siége est à Saint-Pierre. Elle compte plus de 150 membres. Son but est de venir en aide aux sociétaires maládes et estropiés, aux veuves des sociétaires défunts, aux orphelins. Elle a une caisse de secours, alimentée par des cotisations mensuelles.

Caisse de secours ecclésiastiques.

Son but est de venir en aide aux prêtres âgés et infirmes. Elle a été autorisée par un arrêté local du 18 octobre 1858.

Association des anciens élèves du Lycée.

Elle a pour but de venir en aide aux jeunes gens peu aisés; elle paye des bourses.

Association de prévoyance et de secours mutuels des médecins de la Réunion.

Cette association est agrégée à l'Association générale des médecins de France. Elle a le même but que celle-ci. Son président est nommé par l'Empereur.

OEuvres de la propagation de la Foi et de la Sainte-Enfance.

Les aumônes recueillies par elles, en 1861, ont atteint le chiffre de 23,641 francs.

\section{OEuvre apostolique.}

Sous le patronage des saintes femmes de l'Évangile. Établie en 1861, pour venir en aide aux missions et aux églises pauvres. 
Hôpitaux.

Deux hôpitaux militaires : l'un à Saint-Denis, l'autre à SaintPaul.

Deux hôpitaux civils : l'un à Saint-Denis, l'autre à SaintPierre.

Un hôpital thermal, à Salazie.

Une léproserie, à Saint-Denis (67 malades).

Un hospice pour la vieillesse (300 vieillards). Il fait partie de l'établissement de la Pravidence.

Succursale de l'hôpital de Saint-Denis (convalescents), à SaintFrançois, dans le haut de la ville.

Un lazaret, à la Grande-Chaloupe, près Saint-Denis.

La police sanitaire de la colonie est confiée à un conseil de 17 membres. Le service du lazaret, la surveillance des quarantaines, rentrent dans ses attributions.

\section{GHAPITRE IX}

Finances. - Dépenses de l'Etat. - Dépenses locales. - Recettes locales. - Budget des communes. - Banque de la Réunion. - Crédit colonial. - Assurances coloniales. - Crédit agricole.

Nous empruntons aux Notices publiées par ordre du ministre de la marine et des colonies les documents suivants.

Les dépenses publiques de la Réunion sont divisées en deux catégories principales : l'une comprend les dépenses de souveraineté et de protection, auxquelles il est pourvu au moyen de fonds alloués par le budget de l'État; l'autre se compose des dépenses d'administration intérieure, à l'acquittement desquelles est employé le produit des contributions publiques et autres revenus locaux.

DÉPENSES DE L'ÉTAT (EXERGIGE 1862).

Chap. 1er. - Personnel civil et militaire.

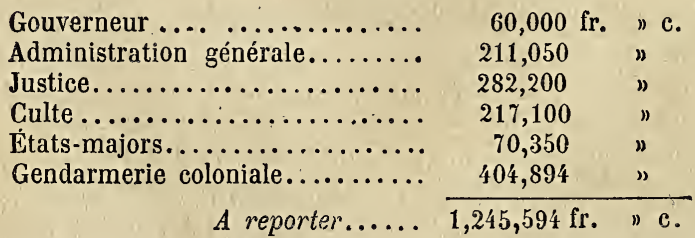




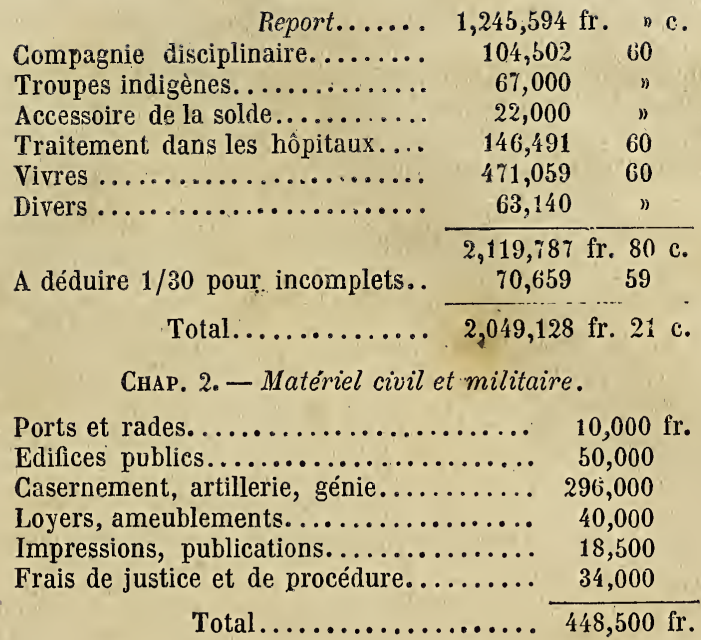

Les dépenses de l'État, tant pour le personnel que pour le matériel, s'élèvent donc à $2,497,628$ francs.

Ces dépenses ne comprennent pas celles de la station maritime locale, ni la solde des troupes d'infanterie et d'artillerie de marine en garnison dans la colonie. Ces dernières sont classées dans les différents chapitres du budget de la marine (service marine); la décomposition par colonies n'en est donnée que dans les Comptes définitifs de chaque exercice. Dans le compte de $\mathbf{1 8 6 0 ,}$ le dernier rendu, les dépenses du service marine effectuées pour le compte de la Réunion se sont élevées à la somme de $1,491,180$ francs.

\section{DÉPENSES LOCALES.}

Ces dépenses, ainsi que les rèssources locales destinées à y pourvoir, sont votées par le conseil général; elles étaient inscrites au budget de 1862 pour la somme de 7,685,252 francs. Savoir :

\section{SECTION 1. - DÉPENSES OBLIGATOIRES.}

Chap. $1^{\mathrm{er}}$ - Personnel.

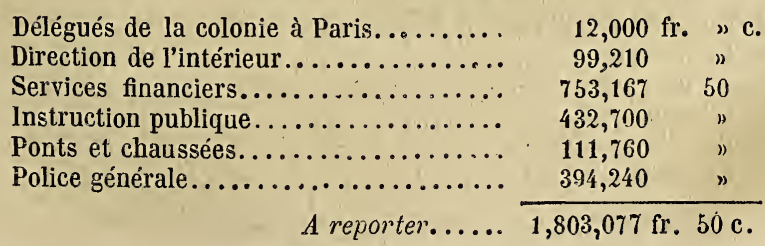




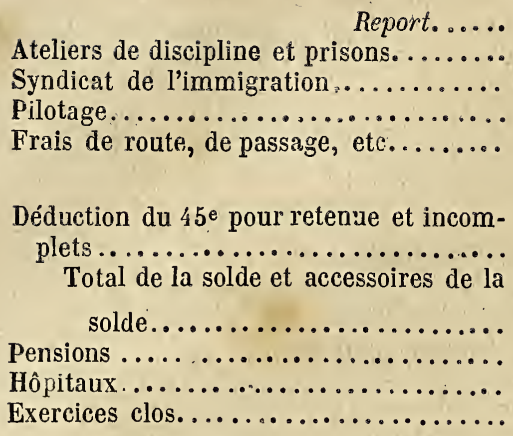

Total.

\begin{tabular}{cc}
$1,803,077$ fr. $50 \mathrm{c}$. \\
90,600 & $"$ \\
61,000 & $"$ \\
12,000 & $"$ \\
39,680 & $"$ \\
\hline $2,006,357$ fr. $50 \mathrm{c}$.
\end{tabular}

$44,585 \quad 72$

\begin{tabular}{rr}
\hline $1,961,771$ & 78 \\
34,113 & 84 \\
58,153 & 50 \\
3,586 & 67 \\
\hline $2,057,625$ fr. $79 \mathrm{c}$.
\end{tabular}

Chap. 2. - Matériel.

Frais de perception de l'impôt.......... Matériel des administrations financières. Loyers, mobiliers................ Menues dépenses des tribunaux et parquets .......................

Casernement de la gendarmerie........ Ateliers de discipline, prisons.......... Entretien de l'atelier colonial et des édifices ....................... Travaux d'entretien coloniaux, des routes, etc..................... Enfants trouvés, aliénés, dispensaires.... Mesures sanitaires................ Achats de terrains et d'immeubles...... Remboursement aux communes sur divers impôts................... Dépenses diverses de matériel.........

Total............ $2,706,652$ fr. 59 c.
$130,000 \mathrm{fr}$. ' $93,200 \quad$ ' 31,800 ' 28,700 (") $81,000 \quad$ " $275,106 \quad 50$ $270,000 \quad 》$ 619,140 $79,700 \quad$ " 110,500 ; $145,366 \quad 46$

$793,139 \quad 63$

$49,000 \quad$ "

\section{SECTION 2. - DÉPENSES FACULTATIVES.}

\section{Chнр. 3. - Personnel.}

Secrétariat et archives du gouvernement....... Personnel secondaire des ponts et chaussées.....

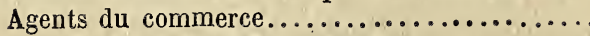

$7,800 \mathrm{fr}$. 43,400

10,500

7,200

44,900

23,112

6,000

9,000

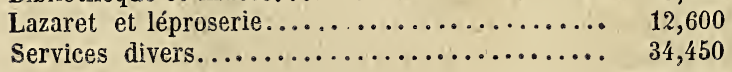

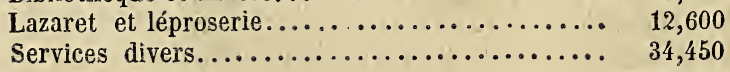

Total.................. 


\section{Chap. 4. - Matériel.}

Travaux maritimes................ Bâtiments civils et édifices coloniaux.... Routes, canaux et ponts.............

Hospice civil en régie...............

Atelier colonial....................

Frais d'impression, de reliure, etc......

Instruction publique................

Subventions pour le service postal avec l'Europe .......................

Subventions diverses...............

Encouragements aux cultures et à l'industrie.......................

Dépenses diverses et imprévues ........

Total............. $\overline{2,724,011 \text { fr. } 75 \mathrm{c} .}$

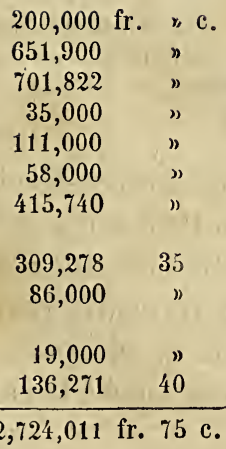

Le total général des dépenses (budget local) est donc de $7,685,252$ fr. 13 c.

\section{REGETTES LOCALES.}

Chap. $1^{\mathbf{e r}_{\mathbf{r}}}$ - Contributions directes.

(Y compris la part afférente aux communes et à la Chambre de commerce.)

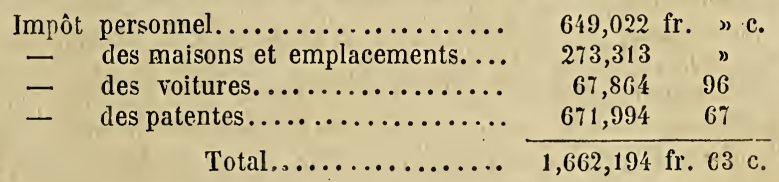

CHAp. 2. - Contributions indirectes.

Droits de sortie en remplacement de l'impôt

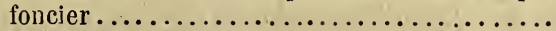

Droits d'importation.

$$
\begin{gathered}
1,600,000 \mathrm{fr} . \\
480,000 \\
3,000 \\
20,300
\end{gathered}
$$

$\begin{array}{rr}\text { Taxes accessoires de navigation.............. } & 20,300 \\ \text { Tarion } & 68,500\end{array}$

Droits accessoires de douanes............ 19,200

Impôt de fabrication des tabacs........... 160,000

- - des spiritueux (y compris

le dixième revenant aux communes)...... 1,700,000

Droits d'enregistrement ............... $\quad 775,000$

- de timbre...................... 162,000

- de greffe.................... 50,000

- d'hypothèques................... $\quad 3,000$

Taxe des lettres.................... 120,000

Total................

Ghap. 3. - Produits divers.

Produits divers................. 110,000 fr. "c.

Taxes des poids et mesures........... 35,000 "

Produits du lycée.................. 274,200 "

A reporter..... $419,200 \mathrm{fr}$. "c. 


$$
\text { Report..... 419,200 fr. "c. }
$$

Taxe d'introduction et de rengagement des immigrants.................... 135,000 "

Recettes diverses................ $308,357 \quad 50$

Total................ $862,557 \mathrm{fr} .50 \mathrm{c}$.

Le total des recettes (pour 1862) a donc été de 7,685,252 fr. $13 \mathrm{c}$. Celui de 1863 a été de 7,661,083 fr. 74 c. qui, déduction faite de la part attribuée aux communes sur les impôts perçus $(1,292,460 \mathrm{fr}$. $30 \mathrm{c}$.), s'est trouvé réduit à $6,388,623 \mathrm{fr} .44 \mathrm{c}$.

A la fin de chaque exercice, l'excédant des recettes sur les dépenses est versé à la caisse de réserve.

BUDGET DES COMMUNES.

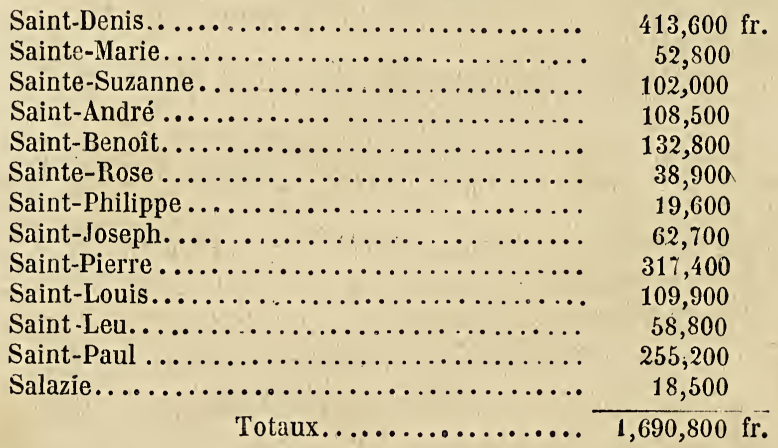

La Réunion compte un certain nombre d'établissements financiers.

\section{Banque de la Réunion.}

Elle a été créée, en exécution de la loi du 30 avril 1849, au moyen d'un prélèvement d'un huitième sur l'indemnité coloniale accordée aux propriétaires des esclaves émancipés en 1848.

La loi organique qui régit cet établissement, adoptée le 11 juillet 1851 par l'Assemblée législative, a été mise en vigueur à la Réunion le 17 mai 1853.

Fondée au capilal de 3 millions de francs, la Banque a le droit d'émettre des billets au porteur de 500,100 et 25 francs.

Elle est autorisée :

$1^{\circ} \mathrm{A}$ escompter des lettres de change et autres effets revêtus de deux signatures au moins;

$2^{\circ} \mathrm{A}$ escompter des engagements, négociables ou non, garantis par des transferts de rentes, des dépôts de lingots ou monnaies, 
des récépissés de marchandises ou des engagements de récoltes pendantes;

$3^{\circ}$ A se charger, pour compte de tiers, de tous effets à payer ou à recouvrer;

$4^{\circ}$ A recevoir des dépôts volontaires de lingots ou d'espèces.

Depuis son origine, la Banque de la Réunion n'a cessé de progresser. Ses actions, émises au taux de 500 francs, valent actuellement 800 francs.

Voici le tableau des dividendes répartis par la Banque depuis sa fondation jusqu'en 1862 inclusivement :

\begin{tabular}{|c|c|c|c|c|}
\hline $1853-1854 \ldots \ldots$ & 28,83 & par action, ou & 5,76 & p. 100 \\
\hline $1854-1855 \ldots \ldots$ & 40,16 & - & 8,07 & - \\
\hline $1855-1856 \ldots \ldots$ & 46,40 & - & 9,28 & - \\
\hline $1856-1857 \ldots \ldots$ & 50,40 & - & 10,08 & - \\
\hline $1857-1858 \ldots \ldots$ & 46,63 & - & 9,32 & - \\
\hline $1858-1859 \ldots \ldots$ & 47,91 & - & $.9,57$ & - \\
\hline $1859-1860 \ldots \ldots$ & 48,79 & - & 9,75 & - \\
\hline $1860-1861 \ldots$. & 51,81 & - & 10,35 & - \\
\hline $1861-1862 \ldots \ldots$ & 58,13 & 一 & 11,62 & - \\
\hline
\end{tabular}

Les opérations de la Banque, du $1{ }^{\text {er }}$ juillet 1861 au 30 juin 1862 , se sont élevées ensemble à la somme de $26,326,028 \mathrm{fr}$. 27 c. Le chiffre de l'exercice précédent n'était que de 22,603,708 fr. $93 \mathrm{c}$.

En 1860, la Banque de la Réunion, comme celles de nos autres colonies, a été autorisée à passer avec le comptoir d'escompte de Paris un traité qui a augmenté les facilités de crédit en procurant aux habitants, soit sur la France, soit sur l'étranger, les traites dont ils peuvent avoir besoin.

\section{Crédit colonial.}

Gréé par décret du 24 oclobre 1860, cet établissement a pour objet de prêter, soit à des particuliers, soit à des réunions de colons, les sommes nécessaires à la construction de sucreries nouvelles ou au renouvellement et à l'amélioration de l'outillage ancien.

Au 30 juin 1862, les prêts réalisés à la Réunion ou en cours de réalisation s'élevaient à 2,065,000 francs.

\section{Assurances coloniales.}

La Société des Assurances coloniales contre l'incendie a été autorisée par décret du 22 septembre 1862.

$\mathrm{Au}$ commencement de $\mathbf{1 8 6 3}$, le chiffre des assurances promises 
à la Société dépassait 10 millions de francs, minimum fixé par les statuts.

\section{Crédit agricole.}

Cette Société, établie par un arrêté du 19 août 1862, a été chargée de pourvoir à tous lés détails relatifs au service de l'immigration.

\section{CHAPITRE X}

Industrie et commerce. - Fabrication du sucre. - Ver à soie. - Construction navale. - Pêche. - Imprimeries. - Commerce. - Régime commercial de la Réunion. - Statistique commerciale de 1815 à 1861. - Importations. - Objets importés. - Exportations. - Réexportations. - Chambre de commerce.

La principale industrie de la Réunion est la fabrication du sucre.

Avant 1815, c'est-à-dire avant l'époque où M. Ch. Desbassyns se mit, en quelque sorte, à la tête de cette industrie, on se bornait à extraire de la canne le jus ou vesou, pour en faire des sirops ou des liqueurs spiritueuses (rhum, arack, tafia).

La canne, broyée entre des cylindres en bois, ne donnait qu'une faible partie du jus; M. Desbassyns, le premier, employa des cylindres en fonte verticaux, mus par une machine à vapeur. Maintenant, les machines puissantes de Derosne et Cail sont adoptées.

La colonie, en 1863, comptait 123 sucreries; 102 avaient des moteurs à vapeur; les autres étaient mues par des moulins à eau. La cuisson se fait au moyen des appareils de Wetzel, des batteries Gimart, des appareils à cuire dans le vide d'Howards. Pour la purgation du sucre, on se sert de turbines à force centrifuge, ce qui permet de livrer presque aussitôt après la cuisson le sucre au commerce.

La plupart des industries de la colonie se rattachent à l'industrie sucrière. On peut citer comme les plus importants :

$1^{\circ}$ La guildiverie, qui convertit les mélasses en rhum. Gette industrie, soumise au régime fiscal, fournit un des plus beaux revenus du gouvernement local et des communes; au budget de 1862 , la recette provenant de cette source s'élevait à la somme de 1,700,000 francs. On compte 25 guildiveries dans la colonie.

$2^{\circ}$ La chaudronnerie, qui occupe plusieurs maisons fort impor- 
tantes à Saint-Denis, dans lesquelles on construit et répare les appareils évaporatoires. L'un des grands ateliers de construction de Paris (Cail et $\mathrm{G}^{\mathrm{ie}}$ ) possède même une succursale à la Marre, aux environs de Sainte-Marie.

$3^{\circ} \mathrm{La}$ charronnerie, qui utilise les bois du pays à la construction de solides charrettes. L'un de ces principaux établissements, à Saint-Denis, fut détruit, il y a peu d'années, par l'incendie, mais quelques mois après il était reconstruit sur un plus vaste modèle.

$4^{\circ}$ La préparation des sacs de vacoua, pour l'emballage du sucre, qui emploie un nombre considérable de femmes, d'enfants ou d'hommes âgés et peu valides qui trouvent leur existence dans cette modeste industrie. Chaque sac peut contenir de 65 à 70 kilogrammes de sucre, et l'on met double emballage. Il se fabrique annuellementà la Réunion environ 3 millions de sacs qui se vendent de 50 à 65 centimes la pièce.

Ver à soie.

Les essais tentés depuis quelques années, satisfaisants sous le rapport des produits, ne l'ont point été sous le rapport du gain. Aussi cette industrie a-t-elle été presque complétement abandonnée.

\section{Construction navale.}

L'absence de ports, qui rend difficiles l'embarquement et le débarquement des marchandises, est loin de favoriser ce genre d'industrie. La création prochaine de plusieurs ports lui permettra de s'exercer sur des navires plus forts de tornage.

\section{Pêche.}

On ne s'y livre que le long des côtes et pour la satisfaction des besoins journaliers.

\section{Imprimeries.}

Il y en a 6 dans la colonie, et deux presses mécaniques pour le tirage des journaux.

Le commerce de la Réunion n'a pris en réalité quelque im-portance que depuis 1815. Auparavant, ses opérations avec la métropole nè se faisaient point directement, mais par l'intermédiaire de l'île de France ou Maurice (à l'Angleterre aujourd'hui). 
En 1815, le principe du monopole réciproque, en vigueur dans les autres colonies françaises, disent les Notices de la marine, fut appliqué à la Réunion; toutefois, la législation n'y fut jamais aussi restrictive qu'aux Antilles. Il existait, notamment pour le commerce de l'Inde, des franchises spéciales qui se maintinrent pendant de longues années et qui subsistent encore en partie. Il était d'autant plus difficile de soumettre cette colonie au régime général, appliqué aux autres possessions de la France, que la situation se compliquait de son éloignement de la métropole et du voisinage de Maurice, avec laquelle on ne pouvait rompre ses relations.

Les gouverneurs furent donc autorisés à laisser le commerce étranger en possession d'une partie de l'approvisionnemeńt de cette colonie, et à permettre aussi, dans certains cas donnés, l'envoi à l'étranger de ses produits. Cependant, les règlements locaux, successivement adoptés en cette matière, furent toujours calculés de manière à ménager un avantage au commerce naiional.

L'ordonnance du 18 octobre 1846 retira aux gouverneurs la faculté d'autoriser, en certains cas, l'admission des bâtiments étrangers et des marchandises étrangères et revisa le régime commercial de la colonie. Toutefois, il y a lieu de remarquer que les dispositions de cette ordonnance ont été un peu moins restrictives que celles qui avaient été adoptées en 1839 et en 1842 pour les Antilles, surtout en ce qui concerne l'exportation des produits locaux à l'étranger. Ainsi, tandis que les Antilles ne pouvaient y envoyer que les tafias et les sirops, la Réunion avait le droit d'expédier à l'étranger tous ses produits, à l'exception des sucres, café et colons. Cette exception n'atteignait pas les șirops ou sucres de basse qualité.

L'ordonnance de 1846 affranchit complétement du droit d'entrée les marchandises françaises importées à la Réunion, à l'exception des spiritueux; elle exempta aussi du droit de sortie les produits coloniaux exportés par navires français, en n'assujettissant à ce droit que les exportations permises par navires étrangers; elle augmenta la nomenclature des marchandises pouvant être importées directement de l'étranger, avec ou sans franchise de droits; enfin, elle régla les rappcrts commerciaux de la colonie avec les établissements français de l'Inde, Mayotte, Mascate, Madagascar, Maurice et la Ghine. Aux termes de cette ordonnance (art. 2), les provenances de Mayotte et dépendances, par 
navires français, jouissent d'une remise des trois quarts des droits, et celles de Mascate et de Madagascar d'une remise de moitié des droits.

Certains produits de l'Indo-Chine, objets de luxe et de fantaisie, sont admis au droit uniforme de 12 pour 100, lorsqu'ils sont importés par navires français.

Le régime commercial de la colonie a été modifié en dernier lieu par la loi du 3 juillet 1861.

Depuis la promulgation de cette loi dans la colonie, celle-ci peut exporter ses produits à l'étranger et recevoir les marchandises étrangères sous tous pavillons. Tous ses produits, autres que le sucre, les mélasses non destinées à être converties en alcool, les confitures et fruits confits au sucre, le café et le cacao, sont admis en France en franchise de droits de douane.

A la Réunion, comme aux Antilles, un décret du 6 octobre 1862 a accordé la franchise douanière aux produits exportés de France et fabriqués avec les matières étrangères admisos temporairement en franchise des droits.

Les ports ouverts au commerce à la Réunion sont ceux de Saint-Denis, Saint-Paul et Saint-Pierre, et c'est là seulement que sont établis des bureaux de douane.

Toutefois, les bâtiments français peuvent, avec l'autorisation de la douane, se rendre sur les autres rades de l'île pour y débarquer des marchandises d'encombrement et y embarquer des denrées coloniales.

Les perceptions des droits d'entrée et de sortie s'effectuent au moyen de mercuriales qui sont revisées périodiquement et définitivement arrêtées par le gouverneur en conseil privé.

\section{Statistique commerciale.}

De 1815 à 1861, le mouvement commercial (importation et exportation) s'est considérablement accru, - de $5,140,000$ francs à $87,081,914$ francs.

Voici au reste la progression depuis 1815 :

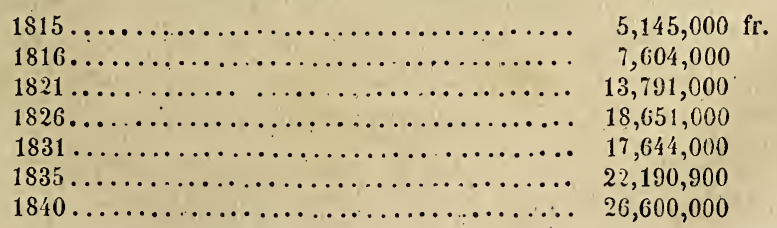




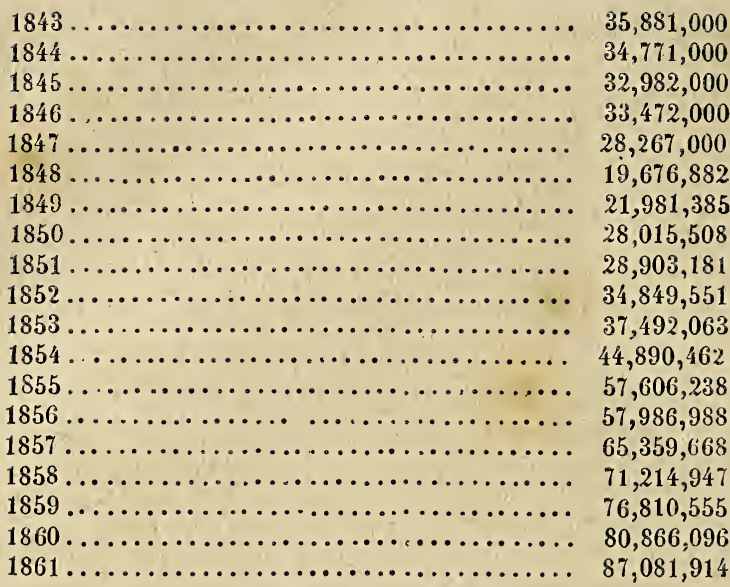

Importations (1861) : 52,791,134 francs. Exportations (1861) : 34,290,780 francs.

\section{Importations.}

Les principales denrées et marchandises importées à la Réunion, pendant l'année 1861, ont été les suivantes :

Chevaux, bêtes à cornes, porcs......

Gibiers, volailles, tortues..........

Produits et dépouilles d'animaux....

Engrais (guano et autres)..........

Poissons secs, salés ou fumés.......

Riz........................

Autres farineux alimentaires.......

Denrées coloniales, sucres bruts, condiments et stimulants...........

Huiles diverses................

Bois........................

Lichens tinctoriaux (de Madagascar).

Marbres sculptés, moulés ou polis...

Chaux.......................

Briques et tuiles..............

Ciment romain.................

Houille ......................

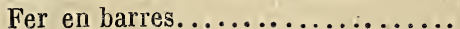

Cuivre laminé..................

Sel..........................

Couleurs et vernis..............

Parfumerie ...................

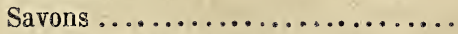

Acide stéarique ouvré............

Tabacs fabriqués...............

Sucre raffiné.................

$\begin{array}{cc}9,168 \text { têtes. } & 4,064,240 \mathrm{fr} . \\ 52,509- & 157,527 \\ \prime & 4,433,336 \\ 8,661,730 \text { kil. } & 2,598,519 \\ 2,443,084- & 1,233,742 \\ 35,271,986- & 9,523,438 \\ 774,534- & 3,909,507 \\ 112,271- & 209,018 \\ 843,897- & 976,123 \\ 5,370 \text { stères. } & 159,465 \\ 394,710 \text { kil. } & 394,710 \\ 45,710- & 228,550 \\ 4,875,994- & 124,670 \\ 1,783,136 \text { mille. } & 482,989 \\ 1,294,094 \text { kil. } & 124,670 \\ 1,924,605- & 769,842 \\ 876,827- & 350,732 \\ 104,873- & 419,492 \\ 1,698,755- & 169,876 \\ 57,783- & 176,709 \\ 37,413- & 187,090 \\ 783,091- & 783,091 \\ 160,743- & 642,972 \\ 48,728- & 292,368 \\ 56,740- & 113,480\end{array}$


Vins en fûts et en bouteilles.........

Bière . . .....................

Liqueurs et spiritueux............

Poteries et verreries..............

Tissus de coton.................

- de laine...................

- de lin ou de chanvre........

- de soie...................

Papier et ses applications...........

Peaux préparées et ouvrées, selleries.

Chapellerie

Cordages .....................

Orfévrerie, bijouterie, horlogerie....

Machines et mécaniques............

Ouvrages en fonte...............

- en fer, tôle et fer-blanc....

Voitures en cuivre et bronze......

Merceries....................

Modes et fleurs artificielles.........

Parapluies et ombrelles...........

Meubles......................

Linge et habillement.

$\begin{array}{cr}3,192,700 \text { litres. } & 3,381,606 \\ 231,681- & 231,681 \\ 342,575- & 645,015 \\ 120,633 \text { kil. } & 363,941 \\ 912,811- & 4,573,383 \\ 38,656- & 633,640 \\ 84,254- & 359,780 \\ 5,333- & 471,185 \\ 106,783- & 839,821 \\ 142,739- & 953,531 \\ 33,143 \text { pièces, } & 423,760 \\ 144,611 \text { kil. } & 211,743 \\ \text { " } & 615,966 \\ \text { " } & 1,633,943 \\ 201,180- & 120,708 \\ 466,180- & 683,001 \\ 21,352- & 119,740 \\ \text { " } & 203,650 \\ 35,622- & 142,688 \\ \text { " } & 516,640 \\ 13,138 \text { pièces. } & 197,070 \\ \text { " } & 488,082 \\ \text { " } & 544,613 \\ & \end{array}$

La valeur des apports de l'étranger, par navires français, en 1861, a été de 1,966,128 francs supérieure à celle de 1860 ; le riz forme le principal élément de cette augmertation.

La marche du commerce étranger, par pavillons étrangers, a également offert des résultats bien supérieurs à ceux de $\mathbf{1 8 6 0}$. Le chiffre de ces importations donne un excédant, en faveur de 1861, de 2,127,702 francs qui repose entièrement sur le guano.

La France fournit principalement à la colonie des tissus, des vins, des articles de modes, des ouvrages en fer et des machines. Les importations des colonies et pêcheries françaises se composent de riz, grains, d̉halls, huiles, tissus de coton (guinées), venues de nos possessions de l'Inde et de poissons provenant de Saint-Pierre et Miquelon. Enfin, les marchandises importées de l'étranger, c'est-à-dire de l'Inde anglaise, de Madagascar, de Maurice, du Cap et du Pérou, consistent principalement en riz, blé, grains, dhalls, bœufs, mules, gibier, volailles, tortues, viandes salées, légumes secs, saindoux, huile à brûler, guano, lichens tinctoriaux, cigares et tabacs fabriqués.

\section{Exportations.}

Au nombre des denrées, du cru de la colonie, exportées en 1861, on voit figurer : 


\begin{tabular}{|c|c|c|}
\hline Pommes de terre et légumes secs... & 328,179 kil. & $97,394 \mathrm{fr}$ \\
\hline Sucre brut....... & $60,054,546-$ & $30,290,703$ \\
\hline Sucre de sirop. & $1,556,554-$ & 233,059 \\
\hline Café ......... & $61,895-$ & 118,728 \\
\hline Girofles (clous et grifles) & $57,316-$ & 29,911 \\
\hline Vanille........... & $15,773-$ & $725,: 30$ \\
\hline Rhum. . & $50,5 \div 8-$ & 30,318 \\
\hline Sacs de vacoua............... & 95,772 pièces. & 57,464 \\
\hline
\end{tabular}

Réexportations.

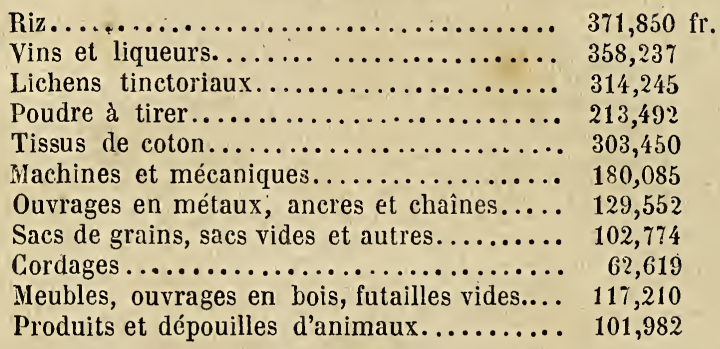

Différence entre les exportations de 1860 et 1861, et en faveur de $1860,4,051,347$ francs.

\section{Chambre de commerce.}

Elle se compose de 11 membres.

Ils sont nommés pour trois ans par le gouverneur et se renouvellent chaque année par tiers.

Leurs attributions sont consultatives.

Un droit additionnel de 1 1/2 p. 100 est perçu chaque année sur toutes les patentes de la colonie; c'est avec ce droit de 1 1/2 que les dépenses de la Chambre sont couvertes.

Les 14 agents de change de la colonie, courtiers de commerce, ont une chambre syndicale qu'ils nomment. Elle se compose de 3 membres.

\section{GHAPITRE XI}

Agriculture. - Sol cultivé. - Nombre d'hectares affectés à chaque culture. Canne à sucre. - Café. - Cacao, coton, etc. - Produit brut et produit net. - Statistique des travailleurs. - Statistique des animaux de trait et bétail. - Exportations : sucre et sirop, rhum, etc. - Chambre d'agriculture. - Expositions; courses, etc.

Les terres cultivées de la Réunion s'élèvent en plan incliné, sur la pente des montagnes, depuis le littoral jusqu'au tiers en- 
viron des hauteurs, et forment autour de l'île une lisière de 5 à 6 kilomètres de largeur moyenne, qui est interrompue seulement au S.-E. par le Grand-Brûlé, et au N.-O. par les montagnes s'étendant du cap Saint-Denis au cap de la Possession. Le sol de cette zone est affecté aux cultures tropicales. Dans l'intérieur de l'île, il existe plusieurs plaines, telles que la plaine des Cafres, la plaine des Salazies et la plaine des Palmistes, où l'on cultive presque exclusivement les vivres du pays. (Notices, etc.)

Nous allons indiquer la quantité d'hectares affectés à chaque culture et la quantité des produits en 1861 .

Canne à sucre.

Nombre d'hectares cultivés.

62,000 hectares.

Quantité des produits.

74,207,960 kilogrammes.

Valeur brute des produits....... 43,297,834 francs.

\section{Café.}

Hectares cultivés..............

Quantité des produits.............

Valeur brute..................

Coton.

Hectares cultivés..............

Quantité des produits............

Valeur brute.................

Cacao.

Hectares cultivés...............

Quantité des produits............

Valeur brute....................

Girofle.

En culture...................

Quantité des produits............

Valeur brute.................

Mûriers.

En culture

2,156 hectares.

412,600 kilogrammes.

813,950 franes.

10 hect. 5

400 kilogrammes.

400 francs.

22 hectares.

919 kilogrammes. 2,100 francs.

321 hectares.

9,000 kilogrammes. 5,500 francs.

46 hectares.

Épices.

En culture..................

Quantité des produits.............

Valeur brute.................

Maïs.

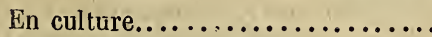

Quantité des produits............. $12,013,650$ kilogranmes.

5 hectares.

500 kilogrammes.

1,000 francs.

Manioc.

En culture...................

Quantité des produits.

1,344 hect. 5 . $6,475,950$ kilogrammes. 
Patates.

En culture...................

Quantité des produits............

Songes.

En culture

Quantité des produits.
857 hectares. $2,107,500$ kilogrammes.

304 hectares. 1,245,000 kilogrammes.

La valeur réunie du maïs, du manioc, des patates et des songes s'est élevée à 4,85̃1,630 francs.

Riz.

En culture

Quantité des produits.

Valeur brute..................

Légumes secs.

En culture

Quantité des produits.

Valeur brute.

Pommes de terre.

En culture.

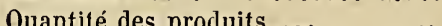

Valeur brute.

$\ldots \ldots \ldots \ldots$

\section{Tabac.}

En culture

Quantité des produits

Valeur brute.................

Blé.

En culture...................

Quantité des produits.............

Valeur brute..................

Avoine.

En culture..................

Quantité des produits.............

Valeur brute.

Embrevades.

En culture

Quantité des produits............

Valeur brute.

Jardinage.

En culture.

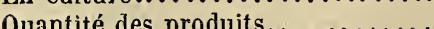

Valeur brute..................

\section{Vanille.}

92 hectares.

62,200 kilogrammes. 98,000 francs.

1,645 hectares.

767,750 kilogrammes. 329,450 francs.

956 hectares.

2,450,000 kilogrammes. 364,680 francs.

375 hectares. 625,939 kilogrammes. $1,351,878$ francs.

10 hectares. 11,500 kilogrammes. 5,070 francs.

281 hectares.

135,000 kilogrammes. 72,750 francs.

2,171 hectares.

1,043,300 kilogrammes. 403,490 francs.

1,377 hectares. $1,006,130$ kilogrammes. 436,739 francs.

116 hectares.

En culture. 
Quantité des produits............

Valeur brute.
3,881 kilogrammes. 388,100 francs.

Les savanes et les volcans occupent 42,706 hectares; les bois et forêts, 49,360 hectares et donnent un produit brut de 2,046,908 francs; les terres en friche, 35,013 hectares, et les dépendances du domaine public, 31,295 hectares.

Le total des produits bruts étant de $54,339,479$ francs, et les frais d'exploitation s'élevant approximativement à $23,753,150 \mathrm{fr}$., il reste, comme valeur nette, une somme de $30,586,329$ francs.

Chiffre des travailleurs employés aux cultures.

Travailleurs de 14 à 60 ans, constituant la partie ac-

tive des ateliers ruraux................. 61,871

Ouvriers de tout âge et de toute profession........ 8,586

Domestiques de tout âge, et des deux sexes........ 12,152

Gardiens ......................... 2,761

Total des travailleurs.......... $\frac{2,761}{85,620}$

Animaux de trait et bétail.

Chevaux ............................. 3,636

Anes................................. 924

Mulets............................ 8,278

Taureaux et bœufs.................... 5,608

Béliers et moutons...................... 4,608

Boucs et chèvres...................... 10,792

Cochons ........................... 60,571

Total...................... 94,417

Capital engagé dans les cullures.

Valeur des terres.................. 142,000,000 fr.

- des bâtiments et du matériel d'exploi-

tation ........................ $42,000,000$

Valeur des animaux de trait et du bétail.... $16,000,000$

- des contrats d'engagement des tra-

vailleurs introduits à la charge des proprié-

taires $(72,000$ contrats à $250 \mathrm{fr}$. $) \ldots \ldots \ldots \ldots \quad 18,000,000$

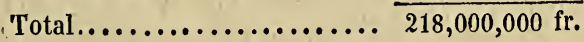

Il résulte de ce dernier total rapproché de celui du produit net des'cultures que, à la Réunion, la terre rapporte environ 7 p. 100.

\section{Exportations de $1851 \dot{a} 1861$.}

Sucre et sirop. 

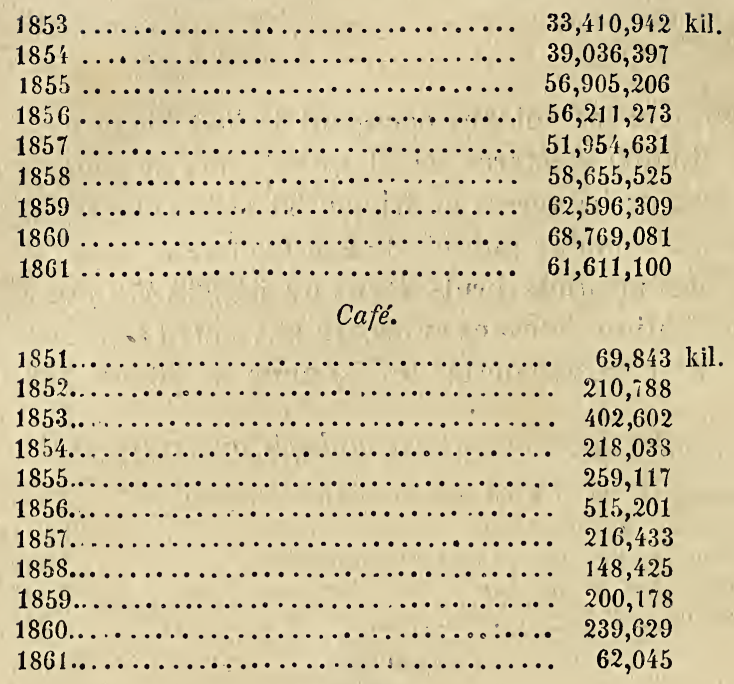

\section{Girofle.}

(Clous et griffes.)

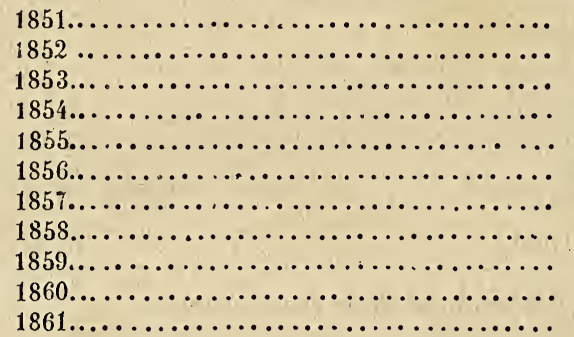

64,748 kil. 44,771 108,845 227,519 259,256 460,695 247,998 19,279 34,152 59.111 57,316

\section{Cacao.}

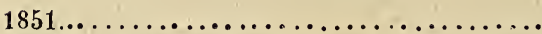

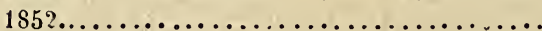

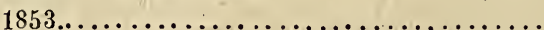

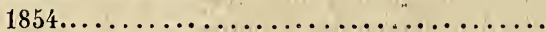

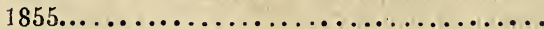

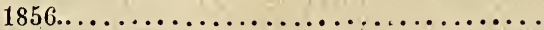

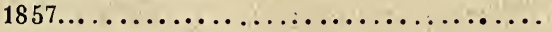

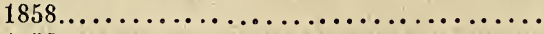

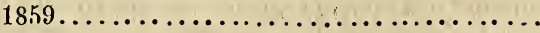

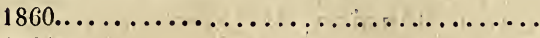

1861

$350 \mathrm{kil}$.

).

)

161

50

755

373

490

260

")

50

Inuscades et macis.

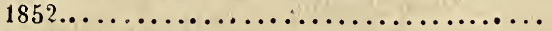

$1853 . \ldots \ldots \ldots \ldots \ldots \ldots \ldots \ldots \ldots \ldots \ldots \ldots$

1854. 
$1855 . \ldots \ldots \ldots \ldots \ldots \ldots \ldots \ldots \ldots \ldots \ldots \ldots \ldots \ldots \ldots \ldots \ldots$

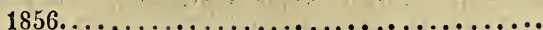

$1857 \ldots \ldots \ldots \ldots \ldots \ldots \ldots \ldots \ldots \ldots \ldots \ldots \ldots \ldots \ldots \ldots \ldots$

$1858 \ldots \ldots \ldots \ldots \ldots \ldots \ldots \ldots \ldots \ldots \ldots \ldots$

$1859 . \ldots \ldots \ldots \ldots \ldots \ldots \ldots \ldots \ldots \ldots \ldots \ldots$

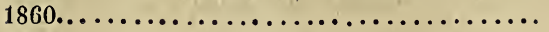

1861.

- Vanille.

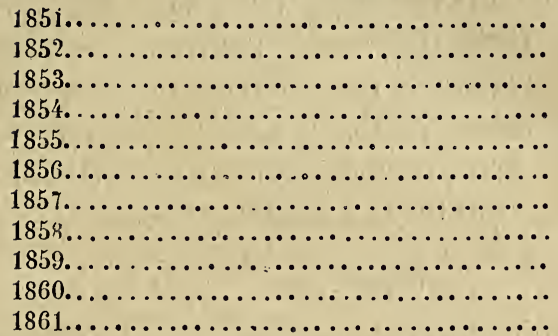

Rhum.

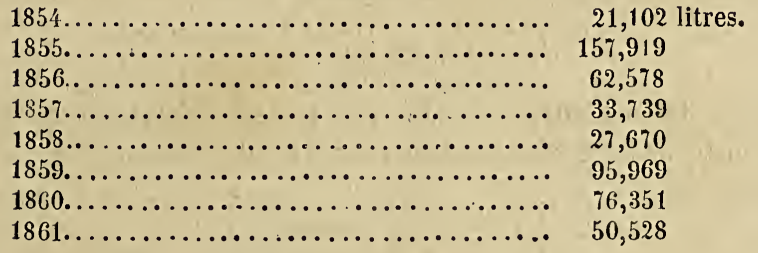

Légumes secs, grains, pommes de terre.

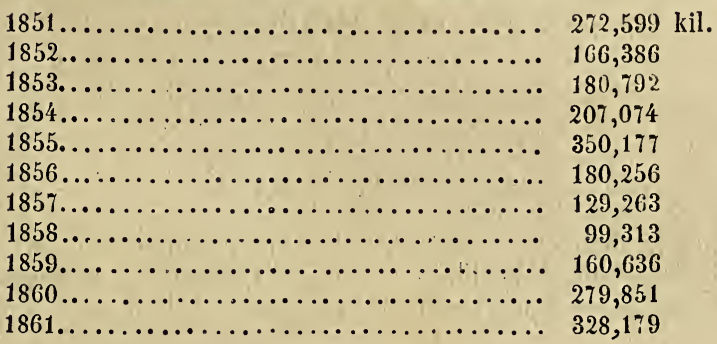

\section{Chambre d'agriculture.}

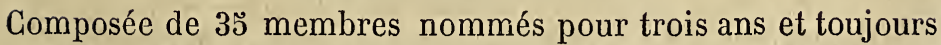
rééligibles. Elle tient une séance annuelle qui ne peut excéder vingt jours. Le directeur de l'intérieur peut la convoquer en session extraordinaire.

La chambre donne son avis sur toutes les questions relatives à l'agriculture. Son avis est d'ordinaire demandé sur les modifica- 
tions à apporter à la législation agricole, la police et l'emploi des eaux, la distribution des fonds généraux ou coloniaux destinés à l'encouragement de l'agriculture, etc. La statistique agricole de la colonie est spécialement confiée à ses soins.

\section{Expositions.}

La première remonte à 1853. Elle a lieu à Saint-Denis. Depuis, il y en a eu en 1854, 1855, 1856, 1858. En 1858, le nombre des exposants fut de 482, y compris une soixantaine d'exposants appartenant à l'île Maurice (aux Anglais).' Le rôle joué par l'agriculture de la Réunion à l'Exposition agricole de Paris (1860) est exposée dans l'appendice, qui termine cette partie.

\section{Courses.}

Elles ont lieu ordinairement en meme temps que l'Exposition. Elles datent de 1846.

\section{Jardin botanique.}

Fondé à Saint-Denis vers 1773. Il possède un herbier local de 1,500 plantes. Il a 2,500 plantes classées et cataloguées.

Socièté d'acclimatation.

Constituée et autorisée par arrêté du 18 septembre 1862. Elle est en correspondance avec la Société de Paris.

\section{GHAPITRE XII}

Les produits de la Réunion. - Historique. - Canne à sucre. - Café. - Girofle. - Muscade. - Gacao. - Vanille. - Coton. - Céréales. - Racines et tubercules. - Légumes. - Fruits. - Thé. - Tabac.

Les principaux produits de la Réunion sont, comme nous l'avons dit :

La canne à sucre;

Le café ;

Le girofle;

La muscade;

Le cacao;

La vanille; 
Le coton;

Les céréales;

Les racines et tubercules;

Les légumes;

Les fruits;

Le the ;

Le tabac.

Jetons un coup d'œil sur l'histoire de ces intéressants végétaux.

\section{Canne à sucre.}

On pense qu'elle est indigène. Toutefois, les espèces introduites dans la colonie à diverses époques sont exclusivement cultivées.

La canne jaune venue, dit-on, de Saint-Domingue, a supplanté la canne de Batavia, d'abord adoptée. Elle donne un vesou plus abondant. C'est cette canne jaune que l'on connaît sous le nom de canne de Bourbon, dans la mer des Indes.

Depuis 1850 , après la maladie terrible qui a ravagé la canne jaune, on a essayé de plusieurs autres plants.

La canne rouge, entre toutes, a le mieux réussi. Toutefois, depuis quelques années, une chenille, introduite dans des plants venus de Geylan, a causé de grands dégâts dans les champs de cannes. On n'a pu encore parvenir à l'en chasser.

C'est de la fin de juin à janvier, dans l'arrondissement du Vent, et un peu plus tard dans l'arrondissement Sous-le-vent, à cause des sécheresses, qu'a lieu la récolte.

La canne est mûre 15 à 30 mois (suivant la qualité et l'altitude) après la mise en terre des plants ou boutures. Une recoupe est ordinairement possible au bout d'un ou deux ans, puis une autre encore deux ans après. La canne est ensuite arrachée et remplacée par du plant nouveau.

\section{Café.}

La canne à sucre tend de plus en plus à se substituer à la culture du café ; le café avait lui-même supplanté la culture des grains dans la colonie.

Il est indigène. Longtemps on fut sans se douter de ses propriétés. En 1715 seulement, de la Boissière, commandant d'un 
navire français, revenant de Moka, ayant apporté à Bourbon des branches et des baies du café d'Arabie, les habitants de l'île furent tout surpris de reconnaitre dans ces baies et ces branches celles d'une plantequi croissait près d'eux. On se réunit en toute hâte, et un conseil provincial décida que le gouverneur de l'île, M. de Parat, serait envoyé en France pour faire part de cet important événèment.

Cependant, après un examen minutieux, on constata que le café indigène manquait de cette suavité si recherchée, si agréable dans le moka. On adopta donc, et presque exclusivement la culture de celui-ci.

L'ouragan de 1806 a porté un coup fatal au moka de la Réunion. La canne à sucre lui en a porté un second. L'île ne produira bientôt plus de café.

Dans notre Science populaire, $1^{\text {re }}$ année (1863), nous donnons une histoire assez étendue du café, de sẹ variétés, de ses effets, de sa préparation, etc. - V. aussi l'appendice.

\section{Girofle.}

La culture du giroflier fut introduite å la Réunion en 1770 par l'intendant Poivre. Après avoir été très-florissante, après avoir, il y a trente ans, produit jusqu'à 800 et 900,000 kilogrammes, elle est sur le point d'être complétement abandonnée.

\section{Muscade.}

Le muscadier, introduit aussi par l'intendant Poivre en $\mathbf{1 7 7 0 ,}$ ne réussit pas d’abord. Mais deux ans après, des plantes et des graines apportées par J. Hubert, réussirent au mieux. Dès lors, le muscadier fut un des éléments de la richesse coloniale.

\section{Cacao.}

On ignore le nom de l'introducteur du cacaotier à l'île de la Réunion. Depuis le commencement de ce siècle, la culture en a été fort négligée. Les produits qu'il donne entrent, à peu près complétement, dans la consommation locale.

Cet état de choses est fâcheux; car le cacaotier, ainsi que l'a prouvé l'Exposition de Paris (1860), donnerait d'excellents résultats à la Réunion, et en général dans toutes leṣ colonies françaises. 


\section{Vanille.}

L'introduction de la vanille à la Réunion ne date que de 1818, M. Perrote en fut l'introducteur. A partir de 1800, la culture de ce précieux végétal a pris des proportions considérables, et en 1860, à l'Exposition générale et nationale d'agriculture, tenue 'à Paris, le jury décernait à M. Turpin-Demorel une médaille d'or pour sa vanille longue, plate et givrée.

C'est párticulièrement sur les petites propriétés que la culture de la vanille est avantageuse. Aussi l'y rencontre-t-on de toutes parts.

Le prix des qualités supérieures qui, dans l'origine, atteignait 150 et 200 francs le demi-kilogramme, est aujourd'hui tombé de 75 à 100 francs.

L'appendice que nous mettrons à la fin de ce travail donnera d'autres détails.

\section{Thé. .}

La culture du thé, introduite tout récemment, a déjà présenté des résultats très-satisfaisants. Ses produits, fort peu abondants jusqu'ici, se distinguent par leur qualité vraiment supérieure.

\section{Tabac.}

Le tabac de la Réunion a figuré très-honorablement (V. l'Appendice) au concours de Paris en 1860. Il se rapproche du tabac de Virginie.

La culture en est libre. Toutefois il est perçu un droit de fabrication de 2 francs par kilogramme de tabac en feuilles et de 20 francs par mille de cigares.

Le tabac, suffisant à peine aux besoins de la consommation locale, ne figure pas dans le tableau des exportations donné ailleurs.

\section{Coton.}

Le coton fut, dit-on, apporté de Surate en 1677, par le père Bernardin.

Au concours de Paris (1860), le coton de la Réunion a remporté deux mentions honorables.

Il est fâcheux que ce produit, d'abord très-abondant, ait été dẹ nos jours à peu près abandonné. 


\section{Céréales.}

Blé. En 1783, la Réunion produisait 4 millions de kilogrammes de blé et faisait face à tous les besoins de la consommation locale. Elle exportait; ses anciens magasins, bien conservés, sont encore là pour attester le fait.

Aujourd'hui, la culture du blé est en pleine décadence.

Dès 1837, le nombre d'hectares cultivés n'était plus que de 1,373 , et le blé récolté ne dépassait pas 395,000 kilogrammes.

Avoines. - Elles réussissent bien. On les emploie, ainsi que le maïs, à la nourriture des bestiaux.

Maïs. - Il est, avec le riz et le manioc, la principale nourriture des travailleurs indiens et des créoles.

Riz. - Sa culture est presque abandonnée. Il était d'une qualité supérieure à celui de l'Inde, d'où on le fait venir aujourd'hui, comme aussi de Madagascar.

\section{Racines et tubercules.}

Manioc. - Le manioc fut introduit à la Réunion par Mahé de la Bourdonnais, directeur général en 1735 . Le suc de cette racine, poison violent en Amérique, perd à la Réunion cette déplorable propriété.

Le manioc est cultivé par toute J'île; les sucreries s'en servent comme d'assolement.

Songes. - D'origine américaine, cette racine porte le nom de chou caraïbe, en Amérique.

Pomme de terre. - La culture en est des plus faciles. Il suffit d'en semer une fois, surtout dans les plaines de l'intérieur et dans les hauts, pour qu'elle se reproduise d'elle-même et à peu près indéfiniment.

La pomme de terre est l'objet d'une exportation très-importante. La population anglaise de Maurice (ancienne île de France) en fait une grande consommation et la paye cher.

Le manioc, la pomme de terre et les songes ou chou caraïbe constituent ce qu'on appelle à la Réunion les vivres du pays.

Dans le tableau des produits de la Réunion (V. l'Appendice), les vivres, en comprenant sous cette dénomination, - outre le manioc, la pomme de terre et les songes, - les embrevades, riz, maïs, haricots, patates, jardinage, les vivres ont occupé en $\mathbf{1 8 3 7}$ 
une surface de 41,134 hectares. En 1857, elle n'était plus que de 27,345 hectares.

\section{Fruits.}

Les fruits d'Europe sont, pour la plupart, cultivés dans les jardins. La plupart des fruits des tropiques se trouvent dans l'île: ananas, avocat, banane, citrouille, datte, figue, fraise, framboise, fruit à pain, mangoustan, mangue, melon, orange, pêche, raisin, sapotille, etc.

Le vacoua mérite une mention particulière. Cultivé partout, mais particulièrement dans les communes de Sainte-Rose et de Saint-Philippe, ce végétal offre une feuille avec laquelle on fait des sacs propres à l'emballage du sucre.

Le nombre de ces sacs a été, en 185\%7, de plus d'un million et demi; la valeur nette a été de 346,000 francs.

\section{Légumes.}

La plupart sont, on l'a vu plus haut, compris, avec le manioc, la pomme de terre et les songes, sous la dénomination de vivres.

Les légumes de France sont cultivés avec succès à la Réunion. Ils y prospèrent; mais il n'en est pas de même des plantes potagères d'Europe. La facilité avec laquelle elles y dégénèrent n'en encourage pas la culture.

En 1857, les vivres ont donné une valeur nette de 2,590,000 francs.

\section{CHAPITRE XIII}

Commerce maritime. - Entrées. - Sorties. - Mouvement de la navigation de 1846 à 1861. - Cabotage. - Son importance. - Effectif de la marine locale. - Législation relative à la navigation coloniale. - Recettes de la douane. Octroi de mer. - Entrepôt de Saint-Denis.

En 1861, le commerce maritime de la Réunion a occupé 222 navires francais, jaugeant 84,583 tonneaux et montés par 3,611 hommes d'équipage, - et 41 navires étrangers jaugeant 24,867 tonneaux.

\section{ENTREES.}

(France.)

Bordeaux.

27 nav. franç. 10,583 tonn. 429 hommes d'équip. 
Marseille.

25 nav. franç. 10,263 tonn. 388 hommes d'équip.

Le Havre.

\begin{tabular}{|c|c|c|c|c|}
\hline 15 & - & 6,874 & - & 272 \\
\hline 94 & - & 38,078 & - & $\begin{array}{l}\text { Nantes. } \\
1,542\end{array}$ \\
\hline & & & & Saint-Malo. \\
\hline t & - & 285 & - & 13 \\
\hline & - & 348 & - & $\begin{array}{c}\text { Dunkerque } \\
14\end{array}$ \\
\hline
\end{tabular}

(Colonies françaises.)

Saint-Pierre et Miquelon.

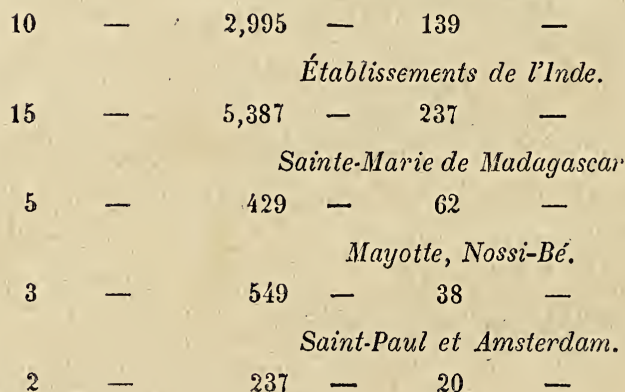

(Pays étrangers).

Inde angluise.

80 nav. franç. 33,843 tonn. 1,319 hommes d'équip. 15 nav. étrang.

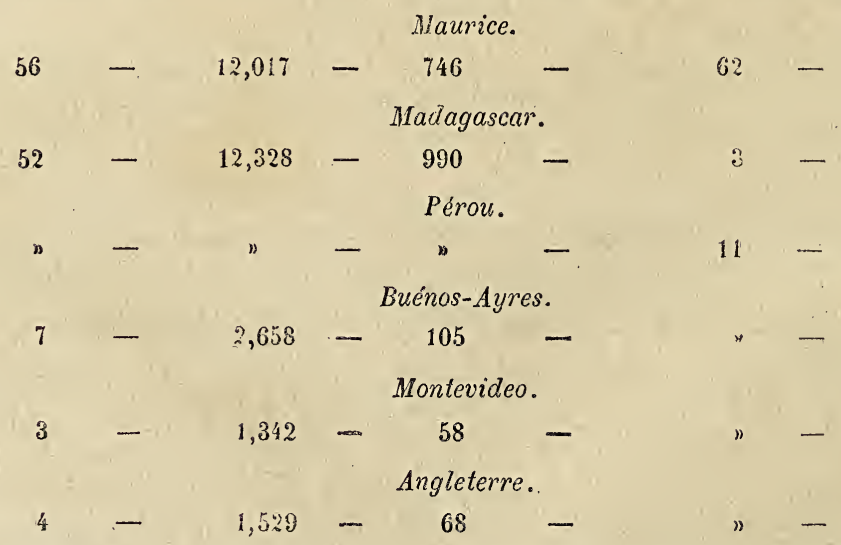




\section{Mascate.}

2 nav. franç. 175 tonn. 16 hommes d'équip. „ nav. étrang. Cap de Bonne-Espérance.

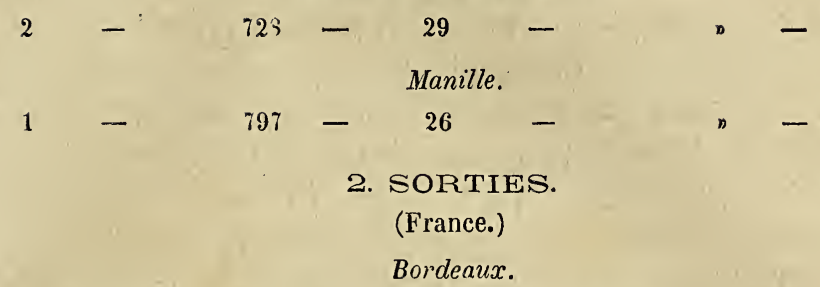

16 nav. franç. 6,071 tonn. 246 hommes d'équip. nav. étrang. Marseille.

$\begin{array}{cccccc}21 & - & 8,542 & - & 324 & - \\ & & & & & \text { Le Havre. } \\ 7 & - & 3,150 & - & 123 & - \\ & & & & \text { Nantes. } & \\ 78 & - & 30,817 & - & 1,225 & -\end{array}$

(Colonies françaises.)

Etablissements de l'Inde.

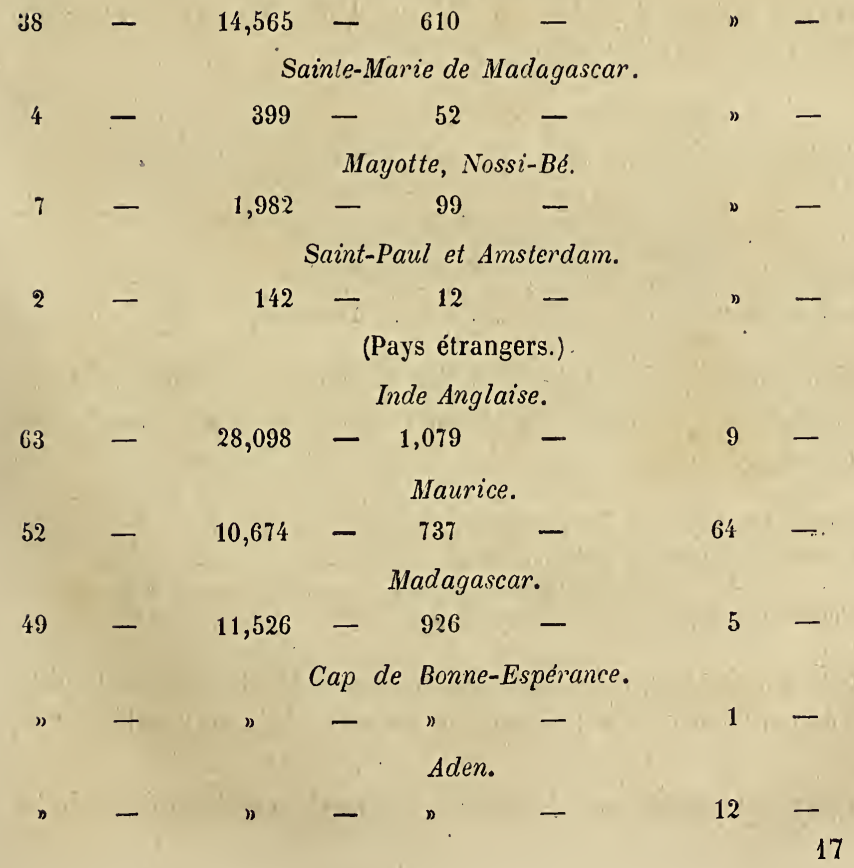




\section{Sydney.}

5 nav. franç. 1,519 tonn. $\quad 73$ homm. d’équip. 1 nav. étrang.

Ceylan.

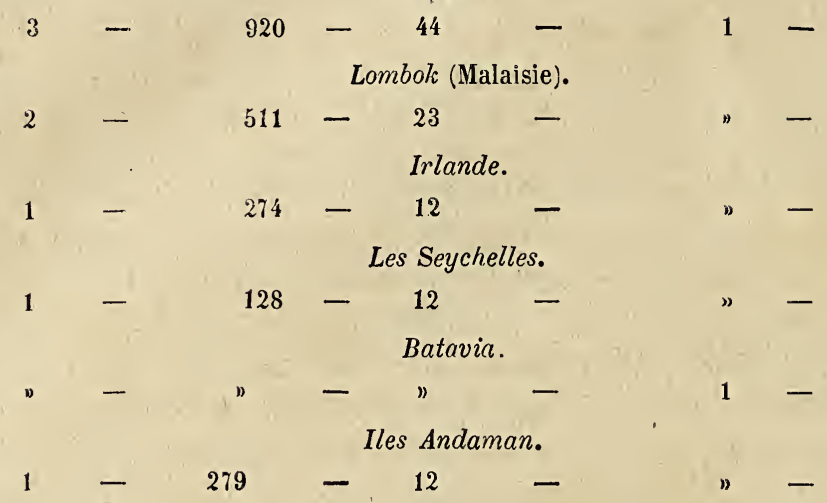

Le mouvement de la navigation qui, en 1846, était de 200 navires français, 51,858 tonneaux, et de 42 navires étrangers, de 3,906 tonneaux, a plus que doublé depuis cette époque jusqu'en 1861.

Le cabotage autour de l'île a porté, en 1861, sur une valeur de 45,023,194 francs se décomposant ainsi :

Marchandises embarquées provenant:

Du cru de la colonie............. 20,748,963 fr. 88 c.

De l'importation............... 4,707,805 75

Marchandises débarquées provenant :

Du cru de la colonie.............. 2,002,003 fr. 68 c.

De l'importation................ 17,565,341 28

La marine locale présentait, en 1856, un effectif de 481 navires, bateaux et goëlettes, affectés tant au long cours qu'au grand ou au pelit cabotage :

Navires employés au long cours ou au grand cabotage.. 11

Bateaux employés au petit cabotage............... 76

- $\quad$ au batelage.................... 114

Pirogues employées à la pêche autour de l'île........ 280

Les Notices publiées par ordre du ministre de la marine et des colonies résument ainsi la législation relative à la navigation coloniale.

Le gouverneur exerce une haute surveillance sur la police de la 
navigation. Il délivre les actes de francisation et les congés de mer, en se conformant aux ordonnances et instructions du ministre de la marine et des colonies.

Les droits de navigation, perçus au profit de la douane et réglés par l'ordonnance du 18 octobre 1846, se composent des droits de tonnage, des droits de congé, ou de passe-ports, des permis de charger on de décharger, des droits de francisation et des droits sanitaires.

Les taxes accessoires de navigation, perçues au compte du service local et déterminées par des arrêtés locaux (23 oct. 1843, 23 juin 1845, 18 juillet 1849, 27 décembre 1861), comprennent les droits de pilotage, de mouillage provisoire, le droit annúel sur les bateaux caboteurs, le droit de jaugeage, de francisation, de phares, d'aiguade, de halage et d'accostage sur les bateaux (ceux de pêche exceptés), enfin des droits de visite sanitaire et de garde à bord des bâtiments.

Les recettes de la douane ont donné, en 1860, la somme de 2,349,392 fr. 06 c., et, en 1861 , celle de 2,359, 733 fr. $43 \mathrm{c}$.

Voici le détail des droits de la douane pour cette dernière année :

\section{SERVIGE LOGAL.}

$1^{\circ}$ Douanes.

Droits de douane à l'importation........

à l'exportation .........

Droits de navigation et de port..........

Taxes accessoires...

Droits accessoires de magasinage........

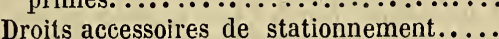

Droits divers. Prélèvement sur le produit des saisies au profit du trésor colonial..

Droits divers au profit du service des pensions civiles. ....................

20 Contributiors.

Contributions directes. Droits à la sortie ou impôt foncier..................

Contributions indirectes. Impôt de fabrication sur les tabacs..............
567,938 fr. 07 c.

$2,706 \quad 79$

$22,870 \quad 57$

$76,197 \quad 17$

$20,555 \quad 10$

$5,755 \quad 95$

$376 \quad 26$

$192 \quad 57$

$529 \quad 46$

$1,068,158$ fr. 71 c.

$100,398 \quad 20$

\section{SERVIGE MUNIGIPAL.}

Octroi à l'entrée par mer. 
Les droits et produits ci-dessus se sont ainsi répartis entre les trois ports ouverts au commerce :

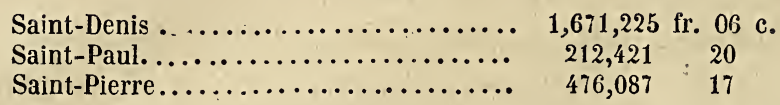

L'impôt de fabrication des tabacs est, on l'a vu, de 2 francs par kilogramme de tabac en feuilles et de 20 francs le mille de cigares.

La taxe coloniale sur l'exportation des denrées, taxe qui remplace l'impôt foncier, est de 2 1/2 p. 100 de la valeur de la vanille et de 4 p. 100 sur tous les produits.

Le droit de douane à la sortie, droit perçu seulement sur les denrées exportées sous pavillon étranger, est fixé à 2 francs par 100 kilogrammes ou par hectolitre de liquide.

Le service des douanes, chargé de la perception de l'octroi de mer, a une remise de 7 p. 100 sur le produit de ce droit.

Le port de Saint-Denis est le siége d'un entrepôt, où sont reçues les marchandises admissibles à la consommation et celles qui sont prohibées dans la colonie et en France. Les marchandises étrangères, non admissibles à la consommation de la colonie, ne peuvent être apportées à l'entrepôt, ni leur réexportation s'effectuer que par bâtiments de 50 tonneaux au moins.

La durée de l'entrepôt est de trois ans. Les marchandises déposées à l'entrepôt sont passibles, à leur sortie, d’un droit de magasinage. Le droit d'entrepôt est fixé, pour les marchandises venant de France ou de l'Inde, à 0,75 p. 100 de la valeur, et pour les marchanảises venant de l'étranger à 1 fr. 25.

Les marchandises françaises, passibles du droit d'octroi, peuvent être mises en entrepôt fictif, ainsi que les huiles destinées à la fabrication des savons à Saint-Denis.

La durée de l'entrepôt fictif est de six mois; à l'expiration de ce terme, les marchandises doivent être mises en consommation, ou réexportées, ou bien être déposées à l'entrepôt réel.

\section{1}

Entrées.

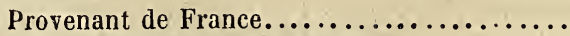

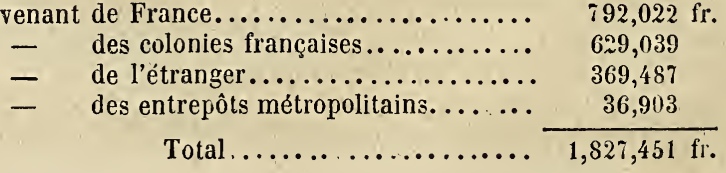


Sorties.

Pour la France................... $33,888 \mathrm{fr}$.

- les colonies françaises................ 98,479

- l'étranger ....................... $\quad 593,376$

- la consommation locale.............. $1,741,887$

Total..................

En 1860, les entrées avaient donné 2,262,182 francs, et les sorties $2,023,048$ francs.

Il y a eu, en 1861, comparativement à 1860, une diminution de 434,731 francs dans les entrées venant de France, et de $15 \% 6,844$ francs dans les sorties pour la France, mais une augmentation de 61,929 francs dans la réexportation pour les colonies et l'étranger, ainsi qu'une augmentation de 539,497 francs dans les sorties pour la consommation locale.

\section{CHAPITRE XIV}

Armée. - Effectif de la garnison. - Etat-major. - Génie. - Artillerie de marine. - Infanterie de marine. - Disciplinaires des colonies. - Gendarmerie coloniale. - Milice coloniale. - Station maritime.

Les troupes de la garnison et les milices locales composent les seules forces militaires de la colonie.

La garnison a un effectif de 46 officiers et de 1,124 sous-officiers et soldats:

$$
\text { État-major. }
$$

1 lieutenạnt de vaisseau, attaché à l'état-major général.

1 capitaine d'infanterie de marine, adjudant de place à SaintDenis.

\section{Génie.}

1 chef de bataillon, directeur;

1 lieutenant;

3 gardes du génie;

1 compagnie indigène d'ouvriers du génie ( 3 officiers, 93 sousofficiers et soldats).

Artillerie de marne.

1 chef d'escadron, directeur;

1 sous-chef, ouvrier d'état;

1 garde d'artillerie de $1^{\text {re }}$ classe; 
1 maitre armurier;

1 batterie d'artillerie de marine ( 4 officiers, 96 sous-officiers et soldats);

1 section de canonniers ouvriers ( 1 officier, 45 ouvriers).

Infanterie de marine ( $4^{\mathrm{e}}$ régiment).

1 lieutenant-colonel;

1 chef de bataillon;

1 capitaine d'état-major;

1 capitaine adjudant-major;

1 chirurgien aide-major;

1 lieutenant, officier payeur;

1 sous-lieutenant, chargé de l'habillement;

4 compagnies ( 3 officiers, 111 soldats pour chacune).

Total : 19 officiers, 444 sous-officiers et soldats.

Disciplinaires des colonies.

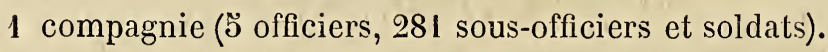

Gendarmerie coloniale.

1 compagnie ( 4 officiers, 162 sous-officiers et soldats, dont 90

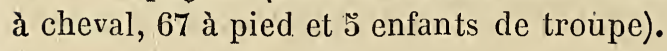

Milice coloniale.

Deux classes : classe mobile, comprenant les habitants valides de 17 à 45 ans; classe sédentaire, comprenant les habitants valides de 4 ว̆ à ら̆つ̆ ans.

La milice coloniale est sous le commandement'supérieur du gouverneur.

Dans chaque commune, elle obéit à un commandant des milices.

L'infanterie est organisée par compagnies et par bataillons; la cavalerie par subdivisions d'escadron.

Quelques communes ont des compagnies d'artillerie et de sapeurs-pompiers.

Les peines disciplinaires sont de ร00 francs d'amende et de 3 jours d'emprisonnement au plus.

Des indemnités de déplacement sont accordées aux hommes de la milice, quand les déplacements ont lieu en dehors des prescriptions réglementaires : 15 francs pour les officiers supérieurs; 
10 francs pour les capitaines; 6 francs pour les lieutenants et sous-lieutenants; 2 francs pour les sous-officiers et soldats.

\section{Station maritime.}

La Réunion, centre de la division navale des côtes orientales d'Afrique, a une station locale qui se compose de trois bâtiments de l'État. Ces bâtiments sont armés de deux canons chacun.

\section{CHAPITRE XV}

Voies de communication. - Itinéraire des routes : Partie du vent. - Partie sous

le vent. - Points de l'intérieur. - Route de ceinture. - Ponts. - Canaux.

- Phare et feux de port.

Voici quelles sont les principales voies de communication à la Réunion.

La route de ceinture, ou route impériale, fait le tour de l'île en longeant la mer. Son parcours est de 232 kilomètres.

La seconde route de ceinture, ou route Hubert-Delisle, présente un parcours de 80 kilomètres, quoique non terminée encore. On l'a commencée en 1856.

La route de l'intérieur a un parcours de 68 kilomètres. Elle traverse toute la partie S.-E. de l'île et se dirige de Saint-Benoît à Saint-Pierre par les plaines des Palmistes et des Cafres.

La route de Salazie a une longueur de 23 kilomètres.

Celle de Cilaos en a une de 38.

\section{ITINÉRAIRE DES ROUTES.}

Partie du vent.

De Saint-Denis à Sainte-Marie............. 12 kilom.

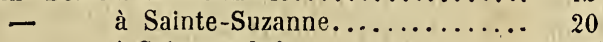

- à Saint-André.............. 26

- à Saint-Benoît.............. 38

- $\quad$ à Sainte-Rose ............... 58

- au milieu du Grand-Brûlé....... 75

De Sainte-Marie à Sainte-Suzanne............ 8

De Sainte-Suzanne à Saint-André............ 6

De Saint-André à Saint-Benoît............... 12

De Saint-Benoît à Sainte-Rose............ 20

De Sainte-Rose au milieu du Grand-Brûlé....... 17 
Partie sous le vent.

Distance de Saint-Denis à la Possession..........

à Saint-Paul...........

34 kilom.

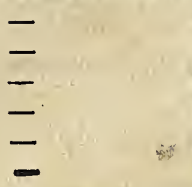

a Saint-Leu . ............ 46

à Saint-Louis $\ldots \ldots \ldots \ldots$. 97

à Saint-Pierre.......... 107

à Saint-Joseph......... 125

à Saint-Philippe ....... 143

au milieu du Grałnd-Brûlé. 157

Distance de la Possession à Saint-Paul......... 12

- de Saint-Paul à Saint-Leu............ 30

- de Saint-Leu à Saint-Louis........... 22

- de Saint-Louis à Saint-Pierre.......... 10

- de Saint-Pierre à Saint-Joseph......... 18

- de Saint-Joseph à Saint-Philippe....... 18

- de Saint-Philippe au milieu du Grand-

Brûlé............................. 13

Points de l'intérieur.

Distance de Saint-André au village de Salazie....

14 kilom.

aux eaux de Salazie..... 23

Distance de Saint-Louis aux eaux de Cilaos..... 33

- de Saint-Pierre au sommet de la plaine

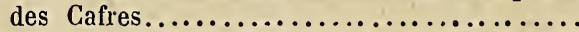

Distance de Saint-Benoît à Sainte-Agathe, dans la plaine des Palmistes................... 35

La route de ceinture a une longueur de 75 kilomètres dans la Partie du vent, et de $\mathbf{1 7 5}$ kilomètres dans la Partie sous le vent.

La construction et la réparation des routes de la Réunion sont confiées à un atelier composé d'immigrants. Il compte 195 hommes. et femmes répartis en dix brigades (arrêté du 23 juin 1856).

L'île de la Réunion qui, en 1815, n'avait qu'un seul pont en bois, en possède actuellement 99 :

Ponts avec culées et piles en maçonnerie et travées en bois, de 4 à 8 mètres d'ouverture............... 31

Id. de 10 à 20 mètres d'ouverture................ 34

$I d$. de 20 à 40 mètres d'ouverture.............. 20

$I d$. de 40 à 60 mètres d'ouverture............. 8

Pont en pierre avec voûte en plein cintre............ 1

Ponts suspendus en fer (sur les rivières du Mât, des Roches

et de l'Est), de 42 à 80 mètres de longueur.......... 3

Ponts en tôle et fer corniers, de 15 à 60 mètres......... 2

\section{Canaux.}

Pas de canaux de navigation. Canaux d'irrigation et de dérivation seulement. Voici les principaux : 
Canal Saint-Étienne. Il a 16,000 mètres de long, prend ses eaux dans la rivière Saint-Étienne, franchit les rivières d'Abord et des Cafres, et va gagner la ravine du Pont.

Canal des Moulins. Il date de 1770 et se trouve dans la ville même de Saint-Denis. - Un autre canal, exécuté en 1836 et 1837 , conduit l'eau de la rivière dans cette ville.

Canal du Champ-Borne ou canal Lancastel. Il distribue dans la partie inférieure du quartiêr Saint-André l'eau qu'il prend à la rivière du Mât.

\section{Phare et feux de port.}

Il y a des feux de port à Saint-Denis, à Saint-Paul et à SaintPierre.

La pointe du Bel-Air (Sainte-Suzanne) possède un phare lenticulaire de deuxième ordre et à feu fixe. Ce phare, élevé de 43 mètres au-dessus du niveau de la mer, est situé par $20^{\circ} 53^{\prime} 11^{\prime \prime}$ de latitude sud et $53^{\circ} 19^{\prime} 12^{\prime \prime}$ de longitude est.

\section{GHAPITRE XVI}

Service postal. - Personnel. - Transport et tarif des lettres à l'intérieur. Ligne anglaise (vid Suez). - Ligne française. - Prix du passage de France à la Réunion. - Taxe des lettres.

- Les Notices de la marine et des colonies fournissent les renseignements suivants :

Le personnel comprend :

1 receveur comptable;

1 contrôleur;

à Saint-Denis.

Des receveurs, dans les autres communes.

Ces agents sont placés sous les ordres du chef du service des contributions.

Dans l'intérieur de la colonie, le transport des lettres se fait par les messageries publiques et par des courriers à pied ou à cheval.

Depuis longtemps, la Réunion s'est efforcée d'établir des communications rapides et régulières avec la France par la voie de Suez, et elle n'a pas reculé devant de grands sacrifices pour atteindre à ce but. Mais, jusqu'en 1858, ses efforts furent infructueux; la plupart des ligues projetées ne purent se fonder; celles qui furent établies ne purent se maintenir. 
A cette époque, une ligne anglaise, la Compagnie péninsulaire et orientale (Peninsular and Oriental Steam-navigation Company), qui faisait déjà le service de l'Inde et de la Chine avec l'Europe, ayant pris la succession de la ligne australienne, le gouvernement de Maurice fit une convention avec cette Société pour l'ouverture d'un service entre l'île Maurice et Aden. L'administration de la Réunion profita de cette circonstance pour sortir de la mauvaise situation que lui avaient faite ses précédents insuccès et elle passa, le 5 juin 18こ8, par l'intermédiaire de M. Imhaus, plus tard délégué de la Réunion, un traité arec la Compagnie péninsulaire.

Aux termes de ce marché (qui expirait au mois de mars 1864) les paquebots-poste de la Compagnie, allant de Maurice à Aden, devaient toucher à Saint-Denis pour y prendre voyageurs et correspondance; ceux venant d'Aden pouvaient se rendre directement à Maurice, mais, dans ce cas, les voyageurs et les lettres pour la Réunion étaient dirigés immédiatement à destination, soit sur le paquebot même, soit sur un autre bateau à vapeur d'une vitesse suffisante pour arriver à Saint-Denis dans la matinée du lendemain.

Une subvention annuelle de 300,000 francs, payable par trimestre, était accordée à la Compagnie par la colonie.

Les relations avec l'Europe ont été rendues plus fréquentes encore par suite de l'ouverture de la ligne française de l'Indo-Ghine qui a eu lieu dans le courant de l'année 1863.

\section{Voie anglaise (viâa Suez).}

Le paquebot, partant de Marseille le 28 au matin de chaque mois, arrive à Alexandrie le 3 du mois suivant;

Celui qui part de Suez le 5 , arrive à la Réunion le 24.

Total : 26 à 27 jours.

Pour le retour, le paquebot partant de Maurice le 6 de chaque mois, touche le 7 à la Réunion et arrive à Suez le 26;

Celui qui part d'Alexandrie le 27 arrive à Marseille le 3 du mois suivant.

Prix du passage : 95 livres sțerling ( 2,375 francs) pour une place dans une cabine commune de plusicurs lits, et 245 livres sterling $(6,12$ francs) pour une cabine résẹvée.

Les voyageurs ont, en outre, à leur charge le prix du transit en chemin de fer entre Alexandrie et Suez : $1^{\text {re }}$ classe, 7 livres 
sterling (175 francs); $2^{\mathrm{e}}$ classe, 3 livres sterling 10 shillings (87 francs).

Les conditions d'échange des correspondances entre la Réunion et la France, ainsi que les pays étrangers auxquels la France sert d'intermẹdiaire, ont été réglées par les décrets des 26 novembre 1856, 19 mai et 13 novembre 1859 , à la suite d'une convention passée entre le gouvernement français et celui d'Angleterre.

\section{Taxe des lettres.}

Lettres affranchies pesant 7 grammes $1 / 2: 0 \mathrm{fr} .50 \mathrm{c}$. Lettres non affranchies : $\quad 0$ fr. $60 \mathrm{c}$.

Les lettres chargées payent double taxe.

L'envoi des mandats n'est pas encore autorisé, sauf pour les militaires et marins servant dans la colonie à qui l'on peut envoyer de France des bons sur la poste.

Pour l'affranchissement des lettres expédiées de la Réunion en France, on se sert de timbres-poste coloniaux spéciaux à nos colonies. En 1858, on a créé des timbres-poste de 40 et de 10 centimes. Ces timbres sont de couleurs semblables à celles des correspondants de France. Ils en diffèrent par la forme; ils sont rectangulaires, et, an lieu de l'effigie de l'empereur, ils portent une aigle impériale avec cet exergue : Colonies de l'empire français. En 1861, on a créé des timbres de 1 et de รั centimes.

En dehors de la voie rapide, des communications sont établies avec la Réunion par la voie des navires de commerce qui doublent le cap de Bonne-Espérance. - La moyenne de la traversée par cette voie est d'environ 90 jours de France à la Réunion et de 100 jours de la colonie en France. - Le prix du passage, calculé d'après cette moyenne, est en général de 1,200 francs, pour l'aller, de 1,300 francs pour le retour.

Les lettres expédiées par les navires du commerce sont taxées à 0 fr. 30 c. par 10 grammes, si elles sont affranchies, et, dans le cas contraire, à 0 fr. $40 \mathrm{c}$; sur le produit de cette taxe, $0 \mathrm{fr} .10 \mathrm{c}$. par lettre sont payés au capitaine du navire qui a effectué le transport.

Les communications entre la Réunion et l'Inde, et en général les pays pour lesquels la France ne sert pas d'intermédiaire, sont subordonnées aux convenances du commerce. Les navires qui partent de la Réunion pour ces pays emportent les correspon- 
dances qui sont affranchies jusqu'au port du pays de destination.

Le prix de ces lettres est de 0 fr. 30 sur lesquels 0 fr. 10 c. appartiennent au capitaine du navire. Des règlements obligent ce dernier, dès son arrivée au bureau de poste du port de débarquement, à déposer le sac des correspondances qu'il a pris au lieu d'origine et dans les escales intermédiaires; de même il est tenu d'emporter à son départ les lettres qui lui sont confiées pour les pays de destination de son voyage. 


\section{DEUXIEME PARTIE}

\section{ILE MAYOTTE (OU MAHORÉ).}

\section{CHAPITRE PREMIER}

Historique.

L'île de Mayotte fait partie du groupe des Comores au milieu du canal de Mozambique, entre la pointe N.-0. de Madagascar et la Mozambique (Afrique).

Située entre les $12^{\circ} 39^{\prime}$ et $12^{\circ} 59^{\prime}$ de latitude sud, et les $42^{\circ} 46^{\prime}$ et $43^{\circ} 2^{\prime}$ de longitude est, Mayotte se trouve à 54 lieues marines à l'O., $10^{\circ} \mathrm{N}$. de Nossi-Bé, à 300 lieues de la Réunion, et à 50 lieues de Madagascar.

Presque ignorée des Européens, jusqu'en 1840, disent les Notices du ministère de la marine et des colonies, l'île Mayotte est cependant habitée depuis six cents ans.

Les premiers habitants connus sont des noirs de la côte d'Afrique, d'une tribu ou d'une partie de côte appelée Mouchambara.

Lorsque les Portugais abordèrent à Comore, le chef arabe qui y commandait échappa à leur tyrannie avec la plus grande partie des siens. Il arriva sans difficulté à Mayotte, dans la baie de Zambourou, où il construisit une ville dont les restes existent encore.

A peu près à la même époque, des Sakalaves de Madagascar vinrent demander à s'établir à Mayotte et obtinrent la cession de cette partie de l'île que l'on nomme aujourd'hui Mon'sapéré.

Pendant que ces Arabes et ces Sakalaves s'établissaient à Mayotte, une riche et nombreuse peuplade de Chiradzy, au nord de Sohély, ayant pour chef Mohammed-ben-Haïssa, s'empara de la Grande-Comore, puis des îles Anjouan et Mohéli, et leur donna pour chefs ses deux fils.

Le même Haïssa, ayant entendu beaucoup vanter Mayotte, vint 
visiter cette île; il fut accueilli en ami et épousa la fille du sultan qui y régnait. A la mort de son beau-père, il lui succéda et fit bâtir une ville sur un des plus riches plateaux de l'île. Cette ville fut appelée Chingouni, et l'on voit encore aujourd'hui, comme témoignage de son existence, les restes dégradés d'une mosquée et d'un tombeau que l'on dit être celui de Moina-Singa, fille de ce sultan, et auquel elle avait succédé dans le gouvernement de Mayotte.

Jusqu'en 1830, l'histoire de Mayotte est assez obscure.

Vers cette époque, Andrian-Souli, roi des Sakalaves, venait d'être chassé par les Hovas de la côte N.-0. de Madagascar, Iorsque le sultan de Mayotte, nommé Amadi, qui s'était lié d'amitié avec lui dans son enfance et qui avait épousé une de ses parentes, lui fit offrir par son fils Buanacombé de partager avec lui la souveraineté de Mayotte.

Andrian-Souli hésitait, lorsque dans l'intervalle Amadi fut massacré par son frère qui prit sa place. Buanacombé renouvela les offres faites par son père et engagea Andrian-Souli à hâter son arrivée. Ce dernier se décida à accepter; l'usurpateur fut renversé, et Andrian-Souli fut reçu à Mayotte comme un père.

Une partie de l'île lui fut assignée en toute propriété, et il commença à la cultiver avec les Sakalaves qu'il avait amenés de Madagascar.

Mais bientôt des querelles s'élevèrent entre les gens d'AndrianSouli et ceux de Buanacombé, et la guerre éclata entre les deux chefs. Buanacombé, chassé de Mayolte, chercha un refuge à Mohéli près de Ramanatéka, à qui il fit cession de son île pour prix de son hospitalité.

En 1836, l'invasion de Mayotte par Ramanatéka, amena l'expulsion d'Andrian-Souli. Mais Abd-Allah, sultan d'Anjouan, chez qui Andrian-Souli s'était réfugié, prêta son assistance à celui-ci, qui bientôt rentra en possession de Mayotte.

Ramanatéka fut bientôt attaqué à Mohéli par Abd-Allah; mais la tentative échoua. L'escadrille de ce dernier fut jetée à la côte, lui-même fut pris par Ramanatéka qui le laissa mourir de faim dans sa prison.

Andrian-Souli fit alors proclamer sultan d'Anjouan le jeune Allaouy, fils d’Abd-Allah. Salim, oncle d'Allaouy, renversa son neveu et fomenta une révolte à Mayotte contre Andrian-Souli. La révolte fut comprimée par celui-ci. 
Telle était la situation quand, en 1841, l'île Mayotte fut visitée par le lieutenant de vaisseau Jehenne. Il en constata les avantages et les signala au gouvernement.

Le capitaine d'infanterie Passot fut envoyé près d'AndrianSouli par le contre-amiral de Hell; il conclut avec le souverain de Mayotte un traité qui assura à la France la possession de l'île, moyennant une rente annuelle de 5,000 francs et l'engagement de faire élever à la Réunion deux enfants du sultan (25 avril 1841). Ce traité fut ratifié en 1843, par le gouvernement français, et la prise de possession de Mayotte au nom de la France (13 juin), ne tarda pas à s'ensuivre.

L'administration des îles Mayotte, Nossi-Bé et Sainte-Marie de Madagascar fut réunie entre les mains d'un même commandant, avec le titre de commandant supérieur de Nossi-Bé et dépendances (ordonn. royale, 29 août 1843), sous l'autorité du gouverneur de la Réunion; mais en 1844, le titre de commandant supérieur de Nossi-Bé et dépendances fut changé en celui de commandant de Mayotte et dépendances (ordonn., 10 nov. 1844).

En 1853, l'île Sainte-Marie de Madagascar a été détachée du commandement de Mayotte.

\section{Commandants supérieurs.}

1843. Rang (P.-G.-A.-L.), capitaine de corvette.

1844. Lebrun (A.-N.), chef de bataillon d'infanterie de marine, intérimaire.

1846. Passot (P.), chef de bataillon d'infanterie de marine.

En 1848, il prend le titre de commissaire de la république.

1849. Livet (S.-F.), chef de bataillon du génie, intérimaire, puis titulaire.

1850. Marguet (A.-J.-F.), sous-commissaire, intérimaire.

1851. Livet (S.-F.).

1851. Bonfils (P.-A.), capitaine de frégate.

1853. Brisset (A.), capitaine d'infanterie de marine.

1855. Vérand(A.-C.), commissaire de la marine.

1857. Morel, chef de bataillon d'infanterie de marine.

1860. Gabrié (G.-L.-B.), commissaire de la marine. 


\section{CHAPITRE II}

Superficie. - Géologie. - Montagnes. - Ruisseaux. - Récifs. - Ilots voisins. - Baies. - Bois. - Villages. - Saisons. - Température. - Pluies. - Marées. - Courants. - Races. - Arabes. - Sakalaves. - Chiffre de la population.

La superficie de l'île Mayotte, et sans y comprendre celle des îles Pamanzi, Zambourou et de plusieurs îlots, est supérieure à 30,000 hectares. Dans sa plus grande longueur, du N.-N.-O. au S.-S.-E., elle a 21 milles marins; sa largeur est de 2 à 8 milles.

Son sol est d'origine volcanique. Il est formé d'une épaisse couche de terre végétale, très-fertile, qui par endroits atteint une profondeur de 15 mètres. Plusieurs plateaux se remarquent à l'intérieur.

Une chaîne de montagnes traverse l'île dans toute sa longueur. Leurs sommets atteignent 600 mètres. Dans le reste de l'île, on rencontre des ravins profonds, où mugissent des torrents pendant les pluies, et où règne la sécheresse pendant l'autre saison.

Mayotte n'a pas de rivières, mais une foule de ruisseaux, dont l'eau est excellente et dont quelques-uns sont assez puissants pour faire mouvoir des machines.

La circonférence de l'île est, dans sa plus grande partie, entourée d'une ceinture de récifs. Ces réciifs s’étendent de 2 à 6 milles des côtes et constituent d'excellents mouillages. Sept passes principales, celle de Bandéli surtout, la plus rapprochée du mouillage de Dzaoudzi, et la plus commode, permettent de franchir les récifs.

Entre la ceinture de récifs qui environne Mayotte et l'île ellemême, quelques îlots, entre autres ceux de Pamanzi, de Dzaoudzi, de Bouzi et de Zambourou, apparaissent.

Le plus important de ces îlots est celui de Pamanzi, sis à l'est de Mayotte. Dans sa partie basse, au sud, il est couvert de pâturages, mais le reste est parsemé de monticules à peu près incultes. Au nord, on remarque un lac aux eaux sulfureuses et, diton, salutaires, qui occupe un ancien cratère.

Dzaoudzi, que relie à Pamanzi une chaussée étroite, est entièrement couvert d'habitations. Un bras de mer, d'un quart de lieue environ, le sépare de Mayotte. Ce bras de mer peut donner passage aux plus grands navires.

Les deux autres îlots, Bouzi et Zambourou n'ont rien qui mé- 
rite d'être signalé. L'îlot Bouzi, toutefois, est très-boisé au sud et à l'ouest.

Toute la partie S.-S.-E. et 0. de Mayotte est découpée par de grandes baies. Les meilleurs mouillages sont ceux que forment entre elles, depuis le N.-E. jusqu'à l'E.-S.-E., les îles Mayotte, Pamanzi et Dzaoudzi. La rade qui entoure ce dernier îlot est sus . ceptible de recevoir une escadre; l'abri y est complet, la tenue excellente et la profondeur de l'eau ne laisse rien à désirer.

Au N.-E. de Mayotte, la baie de Longoni, bien abritée des vents généraux de S.-E. et r̉e S.-0., renferme un petit port naturel très-convenable pour le carénage des bâtiments de toute dimension.

La plus vaste de toutes les baies de l'île est celle. de Boéni, à la côte occidentale, près de Chingouni, l'ancienne capitale; elle est entourée de hautes montagnes qui l'abritent de tous les vents; l'eau y est très-profonde.

Mayotte est assez bien boisée. On y trouve plusieurs arbres très-propres aux constructions navales; les indigènes s'en servent pour la construction de leurs pirogues et boutres.

Le nombre des villages, depuis l'occupation française, s'est accru. Ghingouni, l'ancienne capitale de l'île, a été rebâtie par les naturels. Située à l'ouest de l'île, elle regarde un marais qui, lors des pluies, se transforme en lac.

Le gouvernement local a son siége au village de Dzaoudzi, dans l'île de ce nom; c'était la résidence du sultan de Mayotte. On y a construit un hôpital.

Parmi les villages noureaux, ceux de M'sapiry, de Koëni, de Joungoni, de Dapani, etc., méritent d'être signalés. - Celui de Choa existait avant l'occupation.

Mayotte a deux saisons. Sa température moyenne, en mars et avril, est de $29^{\circ}$ à $31^{\circ} \mathrm{c}$., à midi. Pendant les plus fortes chaleurs (janvier el février), le thermomètre ne monte pas à plus de $34^{\circ}$. La température moyenne de l'année est de $27^{\circ}, 20$.

Mayotte est, parmi les îles Comores, l'une des plus saines.

L'hivernage (saison pluvieuse) est déterminé par les lunes de décembre et de mars. Coups de vent rares, pluies fréquentes et plus abondantes dans l'est que dans le sud de l'île. Lors de la belle saison, les pluies, au contraire, sont moins rares dans le sud.

Dans les syzygies, la mer monte de 11 pieds 2 pouces $\left(3^{\mathrm{m}}, 626\right)$, 
et, dans les marées d'équinoxes, elle monte de 12 pieds 8 pouces $\left(4^{\mathrm{m}}, 112\right)$.

Les courants ont parfois une vitesse de 3 nœuds et demi dans les passes. Leur force et leur direction sont très-variables autour de l'île.

Le flot, selon la position, porte au S.-0. ou au S.; le jusant, dans les passes, porte au N.-E. ou au N. Au commencement du flot et à la fin du jusant, ils suivent la direction des passes.

Deux races distinctes, noires l'une et l'autre, composent la population de Mayotte.

C'est, en premier lieu, la race arabe que l'on rencontre sur toutes les îles de la côte orientale d'Afrique, depuis Aden jusqu'au sud de Madagascar, et que les Portugais ont trouvée régnant dans ces mers à leur arrivée. - Les individus de cette race sont principalement adonnés au commerce maritime et ont des habitudes nomades. - Ils se sont plus ou moins mêlés avec la race indigène des Comores; on désigne sous le nom de Mahori ceux qui sont nés et fixés à Mayotte. - Les Arabes forment le principal élément de la population de l'île.

On remarque, en second lieu, la race Sakalave, provenant des émigrations de Madagascar.

En outre, il existe, disséminés dans les différentes exploitations, un assez grand nombre de travailleurs des diverses races de la côte orientale d'Afrique.

Les Notices du ministère de la marine et des colonies, auxquelles nous empruntons ces détails, ajoutent : Le caractère des habitants est doux et facile; mais, comme la plupart des races noires, ils sont enclins à la paresse et au manque de prévision. On remarque pourtant, dans la construction de leurs cases, une certaine élégance témoignant qu'ils ne sont pas complétement dénués de goût.

Le recensement de 1860 a donné les chiffres suivants pour la population :

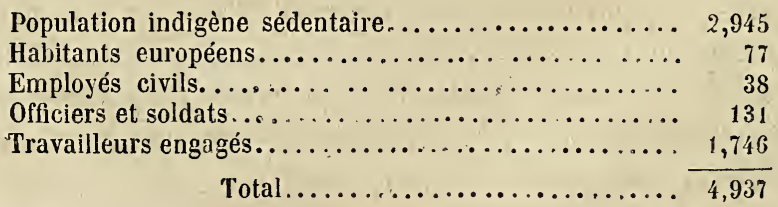




\section{CHAPITRE III}

Administration. - Instruction publique. - Cultes. - Justice.

Mayotte a un commandant supérieur. Il relève directement du ministre de la marine. L'autorité du commandant de Mayotte s'étend sur Nossi-Bé, qui a un commandant particulier.

Un conseil d’administration, composé des principaux fonctionnaires et de deux habitants notables, assiste le commandant supérieur.

Le budget local est voté par ce conseil.

Il délibère sur les questions que lui soumet le commandant.

Les fonctions de secrétaire du conseil sont remplies par le secrétaire-archiviste du gouvernement.

L'administration civile est ainsi composée :

Un commissaire-adjoint de la marine, ordonnateur ;

Un aide-commissaire;

Un commis;

Deux écrivains de marine;

Un aide-commissaire, faisant fonctions de contrôleur.

Service des fonds : un trésorier.

Service de santé : trois chirurgiens de la marine.

Service du port : un maître de manœuvre.

Les Pères de la mission de Madagascar, dont la maison centrale est a la Réunion et qui, depuis 18əั1, sont établis à Mayotte, ont la charge du service de l'instruction publique et du culte.

Un préfet apostolique,

Deux pretres,

Un catéchiste,

Tel est le personnel actuel du culte à Mayotte.

Deux chapelles ont été établies, l'une sur l'îlot de Dzaoudzi, l'autre sur l'île même de Mayotte.

Pour les individus appartenant à la race arabe, et qui en général professent l'islamisme, il a été construit, en 18ðัŏ, une mosquée de pierre.

Les autres habitants, de race malgache, sont pour la plupart idolâtres; mais leur conversion au catholicisme paraît certaine dans un temps plus ou moins rapproché.

Deux écoles ont été fondées par les Pères de la mission de Madagascar : l'une pour les garçons, l'autre pour les filles. 
L'école des filles est dirigée par les sœurs de Saint-Joseph de Cluny.

Une centaine d'enfants des deux sexes fréquèntent ces écoles. Ils y sont logés et nourris; l'État, à cet effet, alloue aux écoles une somme de 6,000 francs par an.

L'instruction professionnelle est, en outre, donnée par une école laïque de fondation récente.

Aux termes des décrets du 30 janvier 1802 et du 29 février 1860 , la justice est rendue par un conseil de justice et un tribunal de première instance.

Conseil de justice.

Le commandant de la station, président;

Le juge du tribunal de première instance, chef du service judiciaire;

Le capitaine d'artillerie;

L'enseigne de vaisseau, commandant la marine locale;

Un chirurgien de première classe ;

Deux lieutenants.

Le conseil connaît en dernier ressort des crimes de rébellion .et d'attentat à la sûreté de la colonie. - Les pénalités sont les mêmes que celles de la législation métropolitaine en cette matière. - La majorité de cinq voix sur sept peut seule entraîner condamnation.

Quant aux erimes commis, soit à Mayotte, soit à Nossi-Bé, par des Français, des étrangers ou des indigènes, sur les personnes ou les propriétés des Français ou des étrangers, la connaissance en est renvoyée par le commandant supérieur à la cour de la Réunion. Il y peut aussi renvoyer celle des crimes commis entre indigènes, si les tribunaux du pays en font la demande.

\section{Tribunal de première instance.}

Il est composé d'un juge unique.

Il connaît des contestations civiles, commerciales et correctionnelles.

Il juge en dernier ressort, quand la demande principale n'excède pas 1,000 francs, et en premier ressort, quand elle excède cette valeur.

L'appel est porté devant la Cour de la Rćunion.

Les délits commis par des indigènes au préjudice de Français 
ou d'étrangers; ceux commis par des. Français ou des étrangers, soit entre eux, soit contre des indigènes, sont jugés correctionnellement par le tribunal. Il juge également, cornme tribunal de police; des contraventions de police et des infractions aux règlements de l'autorité administrative. - Les décisions au correctionnel et en simple police sont sans appel, si la peine n'excède pas un an de prison et 1,000 francs d'amende.

Le juge de Mayotte remplit, en même temps, les fonctions de juge de paix et de juge d'instruction. Les actes attribués aux tribunaux de commerce, il les fait également.

Un officier du commissariat de la marine remplit les fonctions du ministère public près le tribunal. Il y a un greffier institué. Un agent de la force publique remplit l'office d'huissier.

En matière civile, quand la contestation existe entre Français ou étrangers et indigènes; en matière correctionnelle, quand l'un des prévenus est indigène, deux indigènes, pris parmi les notables, sont adjoints au tribunal, et ils ont voix délibérative.

Les contestations entre indigènes sont décidées selon les lois du pays et par les tribunaux indigènes; toutefois l'une des parties peut saisir la juridiction française. - L'appel d'un jugement rendu par un tribunal indigène est porté devant le tribunal français qui, dans ce cas, s'adjoint deux Arabes ou Sakalaves pris parmi les notables.

\section{CHAPITRE IV}

Agriculture. - Productions naturelles. - Constitution de la propriété. - Exploitations de canne à sucre. - Produits sucriers. - Café. - Petite culture.

- Mouvement commercial. - Articles d'importation. - Articles d'exportation.

- Mouvement maritime. - Régime commercial.

L'île de Mayotte a une superficie qui dépasse 30,000 hectares, on l'a vu.

Son sol peut fournir, dans ses parties cultivables, les différentes productions coloniales qui viennent à la Réunion et à Madagascar.

La partie S. et S.-0. est pleine de cocotiers et de bananiers qui poussent sans soins; les orangers, les citronniers, les tamariniers, les goyaviers et les autres fruits, abondent à l'état sauvage; la canne à sucre, le coton, le café, le tabac, croissent spon- 
tanément. Le riz, la patate douce, le maïs, le miel, l'igname, l'ananas, le melon d'eau, le gingembre et le pourpier, viennent très-bien. On recueille dans l'île de la cire et du miel. On y trouve de la gomme copal, une espèce de résine blanche et pàrfumée, et diverses essences de bois propres à l'ébénisterie et aux constructions navales.

La partie 0. et S.-0: de Mayotte, ainsi que l'îlot Pamanzy, fournissent d'excellents pâturages.

Les terres sont cultivées en vertu de concessions accordées suivant les conditions spécifiées dans un décret du 5 mars 18506 , et dont le principe est la taxe progressive qui, partant de 5 francs par hectare au-dessous de 100 hectares, a pour limite 25 francs par hectare pour les concessions de 500 hectares.

Aux termes de ce décret, les concessions sont faites à titre définitif, avec cette réserve que le concessionnaire ne pourra aliéner son terrain qu'après sa complète mise en valeur.

La constitution de la propriété a permis d'organiser le régime hypothécaire dans la colonie et un bureau d'hypothèques a été créé à Mayotte par un décret du 17 mai 1862.

Au $1^{\text {er }}$ janvier 1863 , sur les 30,000 hectares qui forment la superficie de Mayotte, il en avait été concédé à divers colons 18,483 hectares.

La canne à sucre occupait 936 hectares. Il existait également quelques plantations de café, de vanille, de girofle, de cacao, de riz et de plantes alimentaires.

On comptait dans la colonie 18 exploitations de canne à sucre; dont 11 pourvues de machines à fabriquer le sucre. Trois de ces usines avaient une distillerie.

Les dépenses de premier établissement pour ces dix-huit exploitations avaient dépassé 5 millions de francs. La valeur des propriétés atteignait, par suite, le chiffre de $5,840,000$ francs.

Nombre des travailleurs au commencement de $1863: 1,805$.

Produit des cultures pendant 1862 :

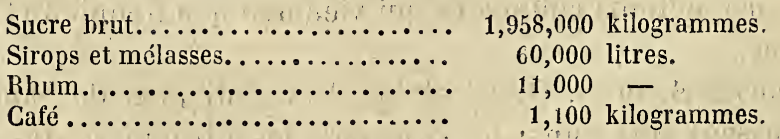

La principale culture de l'île est celle de la canne à sucre. Avant peu, l'île de Mayotte pourra ètre classée parmi les colonies 
productives de la France. Déjà plusieurs expéditions de sucre ont été faites en Australie.

Telle est la richesse du sol, dans les vallées de Mayotte, qu'il n'a pas besoin de recevoir des cultures différentes pour se renouveler. La canne peut occuper le même terrain pendant huit à dix ans et donner à peu près le même résultat.

Le borer, cet insecte qui causa tant de ravages à Maurice et à la Réunion, a paru aussi à Mayotte en 18วั8. On a employé le feu pour le détruire et on a réussi.

La culture du café n'a pas tenu les promesses qu'elle avait données d'abord. Les jeunes plants poussent vite; à la troisième année, ils se couvrent de fleurs et de fruits; mais, au moment de récolter, les arbres périssent, ou bien ils ne présentent que des enveloppes coriaces sans baies.

La petite culture, c'est-à-dire celle du riz, du maïs, du manicc, etc., ne reçoit aucun encouragement des colons qui portent tous leurs soins et ceux de leurs travailleurs sur la culture de la canne. On fait venir du dehors les substances alimentaires. Les indigènes seuls se livrent à la petite culture, mais ne produisent pas au delà de leurs besoins personnels.

Le mouvement commercial de Mayotte n'est pas encore trèsconsidérable. Depuis 18022 , toutefois, il va en progressant. Les chiffres suivants en font foi.

1852

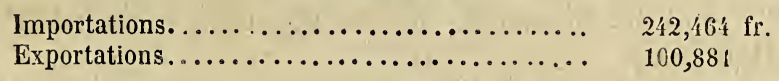

1853

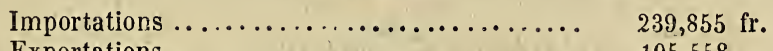

Exportations..................... 105,558

1854

Importations................... $188,622 \mathrm{fr}$.

Exportations................... 153,008

1856

Importations. ................... $340,101 \mathrm{fr}$.

Exportations...................... 428,395

$185 \%$

Importations................ $534,706 \mathrm{fr}$.

1858

Importations

$423,252 \mathrm{fr}$.

Exportations ..................... 342,162 
1859

Importations ..................... $327,537 \mathrm{fr}$.

Exportations........................ 367,207

1860

Importations $\ldots \ldots \ldots \ldots \ldots \ldots \ldots \ldots \ldots \ldots . \quad 536,754 \mathrm{fr}$.

Exportations......................... $877,943$.

186 直

Importations....................... $\quad 529,982 \mathrm{fr}$.

Exportations........................ 1,257,179

Ainsi, le mouvement commercial de Mayotte qui, en 1852, n'a

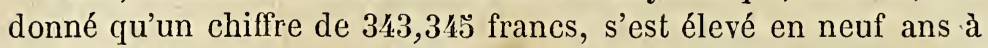
1,787,161 francs. Encore la valeur des marchandises réexportées invendues, montant à 136,863 francs, n'est-elle pas comprise dans ces $1,787,161$ francs.

Le commerce par navires français est cornpris dans le mouvement de 1861 pour une valeur de 1,616,408 francs, et par navires étrangers pour une valeur de 170,753 francs.

\section{Articles d'importation.}

Le riz, les bœufs, venant de la côte orientale d'Afrique, de Madagascar, des Comores;

Les moulins et machines à sucre, le fer, les vins, les spiritueux, les briques, les fruits et la poudre de traite, les faíences, les étoffes de coton, les ustensiles de ménage, etc., venant de France et de la Réunion;

Le charbon, venant d'Angleterre, etc.

Articles d'exportation.

Sucre, cocos, huile de coco, noix d'arec, rhum, curiosités du pays, etc.

De 18522 à 1861, le mouvement de la navigation s'est présenté comme suit :

Entrée.

\section{2.}

74 navires, 3,513 tonneaux.

1855.

96 navires, 4,365 tonneaux. 


\section{4.}

97 navires, 3,340 tonneaux.

\section{6.}

97 navires, 5, 423 tonneaux.

1837.

106 navires, $ّ, 948$ tonneaux.

\section{8.}

100 navires, 6,936 tonneaux.

1839.

88 navires, 8,034 tonneaux.

1860.

117 navires, 6,589 tonneaux.

1861.

154 navires, 8,113 tonneaux.

Sortie.

\section{2.}

71 navires, 3,317 tonneaux.

\section{5.}

100 navires, 3,713 tonneaux.

\section{4.}

97 navires, 3,040 tonneaux.

\section{6.}

73 navires, 4,327 tonneaux.

\section{7.}

108 navires, 5,640 tonneaux.

\section{8.}

102 navires, 6,901 tonneaux.

\section{9.}

82 navires, 7,538 tonneaux.

1860 (moins le $3^{\mathrm{e}}$ trimestre).

79 navires, 5,063 tonneaux. 


\section{1.}

144 navires, 7,740 tonneaux.

Le mouvement maritime de 1861 se décompose ainsi.

Entrées.

Navires français au long cours, venant de France ou de la Réunion........................ 13

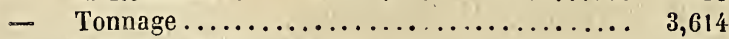

- Hommes d'équipage................. 190

Boutres ou caboteurs du pays................. $\quad 36$

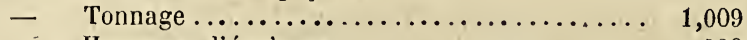

- Hommes d'équipage................. 529

Boutres ou caboteurs é trangers.............. 105

- Tonnage........................ 3,459

- Hommes d'équipage................ 1,760

Sorties.

Navires français au long cours, allant à Nantes et à Mar-

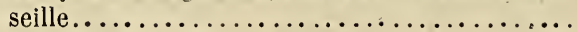

- Tonnage............................... 3,414

- Hommes.......................... 175

Boutres ou caboteurs du pays................ 38

- Tonnage......................... 1,014

- Hommes ....................... 547

Boutres ou caboteurs étrangers... ............ 94

- Tonnage.............................. 3,310

- Hommes .........................652

A Mayotte et dépendances, le régime commercial jouit d'une franchise entière. Toutefois, par mesure de police, le commandant supérieur peut restreindre l'introduction des spiritueux.

Les cafés, sucres et autres denrées coloniales, accompagnés de certificats attestant leur origine, sont admis en France aux droits spéciaux accordés aux produits de la Rémnion.

\section{CHAPITRE V}

Armée. - Effectif. - Marine. - Finances : Budget de l'État. — Budget local.

L'effectif des troupes en garnison à Mayotte et à Nossi-Bé se compose ainsi :

Une section de compagnie d'infanterie de marine (100 hommes);

Deux compagnies de soldats indigènes, de 112 hommes chacune ; 
Un détachement d'artillerie de marine (27 canonniers, 8 ouvriers).

Les deux îles se partagent également cet effectif.

Le cadre de chacune des deux compagnies indigènes comprend :

Deux officiers européens;

Huit sous-officiers, aussi européens ;

Quinze sous-officiers indigènes ;

Quatre-vingt-cinq soldats indigènes.

Le service maritime de Mayotte et dépendarices est fait par une goëlette à voiles et un aviso à vapeur.

Le budget de la colonie se décompose ainsi :

\section{Budget de l'État (1863).}

Personnel du gouvernement et administration.... $76,080 \mathrm{fr}$.

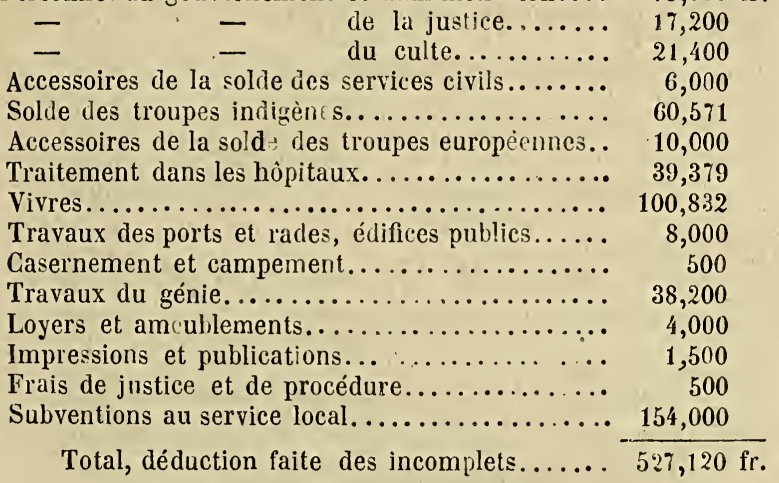

\section{$2^{\circ}$ Budget local (1863).}

Receites.

Contribution foncière (Mayotte)

$10,500 \mathrm{fr}$.

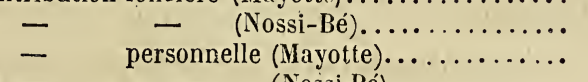

7,500

12,000

3,000

Fabrication et vente du rhum (Nayotte)....... 4,200

- (Nossi-Bé) ....... 10,200

Droits de greffe (Mayotte)................ 200

- (Nossi-Bé) ............... $\quad 300$

Droits de douane (Mayotte).............. 1,900

- (Nossi-Be) .............. 4,200

Taxes de concessions de terre (Mayotte)....... 5,000

Vente des cocos du domaine (Nossi-Bé)........ 5,000

(Mayotte).......................... 1,100 
Vente des cocos du domaine et d'objets divers

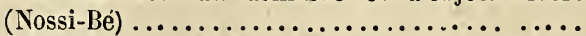

Remboursements faits par divers pour cessions à

eux faites d'objets de matériel, vivres (Mayotte). 140,000

Id. (Nossi-Bé)...................... 40,000

Passe-ports et amendes (Mayotte)........... 640

640

Subvention métropolitaine (Mayotte)........ 141,406

- $\quad$ (Nossi-Bé)......... 12,594

Recettes diverses (Mayotte).............. 2,000

(Nossi-Bé) .............. 500

Total (Mayotte)............ 318,946 fr.

Total (Nossi-Bé)............ 84,034

Ensemble......... $\overline{402,980 \mathrm{fr} \text {. }}$

Dépenses.

Personnel des services administratifs (Mayotte)..

- - C (Nossi-Bé).

- du service des ports (Mayotte) ...... 1,200

- $\quad$ (Nossi-Bé ....... 3,730

- des ponts et chaussées (Mayotte)..... 8,920

- $\quad$ - $\quad$ (Nossi-Bé).... $\quad 4,760$

- de l'instruction publique (Mayotte'.... 13,350

- $\quad$ (Nossi-Bé).... $\quad 8,300$

- de police (Mayotte)............... 9,180

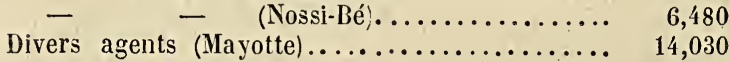

$\begin{array}{lr}\text { (Nossi-Bé)...................... } & 5,805 \\ & 6,200\end{array}$

$\begin{array}{crr}\text { Dépenses assimilées à la solde } & \text { (Mayotte)......... } & 6,200 \\ \text { (Nossi-Bé) } \ldots \ldots \ldots . & 400\end{array}$

Hòpitaux (Mayotte)..................... 3,761

3,761
2,201

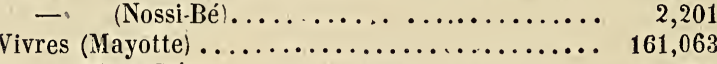

- (Nossi-Bé) .................. 8,098

Travaux et approvisionnement (Mayotte)...... 76,288

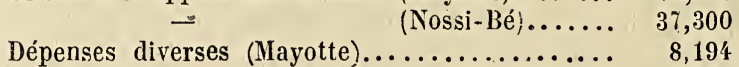

(Nossi-Bé)................ 5,760

Total (Mayotte). ........... 318,946 fr.

Total (Nossi-Bé)............ 84,034

Ensemble.........

\section{CHAPITRE VI}

Service postal. - Mode de transport. - Taxe des correspondances. Ligne anglaise. - Ligne française.

Mayotte a son service postal fait par un préposé de l'adminisration. Il en est de même de Nossi-Bé. Ces deux préposés relèvent l'un et l'autre du chef du service administratif. 
Les règles qui président au mode de transport et à la taxe des correspondances, soit par les navires de commerce, soit par les paquebots-poste, sont les mêmes que pour la Réunion. Toutefois, les correspondanzes destinées à Mayotle et à Nossi-Bé sont déposées à l'île Mahé des Seychelles par les paquebots de la Compagnie péninsulaire et orientale (ligne anglaise), qui desservent la Réunion et Maurice; de l'île Mahé, elles sont transportées à Mayotte, par un des bâtiments de notre station locale des Comores.

L'escale de Mahé est également adoptée pour les lettres adressées de Mayotte ou de Nossi-Bé en France.

On met en moyenne douze jours pour le trajel de Mayotte à Mahé; par conséquent, la correspondance échangée entre la colonie et la France peut arriver à destination en moins de six semaines.

Cependant, comme les paquebots-poste ne peuvent aborder à Mahé pendant les mois de juin, juillet et août, à cause des moussons, les lettres expédiées à cette époque doivent passer par la Réunion, et mettent trois mois environ à parvenir à leurs destinataires.

Notre colonie des Comores est donc reliée une fois par mois à la France, par les paquebots britanniques; l'ouverture de la ligne française de l'Indo-Ghine lui permettra sans doute d'avoir deux fois par mois des communications avec la mère-patrie, par l'intermédiaire de Mahé.

Comme Mayotte et Nossi-Bé sont déjà pourvus d'usines à sucre d'une certaine importance, le département de la marine a jugé utile de favoriser le passage des colons; et, dans ce but, il a autorisé ceux-ci à s'embarquer sur les bâtiments de l'État, qui font le service entre Mayotte et Mahé, sauf à rembourser le prix de table, d'après un tarif fixé par une décision ministérielle du 18 août 1862. 


\section{TROISIÈME PARTIE}

\section{ILE DE NOSSI-BÉ}

\section{CHAPITRE PREMIER}

Coup d'œil historique.

Nos-Bé, ou, suivant la prononciation des indigènes, Nossi-Bé, est la plus grande des îles de la côte N.-O. de Madagascar. On l'appelle aussi Variou-Bé, c'est-à-dire grande île.

Elle est située par $13^{\circ} 10^{\prime} 44^{\prime \prime}$ et $13^{\circ} 24^{\prime} 46^{\prime \prime}$ de latitude méridionale, et par $46^{\circ} 04^{\prime} 32^{\prime \prime}$ et $45^{\circ} 53^{\prime} 47^{\prime \prime}$ de longitude orientale.

Cette île, ainsi que les autres petites îles environnantes, reconnaissait autrefois l'autorité des rois Sakalaves de la côte N.-0. de Madagascar. Elle appartenait au territoire d'Ankara, presqu'île N.-0. de Madagascar, et c'est par le roi d'Ankara, Tsimiare, et par la reine des Sakalaves, Tsioumeik, que Nossi-Bé fut concédée à la France.

Les rois sakalaves, d'après les Notices de la marine, dont la famille était la plus ancienne de la grande île, ont régné sur la moitié de Madagascar. Vihiny, l'une des reines de cette race, avait conquis toute la côte ouest, et plusieurs provinces de l'est et de l'intérieur étaient ses tributaires; elle mourut en 1811.

Andrian-Souli, dont nous avons déjà parlé à propos de Mayotte, était son petit-fils.

Lorsque, battu par les Hovas, il se réfugia à Mayotte, en 1832, il céda ses droits à sa sœur, Ouantitzi, qui mourut ellẹ-même quatre ans après.

Sa nièce, la jeune princesse Tsioumeik, alors âgée de huit ans, seul rejeton de la famille régnante, fut proclamée reine des Sakalaves, le $\mathbf{5}$ avril 1836.

Les hostilités recommencèrent bientôt entre les Hovas et les Sakalaves, et ceux-ci demandèrent des secours à l'iman de Mas- 
cate, qui leur envoya 150 hommes de troupes pour tenir garnison à Bavatoubé. Mais la division s'étant mise parmi les chefs arabes, ces troupes se rembarquèrent pour Mascate.

Réduits à leurs seules forces, les Sakalaves se décidèrent à quitter la grande terre où ils ne se sentaient pas en sûreté, et se réfugièrent en masse, avec leur reine, à Nossi-Bé, dont la population fut ainsi augmentée de 5,000 à 6,000 âmes. Le mouvevement s'opéra dans les premiers jours de mai 1839.

Les arrivants se portèrent sur divers points de l'île, principalement au sud et à l'est, et de nombreux villages s'élevèrent.

Peu de temps après, le 29 septembre 1839, le brick de guerre français, le Colibri, mouilla dans les eaux de Nossi-Bé. Ce navire avait à bord M. Passot, capitaine d'infanterie de marine, qui était chargé d'explorer cette île.

La reine Tsioumeik et les chefs sakalaves, craignant un retour offensif des Hovas, prièrent M. Passot de faire connaître au gouverneur de Bourbon leur désir de se mettre sous la protection de la France et de le supplier de leur envoyer promptement les renforts nécessaires.

En 1840, M. Passot, après avoir fait agréer au gouverneur de Bourbon (Réunion), M. de Hell, les propositions de la reine Tsioumeik, revient à Nossi-Bé. Une convention fut signée, par laquelle la reine céda à la France tous ses droits de souveraineté sur le Bouéni (province de la côte N.-O. de Madagascar) et les îles dépendantes (Nossi-Cumba, Nossi-Faly, Nossi-Mitsiou).

M. F. Gouhot, capitaine d'artillerie de marine, fut, l'année suivante, nommé commandant particulier de Nossi-Bé par le gouverneur de Bourbon.

De $18 \not 2$ à 1849, des colons européens se rendirent de Maurice et de Bourbon (Réunion) à Nossi-Bé. Ils y commencèrent l'œuvre de colonisation.

En 1849, l'île fut attaquée par des pirates et des insulaires de Madagascar. Mais la résistance fut énergique; les assaillants furent repoussés par la garnison. Des travaux de fortification, promptement élevés, protégent efficacement aujourd'hui la colonie. - Depuis lors, une tranquillité complète n'a cessé d'y régner.

\section{Commandarts de Nossi-Bé.}

1841. Gouhot (F.), capitaine d'artillerie de marine, commandant particulier. 
1843. Rang (P.-G.-A.-L.), capitaine de corvette, commandant supérieur de Nossi-Bé et dépendances.

1844. Morel (G.-A.-J.), capitaine adjudant-major d'infanterie de marine, commandant particulier.

1845. Lamy (H.-M.), capitaine d'infanterie de marine, $i d$.

1847. Sonolet (E.-H.), lieutenant de vaisseau, $i d$.

1848. Lamy (H.-M.), capitaine d'infanterie de marine, $i d$.

1848. Marchaisse (J.), capitaine d'infanterie de marine, $i d$.

18วั0. Desbeaux (P.-J.), lieutenant d'infanterie de marine, commandant particulier par intérim.

18ə̌0. Raoult (L.-J.-M.), aide-commissaire de la marine, commandant particulier par intérim.

1850. Berg (A.), enseigne de vaisseau, commandant particulier.

1851. Lapeyrre-Bellair (J.-T.), capitaine d'artillerie de marine, $i d$.

1852. Harmand (V.), lieutenant d'artillerie de marine, $i d$.

1853. Brisset (A.), capitaine d'infanterie de marine, $i d$.

1853. Dupuis (J.-T.), capitaine d'infanterie de marine, commandant particulier par intérim.

1854. Arnoux (L.-A.-E.), capitaine d'artillerie de marine, commandant particulier par intérim.

185๊. Girard (H.-A.), aide-commissaire de la marine, commandant particulier par intérim.

185๊o๊. Septans (M.), capitaine d'infanterie de marine, commandant particulier par intérim.

185̋. Dupuis (J.-T.), capitaine d'infanterie de marine, commandant particulier, sous l'autorité du commandant supérieur de Mayolte et dépendances.

1860. Dérussat, commissaire de la marine, commandant particulier.

\section{GHAPITRE II}

Configuration de Nossi-Bé. - Montagnes. - Sol. - Eaux. - Iles environnantes. - Anses. - Baies. - Climat. - Vents. - Pluie. - Marée. - Courants.

Nossi-Bé a la forme d'un quadrilatère irrégulier. La presqu'île de Navetch et le morne Loucoubé la prolongent, la première au nord, le second au sud. 
De la pointe d'Ampourach à la pointe sud de Loucoubé, la plus grande longueur de l'île est de 22 kilomètres; sa plus grande largeur d'Angouroukarani à Diamakaba, est de 15 kilomètres.

La totalité de Nossi-Bé présente une superficie de 19,500 hectares. Au chapitre relatif à l'agriculture, on verra qu'il n'a guère, jusqu'ici, été tiré parti que d'environ 6,000 hectares.

Trois groupes distincts composent le système des montagnes de Nossi-Bé :

Le groupe du centre, dont le plus haut sommet, le TanéLatsak, s'élève à 500 mètres ;

Le groupe du nord, qui comprend les montagnes de Navetch et d'Ampourach;

Le groupe du sud auquel appartient le morne Loucoubé, point culminant de l'île, haut de 600 mètres, découpé de ravines profondes, et dominant une belle forêt qui couvre toute la côte sud.

La constitution géologique de Nossi-Bé présente aussi trois séries distinctes, correspondant aux trois groupes de montagnes ci-dessus.

La série du centre, essentiellement volcanique, et comprenant les trois quarts de l'île, est formée d'épaisses coulées de laves basaltiques et trappéennes, recouvertes dans divers endroits par des couches de matières arénacées, de tufs et de rapillis volcaniques.

La seconde, celle du nord, est formée de grès rouge ou jaune, traversés par des filons ou massifs de gneiss et de quartz.

La troisième, celle de Loucoubé, se compose de roches gra. nitiques, de gneiss, de micaschistes, de schiste ardoisé et d'argile plastique. (Notices, etc.)

Les principaux cours d'eau sont au nombre de trois; ce sont le Djabala, l'Andrian et l'Ankarankeni.

Le Djabala coule à l'ouest ; c'est le plus important de tous; il passe au pied du plateau de Hellville; la mer le remonte jusqu'à trois kilomètres au delà de son embouchure et le rend navigable en canot, sur une certaine distance.

L'Andrian et l'Ankarankeni coulent à l'est.

En outre de ces cours d'eau, une foule de ruisseaux et torrents sillonnent les ravins sans nombre dont l'île est déchirée.

Toute l'année, l'eau de ces rivières et ruisseaux est potable.

Une source d'eau thermale sulfureuse se trouve sur la rive 
gauche du Djabala. Sa température s'élève à $44^{\circ}$ cent.; elle contient en dissolution de l'acide carbonique et de l'acide sulfhydrique.

Les cratères d'effondrement de quelques montagnes de l'île ont donné lieu à des lacs, de forme circulaire, au nombre de neuf. Pendant la saison sèche, leur niveau s'abaisse de $0^{\mathrm{m}}, 70$ à 1 mètre.

Les marais formés par les eaux de la mer sont plus nombreux que les marais formés par l'eau douce. Les marais de Vouriki renferment des sangsues plus petites que les nôtres.

Quelques petites îles ou îlots environnent Nossi-Bé. Les principales sont Nossi-Cumba et Sakatia.

Nossi-Cumba, située au S.-E. de Nossi-Bé, en est séparée par un canal de 2,600 mètres. C'est un pâté de montagnes. L'un de ses deux sommets ả une hauteur de 622 mètres. Dans les ravines, la végétation est magnifique; dans le S.-E., on remarque plusieurs grands villages.

Sakatia est un îlot séparé de Nossi-Bé par un kilomètre. Il est inhabité; mais les propriétaires sakalaves de Nossi-Bé s'y rendent fréquemment; ils y ont des plantations de manioc, de patates, etc.

Le meilleur mouillage de Nossi-Bé se trouve entre la partie méridionale de cette île, la côte N.-O. de Nossi-Cumba et la petite île de Tani-Kali.

Les deux anses, celles d'Hellville et du plateau, sont bonnes, mais peu spacieuses.

Les autres anses et baies, où les bâtiments pourront trouver un abri, sont surtout celles de Vatou-Zavavi, de Linta, de Tendraka, sur la côte E., et de Fontaka, au N.-O.

La température n'offre pas de variations très-grandes. Le thei'momètre, pendant la belle saison, se tient entre $19^{\circ}$ et $26^{\circ}$; pendant l'hivernage (de nòvembre à avril), il marque de $28^{\circ}$ à $31^{\circ}$.

La moindre élévation du baromètre a lieu en janvier; il marque $0^{\mathrm{mm}}, 75 \%$. Sa plus grande a lieu en juillet; il marque $0^{\mathrm{mm}}, 763$.

“ A Nossi-Bé, les moussons de N.-O. et de S.-E., si constantes dans le canal de Mozambique, ne se font pas sentir d'une manière directe.

"De mai à novembre, les vents sont assez réguliers. Le matin, généralement, il règne une petite brise qui souffle quelquefois du N., mais bien plus souvent du S.-E. ou du S.-S.-E. Vers 
10 heures, cette brise mollit considérablement, et il est rare qu'il n'y ait pas alors un moment de calme; si, au contraire, elle persiste, elle passe au S., puis au S.-0. pour s'établir d'une manière définitive à l'O., vers midi ou une heure du soir. Cette brise du large, faible d'abord, ne tarde pas à devenir plus forte et souffle jusqu'à la nuit. Le calme qui lui succède dure très-souvent toute la nuit. D'autres fois, au contraire, une bonne brise de N. ou de N.-0. souffle jusqu'au matin. Telle est la marche ordinaire des vents pendant la belle saison.

( Pendant l'hivernage, il en est tout autrement; on observe beaucoup moins de régularité dans les brises qui manquent fort souvent.

"Quelquefois, cependant, la brise du large (d'ouest) se lève vers 2 heures du soir, mais elle est bientôt remplacée par la bourrasque qui précède les grains journaliers de cette saison. " (Notices, etc.)

La quantité de pluie tombant annuellement à Nossi-Bé est considérable. Elle a été, du $1^{\text {er }}$ juillet 1855 au 30 juin 18506 , de $3^{\mathrm{m}}, 258$. Le minimum a été de $0^{\mathrm{m}}, 014$ en mai, et le maximum de $0^{\mathrm{m}}, 870$ en janvier.

Pendant les mois de janvier, février et mars, l'île est traversée journellement par des nuages électriques. Beaucoup vont éclater sur le plateau d'Hellville.

Les marées ont une grande régularité. La durée du flot et celle du jusant sont égales. A $4 \mathrm{~h} .36 \mathrm{~m}$., les jours de nouvelle et de pleine lune, la marée s'établit; aux équinoxes, la mer marne de $4^{\mathrm{m}}, \mathbf{4 9}$.

La configuration des côtes fait varier les courants de direction et de vitesse. Généralement, le flot porte à l'E. et le jusant à l'O., arec une moyenne de $0^{\mathrm{m}}, \breve{5}$ à $1^{\mathrm{m}}, 5$, rarement au delà, sauf dans le chenal, entre Nossi-Cumba et la Grande-Terre, où, dans les grandes marées, le flot atteint jusquà 2 mètres et $2^{m}, 5$.

\section{CHAPITRE III}

Population. - Alministration. - Culte. - Instruction publique. - Justice.

La population de Nossi-Bé est répartie entre une cinquantaine de villages. Hellville, siége du gourernement, est le centre principal où la plupart des Européens ont fixé leur résidence, 
Hellville est un village situé sur un plateau de 8 à 10 mètres au-dessus du niveau de la mer. Il forme une pointe avancée entre les baies de Passimen et d'Andavakoutouk.

Quatre villages populeux, depuis les guerres de 1849, ont été créés autour de ce centre par les Sakalaves qui nous sont restés fidèles.

Ce sont les villages d'Andavakoutouk, au fond de la baie de ce nom; de Douëni, ancienne demeure des rois de Nossi-Bé, aujourd'hui faubourg de Hellville; d'Amboudivianou, sur les mornes les plus voisins; d'Ampomboulava, où les PP. Jésuites ont un établissement; c'est le plus peuplé des villages de l'île; il est situé au pied du grand cratère, et relié par une belle route à Hellville.

Les Sakalaves, venus de la Grande-Terre de Madagascar, forment principalement la population de Nossi-Bé. Ils appartiennent à la race noire. Ils ont des qualités naturelles que leur penchant à l'ivrognerie, à la paresse, à la cupidité, au yol, c'est-à-dire les vices d'un état barbare trop longtemps prolongé, n'ont point complétement étouffées. Aussi, quand ils sont dirigés avec sévérité et justice, leur intelligence s'éveille etils deviennent laborieux. Sans religion ni loi écrite, on les voit assez facilement accepter le catholicisme.

Le chiffre de la population indigène était, à la fin de 1860, de 14,005 individus :

Hommes .............................. 8,247

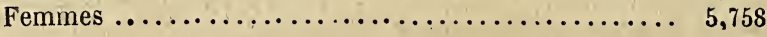

La population européenne se décomposait ainsi:

Fonctionnaires et leurs familles............... 23

Habitants européens ou créoles de la Réunion et de Mau-

rice.................................... 63

Troupes de la garnison..................... 175

Engagés attachés aux exploitations rurales........... 529

Femmes et enfants....................... 67

D'après le $\mathbf{P}$. Finaz, préfet apostolique de Mayotte et dépendances, le chiffre de la population de Nossi-Bé doit être porté à 18,000 individus.

Nossi-Bé est placé sous l'autorité d'un commandant particulier qui, lui-même, est aux ordres du commandant supérieur de Mayotte. Un conseil d'administration assiste le commandant particulier. 


\section{Administration civile.}

Elle se compose de:

Un aide-commissaire, chargé du service administratif ;

Un commis ;

Deux écrivains de marine.

Service des fonds.

Un préposé du trésorier de Mayotte.

\section{Service de santé.}

Deux chirurgiens de marine.

\section{Justice.}

Elle est rendue par un tribunal de première instance.

Ce tribunal se compose d'un seul juge.

Sa compétence est la même que celle du tribunal de Mayotte.

Un officier, ou l'employé du commissariat, désigné à cet effet, remplit les fonctions du ministère public.

Un greffier est institué près du tribunal.

Les fonctions d'huissier sont remplies par un agent de la force publique.

\section{Culte.}

La Mission religieuse de Madagascar, dont le siége est à la Réunion, dessert aussi Nossi-Bé.

Deux prêtres et un catéchiste, relevant du préfet apostolique de Mayotte, forment le personnel du culte.

Hellville a une église en pierre. Huit chapelles en chaume sont dispersées sur plusieurs points de l'île. Les missionnaires s'y rendent pour y faire le catéchisme.

\section{Instruction publique.}

Deux écoles, fondées par les PP. Jésuites, et fréquentées par 120 enfants des decix sexes, reçoivent une subvention.

Hospice de la vieillesse.

Fondé par les PP. Jésuites. Il comptait en 1861 une quinzaine de pensionnaires. 


\section{CHAPITRE IV}

Agriculture. - Fertilité du sol. - Répartition du sol entre les cultures suivantes : Canne à sucre, plantes alimentaires, café. - Savanes. - Forêts. - En friche. - Sucreries. - Fabrication du rhum. - Nombre des travailleurs. - Produc. tion en 1862. - Régime commercial. - Mouvement commercial. - Navigation. - Mouvement maritime.

Le sol de Nossi-Bé est de la plus grande richesse. La canne à sucre, le riz, le manioc, le café, l'indigo, la patate y viennent parfaitement et sans exiger beaucoup de soins. La canne à sucre, cultivée d'abord par les Européens exclusivement, a fini par tenter les indigènes qui, aujourd'hui, la cultivent aussi et contribuent à l'alimentation des sucreries de la colonie.

Au commencement de 1863 les cultures suivantes se partageaient ainsi le sol de l'île :

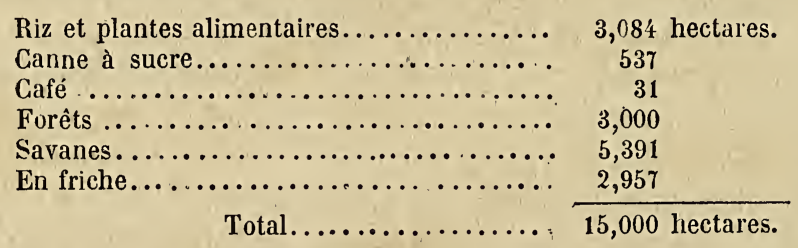

La production, à la date ci-dessus et pendant l'année 1862, avait atteint les chiffres suivants :

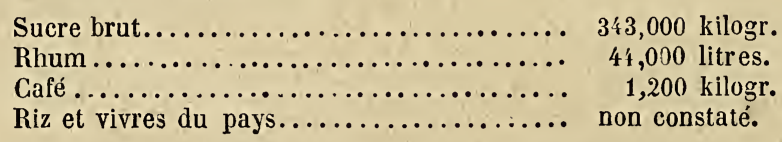

Ce dernier article n'a pu etre évalué qu'approximativement; on croit qu'il a atteint le chiffre de 7 millions de kilogr., dont la valeur s'est élevée à 490,000 fr., le prix moyen des 100 kilogr. étant de $7 \mathrm{fr}$. - La culture du riz et vivres du pays est abandonnée aux indigènes; elle suffil à leur consommation.

La culture du café va toujours en augmentant. Plusieurs sucreries s'en occupent particulièrement.

Ces sucreries étaient au nombre de dix-huit, au commencement de 1863; huit d'entre elles étaient munies d'usines à vapeur, et cinq d'usines hydrauliques. Huit possédaient des alambics pour la fabrication du rhum. Neuf avaient des plantations de café. 
Le nombre des travailleurs employés, en 1862, aux cultures, a été de 1,321.

Dans ce nombre, 938 travailleurs avaient in engagement de travail.

Les règlements de concessions et de travail en vigueur à Mayotte sont aussi mis à exécution à Nossi-Bé. Il en est de même pour le régime commercial : à Nossi-Bé, comme à Mayotte, le commerce est libre.

De 18006 à 1861, le mouvement commercial de l'île a présenté les résultats suivants :

\section{6}

Importations . .................. $503,410 \mathrm{fr}$.

Exportations.................... 119,624

1858

Importations....................... 261,019 fr.

Exportations..................... 39,979

11858

Importations. . . . . . . . $\ldots \ldots \ldots \ldots \ldots \ldots \ldots, 125,583 \mathrm{fr}$.

Exportations.................... 60,795

1859

Importations ..................... $376,014 \mathrm{fr}$.

Exportations..................... 150,488

1860

Importations..................... 426,056 fr.

Exportations..................... 228,429

1861

Importations...................... $395,449 \mathrm{fr}$.

Exportations....................... 144,380

Ce qui donne pour 1856 un total de $623,034 \mathrm{fr}$.

$\begin{array}{llll}- & \text { pour } 1857 & - & 300,998 \\ - & \text { pour } 1858 & - & 186,378 \\ - & \text { pour } 1859 & - & 526,532 \\ - & \text { pour } 1860 & - & 661,585 \\ - & \text { pour } 1861 & - & 539,879\end{array}$

Valeur du commerce par navires francais (1861):

A l'importation..................... 138,573 fr.

A l'exportation....................... 131,465

Valeur du commerce par navires étrangers :

A l'importation.................... 256,876 fr.

A l'exportation.................... 12,915

Principaux objets d'importation :

Riz, bœufs, tissus de coton blanes (toile hamy), mouchoirs de 
coton, bois de sandal, sel, etc., venant de Madagascar, de la côte orientale d'Afrique, de l'Arabie, de l'Inde.

Machines et cutils, vins et liqueurs, bière, étoffes d'habillement, chaussures, huile d'olive, papier, fusils, poudre, etc., venant de France, de la Réuniôn ou de Maurice.

Principaux objets d'exportation :

Sucre, café, rhum, cire, bois d'ébène, bois de Takamaka (excellent pour les constructions navales), bois de sandal, riz en paille, et diverses marchandises provenant de l'importation.

De 1850 à 1861, le mouvement de la navigation a présenté les résultats ci-après :

\section{Entrée.}

\section{6}

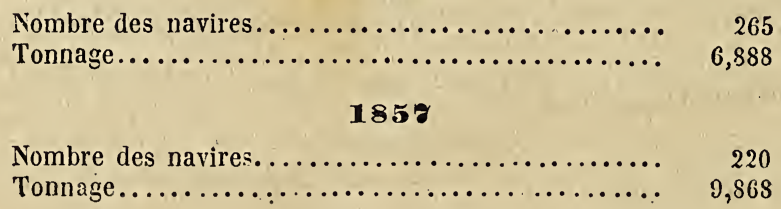

\section{8}

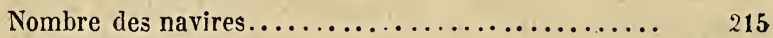

Tonnage........................... 12,917

$18 \times 9$

Nombre des navires..................... 196

Tonnage.............................. 12,174

1860

Nombre des navires... ................. 216

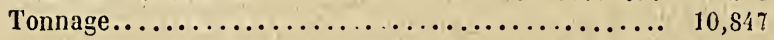

186 1

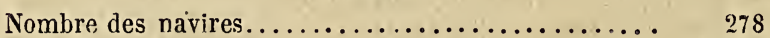

Tonnage.......................... 9,733

Sortie.

1856

Nombre des navires..................... 194

Tonnage............................. 6,461

1858

Nombre des navires...................... 101

Tonnage.......................... 6,340

\section{8}

Nombre des navires..................... 141

Tonnage $. \ldots \ldots \ldots \ldots \ldots \ldots \ldots \ldots \ldots \ldots \ldots \ldots \ldots \ldots, 11,923$ 


\section{9}

Nombre des navires.................... 203

Tonnage........................... 11,745

\section{0}

Nombre des navires..................... 223

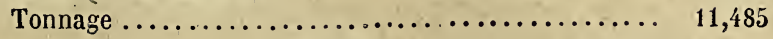

\section{1}

Nombre des navires..................... $\quad 270$

Tonnage.......................... 10,541

Le mouvement maritime s'est décomposé de la manière suivante en 1861 :

\section{Entrées,}

Navires français venant de France ou de la Réunion... 11

- Tonnage $\ldots \ldots \ldots \ldots \ldots \ldots \ldots \ldots \ldots, 2,584$

Hommes d'équipage............ 173

Boutres ou caboteurs français................. $\quad 68$

- $\quad$ Tonnage ................. 1,398

Hommes d'équipage......... 749

Navires etrangers......................... 4

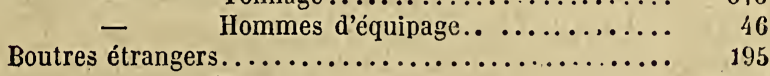

- Tonnage ................. 5,073

— Hommes d'équipage........... 2,782

Sorties.

Navires français, allant de la Réunion à Mayotte ou aux

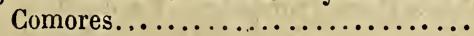

- Tonnage...................... 12

- Hommes d'équipage............. 182

182
75

- Tonnage.......................... 1,805

Navires étrangers Hommes d'équipage............. 886

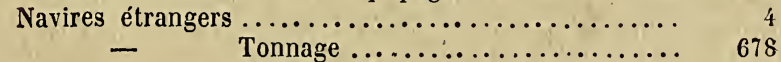

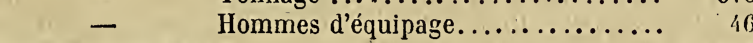

Boutres étrangers......................... 179

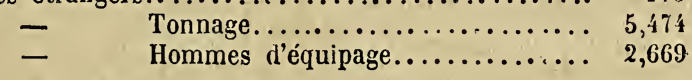




\section{QUATRIÈME PARTIE:}

\section{ILE SAINTE-MARIE DE MADAGASCAR}

\section{GHAPITRE PREMIER}

Historique et éphémérides.

L'île Sainte-Marie de Madagascar, appelée Nossi-Ibrahim par les Malgaches, est située par $17^{\circ}$ latitude S., et $47^{\circ} 34^{\prime} 30^{\prime \prime}$ longi tude E. Un canal, large de 5 kilomètres dans sa partie la plus étroite, et de 8 kilomètres dans sa partie la plus large, la sépare de la côte orientale de Madagascar.

Les Notices du ministère de la marine et des colonies donnent les détails qui suivent sur l'origine de cette colonie.

Les premiers établissements français sur la côte orientale de Madagascar remontent à l'année 1644. Nous y avons possédé successivement : Port-Dauphin, Tamatave, Foulpointe, Tintingue, Sainte-Luce et Sainte-Marie.

La cession de Sainte-Marie a été faite à la Compagnie des Indes, en 1750, par Béti, fille de Ratzimilaho, souverain de l'île.

De 1667 à 1670, Port-Dauphin a été chef-lieu des possessions orientales de la Compagnie des Indes; mais, à la fin de 1671, presque tous les blancs ayant été massacrés par les naturels de Madagascar, ce poste fut abandonné.

Plus tard, vers 1786, nos possessions de la baie d'Antongil, Tintingue et Port-Choiseul entre autres, furent également délaissées, et, lorsque éclatèrent les guerres maritimes de l'empire, nous n'occupions plus à Madagascar que Tamatave et Foulpointe.

En 1811, ces derniers points tombèrent au pouvoir des Anglais, qui détruisirent les forts et abandonnèrent ensuite le pays aux indigènes.

En 1814, le traité de Paris rendit à la France ses anciens droits 
sur Madagascar, et, en 1818 et 1819 , le gouvernement français fit reprendre solennellement possession de Sainte-Marie, de Tintingue, de Fort-Dauphin, de Saìnte-Luce, et plaça ces établis sements sous l'autorité du gouverneur de l'île Bourbon (la Kéunion).

La France, on le sait, n'avait à cette époque aucun port au delà du cap de Bonne-Espérance.

L'île Sainte-Marie fut présentée alors comme réunissant, par sa situation et la beauté de sa rade, les conditions voulues pour un établissement militaire et maritime. En conséquence, une expédition fut envoyée de France pour commencer cet élablissement et débarqua à Sainte-Marie au mois d'octobre 1821. Elle se composait de 79 personnes, comprenant, outre le personnel civil, une compagnie de 60 officiers et ouvriers militaires.

En 1822, Radama I, chef des Hovas, fit occuper Foulpointe par 3,000 de ses soldats; en 1823, il s'empara de Pointe-à-Larrée, située vis-à-vis de Sainte-Marie, incendia et pilla les villages de Fondaraze et de Tintingue; il menaça Sainte-Marie elle-meme.

En 182ð, un corps de 4,000 soldats, envoyé par Radama, s'empara de Fort-Dauphin, occupé par un officier et cinq soldats français. - Les vexations exercées par les Hovas contre les traitants français de la côte orientale de Madagascar, et particulièrement contre ceux de Sainte-Marie, devinrent intolérables. - On se décida enfin à sortir du système de temporisation adopté jusquelà, et l'on organisa une expédition militaire contre le chef des Hovas.

En 1828, mourut Radama I. Une de ses femmes, Ranavalo-Manjaka, lui succéda et continua sa politique contre les Français. Force fut d'intervenir en 1829. Une expédition, composée d'une division navale de 6 bâtiments et de 500 à 600 hommes de débarquement, mouilla sur la rade de Tamatave. Tintingue fut repris et reçut une garnison de 400 hommes. - Les troupes hovas furent battues' à Tamatave, à Ambatoumanoui, à Foulpointe, à la Pointe-à-Larrée. - La reine Ranavalo capitula, consentit un traité, mais en éluda les conditions. - Une nouvelle expédition dut être projetée.

Les événements de 1830 firent oublier un moment les affaires de Madagascar.

En 1831, la France évacua Tintingue, mais en faisant réserve de ses droits. - L'occupation de Sainte-Marie fut maintenue, 
pour assurer des moyens de protection au commerce français sur la côte orientale de Madagascar.

En 1861, mort de la reine Ranavalo. - Rakoto, son fils, lui succéda sous le nom de Radama II. Depuis lors, la situation a changé.

Les rapports politiques qui, sous le règne de Ranavalo, avaient presque complétement cessé entre la France et Madagascar, quoique les hostilités n'eussent pas été reprises entre les Hovas depuis 1829, ces rapports ont été rétablis, à la demande du nouveau souverain, en 1862, et un traité d'amitié et de commerce a été conclu.

\section{Commandants particuliers.}

(Sous l'autorité du gouverneur de Bourbon-Réunion.)

1819. Carayon, officier d'artillerie.

1821. Roux (S.).

1825. Blevec, capitaine du génie.

1829. Carayon, officier d'artillerie.

De 1830 à 1841, aucun officier ne figure comme commandant particulier de Sainte-Marie.

1841. Vergès (R.), capitaine d'infanterie de marine.

\section{Commandants particuliers.}

(Sous l'autorité du gouverneur de Mayotte et dépendances. Ordonn. 27 août 1843.)

1843. Lamy (H.), intérimaire.

1844. Vergès (R.), chef de bataillon.

1849. Mermier (P. B.), capitaine d'infanterie de marine.

1850. Brisset (A.), capitaine d'infanterie de marine, intérimaire (nommé par le gouverneur de la Réunion).

18aั1. Mermier (P. B.), chef de bataillon, intérimaire.

1853. Brisset (A.), capitaine d'infanterie de marine, intérimaire.

1853. Guébert (S.-F.), sous-lieutenant d'infanterie de marine, intérimaire.

1853. Durand, capitaine d'infanterie de marine, intérimaire.

Commandants particuliers de Sainte-Marie (Décr., 18 oct. 1853).

1854. Durand, capitaine d'infanterie de marine.

1855. Raffenel (A.-J.-B.), sous-commissaire de la marine. 
1858. Grange (de la), lieutenant de vaisseau.

En raison de son éloignement des îles de la Réunion et de Mayotte, c'est sous les ordres d'un commandant spécial que se trouve actuellement Sainte-Marie de Madagascar (Décr., 18 oct. 1853).

\section{CHAPITRE II}

Configuration de Sainte-Marie. - Superficie. - Sol. - Montagnes. - Port. Cours d'eau. - Forêts. - Température. - Pluie. - Vents. - Ras de marée. - Marées.

Dans sa partie méridionale, Sainte-Marie de Madagascar est traversée par un bras de mer et divisée ainsi en deux îles. La plus petite a 8 kilomètres de tour. Réunies, elles ont 48 kilomètres de long sur 8 à 12 de large. Leur superficie est de 90,975 hectares.

Le sol de l'île est généralement mauvais. Une zone intérieure, d'une contenance de 20,000 hectares environ, est assez bonne et exclusivement cultivée. - Le fer est abondant, comme aussi les matériaux propres à la construction : terre à brique, pierre, chaux.

I'île n'est qu'un ensemble de monticules formant quatre chaînes principales. Deux de ces chaînes sont basaltiques, les deux autres se composent d'un tuf recourert d'un sable quartzeux. On peut les cultiver dans presque toute leur hauteur qui varie entre 50 et 60 mètres. Les pentes en sont douces.

"Le port de Sainte-Marie, sur la côte ouest de l'île, est situé par $17^{\circ}$ de lat. sud et $47^{\circ} 31^{\prime} 23^{\prime \prime}$ de longitude est; il est formé par un enfoncement dans les terres de 2 kilomètres de profondeur sur une largeur de 1 kilomètre environ. - L'entrée de la baie est défendue par l'îlot Madame, long de 200 mètres et large de 125 mètres environ, et qui porte quelques fortifications, ainsi que les bâtiments du personnel civil et militaire de l'établissement. La passe du N.-E. qui conduit dans le port peut livrer passage aux plus grands bâtiments.

" L'île est bien arrosée par de nombreux ruisseaux formés par des sources abondantes et de bonne qualité. La rivière du port, qui est le plus important de ces cours d'cau, éprouve, assez loin de son embouchure, l'effet de la marée. 
"Les bois de Sainte-Marie occupent une surface de 20 à 30,000 hectares, dans la partie centrale de l'île. Ils alimentent un petit chantier où l'on a construit quelques chaloupes qui servent au cabotage. " (Notices, etc.)

Le climat de Sainte-Marie est humide et malsain. Les écarts de température sont très-grands pendant les mois les plus chauds (janvier et février). De $37^{\circ}$ et demi, qu'atteint le thermomètre pendant le jour, on descend à $33^{\circ}$, à $31^{\circ}$, et pendant la nuit à $25^{\circ}$, à $21^{\circ}$ et même à $20^{\circ}$.

La saison pluvieuse dure près de six mois, de mars à août. La saison sèche n'est pas exempte de pluies. Le nombre des jours de pluie varie entre 220 et 240 . Sainte-Marie est l'une des contrées où il pleut le plus abondamment.

Les vents, pendant la saison pluvieuse, soufflent généralement du S.-O.au S.-E. ; en février et mars, parfois d'E. et de N.-E. Pendant la saison sèche, les vents soufflent du S.-E., de l'E., du N. et du N.-E. La nuit et le matin, la brise d'ouest souffle le plus souvent; à midi, on ressent la brise du large.

Les côtes orientales de Sainte-Marie sont fréquemment assaillies de ras de marée; mais le canal qui sépare cette île de l'île de Madagascar n'en éprouve pas l'atteinte.

Les marées les plus fortes ne donnent entre la basse et la pleine mer que $1^{\mathrm{m}}, 30$ de différence. Aux marées ordinaires, la mer ne marne que de 65 centimètres. A 2 heures de l'après-midi, aux nouvelles et aux pleines lunes, la mer est haute.

\section{CHAPITRE III}

Population. - Villages. - Gouvernement et administration. - Justice. Culte. - Instruction publique. - Force militaire.

La population de Sainte-Marie de. Madagascar s'élevait, en 1860, à 5,701 individus; ce chiffre se décomposait ainsi :

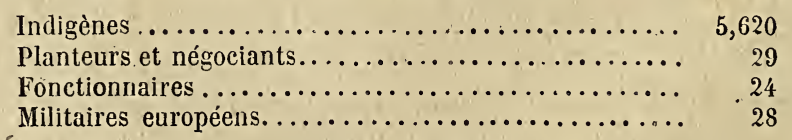

Les indigènes de Sainte-Marie sont des Malgaches que les Hovas ont chassés de Madagascar. Ils se livrent aux diverses cultures. 
Les villages, au nombre de 32, sont répandus sur le littoral et dans l'intérieur. Ces villages sont des agglomérations de cases en bois, couvertes de feuilles de ravenal. Blancs et indigènes n'ont pas d'autre habitation.

Depuis 18\%3, nous l'avons vu, Sainte-Marie a un commandant. en chef, lequel relève directement du ministre de la marine et des colonies.

Le commandant est assisté d'un conseil d'administration.

Composition du personnel administratif :

Le commandant;

Un sous-commissaire de la marine, ordonnateur;

Un commis;

Deux écrivains de marine.

Service des fonds : Un trésorier.

Service des ponts et chaussées : Un conducteur de $1^{\text {ro }}$ classe.

Service de santé : Deux chirurgiens de marine.

Service du port : Deux maîtres charpentiers.

Les fonctions judiciaires sont remplies par le commandant de Sainte-Marie. En matière civile et commerciale, il ne connaît en dernier ressort qu'autant que la demande principale n'excède pas 500 francs. Autrement on peut appeler de ses jugements devant la Cour d'appel de la Réunion.

Le commis d'administration remplit les fonctions du ministère public.

Les affaires criminelles sont instruites par un magistrat que délègue le procureur général de la Réunion et jugées dans cetie dernière colonie.

Les Pères de la mission de Madagascar ont introduit le culte catholique à Sainte-Marie. La plupart des indigènes sont, toutefois, idolâtres.

Personnel : Trois prêtres, deux catéchistes. Ils relèvent du préfet apostolique de Madagascar.

Deux églises en pierre et une chapelle.

L'une des églises est établie à Amboutifouth, près du port de Sainte-Marie; l'autre, à Tsasifouth, sur la côte N.-E. - La chapelle se trouve dans l'îlot Madame.

Un hôpital a été aussi installé dans cet îlot.

L'instruction publique est confiée aux Pères.

Ils dirigent une école de garçons. Les sœurs de Saint-Joseph de Cluny dirigent une école de filles. 
Ces deux écoles sont subventionnées.

A la fin de 1862, l'effectif des forces militaires de Sainte-Marie s'élevait à 106 hommes, ainsi composés :

1 détachement du $4^{\mathrm{e}}$ régiment d'infanterie de marine $(25 \mathrm{hom}-$ mes), dont 1 officier;

1 détachement d'artillerie de marine (3 artilleurs et 2 ouvriers);

1 garde du génie;

1 compagnie de noirs sénégalais, mozambiques et malgaches ( 75 hommes, dont 1 officier et 4 sous-officiers).

Le service local de Sainte-Marie est fait par une goëlette à voiles.

\section{CHAPITRE IV}

Agriculture. - Café, girofle, etc. - Cultures indigènes. - Régime commercial. - Objets d'importation. - Objets d'exportation. - Mouvement maritime. Service des postes.

Dès 1819, c'est-à-dire dès l'instant même où la France reprit possession de l'île Sainte-Marie, diverses entreprises de culture en grand du café, du girofle, etc., furent tentées. Elles durent être assez promptement abandonnées. On y revient aujourd'hui, non sans succès; on a lieu d'espérer que Sainte-Marie dédommagera prochainement de leurs efforts les pionniers courageux qui ont osé les tenter.

Les indigènes ne se livrent guère qu'à la culture des choses nécessaires à leur subsistance : riz, manioc, ambrevades, patates, ignames, fèves, haricots, etc.

Le régime commercial de Sainte-Marie est, comme à Mayotte et à Nossi-Bé, libre d'entraves.

La Réunion, Maurice et Madagascar, sont presque exclusivemenl en rapports commerciaux avec la colonie.

\section{Objets d'importation.}

Biz et bœufs provenant de Madagascar; toileries de toute espèce d'origine française; rhums de la Réunion et de Maurice; sel, marmites en fonte, faïences, verroterie, mercerie, objets de consommation et d'habillement pour les blancs. - Partie de ces articles se vend sur les lieux; le reste est transporté à Ma- 
dagascar et échangé contre les productions du sol ou les produits de l'industrie malgache.

\section{Objets d'exportation.}

Riz et bœufs provenant de l'importation (réexportation); volailles; poisson; peaux de bœuf; écailles de torlue; nattes, pagnes, etc.

La Réunion fournit à Sainte-Marie la plupart des objets qui lui sont nécessaires (sauf le riz et les bœufs que lui procure Madagascar) : vivres, liqueurs, effets d'habillement, etc.

\section{Valeur du commerce.}

Elle atteint, en moyenne, le chiffre de 150 à 200,000 francs.

\section{Mouvement maritime.}

Le commerce de Sainte-Marie se fait par quelques navires français et étrangers, des caboteurs et des pirogues de la colonie et de Madagascar.

Service des postes.

Un préposé de la poste centralise l'envoi et la réception de la correspondance.

C'est par la Réunion que Sainte-Marie communique avec la France.

La moyenne du trajet est d'environ deux mois entre elle et la métropole.

Mêmes taxes, mêmes modes de transport que pour la Réunion.

\section{CHAPITRE V}

Revenus de Sainte-Marie, leur exiguïlé (10,000 fr.). - Budget de l'État. Budget local.

Sainte-Marie est incapable de se suffire à elle-même. Ses revenus, en 1862, n'ont pas excédé 10,000 francs. Il faut que l'État lui vienne assez largement en aide.

Voici, au reste, le détail des dépenses de l'État, d'une part, et des recettes et dépenses de la colonie, de l'autre : 


\section{DÉPENSES DE L'ÉTAT (1862).}

Personnel du gouvernement colonial...........

- de l'administration générale...........

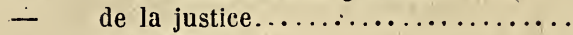

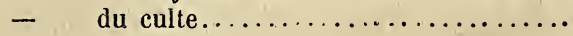

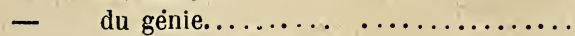

- du service des ports................

Troupes noires (solde)...................

Accessoires de la solde (services civils) ......... - (services militaires)......

Traitement dans les hôpitaux...............

Vivres du personnel......................

Ports et rades (travaux et entretien)............

Édifices publics.......................

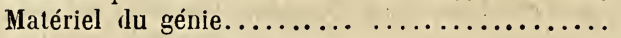

Subvention au service local................

Divers

$12,000 \mathrm{fr}$.

20,700

500

12,600

3,160

5,000

15,419

5,000

3,300

11,513

23,554

7,000

50,000

40,000

80,000

3,500

Total, après déduction des incomplets.

$289,490 \mathrm{fr}$.

\section{BUDGET LOGAL (1862).}

10 Recettes.

Droits sur les emplacements...............

Cote personnelle ......................

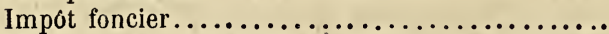

Licence des cabaretiers et droits sur l'entrée des spiritueux.........................

Amendes, timbre et enregistrement...........

Subvention de la métropole (V. Dépenses de

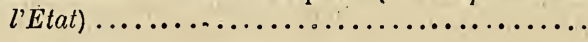

Total.

$4,000 \mathrm{fl}$. 3,000

500

2,000

500

80,000

$90,000 \mathrm{fr}$.

20 Depenses.

Personnel du service administratif............

Police...............................

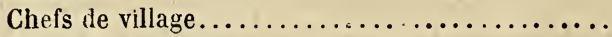

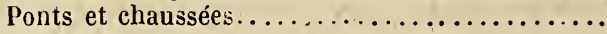

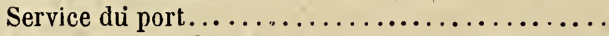

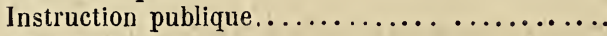

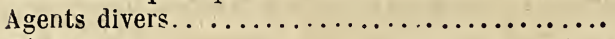

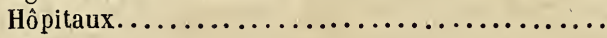

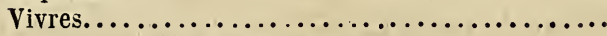

Travaux et approvisionnements.............

Achèvement et entretien des édifices publics.....

Primes pour engagement d'ouvriers...........

Frais d'internat pour 100 élèves des deux sexes. .

Culte et encouragement à l'instruction religieuse.

Encouragements à la colonisation..............

Allocations et secours divers................

Total.................

$2,920 \mathrm{fr}$.

7,010

3,720

6,280

9,034

1,680

7,206

5,400

4,000

12,000

2,000

2,000

8,000

1,500

10,000

7,220

$30,000 \mathrm{fr}$. 


\section{APPENDICE.}

I. Extrait du rapport de M. Jules Duval au jury spécial (Concours général et national d'agriculture de Paris, en 1860,

PREMIÈRE SÉRIE.

$1^{\text {re }}$ SECTIION : Bois. - La collection des bois de la Réunion, par la dimension du plus grand nombre des spécimens qui la composaient, avait un caractère scientifique plutôt qu'industriel. Elle a suffi cependant pour donner une idée de la variété des essences qui peuplent les rivages, les pentes, les montagnes de cette île, située sous le tropique, dans des conditions de climat et de sol éminemment favorables à la végétation forestière. Malheureusement, les nécessités de la culture et les besoins de la consommation domestique ou industrielle ont étendu le défrichement au delà de ses limites naturelles, et amené la destruction plutôt que l'exploitation des bois qui descendaient autrefois des hauteurs sur le rivage, il n'en reste plus qu'une ceinture de 3 à 6 kilomètres de large, entre la zone des cultures et celle des plateaux supérieurs; elle est protégée contre de nouvelles dévastations par l'arrêté du gouvernement local en date du 8 avril 1833. C'est là que croissent naturellement les meilleurs arbres de construction, plus remarquables pourtant par leurs qualités industrielles que par leurs fortes dimensions.

On peut y relever plus de 80 essences dignes d'attention à divers titres et d'une exploitation, assez facile, tandis que d'autres espèces, moins remarquables, quoique utiles encore, peuplent les rares massifs, çà et là épargnés par la hache, au voisinage des cultures, ainsi que les ravines de l'intérieur et les flancs abrupts des montagnes, jusqu'à la hauteur où cesse toute végétation forestière.

Parmi ces diverses essences, l'exposition permanente possède les suivantes, d'un emploi usuel dans l'industrie (sans parler de celles où dominent des propriétés tinctoriales et médicales) :

Andrèse (Celtis madagascariensis). Charronnage et tour.

Affouche, rouge (Ficus cordifolia). Pirogues et lambris, cannes.

Acajou à fruits (Anacardium occidentale). Charpente et menuiserie.

Amer (bois). Bois de tour. 
Acacia bernier (Acacia dealbata) de la Nouvelle-Hollande. Charronnage.

Bassin moiré (Blackwellia paniculata). Construction et ébénisterie.

Benjoin (Terminalia mauritiana). Construction, menuiserie, charronnage.

Blanc (Hernandia ovigera). Planches pour lambris.

Bancoulier (Aleurites triloba). Planches pour lambris.

Balai des bas (Erythroxylon hypericifolium). Charpente.

Bananier à petite feuille (Cascaria fragilis). Tables d'harmonie.

Bois de l'Inde et de buis (Murraya exotica). Tour, ébénisterie, construction.

Caféier marron (Coffea mauritiana). Çannes.

Café moka (Coffea arabica). Tour.

Cannellier marron (Laurus cupularis). Charpente, planches moyennes, bois de fusil.

Combava (Citrus aurantium histrix). Ébénisterie.

Camphrier (Laurus camphora). Ébënisterie.

Cliange-écorce (Ludia heterophylla). Charpente et tonneaux.

Champac (Michelia champaca). Coffres.

Cœur-bleu (Prockia theiformis). Charronnage.

Gyprès étalé (Cupressus horizontalis). Ébénisterie et charpente.

Caoutchouc (Ficus elastica). Menuiserie.

Cèdre de la Jamaïque (Guazuma ulmifolia). Tonnellerie.

Condori ou Corail végétal (Adenanthera pavonina).

Chene blanc.

Cors blanc (Blackwellia paniculata). Construction.

Chirurgien (Olea cernua). Tour, ébénisterie.

Campêche (Hcomatoxylum campechianum). Meubles, archets.

Cerisier du Brésil (Eugenia brasiliensis). Tour.

Cérisier cannelle (Eugenia Michelii). Tour.

Citror doux (Citrus decumana). Ébénisterie.

Cocotier (Cocos nucifera). Poutre; marqueterie (racines).

Évis (Spondias cytherea). Pirogues.

Ébène (Dyospyros ebenium, menalida). Ébénisterie, marqueterie, construction.

Écorce blanc (Fissilia psittacorum). Aissantes, coussinets de meule.

Fer (Sideroxylum cinereum, borbonicum). Construction.

Figuier marron (Dombeya species). Panneaux. 
Filao (Casuarina laterifolia). Construction.

Fandamane (Prockia theiformis). Charpente et douvelles.

Gaulette blanc ou bâtard (Cupania borbonica alternifolia). Charpente, tour, engrenage, mâtures.

Gaulette rouge (Melicocca diversifolia). Charpente.

Gaulette marron (Cupania levis). Charpente.

Giroflier (Caryophyllus aromaticus). Menuiserie, ébénisterie.

Goyavier à fruit blanc (Psidium pyriferum). Petite charpente, avirons, douvelles.

Goyavier sauvage (Prokia theiformis). Charpente, tonnellerie.

Goyavier marron rouge (Ludia sessiliflora). Charpente, avirons. Goyavier du pays à fruit rouge (Psidium pomiferum). Menuiserie.

Hipé (Bassia longifolia). Charpente.

Judas (Cossignia borbonica). Charpente, tour.

Jaune à grandes feuilles (Ochrosia borbonica). Charpente, ébénisterie, tour.

Jamrosa (Jambosa vulgaris). Construction.

Jacquier (Artocarpus jacca, integrifolia). Ébénisterie, charronnage, tour.

Jamlong (Syzygium caryophyllum, jambolanum?). Chevrons, avirons.

Jujubier ( $Z$ izyphus jujuba). Menuiserie.

Joli cœur (Senecio undulata). Petite charpente.

Janvier (Poupartia borbonica). Charpente.

Losteau (Antirhcea verticillata). Charpente, menuiserie.

Lait à cœur rouge (Taberncemontana borbonica). Coffres.

Lilas (Melia azederach). Charpente, charronnage.

Latanier (Latania borbonica). Charpente.

Muscadier (Myristica aromatica). Crayons.

Mahaut (Dombeya punctata). Construction.

Manguier (Mangifera indica). Bourrellerie.

Manguier à grappes (Sorindeia madagascariensis). Menuiserie.

Mabolo (Diospyros mabolo). Charpente, tour.

Maigre (Nuxia verticillata). Chevrons.

Mapou blanc (Andromeda pyrifolig). Planches pour lambris.

Millepertuis (Hypericum lanceolatum). Menbles.

Marlborough blanc (Nuxia verticillata). Bardeaux, charpente.

- Naltes à petites feuilles (Imbricaria petiolaris). Construction, ébénisterie, carrosserie. 
Natte à grandes feuilles (Imbricaria maxima). Ébénisterie, constructions.

Natte cochon (Gortneria vaginata). Ébénisterie.

Nèfle (Jossinia elliptica et mespiloides). Charpente.

Noir blanc (Acacia lebbeck). Tour, ébénisterie, charronnage.

Noir des hauts (Diospyros melanida). Charpente, menuiserie. Noir rouge, id. noir (Acacia lebbeck). Charronnage, ébénisterie, engrenages, courbes pour chaloupes.

Oiseau (bois d') (Geniostoma borbonicum). Construction.

Olivier blanc (Olea lancea). Tour, ébénisterie, menuiserie.

Olivier noir (Olea chrysophylla). Tour, ébénisterie.

Oranger (Citrus auraníum). Ébénisterie.

Orangine (Eriphasia aurantiola). Ébénisterie.

Ouatier (Bombax malabaricum). Planches communes.

Palmiste marron (Areca lutescens). Parasolerie.

Pamplemoussier (Citrus aurantium pampelmos). Marqueterie.

Patte-de-poule (Toddalia paniculata). Planches pour lambris.

Pêcher (Jossinia colixifolia). Charpente.

Pêcher marron (Syzygium paniculatum). Parasolerie, marqueterie, construction.

Perroquet (Fissilia psittacorum). Construction.

Pomme (Syzygium glomeratum). Construction.

Puant (bois) (Fotidia mauritiana borbonica). Construction.

Quatre-épices (Myrtus piment"). Ébénisterie.

Rempart (Monimia myrtifolia). Construction.

Rivière (Leucothoe salicifolia). Ébénisterie.

Ronde (Erythroxylon longifolium). Construclion.

Rouge oriental (Elceodendron orientale). Construction, chaloupes, pirogues.

Sabine (Thuya orientalis). Tour.

Sable (Sideroxylon cinereum). Pirogues.

Sandal (Poupartia borbonica). Tour.

Schinus terebinthaceus. Menuiserie.

Senteur bleu (Assonia populnea). Chevrons, outils de menuiserie. Senteur galet (Olea cernua). Ébénisterie, tour, construction.

Strophantus aurantiacus. Tablecterie.

Tacamahaca blanc (Calophyllum spurium). Constructions, charronnage.

Tacamahaca rouge (Calophyllum niophyllum). Gharronnage, constructions maritimes. 
Tamarinier (Tamarindus indica). Charronnage, courbes d'embarcations.

Tamarinier dès hauts (Acacia heterophylla). Charronnage, courbes d'embarcations, aissantes.

Tan rouge (Weinmannia macrostachya). Gharronnage, constructions maritimes.

Tanghin (Tanghinia venenifera). Menuiserie, ébénisterie.

Teck d'Arabie (C'ordia amplifolia). Planches.

Tourtour de Mozambique (Rhinocarpus longifolius). Ébénisterie.

Vache (bois de) (Leucothoe pyrifolia). Constructions.

Cet aperçu des richesses forestières de la Réunion indique tout au moins les ressources qu'y trouveront, à défaut de l'exportation que ne permet guère le peu d'importance des massifs boisés, les diverses industries locales qui emploient le bois; il signale en même temps au pays l'utilité des mesures protectrices qui substituent un aménagement régulier à des abatages inintelligents.

Le jury a décerné une médaille d'argent à MM. Deshayes et compagnie, à Saint-Pierre, pour les pièces de charronnage qu'ils ont exposées, et qui sortent de leur établissement, où ils débitent mécaniquement les bois du pays.

Il a décerné une médaille de bronze, pour le concours qu'ils ont prêté au commis̊saire du gouvernement chargé de former la collection des bois à :

MM. Desaifres, inspecteur des eaux et forêts à Saint-Denis;

Dierx, directeur de l'établissement de M. LoricourtDeheaulme, à Saint-Denis;

René Pouget, propriétaire à Saint-Pierre.

$2^{\mathrm{e}}$ SECTION : Textiles autres que le coton et la soie. - Les colonies françaises possèdent un grand nombre de végétaux dont les tiges, les écorces, les feuilles, contiennent des fibres résistantes qui, après les préparations convenables, se prêtent aux mêmes emplois que les textiles les plus estimés : fils, tissus, cordages, paniers, corbeilles, hamacs, sacs, nattes, filets, chapeaux, parures, vêtements, cuir végétal, etc. Les essais tentés en Algérie sur l'alfa, le dis et le palmier nain, les emplois déjà connus du mûrier à papier constatent les ressources que. ces textiles offriraient pour la fabrication des carlons et des papiers.

- Parmi les objets destinés au concours général, le jury a distingué la belle collection des matières fibreuses de la Réunion, 
envoyée par $M$. Manès; et, lui tenant compte de ses nombreux et persévérants essais pour découvrir des emplois industriels et fructueux à ces ressources du sol généralement peu appréciées, ainsi que de l'ensemble de sa participation au concours, il lui a décerné une médaille d'or. Les échantillons de M. Manès comprennent surtout des agave, des bananiers, de la bourre de coco, du crin végétal de palmiers, du vacoa (Pandanus-utilis), etc., etc.

Une pareille médaille a été décernée à $M$. Richard, directeur du jardin botanique de Saint-Denis, à la Réunion, qui avait exposé en son nom quelques tibres textiles d'un intérêt particulier (Sanseviera latifolia et $S$. cylindrica, Urtica nivea), et avait, en outre, par ses soins personnels et par les cultures du jardin botanique, concouru aux nombreux envois de l'administration locale. Le jury a voulu honorer, par cette récompense, une longue carrière, tout entière consacrée aux sciences appliquées à la culture, et qui compte, parmi ses titres les plus méritoires, la création au Sénégal d'un jardin d'essai (Richard Toll), il y a près de quarante ans.

Une médaille d'or a été également décernée à $M$. Perrottet..., qui revendique l'honneur d'avoir doté de la vanille l'île de la Réunion....

Une mention honorable a été accordée à mademoiselle Céleste Rivière, de la Réunion, pour ses chapeaux de latanier, remarquables par une légèreté souple qui n'exclut point la solidité. Cette industrie occupe utilement les loisirs de certaines familles de la colonie, et, bien qu'elle n'ait pas de grandes chances d'entrer dans le courant des exportations, elle est un bon élément du travail local.

Sans décerner aucun prix aux sacs à sucre en feuilles de vacoa (Pandanus utilis), parce qu'aucun des objets exposés ne lui a paru marquer un progrès dans la fabrication, le jury a néanmoins examiné, avec intérêt, les produits d'une industrie domestique, qui assure aux pauvres du pain et la monnaie de tous les jours, et qui, après avoir satisfait aux demandes des usines, fournit un excédant que l'on exporte à Maurice.

$3^{\text {e }}$ section : Cotons. - Des mentions honorables ont été attribuées à $M$. Desprez, ainsi qu'à $M$. Torris, de la Réunion, dont les cotons étaient supérieurs aux autres de même provenance, géné= ralement un peu laineux et grossiers, non sans doute par la faute 
du sol ni du climat, mais par le mauvais choix des graines et l'insuffisance des soins.

$4^{\mathrm{e}}$ SEGTION : Ouates et soies végétales. - ... Le jury a remarqué encore des fleurs artificielles, réunissant l'éclat à la fraìcheur et à la légèreté, fabriquées avec les aigrettes plumeuses des graines du Beaumontia grandiflora, arbrisseau sarmenteux qui croît à la Martinique et à la Réunion. La mode parisienne pourrait peutêtre trouver dans cette plante une matière nouvelle pour ses parures.

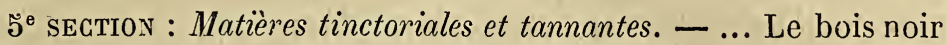
(Acacia lebbeck) de la Réunion a été signalé par le jury.

$6^{\text {e }}$ SEction : Matièrès oléagineuses et savonneuses. - ... A la Rẹ́union, on possède une huile de badamier précieuse pour l'horlogerie, et une autre pour les outils d'acier, que fournit une espèce de chardon....

Deux médailles d'argent ont été accordées, l'une à $M$. Grelot, de la Réunion, pour ses savons à l'huile d'illipé, l'autre à $M$. Vinchant, de la même colonie, pour une belle collection d'huiles de graines de cucurbitacées.

Deux médailles ont été accordées à $M$. Rouman, de la Réunion, pour son huile de bancoul, et à $M$. Toulorge, de la même île, pour cette même sorte d'huile et pour celle de pignon d'Inde.

Une mention honorable a été accordée à $M$. Vireslier, de la Réunion, pour produits analogues.

$7^{\circ}$ SEGTion : Farines et Fécules.

Médaille d'argent à madame veuve des Étangs, de la Réunion, pour la collection des produits de cet ordre qu'elle a exposés et qui donnent une idée de l'important commerce qu'elle a organisé à l'usage des navires qui ont à faire des approvisionnements : ses tapiocas granulés ont été particulièrement remarqués.

Mention honorable à $M$. Levasseur, de la Réunion, pour sa fécule de mangues.

$8^{\circ}$ SEction : Sucres. - ... En présence des lots nombreux qui figuraient au concours, le jury a cru devoir établir trois catégories, suivant les procédés industriels plus ou moins perfectionnés qui ont servi à leur préparation.

Les producteurs français emploient, en effet, trois systèmes de fabrication qui représentent en quelque sorte les trois âges du progrès industriel. Le plus ancien, celui qui est fondé sur une tradition séculaire, consiste à évaporer et à cuire le vesou (jus de la 
canne) dans des chaudières, généralement en fonte, liées entre eiles : c'est ce qu'on appelle le système à feu nu, presque seul usité encore dans les Antilles, mais à peu près abandonné à la Réunion.

Le second système consiste à évaporer le vesou jusqu'à la densité de $28^{\circ}$ à $30^{\circ}$ (à l'aréomètre de Baumé) dans une batterie de huit chaudières qui, du nom de son inventeur, est appelée batterie Gimard; après quoi la cuisson s'opère à l'air libre, dans les chaudières à basse température, dites Wetzelles. Ce procédé n'est guère employé qu'à la Réunion.

Le troisième système corisiste à évaporer le vesou jusqu'à la densité de $30^{\circ}$ (aréom. de Baumé) et à en achever la cuisson dans des chaudières Howard, dont le principe est le vide, et qui sortent généralement de la maison Derosne et Cail.

En outre de ces grandes divisions, qui constituent autant de systèmes, il existe de nombreuses différences secondaires dans les pratiques. Ainsi, dans certaines usines, le sirop, après sa cuisson dans les chaudières et son refroidissement dans de grands réservoirs en bois ou en bitume, vulgairement appelés tables, est déposé dans des caissons où il se purge, tandis que, ailleurs, le sucre cristallisé est puisé dans les tables et porté dans les turbines, admirables machines à force centrifuge qui, en un clin d'œil, purgent le sucre', suppriment en conséquence les caissons, foyer permanent de fermentation, et n'exigent en outre qu'un modeste local. Certains fabricants turbinent le sucre, sans adjonction d'eau ni même de clairce, et les sucres de sirop se trourent mélangés dans la qualité moyenne de la fabrication; certains autres recourent à l'eau et à la clairce. Mais, sans s'arrêter à ces pratiques, le jury n'a établi des types distincts de second ordre que dans le système de cuisson dans le vide, suivant que les spécimens se présentaient sous forme de gros grains, obtenus par une cuite à charges successives, ou en grains fins provenant de cuites par charges simultanées.

A. Première catégorie. - Sucres cuits dans le vide, avec ou sans appareils centrifuges.

Premier type. - Sucre à gros grains.

Médailles d'or : MM. Adam (Réunion), sucre tant du premier que du second jet, sec et nerveux; Deshayes (Théodore), de la Réunion, sucres blancs et d'une brillante cristallisation; Viguerie 
(Réunion), sucres secs, de nuance et de qualité régulières sur une fabrication de 1,500,000 kilogr.

Médailles d'argent: MM. Guy de Ferrières (Réunion) et ThomyLory (Kéunion) : sucres à gros grains bien détachés, mais de nuances inférieures aux précédents.

B. Deuxième catégorie. - Sucres préparés par le "système mixte dit Gimart et Wetzelle.

Médailles d'argent: MM. Duboisé; Hibon et Choppy; Ve Sicre de Fontbrune; Benjamin Vergoz, de la Réunion; la Société des Comores (Mayotte).

Médailles de bronze : MM. Barbe et Rétout; Charles Robin; Valmyre Riquebourg; Wetley, de la Réunion.

C. Troisième catígonie. - Guisson à l'air libre. Procédé traditionnel.

Médailles de bronze : M. Lagourgue, de la Réunion; Thomas (Mayotte).

Mentions honorables : MM. Anicet Orré; Joseph Lelièvre, de la Réunion.

Les sucres de Mayotte, qui ont figuré au concours, sont un précieux spécimen des richesses de eet ordre que peut fournir cette colonic française; elle parait au jury l'une des plus douées d'avenir malgré son peu d'étendue, l'une des plus assurées d'une prochaine et haute prospérité, si des communications régulières la rattachaient à la Réunion, centre du commerce et de la politique française dans les parages de Madagascar, autre plus vaste théâtre ouvert à nos entreprises sous la prolection de notre droit.

$9^{\circ}$ SECTION : Alcools, liqueurs, conserves, huiles essentielles.

Médaille d'argent : M. Louis Élie, à la Réunion, pour son rhum.

Médailles de bronze : MM. André Féry, à la Réunion, pour son rhum; Géringer, à la Réunion, pour son curaçao.

Mention honorable: M. Deguigné, à la Réunion, pour son rhum.

Médaille de bronze : M. Périchon, de Sainte-Marie, pour conserves et fécules.

Médaille d'or: M. Deler, de la Réunion, pour son essence de cannclle.

$11^{\text {e }}$ SECTION : Cafés. - Le café jouait autrefois, dans la production et le commerce des colonies françaises, un rôle dont il est 
bien déchu pour diverses causes : la concurrence de plus en plus triomphante de la canne à sucre, les maladies qui ont frappé à la Réunion le bois noir (Acacia lebbeck), lequel sert d'abri aux jeunes caféiers, et enfin, aux Antilles, l'épuisement des terres et les ravages d'un insecte (elachysta coffeola) qui dévore le parenchyme des feuilles. Malgré ces échecs, cette feuille tient encore le second rang dans l'économie rurale de nos colonies, quoique à grande distance du sucre; dans presque toutes, de sérieux efforts sont tentés pour la remettre en honneur.

C'est à la Réunion que cette renaissance est le plus manifeste. Là, le moka, originaire de l'Arabie et renouvelé à la soure même, il y a une trentaine d'années, n'a rien perdu de son arome exquis; l'arbre pèche seulement sous le rapport de la longévité; trop souvent il périt après avoir donné une belle récolte. Diverses espèces ou variétés iui disputent la faveur publique; la variété dite Leroy, du nom du capitaine qui en fut l'introducteur, compensant une saveur moins agréable par une plus grande rusticité des sujets; le myrte, qui approche du moka par le goût, et le dépasse par la longévité; l'éden, café à très-petits grains, ainsi nommé de la plantation où il prospère le mieux; le marron ou sauvage, indigène à Bourbon et à Maurice, de peu d'arome, mais d'une saveur amère et forte qui relève agréablement la délicatesse des autres. Les quatre premières sortes ne sont que des variétés du coffea arabica, la quatrième constitue l'espèce appelée coffea mauritiana.

A l'occasion des beaux cafés exposés par M. de Floris, de la Réunion, le jury a décerné à ce planteur une grande médaille d'or, spécialement pour ce produit, et généralement pour l'ensemble de ses lots, témoignage des efforts aussi persévérants qu'intelligents qu'il ne cesse de faire pour le maintien et la propagation des cultures secondaires ; c'est à ses exemples et à ses instructions que la Réunion doit la popularité dont y jouit la vanille.

Médailles d'argent : MM. Alphonse Frappier, de la Réunion, pour un café décortiqué par un procédé dont il est l'inventeur, et qui, sur les marchés, assure à ses cafés un prix inférieur de dix pour cent au prix des similaires préparés par les méthodes ordinaires; M. Jean Keur, de Nossi-Bé ; madame veuve Lossandière, de la Réunion, pour son moka.

Médaille de bronze: M. de Villèle, de la Réunion. 
$12^{\mathrm{e}}$ SEction : Cacaos. - Dans toutes nos colonies à culture, les cacaos prospèrent, et dans plusieurs ils rivalisent d'importance avec les cafés.

Médaille d'argent :.M. Bellier-Montrose, de la Réunion.

Médailles de bronze: MM. Jaillet, de la Réunion, pour sọn beurre de cacao; Manlius, de la Réunion; pour ses cacaos en grains.

$13^{\mathrm{e}}$ SECTION : Épices, condiments, aromates. - Dans cette section figuraient ces dons si variés de la nature tropicale qui ne sont que des accessoires dans l'alimentation et les industries de l'Europe, mais que les habitudes raffinées de la civilisation font de plus en plus apprécier, et qui de tout temps ont compté parmi les éléments de la fortune commerciale des peuples navigateurs. L'assortiment presque entier de ces matières figurait au concours: la vanille, la carnelle, le poivre, la muscade, le girofle, le gingembre, le piment, le patchouly, le vétiver, la fève tonka, le bétel, et une foule d'autres moins connues : l'ambrette ou ketmic odorante, le cardamome, la malaguette, le vampi, le carvi, le canang odorant, etc. Le thé seul manque à la production aromatique de nos colonies (1).

Médaille d'or: M. Turpin-Demorel, de la Réunion, pour sa vanille longue, plate, givrée. - G'est une culture qui, depuis quelques années, fait dans l'île les plus grands progrès. Les qualités supérieures de la vanille, ses prix élevés $(70$ à 100 fr. le demikilogr.), quoique bien inférieurs à ce qu'ils étaient au début ( 150 et $200 \mathrm{fr}$.), lui assurent, pour longtemps sans doute, une juste et croissante popularité. Elle est une précieuse ressource pour la petite propriété, qui trouve dans cette culture facile, agréable et lucrative, un point d'appui contre les offres qui tendent chaque jour à l'absorber dans la grande. Elle défierait peutêtre toute concurrence, si les cultivateurs de la Réunion connaissaient, comme au Mexique, l'art de la préparer, sans la tremper dans l'eau chaude. Il en résulte une moins-value dans l'estimation du commerce français, et néanmoins on est réduit à cette pratique, parce que, si on la néglige, la vanille casse, et elle est encore plus dépréciée. Il existe aussi sur cette plante une maladie dont le caractère et le traitement ne sont pas bien connus.

(1) Depuis ce rapport de M. Duval, la culture du thé a été introduite à la Réunion. 
Médailles d'argent: MM. Hubert-Delisle (Réunion), pour ses muscades et macis, et pour son beurre de muscade; Patu de Rosemond (Réunion), pour sa vanille; Ferréol-Lepervenche (Réunion), pour sa vanille.

Médaille de bronze: M. Ferrand (Réunion), pour son cardamome.

14. ${ }^{\mathrm{e}}$ SEGTion : Matières médicinales. - Le jury a décerné une médaille d'argent à M. Mutel, adjoint au maire de Saint-Paul (Réunion), pour l'aide qu'il a prêtée à M. Imhaus, délégué de cette colonie, dans la formation des lots destinés au concours et spécialement ceux des substances médicinales.

$15^{\mathrm{e}}$ SECTION : Graines alimentaires. - Le riz, d'un emploi beaucoup plus général (que les mils), est cultivé dars la plupart de nos colonies, à la Réunion, à Nossi-Bé, à Madagascar....

Dans les lots de haricots et de pois, aux couleurs capricieuses, on distinguait le pois noir de Mascate (Mucuna melanosperma) qui, importé à la Réunion, y est devenu un fourrage précieux par l'épaisseur de la couche végétale dont ses feuilles couvrent le sol, et un engrais servant à l'assolement si on l'enterre en vert à la manière des lupins.

Quelques échantillons de blé et d'orge rappelaient les traces d'anciennes cultures à la Réunion....

Médailles de bronze : MM. de Lanux, Pierre Alexis et Thiébault, de la Réunion, pour leurs collections de haricots et-doliques de la Réunion.

$16^{\text {e }}$ SECTION : Tabacs. - ILes tabacs, qui furent au dix-septième siècle dans nos colonies les premiers articles d'échange et la première monnaie, qui acquirent même à la Martinique, dans le cru de Macouba, un renom qui a survécu aux cultures, les tabacs, après avoir été longtemps délaissés et presque oubliés comme produits d'exportation, ont reparu avec honneur au concours de 1860, et une juste faveur les y a accueillis.

G'est à la Réunion surtout qu'en revient l'honneur. MM. Valentin et Morange présentaient des tabacs de la variété vanille, qui ne laissaient rien à désirer pour la finesse de la feuille, la délicatesse de l'arome, la ténuité des nervures, la combustibilité, et par tous ces mérites se recommandaient pour robes de cigares. Le jury a décerné à ces producteurs une médaille d'argent.

Médailles de bronze : MM. Ducasse, pour ses cigares ; Hou- 
reau, pour ses carottes ; Ed. Lacaussade, $i d_{\text {。 }}$; Langlois, $i d_{\text {. ; Louis }}$ Élie, $i d$. (de la Réunion).

Mayotte avait aussi envoyé des produits qui, sans obtenir de récompense, ont attiré l'attention du jury.

$17^{\mathrm{e}}$ SECT1ON : Spécimens de la flore coloniale. - Médaille d'argent : M. Bernier (Réunion), pour l'herbier cryptogamique de cette colonie, prélude de travaux plus considérables auxquels ce botaniste s'était voué, lorsqu'une mort prématurée est venue l'enlever à la science et au pays.

\section{TROISIÈME ȘÉRIE.}

$1^{\text {re }}$ SECTION : Cuirs et peaux. - La Réunion et la Guyane avaient seules envoyé des peaux sèches et des cuirs ouvrés: se bornant à en apprécier le mérite au point de vue des services rendus à la production agricole par le débouché ouvert aux dépouilles des animaux, le jury a accordé une mention très-honorable à M. La Kermance, tanneur de la Réunion, qui exploite une importante fabrique de peaux.

$2^{\mathrm{e}}$ section : Laines et poils. - Dans cette section, la Réunion seule exposait, et, quoique les laines de cette provenance n'aient point paru assez remarquables pour mériter des récompenses, le jury n'a pas entendu décourager les essais et les perfectionnements de cette catégorie de produits. Il lui a suffi de penser aux troupeaux améliorés qui peuplent les colonies du Cạp et de Natal, sous des latitudes peu différentes, el au commerce de laines qu'ils alimentent, pour reconnaître que rien; dans les conditions géographiques de la Réunion, ne s'oppose à l'élèvé des bêtes à laine, du moins sur les plateaux supérieurs et les montagnes dont l'altitude procure à ces animaux le climat de la zone tempérée.

$3^{\mathrm{e}}$ sECTION : Miels et cires. - Les mouches à miel prospèrent dans toutes nos colonies....

Médailles de bronze; MM. Roussel et Gauthier, dit Guégaine (de la Réunion), pour leurs miels et cires.

$4^{\circ}$ SECTION : Soies. - La production de la soie étant encore à l'état naissant dans nos colonies, il est difficile de prévoir quels échecs ou quels succès l'avenir lui réserve....

Il convient d'inscrire ici, comme ne rentrant dans aucune des séries qui précèdent, une médaille d'argent accordée à M. Maillard, ingénieur des ponts et chaussées de la Réunion, pour un plan en relief et en plâtre, de cette île.... 
En dehors et au-dessus des récompenses ci-dessus, le jury a décerné une grande médaille d'or à M. Imhaus, délégué de la Réunion, pour les produits en grand nombre et de qualité supérieure qui constituent son envoi personnel (sucres, vanilles, cafés, bois, plantes médicinales, tabacs, etc.), et en même temps pour le concours qu'il a prêté comme commissaire du gouvernement, à l'organisation du contingent des lots, envoyés par l'île de la Réunion à l-Exposition permanente de l'Algérie et des colonies. Grâce à l'activité aussi persévérante qu'intelligente de M. Imhaus, la colonie qu'il représente figure avec un éclat exceptionnel et un chiffre de 2,000 lots, dans les galeries du palais de l'Industrie.

Des mentions très-honorables ont été accordées à l'administration de la Réunion pour l'ensemble de ses envois.

A la suite du rapport, dont on vient de lire un extrait, on trouve la statistique suivante:

10 Sucre.

Nombre des habitations rurales.
Nombre d'lectares cultivés.....
Sucre brut fabriqué, kilogr....
Sucre terré, kilogrammes.....
Sirops et mélasses, litres.......
Tafias, litres.. .............
Valeur brute de la production
sucrière, francs............
Frais d'exploitation, francs....
Valeur nette de la production
sucrière, francs.............
Nombre destravailleursemployés
aux cultures...............

\section{8}

159

14,839

$25,963,500$

"

$1,396,110$

479,209

$n$

,

)

24,178
184:

168

23,442

$24,063,689$

"

$3,490,500$

815,750

$14,412,844$

$4,804,281$

$9,608,563$

15,308

Café.

Nombre des caféieries.........

- dhectares cultivés.....

Quantité récoltée, kilogr.......

Valeur brute de la récolte, fr...

Frais d'exploitation, fr.........

Valeur nette de la récolte, fr...

Nombre de travailleurs employés aux cultures.............

$\begin{array}{rrr}701 & 637 & 443 \\ 4,180 & 4,052 & 2,246 \\ 874,200 & 362,750 & 450,350 \\ " \text { " } & 434,580 & 766,575 \\ \text { " } & 108,400 & 373,397 \\ & 326,180 & 393,178 \\ 6,233 & 3,590 & \text { " }\end{array}$

$26,581,606$

n

$3^{\circ}$ Cacao.

Nombre d'hectares cultivés.....

Quantité récoltée, kilogr.......

Valeur brute de la récolte, fr...

Frais d'exploitation, fr.........

Valeur nette de la récolte, fr...

"10,300


40 Vanille.

Nombre d'hectares cultivés.....

Quantité récoltée, kilogr.......

Valeur brute de la récolte, fr...

Frais d'exploitation, fr.........

Valeur nette de la récolte, fr...

5o Tabac.

Nombre d'hectares cultivés.....

Quantité récoltée, kilogr.......

Valeur brute de la récolte, fr...

Frais d'exploitation, fr.........

Valeur nette de la récolte, fr...

60 Girofle.

Nombre d'hectares cultivés.....

Quantité récoltée, kilogr.......

Valeur brute de la récolte, fr...

Frais d'exploitation, fr.........

Valeur nette de la récolte, fr...

$n$
$n$
$n$
$n$
$n+1+1+1$

)

405

1,834

183,350

63,475

119,875

)

$\begin{array}{rrr}542 & 395 & 482 \\ 101,000 & 53,420 & 278,750 \\ " & 213,680 & 662,500 \\ " & 21,308 & 222,375 \\ " & 192,312 & 440,125\end{array}$

$\begin{array}{lrr}2,799 & 2,346 & 576 \\ " & 71,730 & 53,500 \\ 》 & 143,460 & 39,600 \\ " & 36,000 & 14,350 \\ \text { " } & 192,312 & 25,250\end{array}$

¡o Mûrier.

Nombre d'hectares cultivés.....

$8^{\circ}$ Coton.

Nombre d'hectares........... "

Quantité récoltée, kilogr.......

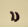

600

9० Vacoa.

Nombre de sacs............. "

Valeur brute, fr............ "

Frais de fabrication, fr.......

Valeur nette, fr............ n

$10^{\circ}$ Blé.

Hectares cultivés...........

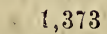

395,000

)
)

Blé récolté, kilogr...........
$1,505,380$
708,054
361,973
346,081

110 Vivres (1).

Nombre d'hectares cultivés.....

Quantité de la récolte, kilogr...

Valeur brute de la récolte, fr..

Frais d'exploitation, fr........

Valeur nette, fr.............

$\begin{array}{crr}41,134 & 28,651 & 27,345 \\ " \prime & 17,008,611 & 25,747,432 \\ 2,084,600 & 2,532,987 & 4,267,990 \\ " \prime & 251,441 & 1,677,880 \\ " & 2,261,546 & 2,590,110\end{array}$

$12^{\circ}$ Renseignements généraux.

Nombre d'habitations rurales autresque sucreries et caféieries.

Nombre de travailleurs employés

aux cultures..............

Nombre total d'hectares cultivés.

$\begin{array}{rrr}3,277 & 4,074 & 5,869 \\ 23,775 & 46,090 & 56,647 \\ 64,882 & 58,913 & \mathbf{7 2 , 2 4 5}\end{array}$

(1) Embrevades, riz, mais, manioc, songes, patates, haricots, pommes de terre, jardinage, cultures diverses. 
Nombre total des habitations rurales .................

Valeur brute totale des récoltes, fr......................

Frais d'exploitation de la récolte entière, fr................

Valeur nette de la récolte entière, fr.....................

Valeur des terres employées aux cultures, fr...............

Valeur des bâtiments et du matériel d'exploitation, fr......

Valeur des animaux de trait et du bétail, fr...............

Valeur totale des propriétés rurales, fr................

Valeur des travailleurs, fr......

Étendue des savanes, hectares. . - des bois et forêts, hect. - des terrains non cultivés, hectares.............

Total général de la superficie, hectares

\begin{tabular}{|c|c|c|}
\hline 4,137 & 4,819 & 6,428 \\
\hline$D$ & $17,739,111$ & $51,175,651$ \\
\hline ") & $5,221,560$ & $21,024,887$ \\
\hline " & $12,517,551$ & $30,150,764$ \\
\hline ') & $77,850,774$ & $154,240,314$ \\
\hline D & $23,367,745$ & $39,184,500$ \\
\hline$n$ & $"$ & $11,828,860$ \\
\hline$n$ & $188,057,979$ & $205,253,674$ \\
\hline & $\begin{array}{r}79,103,800 \\
16,088\end{array}$ & $\begin{array}{l}\text { ") } \\
24,247\end{array}$ \\
\hline & 45,673 & 53,442 \\
\hline & 120,674 & 81,616 \\
\hline & 231,550 & 231,550 \\
\hline
\end{tabular}

II. SITUATION DE LA BANQUE DE LA RÉUNION AU 30 JUIN 1864.

Extrait du rapport présenté à l' Empereur le 4 août 1863 ; - Moniteur du 12 novembre 186 อ̆.

Actif.

Numéraire en caiss

Nume

Effets sur place à deux signatures.

Effets garantis par les actions de la banque. .............

Obligations pour prêts sur récoltes.......

Prêts sur marchandises............

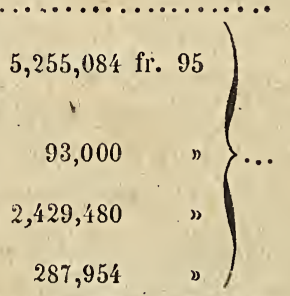

Inscriptions de rentes sur l'Etat (représentatives du

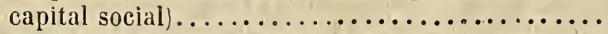

Inscriptions de rentes de la réserve $(3$ p. 100).....

Immeubles de la réserve..................

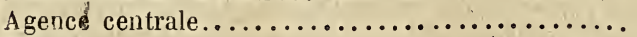

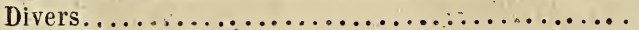

Jetons de présence......................

Valeurs mobilières.......................

Dépenses d'administration
$3,430,856$ fr. 63 c.

$8,065,518 \quad 95$

$\begin{array}{rr}3,000,000 & \text { ") } \\ 818,681 & 75 \\ 374,003 & 44 \\ 5,390 & 16 \\ 5,373 & 27 \\ 1,196 & \text { " } \\ 8,075 & 40 \\ 36,181 & 97\end{array}$

Total de l'actif.............. 15,745,277 fr. 57 c. 


\section{Passif.}

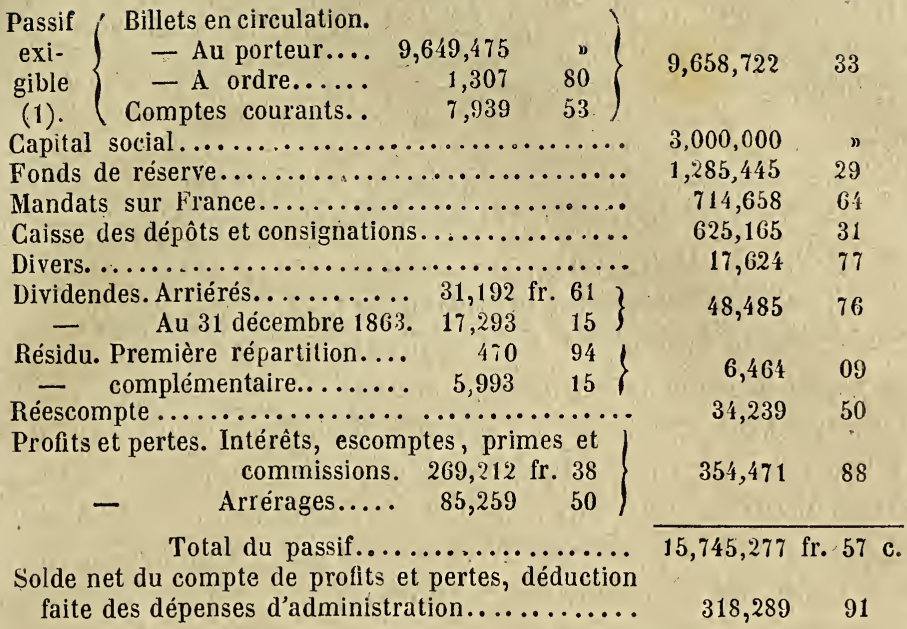

\section{LES OURAGANS DANS LA MER DES INDES.}

(Extrait de la Science populaire, $3^{\mathrm{e}}$ année, par M. J. Rambosson.)

Pendant mon voyage dans l'Océan et la mer des Indes, j'ai pu observer au moins une dizaine de ces terribles ouragans qui porlent la désolation sur leur passage; j'ai recueilli nombre de renseignements de la part de capitaines expérimentés, d'anciens créoles, et, par-dessus tout, j'ai pu profiter des travaux et de l'expérience de M. Bridet, capitaine de port à l'île de la Réunion, savant aussi actif qu'intelligent. J'ai eu l'avantage de publier ses travaux dans mon établissement typographique de la colonie. Outre mes observations personnelles, telles sont les sources abondantes qui ont été mises à ma disposition....

Rien de plus grandiose, de plus effrayant que ces ouragans. Lorsque l'hivernage est arrivé, c'est-à-dire les plus brûlants de ces climats, et qu'un calme sinistre et inaccoutumé se répand dans la nature, chacun consulte le ciel, cherche à lire dans la forme et la direction des nuages, observe le vol des oiseaux et interroge le baromètre. Ces indications ne trompent guère, et on n'est nullement étonné alors de voir bientôt le ciel se couvrir de

(1) En vertu du décret du 15 avril 1863 , la banque peut élever le chiffre de son passif exigible jusqu'à $10,125,000$ francs.

(2) Ce mémoire a été lu par l'auteur, à l'Institut (Académie des sciences) et inséré, en partie, dans les Comptes rendus, no 18, 2 mai 1864. 
nuages fauves qui portent avec eux la terreur, prophétie éloquente du bouleversement prochain. La voix du canon ne tarde pas à donner aux navires le signal d'appareiller et de s'éloigner des côtes hospitalières, qui ne seraient bientôt pour eux que le récif de leur naufrage.

Chacun est dans une attente pleine d'inquiétude; tous s'interrogent d'un triste regard et se communiquent leurs funèbres pressentiments. Dans toutes les habitations les ordres sont donnés, les précautions les plus minutieuses sont prises, les troupeaux sont rentrés du labeur, les fruits sont abrités, les portes et les fenêtres sont doublées de larges planches et consolidées par de fortes barres pour résister aux fureúrs del'ouragan qui, sans cela, les ferait voler en éclats. En plein jour, il fait donc nuit dans les maisons et on travaille aux lumières artificielles, en attendant le dénoûment des convulsions de la nature qui s'approchent. Je ne me rappelle qu'avec effroi ces moments de deuil anticipé qui précèdent ces scènes terribles.

Enfin, un point s'éclaircit dans le sombre horizon; c'est le cratère qui indique la venue et la direction du sinistre: le signal est donné ; en un clin d'œil la nature est bouleversée.

Un souffle violent bat la mer, et l'eau est balayée en poussière, les arbres crient et se brisent, les champs de cannes sont renversés, emportés, et les constructions écroulées; au bout de quelques heures succède à la végétation la plus luxuriante la plus vaste désolation.

Dans ces affreux moments, nous avons vu de fiers créoles verser des larmes, non pas pour la perte qu'ils venaient de faire, mais sous l'émotion inexprimable que leur faisait éprouver le changement qui venait de s'opérer à vue d'œil, et qui avait imprimé aux campágnes les plus fortunées, le plus lugubre aspect,

Ce n'est que quelques jours après le sinistre que l'horizon revêt tous ses crêpes de deuil. Les branches et les feuillages restés sur les troncs solides, mais qui ont été froissés par l'ouragan, jaunissent et donnent aux sites enchanteurs qui rappelaient les jardins d'Armide, un aspect d'automne et de mort auquel le regard du créole n'est pas fait.

Pendant ces crises gigantesques, la mer est tellement brassée que son écume est transportée à plus de trois quarts de lieue dans les terres. On ne voit plus le vaste Océan: ses eaux sont 
réduites en poussière que le tourbillon emporte avec lui; mais on entend sa voix terrible comme son immensité, la vague qui déferle, les cailloux et les rocs quise heurtent, un bruit semblable à celui des flammes qui sortiraient de la gueule d'un four vaste comme les flancs de l'abîme. On dirait que l'on se trouve au milieu du chaos que fécondait l'esprit de Dieu au commencement des jours.

Dans la touchante histoire de Paul et Virginie, Bernardin de Saint-Pierre a décrit d'un pinceau de maître un de ces horribles ouragans.

Entrons maintenant dans les détails scientifiques de ce météore dévastateur.

La théorie des ouragans que nous allons exposer n'est pas le résultat d'études ou de calculs compliqués, mais bien le fruit de conclusions tirées de faits recueillis dans des milliers de journaux de bord...

L'examen des journaux de bord et l'étude d'un grand nombre d'ouragans ont permis de constater que ces phénomènes obéissent à deux mouvements bien distincts : un mouvement de rotation et un mouvement de translation. Les directions des vents autour du point central se sont toujours trouvées orientées de la même manière par rapport à ce point central et par rapport aux points cardinaux du monde, et on a toujours vu le mouvement de translation entraîner l'ouragan dans une direction presque constamment la même.

On a donc conclu avec raison que les ouragans obéissent à des influences presque invariables qui ont conduit à formuler la loi des tempêtes, loi générale pour les deux hémisphères, et se réduisant aux deux principes suivants :

$1^{\circ}$ Les ouragans sont des tourbillons de plus ou moins grand diamètre, dans lesquels la force du vent augmente de tous les points de la circonférence jusqu'an centre où règne un calme d'une étendue et d'une durée variables;

$2^{\circ}$ Ces tourbillons suivent une direction variable pour chaque hémisphère, mais à peu près constante dans chacun d'eux.

"Les ouragans ne sont que de vastes trombes, dont le diamètre considérable n'avait pas permis, jusqu'à ces derniers temps, 'd'apercevoir l'ensemble.

Les lois que nous venons d'énoncer sont générales pour les deux hémisphères, c'est-à-dire que, dans chacun d'eux, les ou- 
ragans sont animés d'un double mouvement de rotation et de translation. Mais le mouvement de rotation ne se fait pas dans le même sens, et le mouvement de translation ne s'opère pas dans la même direction pour l'un et l'autre hémisphère.

$1^{\circ}$ Dans l'hémisphère sud, le mouvement de rotation se fait de telle manière, que tous les points situés au nord du centre éprouvent des vents d'ouest; tous ceux placés à l'est du centre éprouvent des vents du nord; tous ceux au sud du centre ont des vents d'est; et, enfin, les poinls qui se trouvent à l'ouest du centre subissent des vents du sud, etc. Les autres directions des vents se rencontrent dans des positions intermédiaires à celles-ci. (V. dans la Science populaire la planche annexée, fig. 1.)

$2^{\circ}$ Le tourbillon, une fois formé, se met en marche, de son point d'origine, vers l'ouest-sud-onest ou le sud-ouest du monde, continuant dans cette direction jusqu'à ce qu'il ait atteint une certaine latitude; il descend ensuite vers le sud du monde pendant quelque temps pour prendre enfin sa direction vers l'estsud-est ou sud-est, se mouvant ainsi suivant une parabole dont les deux branches s'écartent plus ou moins l'une de l'autre (V. $i d$, fig. 2).

Les ouragans prennent généralement naissance pár une latitude de 5 à 10 degrés : le mouvement vers l'ouest-sud-ouest ou sud-ouest dans la première branche s'accomplit ordinairement jusque par la latitude de 20 ou 25 degrés.

Le mouvement vers le sud n'occupe guère plus de 2 à 3 degrés de latitude, et c'est, dans la plupart des cas, entre les latitudes de 30 à 30 degrés que l'on rencontre la deuxième branche parcourue par l'ouragan...

Une remarque très-importante à faire, c'est que l'un des demi-cercles de l'ouragan est plus dangereux que l'autre, parce que le vent y est animé d'une plus grande vitesse.

Il est facile, en effet, de s'apercevoir que, lorsque la direction des vents produite par le mouvement de rotation se trouve dans le même sens que le mouvement de translation, la force du vent doit être augmentée de cette vitesse de translation, et diminuée de cette meme vitesse en sens contraire.

Metlons, par exemple, que le mouvement de translation d'un ouragan soit de 10 milles à l'heure, et la vitesse du vent de 80,000 milles. Si un navire quelconque se trouve sur son passage de telle manière que les vents soufflent sur lui dans la même direc- 
tion que se trouve le mouvement de translation, ils souffleront avec une vitesse de 90 milles, tandis que si un autre navire se trouvait en même temps et à la même distance du centre, mais dans le sens opposé, c'est-à-dire de manière que les vents soufflassent sur lui dans une direction opposée au mouvement de translation, il n'aurait à supporter qu'un effort de 70 milles; soit une différence de 20 milles ou un peu plus d'un cinquième.

Il en est de même pour tous les points situés dans la même position que les navires, par rapport à la ligne décrite par le centre; il en résulte que l'on a donné le nom de demi-cercle dangereux à celui dans lequel le vent souffle avec le plus de violence, et de demi-cercle maniable à l'autre, et cela à cause de la facilité de manœurres que les navires y rencontrent (V.id., fig. $2, \mathrm{n}^{\text {os }} 1$, 2 et 3$) \ldots . .$.

Il est enfin à remarquer que, suivant la branche de la parabole où se trouve l'ouragan, le demi-cercle dangereux occupe soit la partie est он la partie nord de l'ouragan.

Le but que s'est proposé M. Bridet, dans son excellent travail, regarde exclusivement l'hémisphère sud; cependant il est facile de faire l'application de ces données à l'hémisphère nord; il n'y a que les termes à changer.

Voici succinctement ce que nous enseigne, l'étude de la première partie de la parabole, suivie par les ouragans tropicaux dans les mers du sud :

$1^{\circ}$ Le vent est d'autant plus violent que l'on se rapproche plus du centre d'un ouragan, où règne un calme d'une plus ou moins grande étendue;

$2^{\circ}$ Le baromètre baisse d'autant plus que l'on se trouve plus rapproché de ce point central, où il atteint son minimum de hauteur pour remonter ensuite à mesure que l'on s'en éloigne;

$3^{\circ}$ Sur la trajectoire ou ligne de parcours d'un ouragan, le vent ne souffle que de deux directions complétement opposées, sud-est et nord-ouest; la saute du vent, cap pour cap, n'ayant lieu qu'après un intervalle de calme d'une durée variable;

$4^{\circ}$ Pour les navires qui passent au sud d'un ouragan, et qui se trouvent dans la partie que nous appelons dangereuse, le vent tourne sur la rose des vents de gauche à droite : sud-est, nord-est, nord, c'est-à-dire en sens inverse du mouvement ordinaire des aiguilles d'une montre;

$\check{5}^{\circ}$ Les navires qui passent, au contraire, au nord d'un oura- 
gan, dans la zone que nous avons appelée maniable, voient les vents se succéder du sud-sud-est au sud, sud-ouest, ouest et nordouest, c'est-à-dire de droite à gauche sur la rose des vents, ou mieux encore dans le sens du mouvement ordinaire des aiguilles d'une montre;

$6^{\circ}$ Dans ces trois positions que peut occuper un navire, le vent souffle en augmentant de violence jusqu'au centre, ou jusqu'au point qui en est le plus rapproché, et la durée du temps pendant lequel la force du vent va en croissant est presque toujours plus grande que celle qui est marquée par une diminution progressive de la violence des rafales.

Au milieu du calme qui se trouve au centre de l'ouragan, le ciel se dégage, la pluie cesse, et les apparences du beau temps sont quelquefois assez manifestes pour que l'on puisse croire que tout danger a disparu.

L'intensité de l'ouragan est d'autant plus grande, que l'on se rapproche plus du centre; il en est de même de sa durée, puisque le navire, qui passe par le centre, traverse le phénomène suivant un diamètre, tandis que dans toutes les autres positions il la coupera suivant une ligne d'autant moins grande, qu'il sera plus éloigné du point central; c'est ainsi que le même météore, quelle que soit sa violence, peut offrir cette particularité d'être ouragan pour l'un, coup de vent pour l'autre, et simple bourrasque pour. un troisième.

Il suit de là tout naturellement que la position la plus fâcheuse pour un navire ou un pays, est celle où ils passent par le centre d'un ouragan, et c'est à s'en éloigner que doivent tendre tous les efforts d'un capitaine.....

La science est arrivée au point de se jouer impunément avec un navire, au milieu de ces phénomènes terribles, sans l'exposer à de sérieuses avaries.

Pour un bâtiment à vapeur, toujours maître de sa manœuvre par le moteur qui lui permet de se placer là où le capitaine l'ordonne, à un moment donné, ajoute avec raison M. Bridet, il n'est plus d'ouragan possible. Sans doute qu'il peut être enveloppé dans le tourbillon et $\mathrm{y}$ rencontrer de violentes bourrasques, mais plus de ces rafales terribles, plus de ces sautes de vent qui exposent le bâtiment et les hommes qui le montent à une perte presque certaine. 
Pour un capitaine instruit, un ouragan n'est plus qu'une trombe ordinaire autour de laquelle il circule, s'en écartant ou s'en rapprochant, selon que cela lui est utile.

Par lui tout est prévu; il sait d'avance quelle variation le vent doit présenter, quelle sera la violence des rafales, et il est parfaitement sûr de n'être jamais fatalement entraîné au milieu de ce centre si dangereux, toujours la cause de désastres inévitables, qui peuvent amener la destruction du bâtiment.

Non-seulement le bâtiment à vapeur n'a rien à craindre de ces ouragans jusqu'ici si redoutés, mais ils deviennent, au contraire, pour lui, un auxiliaire important.

Méprisant leur fureur, un capitaine peut aller chercher des vents favorables à sa route, et, s'il ne lui est pas possible d'anéantir la puissance dévastatrice qui le menace, du moins peut-il, en contournant cet ennemi redoutable, en faire servir la violence à le conduire au point de destination qui lui est assigné.

Un navire à voiles n'est pas aussi libre dans ses monvements.

N'ayant pas de force motrice à sa disposition, le capitaine qui le commande peut être surpris par des calmes avant la venue de la tempete, et se trouver ainsi obligé de subir le cyclone auquel rien n'a pu le soustraire; il ne lui est pas toujours possible de se transporter là où il sait trouver des vents favorables à sa route; - la cape est souvent sa seule ressource, mais la science est assez avancée pour qu'il soit assuré, s'il est fidèle à ses indications, d'épargner à son navire les avaries désastreuses qui ont trop souvent jusqu'ici affligé la grande famille maritime.

On est parvenu à connaître dans leurs plus petits détails, nonseulement les lois des ouragans, les manœurres que doivent exécuter les navires pour éviter leurs effets désastreux, mais aussi les causes de ces lois et des signes qui accompagnent ou suivent ces terribles phénomènes.

\section{MADAGASCAR.}

L'importance de cette île, sur laquelle la France a des droits incontestables, fixe aujourd'hui l'attention des hommes spéciaux. $\mathrm{Au}$ point de vue politique, comme au point de vue commercial, Madagascar présente un intérêt tel que nous croyons devoir, en terminant cette partie, donner les extraits suivants qui la font suffisamment connaître. 
1. Extrait de l'Almanach religieux de l'île Bourbon ou de la Réunion, pour 1860. - Saint-Denis, à la librairie catholique.

Madagascar, située sur la côte orientale de l'Afrique et à l'entrée de l'océan Indien, est une des plus grandes et des plus belles îles du globe.

Elle s'étend du $12^{\mathrm{e}}$ au $2 \mathrm{\partial}^{\mathrm{e}}$ degré de latitude sud, et présente sur une échelle de 300 lieues de long et de 130 de large, à peu près autant de superficie que la France.

Les Portugais, qui la découvrirent en 1506, sous les ordres de Lorenzo-Almeida, lui donnèrent le nom de Saint-Laurent, qu'elle échangea contre celui d'île Dauphine au temps d'Henri IV, et contre celui de France orientale sous Louis XIV.

On ne sait d'où lui viennent les noms de Madagascar, Malgaches et Madécasses, usités parmi les Européens, et complétement étrangers aux indigènes, qui appelient simplement leur patrie Tani-bé ou Kiera-bé (grand pays). Chaque tribu, chaque province, a de plus une dénomination particulière, qui caractérise ordinairement les coutumes ou le naturel des habitants; mais il n'existe pas de terme générique pour désigner l'ensemble de la population.

Cette île est parcourue dans toute sa longueur par une ou plusieurs chaînes de montagnes, dont les plus hauts sommets atteignent environ 1,800 à 2,000 mètres d'élévation, et présentent les aspects les plus variés. Vue de la mer, dans le nord-est, elle offre jusqu'à cinq plateaux superposés qui courent parallèlement au rivage, et montent vers l'intérieur en immense amphithéâtre; tandis que, dans le sud-ouest, c'est une série de collines qui ont à peine $\mathbf{1 0 0}$ mètres de haut, et qui se dessinent dans le lointain comme les ouvrages d'une vaste forteresse, dont les lignes uniformes s'étendraient à perte de vue. La chaîne culminante détermine deux versants généraux, celui de l'océan Indien et celui du canal de Mozambique, sillonnés l'un et l'autre par des rivières nombreuses, mais peu considérables. Aucune d'elles n'est praticable aux navires; deux seulement portent bateaux jusqu'à plusieurs lieues dans les terres; toutes les autres sont si obstruées par les sables à l'embouchure, qu'à peine les pirogues peuvent $\mathrm{y}$ passer.

Quoique la plupart de ces cours d'eau n'aient qu'un espace très-limité à franchir, cent lieues au plus, et toujours sous la 
zone torride, ils traverșent en peu de jours toutes les variétés de climats, de saisons, de sites et de cultures. Au-dessous des pics majestueux d'où ils s'élancent en cascades, ils arrosent des vallées salubres et fertiles, pruis des piaines d'une fécondité sans exemple, de vastes savanes où paissent de nombreux troupeaux, et finissent par couvrir le sol abaissé des côtes de ces marécages si funestes aux étrangers.

Sur une terre qui réunit à une exubérante fertilité l'élévation progressive et accidentée du sol, et les influences les plus graduées de la température, on doit s'attendre à trouver dans tout son luxe la végétation propre aux divers climats. Aussi les voyageurs s'accordent-ils à vanter la riches̀se de ses productions naturelles. Celles qui naissent de l'industrie et des sueurs de l'homme sont infiniment plus restreintes.

Généralement paresseux, les Malgaches mesurent leur travail aux impérieux besoins de la nourriture et du simple vêtement; leur ambition et leur prévoyance ne vont pas au delà. Du riz, du maìs, du manioc, des patates, des bananes et quelques légumes, c'est tout ce qu'ils récoltent sur un terrain qui se prête avec succès aux plus riches cultures, telles que la canne à sucre, le café, le girofle, le tabac, le coton, la soie, l'indigo, la vigne et le froment. On en a fait jusqu'ici d'heureux essais, qui attendront toujours pour se généraliser une puissante colonisation européenne.

Nous ne parlerons pas des mines d'or et d'argent si souvent attribuées à Madagascar, parce qu'on n'a encore aucune preuve positive de l'existence de ces métaux précieux.

Dans le règne animal, les oiseaux de cette île se distinguent entre tous par leur rare beauté. C'est une famille complète qui réunit toutes les variétés de la grandeur et de la grâce, depuis-le colibri aux couleurs étincelantes jusqu'à l'aigle noir au sombre el austère plumage. La veuve noire constitue dans cette collection une spécialité touchante qui l'a rendue sacrée aux indigènes, et qui mérite un souvenir. A peu près de la grosseur d'un merle, cet oiseau imite dans les forêts tout ce qu'il entend : voix de l'homme, cris des animaux, bruit des torrents ou des orages, il met son étude à les redire avec fidélité. Aussi, à l'époque d'une grande famine, où les cases retentissaient de gémissements et de sanglots, la pauvre veuve ne faisait que pleurer. Les Malgaches, témoins de sa compassion pour eux, la déclarèrent inviolable, et 
depuis lors ses jours sont respectés par la reconnaissance du peuple. On la prend quelquefois, sans qu'elle s'apprivoise jamais. Aussitôt introduite dans la cage, elle se met incontinent à miauler avec le chat, à japper avec le chien, à lutter de cris avec le coq; mais elle ne veut pas manger; captive, elle meurt en brave, et son dernier chant est encore un écho.

Parmi les animaux sauvages et les énormes reptiles qui peuplent les bois et les marais de Madagascar, on ne signale comme dangereux que le caïman, monstre amphibie de 12 à 15 pieds de long, à la forme de lézard, et à la cuirasse d'écailles que le fer et la balle ne peuvent entamer. Il attaque les hommes dans l'eau, mais il n'ose les poursuivre à terre. On en rencontre souvent sur les bords des étangs et des rivières, où ils dorment le ventre au soleil, toujours prêts, au premier bruit qui les réveillera, à se précipiter dans leur élément favori, ponr y guetter leur proie. "Dans un de mes voyages, écrivait M. Dalmond, on m'avertit qu'il y avait un gros caïman sur le chemin. Je pris avec moi plusieurs hommes armés de fusils et de sagaies, me figurant que, s'il se jetait sur nous, aisément nous pourrions nous défendre. Dès qu'il nous aperçut, cet animal entra dans une caverne, et, tourné vers nous, il ouvrit son effroyable gueule, d'environ un pied de diamètre, et garnie de dents sur toute sa superficie. Il poussait un cri semblable au rugissement sourd du lion. Comptant sur nos armes, nous nous approchâmes à trois pas du monstre, et lui envoyâmes quatre balles dans la gueule qu'il tenait toujours béante, sans plus remuer que s'il ne les avait pas senties. Nous lui enfonçâmes une pioche dans la mâchoire; il la saisit avec force; nous le tirâmes ainsi hors de son antre, et, comme il ne marchait pas, nous fìmes pleuvoir sur lui balles et sagaies pour l'achever, mais inutilement; il n'avait pas même une égratignure. Enfin, nous pûmes le renverser sur le dos, et on le tua en lui ouvrant le ventre. ")

L'intérieur de Madagascar étant inexploré en majeure partie, et les notions les plus élémentaires du calcul peu familières à ses habitants, on n'a recueilli jusqu'à ce jour aucune notion satisfaisante sur le chiffre de sa population. Demandez à un Malgache combien il y a d'insulaires dans son village, il vous répondra : Marou (beaucoup). - Combien dans la province? encore marou. - Combien dans l'île entière? toujours marou; c'est tout ce que vous en aurez. Demandez-lui le nombre de ses enfants, il se mettra à les compter sur ses doigts, avant de pouvoir formuler une ré- 
ponse qu'un père devrait trouver toute prête dans son cœur. Il n'est donc pas étonnant qu'en l'absence de renseignements plus précis, l'évaluation totale des indigènes flotte au hasard entre $1,500,000$ et 17 millions, qui sont les deux chiffres extrêmes accusés par les historiens. Mais celui de 3 ou 4 millions est plus communément reçu comme une vérité approximative. Du reste, la population de Madagascar a beaucoup diminué depuis vingt ans, par la politique barbare des Hovas ou Ovas, qui ont fait une guerre d'extermination à leur's rivaux et changé en solitudes des provinces entières.

Ces peuples sont divisés en vingt et quelques familles, issues à ce qu'on croit d'une source commune, dont chacune avait naguère un ou plusieurs rois, mais dont la moitie environ est aujourd'hui courbée sous le joug des Hovas.

Les principales tribus sont les suivantes :

Celles des Bétaminénas et des Betismitsaraks, à l'est;

Celle des Sakalaves, dans l'ouest;

Gelle des Antakaras, au nord;

Celle des Antatsèmes, dans le sud;

Celles des Hovas, des Massikoras et des Mahafalis, dans l'intérieur.

Les missionnaires ont tous apprécié favorablement les Malgaches. En dernier lieu, M. Carayon, capitaine d'artillerie, a dit d'eux :

"L'hospitalité est encore une des vertus des Malgaches. Le voyageur, qui entre dans leur case au moment du repas, est aussitôt convié à le partager, et l'on attend toujours qu'il ait fini, pour lui demander le motif de sa venue. Pendant les onze années de ma résidence chez les Betismitsaraks, j'ai constamment trouvé en eux un grand fonds de probité... Hors des lieux fréquentés par les navires, il suffisait d'un bâton planté devant une case, ou d'un fil qui tenait la porte fermée, pour indiquer l'absence du maître et en éloigner les passants. L'horreur du vol était si grande, que celui qui en était même soupçonné était souvent forcé de s'expatrier pour échapper au mépris public... Missionnaires catholiques, qui cherchez des peuples à civiliser, tournez les yeux vers ce malheureux pays; jamais peut-être champ plus vaste et plus digne de votre charité ne s'est offert à votre zèle. "

Ce n'est pas le zèle apostolique qui a manqué à l'évangélisation 
de Madagascar. Dès les premiers essais de colonisation, tentés il y a deux cents ans par la France, et successivement renouvelés jusqu'à nos jours par MM. Pronis (1642), Flacourt (1648), Beniowski (1774), de Mackau (1818) et Gourbeyre (1829), les enfants de Saint-Vincent-de-Paul y accoururent, avides de souffirir, au midi comme au nord, sur une terre où leur saint fondateur avait été esclave. Là, comme à Alger, la mort les attendait. Décimés par les fièvres et le martyre, ils n'en continuèrent pas moins avec succès une mission qui prospérait de jour en jour, lorsque, poussés à bout par les iniques vexations des traitants, les Malgaches se ruèrent sur les établissements européens, qu'ils couvrirent de sang et de ruines. L'évacuation de l'île fut alors ordonnée, et Louis XIV défendit à ses navires de toucher à ces parages qui gardent encore, en souvenir de massacre et d'insalubrité, le nom de cimetière des Français.

Mais qu'importe au missionnaire que sa tombe soit creusée d'avance sur le rivage! Il s'y élance avec plus d'ardeur; et c'est parce qu'au fond d’e l'Asie l'échafaud était en permanence que, pressés d'y arriver par le plus court chemin, les apôtres passaient devant Madagascar en paraissant l'avoir oublié. Cependant, en 1837, un saint prêtre, M. Dalmond, s'arrêta sur ces côtes qu'il devait aborder jusqu'à cinq fois avant d'y mourir. Les succès de son ministère furent dignes de sa vertu; une seule Mission lui donna, en huit mois, plus de 400 néophytes. Nommé préfet apostolique de cette île en 1844, il appela à son aide la Congrégation du Saint-Esprit, spécialement dévouée aux colonies, et la Compagnie de Jésus qui jette ses membres à tous les fléaux, sans plus tenir compte des fièvres pestilentielles de Madagascar, que du choléra indien du Madurée (Annales de la Propagation de la Foi, 1849).

Un nouvel effort fut tenté en 1849. M ${ }^{\mathrm{gr}}$ Monnet, familiarisé avec les usages et le climat, reçut de Rome le soin de diriger en. personne la mission malgache; mais l'Évêque missionnaire ne put que saluer la grande île africaine; et, comme François-Xavier en face de la Chine, le prélat avait à peine posé le pied à l'île Mayotte, qu'il mourait le $1^{\text {er }}$ décembre 1849.

Depuis la mort de $M^{g r}$ Monnet, la mission est restée entre les mains des RR. PP. Jésuites. Ces intrépides missionnaires, malgré les efforts de leur zèle, n'ont pu réussir encore (1859) à s'établir solidement sur la grande terre de Madagascar; mais ils ont des 
missions aux petites îles françaises de Sainte-Marie, de Nossi-Bé et de Mayotte, et sont prêts à s'élancer sur la grande île pour y planter la croix.

Déjà bien des tentatives ont été faites, et dans ce moment une nouvelle colonie d'apôtres fait voile pour aller rétablir la mission de Baly d'où les missionnaires, sur le point d'être massacrés, furent enlevés de vive force, en février dernier (18วั9) par M. le vicomte Fleuriot de Langle, qui était venu venger le pillage de la Marie-Angélique et le massacre d'un délégué du gouvernement.

Cependant, malgré ces difficultés, les RR. PP. Jésuites s'occupent toujours de leur mission, et la colonie admire les magnifiques établissements malgaches de Notre-Dame de la Ressource et de Nazareth, où ces saints et savants religieux élèvent les enfants de Madagascar destinés à devenir plus tard les civilisateurs et les apôtres de leur pays.

Il est donc permis d'espérer que cette mission, si stérile maintenant, donnera plus tard les fruits de salut les plus abondants....

2. Extrait du discours de M. Achille Jubinal, au Corps législatif, séance du 16 juin 1863 .

(..... Madagascar a des ports magnifiques; elle présente des - ressources inépuisables!

" En effet, si j'en crois les rapports des ingénieurs, le terrain houiller paraît y occuper une notable partie de la grande teri'e jusqu'à la chaîne qui en forme comme l'axe.

"Je ne veux pas faire ici un cours de géographie;se ulement, j'ajouterai qu'on trouve dans ce pays des mines d'or, des mines d'argent qui, non-seulement sont nombreuses, mais qui peuvent être extrêmement productives. Malheureusement, il y a des obstacles à leur exploitation : les Malgaches, dont l'avidité est connue, aiment mieux cependant laisser ces richesses au sein de la terre que de les laisser passer aux mains des étrangers.

"Mais ce ne sont là que des considérations secondaires : ce à quoi je veux arriver et ce qui m'a fait prendre la parole, c'est ceci : avec le percemenl de l'isthme de Suez, il y a nn trèsgrand intérêt pour la France à avioir, pour ses bâtiments dè commerce, un port dans la mer des Indes. Or, nous n'en avons aucun tandis que l'Angleterre a déjà dans cette mer Aden et Périm et que, dans peu, elle mettra le pied - ce que nous aurions dù 
faire depuis longtemps - sur la grande terre de Madagascar. Que possédons-nous là auprès d'elle? Nous ne possédons que les petites îles de Mayotte, Nossi-Bé, Nossi-Gumba - des rochers! Et vous savez que nous payons encore un tribut, une pension annuelle, si vous voulez, au roitelet de ces rochers, à un certain Tismaros.

“ Cependant, rien n'est plus incontestable que la légitimité de la possession de Madagascar par la France.

a Ce fut par lettres patentes de Louis XIII, èn 1642, qu'un sieur Rigault, comme s'expriment les lettres, capitaine de marine, reçut une mission pour aller dans l'île de Madagascar y fonder un commerce, et y ériger pour lui et ses associés colonies et comptoirs. Cette compagnie prit le nom de Compagnie d'Orient, et créa l'établissement du Fort-Dauphin (V. chap. I).

"Voilà l'origine de la première possession de la France à Madagascar, ou de Madagascar par la France.

a Sous Louis XIV et sous la Régence, malgré les menaces de l'Angleterre, jamais on ne crut devoir abandonner l'établissement colonial français à Madagascar, considéré comme terre française, et des arrêts de juin 1686, de juillet 1711, de mai 1719, empêchèrent toute idée de prescription à cet égard, en déclarant que l'île faisait partie du domaine de la couronne de France.

"Depuis, d'autres tentatives ont été faites. Ainsi, en 1746, ce fut Mahé de Labourdonnaye, gouverneur de l'Ile-de-France; en 1750 , la compagnie des Indes; en 1794, le comte polonais Beniowski, qui, quoi qu'on ait dit, n'était pas un aventurier, mais un héros à la façon de Charles XII; sous le consulat, M. Bory de Saint-Vincent; sous la Restauration, M. de Mackau, et plus tard, le commandant Gourbeyre, qui reçurent des missions officielles pour confirmer les droits de la France sur une partie de Madagascar.

"En 1840, sous Louis-Philippe, il y eut aussi une expédition, qui confirma également nos prétentions.

"A partir de ce moment, notre situation n’a pas changé; elle est restée la même... Nous avons conclu avec le roi Radama un traité, dans lequel nous l'avons reconnu comme roi de Madagascar. Ce traité était très-avantageux pour la Franee : ce n'était pas une abdication de nos droits : c'était une convention synallagmatique pour l'exécution de certaines conventions, et notre abdication, implicite, si l'on veut, avait pour sanction l'exécution du 
traité. Mais le roi Radama, avec lequel nous avions fait nos conventions, a disparu ou a été tué; le traité est resté en suspens, le drapeau consulaire a été amené.

" Je demande quelle est, aujourd'hui, notre situation à Madagascar? Voulons-nous rétablir ou voulons-nous abandonner le traité que nous avions fait avec Radama? Voulons-nous maintenir nos droits ou renoncer à la charte Lambert, qui nous assurait de grands avantages?.... $)$

(Moniteur du 17 juin 1863.) 


\section{AMÉRIQUE}

\section{PREMIÉRE PARTIE}

\section{ILES SAINT-PIERRE ET MIQUELON.}

\section{CHAPITRE PREMIER}

Historique.

La découverte de Terre-Neuve et de ses parages est revendiquée par les Danois, les Norwégiens et les Basques. Il est assez difficile de se prononcer à cet égard.

Ce qui est positif, c'est que Cabot y aborda en 1497, et que, dès $1 \check{0} 04$, les Bretons et les Normands venaient pêcher dans les eaux de Terre-Neuve où la morue était abondante. Toutefois, c'est vers 1604 seulement que les premiers établissements français y furent fondés par les pêcheurs.

En 1710, Terre-Neuve avait 3,000 habitants.

Par le traité d'Utrecht (1713), Terre-Neuve fut abandonnée par la France à l'Angleterre, et lorsque, en $\mathbf{1 7 6 3}$, nous perdîmes le Canada, etc., il nous fallut nous contenter des îles Saint-Pierre et Miquelon comme dédommagement.

Bientôt des établissements de pêche furent établis. De 1765 à 1777, les produits furent considérables : 6,000 quintaux de morue, par an, en moyenne; 220 bâtiments, jaugeant 24,000 tonneaux et montés par 8,000 marins ou pêcheurs, s'employaient à la pêche.

La guerre de l'indépendance américaine, guerre où nous prîmes parti contre l'Angleterre, nous fit perdre momentanément les deux petites îles. Les Anglais s'en emparèrent et en ruinèrent les 
constructions. Les habitants, au nombre de 1,200 à 1,300, durent se réfugier en France (1778).

La paix de Versailles (1783) nous rendit les îles et confirma nos droits de pêche sur les côtes de Terre-Neuve. Les habitants émigrés y furent ramenés.

Dès 1784, 318 navires jaugeant 34,658 tonneaux et montés par 9,520 marins ou pêcheurs, se rendaient dans les îles. Mais, en 1793, les Anglais s'en emparèrent de nouveau.

Elles furent restituées par la paix d'Amiens à la France (1802) et reperdues en 1803. Le traité de Paris (30 mai 1814) nous les rendit de nouveau. Le bourg de Saint-Pierre, détruit en 1795, fut relevé et un autre bourg fut formé à Miquelon.

Depuis lors, les expéditions de pêche n’ont pas cessé.

\section{Gouverneurs et commandants.}

1763. Dangeac, gouverneur.

1773. L'Espérance (baron de), gouverneur.

1784. Dauseville, commandant et ordonnateur.

1816. Bourrilhon (J.-P.), commissaire de la marine, chargé en chef du service.

1818. Borius (A.-V.), lieutenant de vaisseau, intérimaire.

1819. Fayolle (P.-A.-H.), capilaine de frégate honoraire, commandant et administrateur pour le roi.

1825. Borius (A.-V.), capitaine de frégate, commandant et administrateur pour le roi.

1828. Brue (J.-L.-M.), chef de bataillon honoraire, commandant.

1832. Paris (F.-J.-G.), sous-commissaire de marine, intérimaire.

1839. Mamyneau (L.-A.), capitaine de vaisseau.

1812. Desrousseaux (J.-A.), capitaine de corvette.

18ł.ั. Délécluse (J.-M.-F.), capitaine de corvette en retraite.

1849. Bruslé (P.-B.), chef du service administratif, commissaire de la république par intérim.

18ð0. Gervais (J.-F.), lieutenant-colonel d'artillerie de marine.

1855. Gautier (A.-S.), lieutenant de vaisseau.

18วั6. Gervais (J.-F.).

1859. De la Roncière (le comte E.).

1863. Cren (P.V.), chef de bataillon d'infanterie de mariné. 


\section{CHAPITRE II}

Situation. - Saint-Pierre: - Sol, étangs, côtes, rade et port; le bourg de SaintPierre ; îlots voisins. - Miquelon : - Sol, rivière, étangs, baie; le bourg de Miquelon. - Routes. - Canaux. - Quai. - Abattoir, etc. - Température - Climat. - Saisons. - Plujes. - Vents. - Marée. - Aurores boréales. Phares. - Population.

Saint-Pierre, situé par $46^{\circ} 46^{\prime}$ de lat. N. et $58^{\circ} 30^{\prime}$ de longitude 0 ., au sud-est de Miquelon, a 7 kilomètres et demi dans sa plus grande largeur. - Sa superficie est de 2,600 hectares.

Le sol est presque entièrement granitique, inculte et stérile. On y rencontre du minerai de fer et de cuivre.

Les étangs sont poissonneux. Ils sont au nombre de douze et communiquent avec la mer. Les plus grands ont de 600 à 700 mètres. - Pas de rivières, mais de simples ruisseaux.

Les côtes, depuis le cap à l'Aigle jusqu'à la pointe à Savoyard, sont escarpées et pour ainsi dire inabordables. Elle est plus basse depuis cette pointe, et quelques anses abordables s'y rencontrent.

La rade de Saint-Pierre a trois passes par lesquelles elle communique avec la pleine mer. Celle du N.-E. a 900 mètres de largeur et 10 à 27 mètres de fond. Cette rade est très-sûre d'avril à septembre et peut contenir 150 bâtiments.

Le port, à l'extrémité 0 .-S.-0. de la rade, est vaste et pourrait recevoir 100 navires de commerce, mais ils ne doivent avoir qu'un faible tirant d'eau.

Autour du port sont les sécheries établies sur des grèves.

Saint-Pierre, chef-lieu des deux îles, seul centre de population dans l'île du même nom, a un kilomètre dans sa plus grande longueur. Il est assis au pied d'une colline et s'étend jusqu'au bord de la mer.

Sept îlots entourent Saint-Pierre et en dépendent : le Grand et le Petit-Colombier, au N.-E.; l'île aux Chiens, l'île aux Vainqueurs, l'île aux Pigeons, à l'E.; enfin, l'île Verte, à 65 kilom. au N.-E.

Miquelon est située par $47^{\circ} 8^{\prime}$ lat. N.; $46^{\circ} 47^{\prime}$ et $58^{\circ} 40^{\prime}$ long. 0 .

Autrefois, l'île était coupée en deux par une passe qui, depuis 1783, a été comblée par les sables. - Longueur : 36 kilomètres; 
largeur : 24 kilomètres; superficie : 18,423 hectares. - Sise à § kilom. au N.-0. de Saint-Pierre.

Le sol de Miquelon est également granitique. On y rencontre du minerai de fer, quelques sources minérales (ferrugineuses).

La Belle-Rivière, large ruisseau, sillonne l'ancienne petite Miquelon ou Langlade; mais les deux plus grands étangs appartiennent à la grande Miquelon.

Une grande baie, un étang considérable se trouvent à l'extrémité septentrionale de l'île, mais ils ne communiquent pas entre eux. - Le bourg est assis au fond du port.

Saint-Pierre possède plusieurs belles routes : l'une, la route Iphigénie, a 2,200 mètres ; l'autre, la route de Gueydon, a élé, depuis 18509 , prolongée de 4 วั0 mètres.

Il a été construit des canaux de desséchement, un quai de 134 mètres de longueur (dans le port, de Saint-Pierre); les rues de la ville ont été nivelées, des égouts établis.

Deux salles d'asile, une maison de commandement, etc., une caserne pour les gendarmes, deux nouveaux phares, une église, etc., tel est l'ensemble des travaux publics qu'on a menés à bien depuis quelques années.

Le climat des îles Saint-Pierre et Miquelon se distingue de celui des autres îles du golfe Saint-Laurent par une salubrité plus grande. La température, en juillet et aoûl, les mois les plus chauds de l'année, s'élève peu au-dessus de $25^{\circ}$ centig.; en janvier et février, elle descend à $15^{\circ}$ au-dessous de 0 , et quelquefois jusqu'à $24^{\circ}$. La moyenne de température est de $9^{\circ}$ cent. au-dessus de 0 .

L'hiver dure cinq à six mois. La neige est abondante du milieu de novembre à la fin de mars; en mai et juin, les brumes dominent; à la fin d'avril, la belle saison commence pour ne finir qu'en octobre.

Peu de pluies en été; au début de l'automne et du printemps, elles sont abondantes.

Les vents qui règnent pendant la belle saison sont ceux du N.-O.; ceux de S.-E., de S. et de S.-O. amènent du mauvais temps. Les vents du N.-E. (anordies) et ceux du S.-E. (assuéties) sont les plus impétueux.

Aux nouvelles et aux pleines lunes, la hauteur de la pleine mer, à Saint-Pierre, est de $2^{\mathrm{m}}, 60$; l’établissement a lieu à 9 heures. 
La hauteur moyenne annuelle du baromètre est de 752 millimètres. Son maximum est de $765^{\mathrm{mm}}$ et son minimum de $738^{\mathrm{mm}}$.

$\mathrm{Au}$ mois d'avril, les aurores boréales ne sont pas rares. Toute l'atmosphère en paraît quelquefois comme embrasée.

L'un des deux phares est établi sur la pointe à Galantry; l'autre est élevé à la pointe aux Canons. Le premier, dans la saison des pêches, tire deux coups de canon toutes les deux heures, quand il y a brume. La nuit, il répond, coup pour coup, aux navires qui tirent en mer.

La population sédentaire de Saint-Pierre se compose de Normands, de Bretons, de Basques et d'anciens pêcheurs; celle de Miquelon se compose surtout d'anciens Acadiens.

On compte 2,385 individus de population sédentaire, et 689 de population flottante. En outre, il vient de France, chaque année, environ 3,500 pêcheurs et marins. - Presque tout le monde se livre à la pêche de la morue.

En 1861, on a constaté une naissance par 26 individus et un décès sur 34 .

Dans la population sédentaire, le nombre des femmes, sur $\mathbf{2 , 3 8 5}$ individus, était de 1,217 et celui des hommes de 1,168. Dans la population flottante, sur 689 individus, il y avait 153 femmes et 526 hommes.

\section{CHAPITRE III}

Gouvernement. - Administration. - Forces militaires. - Forces maritimes. Justice. - Tribunaux. - Statistique judiciaire. - Culte. - Instruction publique. - Assistance publique. - Budget de l'Etat. - Budget local.

Les îles Saint-Pierre et Miquelon sont confiées, quant à leur gouvernement et à leur administration, à un commandant qui réside à Saint-Pierre.

Pour diriger les différentes parties du service, il a sous ses ordres un officier du commissariat, ordonnateur, et un chef du service judiciaire. La régularité du service administratif est confiée à un contrôleur.

Pour éclairer les décisions du commandant, un conseil d'administration a été institué. Il se compose du commandant, de l'ordonnance, du chef du service judiciaire, du contrôleur colonial et d'un habitant notable. Ce conseil, dans certains cas, statue au contentieux administratif. 
En dehors du commandant, le personnel de l'administration comprend :

1 commissaire-adjoint, ordonnateur ; 2 aides-commissaires ; 4 commis, 3 écrivains de marine, 3 écrivains auxiliaires;

1 sous-commissaire, contrôleur colonial ;

1 trésorier chargé du service des fonds;

2 conducteurs des ponts et chaussées ;

1 capitaine de port; 1 maître de port.

1 syndic et un garde maritime chargés du service de l'inscription maritime.

Le service de santé comprend : 3 chirurgiens, 1 pharmacien de marine, 4 sœurs, 2 infirmiers.

Nos forces militaires, depuis la reprise de possession, en 1816, sont des plus modestes à Saint-Pierre et Miquelon. Elles se composent ainsi : 5 sous-officiers et soldats d'artillerie de marine; 1 détachement de gendarmerie coloniale à pied (1 maréchal-deslogis, 2 brigadiers, 14 gendarmes). - Enfin 50 disciplinaires, détachés de la Compagnie de la Guadeloupe, sont employés aux travaux de la colonie.

Nos forces maritimes comprennent : 3 goëlettes de 35 tonneaux et 1 goëlette de 15 tonneaux.

La législation métropolitaine est en pleine vigueur dans la colonie, ainsi que l'organisation judiciaire instituée par l'ordonnance royale du 26 juillet 1833.

La colonie a deux justices de paix, l'une à Saint-Pierre, l'autre à Miquelon; un tribunal de première instance qui siége à SaintPierre; un conseil d'appel, siégeant aussi à Saint-Pierre.

Le recours en cassation est ouvert, sauf dans les cas prévus par les articles 40 et $\mathbf{4 1}$ de l'ordonnance précitée, contre les arrêts du conseil, soit en matière civile ou commerciale, soit en matière correctionnelle ou criminelle.

La statistique judiciaire de la colonie a présenté, en 1862, les chiffres suivants :

Tribunaux de paix.

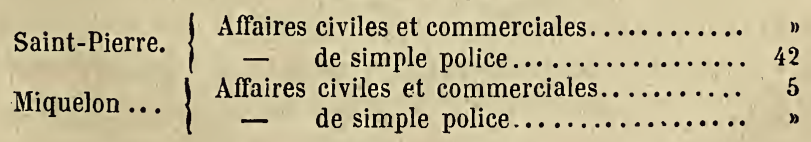

Tribunal de première instance.

Affaires civiles................................. 33

- commerciales.............................. 27 


\section{Conscil d'appel:}

Affaires correctionnelles déférées au conseil........... 6

Appels en matière civile....................... 6

- $\quad$ commerciale...................... 3

Crimes contre les personnes..........................

- la propriété...................... 1

Tribunal muritime commercial.

Nombre des affaires........................... 24

Condamnations........................... 17

Le clergé de la colonie se compose de trois prêtres.

Chaque île a une église.

On compte quatre écoles, deux pour les garçons, deux pour les filles. Ges écoles sont entretenues par la caisse coloniale. Celles des garçons ont pour directeurs six frères de Ploërmel(156 élèves); celles des filles sont dirigées par sept sœurs de Saint-Joseph (134 élèves), qui tiennent également à Saint-Pierre un pensionnat (46 élèves) et des salles d'asile (200 enfants des deux sexes).

La surveillance des écoles est confiée à deux commissions.

- Il y a aussi deux commissions d'assistance publique.

L'hôpital militaire de Saint-Pierre, outre les officiers, marins, pêcheurs et passagers, etc., reçoit, moyennant une rétribution, les habitants qui veulent y être traités; les indigents le sont gratuitement.

Trois chirurgiens de la marine sont attachés à cet hôpital.

Voici quels ont été le budget de l'État et le budget local pour l'année 1863.

\section{BUDGET DE L'ÉTAT.}

I. Personnel civil et militaire.

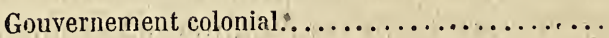

Administration générale $\ldots \ldots \ldots \ldots \ldots \ldots \ldots \ldots \ldots$
Justice $\ldots \ldots \ldots \ldots \ldots \ldots \ldots \ldots \ldots \ldots \ldots \ldots$

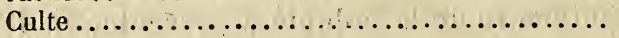

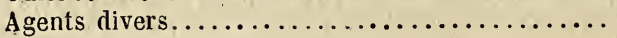

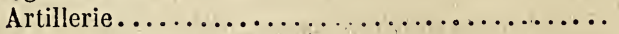

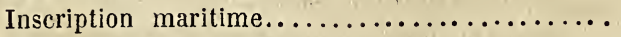

Gendarmerie coloniale. ..................

Dépenses accessoires de la solde...............

Traitements dans les hôpitaux...............

Vivres

Total. $15,000 \mathrm{fr}$. 48,400

19,400

9,576

700

1,450

2,600

29,227

5,500

9,922

2,670

20 e à déduire pour incomplets.

$144,445 \mathrm{fr}$.

4,714

Total du personnel.

$139,731 \mathrm{fr}$. 
II. Matériel civil et militaire.

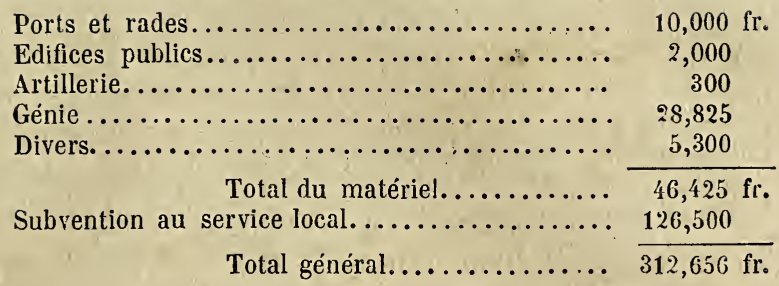

Les dépenses effectuées au compte du service de la marine, qui, en 1861, se sont élevées à 157,980 fr. 70 c., ne sont pas comprises dans le total général ci-dessus.

Le budget local, pendant ladite année 1863, a présenté les chiffres suivants.

\section{BUDGET LOCAL.}

1. Recettes.

Contributions des patentes............. 15,000

Impôt foncier...................... 6,000

Droits de consolidation................ 13,200

de douane....................... 14,000

Taxes accessoires de navigation.............. 25,950

Licences des cabaretiers................ 6,500

Droits de greffe..................... 2,000

- sur les ventes publiques............. 1,500

Recettes de la douane.................. 5,000

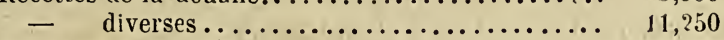

Subventions de l'Etat................. 126,500

Prélèvement sur le fonds de réserve......... 30,000

Total................ $\overline{256,900 \mathrm{fr} .}$

\section{Dépenses.}

(Personnel.)

Services financiers.................... $2,700 \mathrm{fr}$.

Instruction publique.................. 20,082

Ponts et chaussées................... 12,540

Police............................ 500

Comité consultatif (part contributive).......... $\quad 300$

Agents divers........................ 15,400

Accessoires de la solde................. 1,500

Hôpitaux (journées) $\ldots \ldots \ldots \ldots \ldots \ldots \ldots \ldots \ldots \ldots . \quad 8,680$

Vivres ........................ 20,570

Total..................

A déduire pour retenues et incomplets......... $\quad 1,022$

Total du personnel......... $\overline{81,250 \mathrm{fr} .}$ 


\section{(Matériel.)}

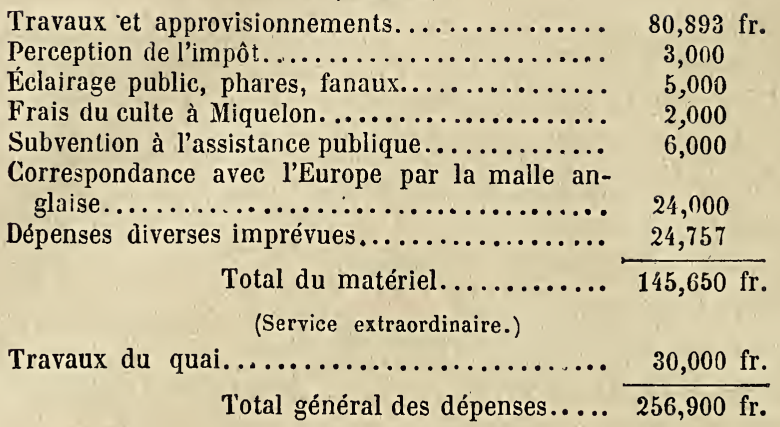

\section{CHAPITRE IV}

Cultures. - Produits naturels. - Industrie : pêche et préparation de la morue. - Armements depuis 1853. - Pèche locale - Importations. - Exportations. - Péche de la morue, du hareng, du capelan et de l'encornet. - Primes d'armement. - Primes sur les produits. - Grèves. - Régime commercial. Mouvement commercial de 1851 à 1862. - Objets d'importation. - Objets d'exportation. - Navigation (régime de la). - Statistique. - Service postal.

Le sol des îles Saint-Pierre et Miquelon peut être considéré comme stérile. L'hiver prolongé et rigoureux qui y règne ne permet pas aux cultures de s'y développer.

Saint-Pierre, rocher presque entièrement privé de terre végétale, n'a guère que des broussailles épaisses, rampantes, et des arbres verts tout au plus hauts de 3 mètres. Sur les plateaux, toutefois, on recueille un peu d'herbe avec laquelle, dans trois fermes, on nourrit quelque bétail. Le sud de l'île possède plusieurs jardins.

Pas d'arbres de haute futaie; mais des genévriers et des arbustes variés. Ges arbustes donnent beaucoup de petits fruits acides antiscorbutiques; les genévriers permettent de fabriquer un excellent genièvre. On remarque aussi plusieurs espèces de thés.

La bière de spruce (variété de pin), connue sous le nom de sapinette, est la boisson du pays, des équipages des bâtiments de guerre en station, des pêcheurs. Les branches de l'arbre, vertes et garnies de leurs feuilles, sont de próférence employées dans la fabricalion de cette bière.

Langlade (petite Miquelon), dont le sol est moins aride que ce- 
lui de Saint-Pierre, possède treize fermes, sur lesquelles on se livre surtout à l'élève des bestiaux. On est certain aujourd'hui, pourtant, que les céréales, les plantes potagères et légumineuses de France y réussiraient au mieux.

Saint-Pierre et Miquelon comptaient, en 1862, 87 chevaux, 24 taureaux, 113 bœufs, 417 vaches, 339 moutons, 305 chèvres et 172 porcs.

La partie de Miquelon, appelée Langlade, a subi de nombreux défrichements depuis 1816. Néanmoins, elle a encore d'assez beaux bouquets de bois. Le sapin, le bouleau, l'érable, l'if, le néflier, le sorbier, le genévrier, le rosier, le pommier sauvage; tels sont les principaux arbres et arbustes qui y croissent.

Saint-Pierre et Miquelon n'ont qu'une industrie sérieuse : la pêche et la préparation de la morue.

La morue est pêchée et préparée ou par des pêcheurs venant de France ou par des pêcheurs résidents, c'est-à-dire habitant la co. lonie.

On désigne ainsi les expéditions qui partent des ports de France pour Terre-Neuve :

Armements pour le grand banc de Terre-Neuve, avec sécherie aux îles Saint-Pierre et Miquelon; avec sécherie à la côte ouest de Terre-Neuve; $i d$., avec sécherie à la côte est de Terre-Neuve.

Armements pour la côte ouest de Terre-Neuve (pêche et sécherie).

Armements pour la côte esl de Terre-Neuve (pêche et sécherie).

Armements pour les îles Saint-Pierre et Miquelon.

Armements pour le grand banc de Terre-Neuve sans sécherie.

Le chiffre des armements pendant les années 1860 à 1863 a été comme suit :

1860

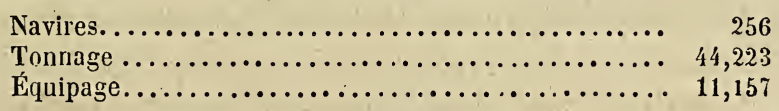

1861

Navires ................................ 255

Tonnage ................................. 42,183

Equipage................................... 10,999

1862

Navires ............................ 238

Tonnage........................... 40,532

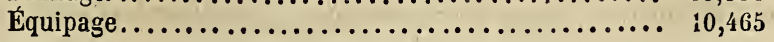


$186 \%$

Navires ............................ 239

Tonnage ......................... 38,033

Équipage........................ 9,448

En 1862, le chiffre des armements locaux s'est ainsi réparti :

308 warys, ayant un équipage de 628 hommes et jaugeant 622 tonneaux.

162 pirogues, avec un équipage de 403 et un tonnage de 476 .

40 canots, avec un équipage de 83 et un tonnage de 120 .

8 chaloupes, équipages 30 , tonnage 75 .

122 goëlettes, équipage, 1,353 , tonneaux 4,249 .

Total : 611 bâtiments, 2,497 hommes, 5,542 tonneaux.

Fn 1862, les produits de la pèche lócale ont été de :

En 1862, les produits de la pêche locale ont élé de :

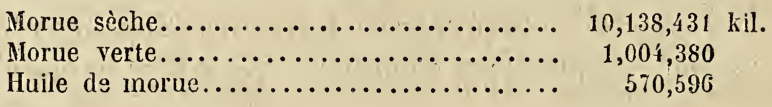

Importations (1862).

Morue sèche. ................. 10,138,431 kil.

Morue verte................... 1,004,380

Huile de morue................ 570,596

Exportations (1862).

Morue sèche................. 10,327,275 kil.

Morue verte.................. 1,004,380

Huile de morue.................. 570,596

Issues de morue.................. $\quad 316,590$

Rogues........................ 25,502

Les produits restant en magasin, au $1^{\text {er }}$ janvier 1863, étaient de $1,791,396 \mathrm{k}$.

Les principanx lieux de destination ont été :

Ceux de Granville, Saint-Malo, Nantes, île de Ré, Bordeaux, Bayonne, Marseille, Cette, Morlaix;

Ceux de la Martinique, Guadeloupe, Réunion;

Celui d'Alicante;

Ceux de Boston, New-York, Halifax.

La pêche à la morue a lieu du $1^{\text {er }}$ avril au $1^{\text {er }}$ octobre.

Elle se pratique, d'après les Notices du ministère de la marine, de la manière suivante.

Indépendamment du filet de Seine, les pêcheurs font usage de diverses espèces de lignes : la ligne de fond, la ligne à la main 
ordinaire, la ligne à faucher ou faux, la vette et la flotte (ligne perdue).

La ligne de fond est, après la seine, le plus puissant engin employé pour la pêche de la morue. C'est une ligne dormante, étendue sur le fond au moyen de petites embarcations; elle rapporte des morues plus grandes que celles qu'emploient les pêcheurs à la ligne ordinaire. Son emploi, qui ne remonte qu'à une trentaine d'années, est interdit dans les eaux de la colonie.

La pêche à la ligne de main se fait du bord; chaque pêcheur est armé de deux lignes qu'il jette et tire alternativement d'un bord à l'autre de l'embarcation.

Quand la morue ne mord pas, on emploie une ligne armée de deux hameçons fixés à demeure sur un morceau de plomb en forme de poisson. Quand la ligne atteint le fond, le pêcheur, par un mouvement assez semblable à celui d'un faucheur, lui imprime un mouvement de va-et-vient, pendant lequel les hameçons s'accrochent aux morues qu'ils rencontrent. De là le nom de ligne à faucher ou simplement faux.

La vette et la flotte sont employées quand la morue quitte les fonds pour se tenir près de la surface de l'ean. La vette consiste dans un morceau de plomb ayant la forme d'un petit poisson, auquel est fixé un hameçon. Le pêcheur la lance à pleine volée et la ramène rapidement à travers les bandes de morue.

La flotte ne diffère de la vette que par la forme du plomb qui est simplement arrondi au lieu de figurer un poisson.

Les appâts employés par les pêcheurs pour amorcer leurs lignes sont : le hareng, le capelan et l'encornet.

Le hareng, paraissant au printemps dans les parages de TerreNeuve en quantités innombrables, sert d'appât ou boittes pour la première pêche qui dure jusqu'au commencement de juin. Une grande partie de cette boitte est apportée par les Anglais de Terre-Neuve.

Le capelan vient ensuite.

L'encornet arrive le dernier, mais il ne fait qu'une courte apparition.

Tous ces petits poissons sont employés frais, comme appât, dans les environs de Saint-Pierre et Miquelon; mais sur les fonds de Terre-Neuve, on se sert presque exclusivement de capelan salé pour le boittage des lignes de fond.

Les pêcheurs ne font sécher qu'une partie de leurs morues; 
ils en réservent une certaine quantité qui sont seulement salées. Ces dernières, que l'on appelle morues vertes, sont destinées à entrer immédiatement dans la consommation en France et dans plusieurs pays du midi de l'Europe. Elles sont tranchées au plat, c'est-à-dire fendues jusqu'à la queue, débarrassées de la tête et de l'arête médiane dans la partie correspondante à la cavité abdominale. On les met ensuite dans le sel, quelquefois en bailles où elles trempent dans la saumure, mais le plus souvent en arrimes, c'est-à-dire en tas, d'où la saumure s'égoutte sans baigner le poisson.

Les sels employés par les pêcheurs sont généralement de quatre provenances : sel des salines de l'ouest de la France, sel de Portugal, sel d'Espagne et sel de la Méditerranée. Plus le sel est blanc, mieux la morue est préparée.

Parmi les produits accessoires, on compte : l'huile de foie de morue pour la corroierie et les usages thérapeutiques, les langues et naus de morues employés comme aliments, les rogues ou œufs de morues salées dont on se sert en France pour la pêche de la sardine.

Le hareng, qu'on ne pêche guère que pour approvisionner les pêcheurs d'appâts, pourrait devenir l'objet d'un commerce d'exportation dans nos colonies ou d'importation en France. Une décision ministérielle (30 janvier 1860) a autorisé l'introduction en franchise de ce hareng dans nos colonies des Antilles, de la Guyane et de la Réunion. Quant à l'importation en France, elle a été fixée par une loi (2๖ mai 1863) au droit de 10 fr. par 100 kil. sous pavillon français, et à celui de $11 \mathrm{fr}$. sous pavillon étranger.

A l'embouchure des cours d'eau de la partie de la côte de Terre-Neure où les traités nous réservent le droit exclusif de pêche, on pêche aussi le saumon: Cette pêche est presque abandonnée par nos nationaux.

La pêche à la morue est encouragée par des primes d'armement et des primes sur les produits (V. Ord. 8 février 1816,21 octobre 1818, 20 fév. 1822; 24 fév. 1825, 7 décembre 1829; lois des 22 avril 1832, 9 juillet 1836,25 juin 1841, 22 juillet 18 ๖ et 28 juillet 1860).

\section{Primes d'armement.}

๖0 francs par homme d'équipage pour la pêche avec sécherie, soit à la côte de Terre-Neuve, soit à Saint-Pierre et Miquęlon, soit sur le grand banc de Terre-Neuve; 
50 francs par homme d’équipage pour la pêche sans sécherie dans les mers d'Islande;

30 francs par homme d'équipage pour la pêche sans sécherie sur le grand banc de Terre-Neuve;

15 francs par homme d'équipage pour la pêche au DoggerBank.

\section{Primes sur les produits.}

20 francs par quintal métrique pour les morues sèches de pêche française expédiées, soil directement des lieux de pêche, soit des entrepôts de France, à destination des colonies françaises d'Amérique, de l'Inde, et aux établissements français de la côte occidentale d'Afrique et des autres pays transatlantiques, pourvu qu'elles soient importées dans les ports où il existe un consul français ;

16 francs par quintal métrique pour les morues sèches de pêche française expédiées, soit directement des lieux de pêche, soit des ports de France à destination des pays européens et des États étrangers, sur les côtes de la Méditerranée, moins la Sardaigne et l'Algérie ;

16 francs par quintal métrique pour l'importation aux colonies françaises de l'Amérique, de l'Inde et autres pays transatlantiques, des morues sèches de pêche française, lorsque ces morues seront exportées des ports de France, sans y avoir été entreposées.

12 francs par quintal métrique pour les morues sèches de pêche française expédiées, soit directement des lieux de pêche, soit des ports de France, à destination de la Sardaigne et de l'Algérie.

Il est, en outre, accordé une prime de 20 francs par quintal métrique de rogues de morue rapportées en France par les navires pêcheurs et provenant de leur pêche.

La loi du 21 juillet 1860 a assujetti les goëlettes armées aux îleș Saint-Pierre et Miquelon à un minimum d'équipage.

Par décret du 7 novembre 1861, la constitution de la propriété des grèves servant à la sécherie des poissons a été régularisée; elles ne sont plus frappées d'inaliénabilité. Par un autre décret du 6 juin 1863, les détenteurs n’ont plus à payer la taxe préalable de $5,10,15$ et 20 centimes par mètre carré; cette taxe est supprimée.

Voici le régime commercial des îles Saint-Pierre et Miquelon : 
Sont exemptes de droits d'entrée les marchandises françaises et étrangères importées par navires français.

Sont soumises à un droit de 1 p. 100 de leur valeur, les marchandises étrangères importées par navires français et par navires étrangers. Exception en faveur des bestiaux, bois de chauffage, hareng, capelan et sel destiné aux opérations de la pêche.

Est interdite l'introduction de la morue, de l'huile ou de tout autre produit de pêche étrangère.

Sont considérés comme produits de pêche étrangère tous produits de pêche préparés hors des possessions françaises.

D'après les états de la douane locale, le commerce des îles Saint-Pierre et Miquelon a présenté les chiffres suivants, pendant la précédente période décennale :

\section{1}

Importations $\ldots \ldots \ldots \ldots \ldots \ldots \ldots \ldots \ldots \ldots \ldots, 2,918,745 \mathrm{fr}$.

Exportations. .................... 4,780,833

Total.

$7,699,578 \mathrm{fr}$.

1852

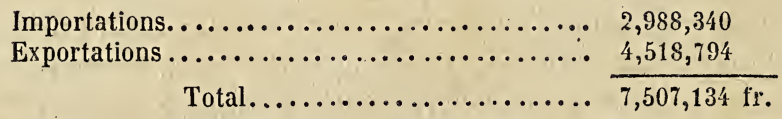

1853

Importations................... $3,213,002 \mathrm{fr}$.

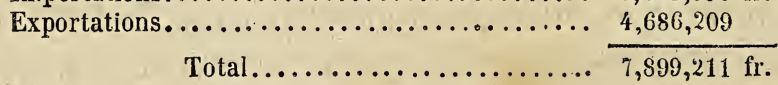

1854

Importations. ................... $3,261,042 \mathrm{fr}$.

Exportations.................... 4,518,049

Total................. $\overline{7,779,091 \mathrm{fs} .}$

1855

Importations. .................. $3,158,434 \mathrm{fr}$.

Exportations..................... $3,826,0$ ' 3

Total................. $\overline{6,984,477 \mathrm{fr} .}$

1856

Importations.................... $3,119,073 \mathrm{fr}$.

Exportations.................... $4,268,817$

Total................ $\overline{7,387,890 \mathrm{fr} .}$ 
1858

Importations....................... $3,776,183 \mathrm{fr}$.

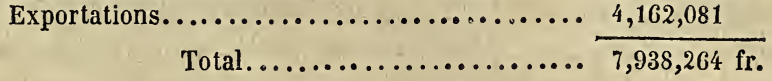

1858

Importations.................... 4,713,303 fr.

Exportations.................... 4,509,710

Total.................. $\overline{9,221,913 \mathrm{fr} .}$

1859

Importations..................... $3,828,001$ fr.

Exportations................... 4,876,781

Total................. $\overline{8,704,782 \mathrm{fr} .}$

1860

Importations.................... 4,084, $861 \mathrm{fr}$.

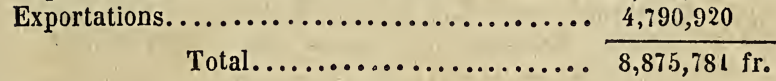

1861

Importations..................... 4,239,567 fr.

Exportations ...................... 4,098,268

Total.................. $\overline{8,375,835 \mathrm{fr} .}$

1862

Importations..................... 3,528,763 fr.

Exportations..................... 5,267,998

Total. ................ $\overline{8,796,761 \mathrm{fr}}$

En 1862, le mouvement commercial s'est ainsi décomposé :

Importations.

Marchandises françaises venant de France........

- $\quad$ des colonies fran-

caises..........

- étrangères venant de l'étranger par

navires français...............

- étrangères par navires étrangers....

$1,340,211 \mathrm{fr}$.

42,097

394,567

$1,751,888$

\section{Exportations.}

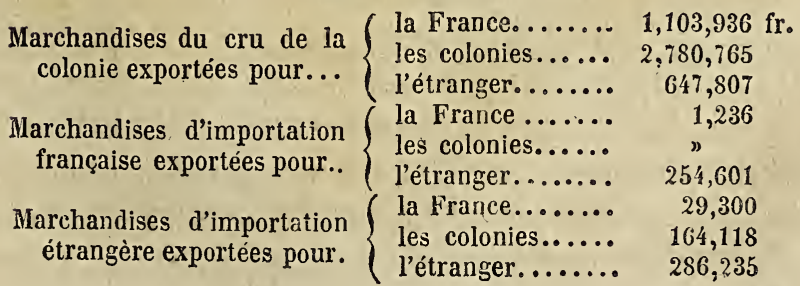


Les principales denrées et marchandises importées sont les suivantes :

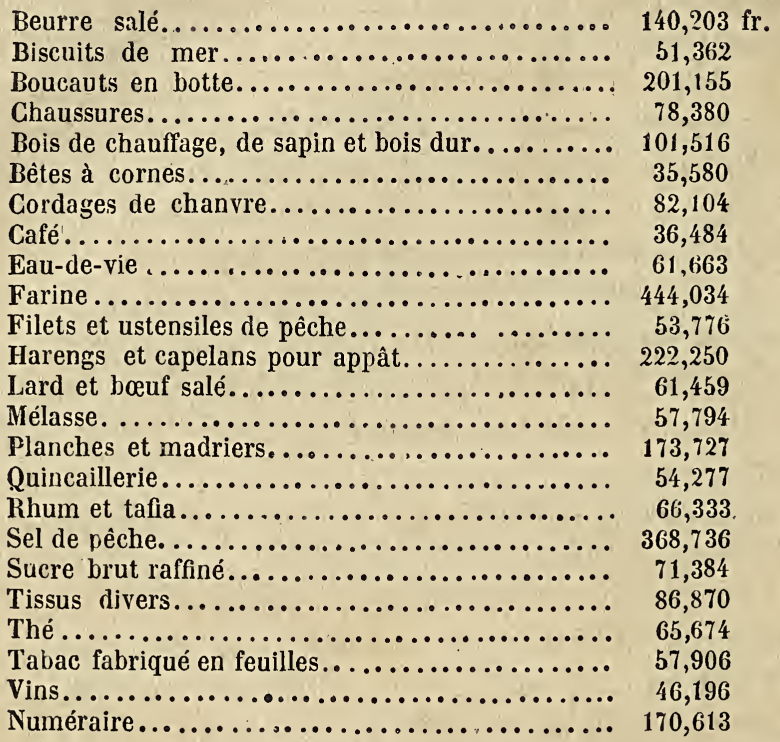

De France, viennent surtout : beurre salé, biscuil de mer, chaussures, cordages de chanvre, eau-de-vie, filets et ustensiles de pêche, sel de pêche, sucre raffiné, tissus divers, vins.

Des colonies des Antilles françaises : sucre brut, mélasse, rhum et tafia.

Des États-Unis et des colonies anglaises de l'Amérique du Nord : boucauts en bottes, bois, farines, harengs et capelans pour appâts, mélasse, planches et madriers, quincaillerie, rhum, tafia, thé, tabac.

Denrées et marchandises exportées en 1862 :

Morue verte $(1,044,380$ articles $)$

401,752 fr.

Morue sèche $(10,327,285$ kilogr. $)$ $3,717,821$

Huile de morue (570,596 litres).

342,357

Issues de morue $(316,590$ kilogr. $) \ldots \ldots \ldots \ldots \ldots .63,318$

Rogues $(25,502$ kilogr.)................ $\quad 5,100$

Cuir vert $(1,440$ kilogr. $) \ldots \ldots \ldots \ldots \ldots \ldots \ldots \ldots . \quad 1,008$

Objets d'histoire naturelle.............. 1,152

Les objets réexportés ont été : les boucauts (pour les colonies françaises des Antilles), les chaussures, les cordages, la farine, le lard salé, le café, le sucre, l'eau-de-vie, la mélasse. 
La navigation entre les poris de France et les îles Saint-Pierre et Miquelon ne peut avoir lieu que sous pavillon français (Acte du 21 septembre 1793).

Droits de navigation et de port.

\begin{tabular}{|c|c|c|c|c|}
\hline Bâtiments français. & Pilotage. & Tonnage. & Feu. & Santé. \\
\hline $\begin{array}{c}\text { Au-dessous de } 150 \text { tonneaux.. } \\
\text { De } 158 \text { tonneaux et au-dessus. } \\
\text { Bảtiments étrangers. }\end{array}$ & $\begin{array}{l}25 \text { fr. } \\
30\end{array}$ & 0,25 c. & $10 \mathrm{fr}$. & (1) \\
\hline $\begin{array}{l}\text { Au-dessous de } 158 \text { tonneaux.. } \\
\text { De } 158 \text { tonneaux et au-dessus. }\end{array}$ & $\begin{array}{l}30 \mathrm{fr} . \\
35\end{array}$ & $0,60 \mathrm{c}$. & $10 \mathrm{fr}$. & 10 \\
\hline
\end{tabular}

Les droits de pilotage subissent une réduction de 10 francs, quand le navire mouille simplement sur rade.

L'exemption des droits est accordée :

Aux bâtiments au-dessous de 30 tonneaux;

Aux bâtiments de tout tonnage, armés dans la colonie pour la pêche et le cabotage;

Aux bâtiments étrangers dont la cargaison est uniquement composée de chauffage et de bestiaux.

Le droit n'est payé qu'une fois, à leur arrivée en France, par les bâtiments pecheurs.

Les navires, relâchant volontairement ou forcément, s'ils ne font dans la colonie aucune opération commerciale, ne payent qu'un droit de 10 francs.

Les mouvements de la navigation française, en 1862, ont été comme suit :

\section{Entrées.}

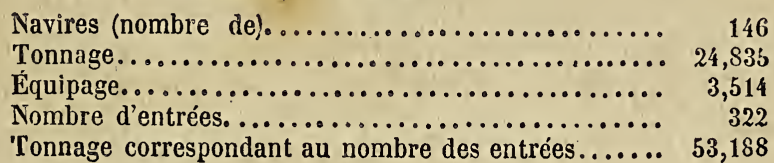

Sorlies.

Nombre................................ 322

Tonnage correspondant aux entrées........... 53,188

Le mouvement de la navigation étrangère, pendant ladite année 1862, a été :

\section{Entrées.}

Nombre de navire

Sorties.

Nombre de navires.................... 8 2 
Six des 88 navires étrangers ont été vendus dans la colonie.

Le service postal fonctionne parfaitement.

Un bureau de poste est établi à Saint-Pierre.

Les correspondances sont emportées le samedi de chaque quinzaine, par les paquebots-poste anglais (Liverpool), qui se rendent à Boston par Halifax (Nouvelle-Écosse). Un service de goëlettes va chercher ou porter à Halifax les dépêches pour ou de SaintPierre et Miquelon. - En été, la correspondance est prise ou expédiée à Sydney (île du cap Breton).

Prix des lettres:

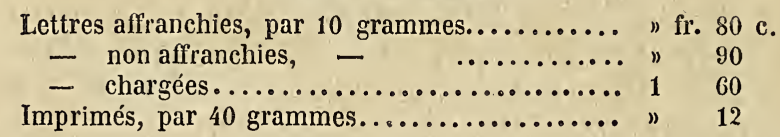

Saint-Pierre et Miquelon ont aussi des timbres d'affranchissement coloniaux.

De février à septembre, il existe des communications autres que celle des voies rapides, entre la France et les deux îles : bâtiments de commerce et bateaux de pêche. Les lettres affranchies, par cette voie, payent 30 c. et 40 c. non affranchies, par 10 grammes. 


\section{$F$}

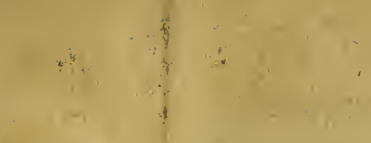

a

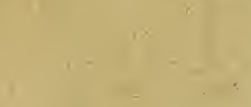

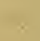<smiles>CC=C(C)C</smiles> 


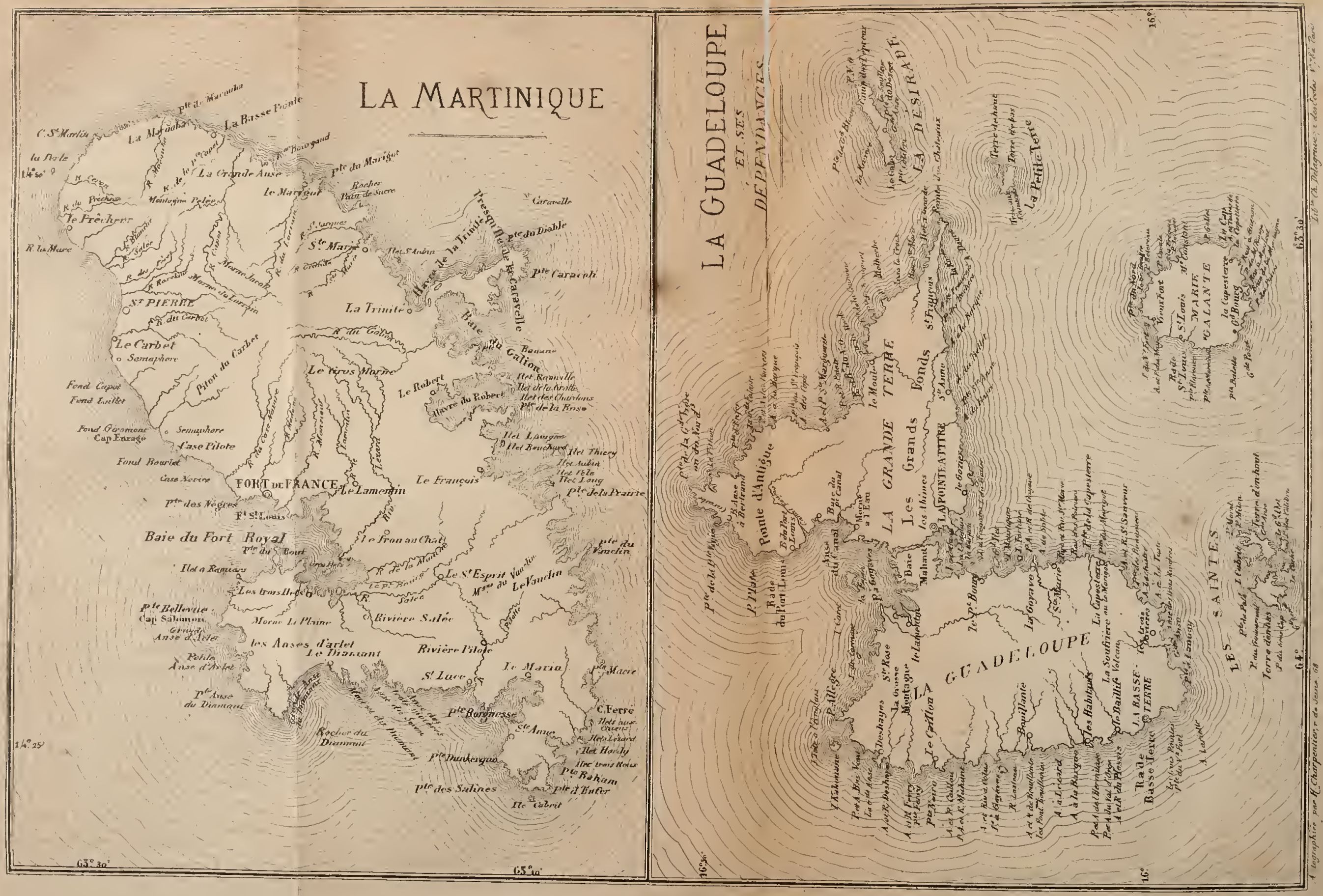




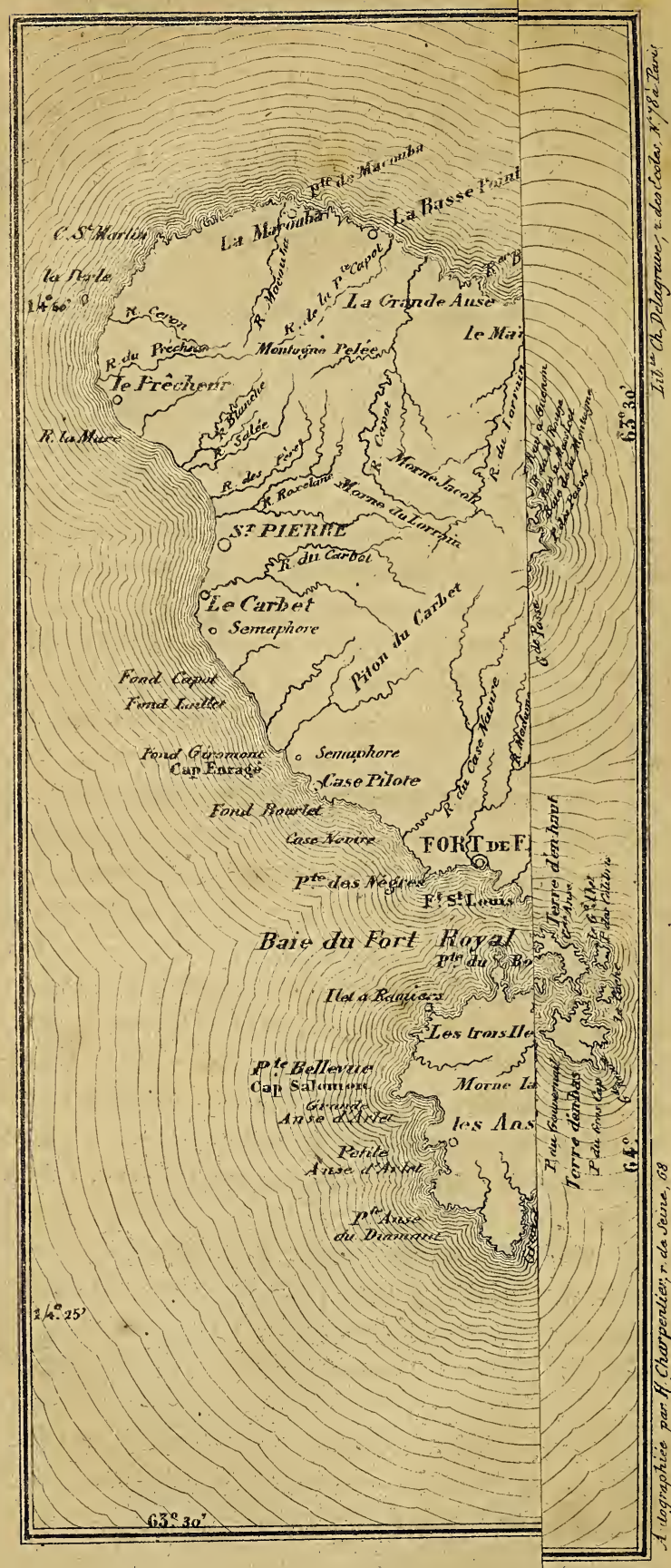




\section{DEUXIEME PARTIE}

\section{MARTINIQUE.}

\section{CHAPITRE PREMIER}

Historique.

L'île de la Martinique appartient au groupe des petites Antilles et fut, comme elles, découverte par Christophe Colomb, en 1493, pendant le second voyage de cet intrépide navigateur.

Elle est située dans l'océan Atlantique, entre $14^{\circ} 25^{\prime} 43^{\prime \prime}$ et $14^{\circ}$ ว2' $47^{\prime \prime}$ lat. N., et entre $63^{\circ} 6^{\prime} 19^{\prime \prime}$ et $63^{\circ} 31^{\prime} 3 \iota^{\prime \prime}$ long. 0 ., à 100 kimètres de la Guadeloupe et à environ 1270 lieues marines du port de Brest.

Le groupe des Antilles auquel elle se rattache est désigné sous le nom d'Iles du Vent.

Les Espagnols dédaignèrent ces îles qui pour eux n'étaient que des cayes (rochers), et les Caraïbes en demeurèrent paisibles possesseurs.

En 1625, deux bâtiments, l'un anglais, l'autre français, abordèrent à Saint-Christophe, et, sans résistance de la part des indigènes, s'établirent dans l'île. Mais bientôt ceux-ci, excités par un de leurs boyés (sorciers), résolurent de se débarrasser des nouveaux venus. Anglais et Français, ayant eu vent de la trame, s'entendirent et d'un commun accord égorgèrent une partie des naturels.

L'île entière passa alors sous leur domination.

Un marin hardi, Pierre Belain, sieur d'Esnambuc, commandait alors les Français. Ses exploits sur mer lui avaient valu, lors de son départ, le titre de Capitaine du roy sur les mers du Ponant.

La colonie fondée, il avisa le gouvernement français de l'état des choses et, sous le patronage de Richelieu, il se forma une Compagnie des îles d'Amérique. 
Belain ne devait pas s'en tenir là.

L'un de ses lieutenants à Saint-Christophe, Charles Lyénard, sieur de l'Olive, était venu en France (1634), s'était associé à Jean Duplessis, sieur d'Ossonville, et avait obtenu de la Compagnie une commission pour fonder une colonie soit à la Dominique, soit à la Martinique, soit à la Guadeloupe. Ils quittèrent Dieppe le 25 mai 1630̃, emmenant 5ొ50 hommes. Un mois après, ils débarquaient à la Martinique, y arboraient les premiers. le drapeau français, mais, trouvant l'île trop montagneuse, ils se transportaient à la Guadeloupe.

Belain, laissant sa colonie de Saint-Christophe, se porta sur la Martinique avec 150 hommes ( $\mathrm{e}^{\mathrm{r}}$ sept. 163̋), et en prit solennellement possession le $\mathbf{1 5 0 ~ d u ~ m e ̂ m e ~ m o i s ~ a u ~ n o m ~ d e ~ l a ~ C o m p a - ~}$ gnie, après avoir traité avec les sauvages.

Les fondements de la nouvelle colonie établis, Belain nomma commandant Jean Dupont et retourna à Saint-Christophe. Dupont eut à lutter contre les Caraïbes qui étaient venus attaquer le petit fort en palissades bâti par Belain, les battit, et prit à son tour la route de Saint-Christophe. La colonie était fondée.

En 1637, on envoya de France, pour remplacer Dupont à la Martinique, un neveu de Belain d'Esnambuc, nommé Duparquet. Celui-ci, peu après son arrivée, prit possession de Sainte-Lucie, de la Grenade et des Grenadilles (Grenadins), au nom de la Compagnie.

En 1650, la Compagnie se résolut à vendre ses îles; elle n'en avait pas retiré tous les avantages qu'elle espérait. Ce fut Duparquet qui les acheta $(60,000$ livres); il en devint ainsi à la fois propriétaire, seigneur et gouverneur.

A sa mort, les Caraïbes s'insurgèrent (1658). On en fit un massacre horrible; ceux qui survécurent, on les expulsa.

Les héritiers de Duparquet furént confirmés par le roi dans les biens, titres et dignités de leur auteur. Mais bientôt le désordre se mit dans la colonie et l'on se décida à enlever ces colonies aux particuliers pour les confier à une autre Compagnie. Les îles furent rachetées aux héritiers Duparquet pour 240,000 livres par le gouvernement qui les rétrocéda à la Compagnie des Indes occidentales, nouvellement formée (1664). Cette Compagnie avait obtenu le droit exclusif de commerce et de navigation dans les mers d'Amérique, pendant quarante ans.

Un conseil souverain, composé du gouverneur et des princi- 
paux officiers, fut institué à la Martinique; toutes les mesures furent prises pour la prospérité de la colonie. Il semblait que la nouvelle Compagnie dût avoir un autre destin que son aînée. Il n'en fut rien:

La guerre, disent les Notices de la marine, qui fut déclarée contre les Hollandais en 1674, accéléra la décadence de la Comgnie; quoique nous eussions eu partout l'avantage sur nos ennemis et que le célèbre Ruyter eût été repoussé avec perte de FortRoyal (juillet 1674), la Compagnie fut dissoute par un édit du mois de décembre, et les îles furent réunies au domaine de l'État; tous les Français, sans distinction, eurent désormais la liberté de s'y fixer.

Les colons de l'île formaient alors deux classes. La première se composait de ceux qui étaient venus de France à leurs frais et qu'on appelait habitants; le gouvernement local leur distribuait des terres en toute propriété, moyennant une certaine redevance annuelle. L'autre classe se composait d'Européens qui, sous le titre d'engagés, étaient contraints de travailler pendant trois années consécutives sur les plantations des colons qui avaient payé les frais de leur passage d'Europe dans la colonie. A l'expiration de l'engagement, les travailleurs recevaient, pour la plupart, des concessions gratuites de terre, dont l'étendue, réduite plus tard de moitié, était de 1,000 pas de longueur sur 200 de largeur.

Mais le nombre des travailleurs n'était pas suffisant, et, dès le début même de la colonie, on fut obligé d'avoir recours à l'introduction des noirs d'Afrique. La traite des esclaves prit promptement une grande extension, et, en 1736 , la population esclave de la colonie ne s'élevait pas à moins de 72,000 noirs.

La perte de nos possessions de l'Amérique du Nord (1713) fut avantageuse pour la Martinique. Le gouvernement porta toute son attention sur les Antilles. En 1717, la Martinique fut affranchie des droits excessifs qui pesaient sur ses produits; elle devint le chef-lieu et le marché général des Antilles françaises. Son agriculture, son commerce, prirent des développements remarquables.

La guerre de 1744, entre l'Angleterre et la France, vint changer la face des choses. On négligea agriculture et commerce; tous les esprits, tous les capitaux se portèrent ailleurs; on ne songea plus qu'à armer des Corsaires.

"Terminées en 1748, les hostilités reprirent en $\mathbf{1 7 5 6}$ contre les 
Anglais. Nos corsaires firent pendant cette guerre des prises considérables et désolèrent le commerce de nos ennemis dans les îles. Le nombre des prises se monta à 950 , et leur produit à plus de 30 millions de livres. Le 14 janvier 1759 , une flotte anglaise de 80 vaisseajux parut devant Fort-Royal; le débarquement s'effectua la nuit; mais le lendemain, l'ennemi, repoussé par les habitants, fut contraint de se rembarquer en toute hâte.

( En 1762, les Anglais, sous les ordres de l'amiral Rodney et du général Robert Monklon, furent plus heureux dans leurs tentatives sur la Martinique. Le 16 janvier de cette année, leur escadre, composée de 230 voiles ei de 15,000 hommes de troupes réglées, mouilla devant la Case-Navire où le débarquement se fit pendant la nuit. Les 1,200 hommes de troupes et les 2,400 habitants ou flibustiers qui formaient toutes nos forces ne purent tenir contre les Anglais, ct le 13 février, après plusieurs combats, le gouverneur, M. de Latouche, capitule à Saint-Pierre.

"La paix avec l'Angleterre fut signée à Fontainebleau le 3 novembre 1762, et, en vertu du traité de Paris, du 10 février 1763, la Martinique fut restituée le 11 juillet de la même année au marquis de Fénelon, envoyé de Frarce pour en reprendre possession. 》

La Martinique, pendant la guerre de l'indépendance américaine (1774), fut le centre des opérations maritimes de nos flottes. Sous le marquis de Bouillé, gouverneur général des îles du Vent, elle participa à la gloire de nos armes.

De 1783, date de la paix, à 1790 , la Martinique reprit son importance agricole et commerciale. L'exportation donna un chiffre de 30,246,286 francs, et l'importation, de 12,538,496 francs. La population se composait de 99,244 individus (83,414 esclaves).

Quand la Convention eut décrété l'abolition de l'esclavage, la guerre civile éclata. Tous les travaux furent abandonnés. Bon nombre d'habitants quittèrent la Martinique. Le 3 février 1794, les Anglais y débarquèrent; l'île fut prise et demeura en leur possession jusqu'en 1802 (paix d'Amiens).

En 1809, les Anglais s'emparèrent encore une fois de la Martinique. Le fort Bourbon, où s'était retirée la garnison, résista à 15,000 Ariglais pendant vingt-sept jours .

Le traité de Paris (30 mai 1814) rendit à la France la Martinique, traité confirmé par celui de novembre 181 . 


\section{GOUVERNEURS.}

1625. Dupont, gouverneur sous l'autorité de Pierre Belain, sieur d'Esnambuc, gouverneur pour le roi.

1637. Duparquet, gouverneur sénéchal de l'île pour la Compagnie des îles de l'Amérique.

1638. De Poincy, lieutenant général des îles de l’Amérique pour S. M.

1645. De Thoisy, $i d$.

1647. De Poincy, id.

16อั3. Duparquet, général.

16ว8. Dyel de Vaudroque, gouverneur.

1664. Prouville, chevalier, seigneur de Tracy, lieutenant général.

1667. De la Barre, lieutenant général.

1669. Baas (le marquis de), premier gouverneur, lieutenant général pour S. M.

1677. Blénac (le comte de).

1691. Éragny (le marquis d').

1697. Amblimont (le marquis d').

1701. Esnotz (le comte d').

1703. Machault (de).

1711. Philipeaux (de).

1715. Duquesne (le marquis).

1717. Lavarenne (le marquis de).

1717. Feuquière (le chevalier de).

1728. Champigny (le marquis de).

1744. Gaylus (de).

17วั0. Bompar (de).

175้7. Beauharnais (le marquis de).

1761. Le Vassor de Latouche.

1762 Rufane (William), Anglais.

1763. Fénelon (le marquis de).

1765. Émery (le comte d').

1771. Valière (le chevalier de).

1772. Nozières (le comte de).

1776. Argoult (le comte d').

1777. Bouilié (le marquis de).

1782. Damas (le vicomite de), gouverneur. général.

1789. Vioménil (le comte de). 
1790. Damas (le vicomte de).

1792. Behague (de).

1793. Rochambeau (de).

1794. Prescott (Robert), Anglais.

1794. Vaughan (sir John), id.

179.̃. Shore Milnes (R.), id.

1796. Keppel (William), id.

1802. Villaret-Joyeuse (l'amiral), capitaine général.

1809. Leekwith (sir George), Anglais.

1810. Brodrick, (le major général John), id.

1811. Wales (le major général Ch.), id.

1814. Vaugiraud (le vice-amiral comte de), lieutenant général. 1818. Douzelot (le lieutenant-général comte), gouverneur et administrateur pour le roi.

1826. Bouillé (le maréchal de camp comte de), gouverneur. 1828. Barré (le maréchal de camp).

1829. Desaulses de Freycinet (le baron).

1830. Gérodias (le colonel), gouverneur intérimaire.

1830. Dupotet (le contre-amiral), gouverneur.

1834. Halgan (le vice-amiral).

1836. Mackau (le contre-amiral baron de).

1838. Rostoland (le colonel).

1838. Moges (le contre-amiral comte de).

1840. Du Valdailly (le contre-amiral).

1844. Mathieu (le contre-amiral A.).

1848. Rostoland (maréchal de camp), gouverneur provisoire.

1848. Perrinon, commissaire général de la République.

1848. Bruat (le contre-amiral), gouverneur.

1851. Vaillant (le contre-amiral).

1853. Brunot, colonel d'infanterie de marine.

18วั4. Gueydon (comte de), capitaine de vaisseau, gouverneur.

1856. Lagrange, commissaire de marine de $2^{\circ}$ classe.

1836. Fitte de Soucy (comte de), général de division.

1859. Lagrange.

18วั9. De Maussion de Candé, capitaine de vaisseau.

1862. Vérand, commissaire de la marine de $1^{\text {re }}$ classe.

1863. De Maussion de Candé, contre-amiral.

1864. De Lapelin, capitaine de vaisseau. 


\section{CHAPITRE II}

Etendue. - Sol. - Montagnes. - Cours d'eau. - Eaux minérales. - Forêts. Côtes. - Rades et baies. - Routes. - Phares. - Divisions territoriales.

Dans sa plus grande longueur, la Martinique a 64 kilomètres et dans sa largeur moyenne 28.

Elle a une circonférence de 320 kilomètres et une superficie de 98,782 hectares.

Les deux tiers de l'île se composent de montagnes; l'autre tiers est occupé par des prairies.

Le sol ne forme point un tout homogène; il varie suivant les lieux. Ainsi, dans les quartiers de la Basse-Pointe et du Macouba, dans les environs du Morne-Rouge, de la Montagne-Pelće et de la Calebasse, la pierre ponce abonde et, mêlée aux détritus végétaux, forme une terre légère et assez fertile. Au sud de l'île, les terres sont fortes, grasses, argileuses. Au N.-0., eilles sont arides et pierreuses.

La Martinique est comme formée de deux îles réunies par un isthme: du rivage au centre, occupé par les montagnes, le sol va s'élevant graduellement.

Six principales montagnes, volcans éteints, s'étendent au centre de l'île. Ce sont : les pitons du Carbet, la montagne Pelée, les Roches-Carrées, le Vauclin, le Marin, le Morne-la-Plaine. On appelle Mornes les montagnes moins élevées et à pentes plus douces que celles des pitons, qui ont une forme conique.

La montagne Pelée a 1,350 mètres; les pitons du Carbet, 1,207. Ce sont les plus hautes élévations de l'île.

Les rivières et cours d'eau sont nombreux. On en compte $77^{\circ}$.

Leur étendue varie entre 4 et 28 kilomètres.

Voici les principaux :

Au vent de l'île, le Lorrain qui se jette dans la mer en deux bras, le Lorrain et le Masse;

Le Galion, la Capote, la Falaise qui se jette dans la Capote;

Les rivières du Macouba, de la Grande-Anse et de SainteMarie.

Sous le vent de l'île, on remarque: la rivière Pilote, la rivière Salée, la Lézarde, la Jambette, la rivière Monsieur, la rivière Madame (celle-ci passe à Fort-de-France); la rivière du Carbet, la rivière du Fort-Saint-Pierre, la rivière du Case-Navire. 
Deux seulement de ces rivières sont navigables : la rivière Pilote et la rivière Salée. Pendant l'hivernage, elles se transforment en torrents impétueux; mais, pendant la saison sèche, leur profondeur n'est pas de plus d'un mètre.

Les deux canaux de la colonie, celui du Lamentin et celui de la rivière Salée, ont une profondeur de 2 mètres et une largeur de 6 mètres. Ils sont toute l'année navigables.

La Martinique possède quatre sources d'eaux minérales.

L'une d'elles, la source Reynal, à 4 kilomètres N.-E. de Fort-de France, a été analysée. Elle contient de l'acide carbonique, du muriate de soude, du muriate de magnésie, du sulfate de soude, du carbonate de chaux, de l'oxyde de fer, de la silice, etc.

La source d'Absalon, à 10 kilomètres N.-O. de Fort-de-France, contient un tiers de son volume d'acide carbonique et un peu de fer. Sa température est de 3 s ou $36^{\circ}$ cent.

La source Roty, à 8 kilomètres de Fort-de-France, est à peu près composée comme celle d'Absalon, mais sa température n'est que de 32 ou $33^{\circ}$ cent.

La source du Prêcheur, au nord de Saint-Pierre, sur le versant de la montagne Pelée, renferme du carbonate de soude, du carbonate de chaux, du carbonate de magnésie, du muriate de soude, de la silice, etc. - Sa température est de 34 ou $35^{\circ}$ cent.

Des forêts impénélrables ceignent les montagnes qui s'étendent au centre de la Martinique. Elles égalent à peu près, croiton, le quart de la superficie de l'île.

Au nord et à l'ouest, les côtes de l'île sont bordées par des escarpements à pic sur plusieurs points. Des bancs de madrépores, à l'est (ou au vent de l'île), rendent les abords d'un accès difficile.

"Cependant, disent les Notices de la marine, les havres du Robert, du François, du Vauclin, y offrent un abri aux petits navires. Le port de la Trinité est accessible à des bâtiments de tonnage moyen. Au sud s'ouvrent la baie du Marin et plusieurs petites anses assez sùres, quand le vent ne souffle point de l'ouest. ")

La rade de Saint-Pierre et la baie de Fort-de-France situées sur la côte occidentale (sous le vent de l'ìle), sont, surtout la première, fréquentées par les navires de commerce qui la quittent à l'époque de l'hivernage, pour aller s'abriter dans le port de Fort-de-France, dont la rade est une des plus belles des Antilles. Des bâtiments du plus fort tonnage euvent en tout temps 
mouiller sans danger dans la baie du carénage et y accoster à quai.

Fort-de-France sert d'escale aux paquebots transatlantiques français de la ligne de Saint-Nazaire au Mexique.

“ Depuis 1860, des travaux considérables ont été entrepris pour approprier le port à sa nouvelle destination; il a reçu le nom de port Chasseloup-Laubat. Un décret du 21 juillet 1860 a autorisé la construction d'un bassin de radoub (aujourd'hui à peu près terminé); et le gouvernement métropolitain a accordé une subvention d'un million de francs pour activer ces travaux qui doivent décidément faire de celte île un des centres commerciaux les plus importants des Antilles. „

Vingt-quatre routes, praticables pour les voitures, traversent l'île.

Deux phares : celui de l'extrémité E. de la presqu'île de la Caravelle, établi en juin 1862, est élevé de 12 mètres et visible à 24. milles en mer. Il se trouve à un tiers de mille dans l'intérieur.

La division territoriale de la Martinique comprend :

2 arrondissements;

9 cantons ;

25 communes;

\section{Arrondissement de Fort-de-France.}

No 1. Canton de Fort-de-France.

1 commune : Fort-de-France.

No 2. Canton de Lamentin.

1 commune : Lamentin.

No 3. Canton de Saint-Esprit.

4 communes : Saint-Esprit,

Ducos,

François,

Rivière-Salée.

No 4. Ganton d'Anses-d'Arlets.

3 communes : Sud,

Trois-Ilets,

Sainte-Luce.

$\mathrm{N}^{\circ}$ ร. Canton de Marin.

丂 communes : Marin,

Vauclin, 
LES COLONIES FRANCAISES.
Sainte-Anne,
Rivière-Pilote,
Diamant.

II. Arrondissement de Saint-Pierre

$N^{\circ} 6$. Canton de Fort.

2 communes : Saint-Pierre.

Prêcheur.

$N^{\circ}$ 7. Canton de Mouillage.

2 communes : Carbet,

Case-Pilote.

No 8. Canton de Basse-Pointe.

3 communes : Basse-Pointe,

Macouba,

Lorrain.

No 9. Canton de Trinité.

4 communes : Trinité.

Sainte-Marie,

Gros-Morne,

Robert.

\section{CHAPITRE III}

Température. - Hygrométrie. - Pluies. - Saisons. - Vents. - Marées. Ras de marée. - Ouragans. - Tremblements de terre. - Population. Blancs et noirs. - Population maritime. - Immigration indienne. - Immigration africaine. - Immigration chinoise.

A la Martinique, le thermomètre marque $35^{\circ}$ et $20^{\circ}$, maximum et minimum de la température à 2 mètres au-dessus du niveau de la mer. Pendant les plus grandes chaleurs, si l'on monte sur les montagnes, à 1,300 mètres au-dessus du niveau de la mer, on n'a pas à supporter au delà de $19^{\circ}$. - De 5ّ à $10^{\circ}$ selon la saison, telle es . Ia variation quotidienne du thermomètre.

L'hygromètre donne pour maximum $100^{\circ}$ et pour minimum $60^{\circ}$. On voit par là combien est grande l'humidité dans la colonie.

La moyenne des pluies qui tombent par an et au niveau de la mer est 217 centimètres. Les années pluvieuses et les années sèohes présentent entre elles un écart de 33 centimètres. 
Deux saisons : une saison pluvieuse (hivernage), du milieu de juillet au milieu d'octobre; une saison sèche et belle, d'octobre à juillet.

Les jours les plus courts sont en décembre; ils durent 11 heures $1 / 4$, ou environ. Les jours les plus longs, au mois de juin, durent 12 heures 1/2. Le jour, aux Antilles, égale donc à peu près la durée de la nuit.

Les vents dominants dans l'archipel des Antilles sont ceux d'E., de N. et de S. Les périodes de domination de ces vents peuvent se réduire à deux.

Pendant la première, qui dure depuis novembre jusqu'en avril, les vents soufflent de l'hémisphère boréal, en passant successivement du N. vers l'E.

Pendant la seconde, qui dure depuis le mois de mai jusqu'en octobre, les vents soufflent de l'hémisphère austral et varient entre l'E. et l'O., en passant vers le S.

Le vent d'O. est le plus rare. Les vents d'E. soufflent pendant les trois quarts de l'année environ. lls ne règnent toutefois avec constance que durant les mois de mars, avril, mai et juin. Ce sont ces vents qui portent le nom de vents alizés et d'où dérivent les expressions au vent et sous le vent, qui servent à désigner dans les Antilles l'orient et l'occident.

La marée, dans son élévation ordinaire, n'excède pas 40 à 50 centimètres. Aux solstices elle ne monte pas même à ce point. Aux équinoxes, elle atteint au plus $0^{\mathrm{m}}, 80$ à 1 mètre d'élévation.

De juillet à octobre, les ouragans ne sont pas rares. Souvent des ras de marée, des tremblements de terre les accompagnent et causent parfois d'irréparables dommages. Chaque année, à la Martinique, on ressent quelque secousse de tremblement de terre.

En 1737 et en $185 \% 9$, les commotions terrestres ont été effroyables. Dans la première de ces années, les cacaoyers ont subi un véritable désastre. C'était alors la principale exploitation agricole de la colonie. Tous, dit-on, furent détruits. En 18ðั9, la ville de Fort-de-France a été presque en totalité renversée, et les plantations environnantes saccagées.

La population de la Martinique, au commencement de 1862, se décomposait ainsi :

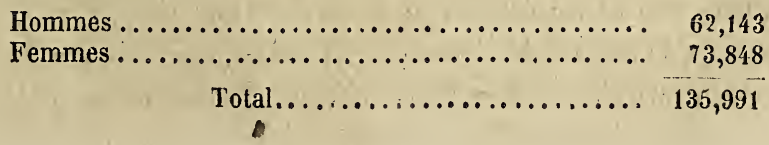


On comprend dans ce total :

Fonctionnaires et employés non proprié-

taires, avec leurs familles........... 666 personnes.

Troupes de la garnison............. 1,509

lmmigrants de toute origine.......... 14,457

Total..............

En 1848, le chiffre de la population sédentaire était de 120,357 individus; en 1862, déduction faite du chiffre des fonctionnaires, troupes et immigrants $(16,032)$, il n'est plus que de 119,959. Diminution : 398 .

La population sédentaire est donc restée stationnaire pendant 15 ans, c'est-à-dire de 1848 à 1862.

$\mathrm{Au}$ point de vue ethnographique, on peut classer ainsi la population entière de la colonie, savoir :

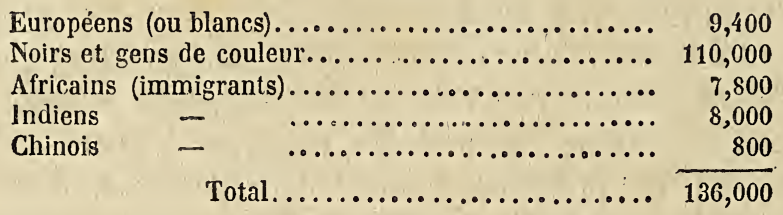

En 1861, la proportion des naissances, décès et mariages a été par rapport à la population sédentaire ainsi qu'il suit :

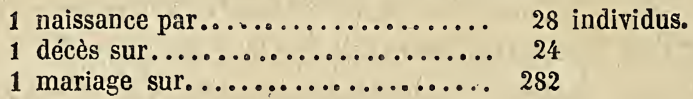

Les naissances ont été de 4,860.

Les décès ont atteint le chiffre de 5̆,539.

Les mariages ont été de 48 s.

La population maritime présentait, en 1858, un chiffre de 2,667 individus, savoir :

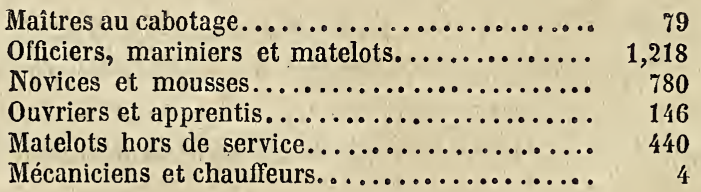

La question de l'immigration a donné lieu dans nos colonies tropicales, à la suite de l'émancipation, à des débats nombreux et approfondis. Les Notices de la marine en donnent un résumé 
très-substantiel que nous demandons la permission de reproduire ici.

A la Martinique, comme dans nos autres colonies, les noirs, à la suite de l'émancipation, désertèrent en grand nombre les habitations agricoles, et il fallut songer à les remplacer par des travailleurs étrangers. Quelques personnes étaient disposées, à cette époque, à provoquer une large immigration européenne, et les Administrations des Antilles furent saisies, en 1852, d'un projet par lequel des spéculateurs proposaient d'introduire à la Martinique et à la Guadeloupe plusieurs milliers de cultivateurs qui seraient recrutés dans les départements de l'Alsace et des Pyrénées. Après des discussions approfondies, ce projet ne fut point adopté.

Le conseil privé de la Martinique fit ressortir avec force que le cultivateur européen ne convenait nullement au climat des tropiques. L'opinion générale était alors qu'une immigration trop nombreuse de travailleurs de celte origine serait beaucoup plus nuisible qu'utile. Employés aux travaux accessoires d'une habitation, les Européens bien choisis peuvent rendre, disait-on, de bons services, mais aucun n'a encore réussi aux travaux de la canne qui sont trop durs pour eux dans ce pays. Les blancs ne peuvent être employés à l'agriculture coloniale que comme conducteurs de voitures, pour les soins à donner au bétail, à la fabrication et à la manipulation des denrées, à tous les travaux enfin qui n'exigent pas leur continuelle présence au soleil. Dans ces limites ils peuvent sans doute rendre des services, et encore ce n'est peut-être qu'à la condition d'être parfaitement choisis, très-ménagés, très-bien nourris. Il n'y a pas là l'élément d'une immigration nombreuse.

Il faut aux colonies ou des Asiatiques ou des Africains pour la culture du sol.

On se tourna donc vers les Indiens qui commençaient à être fort appréciés à la Réunion. Par un décret en date du 27 mars 1852, un capitaine au long cours, M. Blanc, fut autorisé à transporter aux Antilles 4,000 Indiens, dans un espace de six années, moyennant une prime de $500 \mathrm{fr}$. par adulte des deux sexes, et de 300 fr. par immigrant non adulte. Un autre décret de même date établissait avec détail toutes les conditions auxquelles les navires destinés au transport des immigrants dans nos colonies devaient être assujettis. 
La dépense devait être couverte, partie par la colonie, partie par les engagistes. Une caisse dite d'immigration fut instituée à cet effet et formée, dès le principe, par les fonds provenant de l'indemnité accordée à la colonie pour les noirs émancipés du domaine. L'État contribua de son côté et a continué de participer à l'introduction des travailleurs étrangers par une subvention annuelle versée à la caisse d'immigration et qui a varié de 100,000 à 150,000 francs.

M. Blanc introduisit à la Martinique 1,191 Indiens, puis il renonça à la concession que le décret du 27 mars 1852 lui avait faite. Le département de la marine traita alors avec la Compagnie générale maritime pour le transport de tous les coulis indiens qui pourraient être recrutés, pour le compte des Antilles, par la Société d'immigration de Pondichéry. La prime à l'introduction fut fixée à la somme nette de 415 fr. ら̌̆, ainsi répartie: la Caisse d'immigration payait à la Compagnie maritime 318 fr. 0 ŏ par émigrant adulte, et directement à chaque engagé introduit 12 fr. 50. L'engagiste payait de son côté un supplément de $85 \mathrm{fr}$., à la Compagnie maritime, et il remboursait, en outre, à peu près intégralement, la Caisse d'immigration de ses avances au moyen de trois ou quatre annuités, d'un droit d'enregistrement et d'un autre droit proportionnel aux salaires de ses travailleurs. Dans ces conditions, la Compagnie maritime introduisit à la Martinique, dans l'espace de huit années (de 1853 à la fin de 1862), 9,15ั8 Indiens.

La plupart de ces travailleurs se rengagent dans la colonie à l'expiration de leur premier contrat de travail dont la durée est de cinq ans. Ils touchent alors une prime fixée par le conseil général, et qui est de $40 \mathrm{fr}$. pour un rengagement d'un an, de $90 \mathrm{fr}$. pour un rengagement de deux ans, et de $3 \check{0} 0 \mathrm{fr}$. pour un engagement de sept ans. Ceux qui préfèrent retourner dans leur pays sont rapatriés gratuitement. La Compagnie maritime est tenue, par son traité, de disposęr à cet effet un de ses navires qui rapatrie, chaque année, les engagés indiens des colonies de la Martinique, de la Guadeloupe et de la Guyane. Le prix de ces rapatriements, payé par la Caisse d'immigration de chaque colonie, est de $291 \mathrm{fr}$., si le nombre des rapatriés est inférieur à 50 ; de $242 \mathrm{fr} .50$, s'il est inférieur à 100, et de $194 \mathrm{fr}$. seulement si le nombre est de 100 et au-dessus. Jusqu'à présent, le nombre des rapatriés s'est élevé, pour la Martinique, à environ 200 par an. 
La Martinique ne recevait chaque année qu'un faible contingent de 1,200 à 1,500 Indiens; il ne pouvait suffire aux besoins des colons. Un traité qui fut passé au mois de septembre 1850 avec la maison Arnaud et Touache, de Marseille, pour l'introduction de 600 Chinois à la Martinique, et 600 à la Guadeloupe, n'ayant pas donné de résultats (l'opération avorta et ne recrula pas un seul individu), on se tourna vers la race africaine. Un capitaine au long cours de Nantes, M. Chevalier, avail déjà commencé à introduire à la Guyane quelques centaines de noirs recrutés dans les parties de la côte occidentale où l'esclavage n'existe plus (côte de Krou, Libéria, etc.). L'administration de la Martinique conclut à son tour un traité avec le capitaine pour diriger sur la colonie quelques convois d'Africains.

M. Chevalier introduisit, au mois de juillet 18ว7, un contingent de 283 individus ; mais les difficultés de recrutement devinrent telles qu'il dut renoncer à poursuivre l'opération.

Le département de la marine prit alors une mesure décisive. Le recrutement n'avait été jusqu'à cette époque autorisé que parmi les populations africaines originairement libres; on décida de recruler parmi les populations à esclaves. L'esclave devait être racheté à son maître et transporté comme travailleur libre dans nos colonies à des conditions à peu près analogues à celles accordées aux Indiens, et avec la promesse d'être rapatrié gratuitement, à l'expiration de son engagement.

M. Régis, négociant à Marseille, se chargea par un traité du 27 mars $180 \% 7$, d'effectuer les recrutements moyennant une prime de 485 francs net, pour chaque immigrant adulte introduit. Le noir racheté contractait un engagement de 10 ans et remboursait ultérieurement sur ses salaires, au colon qui en avait fait l'avance, une somme de 200 francs pour son rachat.

De 1857 en août 1862, date de larrivée du dernier convoi, M. Régis introduisit à la Martinique 9,090 Africains, exclusivement recrutés au Congo et à Loango. Pendant ce temps, quelques habitants de la colonie faisaient venir directement pour leur compte par l'intermédiaire de la maison Vidal, de Nantes, deux convois recrutés dans notre établissement du Gabon, et comprenant 342 noirs.

Les colons de la Martinique, qui avaient vu d'abord avec une certaine appréhension l'introduction des Africains, s'en sont montrés depuis entièrement satisfaits. On est généralement d'ac- 
cord que l'emploi simultané des deux races, asiatique et africaine, produit sur les ateliers d'excellents résultats. A l'Africain sont dévolus les ouvrages les plus rudes, ceux où une plus grande dépense de force physique est nécessaire ; à l'Indien, les travaux qui exigent plus d'intelligence et d'industrie.

Mais comme le prix de l'introduction de l'Africain est, en somme, moins élevé que celui de l'Indien, que le noir est plus facile à nourrir, qu'il s'acclimate plus vite, on peut dire qu'il est aujourd'hui préféré à tout autre.

On a calculé que le prix de revient de la journée de travail d'un Africain ressort pour le propriétaire à $1 \mathrm{fr}$. 60, le prix de la journée de l'Indien à près de 2 fr. 60 , enfin le prix de la journée d'un Chinois à 4 francs.

Le haut prix de ce dernier travailleur, on le conçoit, le met peu en faveur dans nos colonies.

Trois essais seulement ont été faits à cet égard à la Martinique. On y a reçu 754 Chinois apportés par les navires Amiral, Baudin et Galilée, et recrutés à Canton par les soins de la maison Malavois et $\mathrm{C}^{\mathrm{ie}}$. La colonie avait précédemment partagé avec la Guadeloupe un autre convoi apporté par le navire l'Indien, appartenant à la Compagnie maritime, ef reçu pour sa part 223 Chinois. La prime d'introduction était de $809 \mathrm{fr}$. 60, indépendamment de $61 \mathrm{fr}$. 80 , payés à l'engagé à son départ de Chine et remboursables ultérieurement sur ses salaires. La caisse d'immigration a dû faire l'avance de la totalité de la prime, l'engagé s'obligeant à en rembourser la plus grande partie au moyen d'annuités, dont l'Administration a été obligée de porter le nombre jusqu'à onze. Une pareille mesure indique assez que le Chinois est loin, en général, d'être recherché. Disons cependant que quelques propriétaires ont déclaré être très-satisfaits des travailleurs de cette origine et que des démarches ont été récemment faites par eux pour s'en procurer de nouveaux.

Un nouveau traité récemment conclu avec la compagnie transatlantique fixe la prime d'introduction pour chaque immigrant, adulte ou non adulte, à 415 fr. 55 , sur lesquels l'engagiste rembourse 150 francs au moment où il reçoit l'immigrant; la caisse d’immigration prend à sa charge 26 fr. 55 .

$\mathrm{Au} 1^{\text {er }}$ janvier 1864, la colonie possédait 15,576 immigrants, savoir : 
Indiens......................... 7,676

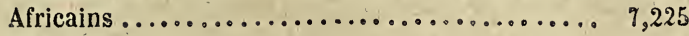

Chinois.......................... 675

On doit ajouter à ce chiffre de travailleurs, 41,000 noirs indigènes, employés sur les exploitations agricoles, savoir :

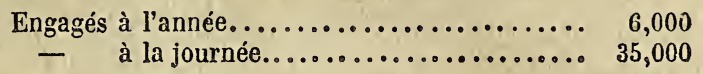

\section{GHAPITRE IV}

Gouvernement. - Administration. - Services de l'ordonnateur. - Services des ports. - Service de santé. - Trésor. - Direction de l'intérieur. - Enregistrement. - Hypothèques. - Service des douanes. - Contributions. - Poste aux lettres. - Police, etc. - Organisation municipale. - Effectif militaire. Station locale, etc. - Justice. - Tribunaux, etc. - Statistique judiciaire.

L'ordonnance royale du 9 février 1827 , modifiée $1^{\circ}$ par l'ordonnance royale du 22 août $1833 ; 2^{\circ}$ par le sénatus-consulte du 3 mai $1854 ; 3^{\circ}$ par le décret du 26 juillet 185 ; $4^{\circ}$ par le décret du 29 août 1855 , a réglé l'organisation du gouvernement de la Martinique.

Un gouverneur, un conseil privé, chargé d'éclairer les décisions du gouverneur, un conseil général, trois chefs d'administration et un contrôleur colonial, telle est la composition du gouvernement local.

Un délégué, élu par le conseil général, et faisant partie du comité consultatif des colonies siégeant à Paris, représente la colonie près du gouvernement métropolitain.

\section{GOUVERneur.}

Le gouverneur a le commandement général et la haute administration, sous l'autorité directe du ministre de la marine et des colonies.

Il représente l'Empereur, est dépositaire de son autorité, rend des arrêtés et prend des décisions pour régler les matières d'administration et de police, et pour l'exécution des lois, règlements et décrets promulgués dans la colonie.

Les pouvoirs du gouverneur, déterminés par l'ordonnance du 9 février 1827, se divisent en ordinaires et en extraordinaires.

Les pouvoirs ordinaires embrassent toutes les parties du ser- 
vice ; le gouverneur les exerce par l'intermédiaire des chefs d'administration, et après avoir consulté le conseil privé, facultativement ou obligatoirement, suivant les cas, mais sans jamais être tenu de se conformer à son avis.

Les pouvoirs extraordinaires sont exercés par le gouverneur, avec obligation de consulter le conseil privé, mais avec toute latitude de statuer ensuite selon son opinion personnelle et sous sa seule responsabilité.

Ces pouvoirs extraordinaires comprennent notamment :

Le droit d'exclure de la colonie, ou d'y mettre en surveillance dans un canton déterminé, les individus qui troublent ou compromettent la tranquillité publique ;

D'interdire l'entrée de la colonic aux individus dont la présence serait reconnue dangereuse;

De suspendre et de renvoyer en France les fonctionnaires de l'ordre judiciaire qui auraient tenu une conduite tellement répréhensible qu'ils ne puissent être maintenus en place.

Le gouverneur peut être poursuivi pour trahison, concussion, abus d'autorité ou désobéissance aux ordres de l'Empereur.

Toutefois, en ce qui concerne l'administration de la colonie, il ne peut être recherché, lorsqu'il a agi conformément aux représentations et aux propositions des chefs d'administration.

Le gouverneur ne peut être, sous quelque cause que ce soit, ni actionné ni poursuivi dans la colonie pendant l'exercice de ses fonctions.

En cas de mort, d'absence on d'empêchement, et lorsqu'il n'y a pas été pourvu d'avance, le gouverneur est remplacé provisoirement par l'ordonnateur et, à défaut de ce fonctionnaire, par le directeur de l'intérieur.

\section{Services de l'ordonnateur.}

Ce personnel comprend :

1 commissaire de la marine, ordonnateur;

2 commissaires-adjoints ;

10 sous-commissaires ;

7 aides-commissaires ;

13 commis de marine.

Ce personnel est réparti en un secrétariat et six bureaux, le tout centralisé au siége du gouvernement, à Fort-de-France.

Le service administratif de Saint-Pierre (revues, armements, 
inscription maritime, hôpitaux, travaux d'approvisionnement, fonds) est fait par un sous-commissaire de la marine, qui a sous ses ordres un aide-commissaire et un commis de marine.

Chacun des cantons de la Trinité et du Marin possède un commis de marine pour diriger le même service.

\section{Service des ports.}

Il comprend à Fort-de-France :

1 capitaine de port ;

1 lieutenant de port;

1 maitre de port;

2 pilotes ;

1 maître charpentier ;

1 maitre forgeron.

A Saint-Pierre, il comprend :

1 capitaine de port;

2 pilotes.

A la Trinité, il y a un pilote;

Au Marin, un pilote;

Au François, un pilote.

Ce personnel est complété par 9 canotiers et 6 gardiens de place.

Service de santé.

Outre les sœurs hospitalières, ce service comprend à Fort-de- . France :

1 médecin en chef ;

9 chirurgiens;

3 pharmaciens.

A Saint-Pierre, il comprend :

1 médecin en chef;

4 chirurgiens ;

1 pharmacien.

\section{Trésor.}

Ce service comprend :

1 trésorier-payeur qui, en même temps, est trésorier des invalides de la marine, caissier des gens de mer et des prises, receveur général des contributions ;

A Fort-de-France, il a sous ses ordres :

1 chef de comptabilité ; 
1 sous-chef ;

1 caissier.

A Saint-Pierre se trouve un trésorier particulier, en même temps receveur particulier des contributions dans l'arrondissement.

\section{Direction de l'intéricur.}

Le personnel comprend :

1 directeur de l'intérieur;

1 secrétaire général;

$\mathbf{5}$ chefs de bureau;

4 sous-chefs;

10 commis ;

9 écrivains.

Ce personnel est réparti en un secrétariat général et quatre bureaux.

Enregistrement, hypothèques, successions vacantes.

Cet important service comprend vingt personnes :

1 inspecteur de $2^{\circ}$ classe, chef du service;

2 vérificateurs de $2^{\mathrm{e}}$ et de $3^{\circ}$ classe ;

11 receveurs ;

1 garde-magasin, premier-commis de direction ;

5 commis-receveurs.

\section{Douanes.}

Ce service comprend :

1 directeur; 2 sous-directeurs ; 1 contrôleur; 10 vérificateurs ; 8 commis; 1 lieutenant ; 8 brigadiers, préposés et agents divers.

\section{Contributions.}

Outre le trésorier-payeur et le trésorier particulier, ce service comprend :

1 inspecteur de $2^{\text {e }}$ classe, chef du service;

1 inspecteur de $3^{\mathrm{e}}$ classe ;

8 contrôleurs ;

12 percepteurs des contributions;

2 vérificateurs des poids et mesures ;

2 commis.

La vente des spiritueux est affermée à des particuliers dans chaque commune. 


\section{Poste aux lettres.}

Le personnel est ainsi composé :

1 receveur-comptable chef, 1 receveur, 3 commis, 5 facteurs (villes de Saint-Pierre et Fort-de-France); 3 préposés buralistes-receveurs (communes).

\section{Police.}

Saint-Pierre : 2 commissaires de police.

Fort-de-France : $1 \quad i d$.

Communes rurales : $7 \quad i d$.

\section{Prisons.}

Fort-de-France : 1 prison centrale; 1 atelier de discipline.

Saint-Pierre : une maison d'arrêt.

Saint-Jacques : 2 ateliers d'éducation professionnelle (un pour garçons, un pour filles).

Le personnel comprend :

4 régisseurs, 3 commis comptables, 8 guichetiers.

L'inspection des prisons est attribuée à un chef de bureau de la direction de l'intérieur.

\section{Ponts et chaussées.}

1 ingénieur, chef du service;

2 ingénieurs coloniaux;

6 conducteurs principaux;

6 conducteurs de $1^{\mathrm{re}}$ et de $2^{\mathrm{e}}$ classe.

Service de l’immigration.

Fort-de-France : 1 commissaire, 1 sous-commissaire, 1 régisseur du dépôt, 1 médecin, 1 syndicat de l'immigration.

Saint-Pierre : 1 sous-commissaire, 3 écrivains, 1 syndicat de l'immigration.

\section{Contrôle colonial.}

1 commissaire de $1^{\text {re }}$ classe de la marine, contrôleur;

2 sous-commissaires (l'un à Saint-Pierre, l'autre à Fort-deFrance);

1 commis de marine. 


\section{Organisation municipale.}

Les 25 communes de la colonie ont, chacune, un maire, un ou deux adjoints nommés par le gouverneur, de 5 à 13 conseillers municipaux aussi nommés par le gouverneur.

Un décret colonial (12 juin 1837), modifié par le sénatus-consulte du 5 mai 1854, a réglé l'organisation municipale à la Martinique.

L'effectif militaire de la Martinique comprend les éléments suivants.

$$
\text { États-majors. }
$$

Deux états-majors : État-major général, état-major des places. - lls se décomposent ainsi :

1 licutenant de vaisseau et 1 capitaine d'infanterie de marine, attachés à l'état-major particulier du gouverneur;

2 chefs de bataillon, commandant, l'un la place de SaintPierre, l'autre à celle de Fort-de-France ;

1 adjudant de place à Saint-Pierre.

\section{Artillerie.}

1 chef d'escadron directeur;

1 capitaine en $1^{\text {er }}$, adjoint;

1 chef ouvrier d'État; 2 maîtres armuriers;

6 gardiens de batterie: 1 portier-consigne;

2 batteries (9 officiers, 202 sous-officiers et canonniers);

1 détachement de 50 ouvriers.

\section{Génie.}

1 chef de bataillon, sous-directeur;

1 capitaine de $\mathbf{1}^{\text {re }}$ classe ;

1 compagnie indigène d'ouvriers (3 officiers, 156 sous-officiers et soldats).

Le génie, outre son service ordinaire, est employé aussi au cadastre.

$$
\text { Infanterie de marine. }
$$

1 lieutenant-colonel, commandant.

2 chefs de bataillon;

1 capitaine-major;

2 capitaines adjudants-majors ; 
1 lieutenant, officier payeur ;

1 lieutenant, officier d'habillement;

2 chirurgiens aides-majors;

8 compagnies (de 114.hommes et 3 officiers).

Gendarmerie coloniale.

1 chef d'escadron, commandant;

1 capitaine;

2 lieutenants;

138 sous-officiers et gendarmes à cheval ;

24 gendarmes à pied.

Sapeurs-pompiers porte-hache.

Fort-de-France : 1 compagnie (60 hommes, dont 3 officiers); Saint-Pierre : 1 compagnie (110 hommes, dont 4 officiers).

Station locale.

1 aviso à vapeur ( 4 canons, 160 chevaux);

1 goëlette à voiles (6 canons);

9 officiers;

163 matelots.

La Martinique est le centre de la division navale des Antilles et de l'Amérique du Nord.

\section{Arsenal maritime.}

Une circonstance récente peut donner une idée de l'importance de cet établissement, fondé en 1828, à Fort-de-France. Au moment de l'expédition du Mexique, il a pu ravitailler 30 bâtiments de guerre.

\section{Bassin de radoub.}

En construction. «Il complétera, disent les Notices de la marine, l'arsenal maritime et en fera le premier établissement de ce genre dans les Petites Antilles."

Les codes métropolitains sont en pleine vigueur à la Martinique. (V. Ordonnance du 24 septembre 1828, décret du 16 août 18ð4, etc.)

Justices de paix. - Dans l'arrondissement de Fort-de-France, on compte cinq tribunaux de paix : à Fort-de-France, à SaintEsprit, aux Anses d'Arlet, au Marin et au Lamentin. 
Dans l'arrondissement de Saint-Pierre, il y en a quatre : au Mouillage, au Fort, à la Basse-Pointe, à la Trinité.

La loi du 25 mai 1838 règle la compétence des juges de paix en matière civile.

En matière commerciale, ils connaissent, en dernier ressort, jusqu'à la valeur de 150 francs en principal, et, en premier ressort, quand la valeur de la demande principale n'excède pas 300 francs.

Ils connaissent aussi des contraventions de police.

Tribunaux de $1^{\mathrm{re}}$ instance. - Il y en a deux : l'un à Fort-deFrance, l'autre à Saint-Pierre.

A Fort-de-France, le tribunal se compose d'un président, de trois juges, d'un procureur impérial, d'un substitut et d'un greffier.

A Saint-Pierre, même composition du tribunal; deux substituts.

Leur compétence est à peu près la même que celle des tribunaux de première instance de la métropole. - Ils exercent les attributions conférées en France aux chambres du conseil.

Cour impériale. - Elle siége à Forl-de-France et se compose d'un président, de sept conseillers, d'un conseiller auditeur, d'un procureur général, de deux substituts et d'un greffier en chef. - Le procureur général est chef du service judiciaire dans la colonie.

Conseil privé. - En matière de commerce étranger, douanes, contributions indirectes, c'est devant ce conseil que les appels sont portés, sauf recours en cassation. (Ordonnance du 9 février 1827.)

Cours d'assises. - Elles sont au nombre de deux et siégent, l'une à Fort-de-France, l'autre à Saint-Pierre. Elles se composent de trois conseillers et de quatre membres du collége des assesseurs, lequel collége est formé de 60 membres choisis parmi les habitants de la colonie. (Qrd. 24 septembre 1828.)

Officiers ministériels. - 20 notaires; 17 avoués; 16 huissiers. Stalistique judiciaire de 1859 à 1861 :

10 Justices de paix.

Jugements en matière civile et commerciale........ 2,471

Jugements en simple police................ 7,085 
20 Tribunaux de première instance.

A. Tribunal de Fort-de-France.

Jugements en matière civile et commerciale........ $\quad 585$

- correctionnelle............ 446

B. Tribunal de Saint-Pierre.

Jugements en matière civile et commerciale........ 917

- $\quad$ - correctionnelle............ 519

$3^{\circ}$ Cour impériale.

Moyenne annuelle des affaires................ 143

40 Cours d'assises.

Moyenne annuelle des affaires................ 97

des prévenus................ 129

\section{CHAPITRE $Y$}

Finances. - Budget de l'Etat. - Budget local. - Banque de la Martinique. Crédit foncier colonial.

En 1864, le budget de l'État a contribué aux charges de la colo. nie comme il suit.

I. BUDGET DE L'ÉTAT.

Total du personnel................... 2,540,908 fr.

Total du matériel................... 593,000

Total général............. $3,133,910 \mathrm{fr}$.

Les dépenses effectuées au compte du service marine ne sont pas comprises dans le chiffre ci-dessus. Ces dépenses, en 1862, se sont élevées à 2,075,603 francs; la guerre du Mexique les avait rendues nécessaires.

II. BUDGET LOGAL.

Total des recettes................ $3,335,307 \mathrm{fr}$.

Dépenses :

¿ Dépenses obligatoires................ 2,130,703 fr.

Dépenses facultatives............... 1,082,597

Dépenses extraordinaires............... 122,066

Total général des dépenses.......

En octobre 1863 , la caisse de réserve de la colonie présentait un disponible de 832,488 francs.

Deux établissements financiers fonctionnent à la Martinique ce sont la Banque de la Martinique et le Crédit foncier colonial. 
La Banque a été constituée au capital de trois millions. (Loi du 14 juillet 18ว1.)

Ses opérations d'escompte, en 1862-1863, se décomposent ainsi :

Effets sur place.

Obligations sur actions............ 1,609,514 04

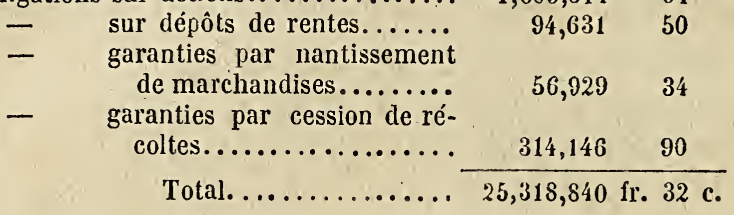

Ses opérations de change ont donné les résultats suivants :

Mandat sur le Comptoir d'escompte de

Paris...................... 11,104,637 fr. 35 c.

Traites négociées par la banque et en-

voyées en remise au Comptoir...... 10,245,097 31

Mandats sur les banques de la Guade-

loupe et de la Guyane..............

Total................

Sommes versées au dépôt............

Comptes-courants .................

Billets entrés en caisse...............

Numéraire entré en caisse.......... 2,471,531 95

Le dividende de la Banque, pour 1862-63, s'est élevé à 7 fr. 39 pour 100 ; soit 36 fr. 95 par action.

Le Crédit foncier colonial a été autorisé par décret du 31 août 1863.

Pendant le premier trimestre de 1864, on a adressé à la So. ciété :

23 demandes de prêts sur immeubles ruraux... 1,599,629 fr.

12

- urbains.. 107,200

\section{CHAPITRE VI}

Culte. - Grand séminaire, etc. - Clergé. - Communautés religieuses. - Bureaux de charité. - Ouvroir. - Hôpitaux militaires. - Hospices civils. Maison coloniale de santé. - Instruction publique. - Petit séminaire. - Institution de Sainte-Marie. - Institut des sœurs de Saint-Joseph de Cluny. Ecoles primaires. - Écoles particulières et laïques. - Cours public. - Presse périodique.

La religion de la grande majorité des habitants de la Marti- 
nique est le catholicisme. Par décret impérial du 8 décembre 1850 , la colonie a été érigée en évêché.

A Saint-Pierre, siége du diocèse, il y a un séminaire où la coIonie entretient 16 boursiers. On y reçoit les jeunes gens qui se destinent à la carrière ecclésiastique.

Le elergé comprend : 1 évêque, deux vicaires généraux et 80 prêtres.

On compte 28 paroisses, plus une mission diocésaine.

Chaque paroisse a un conseil de fabrique, ainsi composé :

Pour les paroisses de 5,000 âmes et au-dessus, le conseil est formé de 9 membres, en dehors du maire et du curé, membres de droit;

Pour les paroisses de moins de 5,000 âmes, le conseil est formé de 5 membres seulement.

Les communautés religieuses sont au nombre de quatre :

$1^{\circ}$ Les Pères du Saint-Esprit, qui dirigent le grand et le petit séminaire;

$2^{\circ}$ Les Frères de l'institut de Ploermel, au nombre de 50, voués à l'instruction.

$3^{\circ}$ Les sœurs de Saint-Joseph de Cluny, au nombre de 86, vouées à l'instruction;

$4^{\circ}$ Les sœurs de Saint-Paul de Chartres, au nombre de 37, vouées au service des hôpitaux.

La colonie possède 27 bureaux de charité, surveillés par un conseil de surveillance.

Ce conseil se compose du président de la cour impériale, président, d'un vicaire général, du trésorier de la colonie, du premier médecin en chef de la marine, du chef du bureau des cultes, inspecteur de l'assistance publique, de deux membres du conseil général, de deux habitants notables.

Une dame charitable, madame Vaillant, a fondé à Port-deFrance un ouvroir pour les jeunes filles. Il est dirigé par trois sœurs de Saint-Paul. Les orphelines y sont élevées et instruites gratuitement; à leur sortie, elles reçoivent un trousseau et une somme d'argent. - L'ouvroir est placé sous le eontrôle d'un comité de 30 dames.

La Martinique a deux hôpitaux militaires, une succursale, deux hospices civils, des établissements pour les convalescents, etc.

L'hôpital militaire de Fort-de-France contient 333 lits ; celui 
de Saint-Pierre en renferme 223. La succursale de l'hôpital de Fort-de-France est située de l'autre côté de la rade, à la pointe du Bout.

Les hospices civils sont établis à la Trinité et au Marin; 34 lits y sont à la disposition de l'Administration pour les salariés de l'Élat.

Les malades ou les convalescents dont la santé réclame l'usage des eaux thermales sont dirigés par le gouvernement sur les établissements hospitaliers des Pitons.

Aux hôpitaux sont attachées dix-neuf sœurs de la congrégation de Saint-Paul de Chartres.

Fort-de-France est le siége d'un conseil de santé ; SaintPierre, d'une commission de santé, et chaque hôpital a une commission sanitaire.

Le service de santé comprend : 1 premier médecin en chef, 1 second médecin en chef, 3 chirurgiens de $1^{\text {ro }}$ classe, $\check{\jmath}$ de $2^{\mathrm{e}}$ classe, 5 de $3^{\mathrm{e}}$ classe, 1 pharmacien de $1^{\text {re }}$ classe, 1 de $2^{\mathrm{e}}$ classe, 2 de $3^{\text {e }}$ classe.

Les hospices civils reçoivent:

$1^{\circ}$ Les indigents, malades, les infirmes, les vieillards indigents, les enfants trouvés et abandonnés;

$2^{\circ}$ Les prisonniers malades et les aliénés dont l'état est encore indécis ;

$3^{\circ}$ Les individus qui demandent à y être trailés à leurs frais ;

4. Les salariés de l'État (officiers, soldats ou assimilés), dans les localités où il n'y a point d'hôpital militaire.

On compte six de ces hospices : à Fort-de-France, à SaintPierre, à la Trinité, au Saint-Esprit, au Marin, à la GrandeAnse.

L'administration en est confiée à un conseil composé des maires, du curé de la paroisse, de trois habitants notables. Il est présidé par le maire de la commune où est établi l'hospice.

Ces divers établissements sont desservis par un chirurgien de la marine, 3 médecins civils, 2 aumôniers, et 13 sœurs de SaintPaul de Chartres.

Les établissements thermaux situés aux Pitons du Carbet et au Prêcheur sont, en outre, très-fréquentés.

Les aliénés reçoivent des soins spéciaux dans la maison coloniale de santé, fondée en 1837 par M. Lemaire. On y compte une soixantaine d'incurables. 
Les établissements d'instruction publique sont au nombre de 78. Sur ce chiffre, 38 sont consacrés aux garçons et 40 aux filles.

En outre, il existe 8 salles d'asile pour les garçons et 7 pour les filles.

Une commission, chargée de délivrer un certificat d'aptitude aux aspirants au baccalauréat ès lettres ou ès sciences, a été instituée en 1857. Les élèves, porteurs du brevet que la commission délivre gratuitement, peuvent prendre les quatre premières inscriptions près des Facultés de droit ou de médecine, avant d'avoir définitivement obtenu le diplôme de bachelier.

Quelques détails sur les divers établissements d'instruction de la colonie.

Le petit séminaire, fondé à Saint-Pierre, en 183̆1, par Mgr Le Herpeur, comptait, en 1862, 273 élèves, dont 116 pensionnaires, 109 demi-pensionnaires et 48 externes; on y suit exactement le programme de l'Université. Des cours d'instruction professionnelle y sont faits.

L'Institution de Sainte-Marie, à Fort-de-France, succursale du petit séminaire de Saint-Pierre, avait, en 1862, 179 élèves. L'enseignement littéraire ne va que jusqu'à la cinquième. L'enseignement commercial qu'on y donne en outre embrasse, avec la langue française, les éléments des mathématiques, de la physique, du droit commercial, de la tenue des livres, de l'histoire et de la géographie.

Vingt et une écoles primaires, dirigées par les frères de Ploërmel, sont entretenues aux frais du gouvernement dans les différentes communes; 2,092 garçons ont fréquenté ces écoles, pendant le premier semestre de $1863 ; 2,341$ adultes ont assisté aux́ instructions du soir et du dimanche; 18,708 ont reçu l'instruction des frères catéchistes.

La rétribution scolaire est de 1 fr. à $10 \mathrm{fr}$. par mois.

Les sœurs de l'institut de Saint-Joseph de Cluny dirigent 22 établissements.

Leur pensionnat de Saint-Pierre est très-renommé. Les jeunes filles des meilleures familles de la Martinique y sont élevées pour la plupart. Le gouvérnement y entretient des élèves boursières; 103 élèves y recevaient l'instruction au commencement de 1863.

Ce pensionnat a deux annexes: un externat et un orphelinat; 
plus au centre de la ville, pour les enfants des parents peu aisés, une succursale-externat.

Les mêmes sœurs dirigent aussi, à Fort-de-France, un externat qui compte une centaine d'élèves; deux écoles primaires à SaintPierre, une à Fort-de-France, et $\mathbf{1 5}$ autres dans les diverses communes ; 1,456 jeunes filles de race noire ou de couleur ont fréquenté ces 18 écoles en 1863.

La colonie compte encore 14 écoles particulières et laïques pour les garçons, et 17 pour les filles: le cỏllége Saint-Louis, une école dés arts et métiers, etc., à Fort-de-France.

En 1864, un cours public sur les sciences et leurs applications a été ouvert à Fort-de-France.

Trois journaux: le Messager, journal officiel, le Propagateur et les Antilles, paraissent deux fois la semaine. Le premier se publie à Fort-de-France, les autres à Saint-Pierre.

L'Annuaire de la colonie, le Bulletin officiel des actes du gouvernement, complètent la publicité coloniale.

\section{CHAPITRE VII}

Agriculture. - Situation agricole. - Genres de culture. - Valeur des produits.

- Habitations rurales. - Statistique des travailleurs. - Bétail et animaux de trait. - Canne à sucre. - Production annuelle. - Café. - Cacao. - Coton - Tabac. - Épices. - Casse. - Vivres. - Bois. - Jardin botanique. Chambre d'agriculture.

L'industrie agricole de la Martinique est en voie de progrès. La culture de la canne est toujours la principale des cultures de la colonie.

a Les terres destinées à la production de la canne ne reçoivent jamais plus d'un ou deux labours en plein, et après qu'elles ont été sillonuées à la charrue; les autres travaux dont elles sont l'objet s'accomplissent au moyen des bras. Sarclage, fumage, entretien des terres et des plantes, tout se fait par des travailleurs qui reçoiven i un salaire quotidien élevé, indépendamment d'une case et d'un jardin. Les cannes sont ordinairement plantées à une distance de 3 pieds $1 / 2$ en moyenne. Sur certaines habitations, cependant, nous devons dire qu'on s'efforce de remplacer autant que possible le travail des bras par celui des instruments aratoires de toute sorte. 
( On cherche aussi à substituer le travail à la tâche au salaire journalier. Depuis 1857, des essais de drainage, encouragés par des primes, ont eu lieu dans la colonie, et ont donné de beaux résultats. » (Notices.)

La surface totale de la Martinique embrasse 98,782 hectares. Voici le nombre d'hectares affecté à chaque genre de culture.

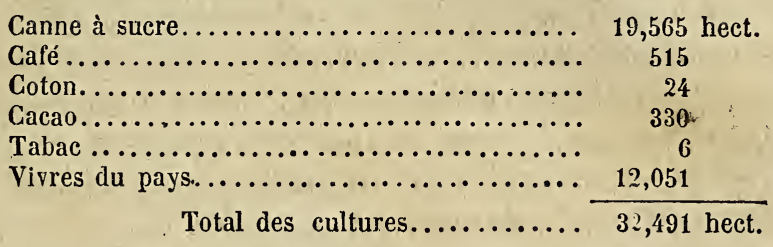

Le reste du sol est occupé par:

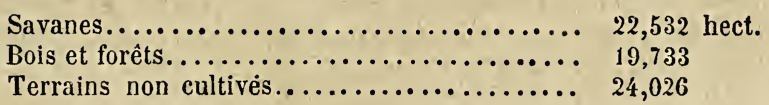

Voici la quantité des produits et leur valeur (1862):

Canne à sucre.

$\begin{array}{crc}\text { Sucre brut......... } & 27,079,300 \mathrm{kil} . . . \ldots \ldots & 11,644,099 \mathrm{fr} . \\ -\quad \text { terré....... } & 550-\ldots \ldots \ldots & 275 \\ \text { Sirops et mélasses.. } & 6,119,876-\ldots \ldots \ldots & 1,162,776 \\ \text { Rhum et tafia...... } & 4,371,143-\ldots \ldots \ldots & 1,333,199 \\ & \text { Café. }\end{array}$

130,630 kil......................... 300,449 fr.

Coton.

6,650 kil $\ldots \ldots \ldots \ldots \ldots \ldots \ldots \ldots \ldots \ldots \ldots \ldots . \quad 9,975$

Cacao.

127,500 kil......................... 121,125

Tabac.

6,000 kil............................ 14,100

En résumé :

La valeur brute des produits de culture atteint le chiffre de 14, $5850,998 \mathrm{fr}$.

Et comme les frais d'exploitation sont évalués à 7,292,999 fr., le produit net serait $7,292,999$ fr.

La colonie comptait, à la fin de $1862,5,612$ habitations rurales, savoir :

Sucreries

Caféières 


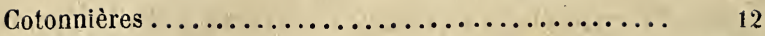

Vivrières $\ldots \ldots \ldots \ldots \ldots \ldots \ldots \ldots \ldots \ldots \ldots \ldots \ldots \ldots, \quad 4,688$

Cacaoyères .............................. 85

Poteries............................... 11

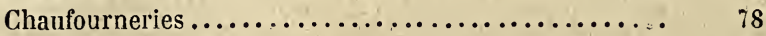

Moulins à vapeur........................ 59

Soit : 5,612 habitations, ou plutôt exploitations, car souvent dans la même habitation plusieurs exploitations sont réunies.

Nombre des travailleurs : 69,100 .

Nombre des animaux de trait et du bétail, savoir :

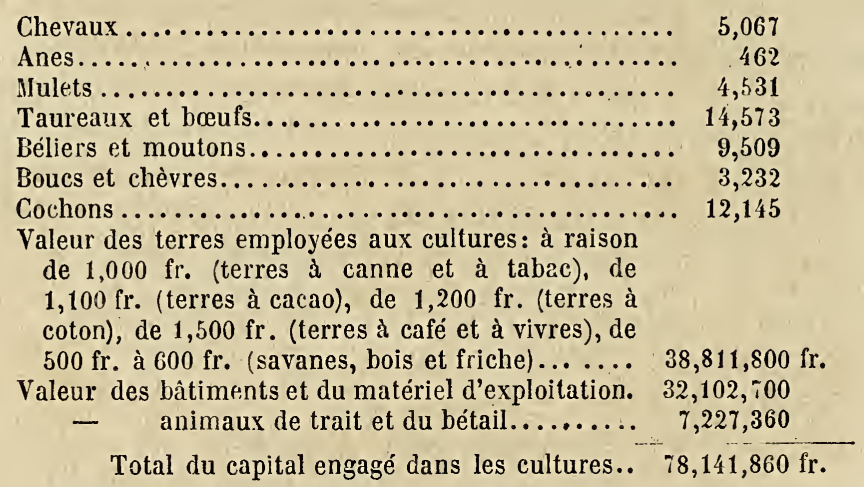

Voici maintenant, d'après les Notices de la marine, quelques détails sur l'origine des principaux produits cultivés à la Martinique.

\section{$1^{\circ}$ Canne à sucre.}

Les premiers Français, qui se sont établis aux Antilles, y trouvèrent la canne à sucre; mais on ne commença à la cultiver spécialement pour en faire du sucre qu'en 1644 à la Guadeloupe, et un peu plus tard, en 165ّ0, à la Martinique; cette dernière colonie dut à Benjamin Dacosta l'introduction de la culture de la canne. La canne créole fut remplacée plus tard par la canne jaune de Batavia, qui y fut apportée en 1787 par Guyot Duclos, et par la canne de Taïti, qui fut introduite en 1789 par l'intendant Foullon d'Écotier.

En 1720, on comptait déjà 238 habitants sucriers à la Martinique. - En 1789, il y arait 19,000 hectares plantés en cannes, qui rapportaient $18,500,000$ kil. de sucre brut.

La production annuelle, jusqu'en 1832, a varié de 15 à 29 millions de kil. 
De 1832 à 1862, elle a été, au plus bas, de 15,842,500 kil. (sucre), de 4,737,028 litres (sirops et mélasses), de 1,316,800 litres (rhum et tafia), et, au plus haut, de $30,988,250$ kil. (sucre), de 6,630,000 litres (sirops et mélasses), et de 4,739,210 litres (rhum et tafia).

\section{$2^{\circ}$ Caféier.}

Introduit en 1720 par le capitaine Declieux. En 1789, époque de la plus grande prospérité des caféières, 6,123 hectares étaient plantés en cafés. Mais, à partir de cette époque, cette culture commença à décroître, sous les ravages d'un petit ver blanc, l'Elachista cofféola, des convulsions terrestres et atmosphériques, et surtout de l'appauvrissement des terres. En 1835, on ne comptait plus que 3,082 hectares plantés en café, que 769 en 185ว, et 515̆ en 1862. Le gouvernement, pour relever cette culture, a accordé des primes d'encouragement, et, depuis lors on compte dans la colonie 109,142 pieds de caféiers nouvellement plantés.

\section{$3^{\circ}$ Cacao.}

Introduit par Benjamin Dacosta. Sa culture date de 1664. - Depuis $18 ð 9$, elle se relève de la décadence où elle en était venue à partir du tremblement de terre de 1727.

\section{$4^{\circ}$ Coton.}

Indigène à la Martinique. Depuis 1779, époque de sa plus grande faveur ( 2,726 hectares étaient alors cultivés), la culture du coton a toujours été en diminuant.

\section{$5^{\circ}$ Tabac.}

Originaire de l'Amérique. Petun était le nom que lui donnaient les Caraïbes. Cette culture, longtemps négligée à partir de 1789 , reprend faveur. En 1862 , elle a donné 6,000 kilog., tandis que, en 1835, elle n'en avait fourni que $427 \mathrm{kilog}$.

$$
6^{\circ} \text { Épices. }
$$

Cette culture est peu étendue. La plus grande partie des produits est consommée sur place.

$$
7^{\circ} \text { Casse. }
$$

La culture du cassier (canéficier dans le pays) est fort ancienne 
aux Antilles ; mais elle n'y a jamais été très-développée. En 1861, pourtant, la casse officinale a produit $445,403 \mathrm{kilog}$.

\section{$8^{\circ}$ Vivres du pays.}

Les plantations de vivres se composent principalement: de manioc, dont la racine fournit une farine substantielle qui forme la base de la nourriture des noirs; de bananiers, végétal dont l'excellent fruit peut se consommer avec ou sans préparation; d'ignames, dont la racine est très-nourrissante et qui, parfois pèse jusqu'à 15 kilog.; de patates, de choux caraibes, des fruits de l'arbre à pain, de maïs, etc.

\section{$9^{\circ}$ Bois.}

Très-difficilement exploitables à cause des escarpements et du manque de routes, mais ils sont fort riches : bois de campêche, de construction, de charronnage, etc.

En 1863, il a été exporté 731,556 kilog. de bois de campêche.

On remarque à Saint-Pierre un jardin botanique, fondé en 1803; on y naturalise les plantes des Indes orientales et surtout les épices; on y collectionne les plantes indigènes, etc.

Un arrêté du $1^{\text {er }}$ juillet 1859 a réorganisé la chambre d'agriculture. Elle siége à Saint-Pierre et se compose de 12 membres.

\section{GHAPITRE VIII}

Industrie : sucre ; - rhums; - tafias ; - poteries ; - chaufourneries ; - pêche. - Commerce. - Exportation, - Importation - Marchandises importées. Marchandises exportées. - Entrepòts. - Navigation. - Douanes̀. - Communications.

Les industries sont peu nombreuses à la Martinique.

On s'y livre particulièrement à la fabrication du sucre.

Les lois de $\mathbf{1 8 6 0}$ et de $\mathbf{1 8 6 1}$, l'une sur le régime des sucres, l'autre sur l'exportation des produits coloniaux à l'étranger, ont imprimé à l'industrie sucrière de l'île une impulsion remarquable. Pour rivaliser avec l'étranger, on a dû abandonner les vieux errements et adopter les nouveaux systèmes.

Après la fabrication du sucre, vient celle des rhums et tafias qui s'y rattache. La qualité de ces spiritueux, qui laissait à dé- 
sirer, a, depuis quelques années, atteint un haut degré de perfection. En 1861, la fabrication de ces produits a été mise en ferme et a rapporté en 1862, dans les diverses communes de l'île, une somme de $602,560 \mathrm{fr}$.

La Martinique possède $\mathbf{1 1}$ poteries et 78 chaufourneries. Les madrépores et les coquillages servent à la fabrication de la chaux.

La pêche a lieu au moyen de canots ou de pirogues non pontées.

La marine locale présentait, en 185̈8, l'état suivant :

Bateaux à vapeur......................... 4

Goëlettes.............................. 8

Bateaux à voiles.......................... $\quad 32$

Gros bois, pirogues et autres embarcations........ 1,421

Antérieurement à la loi de 186I, le commerce de la Martinique étail régi par la loi du 29 avril 1840.

On peut ainsi résumer ce régime antérieur.

Fermeture des marchés étrangers aux produits coloniaux, les sirops et tafias exceptés; traitemerit de faveur accordé aux produits coloniaux sur les marchés français; réserve du marché colonial aux produits français, sauf quelques exceptions; privilége du pavillon national pour les transporis entre la France et les colonies, et réciproquement de colonie à colonie.

Depuis la loi du 3 juillet 1861, promulguée à la Martinique le 6 août de la même année, la colonie est libre d'exporter ses produits à l'étranger et de recevoir les marchandises étrangères sous tout pavillon. La franchise douanière a été, par le décret du 6 octobre 1862, accordée aux produits exportés de France aux colonies, fabriqués avec les marchandises étrangères admises temporairement en France.

La Martinique a cinq ports ouverts au commerce :

Saint-Pierre, Fort-de-France, la Trinité, le Marin, et le port du François (celui-ci à titre provisoire).

Le mouvement du commerce de la colonie, soit avec la France, soit avec l'étranger et les autres colonies, depuis le dix-huitième siècle jusqu'à nos jours, est intéressant à observer.

Voici le relevé de ce mouvement depuis 1736 (avec la France, et depuis 1790 avec l'étranger). 
Commerce de la colonie avec la France.

\section{6}

Importations (marchandises françaises)...... n fr.

Exportations .................... 16,000,000

\section{5}

Importations ................... 14,707,035 fr.

Exportations................... 21,683,741

1880

Importations.................... 19,690,230 fr.

Exportations ................... 23,229,339

1290

Importations.................... 10,442,137 fr.

Exportations .................... 30,246,286

1818

Importations....................

Exportations.................... 15,412,567

\section{5}

Importations. .................... 19,573,626 fr.

Exportations................... 17,157,827

\section{0}

Importations $12,450,825 \mathrm{fr}$.

Exportations. $19,833,277$

\section{5}

Importations $16,658,898 \mathrm{fr}$.

Exportations

$16,244,450$

1840

Importations. $20,869,159 \mathrm{fr}$.

Exportations.

$15,390,374$

\section{5}

Importations. . . . . . . . . . . . . . . . . . .

Exportations $19,791,920 \mathrm{fr}$. $21,729,591$

1850

Importations. $18,644,189 \mathrm{fr}$. Exportations $10,018,952$

\section{5}

Importations $18,720,054 \mathrm{fr}$.

Exportations $14,262,768$

\section{0}

Importations 


\section{1}

Importations.................... 22,343,861 fr.

Exportations ..................... 19,460,937

\section{2}

Importations.................... 20,0 $4,822 \mathrm{fr}$.

Exportations ...................... 19,983,953

Commerce de la Martinique avec l'étranger et les autres colonies francaises.

\section{0}

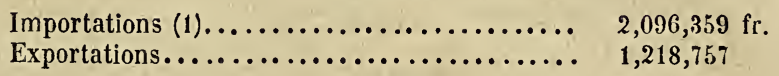

1835

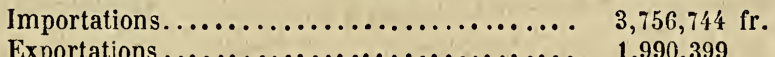

Exportations ..................... 1,990,399

\section{0}

Importations. $5,500,367$ fr. Exportations $3,462,214$

1845

Importations. $6,109,425 \mathrm{fr}$. Exportations. $2,711,974$

\section{0}

Importations $3,783,685$ fr. Exportations $1,742,652$

1855

Importations. $7,116,570$ fr. Exportations . $2,136,671$

\section{0}

Importations. $7,191,331 \mathrm{fr}$.

Exportations. $1,754,501$

\section{1}

Importations $8,632,639$ fr.

Exportations $2,411,628$

\section{2}

Importations. $9,685,447 \mathrm{fr}$. Exportations $2,458,906$

(1) Sous cette dénomination on comprend ici les marchandises venant directement de l'étranger ou des autres colonies, ainsi que les marchandises étrangères venant des entrepôts de France. 
La valeur des divers commerces a été en 1861 et 1862, ainsi qu'il suit :

\section{Importations.}

\section{1}

Marchandises françaises venant de France... 16,640,392 fr.

- des colonies françaises........ 1,560,216

- étrangères par navires français.. $2,304,347$

- $\quad$ - par navires étrangers. $\quad 4,768,076$

1862

$25,273,03 ! \mathrm{fr}$.

Marchandises françaises venant de France... 16,130,849 fr.

- des colonies françaises........ $2,371,490$

- $\quad$ étrangères par navires français.. $\quad 2,791,837$

- $\quad$ par navires étrangers. $\frac{4,521,120}{25,815,296 \mathrm{fr}}$

Exportations.

\section{1}

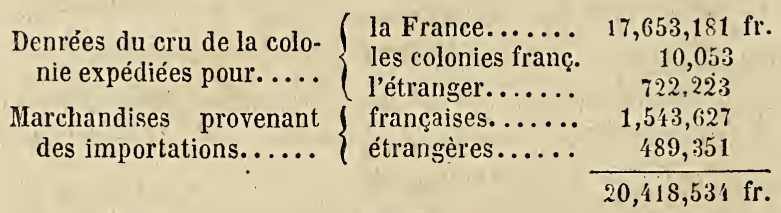

\section{2}

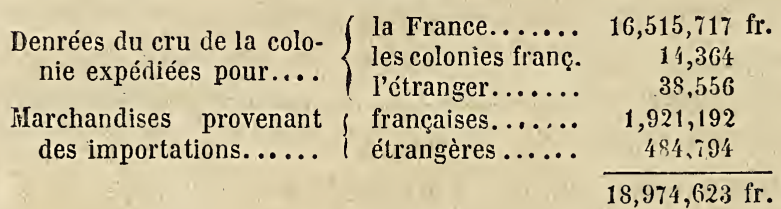

L'augmentation dans les importations de 1862 a été de 1, 43,911 fr.

La diminution dans les exportations de cette même année a été de 542,263 fr.

Et la diminution réelle dans le commerce général a été de $901,646 \mathrm{fr}$.

Les Notices du Ministère de la marine et des colonies fon $\mathbf{i}$ suivre ces chiffres de l'aperçu que nous résumons ci-après :

L'accroissement de 542,265 fr. dans les importations est attribuable au commerce français dans la proportion de 56 pour 100 , et dans celle de 44 pour 100 au commerce étranger.

L'importation des colonies françaises est la seule branche du commerce français qui ait progressé, car les tableaux qui précè- 
dent montrent que les expéditions des marchandises métropolitaines ont décru de 509,543 fr. C'est en partie le fait de la concurrence étrangère admise en 1861.

Les marchandises françaises qui ont lutté avec désavantage - contre les similaires étrangers, sont :

Les viandes salées, la graisse de porc, la farine de froment, les huiles d'éclairage, les chandelles et les bougies.

Autre cause de décroissance des produits français. Elle est dans la réserve que le commerce local a dû prendre pour règle de ses opérations, en présence de la baisse du prix des sucres et du resserrement que la diminution des ressources publiques a déterminé dans la consommation de la colonie. Ainsi se trouve expliquée la diminution dans l'importation des engrais, de l'huile d'olive, dessavons, des peaux, des mules et mulets. Toutefois, quelques articles ont tendu à faire contre-poids, houille, vins, tabacs.

Les importations des colonies, au contraire du commerce de la métropole, se sont accrues extraordinairement. Elles excèdent de $811,274 \mathrm{fr}$. les importations de 1861. Les principaux articles auxquels est due cette augmentation, sont: la morue de TerreNeuve, la farine de froment, le riz.

L'augmentation du commerce étranger a été de $240,534 \mathrm{fr}$. Elle a porté sur la houille, la farine, les chapeaux de Panama, les mouchcirs des Indes et le tabac en feuilles. - Cette augmentation eût été plus considérable encore sans la guerre d'Amérique. Elle a été restreinte, d'un autre côté, par les réductions sur les produits de la pêche que l'abondance de la morue française a écartée des marchés; sur les riz en grains, dont le déficit coïncide avec l'interruption momentanée de l'immigration indienne; sur les cacaos ou fèves de la Trinidad; enfin, sur les bois de construction que les Antilles tiraient autrefois d'Amérique.

Parmi les marchandises et denrées importées en 1862, on remarque :

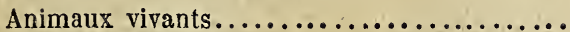

Viandes salées de bœuf et de porc $(608,930$ kil.).

Graisses $(89,636$ kil.)....................

Fromages $(83,030$ kil. $) . \ldots \ldots \ldots \ldots \ldots \ldots \ldots$.

Beurre salé $(399,155$ kil.).................

Engrais divers $(1,086,097 \mathrm{kil}.) \ldots \ldots \ldots \ldots \ldots$.

Poissons secs, salés ou fumés, morue; etc.

$(5,391,948$ kil. $) \ldots \ldots \ldots \ldots \ldots \ldots \ldots \ldots$

Farine de froment $(5,052,453$ kil. $) . \ldots \ldots \ldots \ldots$

Mais en grains $(12,851,300$ litres $)$.
Valeur.

832,488 fr.

581,381

145,813

123,171

918,352

212,048

$2,184,457$

$3,015,473$

195,452 
Riz en grains $(2,007,026$ kil.).............

Légumes secs $(820,193 \mathrm{kil}.) . \ldots \ldots \ldots \ldots \ldots \ldots$

Autres farineux......................

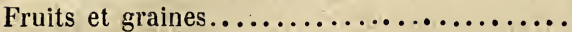

Café $(38,994$ kil. $) \ldots \ldots \ldots \ldots \ldots \ldots \ldots \ldots \ldots$

Tabac en feuilles $(283,616$ kil. $) .. \ldots \ldots \ldots \ldots$.

Autres denrées coloniales.................

Huiles diverses $(719,816$ kil.)..............

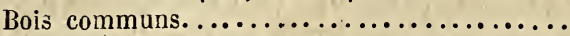

Tourteaux de graines oléagineuses $(2,054,205$ k.).

Houille crue et carbonisée $(34,896,513$ kil.)....

Matériaux de construction.................

Fonte, fer et acier $(646,539$ kil. $) \ldots \ldots \ldots \ldots \ldots$

Cuivre pur $(322,048$ kil. $) . \ldots \ldots \ldots \ldots \ldots \ldots$.

Autres métaux $(77,513$ kil.)..............

Produits chimiques $(691,898$ kil. $) .. \ldots \ldots \ldots \ldots$.

Parfumeries ........................

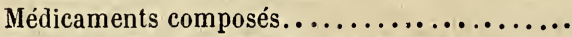

Savons ordinaires $(322,041$ kil. $) . \ldots \ldots \ldots \ldots \ldots$

Acide stéarique ouvré $(84,899$ kil. $)$..........

Chandelles (273,281 kil.)................

Cigares et autres tabacs fabriqués $(4,911,254 \mathrm{k}$.).

Sucre raffiné $(275,251$ kil.)...............

Conserves alimentaires $(45,859$ kil.).........

Vins ordinaires $(2,656,290$ hect. $) .. \ldots \ldots \ldots \ldots$

Vins de liqueur $(153,694$ hect. $) \ldots \ldots \ldots \ldots \ldots$

Bières $(118,310$ hect. $) . \ldots \ldots \ldots \ldots \ldots \ldots \ldots$.

Eaux-de-vie et liqueurs $(175,498$ hect. $) .. \ldots \ldots$.

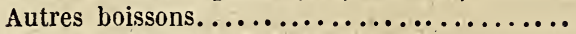

Eau congelée [glace] $(526,000$ kil. $) .. \ldots \ldots \ldots$.

Poteries $(559,940$ kil.)..................

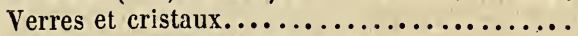

Fils de lin, de coton et de laine............

Mouchoirs des Indes.....................

Tissus de coton $(262,596$ kil. $) \ldots \ldots \ldots \ldots \ldots \ldots$

- de laine.........................

- de lin et de chanvre...............

- de soie...........................

Papier et ses applications................

Peaux préparées et ouvrages en peau $(114,488 \mathrm{k}$.

Chapeaux de paille....................

Cordages de chanvre $(96,98$ । kil. $) .. \ldots \ldots \ldots .$.

Orfévrerie et bijouterie...................

Machines et mécaniques.................

Instruments aratoires et outils.............

Armes de guerre et de commerce...........

Ouvrages en divers métaux $(836,076$ kil. $) .. .$. .

Merceries $(126,228$ kil. $) . \ldots \ldots \ldots \ldots \ldots \ldots \ldots$.

Modes et fleurs artificielles................

Parapluies de soie......................

Ouvrages en bois et meubless..............

Habillements neufs....................

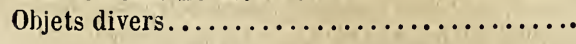

Valeur totale.

Valeur.

$641,013 \mathrm{fr}$.

334,104

297,651

105,437

111,385

549,540

124,001

885,548

601,806

309,803

$1,476,928$

88,421

248,474

92,466

59,467

93,322

61,293

157,944

313,612

246,813

380,441

42,082

336,296

119,799

$1,100,555$

225,661

77,635

229,228

31,569

101,000

219,824

69,407

51,901

370,082

$1,179,357$

202,827

883,818

277,147

156,670

608,895

229,011

118,314

175,042

591,523

84,761

141,402

600,491

362,221

138,472

83,795

651,823

420,398

717,224

$25,976,296 \mathrm{fr}$. 
En 1862, les exportations, on l'a vu, ont été inférieures à celles de 1861 . Il y a eu une différence de $1,443,911 \mathrm{fr}$.

Les Notices publiées par ordre du ministre de la marine nous en apprennent les motifs : c'est la baisse sur lezcours des denrées du cru.

La différence eût été plus considérable encore sans les réexportations qui ont augmenté de $373,000 \mathrm{fr}$., somme qui s'est ainsi répartie :

Réexportation pour la France............. pour les colonies françaises.... pour l'étranger..............
132,215 fr.

154,498

90,852

Les principales denrées et marchandises exportées, ont été, en 1862 :

Sucre brut $(32,101,447$ kil. $) \ldots \ldots \ldots \ldots \ldots \ldots$

Sirops $(348$ lit. $) . \ldots \ldots \ldots \ldots \ldots \ldots \ldots \ldots \ldots$

Mélasse $(62,065$ lit. $) . \ldots \ldots \ldots \ldots \ldots \ldots \ldots \ldots$

Confiture $(10,602$ kil. $) . \ldots \ldots \ldots \ldots \ldots \ldots \ldots$

Cacao et fèves $(284,345$ kil. $) \ldots \ldots \ldots \ldots \ldots \ldots$.

Café $(13,928$ kil. $) .. \ldots \ldots \ldots \ldots \ldots \ldots \ldots \ldots$

Casse $(161,617$ kil. $) . \ldots \ldots \ldots \ldots \ldots \ldots \ldots$.

Fruits et graines $(18,097$ kil.).............

Fruits médicinaux $(28,579$ kil. $) . \ldots \ldots \ldots \ldots \ldots$

Bois de campêche $(550,752$ kil. $) \ldots \ldots \ldots \ldots \ldots$

Eau-de-vie de mélasse $(5,864,635$ lit. $) .. . \ldots$.

Liqueurs $(1,480$ lit.)..................

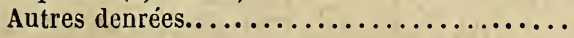

Total.

$14,312,052 \mathrm{fr}$.

1,254

10,805

25,548

271,937

37,321

30,320

9,823

11,159

49,399

$1,787,457$

4,379

17,183

Les denrées et marchandises réexportées en 1862, ont été :

Viandes salées de bœuf et de porc $(63,913 \mathrm{k}$.$) ...$

Peaux brutes $(12,206$ kil. $) . \ldots \ldots \ldots \ldots \ldots \ldots \ldots$.

Graisse de porc $(11,639$ kil. $) . \ldots \ldots \ldots \ldots \ldots \ldots$

Beurre salé $(121,742$ kil. $) \ldots \ldots \ldots \ldots \ldots \ldots \ldots$.

Engrais $(155,181$ kil. $) . \ldots \ldots \ldots \ldots \ldots \ldots \ldots \ldots$.

Poissons salés et autres $(670,561$ kil. $) .. . \ldots$.

Graines et farineux alimentaires $(817,417 \mathrm{kil}$.$) ..$

Sucre brut $(118,064$ kil. $) . \ldots \ldots \ldots \ldots \ldots \ldots \ldots$

Tabac en feuilles $(37,263$ kil. $) \ldots \ldots \ldots \ldots \ldots \ldots$.

Huile d'olives $(138,436$ kil.)...............

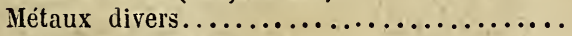

Chandelles $(28,639$ kil. $) \ldots \ldots \ldots \ldots \ldots \ldots \ldots$.

Vins ordinaires $(509,250$ lit. $) \ldots \ldots \ldots \ldots \ldots \ldots$.

Vins de liqueur.....................

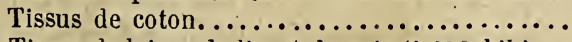

Tissus de laine, de lin et de soie $(8,879$ kil. $) ..$

Peaux préparées et ouvrages en peau........

enrées et marchandises diverses..........

62,334

103,658

16,379

279,807

30,833

293,606

342,481

51, 466

65,796

168,854

90,682

41,545

509,250

29,808

137,231

77,321

36,746

391,430

Total (exportation et réexportation)..

$18,974,623 \mathrm{fr}$. 
La Martinique possède deux entrepôts.

L'un est à Saint-Pierre, l'autre à Fort-de-France.

Les marchandises françaises et étrangères de toute nature, même celles prohibées en France, peuvent y être reçues.

Le droit de magasinage est de 1 pour 100 de la valeur, par an.

Le mouvement des entrepôts en 1861 et en 1862, a été comme il suit :

Entrées.

\section{1}

Marchandises françaises provenant..........

Marchandises étrangères provenant.

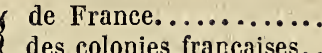

des entrepôts de France.

des entrepôts et des colo-

nies françaises.......

$781,323 \mathrm{fr}$.

15,222

214,927

(de l'étranger...........

13,558

613,031

Total............... $1,638,061 \mathrm{fr}$.

\section{2}

Marchandises françaises provenant .........

Marchandises étrangères provenant.......

de France.............

$644,452 \mathrm{fr}$.

17,569

des entrepôts de France. 182,756

des entrepôts et des colo-

\{

nies françaises....... 43,235

de l'étranger......... 776,061

Total................

\section{Sorties.}

\section{1}

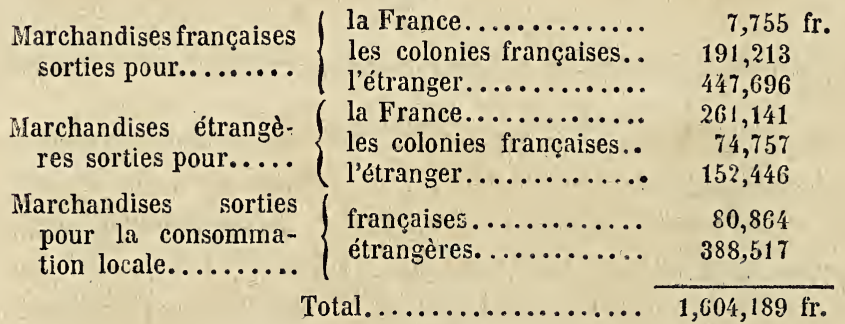

\section{2}

Marchandisesfrançaises sorties pour........

Marchandises étrangè-
res sorties pour.....
Marchandises sorties
pour la consommation
locale.............

$\left\{\begin{array}{l}\text { la } \\ \text { la }\end{array}\right.$

les colonies francaises.

$9,616 \mathrm{fr}$.

$\quad 105,170$

l'étranger .......... 514,199

la France ........... 106,181

Jes colonies françaises.. $\quad 234,676$

l'étranger .......... 133,247

françaises .......... 90,691

étrangères......... 404,236

Total

$1,598,016$ fr. 
Depuis la loi du 3 juillet 1861, l'emploi du pavillon étranger n'est plus interdit dans la colonie que pour la navigation au cabotage, de colonie française à colonie française, et dans la limite assignée à ce genre de navigation.

Les transports de la colonie en France, et de France dans la colonie, peuvent s'effectuer par pavillon étranger, en payant toutefois une surtaxe de 20 fr. par tonneau d'affrétement.

Les importations de marchandises étrangères, par navires étrangers, sont soumises à une surtaxe de pavillon de $20 \mathrm{fr}$. par tonneau d'affrétement, pour les provenances d'Europe, des pays non européens situés sur le littoral de la Méditerranée, et des pays situés sur le littoral du grand Océan, y compris le cap de Bonne-Espérance; cette surtaxe est de $10 \mathrm{fr}$. pour les provenances des pays situés sur le littoral de l'océan Atlantique.

Mouvement de la navigation en 1862.

Entrées.

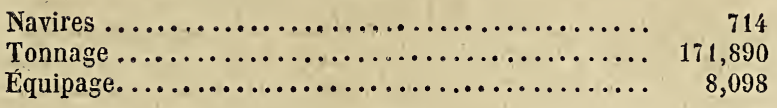

Sorties.

Navires $\ldots \ldots \ldots \ldots \ldots \ldots \ldots \ldots \ldots \ldots \ldots \ldots \ldots, \quad 731$

Tonnage $. \ldots \ldots \ldots \ldots \ldots \ldots \ldots \ldots \ldots \ldots \ldots \ldots \ldots, \quad 116,986$

Équipage.............................. 8,318

Soit : Navires : 1,445 ; - tonnage : 228,876 ; - équipage : 16,416 .

Les navires français venant de France, soit pour compte des transatlantiques, soit pour compte de l'Ėtat, ont été au nombre de 42, ayant un tonnage de 12,044. - Trois autres, venant de l'étranger, présentaient un tonnage de 701.

Les navires étrangers, venant de l'étranger, ont présenté le nombre de 24 et un tonnage de 7,045.

Voici un tableau qui résume la navigation de la colonie avec la France, les colonies et l'étranger en 1862:

Ports et lieux de provenance et de destination.

(Erance.)

Marseille...........

Cette................

Havre
BATIMENTS FBANÇAIS.

\begin{tabular}{|c|c|c|c|c|c|}
\hline \multicolumn{3}{|c|}{ Entrées. } & \multicolumn{3}{|c|}{ Sorties. } \\
\hline mbre. & Tonnage. & Épuipage. & Nombre. & Tonnage. & Épuipage. \\
\hline $\begin{array}{r}40 \\
5\end{array}$ & 11,251 & $\begin{array}{r}498 \\
56\end{array}$ & 65 & 18,148 & $\begin{array}{c}839 \\
\text { ” }\end{array}$ \\
\hline $\begin{array}{r}b \\
42\end{array}$ & $\begin{array}{r}1,155 \\
12,176\end{array}$ & $\begin{array}{r}56 \\
549\end{array}$ & 34 & 8,810 & 422 \\
\hline
\end{tabular}




\section{LES COLONIES FRANGAISES.}

(Erance.) Nombre. Tonnage. Équipage. Nombre. Tonnage. Équipage.

\begin{tabular}{|c|c|c|c|c|c|c|}
\hline Bordeaux........... & 41 & $9,3 \% 0$ & 477 & 35 & 8,037 & 396 \\
\hline Nantes............ & 15 & 4,138 & 19 ' & 17 & 4,581 & 215 \\
\hline Saint-Servan........ & 2 & 380 & 22 & » & ” & $"$ \\
\hline Dunkerque......... & 2 & 450 & 24 & 1 & 206 & 12 \\
\hline Saint-Malo......... & 1 & 189 & 10 & " & ” & 》 \\
\hline Rouen............. & 1 & 248 & 11 & " & ” & 》 \\
\hline Saint-Nazaire ....... & 12 & 9,076 & 869 & 9 & 7,888 & 745 \\
\hline Belle-Ile........... & $"$ & ” & ” & 2 & 641 & 27 \\
\hline Toulon ............ & 2 & 483 & 20 & 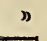 & $”$ & 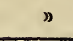 \\
\hline Totaux & 163 & 48,806 & 2,730 & 163 & 48,311 & 2,655 \\
\hline
\end{tabular}

(Colonies françaises.)

Pondichéry ..........

Cayenne............ 19

Terre-Neuve....... . 23

Guadeloupe........ 161

$\begin{array}{r}\text { Saint-Martin. ....... } \\ \text { Totaux........ }\end{array} \frac{1}{205} \frac{53}{16,863} \quad \frac{10}{1,949}-\frac{n}{182} \frac{n}{12,355} \quad \frac{n}{1,712}$

La navigation entre la colonie et l'étranger offre les résultats suivants :

ENTRÉEs.

LieUX DE Provenance. Batiments francais. Batiments étrangers.

Nombre. Tonnage. Équipage. Nombre. Tonnage. Équipage.

\begin{tabular}{|c|c|c|c|c|c|c|}
\hline Cuba.............. & 3 & 3,082 & 319 & $"$ & ” & ” \\
\hline Porto-Rico......... & 18 & 1,267 & 200 & D & $"$ & $n$ \\
\hline Ténériffe.......... & 2 & 635 & 25 & $n$ & $"$ & $n$ \\
\hline Grande-Bretagne... & 16 & 6,403 & 330 & 30 & 8,429 & 344 \\
\hline Nouvelle-Écosse ..... & " & " & " & 25 & 2,624 & 166 \\
\hline Nouveau-Brunswick. . & $"$ & $n$ & ") & 3 & 537 & 24 \\
\hline Guyane anglaise .... & $"$ & $n$ & ” & 5 & 380 & 45 \\
\hline Inde anglaise. & 2 & 691 & 25 & $n$ & $n$ & $"$ \\
\hline Antilles anglaises.... & 16 & 700 & 149 & 131 & 3,634 & 685 \\
\hline Montevideo......... & 1 & 216 & 11 & $"$ & $"$ & $n$ \\
\hline Vera-Cruz......... & 4 & 4,049 & 323 & $"$ & $n$ & 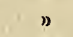 \\
\hline Venezuela......... & 4 & 211 & 52 & 3 & 379 & 29 \\
\hline Congo............. & 8 & 3,378 & 155 & $"$ & $n$ & ” \\
\hline Anvers........... & $"$ & " & $"$ & 2 & 403 & 22 \\
\hline Saint-Thomas....... & 1 & 41 & 10 & 6 & 232 & 39 \\
\hline États-Unis ......... & ” & $"$ & $"$ & 52 & 8,248 & 366 \\
\hline Saint-Barthélemy.... & $"$ & $"$ & ” & 7 & 145 & 36 \\
\hline Surinan........... & $"$ & ” & ” & 2 & 232 & 20 \\
\hline Antilles hollandaises.. & 1 & 46 & 11 & 4 & 195 & 33 \\
\hline Totaux...... & 76 & 20,719 & 1,610 & 270 & 25,443 & $1, \varepsilon 09$ \\
\hline
\end{tabular}

Sorties.

LieuX de PRovenance. Bâtiments français. Bâtiments étrangers.

Nombre. Tonnage. Équipage. Nombre. Tonnage. Équipage.

$\begin{array}{lllllll}\text { Antilles anglaises.... } 22 & 1,685 & 216 & 173 & 11,422 & 1,046\end{array}$

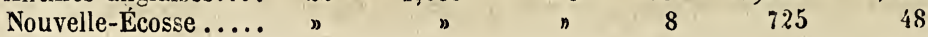




\begin{tabular}{|c|c|c|c|c|c|c|}
\hline Guyane anglaise. & 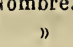 & ") & $"$ & 5 & 270 & $\begin{array}{l}\text { page. } \\
39\end{array}$ \\
\hline Nouveau-Brunswick. . & ” & 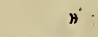 & ” & 1 & 212 & 10 \\
\hline Mexique............ & 10 & 8,578 & 847 & 2 & 1,278 & 43 \\
\hline Saint-Barthélemy.... & $n$ & " & $n$ & 8 & 361 & 43 \\
\hline Porto-Rico .......... & 13 & 1,204 & 144 & 4 & 849 & 35 \\
\hline Santiago............ & 1 & 290 & 11 & ” & " & » \\
\hline 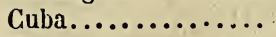 & ” & $n$ & " & 8 & 1,269 & \\
\hline Havane............ & 2 & 629 & 26 & p & ø & $n$ \\
\hline Venezuela........... & 6 & 333 & 56 & 2 & 281 & 21 \\
\hline Surinam........... & $"$ & $"$ & • & 2 & 232 & 20 \\
\hline Antilles hollandaises. & $n$ & $"$ & 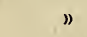 & 6 & 543 & 39 \\
\hline Nouvelle-Grenade.... & 1 & 216 & 11 & " & $n$ & 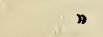 \\
\hline Saint-Thomas....... & 38 & 9,344 & 457 & 41 & 6,705 & 322 \\
\hline Saint-Domingue... & 13 & 3,920 & 167 & 1 & 200 & 10 \\
\hline Congo............. & 3 & 1,364 & 53 & $"$ & " & $"$ \\
\hline États-Unis....... & 6 & 1,914 & 128 & 10 & 2,496 & 90 \\
\hline Totaux..... & $\overline{115}$ & 29,477 & 2,116 & 271 & 26,843 & 1,835 \\
\hline
\end{tabular}

En 1862, les recettes de la douane ont été de 1,100,873 fr. ainsi réparlis :

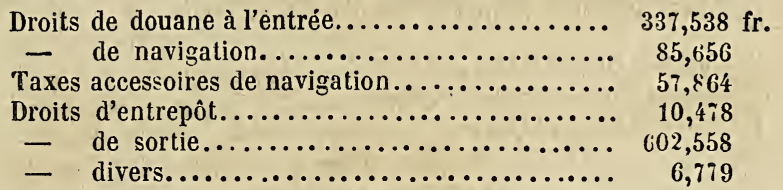

Cette somme de 1,100,873 fr. s'est ainsi répartie entre les ports de la colonie :

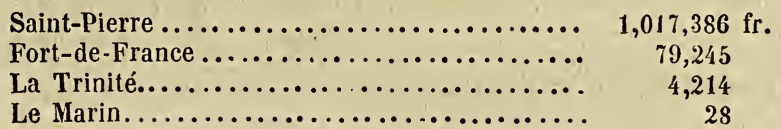

La Martinique a deux chambres de commerce : l'une à SaintPierre, l'autre à Fort-de-France. - Cette institution créée par l'ordonnance du 17 juillet 1820 a été réglementée de nouveau par les arrêtés des 5̆ avril 1848 et 17 mars $185 ั 5$.

Des communications fréquentes sont établies entre la colonie et la métropole, soit par la voie anglaise, soit par la voie française.

Service anglais.

Départ de Southampton les 2 et 17 de chaque mois.

Arrivée à Saint-Pierre les 19 et 4 de chaque mois.

Départ de Saint-Pierre les 27 et 12.

Arrivée à Southampton les 14 et 29.

Prix du passage :

Cabine à l'arrière............... 38 liv. 10 sh. (965 fr.)

- à l'avant............. 33 liv. (825 fr.) 
Service français (compagnie transatlantique).

Départ de Saint-Nazaire le 16 de chaque mois. Arrivée à Fort-de-France le 2 du mois suivant. Départ de Furt-de-France le 27 de chaque mois. Arrivée à Saint-Nazaire le $\mathbf{1 5}$ du mois suivant. Prix du passage :

Cabine de $1^{\text {re }}$ classe (une place)............... 925 fr.

- de $2^{\mathrm{e}}-\quad-\quad \ldots \ldots \ldots \ldots \ldots \ldots \ldots .6 \%$

Place dans l'entre -pont.................... 450

Prix du passage pour les passagers civils et militaires voyageant sur réquisition du gouvernement :

Cabine de $1^{\text {re }}$ classe (une place).............. 465 fr.

- de $2^{\mathrm{e}} \quad-\quad-\quad \ldots \ldots \ldots \ldots \ldots \ldots .420$

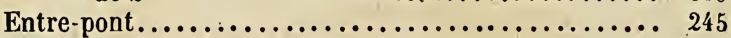

Sur le pont......................... 210

Frais de nourriture à payer en outre :

Passagers (1re et $2^{\mathrm{e}}$ classe)............ $8 \mathrm{fr}$. par jour.

Passagers (entre-pont).................

Pour les autres passagers............. 2 -

TAXE DES LETTRES.

$1^{\circ}$ Voie anglaise.

Lettre affranchie, par 10 grammes.......... »fr. $70 \mathrm{c}$.

- non affranchie, - $\quad \ldots \ldots \ldots \ldots$..... 80

- chargée, $\quad$ - $\ldots \ldots \ldots \ldots$...... 40

Imprimés, par 40 grammes.............. " 12

20 Voic francaise.

Lettre affranchie, par 10 grammes.......... n fr. $50 \mathrm{c}$.

- non affranchie, - $\quad \ldots \ldots \ldots \ldots . . .6$ n 60

- chargée, - $\ldots \ldots \ldots \ldots .1$.

Imprimés, par 40 grammes............... » 12

Il ne peut être envoyé des mandats sur la poste qu'aux militaires et marins.

\section{Navires de commerce.}

Le prix du passage par ces navires est généralement de $500 \mathrm{fr}$. (aller), et $600 \mathrm{fr}$. (retour).

Traversée moyenne : 40 jours (aller), 45 jours (retour).

Taxe des lettres:

Affranchies, par 10 grammes............. " fr. $30 \mathrm{c.}$

Non affranchies, $\quad-\quad \ldots \ldots \ldots \ldots \ldots \ldots ., 40$ 


\section{TROISIÈME PARTIE}

\section{GUADELOUPE - MARIE-GALANTE - LES SAINTES - LA DÉSIRADE SAINT-MARTIN}

\section{GHAPITRE PREMIER}

\section{Historique.}

La Guadeloupe et dépendances appartiennent au groupe des Petites-Antilles ou Iles du Vent.

Leur situation géographique est entre $15^{\circ} 57^{\prime}$ et $16^{\circ} 31^{\prime}$ latit. $\mathrm{N}$.; entre $63^{\circ} 32^{\prime}$ et $64^{\circ} 9^{\prime}$ long. 0 .

La distance qui sépare la Guadeloupe du port de Brest est évaluée à 1,250 lieues marines.

En novembre 1593, lors de son second voyage en Amérique, Christophe Colomb découvrit le groupe d'îles qui se compose de la Guadeloupe, de Marie-Galante, des Saintes et de la Désirade.

Plus d'un siècle s'écoula avant qu'on songeât à tirer parti de ces îles. On les abandonnait aux Carä̈bes. Enfin, en 1635, Charles Lyénard, sieur de l'Olive, lieutenant du gouverneur de Saint-Christophe, et Jean Duplessis, sieur d'Ossonville, représentant la Compagnie des îles d'Amérique, se rendirent à la Guadeloupe et en prirent possession.

Duplessis avait su se concilier les Caraïbes par son esprit de modération; mais il vint à mourir, et l'Olive, moins prudent, déclara la guerre aux indigènes. Elle dura jusqu'en 1660. A cette date, un traité de paix fut conclu entre les belligérants, et les Caraïbes se retirèrent, les uns à la Dominique, les autres à SaintVincent.

En 1649, la Compagnie fut obligée de vendre ses possessions d'Amérique. Le marquis de Boisseret et le gouverneur Houel, son beau-frère, achetèrent la Guadeloupe et dépendances pour 60,000 livres tournois, plus une redevance de 600 livres pesant 
de sucre par an. Les acquéreurs devinrent donc à la fois propriétaires et seigneurs de ces îles qui, toutefois, ne cessèrent pas de faire partie de la Lieutenance générale des îles de l'Amérique.

Cet état de choses dura quinze ans, après quoi Louis XIV, fatigué des plaintes et des désordres auxquels donnaient lieu les exactions des seigneurs propriétaires, racheta les iles, moyennant 125,000 livres tournois.

La Compagnie des Indes occidentales fut alors créée par Colbert; mais cette compagnie n'ayant pas mieux réussi que sa devancière, le roi prononça, en 1674, sa dissolution et réunit les îles au domaine de l'État.

Les progrès furent lents à la Guadeloupe. En 1669, elle avait été mise sous la dépendance de la Martinique, siége du gouvernement général des Antilles. Les bras, de préférence, se portèrent vers la Martinique.

Quoique les Anglais eussent échoué, en 1691, dans leur tentative contre la colonie, ils avaient causé des désastres dont on eut quelque peine à se remettre. Leur seconde tentative contre la Guadeloupe, inutile comme la première, eut aussi des résultats fâcheux.

Ce ne fut donc guère qu'à partir de la paix d'Utrecht (1713), que la colonie put prendre son essor.

La prospérité laissait peu à désirer quand, en 1744, la guerre entre l'Angleterre et la France vint de nouveau mettre en question l'existence de la colonie. Après une résistance héroïque, après un siége de quatre mois, la garnison française, trop inférieure aux assiégeants, dut se rendre, et la domination anglaise commença.

Elle dura un peu plus de quatre années.

Le traité du 3 novembre 1762 rendit à la France ses possessions auxquelles, dès lors, on donna une administration indépendante de celle de la Martinique. Quelques années après, en 1769, sous le gouvernement du général comte de Malartic, on réunit de nouveau l'administration des deux îles, mais on les sépara, en 1775, époque à laquelle $M$. de Malartic quitta ce gouvernement pour celui des établissements français à l'est du cap de Bonne-Espérance. Il choisit, en 1792, l'île de France, pour chef-lieu de son gouvernement, et rendit de si grands services à cette île et à Bourbon, qu'après sa mort les habitants lui élevèrent 
GUADELOUPE. - MARIE-GALANTE. - LES SAINTES, ETC. 405

un monument où on remarque cette inscription : Au sauveur de la Colonie.

En 1789, la Guadeloupe avait atteinl un très-haut degré de prospérité. La révolution lui fut fatale. Aux désordres intérieurs vinrent s'ajouter les calamités de la guerre étrangère. Les Anglais se rendaient maîtres de l'île le 21 avril 1794.

Obligés de la rendre, après sept mois d'une lutte acharnée, au commissaire de la Convention, Victor Hugues, qui déploya dans ces circonstances une indomptable énergie, les Anglais devaient y revenir, deux fois encore, et la reprendre en 1810 et en 1815 .

En 1801, la guerre civile éclata. Le capitaine général Lacrosse dut se retirer. Le général Richepance, envoyé de France avec 3,500 hommes, cut en un mois rétabli l'ordre, réintégréle contreamiral Lacrosse dans ses fonctions, et la loi du 30 floréal an $\mathrm{X}$ (20 mars 1802), qui maintenait l'esclavage dans les colonics, acheva la pacification.

Pendant la guerre qui suivit la rupture de la paix d'Amiens, la Guadeloupe arma des corsaires qui firent subir à l'Angleterre des pertes énormes et lui procurèrent des ressources inespérées en esclaves, en denrées et en argent. Malheureusement, en 1810 , le vice-amiral Cochrane et le lieutenant général Beckwith, à la tête de 5,000 hommes, purent s'emparer de la Guadeloupe, qui ne fut rendue à la France que quatre ans après, lors du traité de Paris (30 mai 1814).

Pendant les Cent-jours, l'émotion fut grande dans la colonie. Dans la crainte de retomber sous la domination anglaise, elle se rallia au régime impérial. C'était courir au-devant de la catastrophe que l'on voulait éviter. Les Anglais, en effet, se rappelant tous les désastres que la colonie leur arait fait subir autrefois, profitèrent de ce que la garnison ne se composait que de 470 hommes et débarquèrent au nombre de 700. Il fallut se rendre.

La chute définitive de Napoléon amena la remise de la colonie au nouveau gouvernement français (24 juillet 1816).

\section{Gouverneurs.}

163ð. De l'Olive et Duplessis, gouverneurs, au nom des seigneurs de la Compagnie des iles de l'Amérique.

1635. De l'Olive, seul, après la mort de Duplessis.

1637. De l'Olive, capitaine général.

1640. Aubert, gouverneur pour la Compagnie. 
1643. Houel, gouverneur et sénéchal.

1644. Marivet, gouverneur intérimaire.

1645. Houel, gouverneur, devenu, par acquisition de la colonie avec le marquis de Boisseret, seigneur de la Guadeloupe, de la Désirade, de Marie-Galante, des Saintes.

1664. Ducoudray, gouverneur intérimaire pour la nouvelle compagnie, la Compagnie des Indes occidentales.

166\%. Dulion, gouverneur.

1669. Réunion du gouvernement de la Guadeloupe à celui de la Martinique.

1674. Réunion des îles au domaine de l’État.

1677. Hincelin, gouverneur, sous l'autorité du gouverneur général des îles et terre-ferme de l'Amérique.

169ð. Auger .

1703. De Boisfermé, gouverneur intérimaire.

1704. De la Malmaison, gouverneur.

1717. Lagarrigue de Savigny, gouverneur intérimaire.

1719. De Moyencourt, gouv.

1728. Giraut du Poyet, gouv.

1734. De Larnage, gouv.

1737. De Clieu, gouv.

1749. De Lafond, gouv. intér.

1750. De Clieu, gouv.

1752. De Lafond, gouv. intér.

1753. Mirabeau (le chevalier de), gouv.

1757. Nadau du Treil, gouv.

1759. Prise de la colonie par les Anglais.

1759. Krumpt (le colonel), gouv. anglais.

1761. Campbell Dalrymple, gouv. anglais.

1763. De Bourlamarque, gouverneur général.

1764. Copley (le baron), gouv. intér.

1765. De Nolivas (le comte), gouv. génér.

1768. De Malartic, gouv. génér.

1769. De Bouillé, gouv. de la Guadeloupe.

1771. Dion (le chevalier).

1773. Tilly (le comte de), gouv. intér.

1775. D’Arbaud (le comte), lieutenant général, gouverneur.

1782. De Damas (le vicomte), $i d$.

1784. Beaumé de Saulais, gouv. intér.

1786. Micoud (le comte de), id. 
1792. D'Arrot (le vicomte), $i d$.

1793. Lacrosse, gouverneur.

1793. Collot.

1794. Hugues (Victor), commissaire délégué par la Convention nationale.

1795. Hugues, Coyrand et Lebas, id.

1796. Hugues et Lebas, $i d$.

1797. Hugues, seul, $i d$.

1798. Desfourneaux (le général), agent particulier du Directoire.

1799. Pâris (le général), Danan et Roche-Rupez, membres du gouvernement provisoire.

1800. Jeannet, Baco et Lavaux, agents particuliers.

1800. Bresseau, Jeannet, Baco, id.

1800. Jeannet et Bresseau, etc.

1801. Lacrosse, capitaine général.

1801. Pélage, Prasans, Danois et Corneille, membres du gouvernement provisoire.

1802. Richepance, général en chef de l'expédition destinée à réintégrer le général Lacrosse.

180\%. Lacrosse, capitaine général.

1803. Ernouf, id.

1810. Sir Georges Beckwith, gouv. anglais.

1810. Sir Hugh Lyle Garmichael, $i d$.

1810. Sir Cochrane, $i d$.

1813. Sir John Shinner, $i d$.

1816. De Lardenoy (comte), gouverneur général.

1823. Jacob (le contre-amiral), $i d$.

1826. Vatable (baron), gouv. intér.

1826. Angot des Rotours (baron), gouverneur.

1830. Vatable (baron), $i d$.

1831. Arnous-Dessaulsay, $i d$.

1837. Jubelin, id.

1841. Goubeyre, $i d$.

1845. Varlet, $i d$. intérim.

1845. Layrle, $i d$.

1848. Gatine, commissaire général de la République.

1848. Fiéron (le colonel), gouverneur.

1849. Fabvire, capitaine de vaisseau, gouverneur, sous l'autorité du gouv. général des Antilles. 
1849. Fiéron, (colonel), gouverneur.

1851. Ghaumont (le colonel), id.

18วั1. Aubry-Bailleul, capitaine de vaisseau, gouverneur.

18วั3. Aubry-Bailleul, $i d$.

1853. Guillet, commissaire général, gouverneur intérim.

1854. Bonfils, capitaine de vaisseau, gouverneur.

1856. Guillet, comm. général, gouv. intér.

1857. Touchard, capitaine de vaisseau, gouverneur.

1859. Bontemps, gouv. intérim.

1860. Frébault, gouverneur.

1862. De Lormel, gouv. intér.

1862. Frébault, gouv.

1864. Desmazes, ordomnateur, gouv. intér.

1864. De Lormel, gouverneur.

\section{CHAPITRE II}

Etendue. - Configuration. - Cours d'eau. - Montagnes. - Eaux thermales. Sol. - Forêts. - Ports, etc. - Caps. - Phares, feux. - Villes. - Division territoriale. - Dépendances : Marie-Galante; les Saintes; la Désirade; île Saint-Martin.

La Guadeloupe est divisée en deux parties par un petit détroit, auquel on donne le nom de Rivière-Salée. L'une de ces parties constitue la Guadeloupe proprement dite; sa superficie est de $\mathbf{9 4 , 6 3 1}$ hectares.

L'autre partie de l'île, à l'est de la Rivière-Salée, a une superficie de 65,631 hectares. On l'appelle la Grande-Terre.

La Grande-Terre n'a pas de montagnes; il n'y a que des collines dont la plus élevée n'excède pas 35 mètres. La Guadeloupe, au contraire, est sillonnée par une chaîne de montagnes volcaniques couvertes de bois, et dont la hauteur moyenne est de 1,000 mètres; la Soufrière a 1,484 mètres au-dessus du niveau de la mer.

La Guadeloupe compte une cinquantaine de ruisseaux et dixsept rivières. Deux sont navigables, la Goyave et la Lézarde. La Rivière-Salée ne l'est pas pour des bâtiments d'un fort tonnage. - La Grande-Terre n'a que des ruisseaux.

Les eaux thermales sont nombreuses. Les unes sont sulfu- 
GUADELOUPE. - MARIE-GALANTE. - LES SAINTES, ETG. 409

reuses, les autres ferrugineuses; toutes se trouvent à la Guadeloupe, la plupart dans les montagnes.

Le sol de la Guadeloupe et celui de la Grande-Terre sont bons. Celui de la première a un fond d'argile, celui de la seconde un fond calcaire.

On n'utilise que le littoral et les pentes des premiers mornes.

On ne cultive plus la canne à sucre au-dessus de 400 mètres ; au-dessus, jusqu'à 800 mètres, on cultive les caféiers ; puis viennent les forêts.

Quelques plaines, à Sainte-Rose, au Lamentin, à la Capesterre, formées d'alluvions, sont très-fertiles.

L'étendue des forêts est de 35 kilomètres ; c'est environ le cinquième de la superficie de la Guadeloupe. La Grande-Terre n'a pas de forêts.

Principaux mouillages : celui de la Basse-Terre, qui offre un bon ancrage, celui de l'Anse-à-la-Barque et de la baie Deshayes, qui peuvent abriter de grands bâtiments, même des navires de guerre, celui de la baie Mahault, d'un accès difficile et environné d'écueils, - à la Guadeloupe, à la Grande-Terre, celui de la Pointe-à-Pître, sont des plus beaux, des plus commodes et des plus sûrs des Antilles, pouvant contenir des vaisseaux de tout ordre ; celui du Moule, port excellent, mais dont l'entrée est difficile.

Notons, parmi les caps, ceux de la Pointe-des-Châteaux, de la Pointe de la Grande-Vigie (Grande-Terre), et de la Pointe-àLaunay (Guadeloupe).

Un phare est établi à l'extrémité E. de la Terre-de-Bas, ilot de la Petite-Terre; il a une portée de 15 milles. Cinq feux, en outre, éclairent les côtes, savoir : un, à l'entrée du port de la Basse-Terre, un sur l'îlot Mouroux, à l'entrée de la rade de la Pointe-à-Pìtre, un à l'entrée du Moule, un sur l'îlot à Gosier, enfin un autre à l'entrée du port du Grand-Bourg (île MarieGalante).

La Basse-Terre (Guadeloupe) est le chef-lieu de la colonie et a une population de 9,480 âmes, garnison non comprise. Elle est le siége du gouvernement et d'un évêché.

La Pointe-à-Pître (Grande-Terre), détruite le 8 février 1843 par un tremblement de terre, a aujourd'hui 150,172 àmes. C'est le chef-lieu commercial de la colonie. 
Le Moule (Grande-Terre), a 8,047 habitants. C'est une petite ville fort agréablement située.

La colonie forme :

3 arrondissements;

10 cantons ;

32 communes.

I. ARRONDISSEMENT DE LA BASSE-TERRE.

$1^{\circ}$ Canton de la Basse-Terre.

Communes : Basse-Terre ;

Sainte-Claude ;

Goubeyre ;

Vieux-Port ;

Baillif ;

Vieux-Habitants.

$2^{\circ}$ Canton de Capesterre.

Communes : Capesterre ;

Trois-Rivières ;

Goyave ;

Ile des Saintes.

$3^{\circ}$ Canton de la Pointe-Noire.

Communes: Pointe-Noire ;

Deshaies ;

Bouillante.

$4^{\circ}$ Canton de lîle Saint-1Vartin.

Communes : Marigot.

II. ARRONDISSEMENT DE LA POINTE-A-PITRE.

$1^{\circ}$ Canton de la Pointe-à-Pîtré.

Communes : Pointe-à-Pître ;

Abymes ;

Gosier ;

Morne à l'eau.

$2^{\circ}$ Canton de Lamentin.

Communes : Larnentin ; 
GUadeloupe. - Marie-Galante. - Les SaIntes, ETG. 411

Baie-Mahault ;

Petit-Bourg ;

Sainte-Rose.

$3^{\circ}$ Canton du Port-Louis.

Communes : Port-Louis ;

Canal ;

Anse-Bertrand.

$4^{\circ}$ Canton du Moule.

Communes : Moule ;

Sainte-Anne.

$\check{5}^{\circ}$ Canton de Saint-François.

Communes : Saint-François ;

Ile de la Désirade.

III. ARRONDISSEMENT DE MARIE-GALANTE.

Canton du Grand-Bourg.

Communes : Grand-Bourg ;

Capesterre ;

Saint-Louis.

Les dépendances de la Guadeloupe sont :

Marie-Galante, île située par $15^{\circ} 53^{\prime}$ et $16^{\circ} 01^{\prime}$ latit. N., et $63^{\circ}$ $31^{\prime}, 63^{\circ} 39^{\prime}$ long. 0 . Sa superficie est de 14,927 hectares. - Le Grand-Bourg, son chef-lieu, a 6,992 habitants. - . Une petite chaîne de montagnes traverse l'île ; elles sont couvertes de bois.

- Sol fertile.

Les Saintes, composées de cinq îlots (Terre-de-Haut, Terrede-Bas, Grand-Ilet, la Loche et Ilet à Cabrit), ont une superficie de 1,422 hectares. - Ge sont des rochers ; on y a établi des fortifications qui ont fait surnommer les Saintes le Gibraltar des Antilles.

La Désirade est traversée par une chaîne de montagnes taillées à pic. Sa superficie est de 2,720 hectares. Sol peu productif.

Saint-Martin n'appartient qu'en partie à la France. La portion S. est à la Hollande. La superficie du territoire appartenant à la France est de 5,177 hectares, les deux tiers de l'île. Sol léger et pierreux. 


\section{CHAPITRE III}

Température. - Climat. - Hygrométrie. - Pluies. - Saisons. - Vents. Marées. - Tremblements de terre. - Population. - Statistique. - Population maritime. - Immigrants.

De juin à septembre, la chaleur est grande à la Guadeloupe. Le thermomètre, à l'ombre, marque souvent 30 et $32^{\circ}$. La température moyenne n'est que de $26^{\circ}$ cent. - De décembre à mars, on tombe à 20 et $22^{\circ}$. Deux brises soufflant régulièrement, l'une le jour, l'autre la nuit, modèrent la chaleur.

L'humidité est consi dérable. L'hygromètre ne descend pas audessous de $61^{\circ}$, et ne marque pas au delà de $97^{\circ}$.

La moyenne annuelle de la quantité de pluie est de 2 mètres 19 sur le bord de la mer, mais elle est plus considérable dans les montagnes. Ce sont les mois les plus chauds qui donnent la plus grande quantité de pluie.

Deux saisons seulement : de décembre à mai, et de juin à novembre. L'hivernage commence à la mi-juillet et finit à la mi-octobre.

Les jours les plus courts durent 11 heures 14 minutes; les plus longs durent 12 heures 56 minutes.

Les vents dominants sont ceux de l'E., du N. et du S. Les vents d'Est, ou vents alizés, ont donné lieu aux expressions au vent et sous le vent, désignant, aux Antilles et ailleurs, l'orient et l'occident.

La plus haute marée n'est guère que de 80 centimètres, aux équinoxes. Aux solstices, elle est inférieure à 40 çentimètres. Pendant l'hivernage, les ras de marée sont fréquents.

Il en est de même des tremblements de terre; chacun se rappelle en frémissant celui de 1843 qui détruisit en grande partie la Pointe-à-Pître.

En 1863, la population de la Guadeloupe el dépendances, s'élevait à 138, כ001 âmes, ainsi répartis :

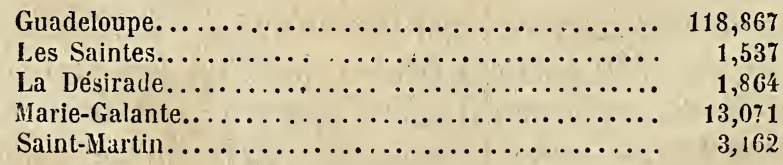

En 1862, on a constaté les mouvements suivants dans la population : 
GUADELOUPE. - MARIE-GALANTE. - LES SAINTES, ETG. 413

Naissances......................... 4,093

Décès.......................... 3,902

Mariages......................... 505

Ainsi : 1 décès sur 3 in individus, 1 mariage sur 274, 1 naissance sur 33.

On comptait, à la fin de $1863,4,084$ individus faisant partie de l'inscription maritime, savoir :

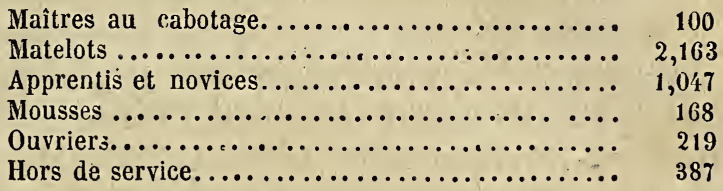

Après l'affranchissement des esclaves, en 1848, la situation de la Guadeloupe fut étrangement compromise. Des 78,000 esclaves occupés sur les habitations rurales, un petit nombre resta au travail. La production sucrière tomba brusquement de 38 millions de kilog. (1847), à 20 millions (1848), puis à 17 millions (1849). Nécessité fut de recourir à l'immigration étrangère. Une caisse d'immigration fut constituée et l'on introduisit successivement à la Guadeloupe, comme à la Martinique, des Chinois, des Indiens, des Africains.

En 1864, on comptait à la Guad eloupe :

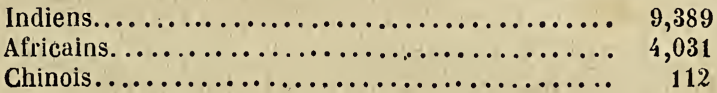

Des personnes très-compétentes ont résumé ainsi le mérite de ces diverses races de travailleurs :

Indiens.

Leur travail est bon, mais coûteux.

Africains.

Bon travail, et le plus économique de tous.

Chinois.

Bons travailleurs à l'état d'isolement; bons domestiques, gabariers, gardiens. 


\section{CHAPITRE IV}

Gouvernement. - Services divers. - Contrôle colonial. - Effectif militaire. Station locale. - Justice. - Culte. - Assistance publique. - Instruction publique.

Le gouvernement local est composé d'un gouverneur, d'un conseil privé, d'un conseil général, de trois chefs d'administration et d'un contrôle colonial.

Un délégué, élu pour trois ans par le conseil général, représente la colonie près du comité consultatif à Paris.

Nous avons vu précédemment, en parlant de la Martinique, quelles sont les attributions du gouvernement de cette colonie; le gouvernement de la Guadeloupe a des attributions identiques.

Au commencement de 1864, le personnel de l'administration de la marine était ainsi composé :

1 commissaire de la marine, ordonnateur;

3 commissaires adjoints ; 10 sous-commissaires ; 9 aides commissaires et 10 commis de marine.

Ces 33 fonctionnaires et employés formaient le secrétariat de l'ordonnateur et cinq bureaux, siégeant à la Basse-Terre.

A la Pointe-à-Pître, à Marie-Galante, aux Saintes et à SaintMartin, il y avait, en outre, quatre chefs de service de la marine.

Le service des ports comprend :

1 capitaine et 1 maître de port à la Pointe-à-Pître;

1 lieutenant de port au Moule;

1 lieutenant de port à Marie-Galante;

1 maître de port à Saint-Martin ;

8 pilotes, 24 canotiers, 1 gardien, 10 gardiens-allumeurs des phares et fanaux.

Le service du Trésor public comprend :

1 trésorier payeur; 1 chef de comptabilité ; 1 caissier (à la Basse-Terre); 1 trésorier particulier et 1 caissier (à la Pointe-àPitre).

Le service de santé, cutre les sœurs hospitalières, comprend :

1 premier médecin en chef, 1 second médecin en chef, 3 chirurgiens de $1^{\text {re }}$ classe, 4 de $2^{\mathrm{e}}$ classe, 6 de $3^{\mathrm{e}}$ classe; un pharmacien de $1^{\text {re }}$ classe, 1 de $2^{\mathrm{e}}$ et 1 de $3^{\mathrm{e}}$.

La direction de l'intérieur a son personnel ainsi composé : 
GUADELOUPE. - MARIE-GALANTE. - LES SAINTES, ETG. 415

1 directeur, 1 secrétaire général, 4 chefs de bureau, 5 souschefs, 10 commis ; un certain nombre d'écrivains.

Ce personnel forme un secrétariat et quatre bureaux.

Le service de l'enregistrement, des domaines, du timbre et de la curatelle aux successions vacantes est dévolu à :

1 inspecteur, chef du service; 2 vérificateurs; 11 receveursconservateurs; 5 commis-receveurs; 7 agents divers.

Chacun des trois arrondissements de la colonie a un conseil de curatelle.

Le service des douanes emploie :

1 inspecteur de $3^{\text {e }}$ classe, directeur provisoire; 2 sous-inspecteurs, 1 contrôleur; 2 commis de direction, 10 vérificateurs, 1 commis général, 6 commis. - Dans le service actif, on compte : 1 lieutenant, 6 brigadiers, 5 sous-brigadiers, 40 préposés à terre, 1 patron de canot, 1 sous-patron, 24 canotiers et 10 préposés matelots.

Le service des contributions comprend, outre le trésorier payeur et le trésorier particulier :

1 inspecteur de $2^{\mathrm{e}}$ classe, chef du service ; 2 sous-inspecteurs; 1 contrôleur principal, 8 contrôleurs, 7 commis principaux, 28 commis, 19 surnuméraires, 2 vérificateurs des poids et mesures.

Le personnel de la poste comprend :

1 receveur comptable du bureau central (Basse-Terre);

1 receveur particulier (Pointe-à-Pitre);

1 receveur (au Moule);

1 id. (Marie-Galante);

Plus, 2 commis, 28 buralistes, 7 facteurs.

Le personnel des ponts et chaussées comprend :

1 ingénieur colonial, chef du service;

1 ingénieur colonial, 1 sous-ingénieur colonial ;

1 conducteur principal; 11 conducteurs ;

1 chef de comptabilité; 1 dessinateur, 2 commis.

Le personnel de la police comprend :

2 commissaires de police de $1^{\text {re }}$ classe;

2 id. de $2^{\mathrm{e}}$ classe;

6 id. de 3 e classe;

2 commissaires de police adjoints et 3 commissaires de police provisoires.

Les prisons, maisons de correction, etc., sont au nombre de treize, savoir : 
A la Pointe-à-Pître : 1 pénitencier flottant.

A la Pointe-à-Pître et au Grand-Bourg (Marie-Galante) : une maison de correction et de discipline pour les individus condamnés a moins d'un an de prison et les disciplinaires ;

A la Basse-Terre : 1 maison de correction et de discipline pour les femmes condamnées à moins d'un an d'emprisonnement et pour les disciplinaires;

A l'Ilet-à-Cabrit (Saintes): 1 maison centrale de force et de correction pour les hommes et les femmes condamnés à plus d'un an d'emprisonnement;

A l'île Saint-Martin : dans la maison de police municipale, un quartier de correction et de discipline;

Aux Abymes : 1 maison d'éducation correctionnelle;

A la Capesterre, au Port-Louis, au Moule, à la Pointe-Noire, à Saint-François, au Lamentin, six prisons cantonales.

Le personnel de ces divers établissements comprend :

3 régisseurs, 3 gardiens-chefs, 10 surveillants et guichetiers, 1 écrivain, 3 aumôniers, 5 chirurgiens, 4 infirmiers.

L'imprimerie du gouvernement comprend :

1 chef, 1 sous-chef, 1 chef ouvrier, 8 compositeurs, $\check{5}$ imprimeurs, 4 relieurs, 1 lithographe, 8 apprentis.

Le personnel du contrôle colonial comprend :

1 commissaire de la marine, contrôleur colonial;

1 sous-commissaire, chef du bureau central ;

2 aides sous-commissaires, 1 commis, 2 écrivains de marine.

Le décret colonial du 20 sept. 1837, modifié par le sénatusconsulte du 5 mai 180 , règle l'organisation municipale à la Guadeloupe.

L'administration de chacune des 32 communes de la colonie se compose d'un maire, d'un ou de deux adjoints, et de huit à vingt conseillers municipaux.

L'effectif militaire comprend 1849 hommes, non compris les milices, dont le maximum est' de 5,700 hommes ( 4,500 à pied et 1,200 à cheval).

La station locale comprend un aviso à vapeur et une goëlette à voiles. L'effectif de ces deux bâtiments est de 130 hommes (étatmajor et équipage).

La Guadeloupe est sous l'empire des codes métropolitains.

La justice est rendue par dix tribunaux de paix, deux tribu- 
GUADELOUPE. - MARIE-GALANTE. - LES SAINTES, ETC. 417

naux de première instance, une Cour impériale, deux Cours d'assises.

Tribunaux de paix : Basse-Terre, la Capesterre, la Pointe-Noire, le Marigot, dans l'arrondissement de la Basse-Terre;

- La Pointe-à-Pître, le Lamentin, le Port-Louis, le Moule et Saint-François (arrondissement de la Pointe-à-Pître).

- Le Grand-Bourg (arrondissement de Marie-Galante).

Tribunaux de première instance : Pointe-à-Pître et Marie-Galante.

Cour impériale : Basse-Terre.

Cour d'assises : Basse-Terre et Pointe-à-Pître.

Le nombre des officiers ministériels est de : 30 avocats et avoués, 21 huissiers, 19 notaires.

La statistique judiciaire pour la période triennale 1859-1861, offrait les résultats suivants, en moyenne et par an :

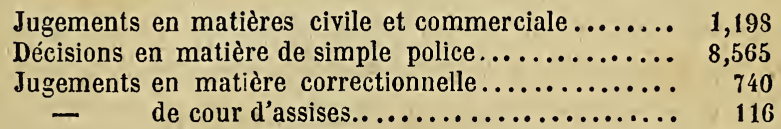

Le personnel du clergé catholique comprend :

1 évêque (Basse-Terre);

61 prêtres (Guadeloupe);

7 id. (Marie-Galante);

2 id. (La Désirade);

3 id. (aux Saintes);

2 id. (A Saint-Barthélemy, île en dehors de la colonie, mais dépendant de l'évêché);

2 id. (île Saint-Martin).

La Basse-Terre, la Pointe-à-Pître et Marie-Galante ont le rang d'archiprêtrés.

La Guadeloupe comprend 29 paroisses; Marie-Galante, 3; la Désirade ; 1 ; les Saintes, 2; l'île Saint-Barthélemy, 2; l'île SaintMartin, 2.

Un pasteur méthodiste est établi à Saint-Martin ; la population de l'île appartient en partie à ce culte.

Un consistoire israélite a été aussi autorisé par décision du 11 mars 1852.

On compte quatre congrégations religieuses :

Les Pères du Saint-Esprit, au nombre de 47; ils dirigent le petit séminaire; 
Les Frères de l'instruction chrétienne ou de Ploërmel, au nombre de 58 ;

Les sœurs hospitalières de Saint-Paul de Chartres, au nombre de 42 ;

Les Sœurs institutrices de Saint-Joseph de Cluny, au nombre de 86.

Les Dominicains, les Capucins, les Jésuites et les Carmes ont tour à tour ou simultanément, autrefois, administré les secours de la religion catholique, à la Guadeloupe. Aujourd'hui, le clergé est presque complétement séculier.

Chacune des 32 communes possède un bureau de bienfaisance. Les bureaux ont reçu, en 1863, une somme de 174,470 francs en ont distribué une de 171,333 francs.

Un ouvroir, dirigé par les sœurs de Saint-Joseph de Gluny, reçoit les petites filles pauvres et orphelines. En 1860, une crèche a été créée.

Un jury médical, trois conseils d'hygiène publique, etc., sont établis.

La Guadeloupe a 6 hôpitaux militaires, Marie-Galante un, SaintMartin un. - On compte, en outre, un hospice de lépreux, à la Désirade, et un hospice d'aliénés, à Sainte-Claude, cinq hospices civils, etc.

L'instruction publique est donnée dans 75 établissements.

Trente-sept de ces établissements sont consacrés aux garçons; trente-quatre aux filles, et quatre aux enfants des deux sexes.

On compte 30 écoles libres.

Écoles secondaires libres (garçons) : le petit séminaire, collége de la Basse-Terre, créé en 18522 par Mgr. Lacarrière; deux autres institutions libres à la Pointe-à-Pître.

Écoles primaires libres (garçons) : 1 externatà la Pointe-à-Pìtre, dirigé par les Frères; 1 externat au Moule, dirigé par les mêmes; 9 écoles primaires dirigées par des laïques.

Écoles primaires communales (garçons) : il y en a 23 .

École secondaire libre (filles): le pensionnat de Versailles, à la Basse-Terre; école gratuite annexée au pensionnat.

Écoles primaires libres (filles) : il y en a 11 .

Ecoles primaires communales (filles): on en compte 22.

Ecoles primaires mixtes : 4 .

Comme à la Martinique, une commission est chargée d'examiner les candidats aux brevets de capacité ès lettres et ès sciences. 
GUADELOUPE. - MARIE-GALANTE. - LES SAINTES, ETC. 419

Un cours de mathématiques usuelles est fait publiquement au Moule. La commune l'entretient à ses frais .

La presse périodique a trois organes : la Gazette officielle de la Guadeloupe, l'Avenir, le Commercial; ceux-ci paraissent à la BasseTerre, celui-là paraît à la Pointe-à-Pître.

Un Annuaire et un Bulletin officiel des actes du gouvernement sont publiés par l'administration.

\section{CHAPITRE V}

Finances. - Budget de l'Etat. - Budget local. - Banque de la Guadeloupe. - Crédit foncier colonial.

En 1864, le budget de l'État et le budget local ont présenté les résultats suivants :

$$
\text { BUDGET DE L’ÉTAT (1864). }
$$

\section{Gépenses.}

Chafitre 1er. - Personnel civil et militaire.

Gouvernement colonial..............

Administration générale.............

Justice......................

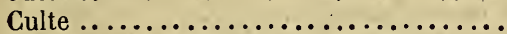

Subvention à l'instruction publique.....

États-majors ....................

Inscription maritime...............

Gendarmerie coloniale..............

Compagnie disciplinaire..............

Troupes indigènes..................

Accessoires de la solde..............

Traitement dans les hôpitaux.........

Vivres ........................

Dépenses accessoires et diverses........

Total, déduction faite du $30^{\mathrm{e}}$ pour incomplets

$\begin{array}{rl}60,000 & \text { fr. "c. } \\ 245,830 & " \\ 373,600 & " \\ 243,700 & "- \\ 100,000 & " \\ 112,632 & " \\ 20,400 & " \\ 481,533 & " \\ 114,786 & 87 \\ 67,116 & 78 \\ 34,800 & " \\ 489,731 & " \\ 587,395 & 50 \\ 41,520 & \text { " }\end{array}$

$2,873,944$ fr. $03 \mathrm{c}$.

Chapitre 2. - Matériel civil et militaire.

Ports et rades (travaux d'entretien)......... 25,000 fr.

Édifices publics..................... 7,000

Casernement et campement............. 4,500

Artillerie et transport................. $\quad 63,000$

Génie.......................... $\quad 313,900$

Loyers et ameublements.............. 75,000

Impressions et souscriptions............ 17,000

Frais de justice et de procédure.......... $\quad 45,000$

Introduction de travailleurs............. 150,000

Total général............. 
Les dépenses effectuées au compte du service marine ne sont pas comprises dans ce chiffre. En 1862, elles se sont élevées à 511,276 fr. 97 c.

BUDGET LOGAL (1864).

\section{Recettes.}

Droits sur les terres cultivées en vivres et fourrages ............................

Droits sur les loyers des maisons............

Contribution personnelle..................

Contribution des patentes.................

Autres contributions sur rôles..............

Droits de sortie sur les denrées coloniales......

Droits d'entrée sur les marchandises étrangères.

Autres droits de douane, de navigation, d'entrepôt et d'octroi.......................

Produit de l'impôt sur les spiritueux..........

Droits d'enregistrement, de timbre, d'hypothèque, de greffe, etc....................

Droit sur la délivrance des passe-ports.........

Domaine .............................

Produit de l'imprimerie...................

Subvention de l'État pour l'instruction publique.

Taxe des lettres.......................

Produit du travail des détenus..............

Recettes diverses......................

Recouvrement des frais de poursuites.........

Prélèvement provisoire sur la caisse de réserve.

Produits des exercices clos..................

Contingent des communes pour les chemins de grande communication................

Total................ $\overline{3,544,601 \mathrm{fr} .}$

$37,000 \mathrm{fr}$.
182,000
ordre.
165,000
20,950
635,271
307,130

204,970
926,600

400,000
2,500
61,880
40,000
100,000
55,000
40,000
64,000
28,000
70,000
74,300

130,000

\section{Dépenses.}

1re section. - Dépenses obligatoires.

Personnel.

Délégué au comité des colonies..............

Direction de l'intérieur..................

Enregistrement, hypothèques, timbre.........

Contributions diverses..................

Poste aux lettres.....................

Vérification des poids et mesures...........

Douane ..........................

Instruction publique .................

Ponts et chaussées...................

Police générale....................

Prisons...........................

Service des ports. ...................

Divers agents.

$12,900 \mathrm{fr}$.

97,800

100,000

252,400

35,220

7,600

217,335

190,950

1,525

40,000

43,500

46,780

49,540 
Pensions ............................

$1,164,550 \mathrm{fr}$. 14,055

Frais de perception de l'impôt. 129,488

A déduire pour retenues. $1,318,093 \mathrm{fr}$.

Accessoires de la solde.

$\begin{array}{r}6,600 \\ \hline 1,312,093 \\ 27,500 \\ 46,380 \\ \hline\end{array}$

Total du personnel.

$1,385,974 \mathrm{fr}$.

Matériel.

Entretien des édifices coloniaux.............

- des routes et cours d'eau...........

- des ports et des feux..............

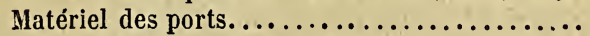

- des services financiers...............

Loyers et mobiliers divers.................

Casernement de la gendarmerie.............

Atelier de discipline et prisons..............

Hospice des aliénés et des lépreux...........

Dépenses diverses, arrérages, etc............

Total du matériel.......... $8 \div 0,015 \mathrm{fr}$.

$60,450 \mathrm{fr}$. 294,160

24,000

6,050

96,105

24,902

65,500

160,705

52,743

75,400

Le total des dépenses obligatoires atteint le chiffre de $2,350,989$ francs.

$2^{\text {e }}$ SEctron. - Dépenses facultatives.

Service de l'immigration..................

Imprimerie du gouvernement..............

Travaux neufs des édifices coloniaux.........

- des routes et ouvrages d'art..........

Curage du port de la Pointe-à-Pitre...........

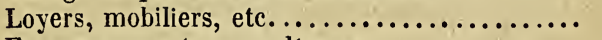

Encouragement aux cultures................

Subvention à l'immigration................

- aux hospices...................

- à l'enseignement scolaire et profes-

sionnel...........................

Autres subventions.....................

Secours et indemnités à divers..............

$47,080 \mathrm{fr}$.

47,200

24,000

125,818

65,000

28,300

85,500

257,732

41,000

31,794

56,700

20,930

29,692

Total des dépenses facultatives... $\overline{860,746 \mathrm{fr}}$.

$3^{\text {e }}$ SECTron. - Dépenses d'ordre et dépenses spéciales.

Restitutions aux communes.................

- à la caisse de réserve...............

Emploi du contingent fourni par les communes pour les chemins de grande communication..

Total.

$132,865 \mathrm{fr}$.

70,000

$\frac{130,000}{332,865 \cdot \mathrm{fr}}$ 
Le total général des dépenses (3 sections) s'est donc élevé, en 1864, à 3,544,601 francs.

La Guadeloupe possède deux établissements financiers dont il convient de dire quelques mots : la Banque (Pointe-à-Pitre) et le Grédit foncier colonial (celui-ci substitué à la Société anonyme du Crédit colonial), dont le siége est à Paris.

Les opérations de la Banque, pendant l'exercice 1863-1864, se décomposent ainsi :

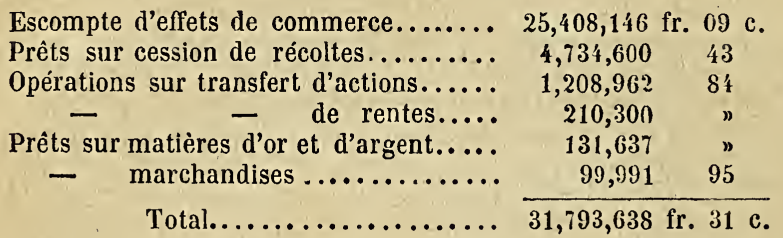

Le montant des mandats émis par la Banque sur le Comptoir d'escompte de Paris a été, en 1863-64, de 8,795,7509 francs.

Le mouvement général des caisses de la Banque (1863-64), a présenté, dans son ensemble, un chiffre de 43,643,942 francs se décomposant ainsi :

A l'entrée...................... 23,414,942 fr.

A la sortie...................... 20,229,000

Les billets figurent, dans ce mouvement, de fonds, pour $39,6309,87$ francs; le numéraire pour 3,984,067 francs.

La moyenne des billets en circulation (1863-64) a été de 3,449, כొ5ั0 francs.

Masse générale des comptes courants : 104,692,920 francs, dont :

A l'entrée....................... 52,795,497 fr.

A la sortie..................... $51,397,423$

Dépenses d'administration : 76,848 francs.

Bénéfices nets : 510,000 francs.

Dividendes : 10 fr. 50 p. 100 , ou 52 fr. 50 c. par action.

Le fonds de réserve, après clôture de l'exercice 1863-64, atteignait 1,122,524 francs.

Le Crédit foncier colonial, autorisé par décret du 31 août 1863 , a un fonds social de 12 millions, divisés en 24,000 actions de 500 francs chacune.

Son objet cansiste : 
GUADELOUPE. - MARIE-GALANTE. - LES SAINTES, ETG. 423

10 A prêter, à des conditions déterminées, soit à des propriétaires isolément, soit à des réunions de propriétaires, les sommes nécessaires à la construction des sucreries dans les colonies françaises ou au renouvellement et à l'amélioration de l'outillage des sucreries actuellement existantes;

$2^{\circ} \mathrm{A}$ prêter sur hypothèques, aux propriétaires d’immeubles situés dans les mêmes colonies, des sommes remboursables par les emprunteurs, soit à longs termes, au moyen d'annuités comprenant l'amortissement et les frais d'administration, soit à courts termes avec ou sans amortissement;

$3^{\circ} \mathrm{A}$ acquérir, par voie de cession ou autrement, et à rembourser, avec ou sans subrogation, des créances privilégiées ou hypothécaires;

$4^{\circ}$ A prêter aux colonies et aux communes dans les colonies, aux mêmes conditions qu'aux particuliers, les sommes qu'elles auraient obtenu l'autorisation d'emprunter, avec ou sans hypothèque ;

$5^{\circ} \mathrm{A}$ créer et négocier des obligations pour une valeur égale au montant des prêts.

A la fin d'avril 1864, il avait été formé 603 demandes de prêts (industriels ou fonciers). Sur ce nombre, 27 araient été admises ; 38 n'avaient pas encore été examinées.

Les demandes admises représentaient une somme de 2,295, 000 francs. - Celles à examiner une somme de 1,929,000 francs.

\section{GHAPITRE VI}

Agriculture. - Nombre d'hectares affectés à chaque culture. - Sucre, café, cacao, etc. - Animaux de trait. - Bétail. - Statistique de la canne à sucre.

- Caféier. - Coton. - Vivres. - Chambres d'agriculture. - Comices.

L'agriculture, à la Guadeloupe, embrasse à peu près les mêmes objets qu'à la Martinique : canne à sucre, café, coton, cacao, manioc, vivres (bananes, patates, ignames, mualangas, madères, pois, couscous, maïs, etc.).

En 1863, la quantité d'hectares affectés à chaque culture, la quantité des produits, etc., ont présenté les chiffres suivants :

Sucre (sirops, mélasse, tafia).

Hectares cultivés. ..................

18,333 hect. 
Quantités exportées :

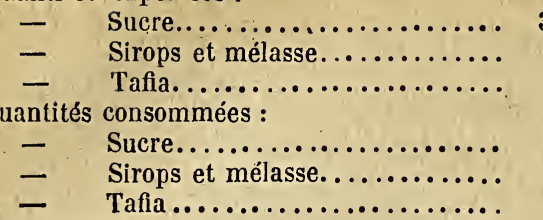

Café.

Hectares cultivés...................

Quantités exportées....................

- consommées.

Coton.

Hectares cultivés.................... Quantités

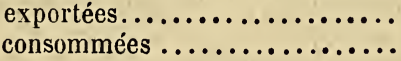

Cacao.

Hectares cultivés.................... Quantités exportées.................... - consommées.

Girofle et poivre, vanille.

Hectares cultivés.

Vanille exportée....................

Girofle et poivre consommés............

Vanille consommée.................

Tabac.

$30,265,936$ kil. 257,696 lit. $1,423,237$ $4,323,705 \mathrm{kil}$. $1,587,024$ lit. $1,343,843$ -

$$
\begin{gathered}
1,962 \\
409,059 \text { kil. } \\
818,118-
\end{gathered}
$$

$$
\begin{gathered}
678 \\
32,502 \text { kil. } \\
10,834-
\end{gathered}
$$

67,925 kil. 33,962 -
Hectares cultivés................... Quantité consommée................

Rocou.

Hectares cultivés................... Quantités exportées.

\section{Casse.}

Quantités exportées

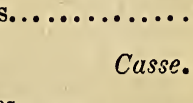

Vivres.

Hectares cultivés.

$$
\text { Vivres. }
$$

\section{1}

5,745 kil.

161

$124,400 \mathrm{kil}$.

$129 \mathrm{kil}$.

$$
4,343
$$

Marioc.

Hectares cultivés

Quantités consommées.................

\section{Campéche.}

Quantités exportées.

Fécule de dictane. 
GuAdeloupe. - MARIE-Galante. - LES SAINTES, ETG. 425

Sel.

Quantités exportées................ 3,600,000 kil.

Valeur brute des produits ci-dessus : 23,126,195 francs.

Le chiffre des principales habitations rurales à la fin de 1863 était comme il suit :

10 Sucreries.

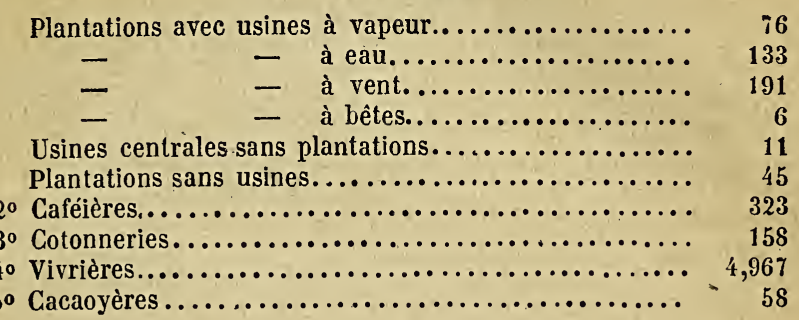

65̃,036 travailleurs étaient employés, à la fin de 1863, à ces diverses cultures.

Le nombre et la valeur des animaux de trait et de bétail existant à la Guadeloupe à la fin de 1863, étaient ainsi estimés :

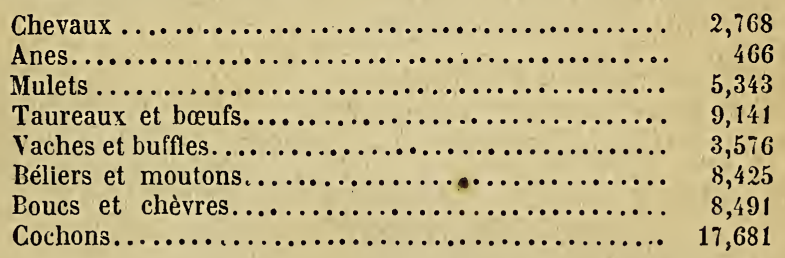

On estimait approximativement à $8,074,870$ francs les animaux de trait et de bétail ci-dessus.

Valeur des terres employées aux cultures.... 44,595,600 fr.

- des bâtiments et du matériel d'exploita-

tion....................... $36,344,725$

- des animaux de trait et du bétail..... $8,074,8 ; 0$

Total................... $\frac{89,015,195 \mathrm{fr}}{89 .}$

Tel était, en 1863, le montant des capitaux engagés dans la culture. On ne l'évaluait, en 1862, qu'à 81,790,927 francs. Cette différence tient à ce que la valeur des terres a été augmentée par le développement des cultures, l'introduction des machines perfectionnées, etc.

G'est en 1644 que la canne fut mise en plantation réglée à la Guadeloupe. La canne de Taïti, supérieure aux cannes créole et 
de Batavia, fut introduite en 1790 et supplanta ses devancières.

Depuis 1835, la canne à sucre a subi des maxima et des minima de production.

En 185\%5, par exemple, 14,491 hectares seulement ont été cultivés; mais, en 1862, il y en a eu 18,6כ6, et en 1863, 18,333.

Voici, au reste, de 1835 à 1863 , quel a été l'état des choses :

1835

Nombre d'hectares cultivés.............

Sucre.............................

Sirops et mélasses.

Tafia..

1840

Hectares cultivés.

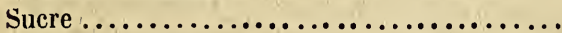

Sirops et mélasses. ..................

Tafia.

1845

Hectares cultivés.....................

Sucre..............................

Sirops et mélasses.....................

Tafia.............................

1850

Hectares cultivés...................

Sucre ............................

Sirops et mélasses...................

Tafia............................

1855

Hectares cultivés......................

Sucre .............................

Sirops et mélasses...................

Tafia...

1860

Hectares cultivés....................

Sucre...............................

Sirops et mélasses....................

Tafia...

1861

Hectares cultivés....................

Sucre..............................

Sirops et mélasses...................

Tafia.

\section{2}

Hectares cultivés.

Sucre
24,809

$36,335,241$ kil.

$6,506,129$ lit.

$2,158,015$ -

23,502

$30,722,041$ kil.

$5,338,08$ s lit.

$2,857,056$ -

22,998

$33,788,485$ kil. $4,802,036$ lit. $2,013,889$ -

15,335

$13,719,918$ kil. $2,526,224$ lit.

630,783 -

14,491

$27,772,239$ kil. $3,584,224$ lit. $2,766,786$ -

17,892 $32,903,019$ kil. $1,086,258$ lit. $3,877,930$ -

17,968

$31,219,226$ kil. $1,724,717$ lit. $3,661,809$ -

18,656 $35,643,069$ kil. 


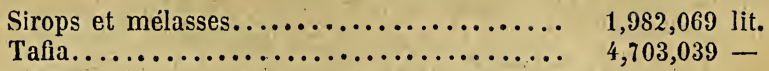

\section{3}

Hectares cultivés ................. 18,333

Sucre ...................... $34,588,641$ kil.

Sirops et mélasses................ 1, 444,720 lit.

Tafia......................... 2,767,080 -

Le produit des terres cultivées en cannes varie considérablement, disent les Notices de la marine, selon le plus ou moins de fertilité du sol, et surtout selon les conditions atmosphériques.

Les années pluvieuses sont toujours les plus abondantes.

Le rapport annuel d'un hectare est, en moyenne, de 1,800 à 2,000 kilogrammes.

La récolte de la canne a lieu du mois de février au mois de juin; une faible partie de la récolte se fait aussi à l'arrière-saison, en octobre et en novembre.

Depuis 1730, date de son introduction à la Guadeloupe, la culture du café a, tour à tour, été en progrès et en décadence. En 1860, il n'y avait plus que 1,591 hectares cultivés, au lieu de 8,174, comme en 1790. En 1863, la culture a atteint le chiffre de 1,950 hectares.

Le caféier est un arbuste délicat, qui croît dans les mornes et dans les terrains à pente rapide. Il ne donne son fruit qu'au bout de trois ans, et n'est en plein rapport qu'à la cinquième ou à la sixième année. La récolte commence en août et finit ordinairement à la fin de décembre. Dans les terrains qui sont à une élévation de 500 et 600 mètres au-dessus du niveau de la mer, la récolte commence un mois plus tard et se prolonge quelquefois jusqu'en mars.

Le produit annuel d'un hectare de terre planté en caféiers est, en moyenne, de 600 kilogrammes de café nettoyé et bon à livrer à la vente.

Le coton longue-soie est indigène aux Antilles. En 1789, on cultivait 8,878 hectares; en 1860, 316 hectares seulement. En 1863, on est remonté au chiffre de 678.

Le produit annuel d'un hectare de terre ensemencé en coton (avec 2 mètres entre deux pieds) est évalué à 200 kilogrammes.

On récolte de mars à juin.

Le prix du kilogramme de coton, récolté à la Guadeloupe, varie entre 3 et 10 francs. 
On sait l'origine du coton longue-soie, dit Sea-Island, de la $\mathrm{Ca}$. roline du Sud (États-Unis); il a été importé par quelques émigrants de Bahama qui avaient, en passant, pris des semences à la Guadeloupe.

Le cacaoyer est rare et peu cultivé. Il commence à produire à six ans, et n'est en plein rapport qu'à huit ans.

Deux récoltes par an : en avril et mai, en octobre et novembre.

On peut planter 950 cacaoyers par hectare. Produit : 500 à 570 kilogrammes.

La Guadeloupe n'a plus aujourd'hui que fort peu de plantes à épices. On cultive pourtant encore un peu le giroflier et le vanillon (sorte de vanille inférieure).

Le cassier ou canéficier, qui produit la casse officinale, est très-commun.

Le tabac, cornme le coton, est une culture fort déchue. Toutefois, les.encouragements de l'administration tendent à lui rendre quelque vigueur.

Le rocouyer, arbrisseau de l'Amérique du Sud, après avoir été très-cultivé, est à peu près abandonné.

A la Guadeloupe et dépendances, on cultive, sous le nom de vivres du pays, un certain nombre de plantes telles que le manioc, la patate, l'igname, la banane, le couscous, le malanga, le toloman, le madère, le maïs, les pois.

La racine du manioc fournit une farine substantielle et rafraîchissante. G'est le principal aliment des noirs.

Un hectare de manioc donne 3,120 litres de farine et 120 litres de moussache, sorte de fécule très-belle qu'on emploie pour amidonner.

L'igname, la patate, le couscous, le malanga, sont des racines. On les mange bouillies, rôties, cuites au four.

Le madère et le toloman sont des plantes à tubercules. On en fait une fécule.

La banane, fruit du bananier, se mange crue ou cuite.

L'arbre à pain, très-commun, offre, deux fois par an, des fruits comestibles, ressource précieuse pour le pauvre.

On cultive deux espèces de céréales : le riz de Malanga et le maïs; quelques légumes : haricots rouges et blancs, plusieurs espèces de pois. 
GUADELOUPE. - MARIE-GALANTE. - LES SAINTES, ETC. 429

On ne cultive, dans toute la colonie, qu'un seul fourrage, l'herbe de Guinée.

Par un arrêté local en date du 3 novembre 18כ2, il a été établi trois chambres d'agriculture et des arts et manufactures agricoles.

Le siége de ces chambres est à la Capesterre (pour la Guadeloupe), au Moule (pour la Grande-Terre), au Grand-Bourg (pour Marie-Galante et autres dépendances). - Ghaque chambre se compose de six membres, présidés ou par le directeur de l'intérieur ou par le maire de la commune où siége la chambre.

Un arrêté du gouverneur en date du 16 janvier 1852 a autorisé une société, dite Société d'agriculture de la Pointe-à-Pitre. Elle se compose de 100 membres titulaires. - La présidence d'honneur appartient au gouverneur.

Dans les communes du district sous le vent, du canton de la Basse-Terre, etc., on compte plusieurs comices agricoles, dépendant de la Société d'agriculture.

\section{GHAPITRE VII}

Industrie. - Sucre. - Guildiveries (distilleries). - Liqueurs. - Alcools. - Confiseries. - Vins d'ananas, d'oranges. - Conserves d'ananas. - Tanneries. Chaufourneries. - Poteries. - Salines. - Pêche. - Marine locale. - ComMERGE. - Régime commercial. - Importations. - Exportations. - Objets importés. - Objets exportés. - Entrepôts. - Mouvement de la navigation. Douanes. - Service postal.

L'industrie de la Guadeloupe est, comme celle de la Martinique, principalement sucrière. En 1864, le nombre des grandes usines centrales était monté à 20 ; quelques-unes, pourvues des appareils les plus perfectionnés, pouvaient produire 2 et même 3,000 barriques (de $500 \mathrm{k}$.) de sucre par an.

Le rendement, grâce aux perfectionnements introduits, atteint aujourd'hui 8, 9 et même 10 pour 100. C'est la moitié de ce que contient en principes saccharins, d'après les chimistes, la canne à sucre.

Chaque sucrerie possède une guildiverie (distillerie). On y convertit les vesous et les mélasses en rhums et en tafias.

On applle rhum, le produit de la distillation du vesou (suc liquide extrait de la canne), et tafia, le produit de la distillation 
des mélasses écoulées du sucre. - Le tafia coloré et de qualité supérieure prend également le nom de rhum.

On emploie une faible partie de ces alcools à confectionner des liqueurs, entre autres des crèmes de sapotes et de magnolia.

Aux fabriques de liqueurs on joint en général une fabrication de confiseries, de vins d'ananas, d'oranges, de conserves d'ananas.

On remarque ensuite dans la colonie des tanneries, des chaufourneries, des poteries. Mais leur importance est très-secondaire.

Les salines établies récemment dans la dépendance de SaintMartin ont, en 1863, produit 3,600,000 kil. de sel.

La pêche à laquelle on se livre sur les côtes de l'île a tous ses produits absorbés par la consommation locale.

En 1864, la marine de l'île se composait ainsi :

28 goëlettes employées au cabotage ;

27 bateaux;

2,013 embarcations diverses; sur ce nombre, la pêche en occupait 1,128.

Le régime commercial de la Martinique est aussi celui de la Guadeloupe. Les dispositions de la loi du 3 juillet 1861 lui sont également applicables. La Guadeloupe est libre d'exporter ses produits à l'étranger et de recevoir les marchandises étrangères sous tout pavillon. D'après le décret du 6 octobre 1862, la franchise douanière est accordée aux produits exportés de France aux colonies, fabriqués avec les marchandises étrangères admises temporairement en France.

La partie française de l'île Saint-Martin, dépendance, a son régime commercial plus libéral encore. Liberté absolue, sauf pour l'entrée des armes et munitions de guerre, qui est interdite. Droits de sortie seulement sur les sucres, la mélasse et l'eau-de-vie de mélasse.

Les ports ouverts au commerce français et étranger, sont ceux de la Pointe-à-Pitre, de la Basse-Terre, du Moule et du Port-Louis (Guadeloupe); du Grand-Bourg (Marie-Galante); du Marigot (île Saint-Martin).

Les Tableaux du commerce général de la France présentent le tableau suivant du commerce de la colonie avec la métropole de 1818 à 1862 . 


\section{8}

Importations de marchandises françaises..... $8,036,664 \mathrm{fr}$.

Exportations en France.............. 18,214,283

Total.................

\section{1}

Importations................... 11,241,450 fr.

Exportations..................... 16,092,385

Total.................. $\overline{27,333,835 \mathrm{fr} .}$

1825

Importations.................... 14,881,180 fr.

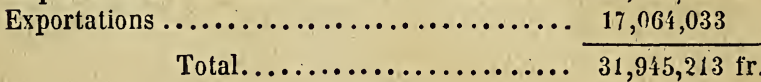

1830

Importations.................... 11,285,909 fr.

Exportations.................... 20,823,871

Total................. $\frac{20,109,780 \mathrm{fr}}{32,}$

1835

Importations. .................. 16,362,029 fr.

Exportations ..................... 23,738,175

Total................... $\frac{23,738,175}{40,100,204 \mathrm{fr} .}$

1840

Importations.................. 16,431,082 fr.

Exportations................... 20,332,506

Total..................

1845

Importations................... 20,758,139 fr.

Exportations...................... 23,806,460

Total.................

1850

Importations................... 14,395, 985 fr.

Exportations ................... 8,528,637

Total................. $\frac{8,22,924,622 \mathrm{fr} .}{28 .}$

1855

Importations................... 16,761,438 fr.

Exportations .................... 14,451,428

Total..................

1860

Importations................... 19,648, $060 \mathrm{fr}$.

Exportations ..................... 19,019,670

Total................ 
1861

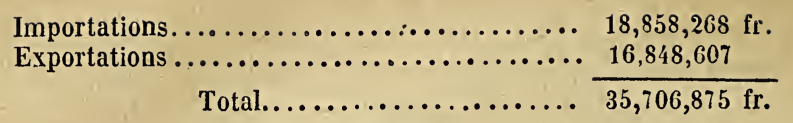

1862

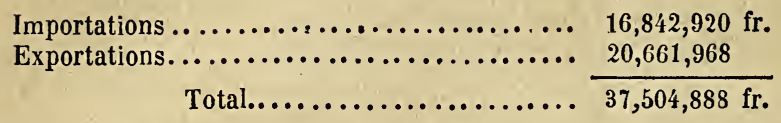

Les états de la douane locale fournissent les renseignements qui suivent, sur le commerce de la Guadeloupe avec l'étranger et les autres colonies françaises:

\section{0}

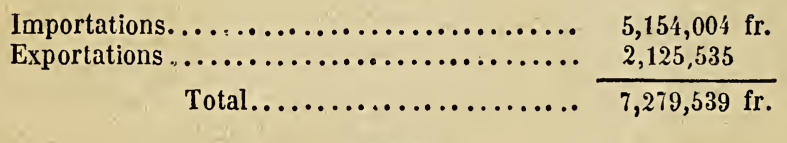

1820

Importations................... $3,679,070 \mathrm{fr}$.

1830

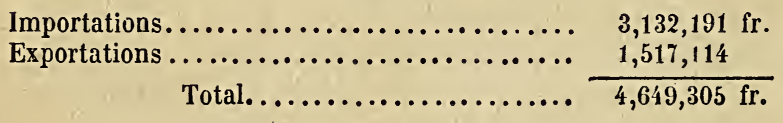

1835

Importations................... $4,406,236 \mathrm{fr}$.

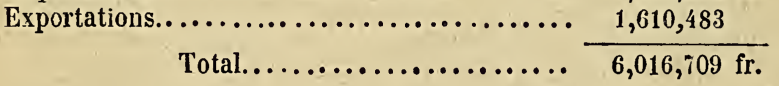

1840

Importations. .................... 4,359,332 fr.

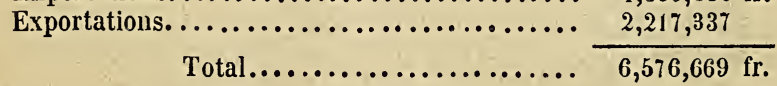

$\mathbf{1 8 4 5}$

Importations .................... $8,382,243 \mathrm{fr}$.

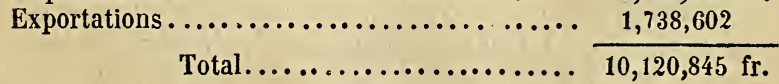

1850

Importations . . . . . . . . . .

Exportations...................... 683,185

Total................ 
GUADELOUPE. - MARIE-GALANTE. - LES SAINTES, ETC. 433

1855

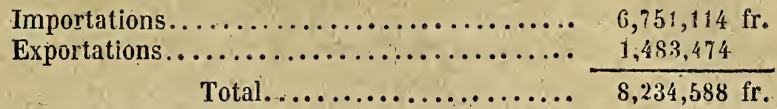

1860

Importations .................... 10,032,457 fr.

Exportations...................... $1,222,458$

Total ................

1361

Importations................... $8,062,363 \mathrm{fr}$.

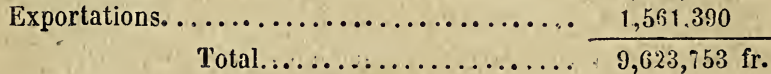

1862

Importations..................... $8,094,750 \mathrm{fr}$.

Exportations...................... $2,450,226$

Total..................

Le commerce général offre les éléments suivants pour 1861 et 1862 :

Importations (1861).

Marchandises françaises venant de France....

- des colonies françaises..........

$14,330,531$ fr.

$1,586,303$

- _ - par navires étrangers.

Total.

$2,744,423$

$3,731,637$

$22,392,894 \mathrm{fr}$.

Exportations (1861).

Denrées du cru de la ( la France.......... colonie exportées les colonies françaises. pour............

l'étranger...........

Marchandises prove-

nant des importat. $\{$ étrangères ..........

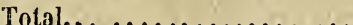

$15,680,614 \mathrm{fr}$.

12,352

90,700

$1,311,786$

541,210

$17,636,662 \mathrm{fr}$.

Iniportations (1862).

Marchandises françaises venant de France....

- des colonies françaises.........

$14,705,459$ fr.

$2,012,402$

$2,783,138$

$\overline{-}$

étrangères par navires français..

$3,299,210$

Total..

par navires étrangers.

$22,800,209 \mathrm{fr}$.

Exportations (1862).

Denrées du cru de la f la France ........ 16,128,999

colonie exportées $\begin{cases}\text { les colonies françaises. } & 51,911\end{cases}$

pour.............

74,379

Marchandises prove- $\{$ françaises......... 2,055,009

nant des importat. \{ étrangères......... 268,927

Total............... 
Ainsi, en 1862, il y a eu, sur 1861, une augmentation :

Dans les importations, de............. 407,315 fr.

Dans les exportations, de............... 942,563

Ce qui, dans le commerce général, donne une augmentation de $1,349,878 \mathrm{fr}$.

Les principales marchandises et denrées, importées en 1862, ont été, savoir :

Chevaux (186 têtes)...................

Mulets, mules, ânes $(1,182$ têtes $) \ldots \ldots \ldots \ldots$.

Bœufs $(1,755$ têtes $) \ldots \ldots \ldots \ldots \ldots \ldots \ldots \ldots$.

Viandes salées $(378,869$ kil. $) . \ldots \ldots \ldots \ldots \ldots \ldots$.

Saindoux et autres graisses $(127,602$ kil. $) .. .$.

Fromages $(66,996$ kil. $) .. \ldots \ldots \ldots \ldots \ldots \ldots$.

Beurre salé $(225,132$ kil. $) . \ldots \ldots \ldots \ldots \ldots \ldots$.

Morues salées $(4,583,090$ kil.).............

Harengs et autres poissons salés $(163,089$ kil.).

Poissons marinés à l'huile $(26,317$ kil. $)$.......

Farine de froment $(3,439,990$ kil. $) \ldots \ldots \ldots \ldots$.

Autres céréales $(786,107$ kil.).............

Pains et biscuits de mer $(184,792$ kil.).......

Pommes de terre et légumes secs (313,010 kil.).

Riz en grains $(2,458,940$ kil. $)$.............

Farineux alimentaires divers $(87,619$ kil. $) ..$.

Fruits et graines $(213,995$ kil. $) \ldots \ldots \ldots \ldots \ldots$.

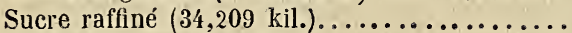

Sucre brut $(282,928$ kil.)................

Cacao en fèves $(65,216$ kil. $) . \ldots \ldots \ldots \ldots \ldots$.

Tabac en feuilles $(105,194$ kil. $) .. . \ldots \ldots \ldots$....

Huile d'olive et autres $(336,0$ t0 lit.)........

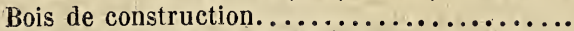

Aissantes, feuillards et merrains............

Tourteaux de graines oléagineuses $(1,366,145 \mathrm{k}$.)

Briques, ardoises, tuiles, etc..............

Houille $(9,166,584$ kil. $) .. \ldots \ldots \ldots \ldots \ldots \ldots \ldots$

Métaux divers $(255,274$ kil. $) \ldots \ldots \ldots \ldots \ldots \ldots$

Produits chimiques et couleurs.............

Médicaments composés.................

Savons ordinaires $(188,778$ kil. $) . \ldots \ldots \ldots \ldots \ldots$

Acide stéarique ouvré $(61,189) \ldots \ldots \ldots \ldots \ldots$.

Chandelles (274,101 kil.)................

Tabacs manufacturés $(3,568$ kil. $) .. \ldots \ldots \ldots$.

Eau congelée | glace] $(635,000$ kil. $) \ldots \ldots \ldots \ldots$

Vins $(1,974,994$ lit. $) \ldots \ldots \ldots \ldots \ldots \ldots \ldots \ldots$

Autres boissons fermentées (168,330 lit.).....

Boissons distillées $(26,287$ lit.)............

Poteries $(463,138$ kil. $) .. \ldots \ldots \ldots \ldots \ldots \ldots$.

Verreries et miroirs $(74,578$ kil.)...........

Tissus de coton.......................

- de laine........................

- de toile........................

- de soie .........................
$118,150 \mathrm{fr}$.

573,070

604,355

414,919

223,115

128,740

528,907

$1,805,817$

66,414

103,428

$1,837,695$

360,946

137,947

317,425

853,394

61,958

82,224

16,420

305,421

68,534

199,824

530,908

445,281

357,779

253,053

234,845

429,299

211,828

170,877

143, 074

185,320

170,556

375,928

36,204

134,900

916,334

100,765

44,401

211,107

86,822

$1,943,402$

215,921

519,180

247,869 
Papier et ses applications (74,370 kil.).......

Chaussures (78,268 kil.)................

Autres ouvrages en peau ou cuir $(20,606$ kil.)..

Chapeaux de paille et de fibres.............

Cordages de chanvre $(113,598$ kil. $) .. . \ldots \ldots$....

Bijouterie, orfévrerie, horlogerie............

Monnaies d'or.......................

Machines et mécaniques.................

Instruments et outils..................

Ouvrages en fonte et en fer...............

Ouvrages, en métaux divers..............

Merceries $(72,222$ kil.)..................

Modes (ouvrages de)...................

Parapluies...........................

Futailles vides........................

Meubles de toutes sortes................

Ouvrages en bois.......................

Effets à usage.......................

Divers............................

Valeur totale.................
277,350
630,673
114,013
129,323
151,035
97,490
201,000
$1,557,787$
72,695
571,606
109,572
484,345
195,074
81,763
367,508
140,494
108,922
307,743
$52 \tau, 460$
22,800,209 fr.

Les principales denrées et marchandises exportées, en 1862, sont les suivantes :

Sucre brut $(31,312,709$ kil. $) \ldots \ldots \ldots \ldots \ldots \ldots$.

Mélasse $(88,736$ lit. $) \ldots \ldots \ldots \ldots \ldots \ldots \ldots \ldots \ldots$

Confitures $(2,811$ kil. $) . \ldots \ldots \ldots \ldots \ldots \ldots \ldots$

Cacao en fèves $(72,063$ kil.)..............

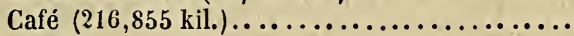

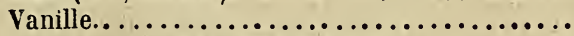

Bois de campêche $(385,358$ kil. $) .. \ldots \ldots \ldots \ldots$

Cocon en laine $(27,494$ kil.)..............

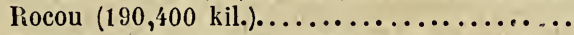

Eau-de-vie de mélasse $(1,863,259$ lit. $) .. \ldots \ldots$.

Autres denrées de la colonie...............

Valeur totale des exportations....

Les principaux objets réexportés, en 1862, ont été :

Animaux vivants (258 têtes)..............

Viandes salées $(38,003$ kil. $) \ldots \ldots \ldots \ldots \ldots \ldots$

Peaux brutes $(48,932$ kil.)...............

Graisses, fromages, beurre $(29,310 \mathrm{kil}.) . . . \ldots$.

Guano et autres engrais $(1,355,517$ kil. $) .. \ldots \ldots$

Morue $(1,541,399$ kil. $) .. \ldots \ldots \ldots \ldots \ldots \ldots \ldots$

Autres poissons $(21,180 \mathrm{kil}.) . \ldots \ldots \ldots \ldots \ldots$.

Farineux alimentaires $(576,581$ kil. $) .. . \ldots \ldots$.

Cacao en fèves $(65,181$ kil. $) . \ldots \ldots \ldots \ldots \ldots \ldots$

Huiles $(78,803$ lit. $) .. \ldots \ldots \ldots \ldots \ldots \ldots \ldots \ldots$

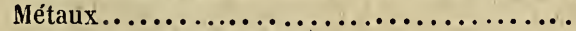

Sel marin $(321,200$ kil. $) \ldots \ldots \ldots \ldots \ldots \ldots \ldots \ldots$

Vins et boissons $(357,936$ kil. $) \ldots \ldots \ldots \ldots \ldots \ldots$

Poteries et verreries....................

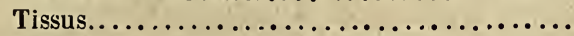

Denrées et marchandises diverses. ..........

Valeur totale.

\begin{tabular}{c}
$14,805,003 \mathrm{fr}$. \\
16,900 \\
11,008 \\
76,429 \\
469,728 \\
1,398 \\
23,157 \\
42,757 \\
190,400 \\
578,197 \\
40,312 \\
\hline $16,255,289 \mathrm{fr}$.
\end{tabular}

$62,980 \mathrm{fr}$.

43,344

27,801

67,171

485,239

576,135

68,696

271,113

68,499

131,616

43,257

9,636

160,629

41,411

56,830

209,549

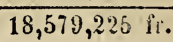


Les entrepôts ouverts sont au nornbre de deux : l'un à la BasseTerre, l'autre à la Pointe-à-Pitre.

Comme ceux de la Martinique, ils peuvent recevoir les marchandises françaises et étrangères de toute nature, même celles prohibées en France.

Les marchandises payent un droit de magasinage de 1 pour 100 de la valeur, par an.

Même droit pour les marchandises qui, étant admissibles dans la colonie, y passent à la consommation (V. ordonnance du 18 juin 1842).

\section{MOUVEMENT GÉNÉRAL DES ENTREPOTS.}

Entrées (1861).

Marchandises françaises importées.

Marchandises étrangères importées..........

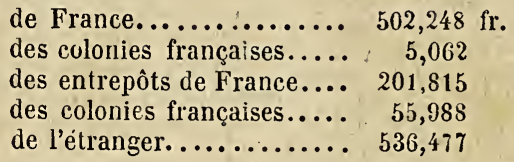

Sorties (1861).

\begin{tabular}{|c|c|c|}
\hline \multirow{2}{*}{$\begin{array}{l}\text { Marchandises françaises } \\
\text { sorties pour......... }\end{array}$} & $\begin{array}{l}\text { la France................. } \\
\text { les colonies françaises...... }\end{array}$ & $\begin{array}{r}9 \\
90,606\end{array}$ \\
\hline & l'étranger... & 233,368 \\
\hline Marchandises étrangères & la France............. & 337,631 \\
\hline ry & l'étranger............. & 71,133 \\
\hline handises $\mathrm{f}$ & sorties pour & 151,065 \\
\hline drchandises étr & sommatio & 775,211 \\
\hline
\end{tabular}

Ainsi, les entrées ont donné, en 1861, un total de 1,301,590fr. ; et les sorties un total de 1,791,469 fr.

En 1862, les entrées ont donné un total inférieur: 883,20ð fr.; il en a été de même pour les sorties : $882,861 \mathrm{fr}$.

A la Guadeloupe comme à la Martinique, la navigation est encore soumise à certains droits $(20 \mathrm{fr}$. et $10 \mathrm{fr}$. par tonneau d'affrètement), sauf dans l'île Saint-Martin où, d'après l'arrêté du 11 février 1850 , les bâtiments français et étrangers ne payent aucun droit de port ou de navigation.

Le nombre des navires français entrés, en 1862, a été de 421, ayant un tonnage de 54,290 et un équipage de 4,355 hommes; celui des navires étrangers entrés a été de 214, ayant un tonnage de 17,941 et un équipage de 1,23د hommes. Total : 635 navires; tonnage, 72,231 ; équipage, 5,5090 .

Le nombre des navires français sortis a été de 429, ayant un 
tonnage de 54,598 et un équipage de 4,438 hommes; celui des navires étrangers sortis a été de 214, ayant un tonnage de 18,472, et un équipage de 1,243 hommes. Total : 643 navires; tonnage, 73,070 ; équipage, 5,681 .

En 1862, les mouvements de la navigation de la Guadeloupe avec la France, les autres colonies et l'étranger, ont été comme suit :

1. Entre la colonie et la France.

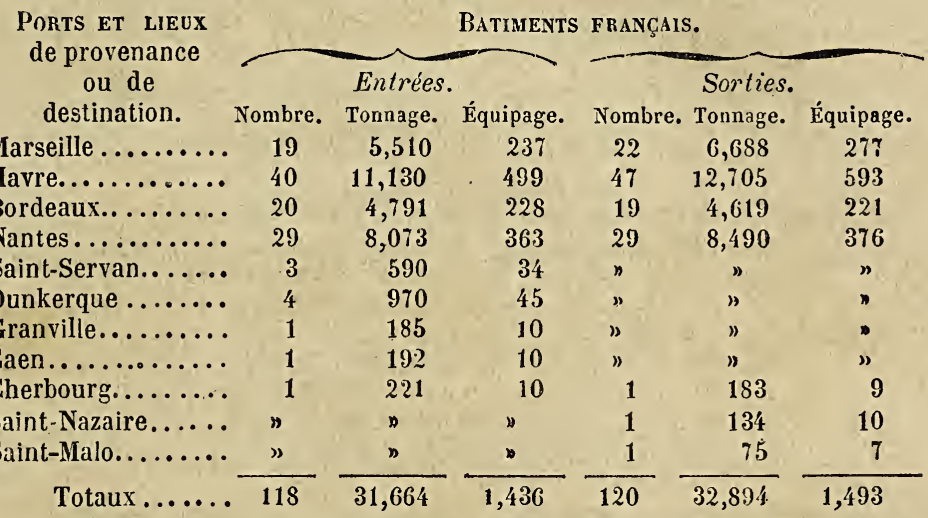

2. Entre la Guadeloupe et les colonies françaises.

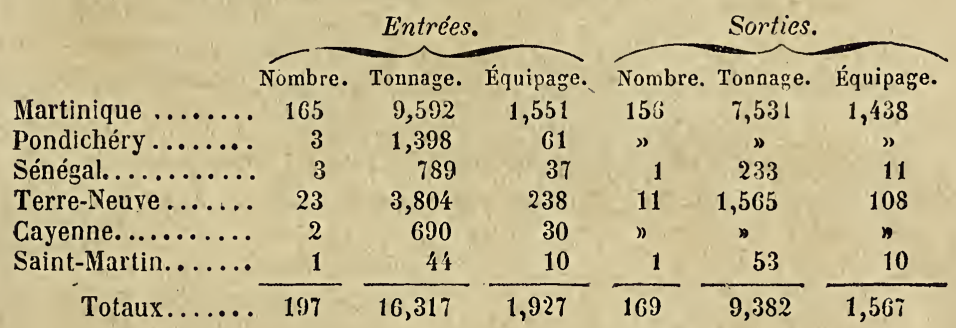

30 Entre la Guadeloupe et l'étranger.

Entrées.

Bâtiments français...... 106 nav. 6,309 tonn. 992 homm.

- étrangers.....214 - 17,941 - 1,235 -

Sorties.

Bàtiments français...... 140 nav. 12,322 tonn. 1,378 homm.

- étrangers.....214 - $18,472-1,243$ -

En 1862 , les recettes effectuées par les douanes au profit de la 
caisse coloniale ont été de $1,182,524 \mathrm{fr}$. et au profit des communes,

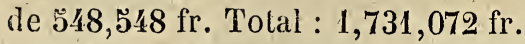

Ces recettes se décomposent de la manière qui suit :

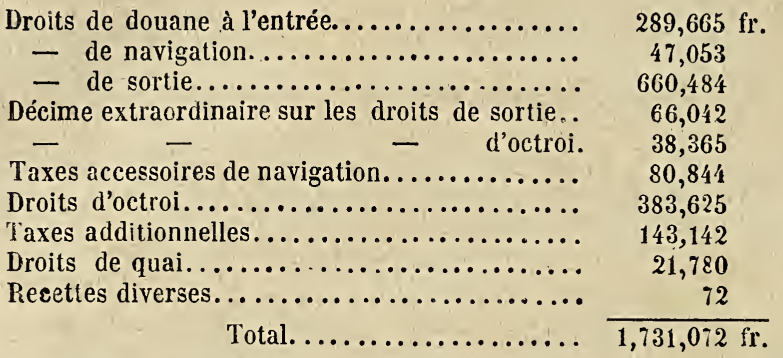

Les quatre bureaux des douanes ont encaissé :

Celui de la Pointe-à-Pitre.

$$
\begin{aligned}
& 1,666,498 \mathrm{fr} \text {. } \\
& \text { - Basse-Terre................ 33,647 } \\
& \text { - Marie-Galante.............. } \quad 4,330
\end{aligned}
$$$$
\text { - Moule...................... 26.5.67 }
$$$$
\text { Total.............. } \frac{1,731,072 \mathrm{fr} .}{1,}
$$

Les communications de la Guadeloupe avec la France sont régulières.

$$
\text { Voie anglaise. }
$$

(Royal mail steam navigation Company.)

Départ de Southampton, les 2 et 17 de chaque mois.

Arrivée à la Basse-Terre, les 19 et 3 (ou 4).

Départ de la Basse-Terre, les 27 et 12.

Arrivée à Southampton, les 14 et 29.

PRIX DU PASSAGE :

Une cabine à l'arrière......... 38 liv. $10 \mathrm{sh} .(962$ fr. 50).
$-$
à l'avant.......... 33
(825 fir.)

Toie francaise.

(Compagnie générale transatlantique.)

Départ de Saint-Nazaire, le 16 de chaque mois.

Arrivée à Fort-de-France (Martinique), ]e 1 ou le 2.

Arrivée du bateau annexe à la Pointe-à-Pitre et à la Basse-Terre, le 2 ou le 3.

Départ du bateau-annexe de la Pointe-à-Pitre et de la BasseTerre pour Fort-de-France (Martinique), le 25 ou le 26. 
GUADELOUPE. - MARIE-GALANTE. - LES SAINTES, ETG. 439

Départ du paquebot transatlantique, de Fort-de-France, le 26 ou le 27.

Arrivée à Saint-Nazaire, le 12 ou le 13.

\section{PRIX DU PASSAGE :}

De Saint-Nazaire à Fort-de-France.

Cabine à l'arrière, à 1 ou 2 couchettes........ 925 fr.

- à 3 et 4 couchettes................ 800

Entre-pont $\ldots \ldots \ldots \ldots \ldots \ldots \ldots \ldots \ldots \ldots \ldots, 450$

De Fort-de-France à la Guadeloupe.

Cabine à 1 et 2 couchettes.............. 40 fr.

- à 3 et 4 couchettes................. 30

Entre-pont ....................... 20

Réduction de 30 pour 100 est faite aux passagers civils et militaires voyageant sur réquisition du gouvernement.

La nourriture est payée en sus:

Passagers de $1^{\text {re }}$ et $2^{e}$ classe......... 8 fr. par jour.

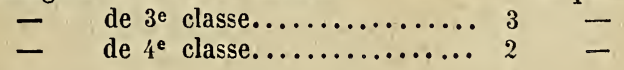

Taxe des lettres.

Lettre affranchie, par 10 gr.. . fr. 50 (voie franç.) „ fr. 70 (voie angl.)

$\begin{array}{ccccccccc}- \text { non affranchie } & - & . & \text { " } & 60 & - & \text { " } & 80 & - \\ \text { Lettre chargée } & - & . & 1 & \prime & - & 1 & 40 & -\end{array}$

Imprimés, par 10 gr....... » 12 -

Navires du commerce.

Prix du passage : $500 \mathrm{fr}$. (aller), $600 \mathrm{fr}$. (retour).

Lettres affranchies par $10 \mathrm{gr} ., 0,30 \mathrm{c}$.; non affranchies, $0,40 \mathrm{c}$.

La moyenne de la traversée est de 40 jours (aller), et 45 jours (retour). 


\title{
QUATRIEME PARTIE
}

\author{
GUYANE
}

\section{CHAPITRE PREMIER}

Coup d'œil historique.

La Guyane française est située entre $2^{\circ}$ et $6^{\circ}$ latit. nord, et entre $52^{\circ}$ et $57^{\circ}$ long. 0 . - Elle s'étend entre l'Orénoque etle fleuve ảes Amazones.

Elle est éloignée de Brest d'environ 1,320 lieues marines.

L'Atlantique la borne au Nord-Est; le Maroni, qui la sépare de la Guyane hollandaise la borne au N.-O. et à l'O., ainsi que plusieurs pays intérieurs peu connus. Sa limite Sud-Est encore indéterminée.

Le $1^{\text {er }}$ août 1498, Christophe Golomb, qui en était à son troisième voyage en Amérique, aborda à la Guyane. Améric Vespuce n'y vint que dix mois après, en mai 1499, avec Alfonso d'Ojeda et Jean de la Cosa.

Toutefois Vincent Yanez Pinçon est le premier qui ait parcouru les côtes de la Guyane dans toute leur étendue (1500).

Un fait assez bizarre, l'existence supposée dans l'intérieur des terres d'une ville extrêmement riche, l'El Dorado, entraîna une foule d'esprits aventureux, dans le courant du seizième siècle, à explorer l'intérieur de la contrée. De ce nombre furent sir Walter Raleigh (1597 et 1617), Laurent Keymis et le capitaine Berrie (1596), Charles Leigh (1604) et Robert Harcourt (1608). On peut voir dans le Monde enchanté, de M. Ferdinand Denis, un certain nombre de détails curieux sur le Dorado, et les folies que la recherche de cette ville hypothétique fit faire à bon nombre.

La Revardière, en 1604, fut chargé par Henri IV d'examiner s'il était possible d'établir une colonie à la Guyane. La Revardière se rendit dans le pays, examina sérieusement les choses, et 


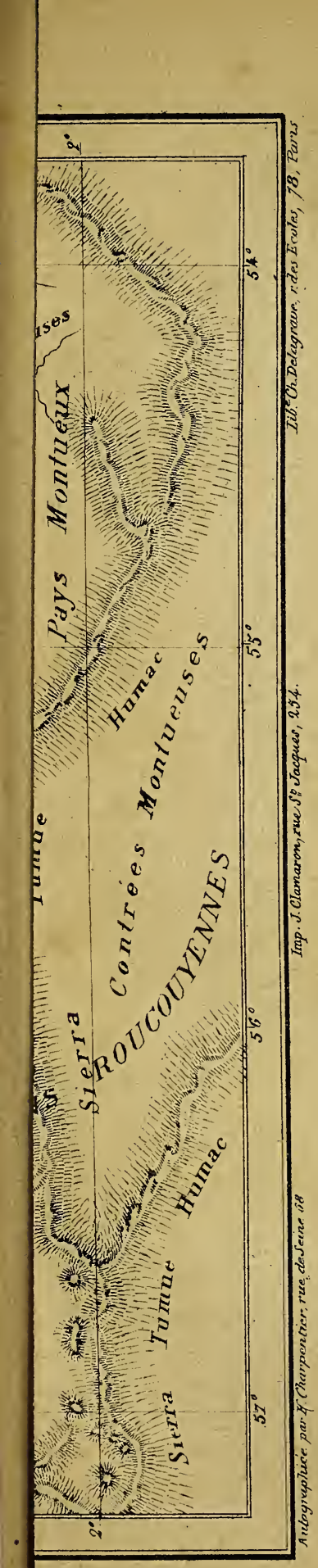





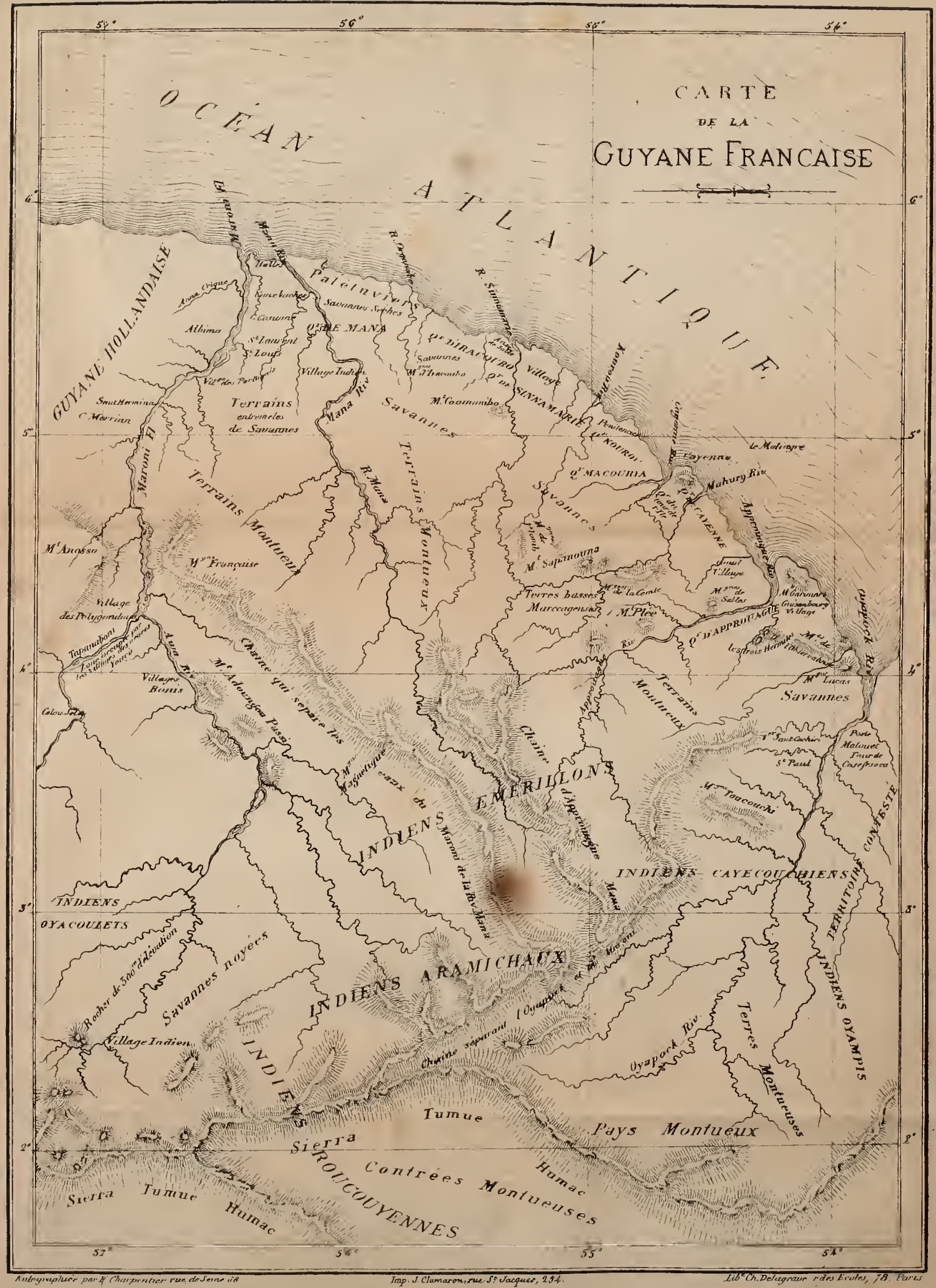



répondit affirmativement. La mort de Henri empêcha qu'il ne fût donné suite au projet.

Le projet fut repris en 1626 par des marchands de Rouen. De 1626 à 1633, plusieurs colonies furent envoyées. Elles se composaient chacune d'un petit nombre d'hommes.

Enfin, en 1633, quelques établissements étaient fondés. Des négociants de Rouen obtinrent le privilége du commerce et de la navigation des pays entre l'Orénoque et l'Amazone. Celte tentative ne réussit pas. Une autre compagnie, celle du Cap Nord se forma sur les ruines de la première en 1643 ; elle n'abontit pas davantage. Un des associés, le sieur Poncet de Brétigny, parti de Dieppe avec trois cents hommes, se conduisit avec une telle barbaric et vis-à-vis de ceux-ci et vis-à-vis des indigènes, qu'on le massacra. Les indigènes (Galibis) n'eurent point de repos qu'ils n'eussent tué ou chassé tous les Français. Deux seulement, d'entre ces derniers, purent parvenir à Surinam, où s'étaient antérieurement établis les Hollandais.

L'expédition de 1645 fut un nouvel échec pour les associés de Rouen. Les quarante hommes qu'ils envoyèrent furent aussi massacrés par les indigènes.

Nouvelle expédition en 1652. Pendant la traversée, le chef de cette expédition, un sieur de Royville, gentilhomme normand, fut poignardé. Arrivés à Cayenne, les directeurs furent en butte à des complots; les Galibis s'insurgèrent, la famine se mit de la partie; bref, en 16 33, il fallut se réfugier à Surinam, d'où l'on gagna les Antilles.

Les Hollandais, sous la conduite de Spranger, prirent Cayenne. veuve d'habitants. Elle leur fut enlevée par la France en 1664.

C'est alors que fut établie la Compagnie des Indes occidentalés. On lui avait concédé la propriété de toutes les colonies de l'Amérique du Nord, des Antilles, de l'Amérique du Sud et de l'Afrique occidentale.

- La ville de Cayenne, fondée dès 1643 par Poncet de Brétigny, fut considérablement étendue et fortifiée. La colonie comptait mille colons. De grands travaux de défrichement furent entrepris.

En 1667, irruption des Anglais. L'île fut ravagée, pillée, puis évacuée.

Il fallut six ans à la colonie pour qu'elle réparât ses pertes.

En 1674, elle subit le sort des autres colonies françaises et 
passa, lorsque la Compagnie des Indes cccidentales fut supprimée, sous la domination du roi.

En 1676, les Hollandais, jaloux de la prospérité de la colonie, l'envahirent et s'emparèrent de Cayenne qu'ils fortifièrent. Elle leur fut reprise, quelques mois après, par le comte d'Estrées.

Les flibustiers, qui vinrent s'y fixer en 1686, consacrèrent leurs capitaux à l'agriculture. Ce fut un moment de prospérité pour la colonie guyanaise. Il dura peu. Par esprit de représailles, on voulut attaquer les Hollandais à Surinam; on échoua, après avoir perdu les hommes les plus actifs et les plus entreprenants de la Guyane.

En 1700, un traité conclu à Lisbonne reconnut le cours des Amazones pour limites des possessions des deux puissances française et portugaise.

"La paix d'Utrecht changea, en 1715, les limites de la Guyane, du côté de l'Amazone. Par l'article 8 de ce traité, la France renonça à la propriété des terres appelées du Cap Nord et situées entre la rivière des Amazones et celle de Japoc ou de Vincent Pinçon. Depuis lors, la cour de Portugal n'a cessé de confondre la rivière d'Oyapock, située sur la côte de la Guyane par $4^{\circ} 15^{\prime}$ lat. $\mathrm{N}$. avec celle de Japoc, qui a la sienne par $1^{\circ} 55^{\prime}$ lat. N. Telle est la source des discussions relatives aux limites méridionales de la colonie. ") (V. Notices de la marine.)

La grande expédition de 1763, qui emporta en Guyane 12,000 colons volontaires, eut une déplorable issue; 12,000 individus seulement revinrent en Europe; quelques familles, épargnées par la mort, se fixèrent entre les rives du Kourou et du Sinnamary. L'entreprise avait coûté 30 millions.

En résumé, après plus d'un siècle, notre colonie était fort peu de chose. En 1775, or n'y complait pas plus de 1,300 personnes libres et 8,000 esclaves; $\mathbf{4 8 8 , 5 9 8}$ livres tournois, tel était le chiffre de l'exportation.

On résolut enfin d'étudier l'état des choses. M. Malouet, commissaire général de la marine, homme très-compétent, fut envoyé comme ordonnateur dans la colonie. Après avoir parcouru chaque district, il se rendit à Surinam, examina le système de culture des Hollandais et revint avec l'ingénieur Guizan, autorisé par la Hollande à entrer au service de la France.

De grands travaux de desséchement, de canalisation, etc., furent aussitôt entrepris. Mais, malheureusement, M. Malouet, 
dont la santé n'était pas roluste, fut contraint à quitter la Guyane, et l'impulsion qu'il avait donnée s'effaça promptement, après son départ.

La Révolution de 1789 amena, comme dans les autres colonies, une révolte des noirs. Les exploitations agricoles furent à peu près abandonnées. Pendant le gouvernement de Victor Hugucs (1800-1809), les prises faites par les corsaires de Cayenne introduisirent quelque abondance dans la colonie, mais détournèrent des travaux utiles.

En 1809, une expédition anglo-portugaise s'empara de la Guyane, et, pendant neuf ans, elle appartint aux Portugais.

Le gouvernement français ne rentra en possession de sa colonie qu'en 1817. Elle comptait alors 15,000 âmes.

En 1820 et 1821, deux tentatives pour introduire de nouveaux cultivateurs, échouèrent. - Celle de 1823 n'aboutit pas mieux.

C'est à l'énergie d'une femme, madame Javouhey, fondatrice et supérieure générale de la Congrégation des sœurs de SaintJoseph de Cluny, qu'on doit, en partie, le succès relatif de la colonisation de la Mana. Quand les colons de 1823 eurent abandonné cetétablissement, elle proposa de continuer l'entreprise et de fonder dans ce quartier des établissements propres à servir d'asile aux enfants trouvés. Son plan ayant été agréé, une expédition, composée de 36 sœurs, 39 cultivateurs engagés pour trois ans, et de quelques enfants, partit, en 1828, aux frais de l'État, sous la conduite de cette dame. En 1831, les cultivateurs abandonnèrent l'établissement, mais madame Javouhey avait tout prévu et cette défection ne changea rien à la situation. " En 183ə,, le gouvernement décida que les noirs de traite, libérés en vertu de la loi du 4 mars 1831, qui se trouvaient alors à la Guyane, seraient successivement envoyés sur l'établissement de la Mana pour s'y préparer, par le travail, à la liberté; 5 on noirs y ont été ainsi réunis, et, depuis cette fondation, le bourg a prospéré. Cet établissement fit retour au gouvernement le $1^{\text {er }}$ janvier 1847, et a formé depuis lors un nouveau quartier de la colonie. ")

L'émancipation des esclaves, en 1848, a porté un coup terrible à la Guyane. Cependant, il a été atténué depuis par l'établissement des pénitenciers, l'introduction des immigrants africains et indiens, l'institution d'une banque, la découverte de mines d'or, la création de vastes chantiers pour l'exploitation des bois, etc. $L a$ vie renaît, la vie reprend dans cette belle colonie. 
GOUVERNEURS ET COMMANDANTS.

1644. Poncet de Brétigny (Charles), assassiné parles indigènes 1645. Laforêt, assassiné par les indigènes.

1652. Navare (le sieur de).

1653. Bragelone (de).

1664. Spranger, Hollandais.

166ว. Barre (de la).

166ว. Noël.

1667. Lézy (de).

1668. Barre (de la).

167วั. Lézy (de).

1679. Férolles (de).

1684. Sainte-Marthe.

1687. Férolles (de).

1688. Barre (de la).

1691. Férolles (de).

1700. Orvilliers (d').

- 1701. Férolles (de)

1705. Riouville.

1706. Orvilliers (d').

1713. Grand ville.

1716. Orvilliers (Clande d').

1720. La Motte-Aigron.

1722. Orvilliers (Glaude d').

1729. Charanville (de).

1730. Lamirande (de).

1736. Grenay (de).

1736. Orvilliers (Gilbert d').

1738. Chateangué (de).

1743. Orvilliers (d').

1751. Dunezat.

1752. Orvilliers (d').

1753. Dunezat.

1757. Orvilliers (d').

1763. Behague(de).

1'64. Friedmond (de).

1764. Turgot (de).

176ว. Behague (de).

1766. Friedmond (de). 
1781. Bessner.

1785. Lavallière.

1785. Fitz-Maurice.

1787. Villeboi.

1788. Allais (d').

1789. Bourgon.

1791. Benoît.

1792. Guillot.

1793. Jeannet-Oudin.

1794. Cointet.

1796. Jeannet-Oudin.

1798. Burnel.

1799. Franconie.

1800. Hugues (Victor).

1809. Marquès, commandant en chef pour le Brésil.

1817. Carra Saint-Cyr.

1819. Laussat.

1823. Milius.

1825. Muysssard (de).

1826. Burghes de Missiessy.

1827. Desaulves de Freycinet.

1829. Jubelin.

1834. Pariset.

1835. Jubelin.

1836. Laurens de Choisy.

1837. Nourquer du Camper (de).

1839. Gourbeyre.

1841. Charmasson.

1843. Layrle.

1845. Cadeot.

1846. Pariset.

18ə00. Maissin.

1851. Vidal de Lingendes.

1851. Chabannes-Curton (de).

1852. Sarda-Garriga.

1853. Fourichon.

1854. Bonard.

185̌. Masșet.

1856. Baudin.

185ั9. Tardy de Montravel. 
1864. Fabre.

1864. Hennique.

\section{GHAPITRE II}

Étendue. - Sol. - Montagnes. - Marais et savanes. - Forèts. - Cours d'eâu.

Lacs. - Routes. - Canaux. - Circonscriptions territoriales.

L'étendue de la Guyane est, environ, de 1,308,739 hectares.

La partie qui occupe le littoral et s'étend jusqu'aux premiers sauts des rivières comprend les terres basses, formées de terres alluviales; l'autre partie, qui s'étend au delà des premières cataractes des rivières, comprend les terres hautes.

Une chaîne de montagnes se prolonge dans l'intérieur, gagnant la chaîne principale du Tumuc-Humac, au sud de la Guyane. Elle a une hauteur de 500 à 600 mètres.

A 60 ou 80 kilcmètres des côtes, les forêts apparaissent. Elles vont, se prolongeant dans l'intérieur, à des distances inconnues encore. Dans les terres hautes, on trouve les bois durs, et les bois mous dans les terres basses.

Les terres basses sont couvertes d'un grand nombre de vastes marais inondés par les pluies diluviales du pays (pripris), ou desséchés et formant d'immenses prairies émaillées de palmiers pinots (d'où leur nom de pinotières). On donne celui de savanes tremblantes à de vastes espaces formés par l'assemblage d'herbes aquatiques reposant sur un fond de vase molle, véritables tourbières en voie de formation.

De nombreux cours d'eau sillonnent le pays. Le Maroni, la Mana, le Sinnamary, le Kourou, la rivière de Cayenne, le Mahury, l'Approuague, l'Onanary, l'Oyapock, dans la portion du territoire non contesté, sont les principaux fleuves à remarquer.

Plusieurs lacs, tels que le Mepecucu, le Macari, le Mapa, ont une importance considérable.

Deux routes, cêlle de Cayenne à Iracoubo, et celle de Cayenne au dégrad des Cannes; un canal, celui de la Brique fouillée, sont les principales voies de communication.

La Guyane compte quatorze communes, dont 13 rurales (quartiers), et 1 urbaine. Celle-ci forme la ville de Cayenne. 
En voici la nomenclature, avec leur contenance el le chiffre de leurs habitants.

\begin{tabular}{|c|c|c|}
\hline Gayenne (ville) .. ........... & 234 hect. & 928 \\
\hline 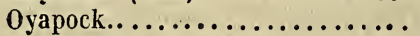 & 163,350 & 620 \\
\hline Approuague ............... & 262,000 & 1,506 \\
\hline Kaw $\ldots \ldots \ldots \ldots \ldots \ldots \ldots$ & 58,900 & 699 \\
\hline 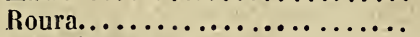 & 90,400 & 1,630 \\
\hline Tonnégrande............... & 42,000 & 688 \\
\hline Tour-de-l'ile.............. & 28,300 & 909 \\
\hline Ile de Gayenne............... & 42,000 & 1,846 \\
\hline 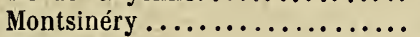 & 21,470 & 882 \\
\hline 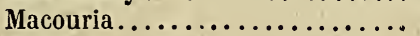 & 42,310 & 1,114 \\
\hline Kourou........ & 80,000 & 975 \\
\hline Sinnamary .... & 28,675 & 797 \\
\hline Iracoubo................. & 62,000 & 573 \\
\hline 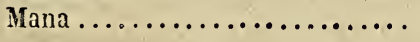 & 387,100 & 894 \\
\hline
\end{tabular}

Gayenne s'élève sur la rive droite de la rivière de ce nom à l'extrémité 0 . de l'île.

Elle est dominée à l'est par un monticule de 3 mètres, la montagne Cépérou, qu'avait fortifiée, en 1644, Poncet de Brétigny, pour mettre la colonie nouvelle à l'abri des indigènes.

A l'embouchure de la rivière, se trouve un port qui peut recevoir des navires de כั00 tonneaux ayant un tirant d'eau de $4^{\mathrm{m}}, 25$. La rue du port mène à la place d'armes; c'est là que sont situés l'hôtel du Gouvernement et quelques autres établissements publics.

Les rues de Cayenne sont larges, bien alignées. Elle renferme entre autres édifices, une église (au centre), le palais de justice, un grand hôpital militaire ; un beau boulevard, s'étendant du nord au sud, sépare la ville de la banlieue.

8,000 habitants.

\section{Cayenne (île de).}

L'île de Cayenne est séparée de la banlieue de la ville à l'O., par la crique Montabo; elle est bornée au N. par la mer, la rivière de Mahury et la Montagne anglaise; au S., par la Crique fouillée. La partie N. de l'île est traversée par une chaîne de collines, hautes de 100 mètres (Table de Rémire), où s'établirent les premiers colons.

Sol très-fertile. On y cultive le sucre, le café, les vivres du pays, le cacas, le rocou. 
En face, et en mer, on remarque l'îlet la Mère, l'îlet le Père, les îlets le Malingre et les Mamelles, rochers stériles.

\section{Tour de l'île.}

Borné au N.-E. par la Crique fouillée, au S.-0. par la rivière du Tour de l'île, au N.-0. par la rivière de Cayenne, au S.-E. par la rivière de Mahury, ce quartier a une superficie de 28,300 hectares.

Après le quartier de l'île de Cayenne, c'est ce quartier qu'on a mis d'abord en culture.

Sol varié, mais d'une qualité médiocre. Bois à brûler.

\section{Tonnégrande.}

Borné au N.-E. par la rivière du Tour de l'île, au S.-E. par celle du Galion, au S.-0. par les grands bois, au N.-0. par le quartier de Montsinéry.

Sol très-médiocre. - Grands chantiers d'exploitation de bois de construction et d'ébénisterie.

\section{ร. Roura.}

Borné au N.-0. par la rivière du Tour de l'île, au N.-E. par la crique Rocamont et les savanes de Kaw, an S.-E. par le quartier de Kaw et ses grands bois, au S. -0. par la rivière du Galion, et le quartier de Tonnégrande.

Bois. Gisements d'or et de fer. Vanillier à l'état sauvage, etc.

Jolie église, presbytère, habitation domaniale (la Gabrielle).

\section{Kaw.}

Borné au N.-E. et à l'E. par l'Océan, au S.-E. par le quartier de l'Approuaguc, au S.-0. par celui de Roura, au N.-0. par la crique Angélique.

Sol fertile; culture du rocou.

Pelit bourg; une église.

\section{Approuague.}

Borné au N.-E. par la mer, au S.-E. par les grands bois, au N.-0. par le quartier de Kaw. Aucune limite précise ne le borne au S.-O. 
Sol excellent pour les cultures tropicales (canne à sucre, cotonnier, etc.). Gisements aurifères importants.

\section{Oyapock.}

Borné au N.-E. et à l'E. par la mer, au S.-E. par l’Oyapock, au N.-0. par le quartier de l'Approuague, au S.-0. par les grands bois.

Gulture de la canne à sucre, café, rocou, vivres du pays.

\section{Montsinéry.}

Borné au N.-E. par la pointe Palicour, au S.-E. par la rivière de Cayenne et le quartier de Tonnégrande, au N.-O. par le quartier de Macouria.

Sol peu fertile. Rivières poissonneuses. Briqueteries.

\section{Macouria.}

Borné au N.-E. par la mer, au S.-E. par le quartier de Montsinéry, au S.-0. par les savanes naturelles, au N.-0. par le quarlier de Kourou.

Sol propice au cotonnier, au caféier, àu manioc, etc.

\section{Kourou.}

Borné au N.-E. par la mer, au S.-E. par le quartier de Macouria, au N.-0. par la rivière de Malmanouri, au S.-0. par les grands bois.

Sol fertile sur certains points. Culture du café, du coton, du rocou, des vivres. Bois de construction et d'ébénisterie. Insalubrité moins grande qu'on ne le croyait autrefois, surtout après la tentative désastreuse de 1763 (V. chap. I). - Église, presbytère, école primaire.

Vis-à-vis de la rivière de Kourou, à 7 milles en mer, sont les iles du Salut, au nombre de trois (ile Royale, île Saint-Joseph, ile du Diable).

Bien boisées. Mouillage sûr.

\section{Sinnamary.}

Ce quartier est compris entre la rivière de Malmanouri et la crique Crossoni.

Sol plat, sablonneux, coupé de savanes sèches et noyées. 
Exploitation de bois. Culture du café, du cotonnier, etc. Gisements aurifères. Rivière navigable sur 52 kilomètres par des embarcations de 40 tonneaux. - Montagnes nombreuses. Élève de bestiaux.

Un bourg, une église, presbytère, école primaire, etc.

\section{Mana.}

Ce quartier est compris entre la rivière d'Organabo et le Maroni qui sépare la Guyane hollandaise de la Guyane française.

La Mana, une des plus importantes rivières de la colonie, a 300 kilomètres de long.

Le Maroni, le plus grand fleuve de la Guyane, est depuis 1858 le centre de la transportation des condamnés. A 20 kilomètres de l'embouchure, on a établi deux pénitenciers.

Sol fertile sur certains points. Grands bois. Bois de construction, d'ébénisterie, gomme de Balata, or, etc. Production du sucre; rhum, café, riz, farine de manioc.

\section{GHAPITRE III}

Climat. - Température. - Saisons. - Pluies. - Vents. - Ouragans, etc. Population. - Indigènes. - Nègres. - Immigrants indiens. - Transportés. - Pénitenciers.

Le climat de la Guyane ne mérite pas la mauvaise réputation qu'on lui a faite. Sans doute, comme tous les climats tropicaux, il exige de tout nouveau-venu des précautions spéciales, mais là s’arrète sa rigueur. Ces précautions prises, - éviter tout excès, ne point s'exposer découvert au soleil, s'éloigner en août, septembre et octobre des endroits sur lesquels souffle le vent des plaines marécageuses, - ces précautions prises, on peut vivre à la Guyane sans beaucoup plus de risques qu'ailleurs. Du reste, les travaux de desséchement et de défrichement auxquels, depuis piusieurs années déjà, on se livre sans relâche, finiront par enlever à la peur à peu près tout prétexte sérieux.

La température habituelle varie entre $25^{\circ}$ et $27^{\circ}$. I e thermomètre ne descend guère au-dessous de $20^{\circ}$ et monte parfois à $36^{\circ}$ et $38^{\circ}$. 
Deux saisons : une saison sèche et une saison pluvieuse.

La première dure de juin ou juillet, jusqu'en novembre ou décembre; la seconde, de novembre ou décembre jusqu'à juillet.

Année commune, il tombe à Cayenne de $3 \mathrm{~m}$. à $3^{\mathrm{m}}, 50$ d'eau. Il en tombe davantage dans l'intérieur. Janvier, février, avril et mai sont les mois les plus pluvieux.

Les vents dominants sur la côte sont ceux du N.-N.-E. et du S.-E. Pendant la saison sèche, les vents soufflent de l'E. au S. Pendant la saison pluvieuse, de décembre en juin, ils soufflent de l'E. au N.

Pas d'ouragans, mais quelques ras de marée relative:.:cnt peu redoutables. Les tremblements de terre ont été rares jusqu'ici. Ceux de 1794, de 1821 et de 1843 les seuls qu'on ait remarqués, n'ont causé que des dommages insignifiants.

Le baromètre subit peu de variations atmosphériques. Il se tient entre $0^{\mathrm{m}}, 758$ et $0^{\mathrm{m}}, 763$.

Les plus longs jours ont une durée de $12 \mathrm{~h} .18 \mathrm{~m}$. et les plus courts, de 11 h. $42 \mathrm{~m}$.

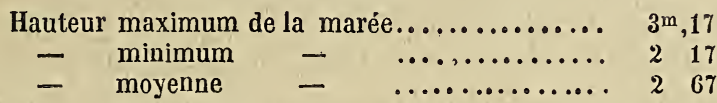

A la fin de 1863, la population de la Guyane se montrait à 24,95ั1 individus, savoir :

Population sédentaire et flottante (y compris la population blanche qui forme le $15^{\mathrm{e}}$ de ce total)........

Immigrants Africains, Indiens et Chinois......... 2,085

Indiens aborigènes..................... 1,500

Réfugiés brésiliens du Para.................. 280

Garnison........................... 1,099

Personnel administratif et médical............. 151

Surveillants............................. 177

Sœurs de Saint-Joseph et de Saint-Paul............ 77

Frères de Ploërmel......................... $\quad 16$

Transportés hors pénitenciers................. ${ }^{3}$

Avec les transportés présents sur les pénitenciers, la population totale arrivait à plus de 30,000 individus.

Le nombre des décès, en 1862, a été de 512 ; celui des mariages, de 72; celui des naissances, de 450 .

Il existe, disent les Notices de la marine, sur le territoire de la colonie quelques tribus d'indiens aborigènes qui forment une 
portion tout à fait distincte de la population coloniale. Ils reconnaissent l'autorité de la France, mais cette reconnaissance ne se manifeste guère qu'au moment où ils élisent un capitaine chef de

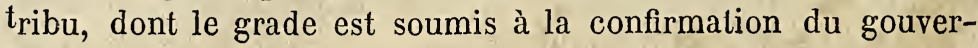
neur.

Leurs mœurs sont paisibles. Ils cultivent un peu de manioc, des ignames, des bananes, mais ils vivent surtout de chasse et de pêche.

Ils sont divisés en plusieurs tribus : les Trios, sur les bords du haut Tapanahoni; les Oyacoulets, entre les criques Ouanimari et Aloué sur le haut Maroni; les Roucouyennes, habitant les deux côtés des montagnes Tumuc-Humac; les Émérillons, établis entre le Maroni et l'Approuague, à la hauteur de la crique Inini; les Aramichaux, au delà des Émérillons, dans le haut de la crique Aroua et au milieu de la chaîne de séparation de l'Oyapock, et du Maroni; les Cayécouchiennes, sur la rive gauche de l'Oyapock, au confluent de ce fleuve et du Camopi; et les Oyampis, sur la rive droite du haut Oyapock.

Outre ces populations aborigènes, on rencontre, en remontant le Maroni, à partir de la réunion de l'Awa et du Tapanahoni, trois tribus de nègres désignés sous la dénomination générale de nègres-Bosh (nègres des bois); ce sont les Youcas, les Bonis et les Polygoudoux. Ces tribus ne sont pas indigènes; elles sont formées d'anciens esclaves et de soldats noirs qui se sont évadés autrefois de la colonie de Surinam. Ils vivent comme les Indiens, principalement de chasse et de pêche, et descendent souvent aux établissements français pour y commercer au moyen d'échanges consistant en bois, gibier ot poisson. Leur nombre peut être évalué à 1,400 ou 1,500 individus.

L'émancipation des noirs, en 1848, jeta la Guyane, ainsi que nos autres colonies, dans une-perturbation à laquelle on dut au plus tôt chercher à remédier. La population esclave se composait de 13,000 noirs; beaucoup d'entre eux quittèrent le travail.

On recruta successivement des noirs africains, des coulis indiens et des Chinois.

Comme dans nos autres colonies, on a constaté la supériorité de l'Africain comme travailleur; il résiste mieux aux durs travaux. La santé de l'Indien est trop délicate pour qu'il puisse marcher longtemps. Le Chinois a donné quelque satisfaction à ses engagistes, mais il coute trop cher (4 piastres par mois). 
Il est fâcheux que l'immigration africaine ait été interdite et qu'on soit obligé de recourir aujourd'hui à l'Indien exclusivement.

On comptait, à la fin de 1863,950 Indiens, 960 Africains et 90 Chinois immigrants.

Une caisse d'immigration a été établie. A la fin de 1863, elle avait un actif disponible de 330,000 francs.

La Guyane a été choisie en $\mathbf{1 8 5 2}$ par le gouvernement français pour être le siége d'une colonie pénale.

On y transporte les forçats, les repris de justice condamnés pour rupture de ban, les étrangers expulsés qui ne peuvent être rapatriés ou engagés dans la légion étrangère, et les condamnés coloniaux d'origine africaine et asiatique.

L'effectif des transportés était, à la fin de juillet 1864, de 6,42 s individus, savoir :

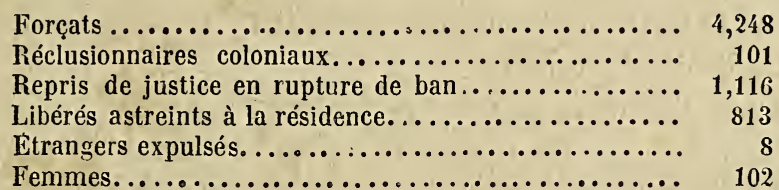

Les pénitenciers sont nombreux; on compte ceux des îles du Salut et îlet la Mère (1,906 transportés); des roches du Kourtou (402 transportés); de la Montagne d'argent (539 transportés); de Saint-Georges (71 transp.); de la Comté (aujourd'hui abandonné pour son insalubrité) ; de Saint-Laurent (1,384 transp.); de SaintLouis (716 transp.). Trois bâtiments en rade de Cayenne servent, en outre, de pénitenciers flottants (738 condamnés). Enfin, le dépôt de Mont-Joly reçoit les condamnés libérés astreints à la résidence ou ceux qui attendent leur rapatriement (196 individus, en 1864).

Les pénitenciers de Saint-Laurent ont surtout prospéré. La localité est très-salubre, puisque la mortalité n'y est que de un à deux pour 100 . 


\section{GHAPITRE IV}

Gouvernement. - Administration. - Services divers. - Contrôle. - Organisation municipale. - Forces militaires. - Station locale.

Le gouvernement de la Guyane est confié à un gouverneur.

Il a sous ses ordres :

Un commandant militaire, un ordonnateur, un directeur de l'intérieur, un chef du service judiciaire et un directeur des pénitenciers.

Un conseil privé est placé près du gouverneur. Au moyen de certaines adjonctions, ce conseil forme la juridiction du contentieux administratif en premier ressort. Le recours au Conseil d'État est de droit.

Sous l'approbation du ministre, le gouverneur peut statuer sur l'assiette, le tarif, la perception des contributions publiques, sauf celle des droits de douanes.

C'est par une ordonnance royale du 27 août 1828, successivement modifiée par les ordonnances du 24 septembre 1831 et du 22 août 1833, puis par deux décrets (27 avril 1848 et 28 mai 1853), qu'ont été réglés le gouvernement et l'administration de la colonie.

L'administration est confiée à un commissaire de $1^{\text {re }}$ classe, ordonnateur, ayant pour coopérateurs et employés :

1 commissaire de $2^{\circ}$ classe, contrôleur colonial; 2 commissaires-adjoints ; こे sous-commissaires ; 11 aides-commissaires ; 10 commis de marine; un certain nombre d'écrivains, etc.

Le personnel du service des ports comprend : 1 capitaine, 1 lieutenant, 1 maitre de port, 1 chef pilote, 4 pilotes, 1 aspirant, 1 apprenti-pilote, 2 guetteurs de vigie.

Le Trésor public a un commissaire ou un commissaireadjoint de la marine pour trésorier payeur.

Le service de santé comprend: 1 second médecin en chef de la marine, 4 chirurgiens de $1^{\mathrm{re}}$ classe, 12 chirurgiensde $2^{\mathrm{e}}$ classe, 16 chirurgiens de $3^{\mathrm{e}}$ classe, 1 pharmacien de $1^{\text {re }}$ classe, 3 de $2^{\mathrm{e}}$ classe et 3 de $3^{\mathrm{e}}$ classe.

La direction de l'intérieur se compose ainsi :

1 directeur, 2 chefs de bureau, 2 sous-chefs, 4 commis, un certain nombre d'écrivains.

Elle comprend deux bureaux : 
$1^{\circ}$ Bureau de l'Administration et du contentieux ;

$2^{\circ}$ Bureau de l'agriculture, du commerce, du culte, de l'instruction et de l'assistance publique.

Le service de l'immigration a un bureau à part.

Le personnel du service de l'enregistrement, des hypothèques et des successions vacantes se compose de 2 receveurs et 2 commis-receveurs.

Le personnel des douanes comprend:

1 sous-inspecteur, chef du service, 2 vérificateurs, 1 brigadier, 5 préposés, こ̋ canotiers.

Le personnel des ponts et chaussées comprend:

1 directeur, 1 sous-ingénicur colonial, 3 conducteurs, 1 agentvoyer, 1 agent comptable, 1 garde des matières, 6 piqueurs.

La ville de Cayenne a, pour diriger sa police, un personnel qui comprend :

1 commissaire de police, 1 commissaire de police adjoint, 1 brigade ( 1 brigadier, 4 gardes, 1 archer-caporal, 8 archers), 1 brigadier de gendarmerie, 4 gendarmes à pied, 57 surveillants.

Cayenne a, en outre, une prison et un atelier disciplinaire de femmes.

Chacun des quartiers de l'Approuague, de l'île de Cayenne, de Sinnamary et de Kourou a un atelier disciplinaire.

Le personnel du service de l'inspection et du contrôle de l'administration coloniale comprend :

1 commissaire de $2^{\mathrm{e}}$ classe de la marine, contrôleur; 1 souscommissaire délégué au magasin général, 1 aide-commissaire chef du bureau central.

L'Imprimerie du Gouvernement publie un Bulletin officiel de la colonie (mensuel), el un journal hebdomadaire, la Feuille officielle de la Guyane.

Son personnel comprend : 1 chef, comptable, 1 sous-chef correcteur, 1 maître compositeur, 5 compositeurs, 3 imprimeurs, 1 lithographe, 3 relieurs, 5 apprentis.

Un décret colonial du 30 juin 1835̆, modifié par un arrêté local du 2 août 1848, a réglé l'organisation municipale de la Guyane.

Cayenne a un conseil municipal, composé d'un maire, deux adjoints, neuf conseillers municipaux, tous nommés par le gouverneur. 
Ghacun des autres quartiers de la colonie a un commissairecommandant et un lieutenant-commissaire, aussi nommés par le gouverneur. Ils remplissent les fonctions de maires et d'adjoints. Les commissaires-commandants sont, en outre, chargés des fonctions de juges de paix et de police.

L'effectif militaire atteignait, en 1864, le chiffre de 1,359 hommes ; la station navale se composait de 5 avisos à vapeur, 5 goëlettes à voiles et 3 pénitenciers flottants.

\section{CHAPITRE V}

Justice. - Tribunaux de paix. - Tribunal de première instance. - Cour impériale. - Statistique judiciaire. - Culte. - Congrégations religieuses. - Hôpitaux. - Léproserie. - Bureau de bienfaisance. - Comité de vaccine. Instruction publique.

Les codes de la métropole sont exécutoires dans la colonie.

La justice est rendue par des tribunaux de paix, un tribunal de $\mathrm{1}^{\mathrm{re}}$ instance, une cour impériale, une cour d'assises.

Les juges de paix ont leur compétence déterminée par la loi du 25 mai 1838, sauf $1^{\circ}$ qu'ils connaissent, en dernier ressort, jusqu'à la valeur de $2000 \mathrm{fr}$. et, en premier ressort, jusqu'à $500 \mathrm{fr}$. pour les actions énoncées en l'article 1 de ladite loi, et $2^{\circ}$ qu'ils connaissent en dernier ressort jusqu'à $250 \mathrm{fr}$. des actions indiquées aux articles 2, 3, 4 et 5.

Le tribunal de première instance siége à Cayenne. Il se compose d'un juge impérial, d'un lieutenant de juge, d'un juge auditeur, d'un procureur impérial, de deux substituts et de deux greffiers. - Le juge impérial remplit les fonctions de juge d'instruction.

La cour impériale siége aussi à Cayenne. Elle comprend : 1 président, 2 conseillers, 1 conseiller auditeur, 1 greffier. - Le procureur impérial ou l'un de ses substituts remplit les fonctions du ministère public.

La cour d'assises se compose du président de la cour impériale, de deux conseillers et de quatre assesseurs, du procureur impérial ou de l'un de ses substituts.

Les juges et les assesseurs délibèrent en commun sur les questions de fait. La déclaration de culpabilité est rendue à la simple majorité. Les juges seuls statuent sur la question de compétence, 
l'application de la peine, les incidents de droit et de procédure, les dommages-intérêts demandés.

La statistique judiciaire de la colonie, pendant la période triennale 1859-1861, donne ce ehiffre moyen d'affaires par an :

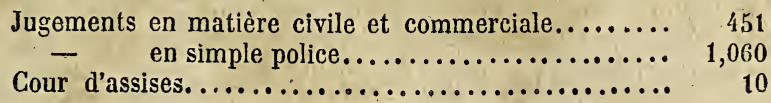

Les officiers ministériels se répartissent ainsị :

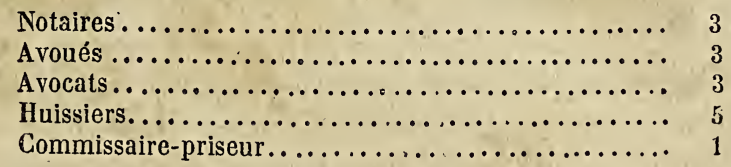

La mission de Cayenne, érigée en préfecture apostolique à la fin de 17 ŏl, est encore aujourd'hui sous ce régime.

Le culte catholique est dominant à la Guyane.

Le clergé comprend :

1 préfet apostolique et 18 prêtres.

La Guyane forme 11 paroisses.

On y compte cinq congrégations religieuses : les religieux du Saint-Esprit, les R. P. Jésuites, les frères de l'Institut de Ploërmel, les sœurs de Saint-Joseph de Cluny, les sœurs de Saint-Paul de Chartres.

Parmi les établissements hospitaliers, on remarque : l'hôpital militaire de Cayenne (800 lits); l'hospice civil du camp SaintDenis, près Cayenne; la léproserie de l'Accarouary, sur la Mana.

Cayenne possède aussi un bureau de bienfaisance, un comité de vaccine, etc.

La Guyane compte dix établissements d'instruction publique : le collége de Cayenne, confié aux frères del'instruction chrétienne, qui a 123 élèves; l'école primaire de Cayenne, aussi dirigée par les frères, qui a 220 élèves ; le pensionnat et les écoles primaires des sœurs, dirigés par les sœurs de Saint-Joseph de Cluny, où les enfants, les jeunes filles, les filles ou femmes adultes, reçoivent une instruction appropriée à leur âge; les écoles primaires mixtes, dirigées par des institutrices laïques, des salles d'asile, une école agricole, confiée aux Pères du SaintEsprit, et qui reçoit des externes et des pensionnaires de 9 à 14 ans. 


\section{CHAPITRE VI}

Agriculture. - Hectares cultivés. - Quantités récoltées. - Valeur des produits. Habitations rurales. - Statistique des travailleurs. - Animaux de trait. Bétail. - Canne à sucre, - Café. - Coton. - Rocou. - Cacao. - Girofle. Vanille. - Tabac. - Vivres. - Fruits. - Pâturages. - Établissements domaniaux. - Comité pour l'Exposition des colonies.

Sous le rapport agricole, la Guyane, avons-nous vu précédemment, se partage en terres hautes et en terres basses ou alluviales.

On a d'abord laissé de côté ces dernières pour cultiver les terres hautes. C'est à partir de l'administration de M. Malouet, en 1778, qu'on a abordé la culture des terres basses.

En 1863, on comptait 5,34د hectares 6 ares cultivés. Les cultures se répartissaient ainsi :

Canne à sucre.

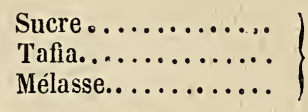

397 hect. $5\left\{\begin{array}{lr}\ldots & 470,373 \text { kil. } \\ \ldots & 263,435 \text { lit. } \\ \ldots & 6,750-\end{array}\right.$

Café.

Hectares cultivés..... $\quad 577.7 \quad \ldots \ldots \ldots . \quad 86,212$ kil.

Coton.

Hectares cultivés..... $\quad 29.2 \quad \ldots \ldots \ldots . \quad 3,526$ kil.

Cacao.

Hectares cultivés..... $\quad 146.5 \quad \ldots \ldots \ldots \quad 43,950$ kil.

Girofle.

Hectares cultivés..... $190.2 \ldots \ldots \ldots . \quad 20,917$ kil.

Rocou.

Hectares cultivés..... $985 \quad \ldots \ldots \ldots . \quad 328,650$ kil.

Epices, Vanille.

Hectares cultivés...... $\quad 21.5 \quad \ldots \ldots \ldots . \quad 450 \mathrm{kil}$.

Vivres du pays.

Hectares cultivés...... 2,998 ...... 2,916,676 kil.

Valeur de ces produits : $528,839 \mathrm{fr}$.

Le nombre des habitations rurales était de 1,415 en 1862, et de 1,462 en 1863:

Sucreries.

$1862 \ldots \ldots \ldots \ldots \ldots$ if $14 \quad 1863 \ldots \ldots \ldots \ldots \ldots 14$ 
GUYANE。

Cafeières.

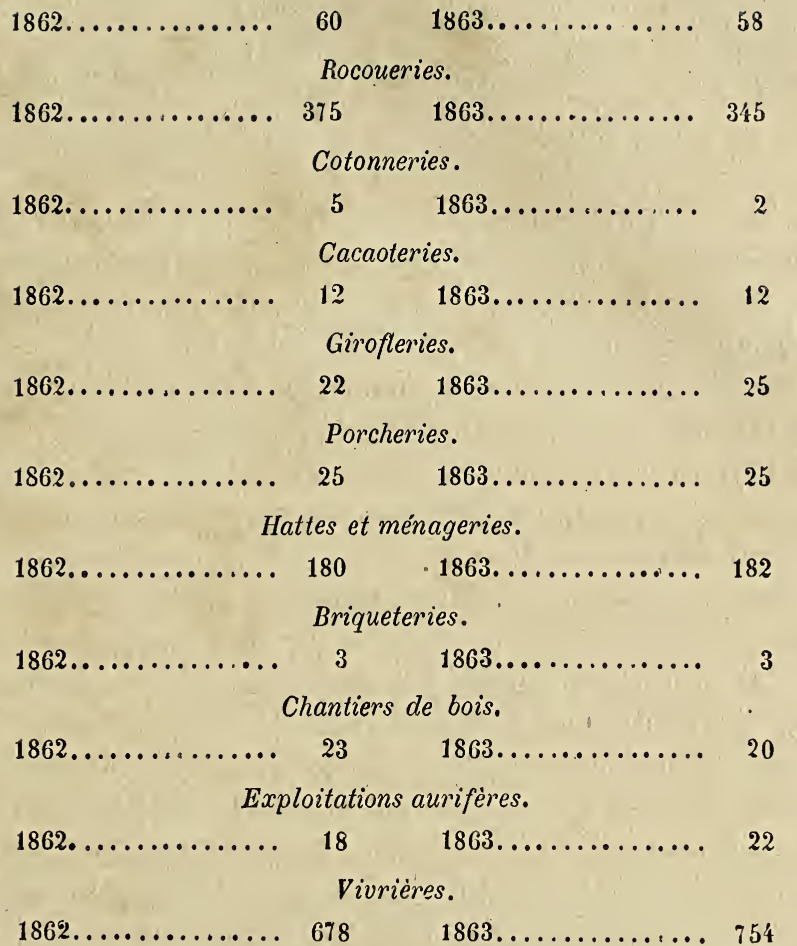

Nombre des travailleurs en 1863 , savoir :

Cultivateurs du pays...................... 7,829

Immigrants ..........................

Transportés.......................... 335

Nombre des animaux de trait et de bétail, avec leur valeur:

\begin{tabular}{|c|c|c|}
\hline Chevaux et juments..... & 98 & 500 \\
\hline Anes et mulets............. & 96 & 100 \\
\hline Béliers et brebis............. & 1,056 & 30 \\
\hline 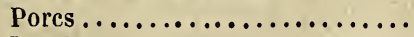 & 5,907 & 20 \\
\hline 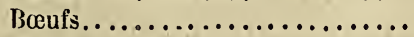 & 1,113 & 150 \\
\hline Taureaux et vaches........... & 3,410 & 180 \\
\hline Veaux et génisses............. & 4,231 & 50 \\
\hline
\end{tabular}

Capital employé aux cultures

Valeur des terres

$1862 \ldots \ldots \ldots 2,212,282$ fr. $\quad 1863 \ldots \ldots \ldots 2,281,897 \mathrm{fr}$. 
Valeur des batiments et du matériel d'exploitation. $1862, \ldots \ldots .3,542,850 \mathrm{fr}$. $1863 . \ldots \ldots 3,662,400 \mathrm{fr}$.

Valeur dés animaux de trait et de bétail. $1862 . . \ldots \ldots 1,045,220 \mathrm{fr}$. $1863 \ldots \ldots 1,226,720 \mathrm{fr}$.

Total pour $1862 \ldots \ldots \ldots \ldots \ldots \ldots \ldots \ldots, 6,800,352 \mathrm{fr}$.

Total pour $1863 \ldots \ldots \ldots \ldots \ldots \ldots \ldots \ldots$ 7,171,017

Les objets, qui donnent surtout matière à culture, sont: la canne à sucre (canne jaune, canne violette de Batavia, canne de Taïti), le café, le coton, le rocou, le cacao, le girofle, le cannellier, le muscadier, le poivrier, la vanille, le tabac, les vivres (manioc, riz, maïs, bananes, ignames, patates, arbres à pain), les fruits (ananas, banane, sapotille, barbadine, oranges, pomme cannelle, corossol, mangue, goyave, avocat, coco, grenade, monbin), les fruits oléagineux (aoura, palmier à huile, yayamadou ou muscadin à suif, noix de coco et de bancoule, carapa).

“ Dans les vastes savanes situées dans les quartiers de Macouria, de Kourou, de Sinnamary, d'Iracoubo, de Mana, sous le vent de Cayenne, et sur les bords de l'Oyapock, se trouvent les hattes ou ménageries consacrées à l'éducation des troupeaux de la colonie. Mais ces prairies naturelles auraient besoin d'être améliorées; il en est qui, pendant l'été, sèchent compléternent et dont l'herbe brûlée par le soleil n'offre plus de nourriture aux bestiaux. Il en est d'autres dont le sol plus marécageux conserve l'eau croupissante, où l'herbe aigrie cesse d'être bonne à manger.

a Il conviendrait de pratiquer, dans ces dernières, des saignées qui, en donnant de l'écoulement aux eaux, préviendraient la fermentation de ces herbes. Quant aux premières, la culture de l'herbe de Guinée et du Para y procurerait un excellent fourrage susceptible d'être consommé à l'étable, à l'époque de l'année où les pâturages viennent à manquer. La pénurie de fourrage est telle qu'on est obligé d'en faire venir de France et de l'étranger. Pour donner l'exemple aux colons, l'Administration a créé, surl'habitation Bourda, des herbages qui ont produit, en 1862 , 200,000 kil. de fourrages verts.

"La colonie est loin de produire tous les bestiaux nécessaires à la consommation locale, malgré les primes fondées en 1837 en faveur des propriétaires qui présenteraient chaque année, à un concours public, les plus beaux animaux, ou qui auraient introduit des améliorations dans le régime de leurs ménageries. » (V. J. Itier, Notices statistiques sur la Guyane franc.) 
Trois établissements agricoles : Baduel, jardin de naturalisation; Bourda, où l'administration a créé des plantations d'herbes pour les bestiaux; la Gabrielle, où l'on cultive spécialement le girofle; enfin, un comité d'exportation, contribueront à donner tout son essor à la colonie.

\section{CHAPITRE VII}

Industrie. - Sucre. - Forêts. - Gisements aurifères. - Vers à soie. - Briqueteries. - Pêche. - Commerce. - Régime commercial. - Statistique commerciale entre la Guyane et la France, de 1855 à 1863. - Importations. Exportations. - Oujets importés. - Objets exportés. - Réexportations. -

- Entrepôt. - Navigation. - Douanes.

La production et la préparation des produits du pays, l'industrie de la Guyane ne sort guère de là.

Elle possède quatorze sucreries ; mais les procédés dont on use sont arriérés; la cuite s'y fait encore à feu nu.

Les forets de la Guyane, disent les Notices du ministère de la marine, offrent des ressources inépuisables aux constructions navales, à l'ébénisterie, au charronnage et aux chemins de fer. Déjà, en 182.’, 1834 et 18วั2, d'heureux essais ont été faits pour notre marine; mais c'est surtout dans ces dernières années, que l'industrie forestière a commencé à se développer avèc l'aide de la transportation. Indépendamment des chantiers établis par le service pénitentiaire, on comptait, en 1862, 24 chantiers particuliers, occupant 413 ouvriers dont 173 transportés.

On compte 76 principales espèces de bois. Les meilleures pour les constructions navales sont: l'angélique, le coupi, le bois de rose mâle, le wacapou, le grignon, le courbaril, le taoul, le balata, le cèdre noir, etc.

La plupart de ces bois sont supérieurs, comme l'ont démontré des expériences récemment faites dans nos arsenaux, aux chênes de France et aux bois de Teck, sous le triple rapport de la durée, de la solidité et de l'élasticité.

La séve de balata fournit une gutta-percha supérieure à celle de l'Inde.

L'arbre à caoutchouc est également abondant à la Guyane, mais on ne le trouve en famille que sur la partie contestée, entre l'Amazone et l'Oyapock. On trouve encore sur une espèce de 
figuier, très-abondant dans le pays, une gomme qui possède des qualités analogues à la gutta-percha.

Le palétuvier est très-commun sur le bord de tous les fleuves. Il contient 5 à 7 fois plus de tannin que l’écorce de chêne.

Les gisements aurifères de la Guyane méritent toute l'attention possible. Pour les exploiter, il ne faut que des bras, qui manquent encore. Outre la grande exploitation de la compagnie concessionnaire de l'Approuague, on en compte 21 autres, situées dans le quartier de Roura.

A la fin de 1862 le nombre des travailleurs occupés aux placers était de 369.

On a trouvé des pépites de 60,93,97, 188 et même de $3 ð 5$ grammes.

L'analyse de divers échantillons a donné, sur 100 parties :

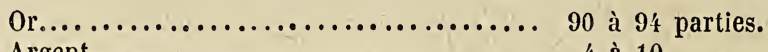

Argent........................ 4 à 10

Depuis 1860, la production de l'or natif a suivi cette progression :

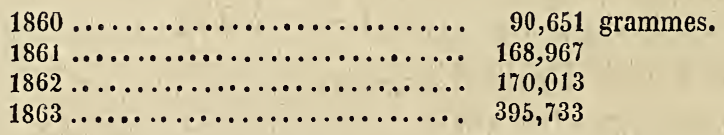

L'élève des vers à soie est susceptible d'une grande prospérité à la Guyane.

En 1858, un habitant du pays, M. Michély, a entrepris des essais d'éducation à l'air libre qui ont parfaitement réussi.

Les éclosions sont échelonnées de manière à obtenir une montée tous les dix à douze jours. Le cocon est confectionné en 36 heures; le papillon donne de 5็ॅ0 à 590 œufs. La nourriture de cette larve est une espèce de mûrier qui peut produire quatre récoltes de feuilles par an.

On a calculé qu'un hectare planté en mûriers pouvait donner, en quatre récoltes de feuilles, au moins 35,000 kilogr. de cocons, lesquels, à こ fr. le kilogr., représenteraient une valeur de $175,000 \mathrm{fr}$.

Les cocons envoyés à Paris par M. Michély ont été reconnus supérieurs, pour la qualité de leur matière soyeuse, à la plupart de ceux que l'on obtient, en France êt en Italie, depuis l'invasion de l'épidémie sur les vers à soie. 
Des sept briqueteries qui fonctionnaient en 1836, il n'en restait plus que 3 à la fin de 1863. C'est une industrie en pleine décadence.

Les rivières et les côtes de la Guyane sont très-poissonneuses. Le produit de la pêche est consommé sur place. Les lacs de l'intérieur possèdent le pirarocou ou curi, très-abondant, dont la chair desséchée est à la fois délicate et d'une conservation longue et facile.

On en pourrait faire un article d'exportation, comme aussi de machoiran, dont les vessies natatoires, sous le nom d'ichthyocolle, sont depuis longtemps exportées .

La colle de Machoiran, employée en Hollande et en Angleterre, à la clarification de la bière, rend moins que la colle d'esturgeon de Russie, mais elle ne coûte que 3 fr. le kilogr.

Le régime commercial de la Guyane est soumis au décret du 24 décembre 1864.

Le port de Cayenne est ouvert aux bâtiments français et étrangers.

Les marchandises et denrées de toute nature et de toute provenance y sont admises par tous pavillons au droit de 3 p. 100. Importées par navires étrangers, elles acquittent, en outre, une surtaxe de pavillon:

10 fr. par tonneau d'affrétement, pour navires venant des pays d'Europe, et des pays non européens situés sur la Méditerranée.

$10 \mathrm{fr}$. id. pour navires venant des pays situés sur l'océan Atlantique, y compris la ville du Cap et son territoire.

20 fr. id. pour navires venant d'ailleurs.

Une taxe de $10 \mathrm{fr}$. est perçue, par tonneau d'affrétement, quand le transport des produits de la colonie ou des objets importés est effectué sous pavillon étranger, pour France, Algérie, Martinique et Guadeloupe; de $20 \mathrm{fr}$. pour la Réunion.

L'introduction dans la colonie du poisson salé par les pêcheurs indigènes donne droit à une prime de $15 \mathrm{fr}$. par 100 kilogr.

Pour tenir lieu de l'impôt foncier, les denrées qui suivent payent des droits de douane à la sortie : 


\begin{tabular}{|c|c|c|c|c|c|c|}
\hline Sucre brut ou terré, les & 100 & & $\begin{array}{c}\text { Navi } \\
0\end{array}$ & $\begin{array}{l}\text { français } \\
70 \mathrm{c.}\end{array}$ & Navi & $\begin{array}{l}\text { étrange } \\
30 \mathrm{c} .\end{array}$ \\
\hline 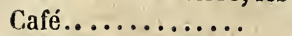 & - & .. & 2 & 50 & 5 & 50 \\
\hline Coton............ & - & $\ldots$ & 2 & $n$ & 3 & 50 \\
\hline Rocou... & . & & 1 & 50 & 1 & 50 \\
\hline Girofle. & - & & 1 & 25 & 2 & 50 \\
\hline Griffes de girofle... & - & $\ldots$ & 0 & 10 & 0 & 40 \\
\hline Tafia, les 100 litres. & & $\ldots$ & 0 & 50 & 0 & 50 \\
\hline Cacao, les 100 kil. & & & 0 & 45 & 1 & 80 \\
\hline Mélasse, les 1,000 ki & & & 0 & 50 & 0 & 50 \\
\hline Peaux de boufs, la piè & ce & & 0 & 25 & 0 & 50 \\
\hline
\end{tabular}

Le commerce de la Guyane avec la France, de 1850 à 1863 , présente les chiffres suivants:

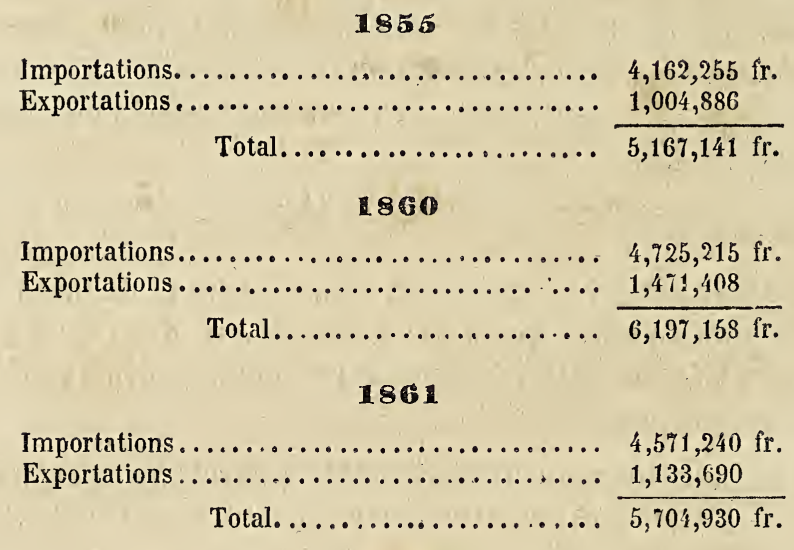

1862

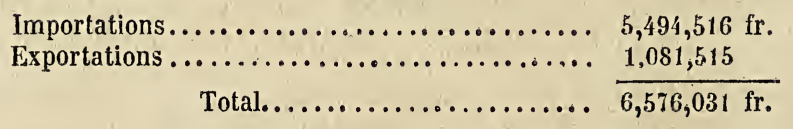

1863

Importations..................... $4,920,480 \mathrm{fr}$.

Exportations .................... 459,992

Total................. $\overline{5,380,472 \mathrm{fr} .}$

Pendant les mêmes années, le commerce de la Guyane avec les autres colonies françaises et l'étranger, a été comme suit:

\section{5}

Importations...................... 1,328,646 fr.

Exportations ...................... 269,959.

Total................. $\overline{1,598,605 \mathrm{fr} .}$ 


\section{0}

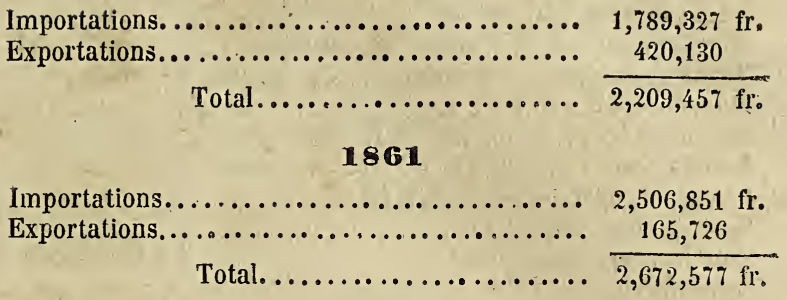

1862

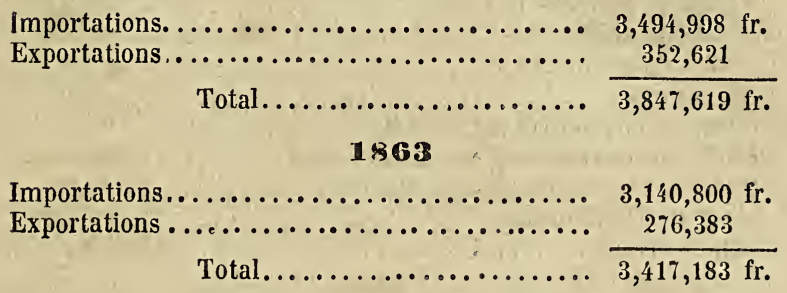

En 1863, le commerce général de la colonie s'est élevé à $9,7650,555$ fr.:

\section{Importations.}

Marchandises françaises venant de France..... - des colonies françaises..........

Marchandises étrangères par navires français... - $\quad$ - par navires étrangers.

Total

\section{Exportations.}

Denrées du cru de
la colonie exportées
pour .............

Marchandises provenant des importat.

Total.

$$
\begin{gathered}
5,653,806 \mathrm{fr} . \\
4,052 \\
553,085
\end{gathered}
$$

$2,583,664$

$8,794,607$ fr.

$694,564 \mathrm{fr}$.

50,393

160,991

50,188

14,312

$970,948 \mathrm{fr}$.

Il y a eu, en 1863, une diminution de 178,172 fr. sur 1862. Les principales denrées et marchandises composant les importations, ont été :

Bœufs vivants $(3,736$ têtes)

Mules et mulets $(24$ têtes).................

Autres animaux vivants.

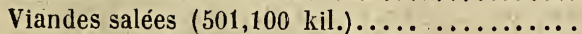

Viandes apprêtées [bœuf bouilli] $(192,170$ kil.).

Beurres et saindoux $(136,145$ kil. $) .. \ldots \ldots \ldots \ldots$.

Fromages $(69,937$ kil. $) . \ldots \ldots \ldots \ldots \ldots \ldots \ldots$

Poissons de mer (451,790 kil.).
$762,026 \mathrm{fr}$.

20,100

30,490

747,708

456,708

317,728

64,763

225,873 
Farine de froment $(1,826,340$ kil. $) . \ldots \ldots \ldots \ldots$

Riz $(428,779$ kil. $) . \ldots \ldots \ldots \ldots \ldots \ldots \ldots \ldots .$.

Légumes secs $(407,264$ kil. $) . \ldots \ldots \ldots \ldots \ldots \ldots$

Huiles de graines et d'olives $(93,149$ kil. $) .. . .$. .

Tabac en feuilles $(41,301$ kil. $) . \ldots \ldots \ldots \ldots \ldots$.

Houille $(4,165,175$ kil. $) .. \ldots \ldots \ldots \ldots \ldots \ldots \ldots$.

Métaux divers $(109,759$ kil.)..............

Savons blancs $(97,594$ kil. $) . \ldots \ldots \ldots \ldots \ldots \ldots$.

Bougies et chandelles $(29,837$ kil. $) . \ldots \ldots \ldots \ldots$.

Sucre raffiné $(59,400$ kil. $) \ldots \ldots \ldots \ldots \ldots \ldots \ldots$

Vins français $(1,806,076$ lit. $) \ldots \ldots \ldots \ldots \ldots \ldots$

Eaux-de-vie $(92,947$ lit. $) \ldots \ldots \ldots \ldots \ldots \ldots \ldots \ldots$

Vitrifications diverses....................

Tissus de lin et de chanvre................

- de laine..........................

- de coton...........................

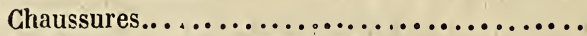

Cordages en chanvre $(52,887$ kil. $) .. \ldots \ldots \ldots \ldots$.

Machines, ouvrages en métaux divers.........

Mercerie, modes et articles de Paris..........

Linge et habillements...................

Objets divers..................... 1,138,142

$1,010,950$

186,554

203,632

207,523

150,972

249,916

95,834

97,594

85,192

65,340

$1,025,326$

105,269

76,180

309,307

87,377

283,648

132,204

86,752

163,746

127,206

280,548

Les denrées et marchandises du cru exportées en 1863 sont

Peaux brutes $(3,283$ kil. $) \ldots \ldots \ldots \ldots \ldots \ldots \ldots$

Vessies natatoires desséchées $(3,030$ kil.)......

12,119

Sucre brut (237,932 kil.).................

97,466

Cacao brut $(24,762$ kil. $) \ldots \ldots \ldots \ldots \ldots \ldots \ldots \ldots$

28,331

Café $(1,392$ kil.).......................

3,063

Coton $(1,974$ kil. $) .. \ldots \ldots \ldots \ldots \ldots \ldots \ldots \ldots$

5,156

Girofle [clous et griffes] $(4,522$ kil. $) .. \ldots \ldots \ldots$.

Muscades et vanille $(73,041$ kil.).............

Bois de construction $(1,225$ stères $) \ldots \ldots \ldots \ldots$.

4,838

902

95,771

Bois d'ébénisterie $(498,096$ kil.).............

46,563

Rocou $(167,949$ kil. $) .. \ldots \ldots \ldots \ldots \ldots \ldots \ldots \ldots$

165,315

1,182

4,293

4,500

Citrons en saumure (432 lit.)..............

Graines de carapa $(15,000$ lit.).............

Or natif $(131$ kil, 911$) \ldots \ldots \ldots \ldots \ldots \ldots \ldots \ldots$

Objets divers.

395,733

3,865

La réexportation a présenté, en outre, une valeur de $64,500 \mathrm{fr}$. Le décret du24 décembre 1864 a porté à un an la durée de l'entrepôt. Cayenne a un entrepôt fictif.

Les douanes ont perçu, en 1863 :

Droits d'entrèe.

$140,832 \mathrm{fr}$.

- fixes de sortie................... 15,184

- de pilotage..................... 14,704

- de magasinage et d'entrepôt.......... 1,307

Total................ 
Depuis le décret du 24 décembre 1864, la navigation française est seulement protégée par une surtaxe d'affrétement qui varie, on l'a vu précédemment, suivant les distances.

Le droit de francisation est de $60 \mathrm{fr}$. pour bâtiments de 100 tonneaux et au-dessous; au-dessus de 300 tonneaux, il est de $15 \mathrm{fr}$. en sus par 100 tonneaux.

Le droit de congé est de 20 fr. pour un bâtiment au long cours et de $15 \mathrm{fr}$. pour un caboteur.

Le droit de pilotage, à l'entrée comme à la sortie, est de $306 \mathrm{fr}$. pour les bâtiments au-dessous de 50 tonneaux; il augmente de 10 fr. par 50 tonneaux jusqu'aux navires de 200 tonneaux, et de 15 fr. par 100 tonneaux au delà de ce tonnage.

En 1863, le mouvement général de la navigation a été comme suit :

A l'entrée: 114 navires; tonnage 23,000.

A la sortie : 109 navires; tonnage 21,784.

La France a fourni, à l'entrée: 47 bâtiments jaugeant 12,124 tonneaux; et à la sortie : 44 bâtiments jaugeant 11,314 tonneaux.

L'étranger a offert, à l'entrée : 67 bâtiments jauggeant 10,876

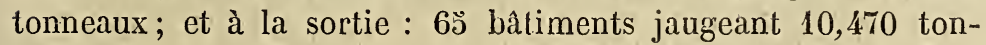
neaux.

\section{CHAPITRE VIII}

Finances. - Budget de l'État. - Budget local. - Banque de la Guyane. - Opérations de cette banque. - Service postal.

La Guyane entre dans les dépenses de l'État pour une somme de $6,832,750 \mathrm{fr}$. se répartissant ainsi :

\section{BUDGET DE L'ÉTAT (1864)。}

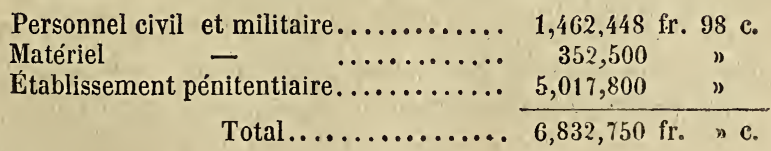

Les dépenses effectuées au compte du service marine et qui se sont, en 1862, élevées au chiffre de 1,059,257 fr., ne sont pas comprises dans le total ci-dessus. 


\section{BUDGET LOGAL.}

\section{Recettes.}

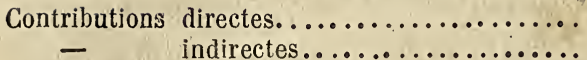

Droits de douane à l'entrée.................

- de navigation, pilotage, etc............

- de douane à la sortie...............

- d'enregistrement, hypothèques, etc......

Produits du domaine.....................

- de l'imprimerie......................

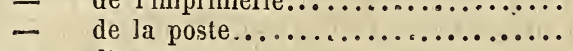

- divers.

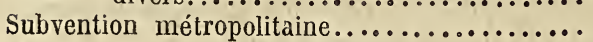

Total des recettes.

$185,700 \mathrm{fr}$.

36,800

145,000

15.060

16,000

46,500

44,940

30,000

10,000

53,600

523,000

$1,106,600 \mathrm{fr}$.

\section{Dépenses.}

A. Dépenses obligatoires.

Direction de l'intérieur.

59,560 fr.

Administration des communes. .............

Police...............................

Services financiers....................

Instruction publique...................

Ponts et chaussées......................

Service des ports.....................

Imprimerie........................

Prisons ............................

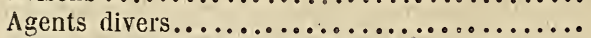

Dépenses assimilees à la solde.............

$30^{\mathrm{e}}$ à déduire pour incomplets......

Traitement dans les hôpitaux...............

Vivres...............................

Total du personnel.

72,450

73,020

52,800

56,050

33,300

19,890

40,700

19,900

17,860

15,000

$460,530 \mathrm{fr}$.

15,351

445,100

23,600

32,400

$501,100 \mathrm{fr}$.

\section{Matériel.}

Travaux d'entretien et de réparation.........

Matériel des services publics................

Loyers et ameublements..................

Entretien d'établissements d'assistance publique.

Subvention à l'immigration................

Recouvrement de l'impôt..................

Dépenses d'intérêt commercial..............

Dépenses diverses.....................

Total des dépenses obligatoires ....

$131,351 \mathrm{fr}$.

47,500

25,360

79,267

25,000

37,000

27,156

82,941

455,576

$956,676 \mathrm{fr}$.

B. Dépenses facultatives.

Travaux neufs ...................... 56,000 fr. Encouragements à la culture et à l'industrie... . 41,750 
Exploitation des habitations domaniales....... 27,684

Dépenses diverses et extraordinaires......... 24,490

Total général des dépenses....... $\frac{149,924}{1,106,600 \mathrm{fr}}$

La Banque de la Guyane, fondée en 183̆ 4 , au capital de 300,000 fr. en 600 actions de 500 fr., a été autorisée en 1863 à doubler son capital.

Elle est en pleine prospérité. Le dividende annuel qu'elle sert à ses actionnaires et qui'n'était en 1825 que de 25 fr., est aujourd'hui monté à 103 fr. (1863-1864).

Voici le mouvement général de ses opérations pendant l'exercice 1863-1864:

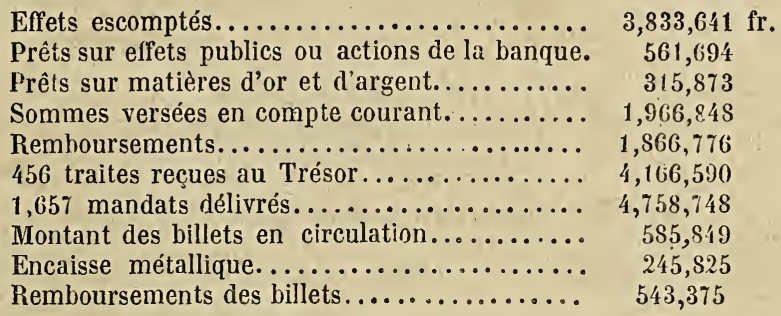

Deux voies, anglaise et française, mettent la Guyane en communication avec la France.

\section{Voie anglaise.}

(Royal mail steam navigation company.)

Départ de Southampton les 31 ou $1^{\text {er }}$ et 16 de chaque mois, passant par Démérari, arrivée à Cayenne les 24 et 9 du mois suivant.

Prix du passage (jusqu'à Démérari).

Cabine à l'arrière.......... 38 liv. st. 10 sh. (962 fr. 50). - à l'avant.......... 33 liv. (825 fr.)

Prix $d u$ passage (de Démérari à Cayenne).

$1^{\text {re }}$ classe (bateau français)............. $69 \mathrm{fr} .40 \mathrm{c}$.

$2^{\mathrm{e}}$ classe $\quad-\quad \ldots \ldots \ldots \ldots \ldots \ldots \ldots{ }_{25} \quad 6 \%$

j re classe (bateau hollandais)............. $114 \quad 70$

$2^{\mathrm{e}}-\quad-\quad \ldots \ldots \ldots \ldots \ldots .62 \quad 82$

2. Voie francaise.

(Compagnie transatlantique.)

(V. Service postal de la Guadeloupe et de la Martinique.) 
Tarif des lettres.

Lettre affranchie, par 10 grammes......... 0 fr. 70 c.

- non affranchie - $\quad \ldots . . . . . .6000$

- chargée, - $\quad$ - ........... 140

Imprimés, par 40 grammes..............; 0 ; 12

On paye $30 \mathrm{c}$. el $40 \mathrm{c}$. aux bâtiments de commerce, selon que les lettres sont ou non affranchies.

Le prix du passage par les navires du commerce est de $600 \mathrm{fr}$. (aller), et de $700 \mathrm{fr}$. (retour). - La moyenne de la traversée est de 50 jours (aller) et de 6 jours (retour). 


\section{ASIE}

\section{PREMIERE PARTIE}

\section{ÉTABLISSEMENTS DANS L'INDE}

\section{CHAPITRE PREMIER}

Coup d'œil historique.

Les établissements français dans l'Inde occupent ensemble une superficie de 49,622 hectares. Ce ne sont plus que des fragments de territoires isolés.

Ces établissements sont :

$1^{\circ}$ Pondichéry et son territoire (districts de Pondichéry, de Villenour et de Bahour); Karikal et les districts (Maganoms) en dépendant, - sur la côte de Coromandel;

$2^{\circ}$ Yanaon, son territoire et les villages (Aldées) en dépendant; la loge de Mazulipatam, - sur la côte d'Orissa ou Orixa;

$3^{\circ}$ Mahé et son territoire; la loge de Calicut, - sur la côte de Malabar;

$4^{\circ}$ Chandernagor et son territoire; les loges de Cassimbazar, Jougdia, Dacca, Balassore et Patna, - au Bengale;

$5^{\circ}$ La factorerie de Surate, — dans le Goudjérate.

Nous empruntons aux Notices publiées par le Ministère de la marine et des colonies les faits historiques qui suivent.

La plupart des nations européennes ont été attirées vers l'Inde par la perspective des immenses ressources qu'offre au commerce, à l'industrie, comme aux explorations de la science, cette riche et magnifique contrée. Les Portugais, les Danois et les Hollandais y plantèrent les premiers leur drapeau; mais leur prospérité n'y fut que passagère. 
L'Angleterre èt la France se disputèrent ensuite la suprématie de l'Inde.

La première expédition française qui se dirigea vers les mers de l'Inde, dans le but de s'y frayer dés débouchés commerciaux, remonte à l'année 1603. L'initiative en est due à une société de négociants de Rouen. L'entreprise échoua; plusicurs autres tentatives qui suivirent eurent le même résultat.

En 1642, création pär le cardinal de Richelieu d'une première compagnie des Indes orientales. Elle n'aboutit à rien.

En 1664, Colbert reconstitua la Compagnie sur de plus larges bases. Il lui accorda une exemption de taxes et le monopole du commerce de l'Inde pendant 50 ans.

En 1678, Caron, chef de la Compagnie, crée un comptoir à Surate. - Cette ville ne répondant pas à l'idée qu'il s'étail forrnée pour un établissement principal, il enlève aux Hollandais la baie de Trinquemalé, dans l'île de Ceylan.

En 1682, la baie de Trinquemalé ayant été reprise par les Hollandais, Caron passe à la côte de Coromandel; il s'y empare de San-Tomé, ville portugaise qui, depuis 12 ans, était au pouvoir des Hollandais.

Caron ne put se maintenir à San-Tomé; il la restitua aux Hollandais en 1674.

En 1683, la ruine de la Compagnie était imminente, sans l'habileté d'un de ses agents, François Martin. Cet actif administrateur rallia sous sa conduite une soixartaine de Français, débris des colonies de Ceylan et de San-Tomé, et vint se fixer à Pondichéry qu'il acheta au souverain ảu pays. Il fortifia la ville, et grâce à son habile administration, la petite colonie ne tarda pas à devenir florissante.

En 1688, Chandernagor est cédé à la Compagnie par le GrandMegol.

En 1693, les Hollandais s'emparent de Pondichéry.

Le traité de Riswick (1699) rendit Pondichéry à la France. Cette ville devint le chef-lieu des possessions françaises dans l'Inde; Martin en fut nommé gouverneur général. — Sous son habile administration, le commerce prit une grande activité.

En 1727, cession de Mahé à la Compagnie.

En 1739, cession de Karikal.

Dans la guerre de 1741, la rupture de la France et de l'Angleterre mit aux prises Pondichéry et Madras. Une escadre anglaise 
croisant dans les mers de l'Inde, paralysait notre commerce et faisait beaucoup de captures. Mahé de Labourdonnais équipa à ses frais une petite flotte de neuf bâtiments, dispersa l'escadre ennemie et vint mettre le siége devant Madras qui capitula le 21 septembre 1746. On la rançonna à dix millions. - Mais bientôt, usant de représailles, les Anglais paraissent devant Pondichéry avec une escadre de 32 bâtiments et 4,700 hommes de troupes européennes, auxquelles se joignent 4,000 hommes. de troupes indiennes. - Dupleix, après avoir défendu la ville pendant 42 jours de tranchée ouverte, contraint les Anglais à la retraite (1748).

La paix d'Aix-la-Chapelle, conclue la même année, mit fin aux hostilités et permit à Dupleix, qui rêvait pour la France un empire dans l'Inde, d'y porter haut sa puissance.

De 1746 à 175ّ6, Dupleix obtint du Grand-Mogol la Nababie de Carnate, se fit le protecteur des soubabs d'Arcate et de Decan, auxquels il fit payer un tribut considérable, -acquit de vastes accroissements de territoire à Pondichéry, à Karikal, à Mazulipatam, à Yanaon, et étendit la domination française sur les quatre provinces de Montfanagar, d'Ellour, de Rajamandri et Chicakal, ainsi que sur l'île de Seringam, formée par deux bras du Cavéry. Ces différents établissements offraient à notre commerce 200 lieues de côtes et un revenu annuel de 20 millions de francs.

Malheureusement, ces splendeurs n'eurent qu'un éclat passager. Dupleix, abandonné à lui-même par la Cour de Versailles, éprouva des revers dans là lutte acharnée qu'il eut à soutenir, avec des forces inégales, contre les princes de Tanjaour et de Maissour et contre les Marattes, conjurés pour notre ruine avec les Anglais, sous les ordres des généraux Clive et Warren-Hastings.

Dupleix fut rappelé à Paris en 1753 .

En 1761, les Anglais nous battent à Vandabachi, s'emparent d'Arcate et investissent Pondichéry. Lally-Tollendal, qui défend la place contre 2,000 Anglais avec 700 hommes, sans munitions et sans vivres, se rend. L'ennemi détruit la ville; les Français sont chassés; notre prépondérance dans l'Inde est anéantie.

Toutefois, en 1763, la paix nous fait rentrer en possession de Pondichéry et de nos autres comptoirs, mais arec de grandes réductions territoriales.

En 1769, abolition du privilége de la Compagnie des Indes. Le 
commerce devint libre; on en conçut quelques espérances et Pondichéry recouvra un peu de son ancienne splendeur. - Quelques années après, en 1778, Pondichéry retombait au pouvoir des Anglais.

Le bailli de Suffren, envoyé au secours de l'Inde, fait preuve de beaucoup de courage et de hauts talents; avec de médiocres ressources, il livre quatre combats aux Anglais en sept mois, bat la flotte de l'amiral Hughes, et reprend en trois jours le fort de Trinquemalé (1782).

Le traité de Versailles (1783) nous rendit Pondichéry et nos autres établissements. - Ce fut pour les évacuer de nouveau et par force en 1793.

La paix d'Amiens nous les rendit encore (1802). Mais, en 1803, Pondichéry passa pọur la quatrième fois aux mains des Anglais.

Les traités de 1814 et 1815 nous rendirent Pondichéry et les autres établissements, réduits dans leurs limites.

L'administration anglaise remit à la France Pondichéry et Chandernagor le 4 décembre 1816.

Elle lui remit Mahé le 12 janvier, Karikal le 14, et Yanaon le 12 avril 1817.

Une convention, conclue le 7 mars 1815 avec legouvernement anglais, avait établi les stipulations suivantes : $1^{\circ}$ Renonciation du gouvernement français au droit de réclamer de la Compagnie des Indes anglaises 300 caisses d'opium au prix de fabrication; payement par la France de la valeur de ces caisses au prix moyen de Calcutta ; $2^{\circ}$ droit concédé au gouvernement anglais d'acheter, à un prix déterminé, le sel fabriqué dans nos établissements et excédant les besoins de leur consommation ; $3^{\circ}$ en compensation du préjudice causé à nos établissements par ces stipulations, payement annuel par le gouvernement anglais à la France d'une rente de 4 lacs de roupies sicca ( 1 million de francs). - Le traité du 13 mai 1818, pour rendre plus complet le monopole de la Compagnie des Indes anglaises, modifie cet état de choses; le droit de fabriquer le sel dans nos établissements nous est racheté moyennant une indemnité annuelle de 4,000 pagodes $(33,600 \mathrm{fr}$.), dont une partie est répartie, à titre d'indemnité, entre les anciens propriétaires de salines à Pondichéry et à Karikal, et dont le reste profite au budget local de nos établissements. Il n'est plus fabriqué de sel sur notre territoire; le gouvernement an- 
glais livre à l'autorité française, au prix de fabrication, le sel nécessaire à la consommation de nos établissements. Ce sel, revendu anx consommateurs" par le gouvernement français, donne un bénéfice qui est versé dans le trésor local.

Directeurs et gouverneurs des établissements de l'Inde.

1672. Caron, directeur de la Compagnie.

1680. Martin (François), gouverneur général.

170ð. Dulivier (P.), inttérimaire.

1707. Dulivier (P.), confirmé.

1708. Hébert (le chevalier).

1713. Dulivier (P.).

1715. Hébert (le général).

1718. De la Prévostière.

1721. Le Noir (Pierre-Christophe).

1723. Beauvallier de Courchant.

1726. Le Noir (P.-C.).

1735. Dumas.

1741. Dupleix.

1754. Godeheu.

17วั. Duval de Levrit.

17วั8. De Lally-Tollendal.

176ə. Law de Lauriston.

1765. Nicolas (François), intérimaire.

1766. Boyelleau (A.), intérim.

1767. Law de Lauriston.

1777. De Bellecombe (Guillaume-Léonard).

1778. D’Albignac, intérim.

1778. De Bellecombe.

178ว. De Goutenceau, intérim.

1785. De Souillac.

1785. De Cossigny (David).

1787. De Conway.

1789. De Fresne.

1793. Leroux de Touffreville, intérim.

1793. De Chermont.

Gouverneurs anglais.

1793. Braitwaite, général anglais. 
1793. Dixon, lieutenant-colonel anglais.

1802. De Méron, officier suisse au service de l'Angleterre.

Gouverneurs francais.

1803. Decaen (le général).

1803. Binot, intérim.

Gouverneurs anglais.

1804. Keit, lieutenant-colonel anglais.

180כ. Fallofield (E.-W.), $i d$.

1811. Lockhart, colonel anglais.

1812. Freser, colonel anglais.

1812. Freser (Y.-S.), capitaine anglais.

Gouverneurs français.

1816. Du Puy (le comte), pair de France, gouverneur civil. 1825. Cordier, capitaine de vaisseau, intérimaire.

1826. Desbassyns de Richemont (le vicomte), commissaire général de la marine, administrateur général.

1828. Scipion, intérim.

1828. Cordier, $i d$.

1829. De Mélay, capitaine de vaisseau.

1835. Saint-Simon (le marquis de), maréchal de camp.

1840. De Nourquer du Camper, capitaine de vaisseau.

1844. Pujol, capitaine de vaisseau.

1849. De Lalande de Calan, capitaine de frégate.

1850. Malassis, commissaire de la marine, intérim.

18วั1. Bédier, commissaire général de la marine.

1851. Malassis, intérim.

1852. De Verninac Saint-Maur, contre-amiral.

1857. Durand d'Ubraye, commissaire général de la marine.

1863. Bontemps, commissaire général de la marine.

\section{CHAPITRE II}

Pondichéry. - Karikal. - Yanaon. - Mazulipatam. - Mahé. - Calicut. Chandernagor. - Surate. - Loges.

1. Pondichéry.

La ville de ce nom est le chef-lieu de nos établissements dans l'Inde. 
Elle est située par $11^{\circ} 55^{\prime} 41^{\prime \prime}$ de latitude N. et $77^{\circ} 31^{\prime} 30^{\prime \prime}$ de longitude $\mathrm{E}$.

Un canal sépare la ville en deux parties: la ville blanche et la ville noire.

La ville blanche est située à l'est, sur le bord de la mer. L'hôtel du gouvernement, l'église paroissiale, l'église des missions étrangères, deux pagodes, le nouveau bazar, la tour de l'horloge, celle du Phare, une caserne, un hôpital militaire, sont les principaux édifices publics dont elle est ornée. Les rues en sont larges, bien percées.

Pondichéry n'a qu'une rade foraine; c'est la meilleure entre celles de la côte. Elle offre deux mouillages, par 3 à 6 brasses pour les petits navires, et par 7 à 9 brasses pour les grands batiments. On communique assez difficilement avec la terre au moyen de chelingues, bateaux à fond plat, sans membrure. Un pont débarcadère a été construit récemment.

La superficie totale du territoire de Pondichéry est de 29,069 hectares. Elle est répartie entre trois districts, ceux de Pondichéry, de Bahour et de Villenour, lesquels comptent 93 villages (aldées) principaux et 141 secondaires.

Huit cours d'eau sillonnent le territoire de Pondichéry: la rivière de Gingy, qui donne naissance à la rivière d'Ariancoupam et au Chounambar; le Pambear, qui se jette dans la rivière de Gingy; le Ceudouvear, qui se jette dans le Chounambar; le Ponnear, le Maltar et l'Oupar.

Les rivières de Gingy et d'Ariancoupam sont les plus importants de cescours d'eau. Elles sont navigables pendant quatre mois sur une étendue de 2 zilomètres.

Les trois districts ont, en outre, 9 grands canaux de dérivation, 5 barrages, 59 étangs, 202 sources, 53 réservoirs.

Le sol est formé d'une terre argileuse mêlée de sable et de terres sablonneuses légères. Il exige de constantes irrigations pour être productif.

\section{Karikal.}

Cette ville est également située sur la côte de Coromandel, par $10^{\circ} 5 \mathrm{ŏ}^{\prime}$ de latitude N. et $77^{\circ} 24^{\prime}$ de longitude E. Elle est à 26 lieues au sud de Pondichéry, et à 1 mille et demi de l'embouchure de l'Arselar, l'une des branches du Cavéry et qui a 16 lieues de cours. - "L'embonchure de l'Arselar est entièrement obstruée 
par les sables durant la saison sèche; elle est dégagée pendant la saison des pluies par les eaux de l'Arselar. - Les petits navires peuvent alors prendre charge à Karikal, et les bâtiments de 200 à 250 tonneaux, à varangues plates, remontent sur lest jusqu'à la ville.

"Le territoire de Karikal, dont la superficie est de 13,515 hectares, se divise en 5 districts ou maganoms, savoir: Karikal, Tirnoular, Nallajendour, Nédouncadou et Kitchéry. Ils renferment ensemble 109 aldées (villages).

«Le sol de ces cinq districts est très-fertile, et arrosé par six petites rivières qui sont autant de bras du Cavéry. Elles ont des débordements périodiques qui fertilisent les terres qu'elles couvrent. Ces irrigations se complètent par 14 canaux principaux et leurs ramifications. " (Notices, etc.)

\section{Yanaon.}

Ce comptoir, sis dans la province de Golconde, se trouve par $16^{\circ} 43^{\prime}$ lat. N. et $80^{\circ} 05^{\prime}$ long. E., à 140 lieues N.-N.-E. de Pondichéry.

"Bâtie à l'endroit où la rivière de Coringuy se sépare de Godavéry, la ville de Yanaon est bornée à l'est et au sud par l'une et l'autre de ces deux rivières. Le territoire qui en dépend couvre une superficie de 1,429 hectares; il s'étend le long du Godavéry, à l'est et à l'ouest de la rivière Coringuy, sur une longueur de 2 lieues et demie, et une largeur qui varie depuis 350 mètres jusqu'à 3 kilomètres. Le sol est très-fertile.

"Le Godavéry se jette dans la mer à 4 lieues au sud-est de Yanaon; son embouchure est obstruée par des bancs de sable. La rivière de Coringuy, au contraire, qui débouche également dans la mer, a un lit profond qui permet aux navires de 200 tonneaux de remonter jusqu'à Yanaon.")

\section{Mazulipatam.}

Depuis 1769, époque où les Anglais ont repris possession de la ville, la France ne possède plus à Mazulipatam qu'une loge avec le droit d'y faire flotter son pavillon. Cette ville est située dans la province des Circars septentrionaux, par $16^{\circ} 10^{\prime}$ lat. N., et $78^{\circ} 48^{\prime}$ long. E. à 110 lieues de Pondichéry et à 25 ou 30 lieues au sud de Yanaon. 
a Une aldée, nommée Francepett, située à 3 kilom. au N.-0. de Mazulipatam, et deux terrains habités par 200 Indiens environ, dépendent de la loge française de Mazulipatam, qui relève ellemême du comptoir d'Yanaon. Par une convention conclue avec l'Angleterre le 31 mars 1853 , nous avons abandonné le droit de vente et de fabrication des spiritueux dans cette loge, pour lesquels les Anglais nous payent annuellement une somme de 3,550 roupies $(8,520 \mathrm{fr}$.), qui figure parmi les recettes de la colonie. "

\section{ร. Mahé.}

Mahé est un comptoir situé sur la côte de Malabar, par $11^{\circ} 42^{\prime}$ $8^{\prime \prime}$ lat. N. et $73^{\circ} 12^{\prime} 23^{\prime \prime}$ long. E., à 104 lieues 0 . de Pondichéry. - Son territoire a une superficie de 5,909 hectares.

"La vilie de Mahé est située sur la rive gauche et près de l'embouchure d'une pelite rivière qui porte son nom, et qui est navigable pour des bateaux de 60 à 70 tonneaux, jusquà une distance de 2 ou 3 lieues dans l'intérieur. L'entrée de cette rivière est barrée par des rochers qu'on peut passer à marée haute; l'eau devient profonde dès qu'on a franchi cet obstacle. Un pont, qui n'est pas achevé, doit mettre en rapport les deux rives de la rivière de Mahé, que l'on passe aujourd'hui en bac.

"Les aldées, qui ont été rétrocédées à la France, sont séparées de la ville, et il a été construit une route pour fréquenter ces villages.

" La terre des fonds des environs est sablonneuse; le riz peut se cultiver sur le bord des rivières, où l'on produit des inondations artificielles. ")

\section{Calicut.}

Ville indo-anglaise sur la côte de Malabar, à 13 lieues S.-S.-E. de Mahé. La France y possède une loge.

\section{Chandernagor.}

Cette ville est située dans le Bengale par $22^{\circ} 51^{\prime} 26^{\prime \prime}$ lat. N. et $86^{\circ} 09^{\prime} 15^{\prime \prime}$ long. E., à 7 lieues au-dessus de Calcutta, à environ 400 lieues N.-N.-E. de Pondichéry. - Un chemin de fer relie Chandernagor à Calcutta.

“Bâti sur la rive droite de l'Hougly, l'un des bras du Gange, à $3 \preceq$ lieues de son embouchure, Chandernagor s'élève au fond d'une belle anse formée par le fleuve. La ville est grande; ses 
rues sont larges et alignées; ses maisons élégamment construites.

"La plus grande longueur du territoire français, du N. au S., est de $ّ, 187^{\mathrm{m}}$, et sa plus grande largeur, de l'E. à l'O., de $1,877^{\mathrm{m}}$. Sa superficie totale est de 940 hectares.

"L'Hougly est remonté en toute saison, jusqu'au-dessus de Chandernagor, par des bateaux à vapeur qui y trouvent constamment un tirant d'eau de 3 mètres. ")

\section{Surate.}

Ville indo-anglaise, par $21^{\circ} 11^{\prime}$ lat. N. et $70^{\circ} 46^{\prime}$ long. E., à 55 lieues N. de Bombay. - La France y possède une factorerie occupée par un gardien. Les jardin et pavillons en dépendant sont loués 2,000 francs.

\section{Loges diverses.}

Nous comprenons sous ce titre : la loge de Balassore, située par $25^{\circ} 37^{\prime} 10^{\prime \prime}$ lat. N. et $82^{\circ} 35^{\prime} 40^{\prime \prime}$ long. O.; celle de Dacca, située par $23^{\circ} 42^{\prime}$ lat. N. et $87^{\circ} 57^{\prime} 20^{\prime \prime}$ long. E. ; celle de Cassimbazar, par $24^{\circ} 10^{\prime}$ lat. N. et $86^{\circ} 9^{\prime}$ long. E. ; celle de Patna, par $25^{\circ}$ $37^{\prime}$ lat. N. et $82^{\circ} 57^{\prime} 10^{\prime \prime}$ long. E.; enfin, celle de Jougdia, située par $20^{\circ} 50^{\prime}$ lat. N. et $88^{\circ} 52^{\prime}$ long. E. Toutes sont dans le Bengale.

Chacune de ces loges se compose d'une maison et d'un petit territoire habité par des Indiens. Elles sont en location.

\section{CHAPITRE III}

Climat. - Pluies. - Marées. - Ports. - Phares. - Races. -

Statistique de la population. - Émigration.

Les Notices publiées par le Ministère de la marine et des colonies donnent sur les diverses questions de notre sommaire les détails qui suivent.

Le climat de Pondichéry est généralement salubre. Pendant les mois de décembre et de janvier, le thermomètre marque, le jour, de $2 כ$ à $28^{\circ}$ centig., et de mai à septembre (mois durant lesquels règne un vent d'ouest très-brûlant), la température varie de $31^{\circ}$ à $41^{\circ}$. Dans les temps ordinaires, la température moyenne est, pendant le jour, de $32^{\circ}$, et pendant la nuit de $26^{\circ}$. 
Du commencement de janvier jusque vers le 15 octobre règne la saison sèche. Le reste du temps appartient à l'hivernage. Les pluies sont généralement fort rares; il n'en tombe avec quelque fréquence qu'en octobre et novembre.

A la côte de Coromandel, la mousson du S.-0. commence vers le 15 mars et finit vers le 15 octobre, et celle du N.-E. dans les premiers jours de novembre et se prolonge jusqu'en mars. Les mois de mai, juin, juillet et août sont marqués par une brise variant de l'O. au S.-O., dite vents de terre.

Le climat et les saisons diffèrent peu, à Karikal, de ceux de Pondichéry.

A Yanaon, la température varie de 18 à $22^{\circ}$ d'octobre à mars, de 26 à $30^{\circ}$ d'avril à juin, et de 22 à $19^{\circ}$ de juillet à septembre. - La saison des pluies commence fin juillet et finit en octobre; il se passe souvent quatre à cinq mois sans pluie en été. - La mousson du S.-O. règne de mars à septembre, celle du N.-E. d'octobre à février. - Les vents d'O. règnent de mai à juillet, comme à la côte de Coromandel.

Chandernagor, à raison du grand nombre de bois et d'étangs qui environnent la ville, possède un climat beaucoup plus frais que Calcutta. - D'octobre en mars, la température moyenne est de $22^{\circ}$; elle tombe à $20^{\circ}$ en décembre et janvier; elle se maintient généralement entre $20^{\circ}$ et 25 en octobre, novembre et février; de mars en octobre, elle est en moyenne de $31^{\circ}$, avec des écarts jusqu'à $37^{\circ}:$ - Le mois de mai est le plus chaud de l'année. En mars et avril les pluies commencent; elles deviennent continues en juin et durent jusqu'à la mi-octobre; au mois d'août, elles sont torrentielles. - Pendant la saison sèche, les vents du S.-E. soufflent généralement; ceux du S. pendant les chaleurs; ceux du N.-O. au printemps et seulement pendant quelques jours ; le vend $d u \mathrm{~N}$. règne en hiver. - Le 5 octobre 1854 , un ouragan a détruit une grande partie de la ville.

Mahé a un climat salubre. Température plus fraîche et plus régulière que dans lès autres établissements de l'Inde. En janvier. février et mars, elle varie de $22^{\circ}$ à $26^{\circ}$; d'avril à septembre, de 2. à $30^{\circ}$; en octobre, novembre et décembre, de $23^{\circ}$ à $27^{\circ}$.

La saison d'hivernage est comprise entre le 15 mai et le 15 octobre; toutefois, la mauvaise saison ne dure que pendant juin, juillet et une partie d'août; en mai, bourrasques qui laissent la mer calme. 
D'avril à octobre, mousson du N. -E.; d'octobre à avril, mousson du S.-O. Les vents de l'O., du N.-E., du N.-O. et du S.-E. sont les plus fréquents.

Les marées indiennes ne sont ni si hautes ni si régulières que sur les côtes de l'Océan en Europe. A Pondichéry, la hauteur de la pleine mer ne dépasse pas habituellement 1 mètre, sauf dans les grandes marées où parfois elle atteint $2^{\mathrm{m}}, 50$ et $2^{\mathrm{m}}, 60$.

A Karikal, elle est, en moyenne, aux nouvelles et aux pleines lunes, de $\mathbf{1}^{\mathrm{m}}, \mathbf{6 2 4}$.

Aux nouvelles et aux pleines lunes, l'heure de la pleine mer est $1^{\mathrm{h}} \cdot 30^{\mathrm{m}}$. à Pondichéry, et 9 heures du matin à Karikal.

Pondichéry possède un phare à feu fixe d'une portée de 12 à 15 milles. Il est établi sur une tour voisine du rivage et élevée de 90 pieds anglais au-dessus du niveau de la mer.

Karikal a un feu fixe d'une portée de 8 à 10 milles. Il est établi sur le mât des signaux à l'embouchure de la rivière et élevé de 34 pieds anglais.

La population des établissements français dans l'Inde se compose de trois principaux éléments :

$1^{\circ}$ D'Européens et de descendants d'Européens;

$2^{\circ}$ De Topas ou gens à chapeau, population mixte ;

$3^{\circ} \mathrm{D}$ 'Indous ou indigènes.

La population indigène se divise en deux classes : les Indous et les Musulmans, chacune ayant son langage, ses mœurs, sa religion et ses contumes.

Les Indous se subdivisent en une foule de castes qui varient dans chacun de nos établissements, mais dans lesquelles on retrouve toujours les quatre classes principales, savoir : la caste sacerdotale ou celle des Brahmés; la caste militaire et royale ou des Kchatryas; la caste agricole et commerçante ou des Vaicyas; enfin la caste servile ou des Soûdras. - Les Parias, que l'on trouve partout, ne sont d'aucune caste.

Les Indous appartiennent par les traits du visage à la race caucasique. Ils sont d'une couleur noir clair. Beaucoup sont petits, faibles, mais agiles dans leurs mouvements; les muscles sont grêles, le système nerveux peu développé. Leurs cheveux sont noirs, touffus, rudes au toucher. Les populations de la côte de Malabar sont généralement plus vigoureuses que celles des côtes de Coromandel et du Bengale.

Les Musulmans, moins nombreux que les Indous, ont sur 
eux une supériorité intellectuelle et physique. La teinte de leur peau est moins foncée que celle des races indiennes. Les traits mâles de leur visage, leur taille élevée, leur barbe noire et bien fournie, leur constitution robuste et nerveuse rappellent la race arabe.

Les Topas ou gens à chapeau sont issus des Européens, généralement des Portugais, alliés aux femmes indigènes. Ils sont d'une couleur de peau moins foncée que celle des Indous. Le sang qui coule dans leurs veines les rattache à la population européenne, dont ils ont pris l'habillement.

Dans nos établissements, les Européens s'adonnent généralement au commerce, les Topas à quelques industries de ville ou à la domesticité, les indigènes à l'exploitation des terres, à la filature du coton, au tissage au métier et à la teinture en bleu des toiles de coton.

La population totale de nos établissements de l'Inde s'élevait, au $1^{\text {er }}$ janvier 1862 , à 220,478 individus, ainsi répartis :

Pondichéry.

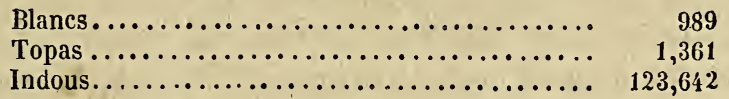

Karikal.

Blancs ............................ 212

Indous . ..................... 52,431

Chandernagor.

Blancs.............................. 239

Topas ............................ 160

Indous.......................... 28,113

Yanaon.

Blancs................................ $\quad 39$

Topas ............................... $\quad 35$

Indous........................ 6,385

Mahé.

Blancs.............................. $\quad 13$

Indous................................. $\quad 6,859$

Dans le chiffre des blancs, on ne comprend pas la garnison européenne qui s'élevait, au $1^{\text {er }}$ janvier 1863 , à 143 sous-officiers et soldats; on y comprend les fonctionnaires au nombre de 852 .

$\mathrm{Au} \mathrm{1}^{\mathrm{er}}$ janvier 1864, la population de nos établissements de l’Inde présentait le chiffre de 229,057 individus. 
En 1861, les cinq établissements ont compté 8,341 naissances, 8,10 décès et 2,714 mariages, c'est-à-dire 1 naissance par 26 individus, 1 décès sur 27 et 1 mariage sur 81 .

De 1848 à 1863, les émigrants indiens partis de Pondichéry et Karikal pour plusieurs de nos colonies (Réunion, Martinique, Guadeloupe et Guyane) ont atteint le chiffre de 70,000.

La société d'émigration établie à Pondichéry n'existe plus. Elle a été renversée par la convention du $1^{\text {er }}$ juillet 1861 , conclue avec le gouvernement anglais, par laquelle tous les ports de l'Inde anglaise sont ouverts à nos recrutements. Dans chaque centre de recrutement (Calcutta, Yanaon, Madras, Pondichéry, Karikal, Mahé, Bombay), le gouvernement français a un agent de son choix qui reçoit une sorte d'exéquatur du gouvernement britannique.

\section{CHAPITRE IV}

Gouvernement colonial. - Administration de la marine. - Contrôle. - Service des ports. - Service de santé. - Administration financière. - Police. Ponts et chaussées. - Effectif militaire.

L'ordonnance du 23 juillet 1840 a organisé le gouvernement et l'administration des possessions françaises dans l'Inde.

Le commandement et la haute administration sont confiés à un gouverneur qui réside à Pondichéry. Sous ses ordres des chefs de service administrent les quatre établissements de Karikal, Chandernagor, Mahé et Yanaon.

\section{Gouvernement colonial.}

1 gouverneur (à Pondichéry); 1 chef de service pour chacun des quatre établissements; 1 sous-commissaire, secrétaire-archiviste; 1 écrivain; 5 interprètes.

Administration de la marine.

1 commissaire de la marine, ordonnateur et directeur de l'intérieur; 3 sous-commissaires; 1 aide-commissaire; 3 commis, 20 écrivains de la marine (à Póndichéry); 8 écrivains de la marine (pour les 4 autres établissements).

\section{Contrôle.}

1 commissaire adjoint de la marine, contrôleur colonial; 
1 aide-commissaire chef du bureau central ; 9 écrivains; 1 interprète (à Pondichéry); $\mathbf{- 1}$ aide-commissaire, 5 écrivains (à Karikal) ; -1 aide-commissaire (a Chandernagor).

\section{Service des ports.}

1 capitaine de port, 1 maitre de port, 2 écrivains, 3 guetteurs, 1 chef de macouas ou bateliers indiens (à Pondichéry); - 1 lieutenant de port, 1 écrivain, 5 agents subalternes (à Karikal); 1 écrivain, 1 garde-pavillon (à Mahé).

\section{Service de santé.}

1 second médecin en chef chargé du service, 3 chirurgiens, 5 pharmaciens ou élèves pharmaciens, 2 écrivains, 4 vaccinnateurs, 3 médecins indigènes ou mestry, 1 sage-femme (Pondichéry); 1 chirurgien de la marine, chef de service; 2 mestry, 2 vaccinateurs, 1 élève pharmacien, 1 infirmier (Karikal); -3 chirurgiens de la marine, 2 mestry-vaccinaleurs, 2 garçons pharmaciens (Chandernagor, Mahé, Yanaon).

Conseil de santé : le second médecin en chef, président; le pharmacien chargé du service pharmaceutique; 1 chirurgien de $1^{\mathrm{re}}$ classe.

\section{Administration financière.}

1 trésorier-payeur (Pondichéry); 1 préposé dans chacun des autres établissements; 1 chef de service des contributions et des domaines; $\mathbf{1}$ chef indien, serestadar; 5 receveurs des contributions et du domaine, dont 3 indigènes (thasildar); 2 inspecteurs des contributions, dont un indigène (sayerdar); 2 sous-receveurs indiens (bechecar); 3 interprètes; 24 écrivains et commis des contributions: 156 agents indigènes, désignés sous les noms de sambouray, gomasta, aminah, rayassôm (dans les 3 districts de Pondichéry). - Notons ici que le nombre des Indiens attachés aux divers services de l'administration sous le titre d'agents, de pions, etc., est très-considérable, parce que les mœurs indigènes forcent à répartir entre plusieurs individus des occupations auxquelles une seule personne suffirait en Europe; leur salaire, il est vrai, est très-peu élevé. (Notices, etc.)

Dans les diverses communes de Karikal, on compte : 2 receveurs des contributions, dont 1 indigène, 7 commis écrivains, 1 interprète, 3 bechecur, chargés des régies et du service des plantations, 126 agents indigènes. 
Chandernagor : 1 receveur, 5 commis ou écrivains, 1 interprète, 7 agents indigènes.

Mahé : 1 receveur, 4 commis ou écrivains, 1 interprète, 2 agents indigènes.

Calicut : 1 percepteur.

Yanaon: 1 receveur, 1 régisseur, 1 interprète, 1 percepteur. Mazulipatam : 1 percepteur.

\section{Police.}

Pondichéry : 1 maire, directeur de la police; 2 inspecteurs européens, 1 directeur de la police indigène (Naïnard), 1 inspecteur (paleagar), 19 agents divers, 125 gardes de police, 60 pions.

Karikal : 1 commissaire el 1 inspecteur de police européens, 52 agents indigènes.

Chandernagor : 1 commissaire de police européen, 70 agents indigènes.

Mahé : 1 commissaire de police européen, 1 interprète, 12 agents.

Yanaon : 1 commissaire de police européen, 1 interprète, 22 agents indigènes.

Ponts et chaussées.

Pondichéry : 1 ingénieur, chef de service; 1 sous-ingénieur, 3 conducteurs.

Karikal : 1 conducteur, 13 agents subalternes.

Chandernagor : 1 conducteur, 1 surveillant.

\section{Forces militaires.}

Les forces militaires de nos établissements de l'Inde sont ainsi composées :

1 détachement d'infanterie de marine (111 sous-officiers et soldats, 3 officiers).

2 compagnies de troupes indigènes (cipayes), l'une de grenadiers, l'autre de fusiliers. - Chacune est commandée par 1 capitaine indigène ou soubédar, 1 lieutenant européen, 1 lieutenant indigène ou gémédar, et 1 sous-lieutenant européen. - Les deux compagnies présentent ensemble un effectif de 244 sous-officiers et soldats. 


\section{GHAPITRE $\mathrm{V}$}

Finances. - Budget de l'ćtat. - Budget local. - Monnaies indigènes.

Le gouvernement de l'Inde anglaise paye chaque année à la France 1 million de francs, d'après la convention du 7 mars 1815 , dont il a été question au chapitre $I^{\text {er }}$. Cette somme, accrue du bénéfice du change $(60,000$ francs environ) figure au budget de l'État parmi les recettes générales du Trésor.

En 1863, la situation financière s'est présentée comme suit :

\section{BUDGET DE L'ÉTAT (DÉPENSES).}

Personnel civil et militaire.

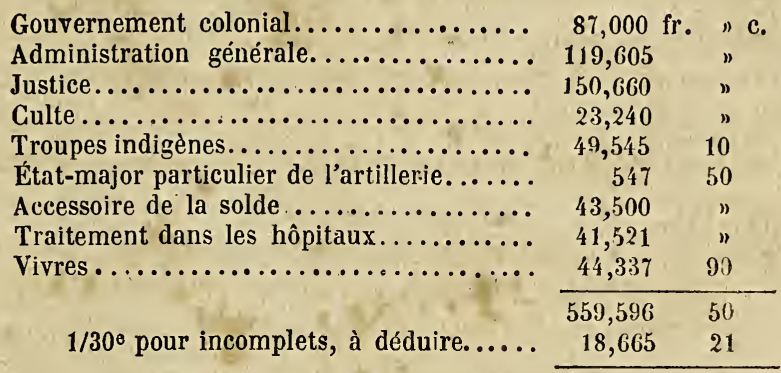

Total................. $541,291 \mathrm{fr} .29 \mathrm{c}$. Matériel civil et militaire.

Génie............................ $500 \mathrm{fr}$.

Loyer et ameublements................ $\quad 5,000$

Impressions et publications.............. $\quad 1,000$

Frais de justice et de procédure........... $\quad 1,000$

Ensemble...............

Les dépenses du service marine se sont, en outre, élevées à 83,742 fr. 61 c.

\section{BUDGET LOGAL.}

\section{Recettes.}

Droit sur les maisons à Mahé...............

Rentes foncières......................

Enregistrement, timbre, droit de greffe, hypothèques, patentes.....................

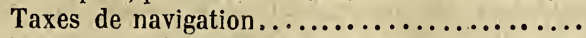

Droits sur l'introduction, la fabrication et la vente des spiritueux....................

Produit de la vente du sol, droits sur l'intro-

$1,410 \mathrm{fr}$.

514,420

61,932

23,100

$293, ? 91$ 
Report.

duction, la culture et la vente du tabac, du bétel et autres marchandises.............. Droits sur les lettres et passe-ports.............

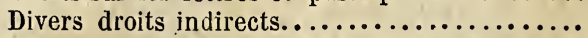

Locations, fermages et revenus des propriétés coloniales .......................... Divers droits et produits domaniaux...........

Amendes........................... Ventes et cessions des magasins à divers...... Inscriptions de rentes sur l'Etat..............

Recettes à titres divers...................

Total..................

$894,153 \mathrm{fr}$.

429,641

11,170

42,988

7,749

4,850

8,954

2,070

41,969

10,022

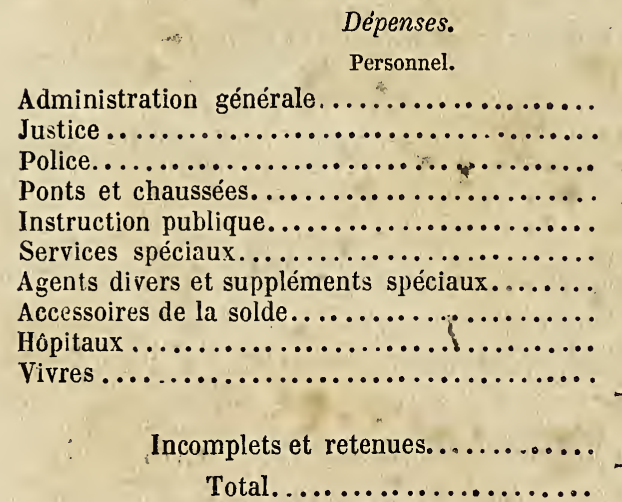

$1,453,566 \mathrm{fr}$.

Matériel.

Travaux et approvisionnements.............

Entretien des mobiliers et du matériel........

Achats de terrains et loyers................

Frais de transport.....................

Impressions et publications..............

Éclairage des établissements publics..........

Frais de justice et de procédure.............

Secours et subventions à divers..............

Encouragements aux cultures, à l'industrie....

Subventions à divers établissements d'utilité

publique ..........................

Pecouvrement des impôts et dégrèvements....

Dépenses diverses et imprévues............

Contingent à fournir à la métropole, d'après l'article 16 du sénatus-consulte du 3 mai $1854 .$. .

Dépenses extraordinaires : Soulte à payer au Trésor public....

Travaux d’assainissement à Chandernagor ..........

$187,620 \mathrm{fr}$. 20,080

76,685

59,960

39,920

25,310

63,254

42,870

16,261

15,500

$547,460 \mathrm{fr}$.

10,949

$536,511 \mathrm{fr}$.

218,500 fr. 31,550

19,446

8,500

4,600

13,000

13,600

80,231

14,450

50,852

101,633

98,161

$654,523 \mathrm{fr}$.

322,000

25,181

55,000

Total............... $\overline{1,593,215 \mathrm{fr}}$. 
La répartition du budget local entre les cinq établissements de l'Inde a eu lieu de la manière suivante (Exercice 1863):

Pondichéry.

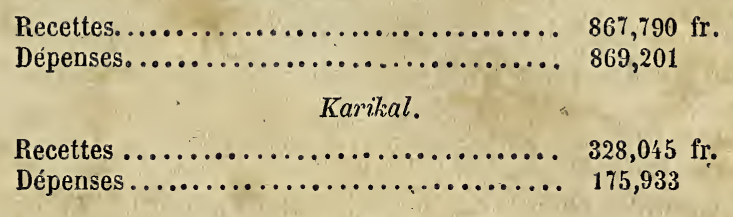

Chandernagor.

Recettes.................... 180,187 fr.

Dépenses.................... 158,252

Mahes.

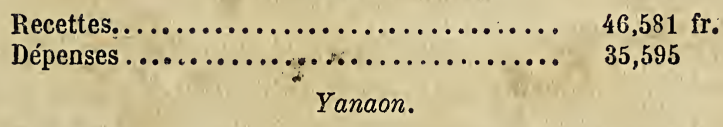

Recettes......................... 30,963 fr. Dépenses...................... 32,234

Monnaies indigènes.

La pagode à l'étoile (en or) vaut....... 8 fr. $40 \mathrm{c}$.

La roupie de Pondichéry (argent)....... 2 40

Le fanon de Pondichéry (argent).......... » 30

La cache (cuivre).................. $011 / 4$

Le lack, monnaie de compte, vaut 100,000 roupies.

Pour l'usage officiel et dans les actes authentiques, le système monétaire français est, en outre, en vigueur.

\section{CHAPITRE VI}

Justice. - Cultes. - Instruction publique. - Assistance publique.

Par arrêté local du 6 janvier 1819, les Codes Napoléon, de procédure civile, de commerce et pénal, ont été promulgués dans nos établissements de l'Inde. Mais ce ne fut que par un arrêté local du 21 avril 1825, que le Code d'instruction criminelle fut mis en vigueur, sauf les dispositions de ce Code relatives au jury, aux Cours d'assises spéciales, à la procédure devant les Cours impériales.

L'arrêté du 17 novembre 1828, l'ordonnance royale du 29 mars 1846 , les décrets des 23 janvier 1852 et 15 janvier 1853 , ont 
successivement accordé aux établissements de l'Inde, le bénéfice des lois métropolitaines.

Les Indiens, chrétiens ou musulmans, doivent, aux termes de l'arrêté organique du 6 janvier 1819, être jugés, au civil, suivant les lois, us et coutumes de leur caste. Au criminel, ils doivent l'être suivant la loi française.

\section{Organisation judiciaire.}

L'ordonnance royale du 7 février 1842 a institué, dans les établissements de l'Inde, des justices de paix, des tribunaux de première instance, une Cour d'appel.

\section{Justices de paix.}

Trois tribunaux de paix siégent à Pondichéry, Karikal et Chandernagor. - Le juge de paix de Pondichéry a deux suppléants salariés. Les autres tribunaux de paix se composent d'un juge et d'un greffier. Les décrets des 2 juillet 1862 et 7 mars 1863 ont rendu applicables aux établissements français de l'Inde la loi du 22 mars 1856, qui modifie celle du 23 mai 1838 sur les justices de paix, et la loi du 4 mai 1861 sur la légalisation par les juges de paix. - Les tribunaux de paix connaissent aussi des contraventions de police.

\section{Tribunaux de première instance.}

Ils jugent en matière civile, commerciale et correctionnelle.

A Pondichéry, le tribunal se compose d'un juge impérial, d'un lieutenant de juge, de deux juges suppléants, d'un procureur impérial, d'un lieutenant de juge, de deux juges suppléants, d'un procureur impérial, d'un greffier et de plusieurs interprètes.

A Chandernagor et à Karikal, le tribunal se compose d'un juge, d'un procureur impérial, d'un gref̣fier et de plusieurs interprètes. Le tribunal de Chandernagor, à raison de son éloignement de la Cour impériale de Pondichéry, connaît en dernier ressort des actions personnelles, mobilières et commerciales jusqu'à 1,000 francs, et des actions immobilières jusqu'à 50 francs de revenu déterminé.

En résumé, au civil comme au correctionnel, la compétence de ces tribunaux diffère de celle des tribunaux métropolitains.

A Yanaon et à Mahé, les fonctions de juge impérial sont remplies par le chef de l'établissement. Il est assisté d'un greffier. 
En matière criminelle, les tribunaux, dans les établissements secondaires, ne peuvent juger qu'au nombre de trois membres, sauf à Mahé où le président peut juger seul en cas d'impossibilité d'adjonction de deux"notables.

A Chandernagor et à Karikal, le tribunal criminel se compose du juge impérial, du juge de paix, d'un fonctionnaire ou officier de la marine.

\section{Cour impériale.}

Elle est établie à Pondichéry.

Elle se compose d'un président, de quatre conseillers, de deux conseillers auditeurs; un procureur général, chef du parquet et chef du service judiciaire; un substitut; un greffier en chef et un interprète en chef.

$\mathrm{Au}$ civil et au correctionnel, la Cour statue souverainement sur l'appel des jugements rendus en premier ressort par les tribunaux civils et correctionnels. Elle se compose alors de trois magistrats au moins.

Au criminel, la Cour connait : $1^{\circ}$ de toutes les affaires qui peuvent emporter peine afflictive ou infamante; $2^{\circ}$ des appels des affaires criminelles jugées à Chandernagor, Karikal, Mahé et Yanaon. - La Cour se compose, au criminel, de cinq magistrats et de deux notables; le procureur général ou son substitut porte la parole. Les arrêts doivent être rendus à la majorité de cinq voix.

\section{Cour de cassation.}

En matière civile, le recours en cassation est ouvert contre les jugements en dernier ressort des tribunaux de première instance et contre les arrêts de la Cour impériale, conformément à la législation métropolitaine.

En matière criminelle, les jugements et arrêts ne sont susceptibles du recours en cassation que dans les cas suivants : $1^{\circ}$ dans celui où les jugements et arrêts sont contraires à la loi; le procureur général a le droit de les dénoncer; $2^{\circ}$ dans celui des articles 441 et 442 du Code d'instruction criminelle.

\section{Barreau.}

Pondichéry : 6 conseils agréés européens; 9 conseils agréés indigènes.

Chandernagor : 3 conseils agréés européens. 
Karikal : 2 conseillers agréés européens ; 6 conseillers agréés indigènes.

Officiers publics.

Pondichéry : 1 notaire; 1 tabellion; 1 commissaire-priseur. Karikal : 1 notaire; 2 tabellions.

\section{STATISTIQUE JUDICIAIRE (1859).}

10 Tribunaux de paix.

Pondichéry : 2,156 affaires jugées.

Chandernagor: $\mathbf{7 3 5} \quad i d$.

Karikal : 1189, id.

Yanaon : $3 \check{\text { İ }} \quad i d$.

Mahé : 14, id.

$2^{\circ}$ Tribunaux de $1^{\mathrm{re}}$ instance.

Pondichéry : 1,049 affaires civiles, commerciales et correctionnelles.

Chandernagor : 267, $\quad$ id.

Karikal : 370, id.

Yanaon : 83, id.

Mahé : 12, id.

$3^{\circ}$ Cour impériale.

Affaires civiles : 238.

Affaires criminelles : 19.

$4^{\circ}$ Tribunaux criminels.

Chandernagor : 7 affaires ;

Karikal : 4 ;

Yanaon et Mahé : 0 .

Dans nos établissernents de l'Inde, on distingue trois cultes : le christianisme, l'islamisme et le brahmanisme.

La population européenne ou de sang mêlé appartient au premier. La plupart des indigènes appartiennent au dernier.

Une préfecture apostolique a pour siége Pondichéry.

Cette préfecture, fondée en 1828, se compose de sept prêtres :

Pondichéry : 1 préfet apostolique, 2 vicaires ;

Chandernagor : 1 curé, 1 vicaire ;

Mahé : 1 curé;

Yanaon : 1 curé. 
Le clergé de Karikal ( 1 curé, 2 missionnaires) appartient à la Congrégation des Missions étrangères.

Indépendamment de la préfecture apostolique, Pondichéry est le siége de la mission française du Malabar, instituée pour la conversion des Gentils. Desservie dans l'origine par les Jésuites, cette mission fut confiée, par lettres patentes du 10 mars 1776, à la Congrégation des Missions étrangères de France. Son chef porte le titre de vicaire apostolique de Pondichéry et administrateur du Goimbatore.

L'action de la mission s'étend sur une partie de l'Inde anglaise ; parmi les 105,000 chrétiens, les 170 églises et les 63 missionnaires qu'elle comprend, 80,000 sont sujets de l'Angleterre, 155 églises et 40 missionnaires se trouvent sur le sol anglais.

Cette mission jouit dans l'Inde d'une grande influence, justifiée à tous les yeux par ses œuvres de charité, de morale, d'utilité, par le dévouement évangélique de ses membres, qui, tous. simples et désintéressés comme au temps de la primitive Église, enseignent par leur exemple la pratique de toutes les vertus.

La mission a fondé un grand et un petitséminaire à Pondichéry, un petit séminaire à Karikal, et environ 65 écoles primaires dispersées sur le territoire qui forme son vicariat. - Le collége colonial de Pondichéry est placé sous sa direction.

La congrégation des sœurs de Saint-Joseph de Cluny compte dans nos établissements 25 sœurs, dont 15 à Pondichéry, 3 à Chandernagor et 7 à Karikal, où elles tiennent des écoles, des asiles et un hôpital.

A Pondichéry, les comités de bienfaisance se composent de 7 membres titulaires, de $\mathbf{5}$ à Karikal et à Chandernagor, de 3 à Mahé et à Yanaon. - lls sont chargés de l'administration spéciale des fonds de charité, de la formation des listes d'indigents, de la répartition des secours.

Le Mont-de-piété, établi à Pondichéry en 1827, possède un fonds de 100,000 fr. Il prête sur gages aux cultivateurs, aux ouvriers, aux petits marchands.

En 1858, un hôpital militaire a été fondé à Pondichéry. Une maison de santé y a été annexée pour les indigènes natifs. Les sœurs de Saint-Joseph de Cluny tiennent ces étabiissements.

Pondichéry a une pharmacie entretenue aux frais de la colonie. Les indigents y trouvent gratuitement les médicaments dont ils ont besoin. 
Les établissements d'instruction publique, à Pondichéry, sont : le collége colonial, le grand et le petit séminaire, le pensionnat de jeunes filles dirigé par les sœurs de Saint-Joseph de Gluny, plusieurs écoles gratuites pour les Européens et les indigènes, plusieurs écoles primaires, deux pensionnats de demoiselles.

Karikal possède un séminaire-collége, une école gratuite pour les blancs et gens à chapeau, trois écoles gratuites pour les Malabars, une école gratuite pour les parias, deux pour les macouas (bateliers indiens), une maison de jeunes filles dirigée par les sœurs de Saint-Joseph de Cluny, et comprend quatre classes (celle des Européennes, celle des topazines, celle des Malabaresses, celle des pariates).

Ghandernagor a une école gratuite pour les garçons, une école gratuite pour les jeunes filles.

A Mahé, il y a aussi une école gratuite.

Enfin, à Yanaon, on compte une école gratuite pour les garçons, un pensionnat et une école gratuite pour les jeunes filles.

La subvention accordée par la colonie à ces divers établissements se monte à $39,920 \mathrm{fr}$. - Ils sont surveillés par une commission siégeant à Pondichéry et à Karikal.

La bibliothèque de Pondichéry, fondée en 1827, compte 12,000 volumes. - Deux imprimeries : celle du gouvernement et celle des Missions étrangères, publiant, la première, le Bulletin et le Moniteur officiel; l'autre surtout les ouvrages religieux utiles à la propagation de la foi; 140,000 volumes en langue tamoule ont été publiés déjà par l'imprimerie des Missions.

\section{CHAPITRE VII}

Agriculture. - Loi malmoul. - Répartition du sol en cinq classes. - Cultures diverses : riz, nelly, indigotier, cocotier, bétel, tabac, canne à sucre, coton, etc. - Arbres à fruits. - Produits donnés par les diverses cultures. - Valeur. Animaux de trait. - Bétail. - Jardin d'acclimatation.

Le système territorial de l'Inde est fort compliqué et soumis à des conditions toutes particulières à ces contrées. Nous nous bornerons à en donner sommairement une idée générale en ce qui concerne nos établissements, et principalement celui de Pondichéry et de Karikal.

D'après la loi malmoul ou coutume du pays, toutes les terres 
à la côte de Coromandel, sont en principe la propriété du souverain. (Il en est autrement à Karikal et à Chandernagor; les terres sont la propriété de leurs possesseurs, à charge par ceuxci de payer à l'État une rente foncière.) - Elles sont divisées en cinq classes principales, savoir :

$1^{\circ}$ Jaguirs, terres abandonnées par le souverain en faveur des princes ou des chefs tributaires;

$2^{\circ}$ Manioms, terres affectées d'une manière irrévocable soit à des fonctionnaires, soit à des établissements publics ou religieux.

$3^{\circ}$ Strotrions, petites portions de terre concédées avec ou sans redevances;

$4^{\circ}$ Adamanoms ou terres dont le souverain a aliéné la jouissance à perpétuité, mais non la propriété, moyennant une redevance en argent;

$5^{\circ}$ Promboes, terrains incultes ou occupés par la voie publique, les savanes, étangs ou cours d'eau.

Le gouvernement français, en succédant aux prince̊s indiens, respecta ces principes fondamentaux: toutefois, en 1824, dans le but de favoriser l'agriculture locale, il entra dans une nouvelle voie en adoptant un système de concessions de terres qui fut définitivement réglé par une ordonnance du 7 juin 1828. Allant même plus loin, l'État renonça, en 185̆4, à son droit de propriété sur les terres adamanom qui sont exploitées par les indigènes. Un décret du 16 janvier de cette année porte : " qu'à Pondichéry et dans ses districts, les détenteurs actuels du sol, à quelque titre que ce soit, qui acquittent l'impôt réglementaire, sont déclarés propriétaires incommutables des terres qu'ils cultivent. " - L'administration s'est seulement réservé un privilége sur les récoltes et au besoin sur le sol, pour le recouvrement.de l'impôt.

Dans le district de Karikal, les terres de chaque aldée sont en général des propriétés indivises, exploitées d'après un mode spécial par leurs possesseurs communs. Ces propriétaires fonciers, qui sont désignés sous le nom de myrasdârs, payent au gouvernement la redevance des terres et ils emploient pour les cultiver des sous-habitants qui, pour leur salaire, ont droit à une partie déterminée dans le produit des récoltes. Ces sous-habitants ont à leur tour sous leur dépendance une classe de travailleurs que l'on somme coolzes. 
En résumé la condition des cultivateurs indiens, loin de s'être aggravée dans nos établissements depuis la reprise de possession, y a élé partout améliorée et y est notamment beaucoup plus heureuse que celle des cultivateurs des autres parties de l'Hindostan.

Principales cultures : riz, nelly et autres menus grains nécessaires à l'administration ; - indigofère, dont la culture a été introduite dans le sud il y a cent ans à peine et qui donne d'excellerits produits servant à la teinture des guinées (toiles bleues); - cocotier, culture très-importante, surtout à Pondichéry et à Mahé : on en tire du coir ou fibre du fruit, des noix sèches décortiquées, connues sous le nom de copra; du callou et du jagre, obtenus du suc de la séve et qu'on boit sans autre préparation; de l'arack, boisson fermentée tirée de la séve; enfin de l'huile.

Cultures secondaires : bétel, tabac, canne à sucre, coton, quelques plantes oléagineuses (sésame, guigely, palma-christi); des arbres fruitiers (bananier, citronnier, oranger, grenadier, pamplemoussier, goyavier, papayer, vigne, manguier, attier, etc.).

Le bétel est d'une consommation universelle; tous les indigènes, hommes et femmes, en mâchent les feuilles saupoudrées de chaux et d'areck.

Nombre d'hectares affectés à chaque culture en 1862 :

10 Pondichéry.

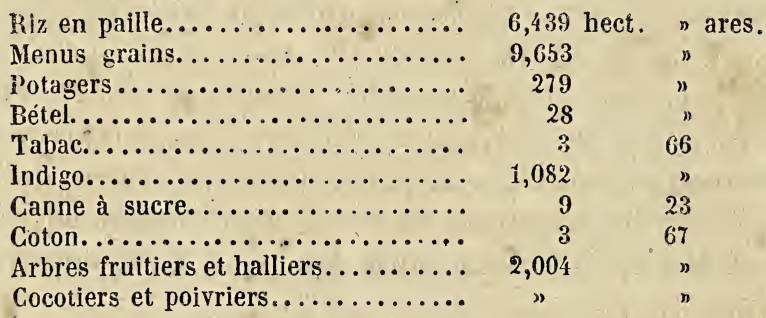

Les cocotiers et les poivriers sont disséminés parmi les aulres cultures, sur les bords des routes, des canaux, etc. On ne peut, par suite, fixer l'étendue qu'ils occupent.

Total des terres cultivées....... 19,501 hect. 56 ares.

Total des terres non cultivées (terrains incultes et vagues, dépendances du domaine public, dépendances des habitations).....

9,615

La valeur de toutes ces terres, cultivées et non cultivées, est approximativement portée à $9,480.009$ fr. 
20 Karikal.

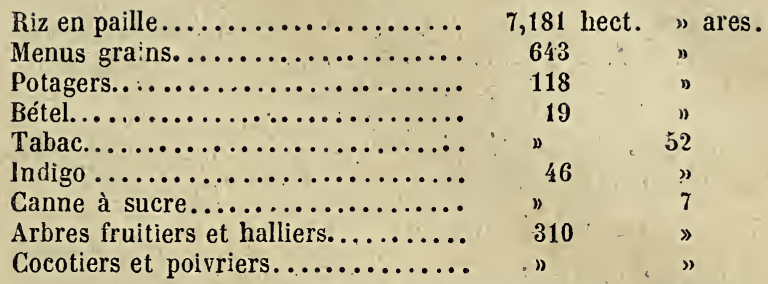

Les cocotiers et les poivrierș sont disséminés parmi les autres cultures, sur les bords des routes, des canaux, etc. On ne peut, par suite, fixer l'étendue qu'ils occupent.

Total des terres cultivées.....

Total des terres non cultivées.

Valeur des unes et des autres..

8,317 hect. 59 ares.

$4,032,759$ francs.

$3^{\circ}$ Mahé.

Riz en paille.......................

Arbres fruitiers et halliers...............

1,469 hect.

Total des terres cultivěes............ $\quad 5,454$

Total des terres non cultivées......... $\quad 455$

Valeur des unes et des autres......... 2,606,000 fr.

\section{Yanaon.}

Riz en paille....................... 711 hect.

Menus grains......................... 973

Total des terres cultivées.............. 1,744

Total des terres non cultivées.......... 1,553

Valeur des unes et des autres.......... 20,160 fr.

On voit, par ce qui précède, que, en 1862, les diverses cultures occupaient,' savoir :

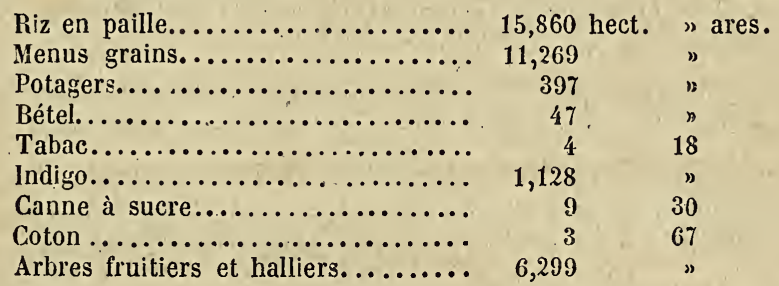

Ces chiffres donnent un total général de 3̋,017 hectares 15 ares (terres cultivées) et 16,819 hectares (terres non cultivées), ayant ensemble une valeur de 16,138,928 fr.

Les quantités et les valeurs données par chaque culture ont été comme suit (1862):

Riz en paille.

Quantité...................... 21,827,062 kil.

Valeur $\ldots \ldots \ldots \ldots \ldots \ldots \ldots \ldots \ldots \ldots \ldots \quad 1,468,959$ fr. 
Menus grains.

Quantité

$10,189,226 \mathrm{kil}$.

Valeur. $658,081 \mathrm{fr}$.

Légumes.

Quantité.

Valeur.

$1,369,825$ kil. 99,720

Feuilles de bétel.

Quantité.

Heuilles de betel.

Valeur.

Feuilles de tabac.

Quantité...........................

Valeur.

Indigo en feuilles sèches.

Quantité............................

Valeur.

Canne à sucre.

Quantité........................... Valeur

Coton en laine.

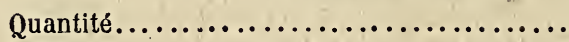
Valeur.

\section{Fruits.}

Quantité............................ Valeur.

Noix de coco.

Quantité........................... Valeur.

Huile de coco.

Quantité........................... Valeur.

\section{Callou.}

Quantité............................

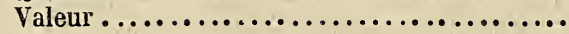

Jagre.

Quantité...........................

Valeur.

Arack.

Quantité..........................

Valeur ............................

Huile de gingely.

Quantité...........................

Valeur.

$434,097 \mathrm{kil}$. 101,645 fr.

5,437 kil. $1,653 \mathrm{fr}$.

\section{6,466 kil. $179,890 \mathrm{fr}$.}

345,000 pieds. $10,530 \mathrm{fr}$.

643 kil. $193 \mathrm{fr}$.

$62,064 \mathrm{fr}$.

$2,802,885$ (nombre). 130,896 fr.

690,291 lit. 569,079 fr.

$2,492,720$ lit. $257,672 \mathrm{fr}$.

38,000 lit. $9,600 \mathrm{fr}$.

25,000 lit. 11,240 fr.

69,438 lit. $31,047 \mathrm{fr}$. 
Huile de palma-christi.

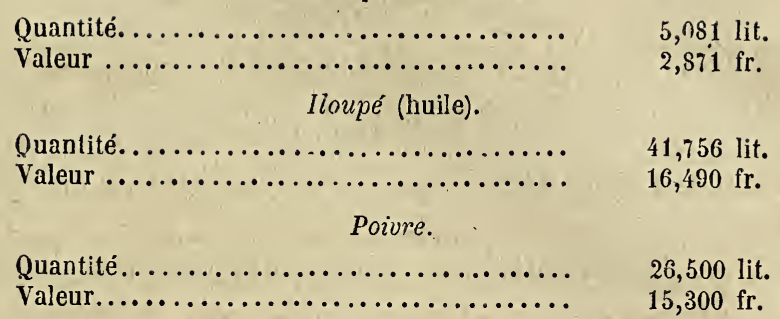

Le nombre des habitations rurales, en 1862, la valeur des bâtiments et du matériel d'exploitation, se répartissait ainsỉ

10 Pondichéry.

\begin{tabular}{|c|c|c|}
\hline \multirow{2}{*}{ Indigoteries ....... } & nombre ....... & 99 \\
\hline & valeur .............. & $124,740 \mathrm{fr}$. \\
\hline Teintureries... & nombre $\ldots \ldots \ldots \ldots \ldots$ & $\begin{array}{r}73 \\
10519 f\end{array}$ \\
\hline ies. & nombre............. & 161 \\
\hline ess. & valeur .............. & $22,343 \mathrm{fr}$. \\
\hline Magnanerie . & ............... & 1 \\
\hline Filatures de & re $\ldots \ldots \ldots \ldots$ & $800,000 \mathrm{fr}$ \\
\hline & $2^{\circ}$ Karikal. & \\
\hline Indigoteri & $\begin{array}{l}\text { nombre } \ldots \ldots \ldots \ldots \ldots \ldots \\
\text { valeur } \ldots \ldots \ldots \ldots \ldots\end{array}$ & $\begin{array}{l}1 \\
720 \mathrm{fr} .\end{array}$ \\
\hline Teinturerie & $\ldots \ldots \cdots \cdots \cdots$ & \\
\hline Savonneries & $\begin{array}{l}\cdots \cdots \cdots \cdots \cdots \cdots \\
\cdots \cdots \cdots \cdots \cdots\end{array}$ & $\begin{array}{r}4 \\
5,280\end{array}$ \\
\hline Huilerie & $\begin{array}{l}\ldots \ldots \ldots \\
\ldots \ldots \ldots \ldots \ldots\end{array}$ & $\begin{array}{r}88 \\
10,656\end{array}$ \\
\hline
\end{tabular}

Ainsi, le nombre des établissements de Pondichéry et de Karikal est de 433. Leur valeur réunie est dè 975 ,711 fr.

Le nombre des animaux de trait et du bétail, en 1862, s'élevait à 71,216 têtes, ayant une valeur de 1,403,759 fr. Ils se répartissaient ainsi entre les établissements :

\section{Pondichéry.}

Chevaux 85 ; bœufs 21,965 ; buffles 3,445 ; béliers et mouton 18,680 ; boucs et chèvres 737 ; porcs 669 ; ânes 311 .

\section{$2^{\circ}$ Karikal.}

Bœufs 11,320; buffles 4,020; béliers et moutons 3,780; boucs et chèvres 4,610 . 


\section{$3^{\circ}$ Mahé.}

Bœufs ว̃79; boucs et chèvres 91 ; porcs 12.

\section{$4^{\circ}$ Yanaon.}

Bœufs 420 ; buffles 412 ; béliers et moutons 62 ; boucs et chèvres 18.

La valeur approximative des terres employées à la culture atteint :

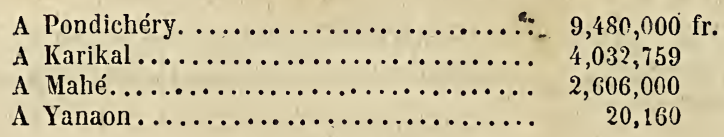

C'est-à-dire, ensemble : 16,138,928 fr.

La valeur approximative des bâtiments et du matériel d'exploitation atteint :
A Pondichéry...................... 957,595 fr.
A Karikal...
A Mahé..... 17,616
A Yanaon
i)
)

La valeur approximative des animaux de trait et du bétail atteint :
A Pondichéry..................... 935,757 fr.
A Karikal........................ 431,556
A Mahé .......................... 14,100
A Yanaon.......................... 22,346

Ce qui, pour les quatre établissements, donne un chiffre de $18,517,899 \mathrm{fr}$.

Deux jardins botaniques fondés, l'un en 1827, l'autre en 1861, existent à Pondichéry.

Le premier occupe une superficie de 18 hectares, mais la mauvaise nature de son sol l'a fait à peu près abandonner. Le second est un jardin d'acclimatation. Il a une étendue de 818 ares. Une magnanerie, dont les produits sont très-estimés, y est attenante. On y doit créer aussi une école d'agriculture pratique. 


\section{CHAPITRE VIII}

Industrie. - Filature. - Tissage. - Teinture. - Sel. - Régime commercial.

- Importations de France. - Exportations en France. - Mouvement général du commerce. - Principaux articles d'importation. - Principaux articles d'exportation.

Principales industries de Pondichéry : Filature, tissage et teinture des étoffes de coton (guinées et mousselines).

Karikal a des industries semblables, mais d'une importance moindre. La ville possède des chantiers pour la construction des navires; il sort de ces chantiers nombre de petites embarcations et parfois des bâtiments jaugeant 200 à 300 tonneaux. ?

Chandernagor, Mahé, Yanaon ont perdu de leur prospérité ancienne sous le rapport de l'industrie des tisserands. Ces villes ont à tirer les matières premières du territoire anglais, et les droits de sortie imposés par le gouvernement anglo-indien, sont trop élevés. De là la paralysie actuelle.

La fabrication du sel, autrefois très-active, a été, depuis la convention de 1818 avec l'Angleterre, complétement abandonnée.

" C'est à M. Desbassayns de Richemont, administrateur général de 1826 à 1828, qu'est due la première idée de la filature à la mécanique. Grâce aux efforts réunis de l'habile fondateur, M. Charles Poulain, et du gourernement qui fournit de larges subsides, cette industrie devint bientôt prospère à Pondichéry.

" Cet établissement emploie aujourd'hui 16,000 broches et 500 ouvriers.

"Depuis 1846, les produits s'élèvent à 1,200 kilogr. de fil par jour et servent principalement au tissage des toiles dites de Guinée.

" Un autre établissement presque aussi considérable alimente les métiers d'un nombre considérable de tisserands indigènes.

"Le tissage à la mécanique remonte également à M. Desbassayns. Quant au tissage natif, il a éprouvé dans nos établissements la même décadence que dans toute l'Inde. Réduit par la concurrence à circonscrire ses produits, ses seules ressources consistent aujourd'hui dans quelques mousselines, les guinées et quelques tissus grossiers à l'usage des basses classes.'Cependant, on compte encore sur le territoire de Pondichéry 4,126 métiers de tisserand.

"Les sources qui se trouvent sur le territoire de Pondichéry fournissent des eaux excellentes pour les teintures; les pays en- 
vironnants envoient des toiles blanches dans cette ville pour y être teintes en bleu. On n'y compte pas moins de 73 teintureries qui teignent annuellement environ 400,000 pièces de toile, mesurant chacune 16 mètres de long sur 1 mètre de large. )(Notices, etc.)

La liberté est la base du régime commercial de nos établissements de l'Inde. $Y$ sont: admises, sans distinction de pavillon et en franchise de droits, les denrées et marchandises de toutes provenances. Quant aux rapports directs avec la France, l'acte de navigation du 21 septembre 1793 a voulu qu'ils ne se fissent que sous pavillon national.

La loi du 9 juin 1845̆, le décret du 20 novembre 1850, ont réservé à certains produits quelques priviléges sur les marchés français : áinsi, les huiles de coço et les graines de sésame, apportées en France sous pavillon national.

Un droit de sortie (๖ centimes par velte) frappe les huiles d'origine française exportées de nos établissements pour les ports de la métropole.

Depuis 1820, date de la reprise de possession, le relevé du commerce donne les chiffres suivants :

\section{5}

Importation de marchandises françaises...... Exporiation en France..................

$775,885 \mathrm{fr}$. $10,540,584$

1830

Importation

$43,567 \mathrm{fr}$.

Exportation.

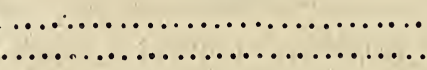

1835

Importation $\ldots \ldots \ldots \ldots \ldots \ldots \ldots \ldots \ldots \ldots$

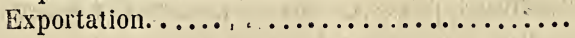

1840

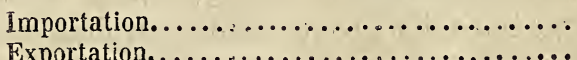

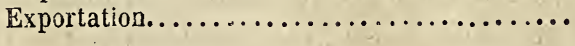

433,321 fr. $3,975,903$

1845

Importation $431,276 \mathrm{fr}$. Exportation $11,667,251$

1 850

Importation 465,657 fr. Exportation $4,944,491$ 
$\mathbf{1 8 5 5}$

Importation

$582,649 \mathrm{fr}$.

Exportation

$11,653,442$

1856

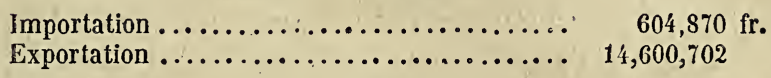

1859

Importation ................... 548,938 fr.

Exportation ..................... 30,600,139

1858

Importation

503,574 fr.

Exportation

$23,187,588$

1859

Importation

$692,134 \mathrm{fr}$.

Exportation $9,246,965$

1860

Importation $444,510 \mathrm{fr}$.

Exportation $3,591,244$

1861

Importation

546,950 fr.

Exportation

$20,761,661$

1862

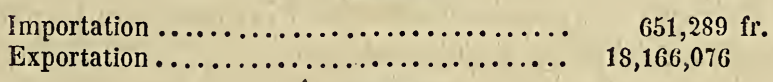

1863

Importation

$682,853 \mathrm{fr}$.

Exportation

$8,266,559$

Pendant cette dernière année (1863), le commerce de la colonie avec la France a présenté les résultats qui suivent :

Marchandises exportées de la colonie et arrivées en France pendant l'année : 8,266,5็59 fr. (valeur officielle) ou 7,744,710 fr. (valeur actuelle).

Marchandises françaises exportées de France pour la colonie : $682,853 \mathrm{fr}$. (valeur officielle) ou $835,894 \mathrm{fr}$. (valeur actuelle).

Le mouvement général du commerce de nos établissements en 1862 s'est élevé à $24,059,375$ fr., somme qui se décomposait ainsi :

\section{Importations.}

Marchandises françaises venant de France............. 369,138 fr.

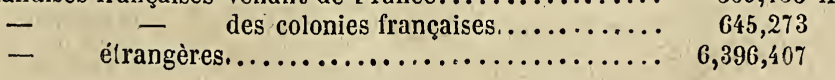




\section{Exportations.}

10 Denrées du cru de la colonie exportées pour France...... 5,297,767 fr.

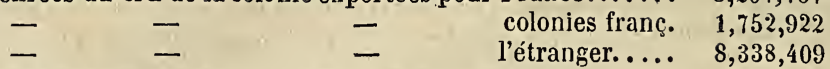

20 Marchandises provenant de l'importation exportées :

Pour France................................ 136,265

Pour les colonies........................... 334,746

Pour l'étranger........................... 728,448

La répartition du commerce entre les divers établissements, s'est faite ainsi :

Pondichéry.

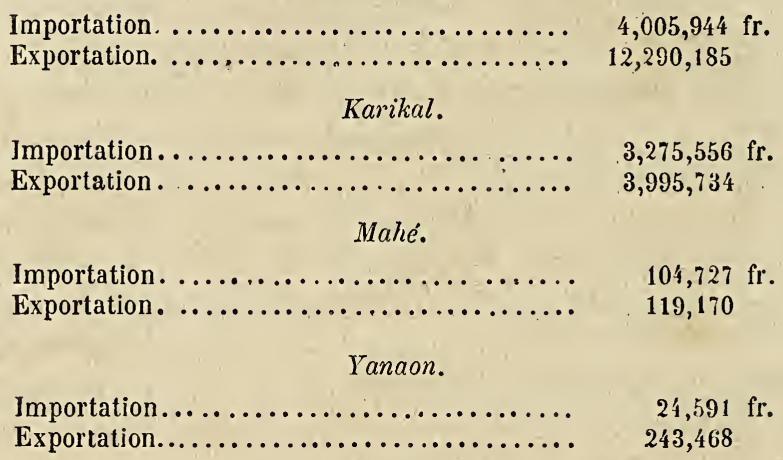

Charidernagor n'a pas de statistique : la plus grande partie de son commerce se fait par Calcutta.

PRINCIPAUX ARTICLES D'IMPORTATION.'

10 Graines et farines.

Pondichéry.........................

Karikal............................

Mahé

Yanaon

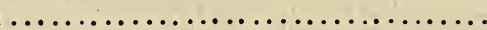

$2^{\circ}$ Noix de coco.

Pondichéry.

3० Graines de palma-christi.

Pondichéry

$4^{\circ}$ Graines de sésame.

Karikal

$5^{\circ}$ Poivre et auires épices.

Pondichéry

Karikal.
$151,509 \mathrm{fr}$.

$352,913 \mathrm{fr}$.

56,070

12,835

,

$160,488 \mathrm{fr}$.

78,588

$92,256 \mathrm{fr}$.

90,708 
6 o Areck.

Pondichéry.

Karikal..

o Jagre.

Pondichéry

Karikal....

Capras.

Karikal

$9^{\circ}$ Huile de coco.

Pondichéry

$10^{\circ}$ Huile de palma-christi.

Pondichéry

$11^{\circ}$ Bois:

Pondichéry

Karikal

Mahé

-..

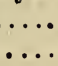

.......

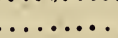

$12^{\circ}$ Coton.

Pondichéry.

$13^{\circ}$ Vieux cuivre.

Pondichéry

Karikal

Pondichéry

Karikal.

Mahé.

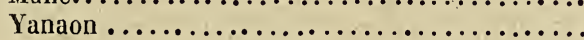

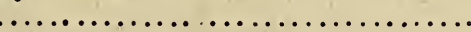

$15^{\circ}$ Tissus de coton.

Pondichéry.

Karikal.

$$
1 y
$$

\section{Tissus de coton.}

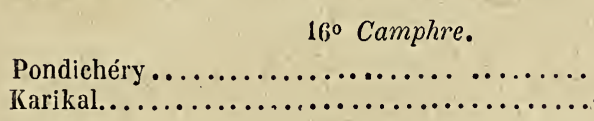

$17^{\circ}$ Encens.

Karikal.

$17^{\circ}$ Encens.

180 Plomb.

Karikal.

$119^{\circ}$ Pétards.

Pondichéry

Karikal.

Karikal
$180,150 \mathrm{fr}$.

239,588

$148,230 \mathrm{fr}$. 27,408

$201,833 \mathrm{fr}$.

$84,900 \mathrm{fr}$.

$44,226 \mathrm{fr}$.

$405,628 \mathrm{fr}$. 192,545

1,495

$280,560 \mathrm{fr}$. $302,100 \mathrm{fr}$. 48,039

$341,824 \mathrm{fr}$.

36,671

34,124

21,078

$1,048,050 \mathrm{fr}$. 838,180

$4,500 \mathrm{fr}$. 44,850

34,427

$41,706 \mathrm{fr}$.

$9,360 \mathrm{fr}$. 31,411

152,550 fr. 


\section{$21^{\circ}$ Tabac.}

Pondichéry $3,864 \mathrm{fr}$.

Mahé 51,825

$22^{\circ}$ Roupies.

Karikal 535,682 fr.

Tous les produits ci-dessus, ou du moins la plupart, viennent des établissements anglais et sont destinés à la réexportation.

PRINCIPAUX PRODUITS D'EXPORTATION.

\section{Riz.}

Pondichéry

$149,124 \mathrm{fr}$.

Karikal. $1,364,765$

Grains divers.

Pondichéry......................... Karikal.

Yanaon

$$
\begin{gathered}
64,062 \text { fr. } \\
326,480 \\
6,404
\end{gathered}
$$

Poissons secs.

Mahé. $16,700 \mathrm{fr}$.

Sésame.

Pondichéry $64,346 \mathrm{fr}$.

Pistaches.

Pondichéry 186,687

Café.

Pondichéry $117,720 \mathrm{fr}$.

Epices.

Pondichéry

$94,246 \mathrm{fr}$.

Karikal

56,849

Mahé $3,180 \mathrm{fr}$.

Areck.

Pondichéry

$53,700 \mathrm{fr}$.

Karikal 34,589

Sucre candi.

Karikal.

$15,246 \mathrm{fr}$.

Tabac.

Pondichéry.

11,676 fr.

Karikal .

21,735

Mahé 60,000

\section{Camphre.}

Karikal 
Huile de coco.

Pondichéry.........................

Karikal

403,260 fr.

Yanaon

700,800

1,584

Huile de pistaches.

Pondichéry.

739,142 fr.

Huile de ricin.

Pondichéry.

$44,614 \mathrm{fl}$.

Yanaon 2,765

Huile de gingely.

Pondichéry

7,005 fr.

Encens.

Karikal.

$43,769 \mathrm{fr}$.

Indigo.

Pondichéry.

$2,698,020 \mathrm{fr}$.

Karikal

5,184

Savon.

Pondichéry.

$74,700 \mathrm{fr}$.

Karikal.

85,341

Toile bleue.

Pọndichéry

Toile bleue.

Karikal

Yanaon

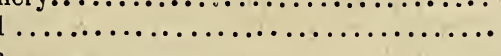

percale bleue.

Pondichéry.

Karikal..

Percale bleue.

Pagnes.

Pondichéry

Pagnes.

Autres tissus de coton.

Pondichéry.

Autres tissus de coton.

Fils de coton.

Pondichéry...........................

Karikal . .

Peaux tannées.

Pondichéry.

\section{Peans tanees.}

Bors d'ébène.

Karikal

Planches.

$455,004 \mathrm{fr}$. 19,440

$5,846,135 \mathrm{fr}$. 993,600 229,880

$306,360 \mathrm{fr}$.

$127,939 \mathrm{fr}$.

15,600 fr. 71,977

363,666 fr.

$12,902 \mathrm{fr}$.

Mahé

$14,251 \mathrm{fr}$. 
Chevaux.

Karikal .................... $14,880 \mathrm{fr}$.

Roupies.

Karikal ..................... 37,003 fr.

On doit faire remarquer ici, disent les Notices du Ministère de la marine, que les ports français de l'Inde ne font guère que l'office d'entrepôts ou de lieux de transit à l'égard d'une partie des marchandises portées aux tableaux ci-dessus, et que la statistique qui précède ne comprend pas tout le commerce de nos établissements. En effet, les marchandises importées par mer peuvent s'écouler par terre, et celles qui s'exportent peuvent aussi provenir du territoire anglais sans que leur destination, leur origine et leur quantité puissent être déterminées par l'administration. Ceci, néanmoins, ne s'applique pas aux toiles de coton, toutes celles qui proviennent du territoire français étant expédiées avec des certificats d'origine.

\section{CHAPITRE IX}

Navigation. - Mouvement de la navigation en 1862, - Service postal.

La navigation avec la France et les colonies françaises est réservée au pavillon national.

Les navires étrangers sont tous admis à faire le commerce dans nos établissements.

Tous les navires, quel que soit leur pavillon, sont soumis aux droits suivants :

Droits de tonnage et de manifeste à Pondichéry,

Karikal at Mahé. Par tonneau........... 0 fr. 20 c.

Droits de phare à Pondichéry. Par tonneau...... 0015

Droits de batelage à Pondichéry........... $4 \quad 88$

MOUVEMENT DE LA NAVIGATION (1862).

1. PONDICHÉRY.

Entrées.

Venant de France. $\left\{\begin{array}{ccr}\text { Navires français. } & \text { Nombre....... } \\ - & \text { Tonnage...... } & 3,456 \\ & \text { Hommes..... } & 149\end{array}\right.$ 


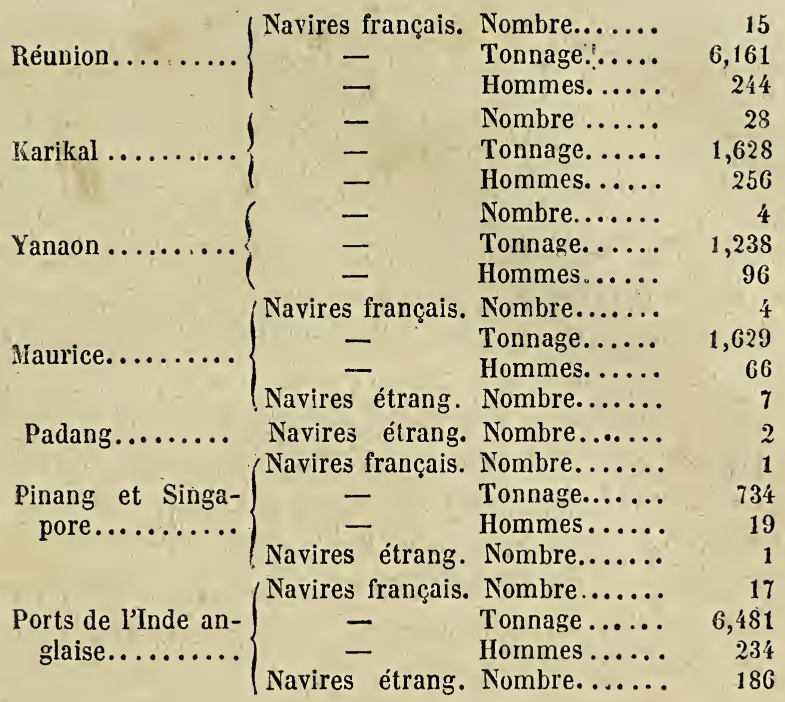

Sorties.

A destination de (Navires français. Nombre....... 23 France....... - Tonnage..... 8,288

Martinique...... $\{$ Navires français. Nombre...... 3

. $\begin{array}{llr} & \text { Tonnage ....... } & 1,660 \\ - & \text { Hommes...... } & 53\end{array}$

Réunion ........ $\begin{array}{llr}- & \text { Nombre....... } \\ - & \text { Tonnage...... } & 8,423\end{array}$

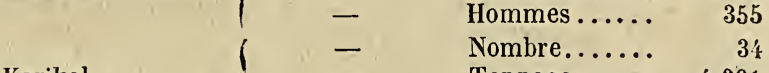

Karikal ....... $\quad$ - Tonnage..... 4,381

- Hommes...... 537

Yanaon........ $\begin{array}{llr} & \text { Nombre...... } & 6 \\ - & \text { Tonnage ...... } & 2,221\end{array}$

- $\quad$ Hommes ...... 99

Londres........ Navires étrang. Nombre...... 12

$\left\{\begin{array}{crr}\text { Navires français. Nombre....... } & 5 \\ - & \text { Tonnage...... } & 1,870\end{array}\right.$

Maurice........ Hommes.....

Navires étrang. Nombre...... 7

Padang ......... Navires étrang. Nombre...... 3

Pinang etSingapore. $\quad-\quad$ Nombre...... 1

Ports de l'Inde an- $\left\{\begin{array}{crr}\text { Navires français. } & \text { Nombre....... } \\ - & \text { Tonnage...... } & 28 \\ \hline & 10,890\end{array}\right.$

glaise......... $\quad$ - $\quad$ Hommes..... 427

Navires étrang. Nombre...... $\$ 93$ 


\section{KARIKAL.}

Entrées.

Réunion, Mayotte, (Navires français. Nombre...... 3.0

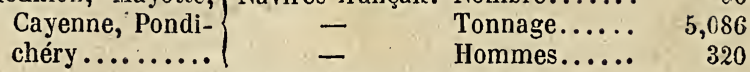

Pinang et Singa- $\begin{array}{cr}\text { Navires français. } & \text { Nombre....... } \\ \text { Tonnage...... } & 1\end{array}$ pore.......... Hommes..... -15

Ports de l'Inde anglaise. Nav étrang. Nombre...... 18

Sorties.

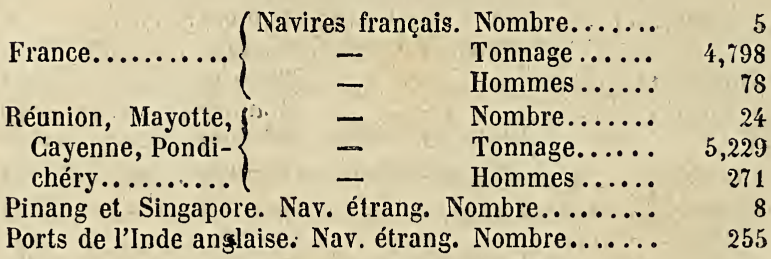

3. МАHÉ.

Entrées.

France......... $\begin{array}{clr}\text { Navires français. } & \text { Nombre....... } \\ - & \text { Tonnage ...... } & 1 \\ - & \text { Hommes..... }\end{array}$

Ports de l'Inde anglaise. Nav. étrang. Nombre...... 74

Sorties.

Ports de l'Inde anglaise. Nav. étrang. Nombre......

4. YANAON.

Entrées.

Pondichéry. Navires français, Nombre.

Sorties.

Pondichéry...... \{ $\begin{aligned} & \text { Navires français. Nombre....... } \\ & \text { Navires étrang. Nombre...... }\end{aligned}$

RÉCAPITULATION.

A l'entrée.

Nombre des navires français.................. 156

Tonnage.............................. 27,060

Équipage $\ldots \ldots \ldots \ldots \ldots \ldots \ldots \ldots \ldots \ldots \ldots \ldots \ldots, \quad \mathbf{1 , 4 1 0}$

Nombre des navires étrangers................ 444

A la sortie.

Nombre des navires français................ 160

Tonnage........................... 46,760 
Équipage.............................. 2,241

Nombre des navires étrangers................ 464

Le service de la correspondance postale échangée entre la France et nos établissements de l'Inde, est centralisé dans des bureaux établis à Pondichéry, Ghandernagor, Yanaon, Karikal et Mahé.

Le service de la poste anglaise pour les lettres expédiées à l'intérieur de l'Inde est dirigé par un agent du gouvernement anglais.

Dès l'ouverture des lignes de bateaux à vapeúr britanniques entre l'Inde et Suez, en 1839, nos établissements ont pu communiquer avec la métropole par la voie de Suez. Mais ce mode de transport des lettres n'a été réglementé pour la première fois que par un décret du 22 juin 1853, rendu à la suite de l'organisation de la compagnie péninsulaire et orientale, en 1852.

Aujourd'hui, les conditions d'échange des lettres, des imprimés et des journaux transportés par paquebots anglais, sont réglées par les décrets des 26 novembre 18506 et 10 octobre 1859 . Mais ces dispositions ont été modifiées par un décret du 7 septembre 1863 , qui a été rendu exécutoire à partir du $1^{\text {er }}$ janvier 1864 .

Taxes.

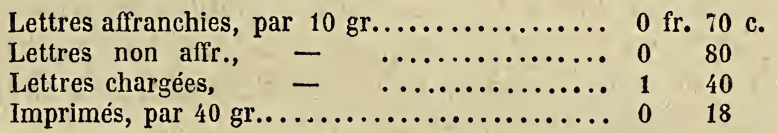

La Compagnie péninsulaire et orientale a quatre services mensuels pour l'Inde : deux sont dirigés sur Bombay et deux sur Calcutta.

Pour le service de Bombay, les paquebots partant de Marseille les 5 et 20 de chaque mois, arrivent à Alexandrie les 11 et 26 . Les départs de Suez ont lieu les 12 et 27, et les arrivées à Bombay les 26 et 10.

Pour le service de Calcutta, les départs de Marseille ont lieu les 12 et 28 , et les arrivées à Alexandrie les 18 et les 4 . Les paquebots quittent Suez les 19 et 4 , et arrivent à Calcutta'les 29 et 13.

Les lettres pour Pondichéry transportées par la voie de Bombay sont expédiées à destination, soit par le chemin de fer qui traverse une partie de la presqu'île de l'Indoustan, soit par des cou- 
reurs indiens. Celles qui sont transportées par la voie de Calcutta sont déposées à Madras, au passage du paquebot, et de là transmises à Pondichéry. Le parcours sur le territoire britannique de l'Inde est soumis à une taxe spéciale de 10 centimes par lettre et de 6 centimes par imprimé. G'est là ce qui explique la surtaxe portant sur la correspondance pour l'Inde comparée à la taxe des autres colonies françaises.

Prix du passage de Marseille à Pondichéry.

Cabine réservée à deux lits (250 liv. st.)........ 6,475 fr.

Cabine à plusieurs lits (100 liv. st.)........... 2,500

En outre, on a à payer les frais de transit en chemin de fer entre Alexandrie et Suez :

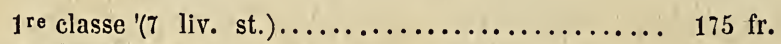

2 e classe $(3$ liv. st. 10 sh.).................. 86

L'ouverture de la ligne française de l'Indo-Chine qui a cu lieu au mois d'octobre 1862, permet d'ajouter un cinquième service pour les communications rapides entre la France et ses établissements de l'Inde.

La compagnie des services maritimes de messageries impériales, adjudicataire de cette ligne par suite d'une convention qui a élé approuvée par la loi du 3 juillet 1861, a établi à Pointe-de-Galles (île de Ceylan) un service annexe, s'embranchant sur la ligne principale de Suez à Saïgon, et chargé de desservir Pondichéry, Madras et Galcutta.

Les paquebots de cette Compagnie partent de Marseille le $\mathbf{1 9}$ de chaque mois, à 2 heures du soir, et arrivent à Alexandrie le 26. Ceux qui partent de Suez le 27 touchent à Pointe-de-Galles le $13 \mathrm{du}$ mois suivant, et le 15 à Pondichéry. Pour le retour, le départ de Pondichéry a lieu le 7, l'arrivée à Pointe-de-Galles le 10, à Alexandrie le 29, et à Marseille le 5 du mois suivant. C'est donc un trajet de 28 jours en moyenne.

Prix du passage de Marseille à Pondichéry.

(Messageries impériales.)

Cabine entière pour une personne........... 5,000 fr.

Cabine à deux couchettes, pont supérieur à l'arrière. 3,125

Cabine à plus de deux couchettes, à l'arrière..... 2,500

Cabines à l'avant..................... 2,250

On a, en outre, à payer le prix du transit égyptien. - Les pas- 
sagers du gouvernement, par suite d'une convention avec le viceroi, ne payent que $81 \mathrm{fr}$. $40 \mathrm{c}$. pour les premières classes et 53 fr. 40 c. pour les secondes classes.

Pour se rendre à Mahé, Yanaon et Karikal, on doit débarquer à Pondichéry; pour se rendre à Chandernagor, on doit prendre le paquebot jusqu'à Calcutta.

Les conditions d'échange des correspondances par la voie française ont été réglées par le décret du 22 octobre 1862 et, à partir du $1^{\text {er }}$ janvier 1864, par le décret du 7 septembre 1863.

Voici la taxe d'après ce dernier décret :

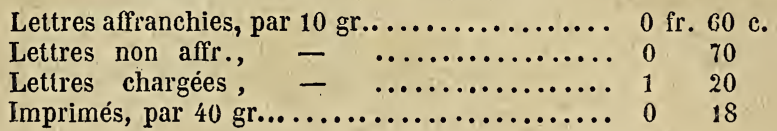

Pour les lettres des militaires et des marins, on perçoit une taxe de 20 c. par 7 grammes et demi, quand elles sont affranchies, et de 30 c. en cas de non-affranchissement. - La correspondance est exemptée de toute taxe.

On se sert dans l'Inde française, comme dans les autres colonies, de timbres-poste coloniaux.

En dehors de la roie rapide, des communications sont établies avec nos établissements de l'Inde par les navires à voiles qui doublent le cap de Bonne-Espérance.

La moyenne de la traversée est d'environ 100 jours de France dans l'Inde, et de 120 jours de la colonie en France. - Le prix du passage, calculé d'après cette moyenne, est en général de $1,500 \mathrm{fr}$. pour l'aller, et de $2,000 \mathrm{fr}$. pour le retour.

Le prix des lettres expédiées par cette voie est de $30 \mathrm{c}$. pour $10 \mathrm{gr}$. lorsqu'elles sont affranchies, et dans le cas contraire de $40 \mathrm{c}$. Sur le produit de cette taxe, $10 \mathrm{c}$. par lettre sont payés au capitaine du navire qui a effectué le transport.

Un bureau du télégraphe électrique anglais, dont les lignes aboutissent aux points les plus reculés de la péninsule, est établi à Pondichéry. (Extrait des Notices, etc.) 


\section{DEUXIEME PARTIE}

\section{COCHINCHINE}

\section{GHAPITRE PREMIER}

Coup d'œil historique.

La Basse-Cochinchine ou pays de Gia-Dinh représente un vaste rectangle formé par la pointe de terre qui termine au sud le royaume d'Annam.

Elle est située entre les 103 et $105^{\circ} 11^{\prime}$ de longitude E. et les $10^{\circ} 5^{\prime}$ et $11^{\circ} 30^{\prime}$ lat. $\mathrm{N}$.

Elle secompose de six provinces. Le traité de Saïgon, du 5 juin 1862, en a attribué trois à la France: celles de Bien-Hoa, de Gia-Dinh ou Saïgon, et de Dinh-Tuong ou Mitho. - Ces trois provinces, aujourd'hui à la France, ont une superficie totale de 22,380 kilomètres carrés (1), dont 5,700 pour la province de Saïgon.

Saïgon se trouve par $104^{\circ} 21^{\prime} 43^{\prime \prime}$ longitude E. et $10^{\circ} 46^{\prime} 40^{\prime \prime}$ lat. N.

La nation annamite, disent les Notices du Ministère de la marine, d'abord gouvernée directement par la Chine au dixième siècle de notre ère; ensuite par deux maisons indigènes, Ly et Tran, sous le protectorat du Grand-Empire, ne s'affranchit de la domination chinoise qu'au cornmencement du quinzième siècle. Ge fut INguyen-Tiên, l'ancêtre des rois actuels, qui opéra cette révolution en 1428, et qui parvint à placer sur le trône Lê-Loi, descendant du grand homme Lé-dai-hanh, dont Ly avait usurpé le trône au dixième siècle.

(1) C'est à peu près 6 fois et demie la surface de la Guadeloupe, 23 fois celle de la Martinique, 10 fois celle de la Réunion, 4 fois et demie celle de la Guyane, $1 / 23^{\mathrm{e}}$ de la France, $31 / 2$ départements français. - Elle égale celle de la Nouvelle-Calédonie. 


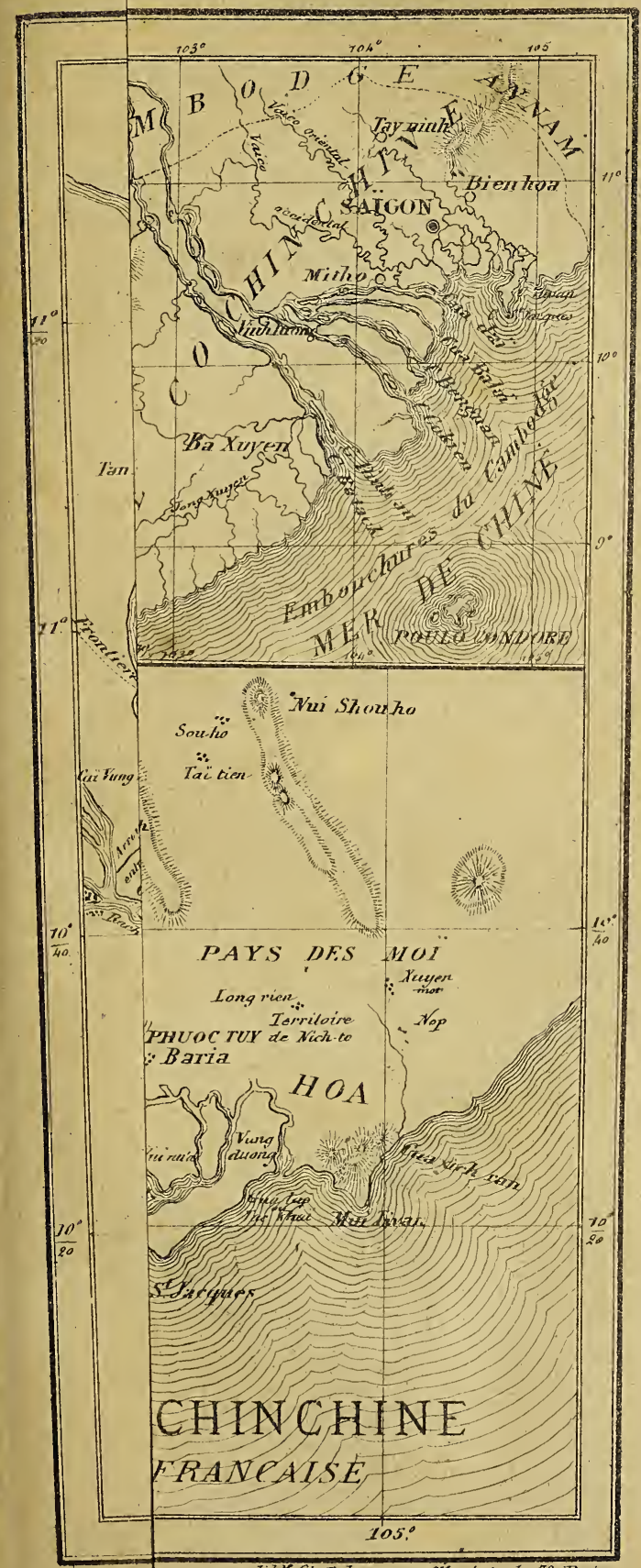





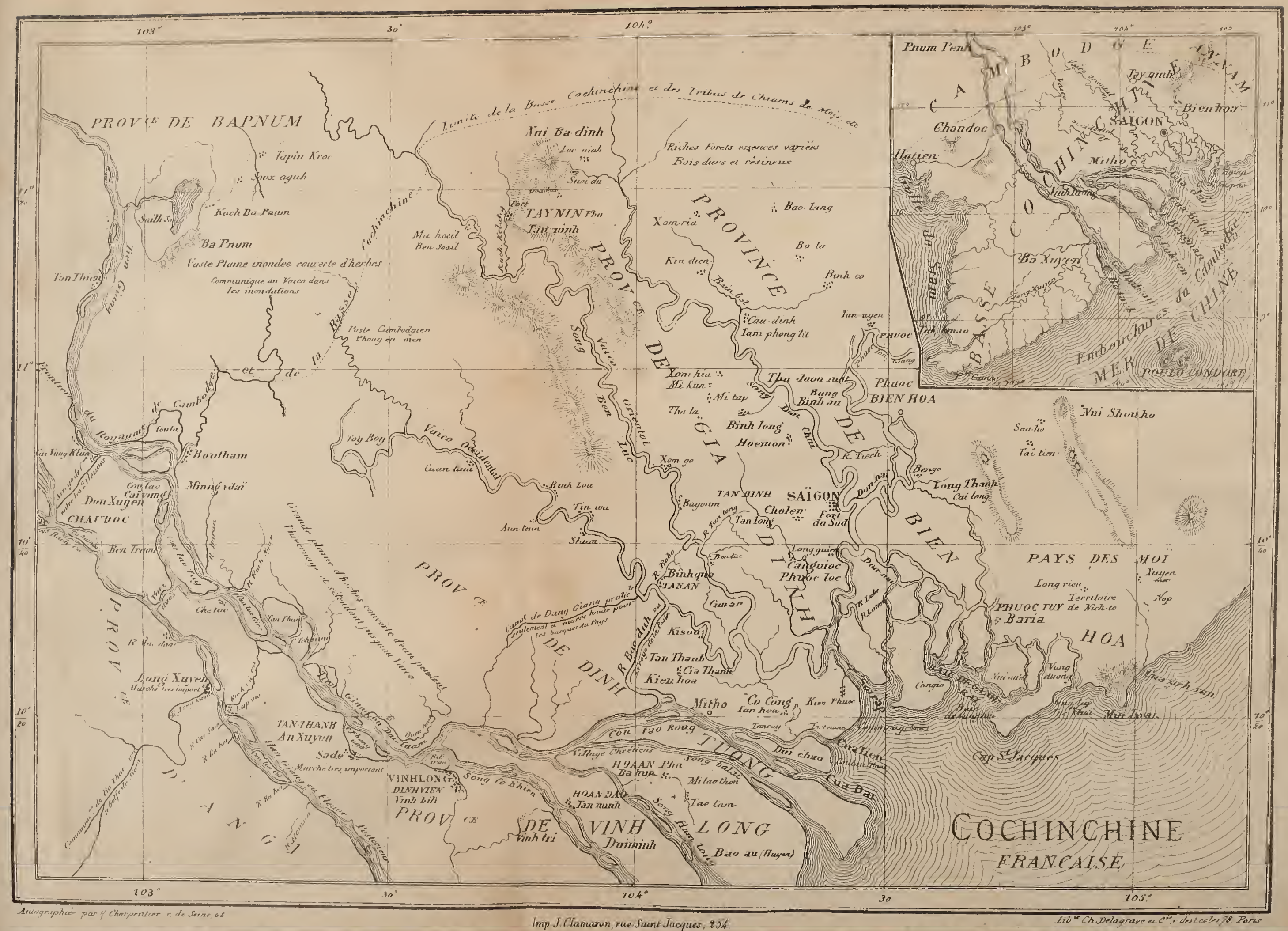



Le pays, alors habité par la nation annamite, n'était autre que le Tong-King; il s'étendait dans le sud jusqu'à la chaîne de montagnes située au nord des provinces actuelles de Hué. Tout le pays au sud de ces montagnes jusqu'au Cambodge appartenait à la nation Tsiampoise.

Nguyen-Tiên et ses descendants, sortes de maires du palais, gouvernèrent effectivement le pays au nom des Lè, sous le titre de Chuà (seigneurs).

Vers le milieu du seizième sièclé, on vit un des descendants de ces Nguyen, Taoi-Cong, s'établir dans les plaines et les montagnes de Hué avec une émigration de mandarins mécontents, de soldats réfractaires et de gens du peuple fuyant la misère et la famine. Son père l'avait déshérité en donnant la seigneurie de Chuà à un de ses employés, nommé Trinh, auquel il avait marié sa fille.

Il se forma alors deux vice-royautés : celle des Trinh au N. et celle des Nguyen au S. des montagnes de Hué.

En 1570, Taoi-Cong se déclara roi sous le nom de Tien-Nguyen, pendant que la dynastie des Lé, ses ancêtres, continuait à régner au Tong-King.

Tien-Nguyen fit avec succès la guerre aux Tsiampois qu'il refoula peu à peu dans le Sud, commençant ainsi l'absorption de la Basse-Cochinchine par la nation annamite.

Vers la fin du dix-septième siècle, les Tsiampnis avaient perdu leur nationalité.

En 16วั8, le roi de Cambodge, qui avait envahi les frontières des Annamites, fut battu par ceux-ci et fait prisonnier. Il ne, recouvra la liberté qu'à là condition de demeurer à jamais vassal du royaume d'Annam.

Après le renversement de la dynastie des Ming en Chine, le général en chef chinois de la province de Canton, Diung-NganNghich, se rendit à Tourane avec 3,000 hommes et 50 ou 60 jonques, pour demander des terres au roi d'Annam. Celui-ci leur désigna le pays de Gia-Dinh, où existaient des terres considérables dépendant du Cambodge, et dont le gouvernement annamite ne s'était pas encore emparé. - Il se débarrassait de la sorte de gens trop hardis pour ne pas derenir bientôt dangereux et en faisait en mêrne temps les avant-coureurs de ses projets de conquete sur le Cambodge.

Les Chinois entrèrent donc en Basse-Gochinchine et s'établi- 
rent à Bien-Hoa et à Mi-Tho, sans opposition de la part du roi du Cambodge, trop faible pour résister à une invasion derrière laquelle il entrevoyait une guerre avec son redoutable voisin (1680).

En 1689, invasion annamite. Le roi du Cambodge, qui résidait encore à Saïgon, est battu et forcé de se réfugier à Houdon, abandonnant aux envahisseurs toute la partie du royaume du Cambodge qui forme aujourd'hui la Basse-Cochinchine.

Les Annamites poussent, en 1715́, leur conquête jusqu'à HaThien, puis jusqu'à Vinh-Long (1733), enfin jusqu'à Chau-Doc (1765). - Saïgon devient la résidence du gouverneur genéral ou vice-roi de la Basse-Cochinchine.

On s'occupe de la colonisation du pays; on y introduit une population nombreuse, composée principalement d'agriculteurs ; on l'attache au sol, aux dépens des indigènes, par des concessions de terres.

En 1772, la guerre éclata entre les royaumes d'Annam et de Siam. - Une armée siamoise s'empare d'Ha-Thien, s'avance jusqu'à Chau-Doc, mais est repoussée finalement par les Annamites.

Un traité de paix est conclu entre les belligérants; Ha-Thien est rendue au roi d'Annam.

Cette même année, une grande révolte éclate, celle des frères Tay-Son. L'affaiblissement graduel de la dynastie royale et légitime des Lé, causé par l'ambition ascendante des Nguyen, qui, dans l'origine, n'avaient pas le titre de souverains, avait excité de très-vifs mécontentements chez le peuple annamite, très-attaché à ses coutumes. Cette situation fut habilement exploitée par le nommé Nhac, riche marchand de la province de Qui-Nhou, qui, à l'aide de ses deux frères, entreprit de se faire un royaume pour lui-même aux dépens de la famille Nguyen. La révolte se répandit bientôt dans tout le royaume, dont la capitale tomba aux mains des frères Tay-Son (montagne de l'ouest, nom du pays de Nhac et de ses frères), vers la fin de $\mathbf{1 7 7 5 .}$

En 1779, le roi Tien-Thon, chassé de Hué, se réfugie à Saïgon. où les rebelles s'emparent de sa personne et le mettent à mort. Son fils, Théto ou Nguyen-Anh, qui plus tard devait régner sous le nom de Gia-Long, parvient à s'échapper.

En 1785, Théto est réduit à se réfugier à la cour de Bang-Kok et à réclamer l'assistance du roi de Siam. Succès, suivis de revers, dus surlout aux exactions des troupes auxiliaires. 
De cette époque date l'intervention militaire de la France en Cochinchine, où elle n'avait jusque-là été représentée que par ses missionnaires et ses martyrs. Au moment où tout paraissait désespéré pour le dernier des Nguyen, héritier légitime du royaume d'Annam (le dernier de la dynastie de Lé était mort en Chine, après avoir été forcé d'abdiquer en faveur d'un des frères Tay-Son), à ce moment, le sort lui fit rencontrer le célèbre évêque d'Adran, Mgr Pigneau de Behaine, qui lui offrit un asile précaire dans sa retraite menacée elle-même. L'évêque lui propose de solliciter l'appui de la cour de France pour faire valoir ses droits et s'offre à passer lui-même en Europe pour y négocier avec le roi Louis XVI une alliance offensive et défensive. Lc fils de Théto, âgé de six ans, accompagne l'évêque danś cette mission.

Traité du 28 novembre 1787, signé à Versailles par le comte de Montmorin et l'évêque d'Adran. Ge dernier revient ensuite dans l'Inde pour en surveiller l'exécution.

Les principales dispositions du traité sont les suivantes:

$1^{\circ}$ La France doit envoyer un corps auxiliaire d'environ 1,500 hommes et tout un matériel de guerre.

$2^{\circ}$ Le roi de Gochinchine cède à la France, en toute propriété et souveraineté, la presqu'île de Tourane et l'île de Poulo-Condor.

$3^{\circ}$ Le port de Tourane doit appartenir concurremment aux deux puissances ; la France y peut créer tous les établissements jugés nécessaires à sa navigation, à son commerce, à la réparation et à la construction de ses bâtiments.

$4^{\circ}$ Liberté absolue pour la France d'échange et de circulation dans tout le pays, à l'exclusion des autres peuples.

Ce traité, malheureusement, demeura sans exécution, par la faute du comte de Conway, gouverneur de nos établissements de l'Inde, chargé de la conduite de l'expédition, et surtout par les événements de 1789 .

Toutefois, l'évêque d'Adran put procurer au roi de Cochinchine un appui assez ferme pour triompher de ses ennemis et restaurer sa dynastie. Les noms des Français qui l'aidèrent dans cette entreprise, Chaigneau, Vannier, Ollivier et Dayot, sont restés populaires dans le pays.

En 1790, le pays de Gia-Dinh est reconquis, grâce à l'appui des Français. - Théto élève Mgrr d'Adran à la dignité de premier ministre. - Les officiers français, désignés précédemment, orga- 
nisent l'armée annamite, forment la marine, bâtissent les fortifications de Saïgon, celles de Hué et les citadelles des provinces.

1799. Mort de Mgr d'Adran. - Le roi accompagne son cercueil avec son fils et la reine, prononce lui-même le panégyrique de l'illustre défunt, et lui fait ériger, aux environs de Saïgon, un tombeau que le gouvernement français, en août 1861, a déclaré propriété nationale.

1802. Théto, ayant reconquis tout son royaume, se déclare roi du Tong-King et de la Cochinchine, sous le nom de Gia-Long.

1820. Les officiers français sont systématiquement écartés sous Minh-Mang, fils et successeur de Théto. Ils reviennent en France (1823), et le pays retombe dans sa léthargie asiatique.

Persécutions contre les chrétiens, en 1820, sous Minh-Mang, en 1810, sous Thieu-Tri, et, en 1847, sous Tu-Duc.

De 1817 à 1831, nos batiments se montrent dans la baie de Tourane pour essayer de renouer des relations politiques avec la Cochinchine (de Kergariou, 1817 ; Bougainville, 1825; Laplace, 1831), et pour protéger, par la vue du pavillon français, nos missionnaires persécutés. Ces tentatives n'aboutissent pas.

1843. Le commandant Lévêque parvient à sauver et à recueillir à bord de l'Héroïne cinq missionnaires (MM. Galy, Berneux, Charrier, Miche et Duclos) désignés pour le supplice.

1845. La corvette Alcmène obtient la délivrance de Mgr Lefebvre, érêque d'Isauropolis.

1847. Le capitaine de vaisseau Lapierre vient à Tourane avec deux navires de guerre pour protéger nos nationaux.

Ses réclamations sont méconnues. Un guet-apens est dressé contre les officiers français par ordre du roi. Le 10 avril, ordre est donné d'attaquer les forts des Annamites; on leur tue 1,000 hommes, on leur coule ou brûle cinq corvettes de guerre.

18วั6. Mission de M. de Montigny, chargé de négocier un traité avec les souverains de Siam et d'Annam. On répond à la lettre qu'il envoie d'une manière évasive et dédaigneuse.

1857. Meurtre de Mgr Diaz, évêque espagnol, vicaire apostolique du Tong-King.

1858. L'amiral Rigault de Genouilly est chargé d'opérer militairement contre les Annamites et d'obtenir par la force la réparation de nos griefs. L'Espagne se joint à l'expédition. - Le 31 août, l'amiral se présente devant Tourane avec une frégate, 
deux corvettes, cinq canonnières, trois transports et un petit vapeur espagnol.

Les forts sont détruits et l'ennemi dispersé. Le 2 septembre, toute la presqu'île de Tourane était en notre pouvoir.

Le but primitif de l'amiral était d'agir sur Hué, mais les maladies particulières à la baie de Tourane, le changement de mousson qui allait rendre plus difficiles les opérations déjà difficiles en cet endroit et les renseignements qu'il reçut sur les provinces de la Basse-Cochinchine, le décidèrent à changer son plan et à se diriger sur Saïgon. Laissant une garnison à Tourane, il quitta cette position le 2 février 1859 .

1859. Le 7 février, l'amiral pénètre dans la rivière de Saïgon et détruit, en la remontant, les forts qui défendent les approches de la ville. - Prise de Saïgon, le 17.

Le 1 כ̆ septembre, l'amiral, de retour à Tourane, attaque les retranchements élevés par l'ennemi qui eśt rejeté sur la route de Hué.

Le $1^{\text {er }}$ novembre, le contre-amiral Page, qui remplace l'amiral Rigault de Genouilly, s'empare de la position de Kien-San, laquelle commande la route de Hué.

La guerre avec la Chine met un terme à ces brillantes opérations. On abandonne Tourane, et l'on se borne à conserver Saïgon, comme base des opérations futures.

1860. Le contre-amiral Page, obligé de partir pour la Chine, laisse à Saïgon le capitaine de vaisseau Dariès avec 700 hommes, deux corvettes et quatre avisos.

“Pendant près d'ure année, cette faible garnison eut à tenir en échec toute l'armée annamite, qui s'était fortifiée dans la plaine de Ki-Hoa autour de Saïgon et tendait chaque jour à nous resserrer dans la ville. Ses attaques furent chaque fois repoussées avec succès. ")

1861. Le 7 février, arrivée à Saïgon du vice-amiral Charner. Le 24, 3,000 Français chassent du camp de Ki-Hoa les 20,000 Annamites qui l'occupent.

"Pendant que les troupes opéraient sur terre, le contre-amiral Page remontait la rivière de Saïgon avec une division composée d'une frégate, une corvette, trois avisos et cinq canonnières, et détruisait les forts et les barrages que l'ennemi avait construits pour assurer sa retraite vers le nord.

"Après avoir expulsé l'armée annamite de la province de Saï- 
gon, l'amiral Charner envoya une double expédition, par terre et par eau, la première sous la direction du commandant de Quilio, la seconde sous celle du contre-amiral Page, pour s'emparer de Mitho. ")

Le 12 avril, prise de Mitho par la division de l'amiral Page. La prise de cette ville nous livre la province de Dinh-Tuong, et tout le pays entre le Donnaï et le Cambodge se trouve ainsi en notre possession.

Le roi d'Annam demande la paix et chercheà soulever le peuple contre notre autorité. Ses manœurres sont découvertes et les négociations rompues.

Le 17 décembre, l'amiral Bonard disperse 3,000 Annamites retranchés à trois lieues au nord de Saïgon, détruitles obstacles élevés sur la route de Bien-Hoa, et s'empare de cette ville.

1862. Le 23 mars, prise de Vinh-Long, d'où les émissaires de Tu-Duc excitaient à la révolte les habitants de la province de Mitho. - Préparatifs d'une expédition sur la rivière de Hué.

Le 5 juin, la paix est signée à Saïgon.

Les clauses du traité sont les suivantes :

$1^{\circ}$ Cession par le roi d'Annam à la France des trois provinces de Bien-Hoa, de Saïgon et de Mitho, ainsi que de l'île de PouloCondor;

$2^{\circ}$ Libre exercice du culte catholique dans l'empire ;

$3^{\circ}$ Autorisation pour les sujets de la France de commercer librement dans les trois ports annamites de Tourane, Balat et Quang-Au ;

$4^{\circ}$ Paiement en dix ans d'une indemnité de guerre de 20 millions de francs.

1863. Insurrections locales. Expédition heureuse sur le territoire de Go-Cong, dans le sud de la province de Saïgon.

Le 15 avril, échange des ratifications du traité, à Hué, où l'amiral Bonard se rend en personne.

Le $1^{\text {er }}$ mai, départ pour la France du vice-amiral Bonard. Il remet le service au contre-amiral de La Grandière.

"Un des premiers soins du nouveau gouverneur fut de régler nos rapports avec le royaume du Cambodge. Au dix-septième siècle, ce royaume s'était reconnu tributaire de l'Annam. Mais l'influence de ce pays sur le Cambodge avait passé progressivement au roi de Siam qui, profitant habilement des querelles de TuDuc avec la France, avait fini, dans ces derniers temps, par gou- 
verner à Houdon, au moyen de l'influence de ses commissaires sur l'esprit du monarque cambodgien. L'amiral de la Grandière entama des pourparlers avec le jeune roi du Cambodge, Phra-Norodon, qui s'est placé sous notre protectorat par un traité du 11 août 1863, et nous a livré, pour y fonder un dépôt de charbon, l'importante position des Quatre-Bras, sur le grand fleuve du Cambodge. "

Le roi Tu-Duc, dans le courant de 1863, envoie à Paris une ambassade. Elle a mission de proposer le rachat de nos trois provinces et la concession du protectorat des six provinces de la Basse-Cochinchine. Après de longues négociations, la proposition est rejetée, et l'on en revient au traité de 1862.

1864. Quelques bandes d'insoumis et de malfaiteurs se fortifient dans le cercle de Baria, sur la frontière du Binh-Tuan. Le lieutenant-colonel Loubère, commandant la province de BienHoa, est envoyé contre ces insurgés. Dans les journées des 22, 23 et $\mathbf{2 4}$ avril, il les bat et détruit leurs forts. - Soumission des Moï des montagnes de Baria.

"Partout, les indigènes ont appris maintenant à apprécier les bienfaits de notre civilisation et se rapprochent de nous chaque jour davantage. En plusieurs circonstances, ce sont les milices indigènes qui ont réprimé elles-mêmes des tentatives d'agitation; ce sont elles, ertin, qui, au mois d'août 1861, ont poursuivi, attaqué le mandarin Quan-Ding, et, après qu'il eut été tué dans le combat, ont rapporté son corps à Go-Gong, c'est-à-dire au lieu même où, dix-huit mois auparavant, ce mandarin, par sa rébellion, s'était acquis une certaine renommée. „) (Notices, etc.)

\section{Commandants et gouverneurs.}

1858-1859. Le vice-amiral, Rigault de Genouilly, commandant en chef de la division navale des mers de Chine et du corps expéditionnaire, s'empare de Tourane le $1^{\text {er }}$ septembre 1858, et de Saïgon le 17 février 1859 .

1859-1860. Le capitaine de frégate Jauréguiberry, commandant à Saïgon. - Le contre-amiral Page directeur des affaires en Cochinchine.

1860-1861. Le capitaine de vaisseau Dariès, commandant supérieur à Saïgon.

1861. Le vice-amiral Gharner, commandant en chef, s'empare des provinces de Saïgon et de Mitho. 
1861-1863. Le contre-amiral Bonard, commandant en chef, s'empare de la province de Bien-Hoa, et de Vinh-Long.

1863-1863. Le contre-amiral de La Grandière, gouverneur.

1865. Le contre-amiral Roze, gouverneur et commandant en chef par intérim.

\section{CHAPITRE II}

Superficie. - Cours d'eau. - Sol. - Forêts. - Les trois provinces de la Cochinchine française. - Saïgon, Mitho, etc. - Ile de Poulo-Condor.

Les trois provinces cochinchinoises possédées par la France ont une superficie totale de 22,380 kilomètres carrés. La province de Saïgon seule en a une dê 5,700 .

Le grand fleuve du Cambodge, ou Meï-cong, divise la BasseCochinchine en deux parties presque égales. Après sa sortie des montagnes du Thibet, il traverse l'extrémité sud-ouest de la Chine, longe toute la partie occidentale du royaume d'Annam; passe dans le Cambodge et se partage en trois branches à Namvan.

Les provinces septentrionales de la Cochirchine, qui appartiennent à la France, sont séparées des trois provinces méridionales par la rive gauche de la troisième branche (dit fleuve Antérieur); celui-ci, parvenu à Hing-Long, se divise en quatre bras qui conduisent ses eaux à la mer par six embouchures.

D'après les Notices, le système hydrographique des trois provinces de la Cochinchine française est admirable. Il se compose de quatre fleuves profonds, quoique de peu d'étendue, parallèles entre eux pendant la plus grande partie de leur cours supérieur, et qui se relient deux à deux pour se jeter à la mer par les deux embouchures du Soirap et du cap Saint-Jacques.

Ces cours d'eau sont, de l'est à l'ouest :

$1{ }^{\circ}$ Le Donnaï, ou rivière de Bien-Hoa;

$2^{\circ} \mathrm{La}$ rivière de Saïgon;

$3^{\circ}$ Le Vaïco oriental ou grand Vaïco;

$4^{\circ}$ Le Vaïco occidental ou petit Vaïco.

Ces quatre cours d'eau, praticables pour les plus grands navires jusqu'à 70 et 80 milles de leur embouchure, ne sont que les artères principales. Une multitude de petites rivières ou arroyos relient 
ces artères entre elles et remplacent avec avantage les voies de transport terrestres.

Le sol peut se diviser en terres basses et en terres élevées.

Les premières embrassent la partie inférieure des bassins fluviaux et se divisent en trois catégories :

$1^{\circ}$ En rizières, d'une superficie d'environ 105,000 hectares, réparties dans les trois provinces;

$2^{\circ}$ En forêts de palétuviers d'une hauteur de 1 à 3 mètres sur le bord des fleuves;

$3^{\circ}$ En plaines immenses, où croissent, à perte de vue, des herbes et des joncs, et qui sont susceptibles d'une culture facile.

Partout, au voisinage des fleuves, le sol est d'une fécondité très-remarquable.

Les terres élevées commencent au-dessus de Saïgon; elles vont s'étendant jusqu'aux limites septentrionales de la province de Bien-Hoa, et se partagent aussi en trois catégories :

$1^{\circ}$ En terres cultivées, d'une superficie de 10 à 15,000 hectares;

$2^{\circ}$ En terres non cultivées, mais pouvant l'être aisément;

$3^{\circ}$ En forets.

Les forêts sont d'une exploitation facile; elles présentent une variété d'essencès très-propres aux constructions navales, au charpentage, à l'ébénisterie. Commençant dans le nord de la province de Saïgon, elles s'étendent dans le nord et le nord-est, sur une vaste superficie.

Quelques groupes de montagnes, dernières ramifications de la chaîne du Thibet, se voient sur la rive gauche de la rivière de Bien-Hoa. - On remarque, plus au sud, le pâté des montagnes. de Dinh et de Baria, immenses blocs granitiques hauts de 300 à 400 mètres, séparant les terrains d'alluvion, bas et noyés, des terrains élevés de la province de Bien-Hoa. Le groupe des monts du cap Saint-Jacques, entre la mer et ces montagnes; les hauteurs du cap Tiwane, plus à l'est; enfin, au nord-ouest de Saïgon, le pic verdoyant de Ba-Dinh (ou Dien-Bau), haut de 500 à 600 mètres complètent cet ensemble.

La Cochinchine française comprend trois provinces, avons-nous vu : $1^{\circ} \mathrm{La}$ province de Gia-Dinh, chef-lieu Saïgon; $2^{\circ}$ la province de Bien-Hoa; $3^{\circ}$ la province de Mitho.

La province de Gia-Dinh est située entre celles de Bien-Hoa et de Mitho, et se divise en 7 arrondissements ou inspeclions.

Saïgon, son chef-lieu et siége du gouvernement colonial, se 
trouve à ら̆ milles de la mer, sur la rive droite de la rivière de ce nom. Elle a plus de 7 kilomètres de longueur sur 5 kilomètres de largeur et renferme plus de 20,000 Asiatiques, dont les trois quarts sont indigènes. - Elle formait autrefois une agglomération de plus de 40 villages, représentant une population d'au moins こ0,000 âmes. Dès le début de notre expédition, tous ces villages, sauf un seul, celui de Choquan, ont été détruits par l'ennemi, qui ne voulait nous laisser que des ruines. Depuis cette époque, onze autres villages se sont formés autour de nous et sous notre protection. Ces douze villages comptent 830 hommes inscrits, ce. qui représente approximativement 8,000 âmes. (V. Notices, etc.)

La partie européenne de la ville renferme la citadelle, la demeure du gouverneur, les bureaux de l'administration, les casernes, l'hôpital militaire, l'église, l'arsenal, etc. A la fin de 1864, on y comptait 557 Européens, 600 Malabars, 1,200 Chinois, non compris les troupes de la garnison ni les équipages des navires et bateaux sur rade.

De nombreux travaux ont déjà été exécutés : rues, canaux, quais, ponts, bassin de radoub, dock flottant, église, hôpital, etc.

Saïgon appartient à l'arrondissement de Binh-duong-huyen. Cet arrondissement renferme 70 villages, 6 marchés et postes militaires, 2 trams; il a 3,302 inscrits et 1,200 Chinois.

L'arrondissement de Binh-long-huyen, au nord de Saïgon, comprend 75 communes, 4 marchés et postes militaires, 4 trams et 2,984 inscrits. Son chef-lieu est Hoc-mou.

L'arrondissement de Tay-ninh, qui s'étend jusqu'à la limite septentrionale de la province, a 43 villages, 6 marchés et postes militaires, 3 trams et $\mathbf{8 4 1}$ inscrits. Son chef-lieu est Tayninh. Belles forêts, sol propre à une grande variété de cultures.

L'arrondissement de Tân-long-huyen, au sud-ouest de Saïgon, comprend 96 villages, 8 marchés et postes militaires, 1 tram, 2, 586 inscrits et 5,000 Chinois. Ville principale : Gholon ou Cholen. - Sol très-fertile.

L'arrondissement de Phuoc-loc-huyen, au sud du précédent, renferme 109 villages, marchés, et 3,740 inscrits. Ville principale : Can-gïoc. - Sol très-fertile.

L'arrondissement de Tân-an, entre les deux Vaïcos, renferme 78 villages, 6 marchés, 1 tram et 3,638 inscrits. - Riz abondant.

Enfin, l'arrondissement de Tan-hoa-huyen, entre le Soirap, au nord, et le bras méridional du Meï-Cong, au sud, comprend 
33 communes, 6 marchés et 3,239 inscrits. Chef-lieu : Go-Cong. - Rizières des plus riches.

La province de Bien-Hoa a qualre arrondissements.

L'arrondissement de Phuoc-chanh-huyen renferme 109 villages, 4 marchés et 3,168 inscrits. Ghef-lieu : Bien-Hoa. - La ville n'est qu'une place forte.

L'arrondissement de Binh-an-huyen renferme 78 villages et 3,873 inscrits. - Marchés très-prospères : Thu-daù-mot, résidence de l'inspecteur; Bung, où se trouve une nombreuse chrétienté; Tu-Duc, où sont les tombeaux de la famille royale.

L'arrondissement de Long-thanh-huyen compte 58 villages, 4 marchés et postes, 4 trams, et 1,112 inscrits. - Tabac excellent.

L'arrondissement de Phuoc-an-huyen comprend 36 villages, 4 grands marchés, 936 inscrits. Ville principale : Baria. - Sites pittoresques. Salines importantes.

La province de Mitho possède 4 arrondissements (huyens).

L'arrondissement de Kieng-hung-huyen comprend 78 villages, 8 marchés et postes militaires. Chef-lieu : Mitho.

Mitho est, après Saïgon, la ville la plus importante de la BasseCochinchine. Elle renferme une citadelle, elle est bâtie sur la rive gauche du bras septentrional du Cambodge, au point où débouche l'arroyo de la Poste. C'est l'entrepôt naturel de tout le commerce du Cambodge. Mitho est à 23 milles de la mer.

L'arrondissement de Kien-hoa-huyen comprend 84 villages et 7 marchés. Chef-lieu : Tan-hoa-thon.

L'arrondissement de Kien-dang-huyen comprend 48 villages et 8 marchés, Chef-lieu : Caï-bé.

Enfin, l'arrondissement de Kieng-phong-huyen comprend 38 villages, 3 marchés et 1 fort.

Vers la fin de 1864, les trois provinces étaient reliées entre elles par un réseau de lignes télégraphiques ayant un développement de 394 kilomètres ; dix câbles traversaient les arroyos, quinze stations étaient ouvertes à la correspondance.

Saïgon était relié par cinq routes principales à Mitho, Tayninh, Bien-Hoa, Baria et Go-Cong. Des travaux considérables étaient en voie d'exécution.

A nos possessions cochinchinoises se rattache l'île de PouloCondor (par $8^{\circ} 38^{\prime}$ et $8^{\circ} 46^{\prime}$ lat. N.; $104^{\circ} 10^{\prime}$ et $104^{\circ} 18^{\prime}$ long. E.). Cette île, au sol volcanique, a une superficie totale de 6,013 
hectares environ. Elle se divise en grande Condor ou Con-non, et en petite Condor ou Bae-vioumg. Un isthme étroit réunit les deux parties de l'île.

La culture du riz, la fabrication de la chaux, l'exploitation des forèts, occupent les habitants et les prisonniers du pénitencier qui y a été établi en 1863.

\section{CHAPITRE III}

Climat. - Température. - Pluies. - Vents. - Marées. - Observatoire.

En Basse-Cochinchine, la température varie entre $20^{\circ}$ et $30^{\circ} \mathrm{c.}$, sauf dans la saison sèche (d'octobre à avril), où le thermomètre monte pendant le jour à $35^{\circ}$ et descend la nuit jusqu'à $17^{\circ}$. En février et au commencemeut de mars, le soleil est le plus ardent.

On a attribué au climat une insalubrité qu'il n'a pas complétement. Si, en janvier et février, la mortalité est grande chez les Annamites, la cause en est dans leur négligence à se couvrir pendant la fraîcheur des nuits. Une simple couverture de laine, innovation que nous avons introduite, a diminué sensiblement la mortalité parmi eux.

De mai à la fin d'octobre, pluies fréquentes, mais intermittentes; très-rares dans la saison sèche.

Les vents régnants sont ceux du N.-E.; ils durent d'octobre à avril ; ceux du S.-O. soufflent de mai à octobre; ils sont violents, mais ne produisent que des bourrasques.

L'Annuaire de la Cochinchine donne sur les marées les renseignements suivants, dus à M. F. Vidalin, sous-ingénieur hydrographe.

Le flot vient du nord, le long des côtes de Cochinchine. Il est, du reste, facile de suivre la marche de la marée dans la mer de Chine. Le plein a lieu les jours de nouvelle et de pleine lune, vers 8 heures du matin, dans les parages des îles Lema, au large de Hong-Kong; puis il arrive vers 9 h. 30 min. à Tourane, $11 \mathrm{~h}$. au cap Varella, 2 h. au cap Saint-Jacques, 2 h. 30 min. à PouloCondor, $10 \mathrm{~h}$. à l'entrée du détroit de Singapore, et $11 \mathrm{~h} .30 \mathrm{~m}$. à l'île Tree, où le flot de la mer de Chine rencontre celui du détroit de Malacca.

L'heure de la pleine mer retarde également en remontant de 
Hong-Kong vers le nord. L’onde de marée formée dans le vaste espace libre de l'océan Pacifique paraît donc pénétrer dans la mer de Chine par le détroit de Formose. Elle atteint d'abord le récif Pratas vers 4 h. du matin, puis elle se présente sur la côte, d'où elle se répand au nord et au sud.

Le groupe des Philippines apporte obstacle à la libre transmission de cette onde; car les marées sont faibles et irrégulières dans la zone formée par cette ceinture d'îles. Il y a une interférence des diverses ondes arrivant par les différents canaux avec des retards successifs, qui altèrent le mouvement simple des marées. Généralement, le niveau de l'eau monte pendant les derniè-res heures de la nuit jusque dans la matinée; puis il descend plus ou moins régulièrement pendant 12 heures. Les courants de flot et de jusant sont souvent très-modifiés par le courant général de la mousson, surtout au large.

Du cap Padaran à l'entrée du détroit de Singapore, les marées sont plus fortes et plus régulières; mais elles se ressentent de l'influence des marées de la zone plus au nord. Ainsi, dans les cours d'eau de la Cochinchine, les basses mers de nuit, concordantes avec la basse mer des parages entre Hong-Kong et les Philippines, atteignent un niveau bien inférieur à celui des basses mers de jour, qui se rencontrent avec la pleine mer de ces mêmes parages.

Les plus hautes marées de l'année ont été observées aux syzygies des équinoxes. Leur niveau, qui atteint $3^{\mathrm{m}}, 80$ au-dessus des plus basses mers, a été sensiblement le même le matin et le soir.

Le jusant prédomine en rivière de Saïgon pendant la saison des pluies (de mai à octobre); tandis que, pendant la saison sèche, il ne se fait souvent sentir que pendant la nuit; dans les mortes eaux de cette saison, les navires restent fréquemment au travers, durant tout le jour.

L'évitage au jusant a lieu généralement une demi-heure ou trois quarts d'heure après la pleine mer; l'évitage au flot retarde souvent davantage après l'heure de la basse mer.

L'observatoire créé à Saïgon possède une lunette méridienne et une pendule. La longitude de Saïgon, d'après les observations de culminations lunaires qu'on y a faites, est de $6 \mathrm{~h} .57 \mathrm{~m} .30 \mathrm{~s}$. à l'est de Paris; ce qui fait une différence de $50^{\prime \prime}$ avec la longitude donnée plus haut d'après M. Manen (104' $22^{\prime} 30^{\prime \prime}$ ).

En 1862, un phare a été installé sur l'un des sommets du 
groupe du cap Saint-Jacques. Sa portée est de 28 milles. Position: $10^{\circ} 19^{\prime} 40^{\prime \prime}$ lat. N.; $104^{\circ} 44^{\prime} 43^{\prime \prime}$ long. E. de Paris.

\section{GHAPITRE IV}

Gouvernement. - Administration indigène. - Personnel européen et indigène. - Forces militaires. - Station locale. - Population indigène. - Mcurs des Annamites. - Chinois. - Européens.

Le gouvernement de la colonie se compose du gouverneur et d'un conseil consultatif.

Le gouverneur est dépositaire de l'autorité impériale. Ses arrêtés sont, én général, soumis à l'approbation du ministre de la marine et des colonies, mais sont exécutoires par provision.

Le conseil consultatif, composé du commandant militaire, du chef du service administratif et du directeur de l'intérieur, assiste le gouverneur dans les actes de son administration.

La direction de l'intérieur, créée par un arrêté du 9 novembre 1864, comprend trois bureaux principaux. Le directeur a les mêmes pouvoirs que ceux des Antilles et de la Réunion. Il relève du gouverneur.

Un commissaire de marine est chargé de l'ordonnancement des dépenses, de la direction des services administratifs de la marine, etc.

L'organisation communale des indigènes a été conservée.

Voici ce qu'elle est, d'après les Notices de la marine.

Sous le gouvernement annamite, les provinces étaient administrées par un gouverneur, tong-doc, au-dessous duquel venait, en première ligne, le mandarin appelé quan-bo, ayant la haute direction des impôts, des registres de la population, des levées de troupes, de la surveillance de l'agriculture, etc.

Après le quan-bo venait le mandarin appelé quan-an, qui, en sa qualité de chef de la justice, collationnait, revisait, approuvait, légalisait toutes les plaintes judiciaires de la province.

Les provinces étaient toutes divisées en un certain nombre de phus et de huyens (préfectures et sous-préfectures), administrées par des fonctionnaires qui, à un degré de hiérarchie différent, étaient chargés de l'administration de leurs circonscriptions respectives, en tant que surveillance générale, impôts, agriculture, justice, etc. 
Ici s'arrêtait dans la province, en fait d'administration, la délégation de l'autorité souveraine. Toutes ces hautes fonctions étaient données à des mandarins lettrés dont les actes étaient rédigés en chinois et écrits en caractères chinois, que ne connaissent pas les populations annamites, et qui, d'ailleurs, ne peuvent s'appliquer à leur langue.

Au-dessous des phus et des huyens se trouvaient le canton, puis la commune, unité administrative du royaume, qui partait de l'homme du peuple pour s'élever jusqu'au chef de canton.

Le huyen était donc divisé en cantons, et le canton en com. munes ou villages.

La commune était administrée par un $X \hat{a}$ (maire) et par un conseil de notables. - Le maire était nommé à l'élection et recevait son cachet ou commission du gouvernement des mandarins. Le caï-tong (chef du canton) était choisi, parmi les maires, présenté par les conseils des notables, et nommé par l'autorité supérieure...

Aujourd'hui le maire est nommé par le gouverneur, mais présenté par le conseil du village. On a maintenu l'organisation ancienne pour le reste.

L'administration supérieure a subi certaines modifications, dont voici les principales :

Dans la province de Gia-dinh, l'arrondissement de Saïgon (ou Binh-duong-huyen), à l'exclusion de la ville européenne, est administré par deux inspecteurs des affaires indigènes qui, en qualité de quan-bo et de quan-an sont chargés des impôts et de la justice indigène.

L'arrondissement de Bing-long a gardé son huyen annamite.

Le reste de la province est divisé en cinq inspections, régies par des inspecteurs indigènes.

Dans la province de Bien-hoa, les quatre inspections sont, comme dans la province de Gia-dinh, régies par des inspecteurs des affaires indigènes.

Dans la province de Mitho, l'ancienne hiérarchie annamite est demeurée intacte, sauf en ce qui regarde le Tong-doc, gouverneur ou commandant supérieur, le quan-bo et le quan-an, qui sont des officiers français. Les quatre huyens sont des fonctionnaires indigènes.

Le personnel européen et indigène se compose ainsi : 
Administration de la marine (30 fonctionnaires et employés).

1 commissaire de la marine, chef du service administratif, ordonnateur;

1 commissaire-adjoint; 4 sous-commissaires ; 9 aides-commissaires, 15 commis de marine.

Direction de l'intérieur (23 fonctionnaires et employés).

1 directeur; 1 secrétaire général; 2 chefs de bureau; 1 souschef; 18 employés ;

Affaires indigènes.

$1^{\circ}$ Personnel européen. - 27 inspecteurs; 6 stagiaires; 42 secrétaires, commis et employés divers. Total : 69 .

$2^{\circ}$ Personnel indigène. -2 phus (préfets); 12 huyens (souspréfets); 36 secrétaires des phus et des huyens, 45 interprètes annamites; 39 lettrés annamites; 3 graveurs annamites et chinois; 1,700 miliciens indigènes; 46 doïs (chefs), 100 caïs (sousofficiers); 40 tholaï (fourriers), 20 trams, 3 doïs chefs de partisans, 50 partisans de Go-cong. Total : 2,095.

Justice européenne et mixte (10 fonctionnaires).

1 procureur impérial, chef du service judiciaire;

1 substitut; 5 juges ; 2 greffiers; 2 interprètes ; 2 huissiers.

1 évêque;

\section{Culte.}

2 grands vicaires ; 1 secrétaire de l'évêché ; 4 curés; 12 dessservants et vicaires; divers desservants et catéchistẹs annamites.

\section{Instruction publique mixte (70̃ fonct.).}

1 Gia-tho (professeur d'enseignement supérieur); 4 Huan-dao (surveillants de l'enseignement); 6 hoc-shanh (élèves ayant subi l'examen); 1 directeur du collége des interprètes français ; 6 élèves du collége; 1 supérieur et 10 frères de la Doctrine chrétienne; 1 supérieure et 4 sœurs de Saint-Paul de Chartres; Pas de maîtres d'école primaire.

Ports et phares (26 fonctionnaires et employés).

1 capitaine et 1 maître de port à Saïgon; 1 maître de port à 
Ghohen ; 6 matelots; 10 bateliers et interprètes annamites; 7 gardiens de phares.

Police (93 fonctionnaires et employés).

2 commissaires de police; $\check{5}$ agents européens; 10 agents de police asiatiques; 4 caporaux et $\mathbf{4 0}$ matas (gardes de police); 3 sergents ; 3 caporaux; 20 gardes de la garde urbaine; 2 interprètes; 4 journaliers.

\section{Prisons.}

1 aumônier ; 3 concierges ; 6 guichetiers ; 6 autres agents.

$$
\text { Hospice indigène de Choquan (17 employés). }
$$

2 sœurs françaises; 2 sœurs indigènes; 6 infirmiers et 6 infirmières asiatiques; 1 concierge; 1 cuisinier.

Services financiers (11 fonctionnaires et employés).

1 trésorier-payeur; 1 inspecteur des finances (mission accidentelle); 1 agent des postes; 1 préposé; 2 vérificateurs du cadastre; 1 conservateur des hypothèques; 1 inspecteur de forêts et 3 gardes.

\section{Service télégraphique.}

1 sous-inspecteur, chef de service; 2 chefs de station; 2 commis principaux; 13 stationnaires; 8 surveillants; 12 plantons; journaliers.

\section{Ponts et chaussées (20 fonctionnaires).}

1 ingénieur colonial, chef du service; 2 sous-ingénieurs coloniaux; 9 conducteurs; 8 piqueurs.

\section{Imprimerie (19 fonctionnaires).}

1 chef typographe; un écrivain autographe; 3 compositeurs; 3 imprimeurs; 2 relieurs; 7 autres agents.

\section{Agents divers.}

1 directeur du jardin botanique;

93 agents employés à divers services.

Les forces militaires employées en Cochinchine se composent de soldats français et de soldats indigènes.

L'effectif comprend des détachements d'artillerie de marine, 
du génie, d'infanterie de marine, de gendarmerie maritime, d'un escadron de spahis, d'une compagnie d'infanterie indigène, et de milices indigènes. - L'effectif normal des troupes européennes n'est pas enccre fixé. - La compagnie indigène.comprend des soldats qui proviennent du recrutement ou d'engagements volontaires.

Le nombre des navires qui doivent composer la station locale n'est pas encore arrêté.

Un arsenal maritime a été construit à Saïgon. Deux bassins recevront l'un des canonnières, l'autre un dock flottant.

La colonie se compose aujourd'hui, outre les indigènes, de Chinois et d'Européens.

M. Pallu, dans son Histoire de l'expédition de Cochinchine en 1861, s'exprime ainsi sur les Annamites et leurs mœurs :

Ce peuple appartient à la variété de l'espèce humaine que les anthropologistes désignent sons le nom de race mongole. Ils sont petits. Ils ont les membres inférieurs bien constitués, le bassin peu développé, le buste long et maigre, les épaules assez larges, la poitrine en saillie, les muscles du cou de même, la tête d'une grosseur proportionnelle avec le reste du corps, les mains étroites et longues avec les doigts noueux.

Leur teint varie beaucoup, suivant l'éducation, le rang ou les travaux, depuis la couleur de la cire d'église jusqu'à celle de la feuille morte et de l'acajou. Le front est rond, évidé par les tempes; les pommettes sont très-proéminentes ; les yeux noirs, assez peu bridés, ont une expression douce, chagrine el timide. Le nez est trop large vers le haut et produit l'effet des pièces anatomiques rapportées après coup : c'est le trait distinctif du visage asiatique.

Les Annamites sont imberbes jusqu'à l'âge de trente ans environ; même alors leur barbe est peu fournie et ne vient que sur les lèvres et au menton. Ils portent les cheveux longs. Les hommes de l'Annam rassemblent cet ornement, auquel ils tiennent beaucoup, de façon à laisser les oreilles découvertes.

Les Annamites ont quelque chose d'étrange et d'aisé dans la démarche; la tête surtout a un port singulier, qui provient sans doute de la mode du chignon et du mouvement particulier dont elle est cause.

Mais, de toutes les coutumes qui peuvent surprendre un Européen dans cette partie de l'Asie, celle de teindre les dents en 
noir, est la plus déplaisante : à une certaine distance, les plus jeunes visages paraissent édentés. Les Annamites, ainsi que tous les peuples de la Malaisie, mâchent constamment une composition dans laquelle il entre du poivre-bétel, •de la noix d'arec, du cardamome, de la chaux et quelquefois du tabac. Cet aromate a une saveur agréable, quoique mordante, et il exerce l'influence des narcotiques. C'est par erreur qu'on attribue la couleur noire des dents chez les Annamites à l'usage du bétel; leurs dents sont noircies avec une drogue de composition chinoise. Les femmes européennes, à Macao, mâchent le bétel en cachette, et leurs dents restent blanches.

La population indigène, pour les trois provinces, peut être évaluée à 900,000 âmes.

On rencontre beaucoup de Chinois. L'immigration de ce peuple en Cochinchine date de la fin du dix-septième siècle. Son centre principal est Gholen, à 7 kilomètres de Saïgon. Ghaque année, bon nombre de marins chinois envahissent la Cochinchine.

Les Européens sont encore peu nombreux. On en comptait 591 en juin 1864; tous se distinguent par une grande activité, et le temps n'est pas éloigné où la colonie française de Cochinchine rivalisera avec ses aînées des Antilles et de la Réunion.

\section{CHAPITRE V}

Justice. - Décret du 25 juillet 1864. - Tribunaux indigènes. - Tribunaux français. - Statistique judiciaire (1864). - Culte indigène. - Culte catholique.

- Assistance publique. - Hôpitaux. - Instruction publique.

Le décret organique du 25 juillet 1864 simplifie la procédure au civil et au criminel. crée un tribunal de première instance, un tribunal de commerce et un tribunal supérieur à Saïgon.

Des interprètes assermentés sont attachés à chacun de ces tribunaux.

Ce sont nos Codes qui sont appliqués.

Toutefois on a fait aux indigènes leur part. La loi annamite régit toutes les conventions et contestations civiles et commerciales entre indigènes et Asiatiques, sauf lorsque, dans un acte, il a été déclaré par les indigènes ou Asiatiques qu'ils entendent contracter sous l'empire de la loi française. - La loi annamite 
régit aussi les crimes et délits des indigènes ou Asiatiques, sauf dans certains cas prévus par le décret organique susdit. - On a maintenu les tribunaux indigènes institués par le Code annamite.

Les conseils de guerre peuvent, sur un ordre du gouverneur, instruire sur les crimes et délits ayant un caractère politique ou insurrectionnel.

$$
\text { STATISTIQUE JUDIGIAIRE (1864). }
$$

Tribunaux indigènes.

Jugements rendus........................... 689

Sur lesquels :

Jugements à mort.......................... 34

- à l'exil ( 6 ans et au-dessus)............... 365

- à la prison (2 ans et au-dessous).......... 290

Bureau judiciaire de Saïgon.

Liquidation de successions d'Européens.............. 14

Actes divers notariés............................ 94

Jugements en matière civile...................... 7

- $\quad$ en matière commerciale.................. 18

Ordonnances sur requêtes....................... 83

La religion de la plus grande partie de la population annamite est une sorte de bouddhisme très-relâché. On adore des génies ou esprits qui, pour la plupart, sont des femmes. Voici quelquesuns de leurs noms :

Ba-chua-ngoc ( $b$ a signifie madame), Ba-chua-dong, Ba-haotinh, Ba-tuy-long; Cô-hong (cô signifie mademoiselle), Cô-hang.

"Cette influence en faveur des femmes est due à ce que, dans le Bat-Quai, et au signe Li, la meilleure place est occupée par le principe femelle. Le Bat-Quai n'est autre chose que le Pa-qua des Chinois, sorte de figure géométrique employée pour la divination. Cette figure comporte huit divisions auxquelles correspondent des signes particuliers que tous les peuples de la Chirie supposent doués de nombreuses influences. Chaque signe du Bat-Quai est composé de trois lignes horizontales, tantôt pleines (mâles), tantôt brisées (femelles); le signe Li est représenté par une ligne brisée entre deux lignes pleines.

"Les Annamites vénèrent l'esprit du foyer, et cet esprit est représenté sous la forme de trois personnes, une femme placée entre deux hommes ; cela n'est autre chose que la représentation de la figure Li. 
"Les pagodes annamites sont construites avec beaucoup de luxe, et sont situées généralement au milieu des bois les plus touffus. Beaucoup de familles ont dans leurs cases un petit autel qui symbolise, la plupart du temps, leur seul culte extérieur; l'on y voit quelques statuettes de Bouddha et de Kouanine, déesse de la miséricorde. » (Notices, ete.)

Depuis le commencement du dix-septième siècle, époque de son introduction, le christianisme a subi bien des vicissitudes en Cochinchine. Les Annales de la propagation de la foi en donneront une idée.

Aujourd'hui, voici la situation :

Les trois provinces comptent environ 22,000 Annamites chrétiens, ainsi répartis: Saïgon, 10,000; Bien-hoa, 7,000; Mitho, 5,000 .

Dix-sept missionnaires sorit, sous la direction de l'évêque, chargés de l'administration spirituelle de ces chrétiens.

Un séminaire a été établi à Saïgon.

Les trois provinces ont quatre couvents de religieuses annamites. On compte, en outre, un couventde religieuses carmélites.

Saïgon possède une belle église. Plusieurs autres ont été relevées ou fondées dans les villages des trois provinces.

Tous les hôpitaux, l'Orphelinat de la Sainte-Enfance, une école de filles sont dirigés par 30 sœurs de Saint-Paul de Chartres.

Les hôpitaux sont au nombre de cinq : l'un (hôpital militaire) à Saïgon; l'autre (hôpital annamite), à Choquan ; les autres (hôpitaux militaires) à Mitho, Bien-hoa et Baria.

La plupart des postes ont une infirmerie.

Ces divers établissements hospitaliers sont desservis par $43 \mathrm{chi}-$ rurgiens et 6 pharmaciens de marine, non compris les chirurgiens embarqués sur les bâtiments de la station navale.

L'instruction publique, en Cochinchine, n'est pas restée en arrière dans les préoccupations du gouvernement français.

"Le corps des lettrés et des fonctionnaires, comme cela existe en Chine, formait, avant notre arrivée dans le pays, une caste qui devait tout son prestige à sa connaissance de la langue chinoise, la seule qui fût écrite et qui fût employée pour les actes de l'autorité. On sait les difficultés qu'exige l'étude de cette langue, le lettré chinois passe au moins la moitié de sa vie à acquérir, non des connaissances, mais l'instrument même de ces 
connaissances, c'est-à-dire les signes idéologiques de la langue chinoise.

a Pour affranchir les indigènes, en même temps que nousmêmes, de ces intermédiaires orgueilleux, il suffisait donc d'enseigner aux Annamites, avec les vingt-quatre lettres de notre alphabet, le moyen de lire et d'écrire leur propre langue. Les missionnaires sont les premiers qui aient tenté cette réforme radicale ; mais avec le peu de ressources dont ils disposaient avant l'expédition française, iln'y a pas lieu de s'étonner que leurs progrès dans cette voie n'aient été qu'insignifiants. Depuis notre établissement dans le pays, tous nos efforts ont eu pour but la diffusion de la langue et de nolre alphabet. (Notices, etc.)

Pour arriver à cet important résultat, nous avons fondé en Cochinchine : un Collége des interprètes français, un Collége des lettrés, une école dite École de l'évêque d’Adran, des Écoles primaires, l'OEuvre de la Sainte-Enfance; on ne s'arrêtera pas dans cette grande et belle voie.

\section{CHAPITRE VI}

Régime financier. - Budget local. - Recettes de 1860 à 1865. - Succursale du Comptoir d'escompte de Paris. - Monts-de-piété. - Impôts. - Tableau comparatif des monnaies, poids et mesures annamites.

Le décret du 10 janvier 1863 a déterminé le régime financier de la Cochinchine. En vertu de ce décret, sont à la charge de la colonie toutes dépenses concernant l'administration, la justice, le culte, les travaux publics, etc.

En 186ว, le budget local a présenté les résultats suivants :

10 Recettes.

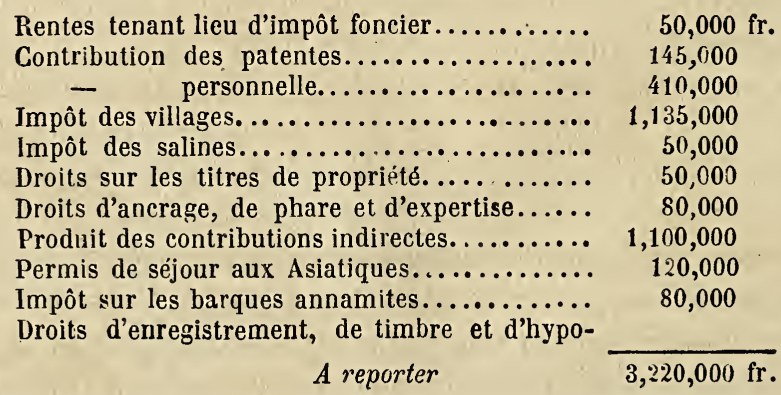




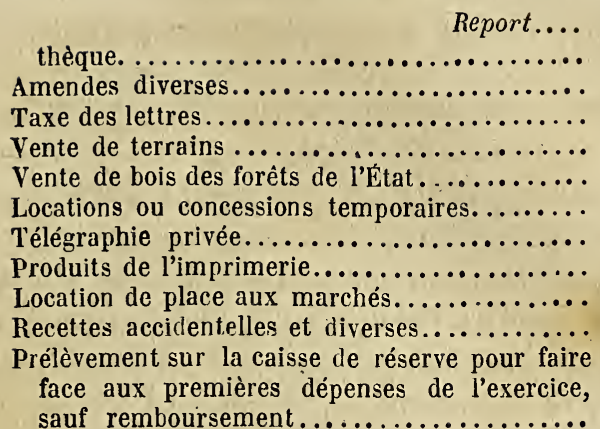

Total ....

\section{Dépenses.}

Administration générale................

Direction de l'intérieur.................

Personnel européen attaché aux affaires indigènes ..........................

Personnel indigène et mixte.............

Justice ........................

Culte ..........................

Instruction publique..................

Ports et phares.....................

Police...........................

Hospice indigène..................

Prisons. ..........................

Services financiers ....................

Service télégraphique................

Agents divers. .....................

Compagnie indigène..................

Ponts et chaussées..................

Imprimerie ......................

Perception de l'impôt...................

Accessoires de la solde.................

Hòpitaux ........................

Vivres ........................

Travaux publics...................

Transports par terre et par eau............

Trains, etc........................

Remboursement au service marine des dépenses

de la station locale....................

Prêts à l'agriculture $\ldots \ldots \ldots \ldots \ldots \ldots \ldots \ldots \ldots \ldots$

Restitution à la caisse de la réserve..........

Dépenses diverses et imprévues............

Total

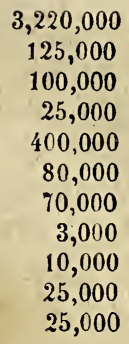

400,000

4,483,000 fr. 89,540

318,800

440,070

79,600

92,000

140,500

32,716

72,666

38,541

59,594

46,360

158,356

44,292

59,714

132,400

64,953

66,237

110,150

59,770

294,726

$1,241,119$

15,000

6,000

200,000

50,000

400,000

155,900

$4,483,000 \mathrm{fr}$

Depuis 1860 , les recettes ont suivi une marche ascendante sensible : 


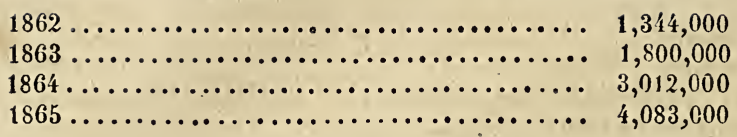

Pas de banque parliculière en Cochinchine. Le Comptoir d'escompte de Paris a établi une succursale à Saïgon.

Saïgon, Cholen, Mitho, Bien-hoa et Baria ont chacune un Mont-de-piété. Le taux de l'intérêt est de 3 p. 100 par mois et l'on prête au moins le tiers de la valeur des objets présentés.

Les impôts sont: l'impôt foncier, l'impôt de capitation, l'impôt des salines, les corvées gratuites, l'impôt pour l'entretien de l'armée, celui des patentes, etc.

MONNAIES, POIDS ET MESURES.

10 Monnaies.

\begin{tabular}{|c|c|c|c|}
\hline Espècb. & Poins. & \multicolumn{2}{|c|}{ VALEUR. } \\
\hline Demi-lingot d'or........... & 10 onces. & 639 & \\
\hline Clou d'or ................. & $5-$ & 138 & 68 \\
\hline Demi-clou d'or............ & $2-1 / 2$ & 63 & 34 \\
\hline Lingot d'argent............ & $10-$ & 81 & 57 \\
\hline Clou d'argent............ & $1-$ & 8 & 15 \\
\hline Demi-clou d'argent......... & $"-1 / 2$ & 4 & 00 \\
\hline Sapèque (zinc)............ & $2 \mathrm{gr} \cdot 1 / 2$ & 0 & 0 \\
\hline Tien $(60$ sapèques,......... & $"$ & 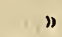 & 10 \\
\hline Ligature, Thuc (10 tiens)... & w & D & $n$ \\
\hline
\end{tabular}

La piastre mexicaine, parmi les monnaies étrangères, a seule cours forcé. Sa valeur varie entre $5^{\mathrm{f}}, 50$ et $6^{\mathrm{f}}, 20$.

La pièce de $\breve{~ f r a n c s ~(f r a n c ̧ a i s e) ~}=\frac{90}{100}$ de piastre.

Le franc $=$ une ligature.

La pièce de $0^{\mathrm{f}}, 10=1$ tien ou taillant de 60 sapèques.

- de $0^{\mathrm{f}}, 0 \mathrm{~s}=30$ sapèques.

\section{$2^{\circ}$ Poids.}

Cân, livre annamite, $=16$ luông $=624^{\mathrm{gr}}, 80$.

Yên $=10$ cân $=6^{\text {kil }}, 248$.

Binh $=50$ cân $=31^{\mathrm{kil}}, 240$.

$\mathrm{Ta}=100$ cân $=62^{\mathrm{kil}}, 480$.

Quan $=500$ cân (picul) $=312^{\mathrm{kil}}, 400$.

Nên $=10$ luông $=390,50$.

Luông $=10$ dông $=039^{\mathrm{gr}}, 0$ š.

Dông $=10$ phân $=3^{\mathrm{gr}}, 90$ s. 


\section{$3^{\circ}$ Longueurs.}

Thuôe (coudée ou pied annamite) de $0^{\mathrm{m}}, \mathbf{4 2 4}$.

Thuôc (mesure des étoffes) de $0^{\mathrm{m}}, 636$.

\section{A. Thuôc (coudée) de $0^{\mathrm{m}}, 424$.}

$\mathrm{Ly}=0^{\mathrm{m}}, 000424$.

Phan $=10 \mathrm{ly}=0^{\mathrm{m}}, 00424$.

Tâc $=10$ phan $=0^{\mathrm{m}}, 0424$.

Thuôc $=10$ tâc $=0^{\mathrm{m}}, 424$.

Tâm $=5$ thuôc $=2^{\mathrm{m}}, 120$.

$\mathrm{Ngu}=7$ thuôc $1 / 2=3^{\mathrm{m}}, 180$.

Truong ou duong $=10$ thuôc $=4^{\mathrm{m}}, 240$.

Sao $=15$ thuôc $=6^{\mathrm{m}}, 360$.

Gông $=10$ tâm $=2 \mathrm{2}^{\mathrm{m}}, \mathbf{4 4 0}$.

Maû̀ $=10$ sao $=63^{\mathrm{m}}, 600$.

$\mathrm{Ly}=0^{\mathrm{m}}, 000636$.

B. Thuôc, de $0^{\mathrm{m}}, 636$.

Phân $=10 \mathrm{ly}=0^{\mathrm{m}}, 00636$.

Tâc $=10$ phân $=0^{\mathrm{m}}, 0636$.

Thuôc $=10$ tâc $=0^{\mathrm{m}}, 636$.

Vôc $=6$ thuôc $=3^{\mathrm{m}}, 816$.

Truong ou duong $=10$ thuôc $=6^{\mathrm{m}}, 360$.

Thât $=1$ cay ou 30 thuôc $=19^{\mathrm{m}}, 080$.

Công $=10$ cay $=190^{\mathrm{m}}, 80$.

\section{$4^{\circ}$ Surfaces. (Thuôc carré.)}

Ly carré $=0^{\mathrm{m}}, 000424$ de côté.

Phân carré $=100$ ly carrés $=0^{\mathrm{m}}, 00424$.

Tâc carré $=100$ phân carrés $=0^{\mathrm{m}}, 0424$.

Thuôc carré $=100$ tâc carrés $=0^{\mathrm{m}}, \mathbf{4 2 4}$.

Tâm carré $=$ s thuôc de côté $=2^{\mathrm{m}}, 120$.

Ngû carré $=7$ thuôc $1 / 2$ de côté $=3^{\mathrm{m}}, 180$.

Truong carré $=4^{\mathrm{m}}, 240$.

Sao carré $=6^{\mathrm{m}}, 360$.

Công carré $=25^{\mathrm{m}}, 410$.

Maû carré $=63^{\mathrm{m}}, 600$.

Hôc $=39^{\text {lit }}, 90$.

5․ Capacités. (Hôc.)

Gia $=1$ luong (ou vuong, ou phuong) $=39^{1}, 80$ (40 litres). 
$\mathrm{Ta}=2$ hôc $=79^{1}, 80$.

Thâng $=2$ hièp $=13^{1}, 30$.

Hièp $=2$ thuôc $=6^{1}, 65$.

$0=1^{1}, 33$.

\section{CHAPITRE TII}

Agriculture. - Riz. - Coton. - Canne à sucre. - Tabac. - Maï, etc. -

Ventes et concessions de terres. - Industrie. - Pêche. - Vers à soie. - Bois. - Carrières, etc. - Commerce. - Importations. - Exportations. - Naviga tion. - Mouvement de la navigation au long cours. - Cabotage. - Entrées et sorties à Saïgon et à Mitho.

L'agriculture est fort remarquable dans la Basse-Cochinchine. Le riz, ce blé des Asiatiques, disent les Notices, est la production par excellence des plaines basses et inondées qui forment le delta du Cambodge. L'étendue de terrain cultivée en riz dans les trois provinces est environ de 105,000 hectares. Cette quantité de rizières fournit, année moyenne, 210,000 tonneaux de riz cargo qui représentent une valeur totale d'environ 35 millions de francs.

L'exportation régulière, avant la guerre, pouvait être évaluée à 1 million de piculs, ou plus de 62,000 tonneaux. En 1860, année de l'ouverture du port de Saïgon, l'exportation monta à près de 100,000 tonneaux.

Le riz se cultive surtout dans les terrains bas et humides, que l'on nomme Thao-dien; ce sont les rizières proprement dites. Les terrains élevés où l'on cultive le riz se nomment Sôn-dien; mais ce riz de montagne est peu répandu et d'un rapport médiocre.

Dans les Thao-dien, le riz se sème préalablement dans de petits espaces réservés appelés Lua-ma; au bout de 30 à 40 jours, lorsque les jeunes pousses ont atteint une certaine hauteur, on les arracbe avec précaution et on fait alors de petites gerbes qu'on repique dans la terre boueuse de la rizière, en laissant entre chaque gerbe un espace suffisant pour lui permettre de se développer. Le temps des semailles commence vers la fin d'août et finit en septembre. Dans les pays où il y a deux récoltes, les premières semailles se font en février, les secondes en juillet. Le riz arrive à maturilé après trois, quatre ou six mois; dans les deux premiers 
cas, c'est du riz hâtif, qu'on récolte dans les champs dits de deux époques; le riz de six mois ou riz tardif est le plus communément cultivé dans la Basse-Cochinchine et vient dans les champs d'une seúle époque.

Quand le riz est mûr, on fait écouler l'eau qui reste dans la rizière où on le fauche. Le riz est ensuite battu et vanné. Lorsqu'on veut le décortiquer, on le fait passer à la meule, et, pour enlever la dernière pellicule, on le bat avec un fléau cylindrique formant levier sur lequel pèsent deux personnes. La substitution de moyens mécaniques au mode actuel de récolter et de décortiquer le riz accroîtra le rendement des terres dans une proportion très-notable.

Le meilleur riz rapporte cent pour un, disent les Annamites. Notons, en passant, que, quand ils parlent de récolte, il s'agit toujours de paddy (riz non décortiqué); la proportion du riz au paddy est, à peu près, de 1 à 2 ; il faut donc deux mesures de paddy pour en faire une de riz.

On distingue deux riz principaux : le riz gras ou gélatineux (lùa-dieù) et le riz ordinaire ou peu gélatineux (lùa-khong-dieù). Chacun de ces riz comprend un grand nombre de variétés.

Le coton vient très-bien en Cochinchine, mais les indigènes n'en cultivent guère que pour leur consommation propre. Les 2,500 hectares cultivés rapportent environ 3, ว00 tonneaux de coton, d'une valeur de 3 millions. Sa qualité est bonne. C'est l'espèce courte-soie qu'on cultive de préférence. Le coton est une culture pleine d'avenir dans la colonie.

Il en est de même de la canne à sucre. Production : 7, 500,000 kilogrammes; valeur : 4 millions.

Ginq variétés : canne rouge, canne blanche, canne verte, canne rouge et blanche, canne éléphant (mia-voi), qui atteint une longueur de plus de 10 pieds et un diamètre de 6 à 7 pouces; son suc est fort doux.

Culture du tabac : 4,000 hectares; produit : $5,000,000$ de kilogrammes; valeur sur place : 1,200,000 fr. D'une qualité excellente, au dire de beaucoup d'Européens.

On cultive trois espèces de maĩs : le jaune, le blanc, le rouge et blanc.

Parmi les légumineuses cultivées, on distingue les fèves ou haricots, les Bien-dau (sorte de haricot), et l'arachide.

L'arachide est employée par les indigènes comme nourriture, 
quand elle est fraîche, soit pour composer des gâteaux, soit surtout pour faire de l'huile. Cette huile est recueillie en telle quantité qu'on ne peut employer une récolte dans l'espace d'un an. On fait avec le résidu de l'arachide des tourteaux qui servent d'engrais : il s'en fabrique plus de 400,000 par an. L'huile d'arachide deviendra un important article de commerce.

La Cochinchine a beaucoup de plantes oléagineuses, outre l'arachide. Son sésame est supérieur à celui de l'Inde.

La culture de l'indigo occupe une superficie dè 400 hectares.

La culture du mûrier embrasse 2,000 hectares.

Quatre espèces de chanvre : le Chi-ma, le Hac-ma, le Ti-ma et le Hoang-hiong.

Le Cay-gaï ou ortie de Chine donne une bonne filasse et croît avec vigueur.

La Cochinchine possède beaucoup de plantes textiles, outre le chanvre, le coton, la soie; on fabrique des cordes, cordages et gros fils avec les roseaux, les jones, les bambous, les rotins et l'écorce du cocotier.

Parmi les plantes à tubercules, on doit mentionner le Ca-mou, qui donne une teinture rouge, quelques ignames (Tu-diù, Son-tu, Phien-tu).

Nombre d'espèces de cucurbitacées. Elles servent à l'alimentation quotidienne.

Les principaux fruits sont : celui du cocotier, la mangue, le mangoustan, le jacq, la banane, l'ananas, le citron, l'orange, l'orange mandarine, la grenade, etc.

Parmi les épices, on remarque : le bétel ou poivre bétel, qui se cultive dans les terres les moins élevées des plateaux moyens; le poivre ordinaire, très-répandu; la noix d'arec, matière tannante, masticatoire chéri des Annamites. - Les aréquiers atteignent 10 mètres de haut et produisent pendant 25 ans.

Le thé n'a pas la qualité de celui de la Chine. Le thé vert (thé tau) est préféré par les indigènes.

En 1864, une pépinière a été créée à Saïgon. Un entrepôt zoologique y a été adjoint. Ces établissements ont pour but, le premier d'acclimater en Cochinchine les plantes étrangères, le second de doter les jardins zoologiques de France des espèces qui leur manquent.

Au nombre des animaux domestiques des Annamites, on distingue: le buffle, employé au labour et aux voitures; le bœuf, 
beaucoup plus rare; le cheval, qui est petit, mais vigoureux; volailles, porcs, etc.

Les terres appartenant à l'État sont ou vendues ou concédées.

Elles sont vendues, soit aux enchères publiques, soit à bureau ouvert et à prix fixe. Dans ce dernier cas, les prix ne peuvent être inférieurs à $10 \mathrm{fr}$. par hectare. Les payements ont lieu en plusieurs annuités.

Le gouvernement s'est réservé le droit d'accorder, moyennant certaines conditions, des concessions gratuites à des militaires ou à des employés de l'État qui veulent se fixer dans le pays.

Pour donner plus de sécurité aux propriétaires indigènes, une décision du 16 mai 1863 a créé des titres de propriété qui, par leur inscription dans les bureaux de l'administration, moyennant un droit de 2 pour 100 de la valeur des biens, leur en garantit à jamais la jouissance.

Les industries cochinchinoises qui sont le plus encouragées et qui méritent le plus de l'être sont: la pêche, l'éducation du ver à soie, l'exploitation des bòis, la fabrication du sel, l'exploitation des carrières.

La Cochinchine est très-poissonneuse. Le poisson est, avec le riz, la base de la nourriture des Annamites. C'est un objet d'exportation en Ghine.

Quoique les pêcheries actuelles ne soient pas encore trèsnombreuses, on peut déjà prévoir qu'elles sont appelées à un grand avenir.

Le ver à soie est cultivé par tous les indigènes sans exception.

"Les cocons, disent les Notices, sont petits, de couleur jaune et ont une apparence grossière; ils donnent environ chacun un phan $\left(0^{\mathrm{gr}}, 4\right)$ de fil. La série des opérations qui constituent l'élevage du ver à soie et la production des cocons et de la graine s'accomplit en une période de 45 à 50 jours. Les œufs ne se gardent que 10 jours; ils éclosent au bout de ce temps. Les vers peuvent se reproduire toute l'année. La production est moins abondante pendant la fin de la saison sèche, à cause du manque de feuilles. La production annuelle, dans nos provinces, est de 6,000 kilog. de soie brute, valant 240,000 fr. Le nord de l'Annam envoie chaque année une certaine quantité de soie a Saïgon. 
" On nourrit presque partout des vers à soie, mais on ne tisse que dans quelques localités, principalement dans la p rovincede Bien-hoa. Les procédés de tissage sont des plus primitifs. Ce métier est généralement réservé aux femmes.

"Les tissus et la soie grège sont malheureusement à des prix trop élevés pour qu'ils deviennent un objet d'exportation. »

Les femmes tissent aussi le coton. Nos procédés de tissage changeront avantageusement cet état de choses. En 1864, il a été expédié de Saïgon dans les provinces annamites environ $\mathbf{4 , 0 0 0}$ pièces de cotonnades indigènes.

La Cochinchine est riche en forets. Leur exploitation a produit bon nombre d'industries : bûcherons, scieurs de long, menuisiers, etc. - Plus de quarante essences différentes peuvent être employées à la teinture, d'autres aux constructions navales, etc.

Toute vente de bois est frappée d'un droit de 25 fr.p. 100 à la charge de l'acquéreur.

L'exploitation des forêts est facilitée par les nombreux cours d'eau qui les sillonnent.

Les salines de la province de Bien-hoa sont très-importantes. Le marché le plus considérable du district est Cho-ben.

Les marais salants des Annamites sont disposés comme en Europe. Ils se composent : $1^{\circ}$ d'un canal ou réservoir dit jas, placé en avant des marais salants et plus profond qu'eux, qui communique avec la mer au moyen d'une écluse, se remplit à marée haute et est destiné à conserver l'eau, afin qu'elle y dépose ses impuretés, et à remplacer celle des autres bassins au fur et à mesure qu'elle s'évapore; $2^{\circ}$ du marais proprement dit, situé derrière le jas; il est divisé en une multitude de cases ou compartiments appelés couches et tables, séparés par de petites chaussées destinées à multiplier les surfaces pour augmenter l'évaporation et recevoir les eaux de plus en plus concentrées. Sous l'influence du soleil, le sel ne tarde pas à se cristalliser; on le retire alors sur le bord des tables où on le laisse égoutter. Il est ensuite mis en mulons ou porté en magasin pour être embarqué plus tard sur les jonques qui doivent l'exporter.

La production des salines de Baria s'élève actuellement à 17 mild e kilog. environ. Le budget de la colonie en retire un produit de $50,000 \mathrm{fr}$.

Dans la même province de Bien-hoa, on trouve des carrières 
de pierres en exploitation. On remarque aussi quelques briqueteries.

Parmi les autres industries des Annamites, mais d'une moins grande importance, mentionnons la distillation du riz, dont ils font une liqueur (vin du Donnaï) très-renommée, la fabrication de grosses pièces de bronze, du fer, de l'argent, de l'or et du cuivre.

Le régime commercial est à peu près sans entraves en Cochinchine, sauf droits d'ancrage, de phare, frais de pilotage.

En 1864, 500 navires européens et chinois, jaugeant ensemble 212,321 tonneaux, sont entrés ou sortis du port de Saïgon.

Les importations ont atteint le chiffre de 14 millions. On y voit figurer :

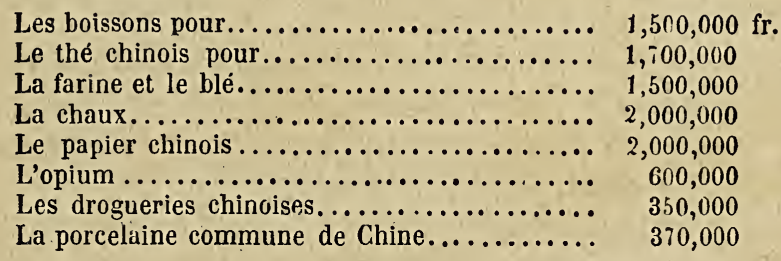

Les exportations se sont élevées à 16,697,787 francs. Les principaux articles exporlés sont:

\begin{tabular}{|c|c|}
\hline rlz & $12,678,000$ \\
\hline Le poisson. & $1,915,279$ \\
\hline Paddy . & 123,936 \\
\hline 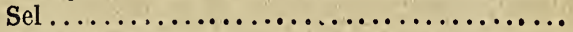 & 225,588 \\
\hline Sacs vides en paille $\ldots \ldots \ldots \ldots \ldots \ldots \ldots \ldots \ldots$ & 391,092 \\
\hline Nattes. $\ldots \ldots \ldots \ldots \ldots \ldots \ldots \ldots \ldots \ldots \ldots \ldots, \ldots$ & 90,361 \\
\hline Cardamome $\ldots \ldots \ldots \ldots \ldots \ldots \ldots \ldots \ldots \ldots$ & 101,500 \\
\hline Peaux de buffles...................... & 79,456 \\
\hline Coton sans graines................... & 207,480 \\
\hline Coton exporté de Mitho par les barques...... & 114,530 \\
\hline Cornes...................... & 166,200 \\
\hline Légumes secs (haricots, féves, etc.). . & 189,474 \\
\hline
\end{tabular}

Le pavillon français figure en première ligne dans le chiffre des navires entrés à Saïgon en 1864. Le nombre des navires français a été de 82 ; les paquebots des Messageries impériales comptent 23 entrées. - Les navires français comptent 79 sorties, y compris les 23 paquebots des Messageries.

Le cabotage, de son côté, n'a point été inactif. Les mouvements de Saïgon et de Mitho seulement ont été de 5,491 entrées et de 5,027 sorties, jaugeant $\mathbf{1 6 8 , 1 9 8}$ tonnnaux, soit par jour 
460: tonneaux de marchandises entrées ou sorties de ces deux ports.

Le cabotage de Mitho se fait, en grande partie, par le Cambodge, chose importante, car les produits de la Cochinchine intérieure sont justement ceux qui nous conviennent le mieux : sucres, soies, sésame, arachides, etc.

\section{GHAPITRE VIII}

Communications. - Service postal.

Les Messageries impériales mettent la France en communication avec la Cochinchine.

Départ de Marseille, le 19 de chaque mois.

Arrivée à Alexandrie, le 25.

Départ de Suez, le 27.

Arrivée à Saïgon, le $24 \mathrm{du}$ mois suivant.

Durée dı voyage : environ 3 jours.

PRIX :

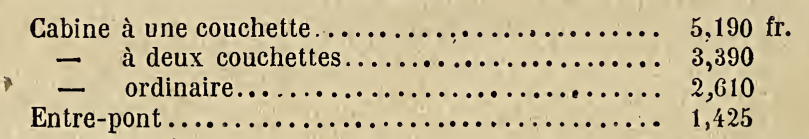

Les enfants payent demi-place.

En outre, on a à payer le transit d'Alexandrie à Suez :

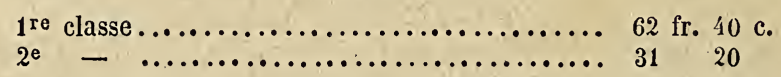

Une remise de 30 p. 100 est accordée aux passagers civils et militaires qui voyagent sur réquisition du gouvernement. Les prix de transport sont, par conséquent, ainsi réduits :

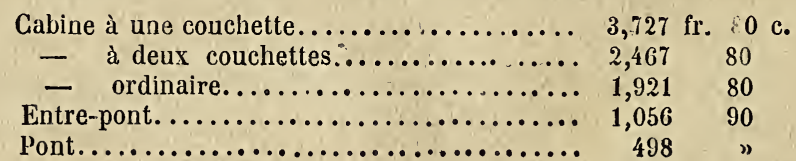

Le prix de la nourriture est payé en sus :

Pour les passagers de chambre.............. 316 fr.

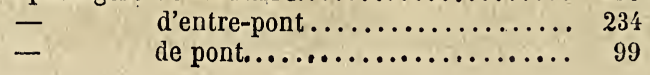


Les paquebots de la Compagnie anglaise (Compagnie péninsulaire et orientale) desservent aussi, mais indirectement, la Cochinchine française.

Départs de Marseille, 12 et 28 de chaque mois.

Arrivées ou retours, 3 et 18.

$$
\begin{gathered}
\text { PRIX DU PASSAGE } \\
\text { (jusqu'à Singapore). }
\end{gathered}
$$

Cabine à plusieurs couchettes....... 2,750 fr. (110 liv. st.) - réservée............... 7,250 (290 liv. st.)

\begin{tabular}{|c|c|c|c|c|}
\hline \multicolumn{3}{|c|}{ (voie franc.) } & \multicolumn{2}{|c|}{ (voie angl.) } \\
\hline Lettres affranchies, par $10 \mathrm{gr} . . . . . . .$. & $0 \mathrm{fr}$ & 50 & & $\therefore 70$ \\
\hline non affr., & 0 & 60 & 0 & $: 0$ \\
\hline chargées, & 1 & $n$ & 1 & 40 \\
\hline $\begin{array}{l}\text { Echantillons et imprimés, par } 40 \text { gr... } \\
\text { Papiers de commerce et d'affaires, par }\end{array}$ & 0 & 12 & 0 & 12 \\
\hline 200 gr. .... & 0 & 60 & 0 & 60 \\
\hline ettres des $\mathrm{m}$ & 0 & 20 & $"$ & " \\
\hline
\end{tabular}

TARIF DES CORRESPONDANCES.

Mêmes taxes pour les correspondances expédiées par les navires du commerce:

Mandats d'argent au profit des militaires et marins exclusivement.

Des bureaux de poste sont établis dans la colonie. 


\section{OCÉANIE}

\section{P R E I E R E P A R T I E}

\section{ÉTABLISSEMENTS DE L'OCÉANIE}

(ILES DE la SOciété, Iles basses ou TUAMOTU, ILES TUbUaI, ILES MARQUISES.)

\section{GHAPITRE PREMIER}

Historique.

Les îles Marquises, les états du Protectorat (îles de la Société et dépendances), nos établissements militaires et maritimes de Taïti, constituent les établissements français de l'Océanie. Depuis 1860, la Nouvelle-Caléd onie forme un établissement à part.

On comprend sous le titre d'Etats du Protectorat:

$1^{\circ}$ Le groupe S.-E. (îles du Vent) de l'archipel de la Société. Les îles sous le vent de Taïti en ont été détachées, sur la déclaration de la reine Pomaré (en 1847) que son pouvoir ne s'étendait pas sur ces îles.

$2^{\circ}$ Les îles Basses ou Tuamotu. - Une administration distincte régit les îlots Gambier ou Mangareva qui forment l'extrémité S.-E. de cet archipel.

$3^{\circ}$ Deux des quatre îles Tubuai.

Notre établissement dans la Polynésie a débuté par l'occupation des îles Marquises; mais le chef-lieu de notre colonie ne tarda guère à être transféré de Taiohae (île Nouka-Hiva) à Papeete (île Taïti), qui est ainsi devenue la capitale des Etats du Protectorat français et le chef-lieu de nos établissements océaniens.

Les Notices publiées par le ministère de la marine et des 
colonies donnent les renseignements suivants. Nous les résumons.

Taïti, la plus considérable et la plus peuplée des îles de l'est de la Polynésie, a été l'objet, au dix-huitième siècle, des récits enchanteurs de ses premiers explorateurs, Wallis, Bougainville et Cook (1767, 1768 et 1769). La salubrité du climat, la fertilité du sol, l'affabilité des naturels : tel était le thème de ces récits qui plus tard furent reconnus d'une exactitude parfaite.

Des missionnaires de la Société des missions de Londres vinrent, en 1797, s'établir à Taïti avec leurs familles. Vingt ans après, ils avaient converti toute la population de l'île au protestantisme. Sous leur influence, le grand chef, Pomare, acquit une prépondérance marquée sur les autres chefs et put enfin se déclarer roi des îles de la Société et dépendances.

Il eut pour successeur son fils Pomare II. Il constitua un gou: vernement représentatif, dans lequel les chefs et des députés réunis en assemblée examinaient les projets de loi d'intérêt général. Les missionnaires, véritables inspirateurs de ces mesures, formulaient en codes les résolutions adoptées par l'assemblée, et Pomare les promulguait comme lois. C'est ce mécanisme de gouvernement qui a si fort émerveillé quelques voyageurs européens, et les a fait se méprendre étrangement sur l'état social des insulaires de l'archipel de la Société.

Après la mort de Pomare II, en 1821, celle de son jeune fils Pomare III, en 1825, Aïmata, sœur de ce dernier, fut proclamée reine sous le nom de Pomare Vahine (femme). Elle règne encore aujourd'hui sur lesîles de la Société et dépendances. Elle porte le titre de Pomare IV.

Des troubles avaient dû, on le conçoit, accompagner ces divers événements. Aussi, pour y obvier dans l'avenir, les missionnaires protestants insinuèrent aux chefs de demander le protectorat de l'Angleterre. Ils ne réussirent pas à les persuader.

Jusqu'en 1842, la situation fut celle-ci : entraves à l'établissement du culte catholique, désordres causés par les étrangers, vexations contre les Français, etc.

A l'instigation de M. Moerenbout, consul de France à Taïli, la reine et les chefs, profitant de l'arrivée à Papeete de l'amiral Dupetit-Thouars, résolurent enfin de demander la protection de la France. L'acte, où cette demande est consignée, porte la date du 9 septembre 1842.

L'amiral accepta, sauf ratification du roi. 
La ratification porte la date du 22 mars 1843 . C'est dans l'intervalle que se produisit l'affaire Pritchard, consul anglais, missionnaire, commerçant, conseillęr de la reine, affaire qui, sous le règne de Louis-Philippe, donna lieu à tant de débats.

Lorsque, au mois de novembre 1843, l'amiral revint à Taïti, accompagnant M. Bruat; gouverneur, commissaire du roi, le désordre était à son comble. Après des représentations à la reine sur son mauvais vouloir relativement à l'exécution de la convention de 1842, l'amiral, pour sortir d'embarras, crut devoir prendre purement et simplement possession de Taïli et dépendances. M. Bruat fut aussitôt installé comme gouverneur. La reine se retira sur un bâtiment anglais ou dans les îles N.-0. de ses Etats.

Cependant, à Paris, on désapprouvait l'amiral Dupetit-Thouars, et, à sa place, le gouvernement royal envoyait l'amiral Hamelin; se renfermer dans les limites de la convention de 1842, telle était la ligne de conduite dans laquelle on voulait se tenir.

Des troubles sanglants ne tardèrent pas à résulter de cette tension. Le commandanl Bruat, qui avait temporisé jusque-là, se résolut à un coup décisif, qui ramenât à nous les indécis et raffermît les chefs, nos partisans.

Depuis quelques mois, un rassemblement de 120 Indiens s'était 'campé et fortifié dans le district de Mahaena, à 20 kilomètres de Papeete. Ils se croyaient à l'abri de toute atteinte, grâce à la protection des montagnes, sans chemin tracé, qui les séparaient du chef-lieu. Ils ne croyaient pas non plus qu'un débarquement fût possible sur leur front, parce que la côte à Mahaena n'est pas protégée par la ceinture de rếcifs qui entoure presque toute l'île, et rend l'accès de la terre extrêmement facile aux embarcations, et souvent même aux grands navires.

Le gouverneur organise une colonne de 500 hommes (soldats de la garnison et marins), s'embarque avec elle, et vient hardiment mouiller devant la position qu'occupent lesinsurgés. On débarque en pleine côte, à la stupéfaction des insurgés. Vigoureusement attaqués, ceux-ci résistèrent avec acharnement; mais enfin ils durent quitter leurs retranchements, laissant une centaine de morts. Nous eûmes 16 tués et 52 blessés.

Rentré à Papeete, le gouverneur Bruat fit faire auprès de la reine des démarches pour l'inviter à rentrer dans ses Etats ; elle n'en tint compte. Il donna alors, suivant l'usage du pays, l'autorité de 
la reine absente, au régent. On revisa le code taïtien et l'on promulgua de nouvelles lois (1 ${ }^{\text {or }}$ oct. 1845).

Toutefois, la pacification ne fut complète qu'après l'affaire d Fatahua, à 6 kilom. de Papeete, où les insurgés occupaient un position presque inexpugnable. Cette affaire fit le plus grand honneur au capitaine de corvette Bonard (17 déc. 1816).

Quelques jours après, les insurgés faisaient leur soumission e venaient à Papeete jurer fidélité au gouvernement du Protectorat. La reine rentrait elle-même à Taïti en mai 1847. Depuis cette époque, la tranquillité a toujours été s'affermissant, ainsi que notre influence. Le peuple taïtien a compris que la France voulait, avant tout, lui faire goûter les fruits de la civilisation.

Par la déclaration du 19 juin 1847, entre l'Angleterre et la France, les îles Basses et deux des îles Tubuai ont été rangées dans les Etats du Protectorat.

La possession des îles Marquises par la France date de juin 1842. Leur importance, a-t-on dit, est peu de chose à côté des Etats du Protectorat, mais ce sont des mailles utiles du réseau d'îles dont l'ensemble forme notre colonie.

En 1844, les îlots Gambier ou Mangareva se sont aussi mis sous la protection de la France. G'est la mission catholique qui dirige les affaires du pays.

L'annuaire de Taïti pour 186ว énumère ainsi le personnel du gouvernement taïtien :

Pomare IV, reine des îles de la Société et dépendances, née en 1813.

Ariifaaite, (second) mari de la reine, né en 1820.

De ce mariage :

Ariiaue, héritier présomptif, né en 1839.

Teriimaevarua, née en 1840, reine de Borabora le 3 août 1860.

Tamatoa V, né en 1842, roi de Raiatea le 19 août 1857.

Teriitapunui, né en $\mathbf{1 8 4 6 .}$

Teriitua Tuavira, né en 1848.

Paraita, né en 1787, nommé régent de Taïti en 1839.

Gouverneurs et commandants.

1843. Bruat (A. J.), capitaine de vaisseau, commandant la subdivision navale de l'Océanie, gouverneur des îles Marquises, puis des établissements français de l'Océa- 
nie et commissaire du roi près la reine des îles de la Sociêté.

1846. Lavaud (C.-F.), capitaine de vaisseau, gouverneur et commissaire.

1818. Lavaud (G.-F.), commissaire de la République.

1849. Lavaud (G.-F.) commissaire de la République aux îles de la Société.

1849. Bonard (L.-A.), capitaine de vaisseau.

1851. Page (T.-F.), id.

1853. Page (T.-F.), commissaire impérial.

18כ4. Du Bouzet (J.-F.-E.), capitaine de vaisseau, gouverneur des établissements français, commandant la subdivision navale de l'Océanie. - Un commandant particulier est installé à Taïti .

1858. Saisset (J.-M.-J.-T.), capitaine de vaisseau.

\section{0.}

Le 14 janvier 1860, décret par lequel les établissements de l'Océanie cessent d'être placés sous l'autorité du commandant de la subdivision navale.

La Nouvelle-Calédonie et dépendances forment un établissement distinct.

Les îles Marquises et les établissements militaires et maritimes de Taïti sont placés sous l'autorité d'un commandant qui remplit en même temps les fonctions de commissaire impérial aux îles de la Société.

\section{Création d’une station locale à Taïti.}

1860. Gaultier de la Richerie (L.-E.), capitaine de frégate, commandant des établissements de l'Océanie et commissaire impérial aux îles de la Société; commandant de la station locale.

1863. De la Roncière (F.).

\section{CHAPITRE II}

Topographie. - Étendue du Protectorat. - Iles de la Société (îles du Vent ou îles Géorgiennes): île Taiti; îlots Tetiaroa; îlot Metia ; île Moorea. - Iles Basses ou Tuamotu. - Iles Tubuai. - Iles Marquises. - Météorologie.

ILa surface occupée par les îles qui relèvent du Protectorat 
français mesure 300 lieues marines du N. au S., et 300 de l'E. à l'O.

\section{Archipel de la Société.}

L'Archipel de la Société se divise en deux groupes :

L'un, au S.-E., composé des iles du Vent ou Géorgiennes, comprend les îles Taïti, Moorea, et les îlots Tetiåroa et Meetia.

L'autre, au N.-0., est composé des Iles-sous-le-Vent ou de la Société.

Le premier de ces groupes est seul placé sous le Protectorat français.

L'île Taïti, avec sa presqu'île de Taiarabu, a une superficie de 104,215 hectares. Taïti a un périmètre de 120 kilomètres et une étendue de 79,485 hectares; Taiarabu a un périmètre de 70 kilo-

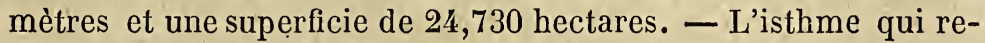
lie les deux parties de l'île a 2,200 mètres de largeur.

Le sol est d'origine volcanique. Le centre de Taïti est occupé par de hautes montagnes, dont l'une, l'Aorai, n'a pas moins de 2,064 mètres.

L'île est à peu près complétement entourée par une ceinture de récifs.

Papeete, chef-lieu de Taïti, capitale des États du Protectorat, se trouve au N.-O. de l'île, et possède un port large et sûr, où l'on pénètre par trois passes. Elle est la résidence de la reine et du commissaire impérial. Elle compte 2,000 âmes, plus le personnel de la garnison et de la station navale.

L'île est divisée en 21 districts et couverte de 21 villages, non compris Papeete.

1. District de Pare. - Le village de ce nom a 1, 244 habitants.

2. District d'Arue et îlots Tetiaroa. - Le village d'Arue a 299 habitants.

3. District de Mahina. - Le village de ce nom a 266 habitants. Il se trouve à la pointe de Vénus. G'est dans le port à l'O. de cette pointe, que les premiers navigateurs venus à Taïti ont débarqué. - Sol sablonneux.

4. District de Papenoo. - Population du village de ce nom : 217 habitants. - " C'est le plus grand des districts de Taïti. La vallée de la rivière de Papenoo s'étend jusqu'au pied des plus hautes montagnes, dont les sommets la couronnent, rangés comme sur une circonférence. Aussi, cette rivière est-elle la plus considérable de toutes celles de ce pays et le passage en est dan- 
gereux par les grandes pluies. La route de Papenoo à Tiarei est fort difficile en quelques points. ")

5. District de Tiarei. - Population du village : 229 habitants.

6. District de Mahaena. - Population du village : 137 habitants. Théâtre, en 1845, d'un combat sanglant.

7. District de Hitiaa. - Population du village : 460 habitants. - Bon port. Bois de construction. Belles vallées susceptibles de riches cultures. Rivières larges et profondes.

8. District d'Afaahiti. - Population du village : 76 habitants.

9. District de Pueu. - Village : 229 habitants.

10. District de Tautira et îlot Meetia. - Population du village de Tautira : 539 habitants.

Ce district est un des plus grands et des plus peuplés. Belle rivière descendant des montagnes du centre de la presqu'île, et formant, à son embouchure, un bon port.

L'îlot Meetia, à 60 milles environ de la pointe S.-E. de l'île Taïti, est un bon point de reconnaissance à l'atterrissage pour les caboteurs et les navires qui veulent venir à Papeete.

11. District de Teahupoo. - Village : 298 habitants.

12, 13, 14. Districts de Mataoae, Vairao et Toahotu. - Population du village de Vairao : 36 habitants.

15. District de Papeari. - Village : 220 habitants.

Très-montagneux, un peu marécageux.

16. District de Mataiea. - Village : 606 habitants.

Bon port à Papeuriri.

De Mataiea on se rend au lac de Vaihiria, sis à 430 mètres audessus du niveau de la mer. Il a 500 mètres de largeur. - C'est probablement un cratère éteint, latéral et indépendant du grand cratère central indiqué par les montagnes de Papenoo.

17, 18. Districts d'Altimaono et Papara. - Village de Papara : 741 habitants.

Ces deux districts, le premier très-considérable et l'un des plus peuplés, sont l'un et l'autre, par l'étendue de leurs terres cultivables, appelés à une grande richesse. Ils présentent des positions propres à de belles exploitations. Une compagnie agricole vient de fonder un vaste établissement entre les territoires des villages d'Altimaono-Papara et de Mataiea. Mille coolies chinois doivent les mettre en valeur. Des émigrants, recrutés aux îles Vatiu et Rorotonga, engagés pour deux années, sont à l'œuvre et plantent du coton. 
19. District de Paea. - Population du village : 427 habitants. Jolies rivières. Belles terres. Plusieurs habitations européennes. 20. District de Punaauia. - Population du village de ce nom : 484 habitants.

La rivière de Punaruu, une des plus considérables de Taïti, coule à Punaauia et arrive à la mer. Elle aboutit au centre de l'île, au Maiao ou Diadème $(1,239 \mathrm{~m}$.) et communique, par là, avec les vallées de Fatahua et de Papenoo.

21. District de Faaa. - Village : 512 habitants.

Culture du café.

L'île Moorea, au N.-0., de Taïti et à quelques milles de cette île, a une superficie de 13,237 hectares et un terrain cultivable de 3,500 hectares.

Elle se divise en 10 districts et compte 4 villages.

1, 2. Districts de Teavaro et de Teaharoa. - Village de Teahoroa : 336 habitants.

3. District de Papetoai. - Village : 263 habitants.

4, 5, 6, 7. Districts de Haapiti, Varari, Moruu et Atimaha. Village de Haapiti : 344 habitants.

8, 9, 10. Districts d'Afareaitu, Haumi et Maatea. - Village d'Afareaitu : 229 habitants .

La population de l'île Moorea se décompose ainsi :

Taitiens.......................... 1,242

Français ............................. 6

Étrangers .......................... 13

Les étrangers se décomposent à leur tour :

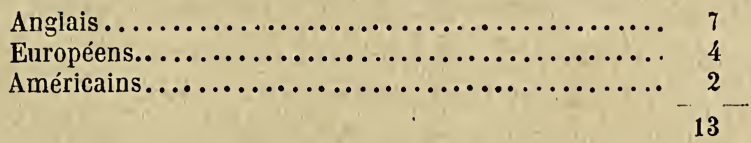

L'île a d'excellents ports, celui de Teavaro, entre autres, éloigné de 11 milles de Papeete.

Le second groupe d'îles de l'Archipel de la Société est, comme nous l'avons vu, en dehors du Protectorat français; on n'a donc point à s'en occuper ici.

L'Annuaire de Taïti pour 1865 donne les renseignements qui suivent sur l'Archipel Tuamotu ou îles Basses.

Les habitants de ces îles témoignent de la plus grande bonne volonté, et montrent une espèce d'amour-propre pour suivre, 
aussi bien que les indigènes de l'île Taïti, les lois communes à toute la famille polynésienne rangée sous le titre de : États du Protectorat français.

Les conseils de villages se constituent dans les îles aussitôt que les indigènes sont aptes à recevoir cette organisation, si favorable à leurs intérêts, à leurs relations avec l'autorité française et au développement de leur civilisation.

La religion catholique domine dans cet archipel. L'île Anaa $\left(\mathrm{n}^{\circ} 13\right)$ est dotée de 4 chapelles bâties aux frais de la mission catholique.

Le nombre des chaloupes pontées appartenant aux naturels augmente tous les jours, et, par suite, les rapports entre le cheflieu et ces îles deviennent plus fréquents et plus réguliers.

Le chiffre de la population de chaque île est approximatif, jusqu'à ce jour il n'a pu être fait de recensement exact.

Toutes les îles Tuamotu, disent les Notices de la marine, sauf Makatea, Tikei, Rekareka et Mangareva, ne sont que de longs récifs madréporiques, de 400 à 500 mètres de largeur, entourant un lac intérieur qui atteint 100 milles de circuit à Rairoa et 90 milles dans l'île Fakarava.

Ces longs récifs, en partie à fleur d'eau, en partie à quelques mètres seulement au-dessus du niveau de la mer, sont accores et n'offrent aucun mouillage du côté du large, tandis que du côté intérieur ils s'abaissent en pente douce jusqu'à de grandes profondeurs. Quelques-uns des lacs, ainsi formés par de réritables digues de corail, offrent des ouvertures ou passes donnant accès à des bâtiments de toute grandeur. Nous citerons la passe des Iles Rairoa, Apataki, Toau, Fakarava, Kauehi, Raraka, Tahanea, Makemo, Rraroia, Hao et Mangareva.

Les petits bâtiments peuvent pénétrer dans les îles Maniki, Takaroa, Katiu et Amaru. Les autres îles sont moins favorisées: toutes n'ont même pas de passe pour embarcations. On est alors obligé de porter ces embarcations sur le récif, afin de les faire pénétrer dans le lac, opération souvent très-dangereuse, même lorsqu'elle est faite avec des Indiens. Mais ceux-ci, excellents nageurs, ne courent aucun risque dans les embarquements et les débarquements, au milieu des brisants. Malgré la largeur des passes indiquées ci-dessus, il n'est pas toujours prudent de s'y engager. Lorsque la mer est grosse, à l'époque des syzygies, l'eau déversée dans le lac par-dessus les récifs s'augmente d'abord du 
flot, et, s'échappant ensuite par les passes au moment du jusant, établit un courant d'une grande violence.

Les marées se font sentir dans toutes les iles, mais les observations manquent encore pour que nous puissions donner des renseignements précis sur les heures de pleine et basse mer. La différence entre la haute et la basse mer varie à peu près entre 60 centimètres et 1 mètre.

Toutes les îles sont plantées de cocotiers. On y trouve de l'eau douce, souvent saumâtre.

Nomenclature des îles de l'Archipel Tuamotu, d'après l'Annuaire de Taïti pour 1865 :

$\mathrm{N}^{\circ}$ 1. Matahiva, Lat. $14^{\circ} 56^{\prime}$; long. $151^{\circ} 00^{\prime} ; 30$ habitants. Cocotiers. Tortues.

№ 2. Makatea. Lat. $15^{\circ} 52^{\prime}$; long. $150^{\circ} .40^{\prime} ; 130$ habitants.

Cette île forme un district. Village de Teura.

Monoi. Tamanus. Grottes curieuses.

$\mathrm{N}^{\circ}$ 3. Tikahau. $15^{\circ} 00^{\prime}$ et $150^{\circ} 30^{\prime} ; 10$ habitants.

Non organisée.

Cocotiers. Taros. Bananiers.

N. 4. Rairoa. $15^{\circ} 09^{\prime}$; et $150^{\circ} 00^{\prime} ; 600$ habitants.

Cette île compte 4 districts.

Bouquets de bois. Quelques éponges. Huile.

$\mathrm{N}^{\circ} 5$. Arutua; $15^{\circ} 22^{\prime}$ et $149^{\circ} 06^{\prime} ; 100$ habitants.

Cette île forme un district avec les îles Kaukura, Niau, Apataki.

Les autorités résident à Kaukura.

Récif boisé. Nacre. Huile de coco.

$N^{\circ}$ 6. Kaukura. $15^{\circ} 48^{\prime}$ et $149^{\circ} 00^{\prime} ; 100$ habitants.

Récif boisé. Huile de coco.

$N^{\circ} 7 . \quad$ Niau. $16^{\circ} 10^{\prime}$ et $148^{\circ} 42^{\prime}$; 30 habitants.

Excellent poisson. Huile. Tamanus.

$\mathrm{N}^{\circ}$ 8. Oahe. $14^{\circ} 30^{\prime}$ et $148^{\circ} 30^{\prime} ; 20$ habitants:

Cette île forme un district avec l'île Manihi, où les autorités résident.

Bouquets de bois.

$N^{\circ}$ 9. Apataki. $10^{\circ} 24^{\prime}$ et $148^{\circ} 46^{\prime} ; 128$ habitants.

Bouquets de bois. Huile.

$\mathrm{N}^{\circ}$ 10. Manihi. $14^{\circ} 24^{\prime}$ et $148^{\circ} 20^{\prime} ; 100$ habitants.

Cette île forme un district avec l'île Oahe.

Bouquets de bois. Huile. 
$N^{\circ} 11$. Toau. $15^{\circ} 57^{\prime}$ et $148^{\circ} 18^{\prime} ; 90$ habitants.

Cette île forme un district avec les îles Arati-Ka, Faaite, Raraka et Taiaro. Les autorités résident à Faaite. Bois. Poissons vénéneux. Huile.

No. 12. Fakarava. $16^{\circ} 18^{\prime}$ et $147^{\circ} 52^{\prime} ; 375$ habitants.

Cette île est partagée en 2 districts : Tikomanu et Tetamanu.

Deux passes. Bon mouillage.

Bois. Huile.

No 13. Anaa. $17^{\circ} 27^{\prime}$ et $147^{\circ} 50^{\prime} ; 1,300$ habitants.

Cette île compte 4 districts : Tuuhora, Putuahara, Tematahoa et Topekite-Otepipi. - Elle est la plus peuplée del'Archipel; ses habitants en sont les plus civilisés.

Huile de coco.

Chenal en construction. - Service mensuel de dépêches entre Tuuhora et Papeete.

$N^{\circ}$ 14. Aratika $15^{\circ} 33^{\prime}$ et $147^{\circ} 48^{\prime} ; 30$ habitants.

Bois. Huile. Poissons vénéneux.

$N^{\circ} 15$. Faaite. $16^{\circ} 42^{\prime}$ et $147^{\circ} 35^{\prime} ; 150$ habitants.

Plantations de cocotiers. Huile.

$N^{\circ}$ 16. Kauehi. $15^{\circ} 50^{\prime}$ et $147^{\circ} 30^{\prime} ; 30$ habitants.

Un village du nom de Tepuna.

Bois.

No 17. Takapoto. $14^{\circ} 39^{\prime}$ et $147^{\circ} 26^{\prime} ; 150$ habitants.

Bois. Huile.

No 18. Hereheretue. $19^{\circ} 48^{\prime}$ et $147^{\circ} 16^{\prime}$; 20 habitants.

Habitants encore sauvages.

Pandanus sur tout le récif.

$N^{\circ}$ 19. Takaroa. $15^{\circ} 27^{\prime}$ et $147^{\circ} 15^{\prime} ; 75$ habitants, Bois. Huile.

$N^{\circ} 20$. Raraka. $16^{\circ} 19^{\prime}$ et $147^{\circ} 15^{\prime} ; 100$ habitants. Bois.

№ 21. Tahanea. $16^{\circ} 53^{\prime}$ et $147^{\circ} 06^{\prime} ; 100$ habitants.

Non organisée.

Bois.

$N^{\circ}$ 22. Taiaro. $15^{\circ} 45^{\prime}$ et $146^{\circ} 57^{\prime} ; 12$ habitants.

Bois. Huile.

No 23. Tikei. $14^{\circ} 57^{\prime}$ et $146^{\circ} 52^{\prime} ; 27$ habitants.

Bois. Huile. 
$\mathrm{N}^{\circ}$ 24. Motutunga. $17^{\circ} 05^{\prime}$ et $146^{\circ} 41^{\prime} ; 100$ habitants.

Non organisée.

Bois.

No 25. Katiu. $16^{\circ} 42^{\prime}$ et $146^{\circ} 41^{\prime}$; 50 habitants.

Cette île forme un district avec les îles Tepoto, Tuanake et Hiti.

Bois. Nacre.

No 26. Tepoto. $16^{\circ} 48^{\prime}$ et $146^{\circ} 38^{\prime} ; .$. habitants.

Bois. Pandanus. Poissons abondants.

No 27. Tuaneke. $16^{\circ} 40^{\prime}$ et $146^{\circ} 38^{\prime}$; ... habitants.

Broussailles. Quelques pandanus.

$\mathrm{N}^{\circ} 28$. Hiti. $16^{\circ} 42^{\prime}$ et $\$ 46^{\circ} 28^{\prime}, \ldots$ habitants

Bois.

$N^{\circ} 29$. Makemo. $16^{\circ} 35^{\prime}$ et $146^{\circ} 20^{\prime} ; 250$ habitants.

Cette île forme un seul district.

Deux passes. - Bois.

No 30. Haraiki. $17^{\circ} 29^{\prime}$ et $145^{\circ} 20^{\prime} ;$... habitants.

Mauvaise passe. - Bois. - Non organisée.

$\mathrm{N}^{\circ}$ 31. Anuanuraro. $20^{\circ} 26^{\prime}$ et $145^{\circ} 51^{\prime} ; \ldots$ habitants.

Bois. - Non organisée.

$\mathrm{N}^{\circ} 32$. Anuanuranga. $20^{\circ} 39^{\prime}$ et $145^{\circ} 35^{\prime} ; \ldots$ habitants

Non organisée.

Bois.

$\mathrm{N}^{\circ}$ 33. Marutea. $17^{\circ} 00^{\prime}$ et $145^{\circ} 32^{\prime} ; \ldots$ habitants.

Non organisée. - Cette île et celle $d u n^{0} 78$ portent

le même nom, quoique différentes.

Bois.

$N^{\circ} 34$. Taenga. $16^{\circ} 19^{\prime}$ et $145^{\circ} 25^{\prime} ; 75$ habitants.

Non organisée.

Bois.

$\mathrm{N}^{\circ} 35$. Reitoru. $17^{\circ} 51^{\prime}$ et $145^{\circ} 27^{\prime} ;$... habitants.

Non organisée.

Bois.

No 36. Nukutipipi. $20^{\circ} 57^{\prime}$ et $145^{\circ} 21^{\prime}$; ... habitants.

Non organisée.

Bois.

No 37 . Nihiru. $16^{\circ}, 42^{\prime}$ et $145^{\circ} 43^{\prime} ; 50$ habitants.

Non organisée. - Bois.

No 38. Hikueru. $17^{\circ} 36^{\prime}$ et $145^{\circ} ; 30$ habitants.

Non organisée. - Bois. 
$\mathrm{N}^{\circ}$ 39. Tekokoto. $17^{\circ} 21^{\prime}$ et $144^{\circ} 37^{\prime} ; \ldots$ habitants. Non organisée. - Broussailles.

$N^{\circ}$ 40. Raroia. $16^{\circ} 06^{\prime}$ et $144^{\circ} 45^{\prime} ; 300$ habitants. Non organisée.

Coraux. - Bois.

$\mathrm{N}^{\circ}$ 41. Marukau. $18^{\circ} 03^{\prime}$ et $144^{\circ} 33^{\prime} ; 60$ habitants.

Non organisée. - Passe pour embarcations et caboteurs de 10 à 15 tonneaux. - Bois.

No. 42. Ravahere. $18^{\circ} 06^{\prime}$ et $144^{\circ} 33^{\prime} ; 30$ habitants.

Non organisée.

Bois. - Nacre.

$N^{\circ}$ 43. Takume. $15^{\circ} 48^{\prime}$ et $144^{\circ} 32^{\prime} ; 60$ habitants.

Non organisée.

Bois. - Poisson.

$\mathrm{N}^{\circ}$ 44. Nengonengo. $18^{\circ} 45^{\prime}$ et $144^{\circ} 00^{\prime} ; \ldots$ habitants.

Non organisée. - Une passe pour embarcations.

No 45. Rekareka, $18^{\circ} 14^{\prime}$ et $143^{\circ} 57^{\prime} ; 30$ habitants.

Cette île forme un district avec les îles Tanere et Amanu. Les autorités résident dans l'île Amanu.

Bois. - Sans passe.

No 46. Tanere. $17^{\circ} 21^{\prime}$ et $143^{\circ} 48^{\prime} ; 30$ habitants. Bois.

No 47. Tetopolo. $14^{\circ} 06^{\prime}$ et $143^{\circ} 43^{\prime}$; 50 habitants.

Non organisée. - Bois.

No 48. Manuhangi. $19^{\circ} 12^{\prime}$ et $143^{\circ} 33^{\prime} ;$... habitants.

Non organisée. - Bois.

No 49. Napuka. $14^{\circ} 12^{\prime}$ et $143^{\circ} 28^{\prime} ; 80$ habitants.

Non organisée.

Bois. - Tortues. - Nacre.

No 50. Angatau. $15^{\circ} 52^{\prime}$ et $143^{\circ} 14^{\prime} ; 150$ habitants.

Non organisée. - Arbustes.

$\mathrm{N}^{\circ}$ 51. Hao. $18^{\circ} 14^{\prime}$ et $143^{\circ} 12^{\prime} ; 400$ habitants.

Non organisée.

Bois. - Cocotiers.

№ 52. Amanu, $17^{\circ} 51^{\prime}$ et $142^{\circ} 58^{\prime} ; 100$ habitants.

Cette île forme un district avec les îles Rekareka et Tanere. - Bois.

$\mathrm{N}^{\circ}$ 53. Paraoa. $19^{\circ} 09^{\prime}$ et $142^{\circ} 52^{\prime} ;$... habitants.

Non organisée. - Bois. 
No 5̌. Temataugi (ou Teku), $21^{\circ} 39^{\prime}$ et $142^{\circ} 57^{\prime} ; 20$ habitants. Non organisée. - Pandanus.

№ 55 . Pinaki. $19^{\circ} 42^{\prime}$ et $142^{\circ} 42^{\prime} ; \ldots$ habitants.

Bois.

N 56. Fakahuia. $15^{\circ} 55^{\prime}$ et $142^{\circ} 25^{\prime} ; 150$ habitants.

Non organisée.

No 57. Pukararo. $19^{\circ} 19^{\prime}$ et $141^{\circ} 49^{\prime} ; 40$ habitants.

Non organisée. - Bois.

No 58. Pukarunga (ou Vairaatea). $19^{\circ} 24^{\prime}$ et $142^{\circ} 32^{\prime} ; 70$ habitants.

Non organisée. - Bois.

No 59. Akiaki. $18^{\circ} 33^{\prime}$ et $141^{\circ} 25^{\prime} ; 40$ habitants.

Non organisée. - Bois. - Tortues.

$\mathrm{N}^{\circ}$ 60. Vanavana. $20^{\circ} 45^{\prime}$ et $141^{\circ} 25^{\prime} ; 20$ habitants.

Non organisée. - Bois.

№ 61 . Vairaatea (ou Moururoa). $21^{\circ} \mathrm{S1}^{\prime}$ et $141^{\circ} 12^{\prime} ; 200$ habitants.

Non organisée.

Nacre. - Poisson vénéneux.

No 62. Pukapuka. $14^{\circ} 50^{\prime}$ et $141^{\circ} 07^{\prime} ; \ldots$ habitants.

Non organisée. - Bois.

$N^{\circ} 63$. Vahitai. $19^{\circ} 20^{\prime}$ et $141^{\circ} 03^{\prime \prime} ; 30$ habitants.

Non organisée. - Bois.

$\mathrm{N}^{\circ} 64$. Nukutavake. $18^{\circ} 45^{\prime}$ et $144^{\circ} 08^{\prime} ; 30$ habitants.

Non organisée. - Bois.

No 65. Ahunui. $22^{\circ} 14^{\prime}$ et $141^{\circ} ; \ldots$ habitants.

Non organisée. - Bois. - Poisson vénéneux.

No 66. Vahitahi (ou Pinake). $19^{\circ} 27^{\prime}$ et $140^{\prime} 55^{\prime} ; 30$ habitants.

Non organisée.

Bois. - Bon poisson.

No 67. Tatakotoroa. $17^{\circ} 22^{\prime}$ et $140^{\circ} 46^{\prime} ; 120$ habitants .

Non organisée. - Bois.

No 68. Tureia. $20^{\circ} 47^{\prime}$ et $140^{\circ} 45^{\prime} ; 110$ habitants.

Non organisée. - Bois.

No 69. Tetakotopoto. $17^{\circ}$ et $140^{\circ} 35^{\prime} ; 130$ habitants.

Non organisée.

No 69 bis. Anaa-Iti, $22^{\circ} 15^{\prime}$ et $139^{\circ} 50^{\prime} ;$... habitants.

Non organisée.

№ 70. Morane. $23^{\circ} 0 \mathrm{ŏ}^{\prime}$ et $139 \circ 39^{\prime} ; 20$ habitants.

Non organisée. - Bois. - Cocotiers.

No 71. Pukaruka (ou Namanu). $18^{\circ} 20^{\prime}$ et $139^{\circ} 19^{\prime} ; 30$ habitants. Non organisée. - Bois. 
$\mathrm{N}^{\circ}$ 72. Tenararo (ou Nararo). $21^{\circ} 18^{\prime}$ et $138^{\circ} 55^{\prime} ; 20$ habitants. Non organisée. - Bois.

$\mathrm{N}^{\circ}$ 73. Maturevavao (ou Narunga). $21^{\circ} 19^{\prime}$ et $138^{\circ} 50^{\prime}$; inhabitée. Non organisée. - Bois.

No 74. Nania. $21^{\circ} 18^{\prime}$ et $138^{\circ} 44^{\prime}$; inhabitée.

Non organisée. - Bois.

No 7ŏ. Natupe (ou Reao). $18^{\circ} 36^{\prime}$ et $138^{\circ} 37^{\prime} ; 20$ habitants.

Non organisée. - Bois.

$\mathrm{N}^{\circ} 76$. Tenarunga (ou Maturevavao); $21^{\circ} 27^{\prime}$ et $138^{\circ} 35^{\prime} ; 30$ habitants.

Non organisée. - Bois.

№ 77. Maria. $21^{\circ} 59^{\prime}$ et $138^{\circ} 31^{\prime} ; 36$ habitants.

Non organisée. - Bois. - Quelques cocotiers. Nacre.

No 78. Marutea. $21^{\circ} 32^{\prime}$ et $137^{\circ} 43^{\prime} ;$... habitants.

Ne pas confondre avec le $\mathrm{n}^{\circ} 33$.

Non organisée. - Bois. - Nacre abondante et de belle qualité.

$\mathrm{N}^{\circ}$ 79. Mangareva (Gambier). $23^{\circ} 08^{\prime}$ et $137^{\circ} 20^{\prime} ; 1,500$ habitants. Sous cette dénomination il faut comprendre un petit groupe de 4 ou 5 îlots élevés, entourés d'une même ceinture de coraux.

Ces îlots sont généralement connus sous le nom de Gambier.

Les indigènes forment, depuis 1844, une administration séparée de celle de la reine Pomare.

Maria Eutokia est actuellement régente de Mangareva, pendant la minorité de son fils.

Cette île est le siége d'un établissement considérable fondé par la mission catholique. - La population tout entière est catholique.

Mangareva est très-riche en nacre, qui produit des perles d'une très-belle eau.

No 80. Timoe. $23^{\circ} 21^{\prime}$. Inhabitée.

Les habitants de cette île se sont établis à Mangareva.

Récif couvert de pandanus.

Les îles de l'Archipel Tubuai, sont élevées et rappellent les îles Taïti et Moorea. 
Sur ces 4 îles, 2 seulement sont sous le Protectorat français; ce sont :

$1^{\circ}$ Tubuai, et $2^{\circ}$ Raevavae.

Les 2 autres îles, Rimatara et Ruturu, ne sont pas soumises au Protectorat.

L'île Tubuai ( $23^{\circ} 22^{\prime}$ lat. et $151^{\circ} 55^{\prime}$ long.) a 253 habitants. Son étendue est de 6 milles de l'E. à l'O. et de 3 milles du N. au S. Elle est entourée d'un récif. Un mouillage pour les grands bâtiments se trouve au N., en pleine côte, il n'est pas bon.

On cultive dans l'île le tabac, l'arrow-root, la banane, etc.

L'île Raevavae ( $23^{\circ} 55^{\prime}$ lat. et $150^{\circ} 06^{\prime}$, long.) a 300 habitants. Du N. au S., elle mesure 3 milles et de l'E. à l'0. 4 milles. Port. - Corail. - Construction de goëlettes avec le bois du pays par des charpentiers européens.

L'archipel des Marquises se compose de 11 îles ou îlots dont plusieurs sont déserts. Ces îles forment deux groupes éloignés l'un de l'autre de 2 s̆ lieues, du S.-E. au N.-O.

Le groupe N.-O. ou sous-le-vent, désigné sous les noms d'îles de la Révolution, îles de Washington, etc., renferme six îles :
10 Eiao;
$4^{\circ}$ Nukahiva (1);
$2^{\circ}$ Motuiti;
$\check{5}^{\circ}$ Hapu;
$3^{\circ}$ Hatutu;
$6^{\circ}$ Hauka.

Le groupe S.-E., ou du vent, désigné sous les noms de Marquises de Mendoza, puis seulement Marquises, nom qui a été étendu à tout l'archipel, renferme les cinq autres :
$7^{\circ}$ Tauata;
$10^{\circ}$ Motane;
So Hivaoa;
$11^{\circ}$ Fatuhiva.
$9^{\circ}$ Fatuhuku;

Ces îles, dit l'Annuaire de Taïti, à qui nous empruntons"ce qui précède, ont été visitées par tous les navigateurs de différentes nations, envoyés en voyage d'exploration depuis un siècle. Aussi, à chaque instant, leur nom a été changé, chacun de ces explorateurs croyant de son droit et de son devoir de leur imposer un nom nouveau.

\section{Groupe N.-O. (îles-sous-le-vent).}

$N^{\circ}$ 1. Eiao. $8^{\circ} 01^{\prime}$ de lat. et $143^{\circ} 03^{\prime}$ de long.; inhabitée. On l'appelle encore île Masse, une des îles Roberts.

(1) Dans les états du Protectorat, tous les $u$ se prononcent ou. 
Élévation : 640 mètres.

Petit port dans le N.-O., où il serait imprudent de mouiller.

No 2. Motuiti. $8^{\circ} 44^{\prime}$ et $144^{\circ} 59^{\prime}$. Inhabitée.

On l'appelle aussi : les deux Frères, îles Hergest. Deux îlots.

Élévation : 40 mètres.

Guano. - Beaux poissons rouges.

$\mathrm{N}^{\circ} 3$. Hatutu. $7^{\circ} 55^{\prime}$ et $142^{\circ} 56^{\prime}$. Inhabitée.

Autrement appelée : île Chenal; elle fait partie des iles Roberts.

Élévation : 420 mètres.

$N^{\circ}$ 4. Nukahiva. $8^{\circ} 55^{\prime}$ et $142^{\circ} 20^{\prime} ; 1,200$ habitants $(1)$.

Autrement appelée : île Baux; île Martin.

Élévation : 1,178 mètres.

Plusieurs baies importantes.

Cocotiers, bananes, canne à sucre, arbres à pain, taros, caféiers, cotonniers, maïs, en petite quantité.

Chef-lieu : Taiohae, à 250 lieues de Papeete (Taïti).

No 5. Hapu ou Roa Poua. 9० $24^{\prime}$ et $142^{\circ} 26^{\prime} ; 400$ habitants (2).

Autrement : Ile Trévanion.

Mauvais mouillages.

Élévation : 1,190 mètres.

№ 6. Hauka ou Roa Honga. $8^{\circ} 56^{\prime}$ et $143^{\circ} 53^{\prime} ; 450$ habitants.

Autrement appelée : île du Soleil; île Washington.

Bon mouillage à Vaitake, au S.-O., mais entrée trèsétroite, et partant dangereuse.

Deux mauvais ports.

Élévation : 740 mètres.

Groupe S.-E. (îles-du-vent).

№ 7. Tauata (ou Vaitahu). $9^{\circ} 56^{\prime}$ et $141^{\circ} 30^{\prime} ; 630$ habitants Autrement appelée : île Santa-Christina.

Élévation : 1,000 mètres.

Bon mouillage.

$\mathrm{N}^{\circ}$ 8. Hivaoa (ou La Dominique). $9^{\circ} 45^{\prime}$ et $141^{\circ} 27^{\prime} ; 600$ habitants.

Autrement : Grand sommet.

(1-2) En 1863-1864, une épidémie variolique a détruit la moitié de la population de Nukahiva et de Hapu. 
Élévation : 1,260 mètres. - Plusieurs mouillages.

№ 9. Fatuhuku (ou île Hood). $9^{\circ} 26^{\prime}$ et $141^{\circ}$ 18'. Inhabitée.

Élévation : 360 mètres.

Pêche productive.

$N^{\circ}$ 10. Motane (ou San-Pedro). $9^{\circ} 58^{\prime}$ et $141^{\circ} 11^{\prime}$; inhabitée. Ilot aride.

Élévation : 520 mètres.

$N^{\circ}$ 11. Fatuhiva (ou La Magdeleine). $10^{\circ} 26^{\prime}$ et $141^{\circ} 01^{\prime} ; 1,000$ habitants.

Deux mouillages : Omaa et Hanavave.

Élévation : 1,120 mètres.

Nous terminerons ce chapitre un peu long par quelques renseignements sur la météorologie du pays.

Comme toutes les contrées tropicales, Taïti a deux saisons : l'une sèche, c'est la belle saison, commençant en avril et finissant en décembre; l'autre pluvieuse (hivernage), commençant vers le milieu de décembre pour finir en avril.

Moyenne du baromètre : $1^{\mathrm{mm}}, 40$.

Moyenne du thermomètre : belle saison, $27^{\circ}$ jour, $20^{\circ}$ nuit; hivernage, $29^{\circ}$ jour, $23^{\circ}$ nuit.

Maximum du thermomètre : jour, $34^{\circ}$.

Ces indications s'appliquent à Papeete. C'est le séjour le plus chaud de l'île. Il en est autrement sur les autres points.

L'humidité est excessive. L'hygromètre ne descend jamais andessous de $70^{\circ}$.

Dans les îles Basses, la chaleur est plus grande qu'à Taïti, mais toutefois très-supportable.

Aux Tubuai et aux Gambier, la température est assez fraîche.

Aux Marquises, la température est sensiblement plus élevée. La nuit, le thermomètre ne descend pas au-dessous de $23^{\circ}$.

Pas d'ouragans, mais violents coups de vent et ras de marée, dont les navires, près des îles, doivent se défier.

En somme, la salubrité du climat, dans toutes ces îles, est bonne. Les cas d'insolation, d'ordinaire si fréquents dans les contrées intertropicales, sont fort rares dans les îles du Protectorat. - Pourtant la variole, en 1863-1864, a exercé de grands ravages dans deux des îles Marquises, comme on le verra dans le chapitre suivant, et comme nous l'avons mentionné dans le chapitre précédent. Mais il est probable que ce fait est le résultat 
d'une cause dont le climat n'est pas responsable; la variole nous paraît un produit tout exotique, probablement européen.

\section{GHAPITRE III}

Population. - Origine. - Mœurs. - Statistique. - Immigrants.

La Revue maritime et coloniale (juillet, août et septembre 1865) contenait un curieux article sur l'origine de la population de nos possessions polynésiennes. Nous le mettrons à contribution.

Cette population appartient à la race cuivrée. Elle se distingue par une teinte uniforme, la beauté des formes, une taille au-dessus de la moyenne, une expression de visage assez douce, à moins que le tatouage n'ait procuré à quelques-uns une laideur factice, destinée à les rendre terribles. Ces Indiens se reconnaissent tous à la première vue et aux premières paroles, comme appartenant à une même race qu'ils désignent sous le nom de Mahori. Ils habitent les îles comprises dans un polygone dont les sommets seraient : la Nouvelle-Zélande, les îles Wallis, l'archipel des Navigateurs, les îles Sandwich et les îles Basses. Les Taïtiens occupent une position à peu près centrale dans ce polygone : les liens qui unissent ces populations sous le rapport des traditions et de la langue sont reconnus par tous les voyageurs. Les habitants des Sandwich prétendent, encoreaujourd'hui, descendre de Borabora, une des îles de la Société.

Ce n'est point de l'est ou du continent américain, mais de l'ouest, qu'est venue l'immigration qui a peuplé ces îles. Les savants, contredisant sur ce point l'opinion des anciens et premiers navigateurs, paraissent actuellement d'accord à ce sujet.

La vie nomade, l'habitude de peu planter, mais de récolter seulement les produits spontanés du sol, sont des causes qui devaient demander de grands espaces pour fournir la nourriture des chefs et du peuple. Quand on parcourt l'intérieur de Taïti, on trouve, dans plusieurs grandes vallées, des traces d'anciennes habitations, des sépultures qui ont fait croire que la population, trop nombreuse pour vivre tout entière au bord de la mer, avait, à une époque reculée, reflué vers l'intérieur. L'exemple de ce qui s'est passé sous nos yeux, dans les dernières guerres, semble indiquer que cette opinion est erronée. - Poursuivi par le vain- 
queur, dont il n'avait à espérer aucun quartier, le parti vaincu abandonnait ses habitations et se réfugiait au fond des vallées, où il lui était plus facile de se défendre, et où l'on se hasardait rarement à le poursuivre. Là s'élevaient de nouvelles cases et de nouvelles clôtures; là se construisaient des maraë (temples) et s'ensevelissaient les morts, jusqu'au jour où un revirement de fortune ou une paix, souvent momentanée, permettait à chacun de revoir son district et le bord de la mer que le Taïtien aime tant.

Les chefs ne désiraient pas voir la population s'accroître au delà de certaines limites, car il eût fallu pourvoir à sa subsistance par des moyens nouveaux. Les règlements eux-mêmes de la célèbre société des Areois peuvent donner une preuve de l'exagération des estimations anciennes de la population de Taïti. On sait que l'infanticide était une des règles de cette société religieuse et politique, et qu'aucune femme n'en pouvait faire partie qu'à la condition d'étouffer à sa naissance l'enfant dont elle devenait enceinte. Les prêtres ont été les premiers législateurs chez tous les peuples de la terre, qu'on a d'abord cherché à conduire au nom de Dieu. Derrière toutes les coutumes religicuses anciennes on trouve presque toujours un but politique qui nous apparait aujourd'hui. Ainsi entre toutes les raisons qui expliqueraient cette coutume barbare des infanticides à Taïti, une des plus importantes serait la nécessité de s'opposer, par tous les moyens possibles, à l'accroissement de la population au delà de certaines limites, passé lesquelles le sol n'aurait pu la nourrir dans les conditions de vie vagabonde.

Aujourd'hui les Areois ont disparu, eux et leurs règles impitoyables. Les femmes de Taïti sont de bonnes mères.

Le chiffre de la population de Taïti a été fort exagéré. D'après Cock, il atteindrait 240,000 âmes, et, d'après Forster, 120,000. Le missionnaire Wilson, en 1797, l'a réduit à 16,000.

Malgré la difficulté des recensements dans le pays, on est arrivé à une précision presque satisfaisante. On a constaté que, en 1848, la population des îles Taïti et Moorea, arrivait à 9,969 individus, et, en 1862, à 11,007. De 1848 à 1862, la population avait donc augmenté de 1,038 individus.

Pendant deux années consécutives, 1853 et $180 \%$, une épidémie de variole a sévi sur les deux îles. Le chiffre des décès, en 18503 , 
a dépassé de 84 celui des naissances; en 1854, il l'a dépassé de 699.

Depuis lors, l'excédant des naissances sur les décès n'a cessé de se maintenir.

Notons en passant que l'épidémie a respecté les Européens. Il est probable que, si elle a été aussi meurtrière pour les Indiens, cela a tenu à leur peu de soin et à leur habitude de se plonger danś l'eau froide à toute heure du jour. Des mesures efficaces ont, du reste, été prises pour faire face à une nouvelle invasion.

Voici quelle était, en 1863, la population de nos îles et des îles avoisinantes :

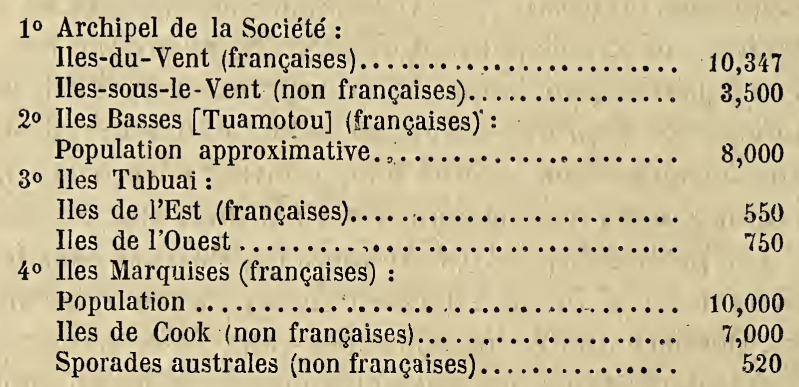

Ainsi la population des îles relevant de la France s'élèverait à 28,897 ; et celle des îleś en dehors de nous, à 11,770 .

Les Européens, dans ces chiffres, ne figurent que pour 800 .

En l'absence de travailleurs indigènes, trop peu nombreux dans nos îles, on a dû faire appel à l'immigration chinoise. En 1864, le gouvernement local a autorisé l'introduction de 1,000 Chinois, hommes, femmes et enfants. On compte beaucoup sur le résultat de cette mesure.

\section{CHAPITRE IV}

Gouvernement. - Administration. - Forces militaires. - Forces maritimes. - Justice. - Cultes. - Assistance publique. - Instruction publique. - Finances.

L'ordonnance du 28 avril 184:3 règle le gouvernement et l'administration de nos établissements océaniens.

Peu après l'occupation des îles Marquises, l'acceptation du protectorat sur les îles de la Société amena la France à placer le 
chef-lieu de ses établissements à Papeete (île Taïti). Le gouverneur, commissaire du roi aux îles de la Société, fut investi d'une autorité très-étendue; le pouvoirlui fut conféré de s'entendre avec la reine et les grands chefs.

De cette situation, disent les Notices, il est résulté une série d'actes locaux, constituant pour la colonie une administration toute particulière, dans laquelle l'élément indigène a conservé, aux îles de la Société et dépendances, la part d'autorité intérieure que lui réservait l'acte du protectorat du 9 sept. 1842. Cependant, la pratique des choses a amené une liaison trèsintime entre les̃ affaires européennes (celles concernant les Français et les étrangers) et les affaires taitiennes. Naturellement, une prépondérance considérable, et qui ne peut que s'accroître chaque jour, s'est développée du côté des affaires européennes : la plupart du temps, les indigènes eux-mêmes demandent que nos lois leur soient appliquées. C'est donc aux mains de l'administration française que revient la direction supérieure des affaires, tant extéricures qu'intérieures, dans le protectorat. Pour celles-ci, l'élément indigène a une très̀-grande parl d'action, notamment dans les contestations relatives au droit de propriété des terres. Ces sortes d'affaires sont jugées exclusivement par les tribunaux taïtiens. Les pouvoirs du commissaire impérial s'exercent d'accord avec la reine, suivant la teneur des lois taïtiennes, dans tout ce qui concerne le régime applicảble aux Taïtiens.

\section{Assemblée législative.}

Elle est formée des trois éléments suivants :

Les députés, élus pour trois ans par le suffrage universel et direct;

Les chefs de districts;

Les toohitu ou grands juges.

Elle est convoquée par ordonnance de là reine et du commissaire impérial aux îles de la Société.

\section{Administration intérieure.}

Le territoire des États du Protectorat est partagé en districts, et la population est groupée par villages. Chaque habitant est tenu de posséder une case établie dans de bonnes conditions de propreté et de salubrité. 
Lorsque la population du district est peu nombreuse, elle est réunie à celle des districts voisins pour former le village ou commune.

Depuis 18ว̌5, le village est administré par un conseil dont les attributions sont très-étendues; tous les intérêts de la communauté sont confiés à ce conseil. Il est formé :

Du chef, président;

Du juge;

Du chef-mutoi,

Et de deux conseillers élus par les habitants.

(Annuaire de Taïti pour 1865.)

Administration francaise.

Un ordonnateur dirige les différentes parties du service administratif, des troupes, de la marine, des finances coloniales et locales, et du service de l'administration judiciaire.

Le secrétaire général du commissaire impérial dirige les affaires civiles du pays; il s'occupe des intérêts des habitants français ou étrangers; et de toutes les affaires taïtiennes, dans lesquelles notre administration intervient à un titre quelconque.

Des Résidents ont été établis dans quelques îles éloignées du chef-lieu : $1^{\circ}$ A l'île Moorea, au port de Papetoai, ouvert au commerce extérieur; $2^{\circ}$ à l'île d'Anaa, la plus importante des îles Basses; $3^{\circ}$ à Taiokae (île Nouka-Hiva). Le résident de Taiokae est chargé du service du port et des fonctions de juge de paix dans le ressort des Marquises.

Le commissaire impérial a près de lui un conseil d'administration, et la colonie a, comme élément de représentation nationale, un comité consultatif d'administration, d'agriculture et de commerce.

\section{Commissariat de la marine.}

1 Commissaire - adjoint, ordonnateur; 1 sous-commissaire ; 1 aide-commissaire; 2 commis de marine.

\section{Secrétariat général.}

1 Commissaire-adjoint de la marine, secrétaire général; plusieurs officiers ou employés pris dans la colonie.

Service des ports.

1 Officier, détaché de la station locale, capitaine de port à 
Papeete, directeur des ateliers de la marine à l'arsenal de Fareute; 1 maitre de port; 2 pilotes, 2 élèves-pilotes.

Service des ponts et chaussées.

Confié au génie militaire.

\section{Scrvice de la police.}

Confié à la gendarmerie coloniale à Papeete. Deux brigades dans l'intérieur de Taïti une brigade à Taio-hae (île NoukaHiva). - Les chefs de village, où il n'y a pas d'agents français, sont aussi chargés de la police.

\section{Services financiers.}

1 Trésorier-payeur, 1 vérificateur de $3^{e}$ classe, 1 commis-receveur de l'enregistrement et des domaines, 1 préposé de la poste aux lettres.

Service de santé.

1 Chirurgien de la marine de $1^{\text {re }}$ classe 1 de $2^{\mathrm{e}}$ classe ; 1 pharmacien de $2^{\mathrm{e}}$ classe.

Les forces militaires et maritimes sont peu considérables.

A Papeete, il y a une direction d'artillerie et une chefferie du génie. La garnison se compose de détachements de la gendarmerie coloniale, d'artillerie de la marine et des colonies, d'infanterie de marine.

Direction de l'artillerie : le capitaine-commandant; 2 officiers, 2 gardes, 1 chef-ouvrier d'État, 1 sous-chef artificier.

Chefferie du génie : 1 capitaine, 3 gardes.

La gendarmerie se compose de : 1 sous-officier, 14 brigadiers et soldats. - L'artillerie est formée d'une demi-batte riede 50 hommes; 24 chevaux ou mulets ; 40 ouvriers. - L'infanterie compte 2 compagnies de 115 hommes chacune.

La garde d'honneur de la reine se compose de quelques cavaliers indigènes, qu'on emploie à la transmission des dépêches.

Ni milices ni corps de pompiers.

Nos forces navales se composent d'un aviso à vapeur de 50 chevaux et de 3 transports à voiles:

L'arsenal provisoire, établi dans le port de Papeète, promet d'acquérir de l'importance. 
L'organisation de la justice actuelle date de la publication du Code de procédure du Protectorat (1850), qui a institué :

Une justice de paix;

Un tribunal de première instance et de commerce;

Une cour d'appel;

Un tribunal correctionnel;

Un tribunal d'appel des jugements correctionnels;

Une cour d'assises (tribunal criminel).

La justice se rend dans ces tribunaux, au nom de l'Empereur et du gouvernement du Protectorat.

En 1855, l’organisation de la justice indigène a été revisée. Elle comprend :

Une justice du district;

Un tribunal d'appel ;

Une haute-cour indigène ou tribunal des Tookitu, dont Ariifaaite, mari de la reine, est premier président.

Le divorce est admis par les lois taïtiennes. La femme suit la condition du mari, Français ou Taïtien, qu'elle épouse.

Les cultes sont au nombre de deux : catholique et protestant, à Taïti et Gambier. Aux Marquises, le paganisme n'est pas encore complétement éteint, malgré les efforts de nos missionnaires (société de Picpus).

Deux évêchés in partibus ont été créés depuis 1842.

Papeete a un curé, un vicaire, une grande église non achevée.

La mission de Taïti compte 9 prêtres missionnaires; celle des Marquises, 6.

Plusieurs chapelles ou églises de campagne s'élèvent dans l'intérieur.

Les 22 villages de Taïti et Moorea ont chacun un pasteur protestant, et un temple.

L'assistance publique n’a pas eu jusqu'ici à se préoccuper de venir en aide à la misère. Le pays suffit à la nourriture des indigènes et le travail est assez rémunérateur pour les Européens immigrés. On s'est donc borné à établir, dans l'hôpital militaire de Papeete, une salle d'hospice de quatre lits.

Une surveillance très-active s'exerce au sujet du mal vénérien. Dans un dispensaire spécial, on soigne les femmes malades. Il a été reconnu que Papeete offrait moins de dangers que la plupart des villes de l'Amérique du Sud dans le Pacifique, quoique les mœurs indigènes soient toujours extrêmement libres. 
L'instruction publique a d'abord été dirigée par les missionnaires protestants. Grâce à leurs efforts, nous avons trouvé à notre arrivée dans l'île de Taïti, tous, hommes et femmes, sachant lire et écrire.

La situation de l'instruction publique n'a pas déchu depuis. En octobre 1864, on comptait:

A Papeete : 2 écoles, tenues par 7 frères de l'instruction chrétienne et 11 sœurs de Saint-Joseph de Cluny;

A Mataiea : 1 école; 4 frères.

A Taio-hae (Marquises) : 2 écoles; 4 frères ; 4 sœurs. 250 enfants fréquentaient ces écoles.

Papeete possède, en outre, quatre écoles libres.

En 1864, les diverses écoles des îles de la Société avaient 2,040 enfants (1,063 garçons, 977 filles).

Papeete a une imprimerie bien organisée. On y publie un journal, le Messager de Taïti, journal officiel, paraissant le samedi.

Passons aux finances.

\section{BUDGET DE L'ÉTAT.}

1861

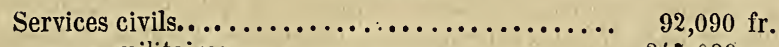

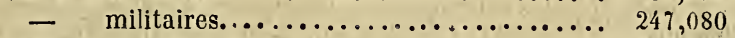

Subvention à la colonie................. 300,000

Total.................

1862

Services civils..................... $95,960 \mathrm{fr}$.

- militaires..................... 271,0i0

- Subvention à la colonie............ 300,000

Total............... $667,830 \mathrm{fr}$.

1863

Services civils.................... $97,410 \mathrm{fr}$.

- militaires..................... 273,330

Subvention à la colonie................ 300,000

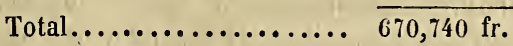

1864

Services civils..................... 97,760 fr.

- militaires.................... 286,000

Subvention à la colonie................... 300,000

Total................. $\overline{686,760 \mathrm{fr}}$. 
2. BUDGET LOGAL.

1863

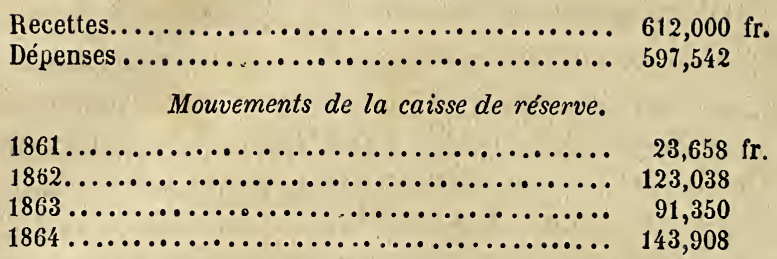

Caisses indigènes (1864).

Recettes prévues..................... $\quad 79,100 \mathrm{fr}$.

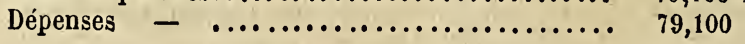

Caisse agricole (1864).

Actif........................ 64,395 fr. 11 c.

Passif......................... $44,374 \quad 46$

Les monnaies d'argent et d'or ont cours dans toute la colonie.

\section{CHAPITRE V}

Agriculture. - Café, coton, canne à sucre, oranger. - Essences diverses. - Bétail. - Poissons. - Huîtres. - Jardin botanique. - Industrie. - Charpenterie, etc. - Briqueteries. - Régime commercial. - Importations. - Exportations. - Objets d'exportation. - Navigation coloniale. - Mouvement de la navigation. - Service postal.

Le sol de Taïti se prête à tọtes les cultures de l'île de la Réunion. Jusqu'ici, toutefois, l'agriculture n'a pas atteint le degré de développement auquel elle est appelée. Le café, le coton, la canne à sucre, l'oranger, etc., prospéreront certainement bientôt, et donneront d'excellents produits. Deux grandes entreprises agricoles se sont formées, qui semblent devoir mener à bien les projets et plans qu'elles ont conçus.

Un préjugé très-répandu, disent les Notices de la marine, existe sur le peu de terres, que l'île de Taïti offre aux travaux de l'agriculture. L'île de Taïti seule est plus étendue de 6,000 hectares que notre colonie de la Martinique : ses nombreuses dépendances lui dennent des développements considérables.

La vraie difficulté consistait, et consiste encore, pour l'établissement des colons, dans l'achat des terres. Les indigènes, avant l'arrivée des Européens, occupaient le sol, sans se préoccuper 
beaucoup des limites de leurs propriétés, et jouissaient en commun de ses produits spontanés.

Ils ont compris quel intérêt il y avait pour eux à ne pas se déposséder aveuglément en faveur des étrangers. Les lois taitiennes et les arrêtés du commissaire impérial entourent de garanties toutes spéciales la propriété indigène, et veillent à ce qu'elle ne puisse être acquise par des Français ou par des étrangers que suivant des transactions soumises à une procédure régulière.

Dès $1845^{\circ}$, la loi taïtienne a investi le commissaire impérial du droit de s'opposer à toute vente de terres des indigènes à des Français et à des étrangers. Nos protégés ont compris que nous saurions mieux qu'eux-mêmes les prémunir contre de funestes entrainements. Mais les terres disponibles ne manquent pas, et l'administration locale, en constituant, le 30 juillet 1863, une caisse agricole, a youlu elle-même acheter les terres offertes par les indigènes, dans des conditions qui ne puissent nuire, ni à l'intérêt particulier des vendeurs, ni à l'intérêt commun de leurs villages.

Sans entourer d'aucune barrière les villages taïtiens, l'administration pensait qu'il importait de placer de préférence les colons sur les terrains situés entre ces villages, afin qu'un mélange trop brusque de gens ayant des idées très-différentes sur l'exercice du droit de propriété n'amenât pas des conflits regrettables.

Parmi les végétaux du pays, on remarque : le tamanu et le miro (bois de rose), très-durs et excellents, le tiairi (bancoulier), le bois de fer, le burao, le sandal, le maiore (arbre à pain), le cocotier; l'oranger et le goyavier, l'un et l'autre importés et qui prospèrent.

Le nombre des animaux s'accroît sensiblement. En juillet 1863 , les îles Taïti et Moorea avaient :

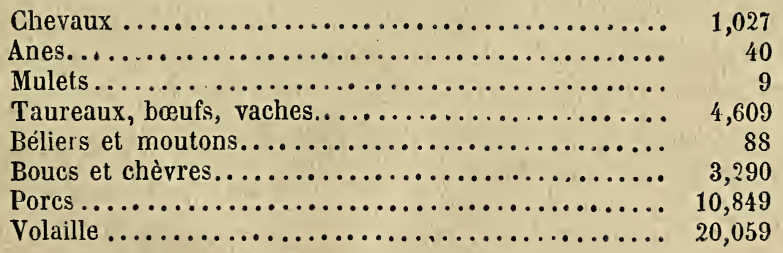

Les oiseaux sont rares, mais le poisson abonde. Aux îles Basses, les huitres perlières sont nombreuses.

Les naturels mangent l'animal contenu dans la coquille. Il est hors de doute que ces huîtres pourraient être exploitées avec des 
précautions et une prévoyance qui ont fait défaut jusqu'à ce jour. On augmenterait ainsi une richesse naturelle bien utile pour procurer, par les échanges du commerce, tout ce qui manque au bien-être de nos insulaires. La nacre est vendue d'ordinaire au poids, à 15 francs environ les 100 kilogrammes; mais si le payement a lieu en étoffes, le bénéfice du négociant va au delà. Il en est de même du cocotier. Ces précieux et magnifiques végétaux, couvrant des îles à fleur d'eau, semblent sortir de la mer ellemême. Ils offrent de grands éléments de commerce. L'huile de coro se vend en moyenne 50 francs les 100 litres.

On doit donc revenir au plus tôt du préjugé qui plane sur la possibilité d'étendre l'agriculture à Taïti et dépendances.

A l'intérieur de l'hôpital militaire de Papeete, il y avait, avant 1864, un petit jardin botanique qui a été transféré en dehors, et plus avantageusement. On espère y acclimater l'arbre à quinquina.

L'industrie n'est pas très-avancée encore. Cependant, elle est en progrès. On trouve à Taïti des constructeurs de pirogues, des charpentiers, des maçons, des confectionneurs d'étoffes en écorces d'arbres, etc.

Des carrières de pierre sont exploitées à Papeete. Les coraux de la côte donnent une excellente chaux, et le corps des ponts et chaussées fabrique de bonne brique.

Le régime commercial est déterminé, en l'absence de toute loi métropolitaine, par le commissaire impérial.

Il a été ouvert au commerce extérieur et à la navigation au long cours deux ports : celui de Papeete (avec un avant-port, Tanoa), et celui de Papetoai(île Moorea). Le cabotage du pays a la jouissance des autres ports des:îles Taïti.

Le port de Taïohae (îles Marquises) est complétement libre.

Le port de Mangareva (îles Gambier) est également libre.

Celui de Papeete, toutefois, peut seul recevoir des liquides.

Un seul impôt: l'impôt des patentes. Les douanes ont été supprimées le $1^{\text {er }}$ janvier 1865 .

MOUVEMENT COMMERCIAL DE PAPEETE.

\section{3}

Valeurs importées.................. 2,105,762 fr.

- exportées ...................... 1,009,830

- réexportées .................. 131,377

Droits perçus à l'importation............ 152,450 
1864.

Valeurs importées..................... 2,426,312 fr.

- exportées ....................... 1,178,637

- réexportées $\ldots \ldots \ldots \ldots \ldots \ldots \ldots \ldots \ldots . \quad 198,369$

Droits perçus à l'importation.............. 131,858

Il est à peu près impossible actuellement de se rendre compte du mouvement commercial des Marquises, etc.

Objets d'exportation (1864).

Huile de coco $(565,626$ lit.)................ 356,998

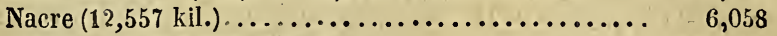

Oranges $(4,948,000$ pièces $) \ldots \ldots \ldots \ldots \ldots \ldots \ldots \ldots \ldots \quad 171,145$

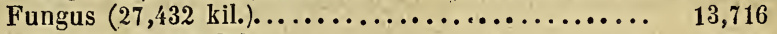

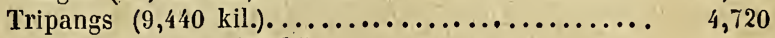

Jus de citrons $(25,470$ kil., ................ 8,499

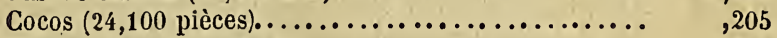

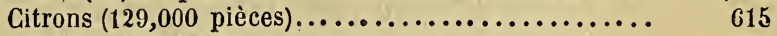

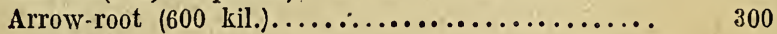

Café $(28$ kil.)........................... $\quad 85$

Vanille $(181$ kil. $) \ldots \ldots \ldots \ldots \ldots \ldots \ldots \ldots \ldots \ldots \ldots . .6,9,350$

Coton (6 kil.).......................... $\quad 75$

Confitures de goyaves (433 kil.).............. $\quad 3,665$

Bois de construction $(20 \mathrm{~m}$. cubes)............ $\quad 2,000$

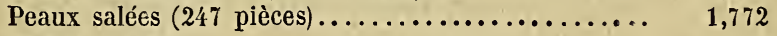

Perles (1 lot) $\ldots \ldots \ldots \ldots \ldots \ldots \ldots \ldots \ldots \ldots \ldots \ldots \ldots, \quad \mathbf{1 , 2 5 5}$

Rhum du cru (723 litres)................. $\quad 723$

Le commerce de Papeete se fait surtout avec :

San-Francisco (Amérique du Nord);

Valparaiso (Amérique du Sud);

Sydney (Australie);

Les îles Sous-le-Vent, l'archipel de Cook e l'archipel des

Navigateurs.

Des navires de commerce français partent tous les six mois, de Bordeaux pour Papeete. Les marchandises qu'ils apportent trouvent leur placement, mais les éléments d'un fret de retour leur manquent.

Plusieurs actes locaux régissent la navigation coloniale.

Le petit cabotage ne s'étend pas au delà des eaux des archipels.

Le grand cabotage comprend l'océan Pacifique jusqu'aux environs des côtes de l'Amérique et de l'Australie.

Enfin, le long cours comprend les voyages à la côte d'Amérique, d'Australie, et d'au delà.

Le nombre des petits caboteurs, en 1863, la plupart apparte- 
nant à des indigènes, a monté à 55 bateaux, d'un tonnage de 472 tonneaux.

Le nombre des navires armés au grand cabotage s'élevait à 6 , jaugeant 262 tonneaux.

On ne compte plus, à Papeete, qu'un petit nombre de baleiniers.

\section{Service postal.}

Les lettres, etc., de France à Taïti, sont réunies en dépêches closes par les bureaux du Havre et de Paris à Calais (bureau ambulant). - Les navires anglais les transportent de Southampton à Payta (Pérou) en 28 jours. - Un bâtiment de la marine impériale ou du commerce vient le $\mathbf{1 5}$ de chaque mois les prendre à Payta et les transporte à Papeete (Taïti).

Les lettres de Taïti à Paris, mettent 30 jours de plus, à cause de la difficulté opposée au retour par les vents généraux du S.-E.

Taxe des lettres.

(10 grammes et au-dessous.)

France et Algérie.................... 1 fr. 20

Colonies françaises (en passant par la France).... 180

Espagne, Portugal, Gibraltar.............. 130

Belgique, Pays-Bas, Suisse, États d'Allemagne, Ita-

lie, Gran le-Bretagne, Malte............. 170

États-Pontificaux, Danemark, Alexandrie d'Égypte, Suez, Smyrne, Constantinople, ètc........... 200

Suède, Norwége, Russie, Pologne, Grèce, Brésil, Shang-Haï, possessions anglaises d'Asie, Canada, Terre-Neuve, États-Unis, etc............. 210

Les lettres chargées payent double taxe ; affranchissement obligatoire.

Taxe des joürnaux, brochures, ouvrages périodiques,

(par 40 grammes ou fraction de 40 grammes; affranchissement obligatoire).

France et Algérie.................... $0 \mathrm{fr} .22$

Espagne, Portugal, Gibraltar................ $0 \quad 24$

Colonies françaises...................... $0 \quad 35$

Pays étrangers (frontières de France)......... 0

Les transatlantiques français mettent Taïti en cormmunication directe avec la France. L'île est actuellement trois fois. parmois en correspondance avec la métropole. 


\section{DEUXIEME PARTIE}

\section{NOUVELLE-CALÉDONIE}

\section{GHAPITRE PREMIER}

Résumé historique.

Découverte par Cook, le 4 septembre 1774, la Nouvelle-Calédonie est l'une des îles les plus considérables de l'océan Pacifique et de la Mélanésie.

Elle est siluée entre les $20^{\circ} 10^{\prime}$ et $22^{\circ} 26^{\prime}$ de latitude S., et entre les $161^{\circ} 35^{\prime}$ et $164^{\circ} 40^{\prime}$ de longitude $\mathbf{E}$. du méridien de Paris.

Les principaux faits historiques se rattachant à cette île sont les suivants :

La visite qu'y dut faire la Pérouse, en 1788, après avoir quitté Botany-Bay; - la carte qui fut dressée de l'île par BeautempsBeaupré, géographe de l'expédition en 1791 à la recherche de la Pérouse; - la découverte du port . Saint-Vincent, sur la côte Ouest, par le capitaine Kent (1793 ou 180כ).

Jusqu'en 1843, aucun navire de guerre ne visita la NouvelleCalédonie; mais à cette époque, une corvette, le Bucéphale, commandée par M. Julien de la Ferrière, vint mouiller à Balade, et y déposa Mgr Douarre, évêque d'Amata, les RR. PP. Viard et Rougeyron, et deux frères laïques. Tel fut le premier noyau de la mission dont la Nouvelle-Calédonie est actuellement le centre.

En septembre 18ło, M. Bérard, lieutenant de vaisseau, commandant du Rhin, se rendit à Balade; l'année suivante, la Seine, commandant Le Comte, se perdit sur la côte entre le cap Colnett et Balade. Pendant leur séjour forcé, M. Le Comte et ses officiers explorèrent le pays, qu'ils ne quittèrent que deux mois après leur naufrage.

Au mois d'août 1847, les naturels attaquèrent les missionnaires. 
Ceux-ci furent contraints momentanément à se retirer. La Brillonte, commandant du Bouzet, les recueillit.

Le comte d'Harcourt, commandant l'Alcmène, vint mouiller à Balade au commencement de 1851. Pendant le séjour de ce bâtiment, il se passa un fait qui fut en partie le point de départ de notre prise de possession. Une chaloupe, commandée par deux aspirants de marine, MM. Devarenne et de Saint-Phalle, avait été envoyée à dix lieues pour opérer une reconnaissance hydrographique; les indigènes se ruèrent dessus et massacrèrent l'équipage ; trois matelots seulement sur quinze purent regagner le bâtiment; quant aux deux aspirants, ils avaient péri des premiers.

Après avoir vengé d'une manière éclatante et rapide nos malheureux compatriotes, M. d'Harcourt rendit compte au gouvernement de ce qui avait eu lieu. On résolut de s'emparer de la Nouvelle-Calédonie.

Le 24 septembre 1853, le contre-amiral Febvrier-Despointes, commandant en chef les forces navales dans le Pacifique, arriva à Balade, et, sans opposition de la part des indigènes, il prit immédiatement possession, au nom de la France, de la NouvelleCalédonie et dépendances.

Le 29 du même mois, l'amiral se rendait à l'île des Pins. Les naturels, éclairés par les missionnaires, s'empressaient aussitôt de faire leur soumission à la France, ce qu'ils avaient refusé, quelques semaines auparavant, à l'Angleterre. De retour à $\mathrm{Ba}-$ lade, l'amiral fit commencer la construction d'un blockhaus qui fut promptement terminé.

M. Febvrier-Despointes quitta l'île le 31 décembre 1853. Il eut pour successeur M. Tardy de Montravel, capitaine de vaisseau. Celui-ci, pendant un séjour de près d'un an à la Nouvelle-Calédonie, compléta notre prise de possession, fit reconnaître aux principaux chefs notre souveraineté, explora les côtes, et fonda sur la baie de Numea (côte S.-O.) Port-de-France, aujourd'hui chef-lieu de l'établissement français.

$\mathrm{Au}$ commencement de 1855 , M. du Bouzet, capitaine de vaisseau, vint relever M. Tardy de Montravel, appelé dans les mers de Ghine. Après avoir fait construire une caserne et les édifices nécessaires à toute colonie nouvelle, M. du Bouzet visita Balade et Poébo, accompagné de M. Testard, chef de bataillon d'infanterie de marine. Au retour, l'Aventure qu'ils montaient se perdit 
sur les récifs de l'île des Pins dans la nuit du 28 au 29 avril 185็ ; les indigènes convertis vinrent avec le plus louable empressement en aide aux naufragés.

En octobre de la même année, M. Testard, commandant en l'absence de M. du Bouzet, parti pour Taïti, fit quelques concessions de terre à des colons dans le voisinage de Port-de-France. On concéda aussi aux missionnaires 3,400 hectares dans la baie de Morari ou Bulari, sous la condition d'y établir à leurs frais un village qui servît de poste avancé contre les sauvages. Telle est l'origine de Conception, situé à 10 kilomètres au sud de Port-deFrance. Dès le $1^{\text {er }}$ nov. 185 s̆, le R. P. Rougeyron, chef de la mission, $\mathrm{y}$ amenait 150 indigènes chrétiens. Ces indigènes, dont le nombre s'est accru, nous ont, depuis lors et en plus d'une circonstance, rendu d'importants services.

De nouveaux colons, en juin 1856, acquirent d'un chef indigène la belle vallée de Bulari, à quelque distance au sud de Portde-France; ils en furent chassés par les naturels. Cet insuccès ne découragea point $M$. Bérard qui, peu après, s'associa à plusieurs Européens, reprit possession de la vallée, y fit de grandes plantations de canne à sucre et y monta un moulin à canne.

G'était prématuré. Les indigènes, sous les ordres du chef Kouinedo, n'avaient pas cessé leurs hostilités. Après avoir successivement massacré trois indigènes de Conception et quatre colons, ils envahirent, le 19 janvier 1857, l'établissement de M. Bérard, qu'ils assassinèrent avec onze autres blancs.

Il fallut intervenir. De fréquentes expéditions furent dirigées contre les indigènes réfugiés dans les montagnes et les vallées voisines de Port-de-France; au commencement de 1848, le chef Kouinedo fut enfin surpris et contraint à livrer des otages.

L'état des choses n'était pas plus satisfaisant sur la côte orientale. En mars 18ä6, sept colons, qui se dirigeaient de Kanala vers le nord de l'île, avaient été attaqués, et six avaient péri assassinés; le poste de Balade était menacé; l'église de la mission, à Poébo, était la proie des flammes. Trois expéditions durent etre lancées contre les indigènes, et Bouarat, chef d'une tribu révoltée (aujourd'hui devenu notre fidèle allié), fut déporté à Taïti.

M. du Bouzet, revenu dans la colonie en mai 1857, en partit pour France en octobre 1858. Son successeur, M. Saisset, capitaine de vaisseau, arriva à la Nouvelle-Calédonie en rnai 1859.

Une reconnaissance à travers l'île fut immédiatement com- 
mencée par-lui. De Yaoué ou Pont-des-Français, à 8 kilomètres de Port-de-France, il se rendit à Boulari, où furent trouvés presque partout des affleurements de houille, mais non des couches exploitables. De là, l'expédilion gagna par terre les villages d'Ounia et de Yaté, puis par mer Kanala, où fut assis, au fond de la baie, l'établissement de Napoléonville.

Le 31 anût 1820 , une colonne de 175 hommes, sous les ordres du commandant Saisset, marcha contre la tribu de Yenguène, une des plus belliqueuses de l'île, qui, quoique privée de son chef Bouarat, persistait à montrer des intentions hostiles, excitée par des Européens qui convoitaient la succession de ce chef exilé à Taïti. En huit jours, la tribu fut dispersée; trois Européens, pris les armes à la main, furent fusillés.

L'expédition nous coûta deux hommes tués (le capitaine Tricot fut de ce nombre), et 25 blessés. On revint ensuite à Kanala, d'où, après avoir traversé l'île dans toute sa largeur pour se rendre à Ouaraye (Uarai), sur la côte ouest, on gagna par mer Port-deFrance.

Les chefs Jack et Kandio, principaux meurtriers de M. Bérard, furent saisis dans le même temps. On les fit passer par les armes.

Au mois de décembre 18ð9, une amnistie fut accordée aux débris des bandes indigènes des environs de Port-de-France.

M. Saisset quitta la colonie le 4 avril 1860, et fut remplacé par M. Durand, chef de bataillon d'infanterie de marine, qui luimême eut pour successeur, le 2 juin 1862, M. le capitaine de vaisseau Guillain.

Depuis lors, disent les Notices publiées par ordre du Ministre de la marine et des colonies, notre influence s'est accrue chaque année. Toutefois, des expéditions ont été rendues nécessaires de temps à autre, tant pour faire rentrer dans l'ordre certaines tribus récalcitrantes que pour venger des attaques et des massacres de la part des indigènes. Parmi les plus importantes de ces expéditions, nous citerons celles de Wagap (janv. 1862), de Monéo (28 mars, 4 avril 1864), des Loyalty (juin 1864) et de Gatope (sèpt. 1865). - A la suite de ces expéditions, deux postes militaires ont été créés, l'un à Wagap, sur la côte est, l'autre à Gatope, sur la côte ouest. La sécurité de nos relations avec le nord de la colonie se trouve ainsi assurée. - Quant à l'occupation militaire des îles Loyalty, où nos missionnaires étaient établis depuis 1859 , elle remonte au mois de mai 1864 . Un petit poste de 25 hommes, 
sous les ordres d'un lieutenant d'infanterie de marine, avait d'abord été installé à Enou, sur la partie nord du littoral de la baie de Sandal (île Lifou). Mais deux des tribus de l'île ayant manifesté des intentions hostiles et cherché à soulever contre nous le reste de la population indigène, le gouverneur, M. le capitaine de vaisseau Guillain, résolut de venir lui-même sur les lieux. Il partit de Port-de-France le 19 juin 1864, emmenant avec lui 200 hommes de troupes. En passant, il s'arrêta à Maré, la plus méridionale des îles Loyalty, pour y faire reconnaître notre autorité, et, le 21 au matin, l'ancre fut jetée dans la baie du Sandal, en face du poste d'Enou. Une partie des troupes fut débarquée pour renforcer ce poste, tandis que le Fulton transportait sur la côte sud de l'île 125 hommes d'infanterie de marine destinés à parcourir l'île du sud au nord et revenir joindre le gouverneur sur la côte ouest. - Le 24, les forces qui étaient restées dans la baie de Sandal occupèrent Chépénéhé, gros village situé à petite distance au sud d'Enou et qui était devenu le foyer de l'insurrection.

Pendant ce temps, les 125 hommes, sous les ordres du commandant Testard, débarquaient sur la côte sud-est, à Louengani. Le lendemain, ils se mettaient en marche pour la baie du Sandal. Chemin faisant, la petite colonne dut faire usage de ses armes pour repousser les indigènes. L'état de siége fut prononcé. Le 27 juin, Boula, un des trois grands chefs de l'île, fit sa soumission, et, dès le 29, le gouverneur put repartir pour Port-deFrance, laissant à M. Testard, commandant supérieur des forces de terre et de mer, le soin de rétablir complétement l'ordre et la paix.

Les indigènes ne tardèrent pas à comprendre nos intentions pacifiques. Leur soumission en fut la conséquence. Aujourd'hui ils s'occupent assez activement de la plantation du coton et "surtout de celle des cocotiers.

Le groupe d'Uvea est actuellement divisé en trois districts. Chacun d'eux est administré par un chef indigène qui relève du commandant de Lifou.

\section{Gouverneurs et commandants.}

1853. Febvrier-Despointes, contre-amiral.

1854. Tardy de Montravel, capitaine de vaisseau.

1854-1858. Du Bouzet, capitaine de vaisseau. 
1838. Testard, chef de bataillon d'infanterie de marine, commandant particulier.

1859-1860. Saisset, capitaine de vaisseau, gouverneur des établissements français de l'Océanie.

1858-1859. Durand, chef de bataillon d'infanterie de marine, commandant particulier de la Nouvelle-Calédonie.

1860. Un décret du 14 janvier sépare la Nouvelle-Calédonie et ses dépendances des autres établissements de l'Océanie et les érige en colonie distincte.

1860-1862. Durand, chef de bataillon, puis lieutenant-colonel, commandant de la Nouvelle-Calédonie et dépendances.

1862. Guillain, capitaine de vaisseau, gouverneur.

\section{CHAPITRE II}

Climat. - Température. - Saisons. - Vents. - Ouragans. - Pluies.

Le climat de la Nouvelle-Calédonie est très-salubre. Point de chaleurs excessives. A chaque instant, des brises de terre ou de mer qui modèrent l'ardeur d'un soleil tropical. A toute heure du jour, l'Européen comme l'indigène peut se livrer à des travaux sans danger.

En janvier et février, époque des plus grandes chaleurs, le thermomètre ne franchit guère $32^{\circ}$; en juillet et août, mois les plus frais de l'année, il descend à $16^{\circ}$ pendant le jour; de mai à norembre, il descend, pendant la nuit, à $10^{\circ}$ et $9^{\circ}$. La moyenne annuelle est entre $20^{\circ}$ et $24^{\circ}$.

Le baromètre oscille entre 7 כั et $766^{\mathrm{mm}}$.

Deux saisons seulement, comme dans les pays intertropicaux : une saison pluvieuse et chaude (hivernage), de janvier à avril ; puis une saison sèche ou fraîche.

Les vents qui dominent sont les vents alizés de l'E.-S.-E. A l'époque des pluies viennent les calmes et les vents irréguliers.

Les ouragans sont beaucoup moins redoutables qu'aux Antilles. Ils durent au plus 48 heures et ne se font sentir qu'en janvier.

Pendant l'hivernage, les pluies sont abondantes; elles tombent de un à cinq jours; le beau temps y fait suite. Pendant la saison sèche, on a des ondées bienfaisantes. 
En 1863, à Port-de-France; le nombre des jours pluvieux a été de 118, et la quantité d'eau tombée; de $1^{\mathrm{m}}, 2795$ :

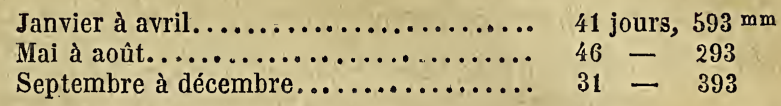

Napoléonville (Kanala), sur la côte est, a eu 142 jours de pluie, en 1863. La quantité d'eau tombée a dépassé 2 mètres $\left(2^{\mathrm{m}}, 1643\right)$.

Suivant le père Montrouzier, les Néo-Galédoniens sont originaires du sud de l'Asie. Voici ses raisons :

$1^{\circ}$ Comme en Asie, les Néo-Calédoniens admettent la distinction des castes; $2^{\circ}$ comme les Asiatiques, ils ont l'institution du Tabou (objet déclaré sacré); $3^{\circ}$ la circoncision existe aussi chezeux; $4^{\circ}$ ils emploient aussi un langage d'étiquette à l'égard des chefs; $5^{\circ}$ dans la vie civile, on rencontre beaucoup d'usages semblables: celui de fiancer les enfants dès leur bas âge, l'emploi d'un même mot pour exprimer la parenté entre frères et entre cousins, etc.

D'après M. Braine, les Néo-Galédoniens viendraient des îles Wallis (Uvea), dans la Polynésie.

Enfin, d'après le docteur de Rochas, la Nouvelle-Calédonie aurait reçu sa population de diverses sources. Les Papouas de la Nouvelle-Guinée et d'autres peuplades noires de l'Asie australe, ont dû y arriver, tout comme la race jaune polynésienne y a envoyé elle-même des colonies. Du mélange de toutes ces races est sortie la variété Néo-Calédonienne, où l'on reconnait encore aujourd'hui plus ou moins des Endamènes d'Australie, des Papouas et des Polynésiens. Dans un savant ouvrage d'une haute importance sur les Polynésiens, M. de Quatrefages, de l'Institut, vient de démontrer que la Polynésie s'est peuplée par migrations et qu'aucune de ces migrations ne remonte au delà des temps historiques.

Les Néo-Galédoniens se distinguent par une constitution robuste, leurs traits sont peu agréables, leur teint plus noir que celui des Polynésiens, moins noir que celui des nègres, leurs cheveux crépus, leur front peu évasé, leurs lèvres légèrement saillantes.

“ Leur nez est épaté artificiellement; généralement leurs oreilles sont largement percées au lobe inférieur. Ils n'ont pas les membres grêles des Australiens; leur barbe est fournie, mais le 
plus grand nombre ne la laisse pas pousser. En naissant, les enfants sont presque blancs.

"Les vieillards sont rares et n'arrivent jamais à un âge trèsavancé. Les Néo-Calédoniens ont généralement peu d'enfants; encore s'en débarrassent-ils souvent. » (V. Notices de la marine.)

Le R. P. Montrouzier donne du caractère néo-calédonien une idée peu favorable.

a Depuis longtemps que j'étudie ce peuple, dit-il, je suis encore à chercher en lui une vertu. Il est intelligent, c'est incontestable; mais il est paresseux, fourbe, cruel et orgueilleux, au delà de toute expression. Il a vu, depuis plusieurs années, les Européens de près; il ne conteste pas la supériorité de leur système, leur confort, leur bien-être; mais il répète : Souffrir pour souffrir, j'aime mieux avoir faim que de travailler.

"La fourberie est le fond de son caractère. Le bon Néo-Calédonien doit savoir composer son visage de manière à ce que jamais l'émotion ne le trahisse. Un des meilleurs chrétiens de Balade avouait aux pères missionnaires qu'autrefois il avait été bien aimé des anciens, qui le désiraient pour leur chef, parce qu'il était si habile dans l'art de tromper que jamais, dans l'occasion, il n'était sans trouver un mensonge juste à propos pour se tirer d'embarras. La cruauté, la férocité de ce peuple se révèle par l'existence, trop souvent constatée, de l'anthropophagie, par l'usage de mettre les têtes des ennemis mangés comme un trophée au-dessus des maisons, de massacrer sans pitié les naufragés, etc. Enfin, son orgueil se montre dans la répugnance qu'il témoigne à accepter ce qui vient des étrangers, habillement, langue, usages.

"Malgré ses vices, la population de la Nouvelle-Calédonie offre des ressources. Elle est intéressante, non-seulement aux yeux de la foi pour le missionnaire qui se dévoue à l'arracher à ses erreurs, mais pour la politique qui veut coloniser et assurer aux colons des travailleurs à bas prix. En gagnant sa confiance, en la traitant avec bonté, mais sans faiblesse, on se préparera une génération qui vaudra mieux que ses pères et qui fera honneur à ses maîtres. (Le P. Montrouzier, Notice sur la Nouvelle-Calédonie.) MM. Vieillard et Deplanche évaluent la population totale de la Nouvelle-Calédonie et dépendances à 42,480 individus, répartis en 38 tribus, qui, par l'état d'hostilité où elles sont toujours entre elles, assurent notre paisible domination.

La population blanche, non compris les troupes et le person- 
nel administratif, est de 500 individus. Ils habitent principalement Port-de-France et les environs. La plupart sont venus d'Australie. Quarante orphelines, envoyées de France en 1863 et 1864, sont aujourd'hui convenablement mariées ou établies dans la colonie.

On a établi, en 1864, un pénitencier sur l'île Nou. Deux convois de forçats ( 450 hommes) y ont été amenés de Toulon en 1864 et 1866. Ce sont tous ouvriers des divers corps d'état ou des condamnés à la résidence perpétuelle.

\section{GHAPITRE III}

Étendue. - Montagnes. - Sol. - Cours d'eau. - Caps. - Côtes, ports, rades, baies. - Iles dépendant de la Nouvelle-Calédonie : Lifou, Maré, Uvea, Mouli et Tika.

La Nouvelle-Galédonie occupe une superficie de 1,200 lieues carrées. Sa longueur moyenne est de 280 kilomètres et sa largeur moyenne de 55 kil.

Elle est entourée d'un récif madréporique qui se prolonge au $\mathrm{N}$. et au S. d'environ 125 lieues marines.

On connaît fort peu encore la configuration géographique de l'intérieur de l'île.

Elle est traversée du S.-E. au N.-0. par une chaîne de montagnes dont le sommet le plus élevé atteint 1,500 mètres. Les pentes en sont assez douces; elles sont cultivables à plusieurs centaines de mètres au-dessus du niveau de la mer.

Ces montagnes, d'après le R. P. Montrouzier, sont formées dans le sud par des serpentines et autres silicates magnésiens qui s'étendent du cap de la Reine-Charlotte à Uaïlu, et dont les profondes échancrures forment les ports de Yaté, Port-Bouquet, Nakete, Kanala, Kuaua et Uaïlu.

Au nord de Uaïlu apparaissent les schistes argileux et ardoisés; ils occupent toute la côte jusqu'à Poébo, où ils sont remplacés insensiblement par les gneiss et les micaschistes, riches en grenats, qui composent presque exclusivernent le versant N.-E. de Balade, jusqu'à l'embouchure du Diaot, les schistes ardoisés ne se montrant plus que de loin en loin, au pied des montagnes ou dans le fond des vallées. 
Sur un seul point de la côte entre Yenguène et Touo, au-dessus des schistes argileux, apparaissent des calcaires grisâtres, cristallins, traversés par des filons de quartz et dont les couches sont plissées, comme satinées, presque verticales.

Malgré l'absence des fossiles, les caractères physiques, la position et les analogies avec les roches siluriennes de la NouvelleHollande, permettent évidemment de les ranger dans cette formation. Ainsi, le versant N.-E. ne présente que des roches plutoniques ou de transition. Les côtes sont plus abruptes. Il n'existe pas d'autres plaines que les deltas souvent considérables formés par les torrents, dépôts absolument récents, dont la formation se continue sous nos yeux.

L'intérieur et la côte S.-0. sont moins connus et offrent certainement plus d'intérêt. Après avoir quitté les micaschistes sur le versant S.-0. des montagnes de Balade, on trouve une deuxième série de schistes ardoisiers formant le bassin du Diaol. Ils sont traversés en tous sens, de même que les micaschistes, par des filons de quartz et de roches magnésiennes, surtout des stéatites. Plus loin se présentent des couches épaisses d'argiles blanchâtres, tachées d'ocre, des collines calcaires, des grès houillers avec trace de houille, et enfin deux séries de collines d'un calcaire dur, blanchâtre, non cristallin, entremêlé de filons de chaux spathique et de quartz blanc laiteux.

$\mathrm{Au}$ sud, à Yaté, au-dessus des serpentines qui forment la chaîne principale de la côte N.-E., on trouve des argiles rouges, contenant en abondance du fer à l'état de limonite, des calcaires probablement métamorphiques, un bassin étendu des mêmes argiles rouges avec minerai de.fer, des argiles de conleurs diverses, traversées par des pegmatites, dont la décomposition forme un kaolin quelquefois pur, plus souvent taché par l'oxyde de fer. La serpentine apparaît de nouveau, formant le Mont-d'Or, et enfin les terrains houillers se montrent sur le rivage de Morari et dans les îlots voisins. Les calcaires reparaissent sur quelques points avancés, comme à l'extrémité du cap sur lequel est bâti Port-deFrance.

La Nouvelle-Galédonie est sillonnée par de nombreux cours d'eau, dont le Diaot est le plus important.

Le Diaot a son embouchure au nord de l'île, dans la baie d'Harcourt en face de l'île Pam. Sa profondeur est de 2 à 3 mètres ; son cours de 40 milles. On peut la remonter jusquà 27 milles avec 
des embarcations et des chalands. Toute la vallée que traverse le Diaot présente une grande fertilité.

La Nouvelle-Calédonie compte, parmi ses principaux caps : le cap Colnett, le cap Tuo, les caps Baye, Bocage, Bégat, Dumoulin, Puareti ou Coronation, de la Reine-Charlotte, etc.

Parmi les principaux ports, rades ou baies de l'île, on doit signaler: le havre de Balade, sur la côte N.-E., qui, à cause de l'éloignement des récifs madréporiques qui entourent l'île, n'offre qu'un mouillage peu sûr; le port de Poébo, à quelques milles au sud de Balade, assez bien abrité et d'une largeứ de 600 mètres ; le mouillage de Yenguène, à 26 milles au sud de Poébo; la baie de Tiouaka, à 30 milles au sud de Yenguène; la baie de la Bayonnaise; le port de Bâ ; la baie de Uaïlu; la baie de Kanala, un des plus vastes et des meilleurs mouillages de la colonie; la baie de Nakéti; la baie de Yaté; la baie du Sud ou du Prony, qui s'enfonce à 7 milles dans les terres; la petite baie qui se trouve à l'extrémité du canal Woodin, à l'extrémité de l'île Uen, et qui offre un excellent mouillage; les petites baies d'Uie et de Ngo; la grande baie de Morari ou Boulari; la baie de Dumbéa; la baie de Saint-Vincent; enfin la magnifique rade de Port-de-France, à l'entrée de la grande baie de Dumbéa, rade très-vaste, d'un accès facile et bien abritée.

Les îles qui dépendent de la Nouvelle-Calédonie, sont:

$\mathrm{N}^{\circ \mathrm{s}}$ 1, 2. L'île Huon et l'île de la Surprise, aux extrémités N. et S. des récifs d'Entrecasteaux.

No 2. Le groupe Belep, formé des îles Poot, Art et Dau-T'eama. - Terres hautes, peu fertiles; établissement de missionnaires. No 3. Le groupe de Nénéma, formé des îles Pauaba, Tanlo, Iandé, Ienegéban, Néba, Pum, Tanlep. - Toutes sont habitées; leur richesse consiste surtout en cocotiers.

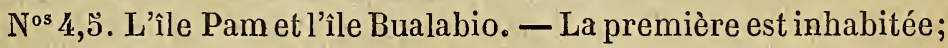
l'autre a 50 habitants.

$N^{\circ} 6$. Groupe de la côte Est, comprenant de nombreux îlots inhabités, entre autres l'île du Pin (elle ne possède qu'un seul arbre, un pin), importante pour la navigation, près du récif de Ti-Uaka.

$N^{\circ} 7$. L'île des Pins ou Kunié, centre d'un groupe d'îlots boisés et couverts de pins. - Abord difficile; sol ferrugineux; prairies étroites, mais très-fertiles. Autrefois centre des missions NéoCalédoniennes. 
$\mathrm{N}^{\circ} 8$. L'îlot Amède, où se trouve un phare de premier ordre.

No 9. L'île Nou ou Du Bouzet, qui, par sa situation à l'entrée de la rade de Port-de-France, contribue à former cette rade importante.

Nos 10,11,12. Les îles Hugon, Ducos et Le Prédour.

$\mathrm{N}^{\circ}$ 13. Groupe d'îlots insignifiants (Contrariété, Grimoult, Konié, etc.).

$\mathrm{N}^{\circ}$ 14. Iles Loyalty. - Ces les, à 60 milles dans l'est, sont les plus considérables de celles qui dépendent de la Nouvelle-Calédonie. - Trois îles principales : Maré, Lifu et Uvéa, et nombreux îlots. - A Lifu, on trouve cocotiers, pins, coton, tabac, vigne, plantes rares et fleurs variées (importées), etc. La population est divisée en trois tribus, comprenant ensemble 7,500 individus. Poste militaire à Chépénéhé, village principal. Sol formé d'un calcaire coquillier. - L'île Maré a son sol composé comme celui de Lifu, 4,300 habitants. - L’île Uvéa, aussi boisée que Lifou, possède plus de terres végétales et arables; la culture y est plus avantageuse. Deux grandes tribus, comprenant ensemble 2,כ00 à 3,000 individus. Vaste église, construite au village de Saint-Joseph par les missionnaires. - Dans la partie sud de l'île Maré, le cannibalisme n'est pas encore entièrement détruit.

\section{CHAPITRE IV} Gouvernement. - Administration. - Personnel. - Forces militaires. - Service

La Nouvelle-Calédonie, d'abord placée sous l'autorité du commandant de la station de l'océan Pacifique, en résidence à Taïti, et administrée par des commandants particuliers, a eu son gouvernement distrail de celui de nos établissements océaniens par le décret du 14 janvier 1860 qui l'a érigée en colonie distincte.

L'article 7 de ce décret autorise le gouverneur à faire tous règlements et arrêtés nécessaires à la marche du service administratif, à l'intérêt du bon ordre et de la sûreté de la colonie.

Conseil d'administration. - Un arrêté du 11 septembre 1860 a créé ce conseil. Il donne au gouverneur son avis sur les questions qui lui sont soumises.

Il se compose du gouverneur (président), de l'ordonnateur, du 
secrétaire colonial, des chefs des services de l'artillerie, du génie et de santé, et de deux habitants notables.

Ordonnateur. - Il est nommé par décret impérial et chargé de l'administration de la marine, des troupes, du trésor et de la justice, de la direction supérieure des travaux de toute nature, de la comptabilité des divers services. Il est sous les ordres du gouverneur.

Secrétariat colonial. - Il a été créé par arrêté du 22 janvier 1864. Il est chargé, sous les ordres du gouverneur, de l'administration intérieure de la colonie, de la police générale et de l'administration des contributions directes et indirectes, des affaires européennes et indigènes.

Le personnel administratif est ainsi composé :

$1^{\circ}$ Commissariat de la marine.

1 commissaire ordonnateur ;

1 sous-commissaire;

2 aides-commissaires;

2 commis ;

3 écrivains.

$2^{\circ}$ Secrétariat colonial.

1 secrétaire colonial;

1 commis ;

2 écrivains de marine.

Le bureau des affaires européennes comprend:

1 sous-commissaire, chef;

1 commis;

1 interprète;

1 écrivain.

Le bureau des affaires indigènes comprend :

1 officier, chef;

3 interprètes, dont 1 à Lifou (îles Loyalty).

$3^{\circ}$ Service du cadastre.

1 ingénieur colonial, chef;

2 conducteurs;

1 écrivain dessinateur.

$4^{\circ}$ Service des mines.

1 ingénieur colonial. 


\section{$5^{\circ} \dot{E}$ tat civil.}

1 secrétaire de la mairie.

$$
6^{\circ} \text { Services financiers. }
$$

1 trésorier payeur.

Nommé par décret impérial, il remplit les fonctions de receveur de l'enregistrement et des domaines, de conservateur des hypothèques, est chargé de l'encaissement des recettes et du payement des dépenses de toute nature.

\section{$7^{\circ}$ Ponts et chaussées:}

1 capitaine du génie, chef du service ;

2 gardes du génie;

1 conducteur auxiliaire;

1 écrivain dessinateur;

2 surveillants des travailleurs indigènes.

$8^{\circ}$ Police.

1 commissaire de police (ville de Port-de-France).

1 agent de police (banlieue).

$$
9^{\circ} \text { Service des ports et pilotage. }
$$

1 lieutenant de port;

1 maître de port;

1 pilote major;

2 pilotes;

6 aspirants pilotes;

1 contre-maittre charpentier ;

Matelots indigènes.

1 chef;

$10^{\circ}$ Imprimerie.

9 ouvriers compositeurs, lithographes, relieurs, etc.

En 1865, l'effectif militaire de la colonie se montait à 904 hommes, ainsi répartis :

$$
\text { État-major général. }
$$

2 officiers ayant rang de capitaine, attachés à l'état-major du gouverneur. 


\section{Artillerie (100 hommes).}

1 capitaine, commandant le détachement d'artillerie et faisant fonctions de directeur de l'artillerie;

2 gardes;

1 sous-chef ouvrier d'état;

2 seconds-maitres armuriers;

1 officier et 52 hommes formant une demi-batterie d'artillerie ;

1 officier et 40 ouvriers d'artillerie.

\section{Génie (3 hommes).}

1 eapitaine, chargé du service des ponts et chaussées.

$$
\text { Gendarmerie (30 hommes). }
$$

1 capitaine commandant;

19 gendarmes à cheval;

10 gendarmes à pied.

\section{Infanterie de marine (472 hommes).}

4 compagnies à 114 hommes et section hors rang;

1 chef de bataillon;

13 officiers.

1 capitaine ;

\section{Disciplinaires (292 hommes).}

3 lieutenants;

2 sous-lieutenants;

286 disciplinaires coloniaux.

Service de santé.

5 chirurgiens de marine.

Station navale.

Elle est placée sous les ordres du gouverneur, chef de division navale; elle comprend un aviso à vapeur et quatre goëlettes à voiles.

La Nouvelle-Calédonie est divisée en 5 circonscriptions militaires :

Celle de Port-de-France (partie sud de l'île);

Celle de l'Est, dont le chef rési de au poste de Napclécriville avec 40 hommes; 
Celle du Nord-Est, dont le chef réside au poste de Wagap avec 46 hommes;

Celle du Nord-Ouest, dont le chef réside au paste de Gatope ;

Celle des îles Loyalty, dỏnt le chef réside à Chépénéhé (île Lifou) avec 70 hommes.

Une brigade de gendarmerie occupe le poste de police à Poébo.

Le service sanitaire de la Nouvelle-Calédonie comprend 1 hôpital et 2 infirmeries. Il comptait en 1864 :

2 chirurgiens de $\mathbf{1}^{\text {re }}$ classe, l'un d'eux chef de service;

$1 \quad$ - de $2^{\mathrm{e}}$ classe;

$4 \quad$ - de $3^{\mathrm{e}}$ classe ;

1 pharmacien de $\mathbf{1}^{\mathrm{re}}$ classe.

Le nombre des malades traités en 1864 à l'hôpital de Portde-France a été de 483 . La moyenne journalière de ces malades a été de 34,3. La plupart appartenaient au personnel militaire et maritime de la colonie.

La mortalité, parmi eux, a été d'un peu plus de 1 pour 100.

Dans la population civile, évaluée à 800 âmes, la mortalité a été de 3 pour 100 . - Le nombre des naissances a été de 36 (16 garçons et 20 filles).

A l'infirmerie de Napoléonville, il a été traité, en 1864, 201 malades; à celle de Wagap, 166. Aucun malade n'est mort.

Le climat de la Nouvelle-Calédonie, déjà considéré antérieurement comme favorable aux émigrants européens, ne s'est point démenti, comme on le voit, en 1864.

\section{CHAPITRE V}

Justice. - Cultes. - Instruction publique. - Finances.

Le 17 octobre 1862, le gouverneur de la Nouvelle-Calédonie a, par un arrêté, déclaré exécutoires dans cette possession les codes métropolitains et un certain nombre de lois ou décrets en matière civile et criminelle.

Par le même arrêté, il a été institué un tribunal de paix, un tribunal de $\mathbf{1}^{\text {re }}$ instance et un conseil d'appel à Port-de-France. 
1. Tribunal de paix.

Le juge de paix connaît des actions civiles, soit personnelles, soit mobilières, et des actions commerciales:

En dernier ressort lorsque la valeur de la demande principale n'excède pas 400 francs;

En premier ressort, quand la valeur de cette demande n'excède pas 1, 000 francs.

Le juge de paix connait aussi des contraventions de police.

2. Tribunal de $\mathbf{1}^{\mathrm{re}}$ instance.

Il se compose d'un président, de deux juges et de deux suppléants, d'un procureur impérial et d'un substitut.

Les jugements sont rendus par trois juges au moins.

Le tribunal de $\mathbf{1}^{\text {re }}$ instance connaît des affaires civiles, commerciales et correctionnelles.

Tribunal civil, il juge en dernier ressort des actions civiles, réelles ou mixtes, quand la valeur de la demande principale n'excède pas 1,כ000 fr.; il juge en premier ressort, quand la demande principale excède cette somme.

Tribunal de commerce, il juge en dernier ressort quand la valeur de la demande principale n'excède pas 1,500 francs; en premier ressort, quand la demande principale est supérieure à cette somme.

Les parties ne sont point obligées, en matière civile ou commerciale, de recourir au ministère des avoués et des agréés.

Tribunal correctionnel, le tribunal de $\mathbf{1}^{\text {re }}$ instance connaît en dernier ressort de l'appel des jugements du tribunal de simple police, et en premier ressort des contraventions et délits échappant au tribunal de simple police.

On peut appeler des jugements correctionnels, quand l'emprisonnement prononcé excède 15 jours, ou quand l'amende excède 500 francs.

Le juge de paix remplit les fonctions de juge d'instruction.

\section{Conseil d'appel.}

Il se compose de cinq conseillers; l'un d'eux remplit les fonctions de président.

Le procureur impérial remplit les fonctions du ministère public. 
Le conseil connait de l'appel des jugements du tribunal de $1^{\text {re }}$ instance et du tribunal correctionnel.

Il statue, comme chambre d'accusation, sur les instructions en matière criminelle, correctionnelle et de police.

Il prononce le renvoi devant les juges compétents ou déclare qu'il n'y a pas lieu à suivre.

En matière civile et commerciale, il connait des demandes formées par les parties ou par le procureur impérial, dans l'intérêt de la loi, en annulation des jugements en dernier ressort de la justice de paix et du tribunal de $1^{\mathrm{re}}$ instance, pour incompétence ou excès de pouvoir.

En matière de police, il connaît des demandes formées par le ministère public dans l'intérêt dè la loi, et par les parties, en annulation des jugements en dernier ressort du tribunal de simple police ou du tribunal correctionnel pour incompétence, excès de pouvoir, contravention à la loi.

Il se constitue en tribunal criminel pour juger des crimes de nature à emporter peine afflictive ou infamante. Dans ce cas, il se complète par l'adjonction de quatre membres assesseurs, choisis parmi les habitants notables. - La présence de trois membres, le président compris, suffit pour qu'il y ait arrêt.

En matière civile ou commerciale, tous les arrêts du conseil d'appel peuvent être attaqués en cassation dans les cas prévus.

En matière criminelle, les jugements et arrêts ne sont pas susceptibles du recours en cassation, sauf: $1^{\circ}$ le droit du ministère public de dénoncer au gouverneur les jugements et arrêts contraires à la loi; $2^{\circ}$ le droit que réservent les art. 441 et 442 , Code instr. crim., au gouvernement et au procureur général près la Cour de cassation.

La religion des Néo-Calédoniens est assez difficile à définir. C'est un ensemble de superstitions, ridicules pour la plupart. Toutefois, on remarque que, s'ils n'ont pas l'idée d'un Dieu créateur, ils admettent une sorte de divinité, Neuengut (l'âme du monde), qui gouverne tout, qui produit tous les phénomènes qu'on ne saurait expliquer.

En outre de cette divinité, dit le P. X. Montrouzier, il est une foule de génies attachés à divers lieux et appliqués à diverses fonctions. Ainsi, il en est que l'on prie pour obtenir une pêche abondante; d'autres qui accordent le vent, la pluie, le soleil. Ceux-ci résident dans les bois, ceux-là dans les cimetières. Tous 
ont leurs prêtres, qui exploitent la crédulité du peuple ou vivent à ses dépens. Ces prêtres ou prieurs se divisent en plusieurs classes : les uns sont chargés de jeter des maléfices, d'autres de découvrir les auteurs des maléfices. Il y en a qui donnent des amulettes pour être invulnérables, réussir dans une entreprise, se rendre invisibles; d'autres enfin qui ont le don de voir et d'entretenir des génies tantôt mâles, tantôt femelles, vivant dans les bois, principalement près des sources, ayant un corps invisible aux profanes, d'une ou deux coudées de haut, volant dans les airs et portés au mal.

L'existence d'une vie future est aussi admise par les Néo-Calédoniens. Quel sera le sort des bons et quel sera celui des méchants? Ils supposent que chacun conservera après la mort la position qu'il occupait sur la terre, que les chefs resteront chefs, que les sujets resteront sujets, mais que les uns et les autres seront plus heureux qu'ils n'étaient ici-bas, mangeant des bananes mûres et se plongeant dans le plaisir des sens.

Souvent ils se croient obsédés par les âmes de leurs ancêtres; ils font alors des choses extraordinaires, grimpent sur les cocotiers, gravissent les montagnes avec une agilité extraordinaire, déploient beaucoup de force, battent quelquefois ceux qu'ils rencontrent, et ne reviennent à leur état normal que lorsqu'un prieur a mâché quelques herbes et les leur a crachées à la figure.

La conversion de ces peuples a été d'abord entreprise par les Pères Maristes : $M^{\text {gr }}$ Douarre, évêque d'Amata, les RR. PP. Viard et Rougeyron, avec deux frères de leur congrégation, débarquèrent à Balade cn décembre 1843. Après des difficultés sans nombre, manque de vivres, persécutions des indigènes, la mission de Balade fut contrainte à se réfugier à Poébo, où s'était établi le R. P. Rougeyron. La mission de Poébo ne tarda pas à être attaquée par les naturels; il fallut abandonner momentanément la Nouvelle-Calédonie. Les missionnaires se retirèrent à Sydney, puis à Annatom, île du groupe des Nouvelles-Hébrides. En 1848, deux d'entre eux, accompagnés de quatre frères, se rendirent à l'île des Pins.

$M^{\text {gr }}$ d'Amata, nommé vicaire apostolique, revint de France en septembre 1849, amenant avec lui lés RR. PP. Bernin, Forestier, Vigouroux, Anliard et un frère. Il laissa à Annatom deux pères et un frère, plaça à l'île des Pins le R. P. Goujon, et partit avec les RR. PP. Roudaire, Rougeyron, Bernin, Anliard 
et Forestier, pour visiter la côte est de la Nouvelle-Calédonie.

Ils séjournèrent quelque temps à Yenguène et à Yaté; mais bientôt l'attitude menaçante des indigènes les força de nouveau à quitter l'île. Ils se retirèrent, emmenant avec eux un certain nombre de Néo-Calédoniens convertis, et passèrent à l'île des Pins et à Sydney.

En 1850, $\mathrm{M}^{\mathrm{gr}}$ d'Amata revint à Balade avec ses missionnaires. Cette fois la mission fut plus heureuse. L'établissement de Poébo put même, comme celui de Balade, être relevé. En février 1853, un nouveau missionnaire, le R. P. Montrcuzier, arriva. Malheureusement, au mois d'avril suivant, $M^{\mathrm{gr}}$ Douarre mourut.

Il fut remplacé par le R. P. Rougeyron en qualité de provicaire. Gelui-ci resta à Poébo avec le R. P. Gagnères; le R. P. Montrouzier fut chargé de la mission de Balade, et le R. P. Forestier de celle de Tuo.

Le R. P. Vigouroux, qui n'avait pu s'établir à Yenguène, malgré l'appui du chef, se transporta dans la tribu de Tiwaka.

Telle était la situation lorsque, au mois de septembre 1853, le contre-amiral Febvrier-Despointes prit possession de la NouvelleCalédonie, et fonda un blockhaus à Balade.

En 1855, une partie de la tribu de Balade montra des intentions hostiles. Le R. P. Montrouzier, qui dirigeait la mission de ce lieu, se vit dans la nécessité de l'abandonner. Il se retira à Port-de-France, à l'instigation du gouverneur, dont il devint premier aumônier. Mais les indigènes chrétiens, restés à Balade, persécutés par les non-convertis, prièrent le R. P. Rougeyron, à Poébo, de leur chercher un asile. On obtint pour eux une concession dans les belles contrées, au sud de Port-de-France, dans la vallée de Boulari. Ils allèrent s'y établir et fonder Conception, aujourd'hui centre de la mission Néo-Galédonienne.

Trois autres stations ont été successivement établies par le provicaire apostolique : aux îles Belep, en 185ว ; à Uvea (îles Loyalty), en 18506 ; à Lifou, en 1857.

La mission Néo-Calédonienne se compose actuellement de 24 pères et de $\mathbf{1 0}$ frères de la société de Marie.

Ils sont répartis dans 17 résidences principales.

Port-de-France a un curé et un vicaire.

Le pénitencier de l'île Nou a un aumônier.

Conception est la résidence du provicaire apostolique, supérieur de la mission. 
Les autres résidences sont: Saint-Louis, près de Conception, dans la baie de Boulari ; l'île Ouen, station centrale d'où un missionnaire visite Touaourou; Yaté et l'ịle des Pins; Ouagap ou Tiwaka, d'où un missionnaire visite Amoua, Ouindou, etc.; Touo; Poébo; Arama; Bondé; Art et Poot (îles Belep); Uvea (deux stations) et Lifou, dans les îles Loyalty (deux stations).

En 1864, on comptait que, sur 10,000 chrétiens évangélisés par les missionnaires, le baptême avait été administré à 5,000 .

L'instruction est encouragée dans la colonie. Un arrêté du 15 octobre 1863 a réparti les écoles en deux classes : les écoles publiques, où l'instruction est gratuite, et les écoles privées, que des particuliers ou des associations ont fondées.

L'enseignement porte sur l'instruction morale et religieuse, la lecture, l'écriture, la langue française, le calcul, le système légal des poids et mesures.

Un comité de surveillance et d'inspection est chargé de la surveillance des écoles. Il est en permanence.

Les écoles de la colonie étaient au nombre de sept, à la fin de 1864: 3 à Port-de-France, 1 à Payta, 1 à Napoléonville, 1 à Lifou, 1 à Wagap.

Des trois écoles de Port-de-France, deux sont affectées à la jeunesse européenne, l'une pour les garçons, l'autre pour les filles. La troisième est réservée aux enfantș des indigènes.

L'école européenne des garçons, tenue par un professeur et un moniteur, avait 12 élèves en 1864. - Gelle des filles, tenue par un religieux de l'ordre de Saint-Joseph de Gluny, a eu, en 1864, une trentaine d'enfants.

L'école des jeunes indigènes comprend deux sections: dans l'une on forme des ouvriers, dans l'autre des interprètes. Une cinquantaine d'élèves fréquentaient l'école en 1864.

L'école de Payta, fondée par des colons de ce village, donne l'instruction à une douzaine d'enfants.

A Napoléonville, à Wagap et à Lifou, les écoles sont confiées à un militaire choisi dans la garnison. Une cinquantaine d'enfants ont fréquenté ces écoles en 1864.

Une autre institution d'une utilité évidente est l'orphelinat que dirigent à Port-de-France les sœurs de Saint-Joseph. On y envoie de France, jusqu'à leur établissement, les jeunes filles de l'Administration de l'Assistance publique de Paris. En septembre 1863, un premier convoi de dix jeunes filles arriva à Port-de-France; 
avant la fin de l'année, toutes étaient mariées. Surles trente élèves envoyées en février 1864, douze étaient mariées la même année et les autres occupaient divers emplois. - L'orphelinat tient aussi lieu de salle d'asile.

Les dépenses de l'État, pour assurer les différents services de la colonie, se sonl élevées, en 1865, à 1,291,612 francs, non compris celles portées au compte du service marine. Celles-ci, en 1863,

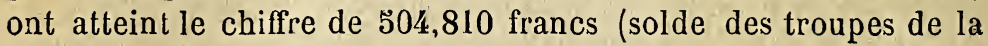
marine, frais de passage, entretien de la station locale).

\section{BUDGET DE L'ÉTAT (1865). \\ I. Personnel civil et militaire.}

Gouvernement colonial............... 16,966 fr. 67 c. Administration généra le............. 50,530 "

Justice..................... 7,400 "

Culte........................ 10,600 "

États-majors..................... 39,800 "

Gendarmerie.................... 80,183 "

Disciplinaires coloniau x............. 121,028 n

Accessoires de la solde.............. 36,000 "

Hôpitaux...................... $79,197 \quad 50$

vivres $\ldots \ldots \ldots \ldots \ldots \ldots \ldots \ldots \ldots \ldots \ldots \ldots \ldots \ldots \ldots \ldots \ldots \ldots \ldots \ldots, 356,514 \quad 40$

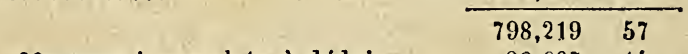

$30^{\circ}$ pour incomplets à déduire.... $\frac{26,607 \quad 14}{-771,612 \text { fr. }}$

Total du personnel............ $771,612 \mathrm{fr} .43 \mathrm{c}$.

II. Matériel civil et militaire.

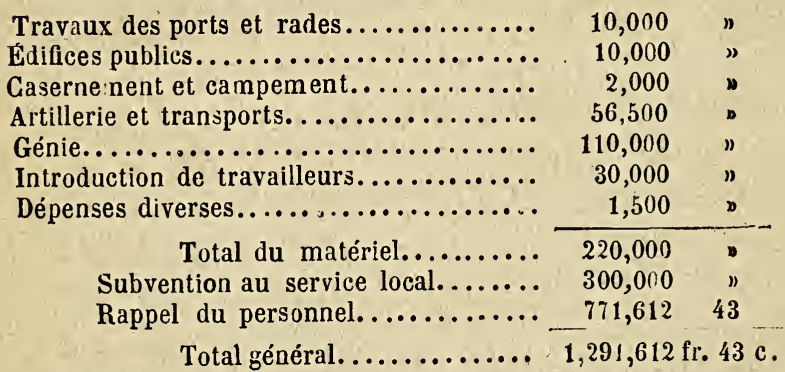

Voici, maintenant, les divers éléments du budget local.

$$
\text { BUDGET LOGAL (1865). }
$$

1. Recettes.

Contributions foncières............. $7,424 \mathrm{fr} .82 \mathrm{c}$.

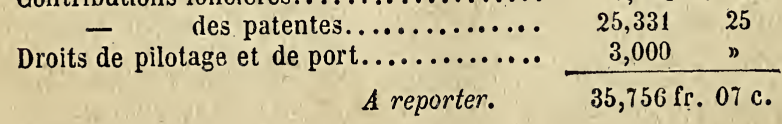


Report.

Droits de greffe.....................

Locations de chalands.................

Vente de terrains domaniaux...........

Locations de terrains.................

Rentes foncières.....................

Coupe et cession de bois................

Produits de la ferme modele.............

Droits d'enregistrement et d'hypothèques...

Droits de timbre.

Taxes des lettres...................

Produits de l'imprimerie...............

Bons de $50 \mathrm{fr}$. payables en terres..........

Subvention de la métropole..............

Subvention pour la construction d'un phare.

Recettes diverses....................

Produits du four à chaux..............

- de la briqueterie..............

Total des recettes.
35,756 fr. $07 \mathrm{c}$.

2,500

900

28,000

3,200

6,000

5,350

5,000

10,500

1,500

4,800

3,600

4,500

300,000

100,000

6,650

12,000

10,000 (

540,456 fr. $07 \mathrm{c}$.

\section{Dépenses.}

Ghapitre premier. - Personnel.

Direction de l'intérieur.

Services financiers...................

Instruction publique.................

Ponts et chaussées..................

Police............................

Pilotage.........................

Accessoires de la sol le................

Administration générale..............

Mission scientifique .................

Agents divers.....................

$50^{\mathrm{e}}$ à déduire pour incomplet. ........

Total.

Hôpitaux ......................

Vivres........................

Total.

Chaprtra II. - Matériel.

Approvisionnement.................

Briqueterie.......................

Four à chaux....................

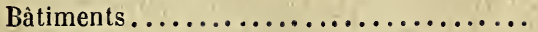

Routes, ponts et canaux...............

Voirie..........................

Frais généraux...................

Service du cadastre..................

Service du port et du pilotage...........

Approvisionnements divers..............

Ameublement.....................

$A$ reporter.

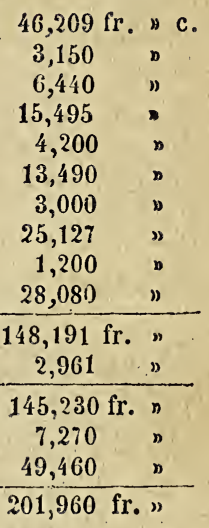

20,000 fr. "c. 14,000 D

$11,000 \quad$

24,008 "

12,000 D

45,000 口

18,000 "

3,000 "

5,000 口

7,000 口

6,800

165,808 fr. " c. 
Célébration des fètes publiques......... 6,000 - "

Dépenses de la ferme-modèle et du jardin d'acclimatation................... $12,300 \quad$,

Dépenses diverses et imprévues.......... $54,392 \quad$ " Total...................

Chapitre III. - Dépenses extraordinaires.

Dépenses du phare................. 100,000 fr. "

Les dépenses réunies donnent un total de 540,460 francs.

Les recettes, faibles encore, ont cependant suivi, depuis $\mathbf{1 8 5 9}$, une progression sensible.

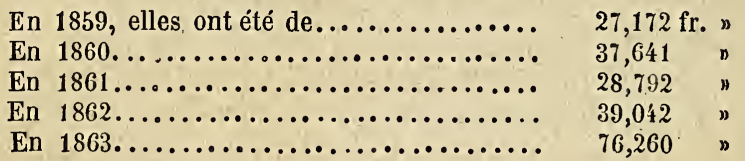

Enfin, pour 186:, elles ont été, comme on l'a vu, non compris la subvention de l'État, de 140,456 fr. $07 \mathrm{c}$.

\section{CHAPITRE VI}

Agriculture. - Igname. - Patate douce. - Taro. - Canne à sucre. - Banane. - Coco. - Coton. - Tabac. - Café. - Céréales. - Oléagineuses. - Bestiaux. - Concessions. - Marchés. - Ferme-modèle. - Société agricole de Yaté. Terres domaniales. - Impôt foncier.

La fertilité du sol Néo-Calédonien est incontestable. Mais, comme pour les terres vierges, sa mise en culture exige un travail immense. Les indigènes, peu laborieux, cultivent par des procédés tout primitifs; pendant que les hommes remuent la terre avec des pieux effilés, les femmes écrasent les mottes avec des masses en bois.

Les principales productions végétales dont les Néo-Calédoniens tirent parti pour leur nourriture, sont l'igname, le taro, la patate douce, la canne à sucre, la banane, la noix de coco.

L'igname est naturelle au sol. On en cultive les diverses espèces, surtout celle du Dioscorea alata avec le plus grand soin. G'est le blé des indigènes. Elle exige un sol meuble et profond.

On plante en juillet et août.

Les tubercules sont arrachés au bout de sept à huit mois, 
quand les feuilles sont complétement flétries. On les mange cuits au four, ou grillés sur les charbons.

Le taro, qui vient après l'igname, est le nom sous lequel on désigne les rhizomes féculentś et alimentaires de plusieurs aroïdées, entre autres ceux des Colocasia esculenta et des Eucolocasia esculenta Arum.

Il veut une terre basse et humide ou le flanc des montagnes facilement arrosables.

L'accroissement complet des plantes n'a lieu qu'à la fin de la seconde année.

Inférieur à l'igname comme rendement, le taro lui est supérieur en qualité. L'igname cuite peut se conserver plusieurs mois, le taro huit ou dix jours; mais il pousse et mûrit toute l'année.

La patate douce entre aujourd'hui pour une part notable dans la nourriture des indigènes. Sa culture est facile, ses produits sont abondants et bons. Les femmes emploient son suc laiteux pour le tatouage. Les Européens en mangent les feuilles comme celles d'épinard.

La canne à sucre est abondante et vient fort bien, malgré la mauvaise culture des indigènes. Ils l'utilisent comme plante alimentaire; presque toujours ils ont un morceau de canne à la main pour se rafraîchir.

Les plants des indigènes mettent environ dix-huit mois pour atteindre tout leur développement; on les coupe dès le neuvième mois. Quelques colons ont de magnifiques plantations aux environs de Port-de-France.

La canne à sucre de la Nouvelle-Calédonie pourra rivaliser avec les meilleures espèces des autres pays. .

La banane, crue ou cuite, entre aussi pour beaucoup dans la nourriture des indigènes. On en cultive six espèces.

Le cocotier n'a pas, à la Nouvelle-Galédonie, la végétation luxuriante de celui des îles rapprochées de la ligne. La récolte d'un arbre est par an de 70 à 80 cocos. Le cocotier est vigoureux au nord, mais beaucoup moins au sud; sur la côte nord-est, il est beaucoup plus abondant que sur la côte nord-ouest. L'île en possède une douzaine de variétés.

Le coton est aussi cultivé à la Nouvelle-Calédonie. On y trouve deux variétés. L'une d'elles semble être indigène, l'autre a été importée. 
Des essais tentés par quelques colons, il est résulté :

Qu'un hectare planté en coton longue-soie a produit $1,460 \mathrm{ki}$ logrammes de coton brut, et 267 kilogrammes de coton net, d'une valeur de 2,136 francs;

Qu'une culture de coton jumelle a donné à l'hectare 1,676 kilogrammes de coton brut, $\mathbf{3 7 5}$ kilogrammes de coton net d'une valeur de 937 francs.

La culture du tabac est très-active et très-étendue. La qualité rivalise avec celle des tabacs de la Réunion. Tout le monde fume dans la Nonvelle-Calédonie, femmes, hommes, enfants même.

La circonscription de Wagap, au commencement de 1865, avait 30,000 pieds qui, en deux coupes, pouvaient fournir 2,000 kilogrammes de tabac.

L'hectare peut contenir $\mathbf{1 0 , 0 0 0}$ pieds de tabac et rendre $\mathbf{7 5 0}$ kilogrammes.

La consommation annuelle dans l'île n'est pas inférieure, croiton, à 27,000 kilogrammes de tabac.

Le café a été introduit par les colons d'Europe. A Conception, chez les RR. PP. Maristes, il y a aujourd'hui 2,000 plants de café. On s'occupe activement de sa culture à la ferme-modèle.

Les céréales européennes, les plantes légumineuses et fourragères, ont parfaitement réussi. On voit sur plusieurs points de superbes jardins potagers (île Nou, Conception, Lifou).

La vigne donne deux récoltes (janvier et août).

Le mûrier est toujours vert.

Parmi les oléagineux, qui sont assez nombreux, le ricin et le bancoul se distinguent par l'excellente huile qu'ils donnent.

L'élevage des troupeaux n'est pas en faveur auprès des indigènes. Mais ils prospéreraient très-certainement dans les fertiles pâturages de l'île. Les essais des missionnaires et des colons ont complétement réussi : bêtes à cornes, moutons, chevaux, ânes, prospèrent à merveille. A l'exposition de Londres (1862), des laines envoyées par les missionnaires ont été mises sur le même rang que celles d'Australie.

Nos volatiles de basse-cour sont très-bien acclimatés.

Le cochon seul est prisé par les indigènes. On laisse cet animal à peu près complétement libre; aussi arrive-t-il souvent qu'il retourne à l'état sauvage.

Pour donner une idée de l'état des cultures à la Nouvelle-Calé-donie, disent les Notices du ministère de la marine et des colo- 
nies, voici quelques renseignements sur les principales exploitations des environs de Port-de-France.

Sur la concession des RR. PP. Maristes, on comptait, au commencement de 1864, trois cents indigènes définitivement fixés dans deux villages : Conception et Saint-Louis. Les missionnaires leur enseignent eux-mèmes à conduire la charrue et à labourer. Les adultes vivent en famille, cultivent pour leur propre compte les terres qui leur ont été distribuées et dont ils sont les fermiers, à titre gratuit jusqu'à présent. En outre, ils font avec la ville un commerce actif de légumes européens, de lait, beurre, œufs, volailles, poissons, etc. Ce commerce, qui leur plait beaucoup, les met en contact avec les Européens, dont l'exemple, au point de vue du travail, leur est très-utile; les ressources que ce petit commerce leur procure, leur permettent d'acheter des vêtements, des outils et d'autres objets nécessaires à leur bien-être.

Les jeunes gens et les enfants vivent dans un établissement qui leur est spécialement destiné, à Saint-Louis, et composé d'une école primaire, d'ateliers divers et d'une ferme d'environ 25 hectares, dont tous les travaux sont exécutés par eux d'après un bon système de culture européenne. Les eaux d'une belle rivière qui coule à une distance de 2 kilomètres ont été amenées sur l'établissement et font marcher deux scies, un moulin à farine, un tour, etc., et permettent d'établir un moulin à cannes aussitôt que les cultures seront assez considérables pour qu'on puisse en tirer parti.

Les missionnaires entretiennent, en outre, dans les belles prairies de leur concession des troupeaux considérables de bœufs, de vaches, de moutons et de porcs.

L'établissement de M. Joubert appelle aussi l'attention. En 1858, M. Joubert obtint une concession de 4,400 hectares, s'étendant du Pont-des-Français jusqu'à la rivière de la Dumbéa. Ce colon, qui habitait Sydney depuis de longues années avait amené avec lui une vingtaine de familles. Aujourd'hui la concession est divisée en deux parties, régies chacune par un des fils du propriétaire. On compte déjà sur l'une de ces deux exploita tions, 1,700 têtes de bétail. La viande de boucherie pour les rationnaires est fournie, par traité avec l'administration, dans cette exploitation, à raison de 1 franc le kilogramme au lieu de 2 francs payés jusque-là. Sur la seconde exploitation, on cultive la canne à sucre et l'on vient d'y monter le premier moulin à cannes de 
la colonie. L'inauguration en a eu lieu en septembre 1865, et le vesou obtenu a fourni du sucre de bonne qualité.

La concession de M. Paddon, à Payta, port Laguerre, n'est pas moins digne d'intérêt. En même temps que M. Joubert, il avait obtenu 4,400 hectares, sur lesquels il amena une yingtaine de familles anglaises et allemandes. Dix familles s'y sont définitivement fixées et ont reçu 20 hectares de terre cultivable, chacune : elles jouissent actuellement d'une grande aisance. Le reste des terres (4,000 hectares environ) est exclusivement employé en pacages et nourrit un troupeau de 500 têtes de gros bétail appartenant aux héritiers de M. Paddon.

La concession de M. Adam ( 500 hectares), aujourd'hui à son petit-fils, M. Duboisé, de la Réunion, paraît devoir posséder trèsprochainement de fort belles cultures. On y remarque des travailleurs indiens.

La société agricole de Yaté date du mois de janvier 1864. Elle se compose de vingt colons français. Il lui a été fait une concession de 300 hectares (en vertu de l'article 8 de l'arrêté du 5 octobre 1862, qui accorde un bon de 150 francs payable en terres, à tout immigrant exerçant une profession utile à la colonie). La plaine de Yaté, située sur la côte sud-est, au pied des montagnes de Coronation, est un territoire très-fertile.

Dès 1862, une ferme-modèle était créée à 10 kilomètres de Port-de-France. Placée sous la direction d'un ingénieur agricole, elle a pour but de former une pépinière d'arbres, d'arbustes et de plantes dont l'acclimatation peut être utile à la colonie. On y remarque des légumes d'Europe, de la volaille, des lapins, des porcs, des bœufs, des vaches, un petit troupeau de moutons à poil ras et à longue queue, importés du Cap.

On a établi deux marchés à Port-de-France; l'un est pour le poisson, l'autre pour les-légumes, la volaille, les fruits, etc. Voici quelle était, en septembre 1865, la valeur des diverses denrées.

Carottes, 40 c. le kil.; navets, 25 c.

Radis, 5̆5 c.; choux, $80 \mathrm{c}$.

Salade, 30 c.; oignons et ciboules, 45 c.

Poireaux, $1 \mathrm{fr} .50 \mathrm{c}$; ; aubergines, $75 \mathrm{c}$ :

Pommes de terre, 60 c.; beurre, 5 à 8 fr. le kil.

Lait, 50 c.; fromage, 50 c. l'un;

OEufs, 2 fr. 50 c. la douzaine. 
L'arrêté du 5 octobre 1862 règle les aliénations de terres domaniales. Il y a quatre modes d'aliénation : ventes à prix fixe, ventes aux enchères publiques, concessions gratuites, ventes ou locations par contrats de gré à gré.

Les militaires ou marins congédiés qui désirent s'établir dans la colonie peuvent obtenir des concessions gratuites représentées par des bons de 150 fr. payables en terres. Les immigrants français des deux sexes, venus sans engagement, mais capables d'exercer une profession utile, peuvent participer au même avantage.

Des concessions gratuites représentées par un bon de terre d'une valeur de 500 fr. sont également accordées aux officiers civils et militaires ou assimilés, en retraite, qui veulent se fixer dans la colonie.

L'impôt foncier est de 1 pour 100 par an sur la valeur des propriétés rurales et de 2 pour 100 sur celle des propriétés urbaines.

On prend pour base de l'évaluation le prix moyen de l'hectare dans le même périmètre (pour la propriété rurale) et le prix moyen de l'are (pour la propriété urbaine).

Une décision du gouverneur fixe, chaque année, le prix moyen.

\section{GHAPITRE VII}

Industrie. - Peche. - Constructions navales. - Mines. - Bois. - Commerce. - Importations et exportations (de 1861 à 1864). - Navigation. - Service postal.

Les Néo-Calédoniens ne se livrent pas à de nombreuses industries. La pêche, la fabrication des filets, des frondes, de quelques armes en bois et en pierre, d'étoffes et de poteries grossières, sont à peu près les seules qu'ils connaissent.

Ce ne sont pas les hommes exclusivement qui s'occupent de pêche; les femmes s'y adonn ent aussi. La peche en pirogue, en dedans de la ceinture des récifs de l'île, est le partage des hommes; la pêche sur le rivage et les récifs à marée basse, est celui des femmes.

Les pirogues, disent les Notices, consistent en un tronc d'arbre creusé et effilé à ses deux extrémités, de 4 à 7 mètres de lon- 
gueur, et muni d'un balancier qui maintient l'équilibre de la fragile nacelle; c'est une espèce de châssis formé de deux perches liées par une de leurs extrémités à l'un des bordages et unies par l'autre extrémité à un flotteur longitudinal. Les plus grandes pirogues sont doubles, c'est-à-dire que deux nacelles sont accouplées et maintenues par des traverses à une distance de 50 centim. à 1 mètre. Il y a des pirogues pontées d'un bout à l'autre et munies d'un ou deux mâts, avec voile triangulaire en natte de jonc.

On rencontre partout dans l'île des bois propres aux constructions navales, entre autres le Niaouli, qui fournit des bois courbes excellents. Plusieurs bateaux et goëlettes ont déjà été construits dans la colonie.

Les eaux de la Nouvelle-Calédonie possèdent peu de baleines, mais elles donnent des épaulards, sorte de cétacés dont les missionnaires de l'île des Pins ont tiré de l'huile, des huîtres perliẻres de petite dimension, des nautiles aux belles cloisons nacrées, deux espèces de tortues (ox-bill-turtle et green turtle), la biche de mer ou trépang (Holothuria edulis), qui constitue la branche de commerce la plus importante.

On évalue à 100,000 fr. par an le chiffre des exportations de la biche de mer. Ginq variétés sont admises comme commerciales, savoir :

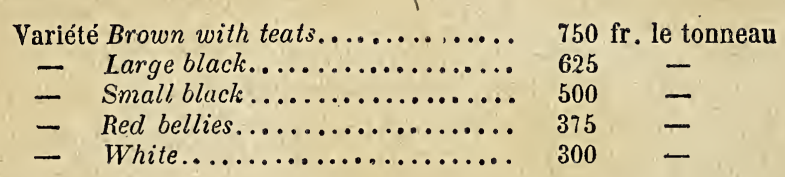

On les prépare en les faisant cuire 20 minutes dans leur eau; on les fend ensuite de la tête à l'anus et on procède à la dessiccation, laquelle doit être complète, si l'on veut que la cargaison arrive à destination en bon état. En Chine, la première qualité se vend jusqu'à 2,250 et 2,500 fr.

Parmi les richesses minérales de l'île, on doit citer : la pierre à bâtir qui se trouve partout, la chaux hydratée, le spath, les coraux qui donnent une chaux excellente; de nombreux gisements de schistes ardoisiers; du fer en abondance; de l'or, des argiles fines (kaolin, terre anglaise, etc.); des schistes pyriteux fort riches en sulfate d'alumine.

La houille paraît devoir s'y rencontrer aussi. Jusqu'à présent, 
toutefois, on n'a constaté que des affleurements. En 186\%, un ingénieur, M. Garnier, a adressé sur la question au gouvernement de la colonie un rapport où nous lisonş que le combustible extrait à Karigou (dans la vallée de la Dumbéa) doit être rangé dans la classe des anthracites, par son aspect d'un brillant métallique, sa dureté, sa pesanteur spécifique, la difficulté qu'on a pour l'enflammer, sa combustion accompagnée d'une légère flamme, quoique développant beaucoup de chaleur. Or, dit ce rapport, la houille que nous recevons ici de la Nouvelle-Hollande est trèsgrasse. Elle a même en excès ce qui manque à notre combustible; aussi reproche-t-on généralement aux charbons australiens de brûler trop vite, ce qui revient à dire que le pouvoir calorifique est faible, conséquence de la grande quantité de matières bitumineuses qu'ils contiennent, et dont la grande partie se volatilise pendant la combustion, produisant cette fumée abondante et noire, qui se dégage des cheminées de nos bateaux à vapeur. Le mélange de ces deux combustibles doit nécessairement en former un troisième donnant de meilleurs résultats que ceux produits par chacun d'eux employé isolément.

Jusqu'ici, le charbon de Karigou n'a pas été d'une qualité très-homogène; dans le milieu d'une couche, il est vitreux et d'une pureté presque absolue; mais à mesure que l'on approche des schistes auxquels se termine le banc, le combustible s'en imprègne peu à peu lui-même et finit insensiblement par se fondre dans ces roches. - De ces faits il résulterait que la formation carbonique a eu un grand développement dans cette contrée, dit en concluant M. Garnier.

L'or, jusqu'à ce jour, n'a point été trouvé en quantité suffisante pour rémunérer le travail de ceux qui le recherchent. Mais son existence est incontestable. Deux échantillons de gisements aurifères, adressés à l'Exposition permanente des colonies, à Paris, ont été analysés et ont donné les résultats suivants :

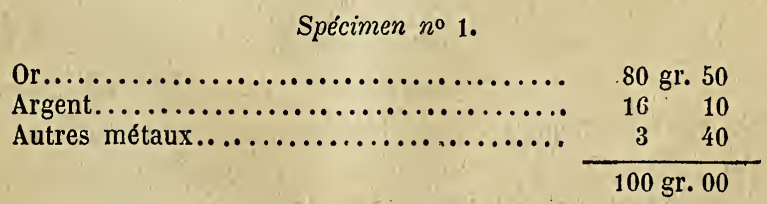




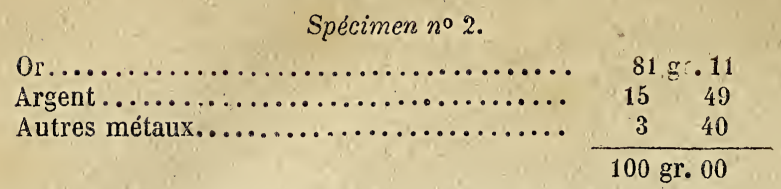

D'après leur titre, la valeur commerciale de ces deux spécimens serait pour le kilogramme :

Spécimen no 1.

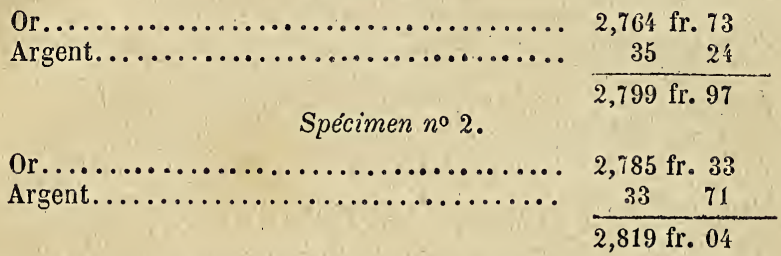

Les richesses forestières de l'île sont considérables; mais les arbres de grande dimension sont assez rares. Outre le Niaouli, dont on a déjà parlé, on remarque : le Bancoulier (Aleurites tribola) au bois poreux et très-léger; l'Acacia spirorbis, au bois très-dur et facile à travailler; le Blackburnia primata au bois coloré et d'un travail difficile; le bois de fer (Casuarina nodiflora); le bois de rose (Thespesia populnea), très-recherché et très-rare; quelques faibles taillis de Sandal.

Le commerce néo-caléd onien est libre ; aucun droit de douane, droits de pilotage seulement.

L'exportation embrasse les objets suivants :

Huile de coco, peaux de bœuf et de mouton, trépangs, écailles de tortue, laines, bois de Sandal.

L'importation comprend :

Bœufs, moutons, chevaux, farines, biscuits, sucre, café, haricots, charbon de terre.

G'est d'Australie que viennent la plupart des objets importés.

Pendant les quatre années 1861 à 1864, l'importation a présenté les résultats suivants :

\section{Importation.}

\section{1}

Denrées et marchandises françaises importées de l'étranger par navires étrangers....... 1,257,000 fr.

Produit des îles.................... 11,500

Total.................... 
1862

Denrées et marchandises françaises importées de l'étranger par navires français.... par navires étrangers.............

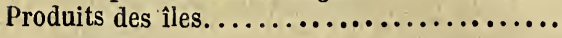
Total $148,930 \mathrm{fr}$. $1,079,450$ 250

$1,228,630 \mathrm{fr}$.

\section{3}

Denrées et marchandises importées de France par navires français..................

Denrées et marchandises françaises importées de l'étranger par navires français...

- par navires étrangers.............

Produit des îles.......................

Total

$$
50,000 \mathrm{fr} \text {. }
$$

171,700

$1,262,300$

"

$1,484,000 \mathrm{fr}$.

\section{4}

Denrées et marchandises importées de France par navires français..................

Denrées et marchandises importées de l'étranger par navires français...........

- par navires étrangers..............

Total ....................... $100,000 \mathrm{fr}$.

$$
\begin{array}{r}
70,000 \\
1,435,000 \\
\hline 1,605,000 \mathrm{fr}
\end{array}
$$

\section{Exportation.}

\section{1}

Denrées et marchandises françaises ou étrangères provenant de l'importation........... Produits de la colonie et des îles exportés pour l'étranger...........................

Total........................

\section{2}

Produits de la colonie et des îles, exportés pour l'étranger.

$55,443 \mathrm{fr}$.

\section{3}

Produits de la colonie et des îles, exportés pour l'étranger.

$$
\begin{aligned}
& 3,500 \mathrm{fr} . \\
& 43,450 \\
& \hline 46,950 \mathrm{fr} .
\end{aligned}
$$
$46,112 \mathrm{fr}$.

\section{4 .}

Produits de la colonie et des îles, exportés pour

l'étranger..........................

En résumé, le total des importations et des exportations a été comme suit :

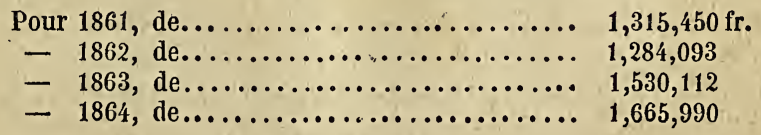


Les marchandises et denrées apportées pour le compte de l'Administration par les bâtiments de guerre et de commerce ne figurent pas dans le tableau ci-dessus.

Le mouvement maritime pendant les quatre années 1861-1864 a étẻ :

\section{Entrées.}

\section{1}

Nombre des navires français.................. $\quad 2$

Tonneaux.............................. 745

Nombre des navires étrangers................ 32

Tonneaux ........................... 5,269

Soit, ensemble, 34 navires et 6,014 tonneaux.

\section{2}

Navires français.......................... 3

Tonneaux............................. 990

Navires étrangers........................... $\quad 16$

Tonneaux $\ldots \ldots \ldots \ldots \ldots \ldots \ldots \ldots \ldots \ldots \ldots \ldots \ldots, \quad 2,818$

En tout, 19 navires et 3,808 tonneaux.

1863

Navires français...........................

Tonneaux ...........................

Navires étrangers.....................

Tonneaux............................ 3,117

En tout, 27 navires et 6,224 tonneaux.

1864

Navires français........................... 4

Tonneaux............................. 2,063

Navires étrangers........................ 23

Tonneaux............................ 6,137

En tout, 27 navires, 8,200 tonneaux.

Sorties.

1861

Navires étrangers.........................

Tonneaux............................ 745

Navires étrangers $\ldots \ldots \ldots \ldots \ldots \ldots \ldots \ldots \ldots \ldots \ldots \ldots, \quad 29$

Tonneaux ......................... 4,953

Total : 31 navires; 5,698 tonneaux.

1862

Navires français.......................... 3

Tonneaux............................ 990 
Navires étrangers........................... $\quad 19$

Tonneaux............................. 3,337

Total : 22 navires; 4,367 tonneaux.

1863

Navires français............................ 7

Tonneaux................................ 2,716

Navires étrangers........................... $\quad 17$

Tonneaux $\ldots \ldots \ldots \ldots \ldots \ldots \ldots \ldots \ldots \ldots \ldots \ldots \ldots \ldots \ldots \ldots \ldots \ldots \ldots \ldots \ldots \ldots \ldots \ldots, 2,527$

Total : 24 navires; 5,243 tonneaux.

1864

Navires français.......................... $\quad 7$

Tonneaux..................................

Navires étrangers.......................... $\quad 24$

Tonneaux............................ 6,181

Total : 24 navires; 8,155 tonneaux.

Le commerce d'échange (navigation de cabotage) entre Portde-France et les côtes de l'île, pendant lesdites années 1861 1864, a donné les résultats suivants :

\section{1}

Valeur des produits importés à Port-de-France...... $\quad 71,100$ fr. Valeur des produits exportés de Port-de-France...... 64,465

Total des valeurs mises en circulation........

\section{2}

Valeur des produits importés à Port-de-France...... $66,395 \mathrm{fr}$.

$$
\text { - } \quad-\text { exportés de - } \quad 105,587
$$

Total des valeurs mises en circulation....... $\overline{171,982}$

\section{3}

Valeur des produits importés à Port-de-France...... $112,300 \mathrm{fr}$.

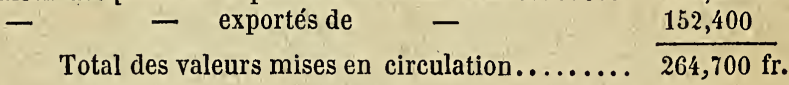

\section{4}

Valeur des produits importés à Port-de-France..... 128,235 fr.

$-\quad-$ exportés de $\quad-\quad$ Total des valeurs mises en circulation......... $\frac{146,630}{274,865 \mathrm{fr}}$.

Le service postal est ainsi réglé.

Tous les mois, la Nouvelle-Calédonie peut communiquer avec la France, par l'intermédiaire des paquebots-poste anglais de la compagnie Péninsulaire et Orientale qui desservent l'Australie.

Le 28 de chaque mois, départs de Marseille.

Le 14 du $2^{\mathrm{e}}$ mois qui suit le départ, arrivée à Sydney. 
Des bâtiments de la station locale assurent les relations entre Sydney et Port-de-France.

Prix du Passage (service anglais).

Cabine commune............ 120 liv. st. (3,000 fr.)

Cabine réservée.............. $300-(7,500$ fr. $)$

On paye, en outre, le prix du transit en chemin de fer, entre Alexandrie et Suez, savoir :

$1^{\text {re }}$ classe $: 175$ fr.

$2^{\mathrm{e}}$ classe : 87.

Tarif des lettres, etc. :

Lettres affranchies, $\operatorname{par} 10 \mathrm{gr} . \ldots \ldots \ldots \ldots \ldots . . .6 \mathrm{fr} .70 \mathrm{c}$.

- non affranchies, par $10 \mathrm{gr} . \ldots \ldots \ldots \ldots \ldots$...... 0 80

- chargées......................... 140

Échantillons et imprimés, par $40 \mathrm{gr} . \ldots \ldots \ldots \ldots . . .112$

Papiers de commerce et d'affaires, par $200 \mathrm{gr} . . \quad 0 \quad 0 \quad 60$

En 1862, le bureau de Port-de-France a expédié ou reçu 10,844 lettres.

En 1863, il en a expédié ou reçu 13,112.

En 1864, le nombre des lettres expédiées ou reçues (bureau de Port-de-France) n'a pas été inférieur à 17,108.

Les navires du commerce, qui doublent le cap de BonneEspérance, mettent en moyenne 120 jours de France à la Nouvelle-Calédonie, et 150 jours de la colonie en France. Prix du passage : 2,000 fr. (en moyenne) pour l'aller; 2,500 pour le retour.

Par la voie de ces navires les lettres qu'on expédie payent affranchies, $3 \dot{u}$ cent. par 10 gr., et non affranchies, 40 cent.

On peut affranchir les correspondances expédiées de la colonie avec les timbres-poste spéciaux aux possessions françaises d'outre-mer. Ces timbres sont de 1 cent., כ̋ cent., 10, 20,40 et 80 centimes.

Les militaires et marins en garnison, les transportés qui se trouvent dans les établissements pénitentiaires, peuvent seuls recevoir des mandats sur la poste adressés de France. 


\section{APPENDIGE}

\section{EXPOSITION DE 1867}

Produits des colonies rarangaises.

\section{A L GÉ R I E}

Nous ferons, à propos de l'Algérie, l'observation que nous faisons plus loin pour les colonies françaises : nous avons tâché de ne point répéter ce qui déjà avait été dit dans les pages qui lui ont été spécialement consacrées au corps de l'ouvrage. Aussi ne doit-on s'attendre à trouver ici que les documents qui nous complètent, et non tous les documents fournis par l'Exposition. Le lecteur qui désirera tous ces documents ensemple devra se reporter au Catalogue spécial à l'Algérie, publié par MM. Challamel aîné et Dentu.

I. Beaux-arts.

Peinture. - Les trois toiles de mademoiselle Nathalie Courvoisier, celle de M. Abraham Moatty, ont représenté la peinture algérienne à l'Exposition. Ces toiles sont fort loin d'être sans mérite.

Sculpture et gravure sur médailles. - Deux bustes en plâtre de M. L. G. Fulconis.

Dessins et modèles d'architecture. - Nous mentionnerons seulement : le modèle en plâtre du tombeau de Syphax, connu sous le nom de Medraçen; ce modèle, exécuté sous la direction de M. le général Périgot, commandantla province de Constantine, est 
dû à M. Bauchette, garde principal du génie; - le modèle en plâtre du monumentsépulcral des rois de Mauritanie, connu sous le nom de Tombeau de la Chrétienre, exécuté par M. Latour fils sous la direction de MM. Berbrugger et de Mac-Carthy; - le plan et projet d'une ferme en Algérie, par M. G. Leroux; - les vues d'Alger, d'Oran et de Constantine, par le Service des ponts et chaussées, etc.

\section{Produits d'imprimerie et de librairie.}

Toutes les villes importantes d'Algérie ont leurs imprimeries; on y édite des ouvrages, soit en caractères français, soit en caractères arabes.

Les bibliothèques publiques, quelques bibliothèques particulières possèdent des manuscrits arabes que distinguent leur ancienneté, leur bơnne conservation, leur belle exécution calligraphique. La bibliothèque d'Alger contient environ 20,000 manuscrits traitant de la plupart des connaissances humaines, ou plutôt arabes.

Le nombre des journaux est considérable. Ce sont:

Le Moniteur de l'Algérie, le Mobacher (arabe-français), l'Akhbar, le Courrier de l’Algérie, - à Alger; - le Tell, la Mitidja, -à Blidah (province d'Alger).

Le Courrier d'Oran, l'Écho d’Oran, - à Oran ; - le Courrier de Mostaganem;- le Courrier de Tlemcen (province d'Oran).

L'Africain, l'Indépendant, - à Constantine ; - la Seybouse, à Bône; - le Zéramna, le Messager algérien, - à Philippeville; - le Commerce algérien, - à Sétif (province de Constantine).

Les ouvrages écrits en Algérie, soit en arabe, soit en français, qui ont figuré à l'Exposition, ont été assez nombreux. La plupart étaient relatifs à l'instruction des Arabes, à l'agriculture, etc.

\section{Instruments de musique.}

Le matériel instrumental des Arabes n'est pas très-important. On répartit en trois classes leurs instruments : musique de ville, musique de guerre, musique de la tente.

La première classe comprend : la Kouitra, espèce de mandoline à 8 cordes; la Kamendja, violon à 4 cordes; le Rebeb, violoncelle à $\mathbf{2}$ cordes; le Kanoun, sorte de harpe horizontale, l'antique psaltérion; le Thar, tambour de basque; la Derbouka, 
tambour formé d'une poterie recouverte d'un parchemin; le Djouak, flûte en roseau.

La seconde classe comprend: la Kaïtra, hautbois; le Teboul, grosse caisse; les Naghats, petits tambours plats qu'on frappe avec une baguette; les Nararats, cymbales.

La troisième classe est la plus pauvre; elle comprend: la Guesba, grosse flûte en roseau, et le Bendir, gros tambour de basque.

Tous ces instruments, sauf les tambours et la Guesba, sont fabriqués par les indigènes des villes.

IV. Matériel de l'enseignement des sciences.

Plusieurs herbiers ont été envoyés à l'Exposition; celui de M. Durando (4 plantes), ceux du jardin d'acclimatation du Hamma d'Alger (344 espèces de plantes exotiques cultivées au jardin), de M. Pottier (100 plantes médicinales), etc., ont particulièrement attiré l'attention.

Les végétaux cultivés dans le jardin d'acclimatation du Hamma sont représentés par 166 familles, 1,172 genres, 4,334 espèces, et 3,879 variétés qui n'existaient pas dans le pays; ils y ont été introduits du dehors depuis la conquête.

A la fin dé 1866, le jardin d'acclimatation avait livré 1,300,000 pieds d'arbres, 500,000 végétaux herbacés, et 35,000 kilogr. de graines diverses, bulbes, tubercules, etc., représentant une valeur de 1,938,811 fr.

\section{Cartes et appareils de géographie.}

Le dépôt de la guerre a publié, d'après les travaux des officiers d'état-major, les cartes suivantes :

Carte générale de l'Algérie;

L'Afrique sous la domination romaine;

Provinces d'Alger, d'Oran et de Constantine ;

La Grande-Kabylie;

Les Oasis algériennes;

Le Sahra algérien ;

Le Sahra oriental ;

La partie centrale du Sahra, indiquant les relations du Soudan avec les possessions françaises de l'Algérie et du Sénégal ; etc., etc. 


\section{Meubles de luxe.}

Les ouvriers européens établis en Algérie et les fabricants français fournissent le mobilier des Européens. - L'ameublement des indigènes se compose de nattes, tapis, matelas, coussins servant pour le coucher; de tables-basses (tefou ou midi, suivant la forme), et de coffres (sendouk) en bois de thuya, de pin ou de noyer. Ces coffres, le plus souvent ouvragés, incrustés, peints ou ornés de clous de cuivre, renferment tous les objets précieux du ménage; linge, bijouterie, armes, vêtements, etc.; leur dimension varie; ils ont au moins un mètre cube. Un coffre ancien indigène, style mosaïque, exposé par M. Bernard Dennery, est estimé $3,000 \mathrm{fr}$.

Les objets en bois, en marbre et en onyx d’Algérie, exposés par MM. Boutung, Mazaroz-Ribaillé et Cie, A. Donnadieu, de Paris, et G. Coulhon, d'Alger, ont montré tout le parti qu'on pouvait tirer de ces produits pour l'ameublement.

\section{Ouvrages de tapissier et de décorateur.}

Ces sortes d'ouvrages sont fort peu connus des Arabes. L'ameublement des riches est peu compliqué; celui des Arabes de classe inférieure l'est moins encore. Il se réduit à des nattes (hacera) en palmier nain (docem) ou en alfa, à des tapis grossiers sur lesquels on couche la nuit, à des tellis, des rehals et des oucadas, espèces de sacs qu'on emploie successivement pour renfermer le linge et les objets précieux, et comme traversins. Les indigènes se servent aussi, pour remplacer la couverture et le drap de lit, d'une sorte de haïck en laine (hambel et haouli-boutouil) dont les dimensions sont variables, comme les dispositions et les couleurs. Tous ces objets sont fabriqués sous la tente et par la main des femmes. Un métier droit, composé de quatre perches et d'un peigne en fer à cinq dents, forme tout le matériel de l'ouvrière. - Depuis quelques années, l'industrie s'est emparée d'une plante, qui avait été jusque-là le fléau de l'agriculture algérienne, le palmier-nain (chamarops humilis), qui est pour les cultures coloniales ce qu'est le chiendent pour les producteurs français. On tire aujourd'hui du palmier-nain, au moyen de certaines préparations, un crin végétal, bien connu dans le commerce parisien. Une seule exploitation de la province d'Alger fabrique annuelle- 
ment 8 à 900,000 kil. de cette matière qu'elle livre au prix de $25 \mathrm{fr}$. les 100 kilogr.

M. P. Averseng, de Cheragas, province d'Alger, a exposé plusieurs espèces de crins de palmier-nain, et bon nombre d'objets fabriqués avec ce crin végétal.

VIII. Porcelaines, faïences, poteries de luxe.

La peau de bouc est l'ustensile de ménage pour l'Arabe de la tente ; mais le Kabyle sédentaire a réellement l'instinct de la céramique. La poterie kabyle consiste particulièrement en amphores de toute taille, à ventre rebondi et à col court et évasé, en gargoulettes variées, en bassins de différentes formes. Elle n'est pas vernie, mais elle est généralement recouverte d'une couleur noire, avec des dessins et des arabesques un peu primitifs, ayant toutefois une certaine originalité.

Dans quelques parties de l'Algérie on confectionne en bois de grands plats pour la préparation du couscoussou et des cuillers pour le manger. Dans d'autres tribus, les plats sont fabriqués avec de l'alfa qu'on enduit d'une couche de goudron.

\section{Tapis, tapisseries et autres tissus d'ameublement.}

On ne se livre guère à cette branche d'industrie, chez les indigènes, que pour les besoins de la famille. - Les femmes arabes lavent, peignent, cardent et filent elles-mêmes la laine destinée à la préparation des tapis. Les fils sont teints par les teinturiers juifs qui ont presque seuls la spécialité de ce travail. Le tissage se fait ensuite par un ouvrier spécial qui compose en même temps le dessin; il est aidé dans ce travail par les femmes de la famille.

C'est à Kalace et aux environs de Mascara, dans les tribus des environs de Biskra et de Constantine, que se fabriquent plus particulièrement les tapis.

\section{Coutellerie.}

Dans la province de Constantine, Bou-Saada est le siége d'une industrie assez sérieuse. On y fabrique des couteaux connus au loin sous le nom de bousaadis et qui jouissent d'une certaine réputation. Ces couteaux se composent d'une lame de forme particulière et pointue, d'un manche en bois ou en os consolidé par un filigrane de laiton ou d'argent et d'une gaîne enveloppée dans un étui en bois recouvert en cuir dit flali plus ou moins orné 
de broderies. La gaîne se rattache au couteau par une petite lanière qu'on passe dans le manche. - Ces couteaux, d'une forme -originale, sont d'une grande utilité pour les indigènes auxquels ils servent à une foule d'usages, et principalement à se raser la tête, la barbe et d'autres parties du corps. - Certains de ces couteaux portent des manches élégants et riches.

\section{Parfumerie.}

Avant notre arrivée en Algérie, la fabrication se bornait aux essences de rose, de jasmin et de fleurs d'oranger. Mais, depuis, elle a pris un grand développement.

Parmi les essences, citons : le néroli, qui vaut de 3 à $400 \mathrm{fr}$. le kil.; l'essence de géranium, le petit grain, la menthe poivrée, qui valent de 70 à $80 \mathrm{fr}$. le kil.

Aucun climat n'est plus favorable que l'Algérie à la production des plantes à essences.

\section{Maroquinerie, tabletterie, vannerie.}

Les objets de ce genre sont généralement confectionnés avec des bois blancs recouverts de peintures aux vives couleurs. Ils consistent en étagères (merafa) et crémaillères (fchouatan) pour recevoir des armes et des pipes; appliques (rchakat) destinées à supporter des bougies; petites tables rondes (koursi) ou à pans coupés (skamela) sur lesquelles on place des fleurs; coffrets en bois (rouba) dans lesquels on dépose l'argent et les bijoux; petites cassettes à tiroirs (fnik), etc.

XIII. Fils et tissus de coton, de lin, de chanvre, etc.

Les objets de cette classe ont été fabriqués en France, mais avec des matières algériennes.

Toutefois, dans les cercles de Bougie et de Djidjelli, les Kabyles tissent, avec des chanvres et des lins du pays, une toile grossière, mais très-solide, dont le prix est de 5 fr. 50 la pièce de $3^{\mathrm{m}}, 50$ de long sur 70 cent. de large.

XIV. Fils et tissus de laine peignée et cardée.

Chez les indigènes de l'Algérie, le tissage des étoffes de laine est une industrie purement domestique : ils n'ont pas de fabriques. L'industrie française a le monopole à peu près exclusif de 
la fourniture des étoffes de laine aux Européens fixés en Algérie. L'exposition de 1867 a démontré tout le parti qu'on peut tirer des laines indigènes.

$\mathrm{XV}$. Soies et tissus de soie.

Alger fabriquait, avant la conquête, la plus grande partie des étoffes de soie employées dans la Régence; Tunis seule lui faisait concurrence. Mais peu à peu l'industrie lyonnaise s'est emparée de cette fabrication, et aujourd'hui elle est entrée en possession presque complète de l'approvisionnement algérien. Toutefois la ville d'Alger a conservé la confection des broderies et passementeries particulières avec lesquelles les indigènes ornent leurs vêtements. - La soie dont on se sert est de provenance française, car les Arabes n'élèvent pas de vers à soie, quoique le mûrier réussisse très-bien en Algérie. - Les étoffes de soie, présentées à l'Exposition, ont été tissées par les premiers fabricants de Lyon, avec des soies récoltées et filées par des colons algériens.

\section{Bonneterie, etc., lingerie.}

Les bas ou les chaussetles ne sont guère usités que chez les Israélites aisés, les musulmans des villes et quelques chefs de grandes tentes. En fait de lingerie, on ne connaît guère que la chemise en étoffe de coton, et la gandoura. - Usage très-restreint du mouchoir; point de gants. Eventails, écrans, cannes.

XVII. Habillements des deux sexes.

Les différentes pièces de l'habillement des habitants de la ville sont : La Kamidja, chemise en calicot; le seroual, large pantalon à plis; deux bedaïa, gilets sans manches et fermés; un hebaïa, gilet ouvert et flottant; une rlila, veste coupée à la hauteur de la taille et à manches étroites; un hazem, large ceinture en soie, laine ou cachemire.

La coiffure se compose d'une ou plusieurs calottes en laine blanche, cabouz, par-dessus laquelle on en place une seconde plus grande de laine rouge, chechia, et autour de laquelle on enroule le turban.

Les chaussures sont de larges bahouches, sabat, à bouts arrondis et sans talons; rarement des bottes, mest.

Par-dessus ce costume se pose le burnous, en laine blanche et léger pour l'été, en "drap ou en poil de chameau pour l'hiver. 
L'Arabe de la tente a un costume beaucoup moins compliqué.

Le costume des femmes dans les villes se compose, outre la chemise :

D'un caftan, long vêtement en drap avec manches, ouvert sur le devant qui est brodé ou garni de passementeries en or, argent ou soie. Sur le caftan, deux ou trois gandouras, robe sans manches en drap, soie ou cotonnade, le tout serré à la taille par une ceinture de laine ou de soie. Quand les femmes sortent, elles posent sur leur visage un voile, adjar, en mousseline, qui ne laisse à découvert que les yeux et la naissance du nez, et par-dessus un haïck qui, partant du front, enveloppe la tête et le reste du corps.

Les rêtements des enfants sont les mêmes que ceux des parents.

Les exposants indigènes d'habillements ont été au nonbre de 49 ou วั0.

\section{Joaillerie et bijouterie.}

Les indigènes sont passionnés pour les bijoux. Les femmes en portent littéralement de la tête aux pieds. Les Isrálites des grandes villes ont à peu près le monopole de la fabrication; depuis quelques années, un service de garanties a dû être établi, pour mettre obstacle aux fraudes qui se commettaient dans les titres des objets.

XIX. Armes portatives.

Treize exposants indigènes. - Autrefois, l'industrie de l'armurerie était très-active sur tous les points de la Régence. Aujourd'hui, par suite de l'occupation française, elle a considérablement diminué.

XX. Objets de voyage et de campement.

Les inđigènes fabriquent eux-mêmes ces objets. - Une tente ordinaire vaut de 250 à 500 fr. - 53 exposants.

XXI. Mines et métallurgie.

Nous n'avons rien à ajouter à ce qui a été dit dans la partie relative à l'Algérie.

XXII. Produits des exploitations et industries forestières.

Les principaux de ces produits sont: le liége; les bois de construction (marine, bâtiments, traverses de chemins de fer, 
merrains); les bois de travail (parquetage, menuiserie, ébénisterie, marqueterie, tabletterie); les résines; les écorces à tan et les matières colorantes.

Les concessions de chêne-liége embrassent aujourd'hui 141,731 hectares ; 123,000 sont en exploitation, et 80,000 commencent à rapporter.

XXIII. Chasse, pêche et cueillettes.

La faune algérienne est riche. Outre le lion, la panthère, la hyène et quelques autres espèces que la civilisation éloigne de plus en plus chaque jour, on trouve partout du gibier.

Toutefois l'autruche devient rare. - C'est pour parer à sa disparition prochaine que des essais ont été tentés pour la domestiquer. Le jardin d'acclimatation d'Alger, celui de Marseille, un autre établissement privé en Italie, possèdent aujourd'hui plusieurs générations d'autruches nées en domesticité.

L'autruche, outre ses plumes, donne 50 œufs par an. Le poids moyen de chacun est de 1 kilogramme 565 grammes ; soit 78 kilogrammes 200 grammes pour l'ensemble; ce qui représente à peu près 1,200 œufs de poule d'Espagne. Leur goût est moins délicat peut-être, mais ils sont très-mangeables.

Les rivières d'Algérie sont peu poissonneuses. Mais sur les côtes de la Méditerranée on trouve le thon, la sardine, l'anchois, etc. Dans les lacs, on recueille des sangsues d'une réputation égale à celle des sangsues bordelaises. Le corail se rencontre surtout sur les côtes de l'Algérie, aux environs de la Calle; il y forme des forêts de 30 à 200 mètres de fond.

Il existe en Algérie un nombre assez considérable de bois résineux, cèdre, pin d'Alger, genévrier, qui se rencontrent, soit à l'état de forêts, soit disséminés au milieu des autres essences. Les massifs les plus importants sont ceux de la province d'Alger.

\section{Produits agricoles de facile conservation.}

$1^{\circ}$ Coton. Le cotonnier donne en Algérie des rendements satisfaisants; ils sont de 8 à 10 quintaux bruts à l'hectare, souvent plus. Quelques planteurs ont retiré jusqu'à 18 quintaux.

$2^{\circ}$ Lin. On estime la récolte en tiges de lin à 50 quintaux, en moyenne, par hectare; le rendement en graines est de 7 quintaux. 
$3^{\circ}$ Autres matières textiles. Ce sont l'abutilon indicum, dont on peut extraire, au bout de trois mois de culture, 20 à 22 quintaux de filasse à l'hectare; le corite textile; l'agave d'Amérique et du Mexique, l'agave fétide, le bananier, le chanvre, l'alfa, etc.

$4^{\circ}$ Laine. On évalue à 15 milliòns de kilogrammes en moyenne le chiffre total de la production de la laine par an. Sur cette quantité, 7 à 8 millions sont exportés, surtout en France. - Les 100 kilogrammes en suint valent aujourd'hui, en moyenne, $140 \mathrm{fr}$.

$5^{\circ}$ Cocons de vers à soie. - Avenir assuré.

$6^{\circ}$ Plantes oléagineuses : lin, colza, ricin, olivier, arachide, cameline, carthame, hélianthe, pavot, sésame, navette, etc.

$7^{\circ}$ Cire et miel. Produits de qualité supérieure.

$8^{\circ}$ Tabac. La production annuelle varie entre 8 et 10 millions de kilogrammes.

$9^{\circ}$ Matières tannantes : différentes variétés de chênes, sumac thezera, teggaout, pyrèthre, lentisque, tocezala, garou, aubépine, écorce de grenade, etc.

$10^{\circ}$ Matières tinctoriales : curcuma, garance sauvage (fou $)$, écorce de grenade sauvage, chebouba, écorce d'aubépine, kermès du quercus coccifer. On cultive, en outre, la garance, le carthame, le nopal à cochenille, l'indigotier, le henné.

$11^{\circ}$ Fourrages. Les prairies naturelles de l'Algérie sont d'une richesse et d'une beaulé incomparables. Chaque année on exporte sur différents ports de la Méditerranée plusieurs centaines de milliers de quintaux de fourrages.

\section{Eaux minérales et thermales.}

Elles sont nombreuses dans les trois provinces.

Les plantes médicinales le sont davantage encore. Le pavot à opium a toutes les qualités des meilleures espèces de l'Inde et de Smyrne. On vient de tenter au jardin d'acclimatation d'Alger, dirigé par le savant M. Hardy, l'introduction du quinquina.

\section{Cuirs et peaux.}

Le nombre des cuirs entrant chaque année dans la fabrication est considérable. On l'évalue pour Constantine seulement à 20,000 peaux de bœufs, 6,000 peaux de veaux, 80,000 peaux de moutons et 100,000 peaux de chèvres. Les prix de ces cuirs suivent les prix des marchés de France. 
XXVII. Bourrellerie et sellerie.

La sellerie et le harnachement se fabriquent dans les principales villes, à l'exception des corps de selle (el adam) qui se préparent dans certaines tribus dont ils sont la spécialité.

Les cuirs employés pour la sellerie indigène sont de deux qualités. Les plus belles selles sont fort souvent recouvertes de broderies en soie, en or ou en argent qui se font en plusieurs endroits, notamment à M'sila, province de Constantine.

Une selle sans broderies, ordinaire, avec sa bride, monte à 150 francs. Une selle et une bride brodées très-simplement vont à 250 francs. Une selle et une brides brodées et ornementées montent jusqu'à 4.50 francs. I.es selles en velours ou cuir, complétement brodées en or et en argent (kerbsoun) s'élèvent jusqu'à 4 ou 5,000 francs; mais il en est peu de fabriquées aujourd'hui.

XXVIII. Céréales et autres produits farineux et comestibles.

$1^{\circ}$ Blé dur. Recherché et préféré pour la préparation des pâtes alimentaires et pour la panification. Il a un poids plus élevé que les blés tendres. Il pèse souvent 86 kil. à l'hectolitre; la moyenne est de 79 à 80 kil. La farine, moins blanche que celle du blé tendre, a plus de gluten et par suite plus de qualités nutritives; elle donne aussi un rendement plus consi dérable en pain ( 140 kil. de pain pour 100 kil. de farine). On sème en novembre pour récolter dans la seconde quinzaine de mai.

$2^{\circ}$ Blé tendre. On préfère en Algérie la variété à barbes; elle résiste mieux aux influences atmosphériques et s'égrène plus difficilement que les autres sortes.

$3^{\circ}$ Seigle. On le cultive dans les rares contrées où le sol est pauvre : らั à 600 hectares cultivés par an.

$4^{\circ}$ Orge. Production de première nécessité en Algérie; elle remplace l'avoine dans l'alimentation des chevaux, et, dans les années de disette, les indigènes en font leur principal aliment. - Tandis que les indigènes ne récoltent par hectare que 12 à 15 hectolitres, les Européens récoltent 20 à 25 hectolitres. L'hectolitre pèse en moyenne 60 kilogr. - On récolte par an 10 à 15 millions d'hectolitres.

$5^{\circ}$ Avoine. En Afrique, l'avoine doit être donnée avec ménagement aux animaux; elle les surexcite trop. Aussi l'orge l'y remplace-t-elle à peu près partout. 
$6^{\circ}$ Riz. Culture à peu près abandonnée pour cause d'insalubrité.

$7^{\circ}$ Maïs. Culture en bonne voie.

$8^{\circ}$ Millet. Cultivé surtout par les indigènes.

$9^{\circ}$ Sorgho. Culture remplie d'avenir, si l'on ne se laisse pas décourager par les quelques échecs subis. Le rendement est de 800 quintaux métriques à l'hectare. Les cannes donnent $15 \mathrm{p} .0 / 0$ de sucre non raffiné, ou 50 p. $0 / 0$ de sucre raffiné. On récolte aussi 30 quintaux de graines dont on obtient 600 litres d'alcool d'une valeur égale au $3 / 6$ du commerce; somme toute, les résultats équivalent à ceux des meilleures cultures.

$10^{\circ}$ Farine. Depuis l'occupation française, la fabrication des farines a lieu au moyen des moulins à vent, à eau et même à vapeur. - A la mouture d'après les procédés français, les blés rendent en farine, par quintal, savoir : pour le blé dur, 78 à 80 kil. et même 86 kil.; pour le blé tendre, 70 à 72 kil.; pour l'orge, environ 60 kil. par quintal.

$11^{\circ}$ Semoules, pâtes, etc. Fabrication très-prospère.

\section{Corps gras alimentaires, huiles combustibles, etc.}

$1^{\circ}$ Lait et beurre, 33 à 45 cent. le litre de lait; 3 à 4 francs la livre de beurre.

$2^{\circ}$ Huile d'olive. L'Algérie est la véritable patrie de l'olivier. - La culture de ce végétal et la production de l'huile prennent chaque année une extension plus grande, en même temps que la qualité des huiles va en s'améliorant. Pour ne citer qu'une des trois provinces, celle de Constantine, qui comprend, il est vrai, une partie de la Kabylie, produit annuellement, en moyenne, 150,000 hectolitres d'huile dont un tiers a été livré à l'exportation. Bougie seule a donné 58,000 hectolitres pendant la dernière campagne.

\section{Légumes et fruits.}

Le jardin d'acclimatation d'Alger a introduit dans la colonie une foule de légumes et de fruits européens.

L'oranger croît sur tous les points de la colonie.

En 1865,le nombre des planteurs était de 3,095; celui des arbres en rapport, de 130,411; le nombre des jeunes arbres, de 72,447; la quantité de fruits exportés s'est élevée à 14,285,580.

Isa province d'Alger renferme sensiblement plus d'orangeries 
que les deux autres, et Blidah est le principal centre de cette production; les orangers forment autour de cette ville une ceinture toujours verte de plus de 200 hectares.

Viennent ensuite le dattier, l'arbre des régions sahariennes, dit M. Hardy, le bananier, la goyave, etc.

XXXI. Boissons fermentées.

Dès les débuts de la colonisation, les Européens introduisirent des plants de vigne tirés de France. Auparavant, on ne faisait pas de vin en Algérie; on mangeait simplement le délicieux raisin des treilles (le Koran, comme on sait, interdit l'usage du vin). Aujourd'hui, il en est autrement. En 1865, les plantations de vignes embrassaient 10,897 hectares. Sur ces étendues, 3,000 hectares environ appartenaient à des cultivateurs indigènes dont la récolte a été consommée en grappes. Les Européens ont produit à peu près 70,000 hectolitres de vin, dont 12,000 hectolitres de vin blanc.

La distillation a suivi aussi une marche ascendante. Après les alcools de raisin viennent les alcools de sorgho, de caroube, de jujube, de figues douces, de figues de Barbarie, etc.

Cette abondance de végétaux sucrés permet de préparer des liqueurs d'un goût parfait. L'exposition de 1867 l a prouvé surabondamment. 


\section{EXPOSITION DE 1867}

\section{COLONIES FRANÇAISES}

Pour que cet article ne fasse pas double emploi avec ceux que nous avons déjà donnés sur le même sujet (Exposition de 1860), nous ne parlerons ici que des produits qui n'ont pas figuré à cette Exposition ou qui n'y ont figuré que très-incomplétement. (V. Catalogue des produits des colonies françaises, 1867).

\section{Age de pierre des colonies.}

La Guadeloupe a présenté une collection d'idoles, armes et ustensiles en pierre, en usage chez les Caraïbes avant la découverte de l'Amérique. Parmi ces débris de l'industrie d'une race disparue, on remarque une petite idole en roche verdâtre trouvée à la pointe des châteaux de Saint-François, et un vase lampadaire en pierre dure, longtemps conservé à l'anse Bertrand comme ayant appartenu au dernier cacique des fonds caraïbes.

La Guyane et l'Inde n'ont présenté que deux haches en pierre et en diorite.

Tahiti et dépendances ont aussi offert plusieurs haches en pierre. Ces instruments, montés sur un manche coudé un peu long, ont longtemps servi exclusivement, dans les îles du Protectorat, à la confection des pirogues, des planches et des habitations; on en fait encore usage aux Marquises.

A la Nouvelle-Calédonie, l'usage des armes en pierre existe toujourś. La hache ordinaire, en serpentine (Guié), a la forme d'un coin dont le tranchant, aminci par un frottement long et pénible, est moitié environ plus large que l'extrémité supérieure; elle est supportée par un manche court, avec lequel elle forme un angle aigu, à la manière de nos herminettes. Peu employée à la guerre, elle sert principalement aux travaux de charpentage. La hache des chefs (Nargota) est composée d'un disque mince en serpentine très-tranchant et garni d'un manche 
droit auquel il est relié par des cordons en poil de roussette; elle ne sert, en général, que comme arme d'ornement.

\section{OEuvres d'art.}

Colonies qui ont exposé: Martinique, Sénégal, Cochinchine, Inde.

III. Matériel et application des arts libéraux.

10 Imprimerie. - Sauf les établissements de Sainte-Marie-deMadagascar, de Mayotte et de Nossi-Bé, toutes les colonies françaises ont des établissements appartenant soit au gouvernement, soit aux missions, soit à des particuliers. Toutes ont envoyé quelques spécimens de leurs produits.

$2^{\circ}$ Application du dessin et de la plastique aux arts usuels. - Dans la plupart de nos grandes colonies, on possède des presses lithographiques; mais ce n'est qu'à la Réunion qu'elles ont été appliquées au dessin, en vue de la reproduction des types et sites joints à l'album de cette colonie publié par M. Roussin. Les établissements français d'Asie produisent, en outre, d'assez habiles graveurs, sculpteurs et mouleurs indigènes.

$3^{\circ}$ Épreuves et appareils photographiques. - La plupart de nos colonies ont des appareils. Quoique l'intensité de la lumière, et la détérioration rapide des produits chimiques soient pour les photographes tropicaux des obstacles considérables, des épreuves dignes d'attention et d'éloges ont été envoyées à l'Exposition.

$4^{\circ}$ Instruments de musique. - Collections envoyées de la Guyane, du Gabon, etc.

$5^{\circ}$ Appareils et instruments de l'art médical.

$6^{\circ}$ Instruments de précision et matériel de l'enseignement des sciences.

Parmi les herbiers envoyés des colonies, il faut distinguer celui de la Nouvelle-Calédonie qui, sous le rapport botanique, offre le plus d'intérêt parmi toutes nos possessions. L'herbier de la Guyane vient en seconde ligne, et celui du Gabon en troisième.

\section{Meubles et autres objets destinés à l'habitation.}

Meubles de luxe, œuvres de tapissier et de décorateur, porcelaines, faïences et autres poteries, tapis, tapisseries et autres tissus d'ameublement, coutellerie, orfévrerie, bronzes d'art, appa- 
reils de chauffage et d'éclairage, parfumerie, l'Exposition a reçu des spécimens de ces diverses catégories.

Parmi les bronzes, on a remarqué une collection de divinités de l'Inde (Siva, Vishnou, etc.).

V. Vêtements (tissus compris) et autres objets portés par la personne.

Fils et tissus de coton. Fils et tissus de lin, de chanvre, de laine, de soie, etc. Dentelles, tulles, broderies. Articles de bonneterie. Habillement des deux sexes. Joaillerie, bijouterie. Armes portatives, etc.

$\mathrm{Au} 1^{\text {er }}$ janvier 1865, Pondichéry possédait trois filatures de coton à la mécanique. On comptait, en outre, 4,750 métiers natifs à Pondichéry, 2,400 à Karikal et 1,400 à Chandernagor.

VJ. Produits de l'exploitation des mines et de la métallurgie.

Parmi les colonies françaises qui, sous ce rapport, ont le plus fixé l'attention, on doit citer : les Antilles, la Guyane, la Réunion, la Nouvelle-Calédonie, l'Inde et la Cochinchine.

VII. Produits des exploitations et industries forestières.

$1^{\circ}$ Martinique. - Elle compte environ 20,000 hectares de bois propres à la construction, à l'ébénisterie, au charronnage et à la teinture; mais le manque de communications et l'escarpement des lieux boisés en rendent l'exploitation difficile; de sorte que les meilleures essences sont chaque jour transformées en charbon, sans grand profit pour les propriétaires; il est hors de doute, cependant, que la colonie pourrait fournir en planches, bardeaux et madriers, de quoi suffire à sa consommation et à celle de quelques îles voisines.

$2^{\circ}$ Guadeloupe. - L'étendue de ses forêts est de 36,000 hectares environ, $y$ compris les dépendances des Saintes, de la Désirade, de Saint-Martin et de Marie-Galante. L'ébène verte, le laurier-rose montagne, le noyer des Antilles, le campêche, y croissent en abondance, mais ne donnent lieu, faute de chemins, qu'à de faibles exploitations; il en est de même des nombreuses essences propres à la charpente, à la tonnellerie, au charronnage et aux constructions maritimes.

$3^{\circ}$ Guyane. - D'après un rapport de M. de Lapparent, directeur des constructions navales, il y aurait lieu de donner une 
grande extension à l'exploitation des immenses forêts de la Guyane dont certaines essences annoncent des qualités exceptionnelles d'élasticité et de durée. Ainsi, tandis que le chêne de France présente une élasticité représentée par 1.000 et une résistance aussi représentée par 1.000 ; tandis que le Teck de l'Inde, qualité supérieure, offre une élasticité représentée par 2.000 et une résistance représentée par 1.920 ; tandis que le hêtre injecté au sulfure de cuivre donne pour élasticité 1.420 et pour résistance 1.100, on voit que les bois de la Guyane donnent :

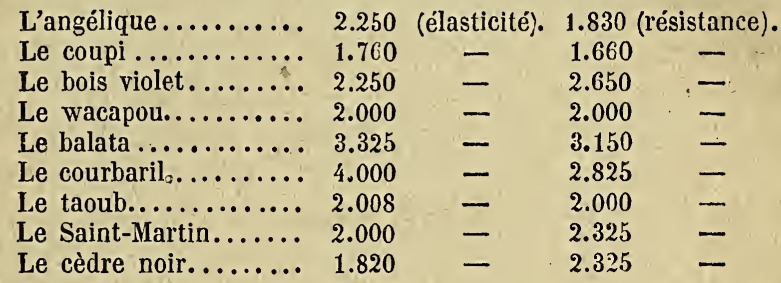

Après six mois de séjour en terre ou dans le fumier, la perte de force est, pour le chêne de France, de $301 / 2$ pour 100 , et pour le Teck supérieur, de 16 1/2. Elle est, pour les bois de la Guyane :

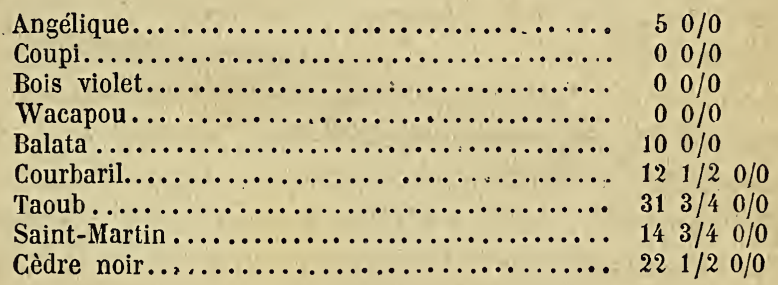

$4^{\circ}$ Sénégal et dépendances.

$5^{\circ}$ Gabon. - Les forêts du Gabon sont très-riches, mais peu exploitées. Le sandal et l'ébène sont seuls l'objet d'un commerce

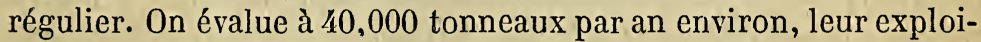
tation sous pavillons français, anglais et américain. - La famille des légumineuses est celle qui prédomine dans la composition des forêts de ce pays.

$6^{\circ}$ Madagascar.

$7^{\circ}$ Nossi-Bé.

$8^{\circ}$ La Réunion. - Cette colonie française possède encore aujourd'hui 57,701 hectares de forêts occupant, à une hauteur de 
4 à 500 mètres, l'espace circulaire compris entre le sommet des terres cultivées et la chaîne de montagnes qui partage l'île du nord au sud; leur sol se compose de tuf, d'argile, de scories volcaniques et de détritus végétaux; mais il manque généralement de profondeur. Aússi les arbres, quoique se développant avec une remarquable promptitude, n'y atteignent-ils pas une grande élévation. Les plus estimés sont le petit natte, le bois puant et le tamarin des hauts; mais à part les derniers protégés par leur position au sommet de l'île, ces précieuses essences sont devenues assez rares, soit à cause de leur emploi spécial dans les constructions, soit par suite des déprédations des maraudeurs, des incendies ou de l'établissement de nouvelles plantations. Suivant M. Imhaus, la valeur moyenne des espèces de première qualité est de 90 à 150 fr. le mètre cube, pour les bois durs de $0^{\mathrm{m}}, 11$ d'équarrissage, de 150 à $180 \mathrm{fr}$. pour ceux de $0^{\mathrm{m}}, 11$ à $0^{\mathrm{m}}, 22$, et de 300 à $600 \mathrm{fr}$. pour les beaux échantillons dépassant cette dimension. Les madriers de 4 mètres de long sur $0^{\mathrm{m}}, 25 \mathrm{de}$ large et de $0^{\mathrm{m}}, 13$ d'épaisseur reviennent à 3 et $4 \mathrm{fr}$. la pièce. Les bois durs de deuxième qualité sont cotés un tiers de moins environ; quant aux bois blancs, ils valent à peine le tiers du prix des bois de première qualité.

La Réunion possède de beaux bois d'ébénisterie, tels que le grand natte, le pêcher marron, l'olivier, le noir de l'Inde, le bassin, etc., etc. En charronnage, les espèces préférées sont le bois noir pour moyeux et jantes, le petit natte pour rayons et ridelles, le faux benjoin pour jantes, le takamahaca pour moyeux, jantes, brancards et flèches, le tan rouge pour moyeux, jantes et attelles, le cour bleu pour moyeux, jantes et brancards, le lilas du pays pour brancards et flèches.

Le pays possède, en outre, quantité d'essences forestières utilisables, soit en médecine, soit en teinture, soit dans l'industrie.

$9^{\circ}$ Bois de l'Inde francaise. - Le territoire des établissements français, dans l'Inde, est trop bien cultivé et trop exigu pour offrir des ressources forestières considérables. Tout déboisé qu'il est, cependant, il présente une assez grande variété d'espèces dont l'étude ne manque pas d'intérêt.

$10^{\circ}$ Bois de la Cochinchine et du Cambodge. - Les bois constituent une des richesses de la Cochinchine. Les forêts les plus considérables se trouvent précisément dans la province française de Bien-Hoa; les autres massifs ont moins d'importance, à part 
ceux des environs de Tay-Ninh, composés en grande partie d'essences résineuses dont on tire du goudron et de l'huile. Mais c'est surtout dans les bois du Cambodge que le commerce doit trouver d'importantes ressources. Leur exploitation a lieu chaque année, du mois de mai au mois de décembre, c'est-à-dire pendant la saison des grandes eaux favorables à leur transport; mais elle est encore bien imparfaite; il serait à désirer de voir substituer des scieries mécaniques aux moyens grossiers employés jusqu'à ce jour par les indigènes. Un établissement de ce genre situé à Rhnôm-Peuh ou à Compong-Luong, présenterait des avantages considérables. M. Petit a envoyé une collection de 120 espèces de bois.

$11^{\circ}$ Bois des îles du Protectorat français dans l'Océanie. - Les bois des établissements de Tahiti et dépendances se réduisent à peu d'espèces. Le sandal, qui faisait autrefois leur richesse, ne s'y rencontre plus qu'en petite quantité, et les seules essences exploitées aujourd'hui sont le Tamanu et le Miro dont l'usage commence à se répandre en France et en Angleterre.

$12^{n}$ Bois de la Nouvelle-Calédonie. - Les ressources forestières de la Nouvelle-Calédonie sont assez étendues. Les arbres les plus communs sont les Niaoulis (Melaleuca leucodendron et viridiflora), dont le bois ne le cède en rien à aucun autre, comme force, élasticité et puissance de durée. Viennent ensuite les Acacia spirorbis, les Blackburnia, le Casuarina ou bois de fer, le Thespesia populnea, le $P$ in à mâture, le Bancoulier, et enfin le Sandal odorant, dont on ne rencontre plus sur les côtes que des sujets de faible dimension. Ces belles forêts ont été longtemps dévastées par le commerce américain et anglais, et ce n'est plus que dans l'intérieur que se trouvent les arbres séculaires; mais elles ne peuvent manquer de reprendre, sous la protection française, leur ancienne célébrité.

VIII. Produits de la chasse, de la pêche et des cueillettes.

Le commerce des pelleteries est peu considérable dans les colonies françaises; il se réduit à quelques peaux de tigres, de lion et de singe; les comptoirs de la Côte-d'Or pourraient fournir une certaine quantité de ces dernières. On tire des établissements de Terre-Neuve quelques belles fourrures, provenant en majeure partie d’échanges avec les Micmacs de Terre-Neuve. 
De la plupart des colonies françaises on pourrait tirer une assez grande quantité de plumes à couleurs vives, propres à la confection d'objets de toiletle; mais la Guyane et la Cochinchine sont les seules où ce commerce ait une certaine importance; les queues de paon et les ailes des martins-pêcheurs sont en ce dernier pays l'objet de transactions suivies avec la Chine. Le Sénégal dont on pourrait aussi tirer un riche assortiment de plumes de couleur, n'exporte que des plumes d'autruche et de marabou.

La plus grande partie des cornes et pieds de bœufs abattus dans la Sénégambie est perdue pour le commerce; on n'en exporte annuellement qu'une dizaine de mille kilogrammes.

Le prolongement des récifs d'Entrecasteaux et le canal qui sépare la Nouvelle-Calédonie de ses dépendances, sont très-propres à la pêche de la baleine et du cachalot.

A la côte de Malabar on fait une assez grande quantité d'huile de poisson. La pêche est la principale industrie de notre établissement de Mahé. - Dans la Basse-Cochinchine, l'huile de poisson donne lieu à un commerce important. A Saint-Pierre et Miquelon, l'huile de foie de morue est en prospérité ; en 1865, les foies s'achetaient, à Saint-Pierre, $3 \mathrm{fr}$. 50 les 8 litres. Annuellement, la colonie exporte environ 500,000 kilogrammes d'huile brune de foie de morue, vendus en France de 120 à 140 fr. les 100 kilogrammes. La fabrication de l'huile de loup marin, si elle était encouragée, pourrait prendre de grands développements dans nos établissements de Terre-Neuve; on l'obtient par la fermentation au soleil; elle est bonne pour l'éclairage, le corroyage, la mécanique.

Les Antilles peuvent fournir une grande quantité d'éponges communes; on en trouve aussi d'excellentes et en abondance sur les côtes des îles de la Société.

Dans le haut Sénégal, la Casamance, les cours d'eau de la Côte-d'Or et du Gabon, en Cochinchine, les hippopotames sont assez communs; mais les lamentins, dont la peau est employée à la confection des cravaches, deviennent de plus en plus rares.

La pêche des huîtres perlières est une des principales industries des Kanacks dans les établissements français de l'Océanie. - Les nautiles, très-abondants sur les plages de la Nouvelle-Calédonie, donnent une nacre très-estimée. En Cochinchine, le commerce 
de la nacre est considérable; on emploie cette matière à la fabrication des objets de luxe.

Les Antilles, la Guyane, la Réunion, les comptoirs de la côte occidentale d'Afrique et les établissements français de l'Océanie possèdent des tortues comestibles et à écailles; mais il n'en est fait de commerce un peu important qu'en Cochinchine, à Mahé, à Mayotte et dépendances. Les époques de pêche, à Nossi-Bé, ont lieu de septembre à mars. Chaque tortue fournit douze feuilles, dont 4 grandes du poids maximum de 2 kil. 500. Le prix moyen est de 50 fr. le kil.

Nos colonies de Saint-Pierre et Miquelon, de la Guyane, du Sénégal et de la Cochinchine pourraient fournir des quantités énormes de vessies natatoires de poissons, mais elles sont en partie perdues. A la Guyane, pourtant, elles sont l'objet d'un certain commerce; en 1865, il en a été exporté 3,088 kilogr., au prix moyen de 3 fr. le kil.

Le Gabon fournit encore d'assez grandes quantités d'ivoire. La Basse-Gochinchine pourrait en donner également; mais ce produit est, presque en totalité, exporté en Chine.

Le Sénégal et dépendances exportent annuellement 100,000 kil. de cire environ.

Les lichens de la Réunion, employés à faire des gelées qui sont excellentes, pourraient etre utilisés en pharmacie pour la fabrication des capsules.

Les matières gommeuses et résineuses sont abondantes et variées dans les colonies françaises; mais peu d'entre elles sont exploitées sur une large échelle. Citons en première ligne, la gomme du Sénégal, le caoutchouc du Gabon, les résines, gommes, etc., des Antilles, de la Guyane, de la Cochinchine, et de nos établissements océaniens. - La récolte de gomme s'est élevée, au Sénégal, en 1866, à 2 millions de kilogr.

\section{Matières textiles.}

La plupart de nos colonies produisent une quantité de plantes textiles qui pourraient devenir l'objet d'une exportation considérable. L'attention du commerce doit être vivement appelée sur les ressources de ce genre que présente chacun de nos établissements, surtout la Réunion et la Guadeloupe où l'agave croît en abondance. Jusqu'à présent, l'Inde seule tire parti des fibres 
que produit spontanément son territoire où l'industrie des toiles de jute a pris une certaine irnportance; mais aux Antilles, à la Guyane, sur la côte occidentale d'Afrique, on laisse perdre une foule de richesses.

On peut considérer les Antilles comme la terre natale du coton longue soie. Cependant, la Martinique n'a jamais cultivé soigneusement le coton; elle n'en a exporté en 1863 que 46,283 kilogr. A la Guadeloupe, il y a progrès ; en 1865, l'exportation a été de 248,801 kilogr.

La Guyane n'a exporté en 1863, que 4,873 kil. Les cotons de cette provenance tiennent le milieu entre les longues et les courtes soies, s'allient parfaitement à la laine et donnent plus de main aux étoffes que les autres sortes.

Le Sénégal est très-propre à la culture du coton; partout il croît à l'état sauvage. La production de 1865 a été de 100,000 kilogr.

Quoique son sol soit très-favorable à la culture du coton, la Réunion a vu ce produit diminuer depuis 1815. En 1865, l'exportation s'est réduite à 16,793 kilogr.

Les cotons des établissements français dans l'Inde sont généralement de bonne qualité et préparés avec soin, mais ils sont presque entièrement consommés dans le pays par les nombreux métiers qui constituent sa principale industrie.

En Cochinchine (partie française), la production du coton est évaluée à 8,500 tonneaux d'une valeur de $3,000,000$ de francs; elle est susceptible d'un immense développement, sans compter ce que pourrait fournir le Cambodge. La production de 1866 est évaluée à 1,200 balles environ.

La Nouvelle-Calédonie se prête admirablement à la culture du coton; mais jusqu'ici, aucune plantation sérieuse n'a encore été faite.

Les matières oléagineuses abondent dans nos colonies; beaucoup sont encore inexploitées (ainsi les noix de Carapa de la Guyane, les amandes de palme sur la côte occidentale d'Afrique, les noix de bancoule aux îles de la Société, etc.). Celles qui fournissent le plus de fret à notre marine marchande sont, à la côte occidentale d'Afrique : les arachides, le sésame et le béraf du Sénégal, les amandes, huiles de palme et pourgueires de la Casamance et des comptoirs de la Côte-d'Or; - dans nos établissements de l'Inde : le sésame et l'huile de coco, etc.

La production du tabac a été, pendant longtemps, une des 
principales ressources de nos colonies : la réputation du Macouba est encore proverbiale; mais la canne à sucre a fini par absorber presque toutes les bonnes terres. Il est à espérer que les encouragements donnés par la régie à de récents envois faits par la Guyane, la Gochinchine et la Réunion, détermineront les habitants de ces colonies à renouer avec la manufacture impériale des tabacs, des relations malheureusement abandonnées depuis longtemps. Parmi les envois faits à l'Exposition, on a remarqué ceux de la Martinique et de la Guadeloupe, de la Guyane, du Sénégal, de Mayotle et Nossi-Bé, de la Péunion, de la Cochinchine.

Les matières tinctoriales et tannantes, croissant en quelque sorte sans culture, constituent une richesse pour nos colonies : bois de campêche (Antilles), rocou (Guyane), henné, indigo, (Sénégal), santal rouge (Gabon), curcuma (Réunion), indigo (Pondichéry), etc. - En 1865, la Martinique a exporté 410,185 kilogr. de campêche, et la Guadeloupe 156,010 kilogr.

La collection de l'Exposition compte près de 700 spécimens de substances médicinales. Sous les tropiques, l'emploi des végétaux en médecine est beaucoup plus répandu que dans les régions tempérées. La Góchinchine est de nos colonies celle qui tire le meilleur parti de ses matières médicinales; en 1865 , elle en a exporté 750 piculs (le picul $=60 \mathrm{kilogr}$.), valant $2,081,250 \mathrm{fr}$. La Martinique a exporté 369,828 kil. de casse et la Guadeloupe 709 kil. En 1866, la Guyane a exporté 4,082 kil. d'écorce de simarouba.

X. Céréales et autres produits farineux.

Gitons en passant le riz en paille mondé envoyé à l'Exposition par Mayotte et Nossi-Bé; le riz de montagne, en paille, de la Réunion; le riz en paille, décortiqué, de la Cochinchine.

\section{Viandes et poissons.}

La Gochinchine a exposé plusieurs spécimens de viande de buffle séchée et de canards salés. L'exportation de la première est peu considérable; mais les canards forment le fond d'un grand commerce avec la Chine. Les produits de pêche, en 1865 , exportés de Saïgon, ont été de 81,515 piculs (4,890,900 kilogr.).

Mentionnons encore : Poissons secs (Inde), morues sèches, morues salées, flétan dans le sel, harengs salés, capelans pressés, 
encornets, issues de morue (Saint-Pierre et Miquelon), encornets secs (Cochinchine), bichiques secs et en saumure de SaintBenoît (Réunion), curi ou pirarocou sec (Guyane), etc.

La Gochinchine et la Réunion ont, en outre, exposé des nids comestibles d'hirondelles salanganes.

XII. Condiments et stimulants; sucres et produits de la confiserie.

La Guadeloupe a exposé du vanillon, qui, en 1865, a donné lieu à une exportation de 1,271 kilogr.; la Guyane, la Martini que, Mayotte et Nossi-Bé, la Réunion, l'Inde, Tahiti, la NouvelleGalédonie ont envoyé des spécimens de vanille. En 1865, la Réunion a fourni au commerce 28,850 kilogr. de gousses et 6,521 de vanille ; son prix qui, en 1849 , était de 500 fr. le kil. est actuellement descendu à $40 \mathrm{fr}$.

Toutes nos colonies produisent ou sont susceptibles de produire du café. L'exportation, pour la Martinique, a été en 1865 de 44,981 kilogr., et, pour la Guadeloupe, de 447,170 kil. Pour la Réunion, elle a été, en 1865, de 215,331 kilogr.

Le thé promet de devenir, pour la Réunion, et quelques autres de nos colonies, une abondante source de revenus, dès que sa culture sera sérieusement encouragée.

Une autre culture à laquelle on devrait donner quelques encouragements est celle de la coca. La Martinique en a envoyé à l'Exposition.

- La coca (Erythroxylon Coca) n'est cultivée à la Martinique que comme espèce botanique au jardin de Saint-Pierre; la culture pourrait en etre avantageusement entreprise sur les plateaux élevés de l'île. Cette plante possède, au plus haut degré, des facultés stimulantes. Les feuilles mâchées à doses modérées de trois en trois heures mettent un homme à même de se passer de nourriture pendant trois jours, tout en le rendant capable d'un développement extraordinaire de force musculaire, le garantissent contre l'insalubrité du climat et lui procurent un grand sentiment de bien-être et de gaieté. Son principe excitant dépasse trois fois celui du café et quatre fois celui du thé. La coca serait donc une précieuse ressource pour l'armée, pourles voyageurs et les mineurs. Là ne se bornerait pas son rôle, d'après $M$. Ach. Genty, un de nos confrères de la presse scientifique ; la coca, prise à doses très-modérées et préparée à l'alcool, produirait d'excellents effets dans les fièvres ataxiques, dans les convalescences, et 
généralement chez toutes les personnes débilitées par l'âge, par les influences atmosphériques, par les excès de travail ou autres, etc. ; la coca n'est point un aliment, mais elle facilite singulièrement l'assimilation des aliments.

La Réunion a exposé du thé ayapana ou thé de l'Amazone, longtemps préconisé comme panacée, des feuilles de faham, dont l'infusion a un arome exquis, sans compter ses vertus pectorales, etc.

La Martinique, la Guadeloupe, la Réunion, la Guyane, le Gabon ont envoyé des spécimens de cacao. En 1865, l'exportation de ce produit a été de 258,425 kilogr. (Martinique), de 79,35ั4 kil. (Guadeloupe); en 1866, elle a été pour la Guyane de 31,801 kilogr.

Des échantillons de sucre ont été envoyés par la Martinique, la Guadeloupe, la Guyane, Mayotte et dépendances, la Réunion, l'Inde, la Cochinchine, la Nouvelle-Calédonie, Tahiti et dépendances.

En 186̊, l'exportation du sucre a été pour la Martinique de 30,491,467 kil. et celle de la mélasse de 352,810 litres. - Guadeloupe : $24,456,684$ kil. (sucre); 160,937 litres (mélasse). Guyane : 339,026 kil. sucre, en 1865, et en 1866, 320,584 kil. Mayotte (1865) : 2,154,715 kil.-Réunion (1865) : sa production, sous l'influence de la maladie et des ravages du borer, est tombée à $44,876,9508$ kilogr. - Cochinchine : On évalueà 7,500 tonneaux d'une valeur de 4 millions de francs environ, la production du sucre dans les provinces de Bien-Hoa, Gia-Dinh et Dinh-Tuong. Cette culture est susceptible d'un immense développement, et la Chine offre aux producteurs des débouchés considérables. Nouvelle-Calédonie : en 1866, l'exportation a commencé avec l'Australie.

\section{Boissons fermentées.}

Parmi ces boissons, le rhum occupe la première place. A la Martinique, la production a pris de grandes proportions, et la qualité s'est améliorée au point que ce produit peut rivaliser avec les meilleurs. Certains échantillons, fabriqués directement avec le vesou, conservent indéfiniment l'arome de la canne à sucre; ce sont des qualités tout à fait hors ligne. En 186ə, l’exportation a

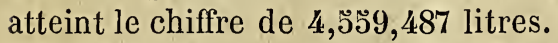

La fabrication prend aussi de l'accroissement à la Guadeloupe. Exportation en $1865: 1,126,452$ litres. 
Le rhum de la Guyane n'a donné lieu, en 1865, qu'à une exportation de 1,007 litres. La colonie consomme à peu près tout ce qu'elle produit.

Le rhum de la Réunion (1865) a fourni à l'exportation : 115,727 litres ; la fabrication moyenne, depuis quinze ans, donne, en dehors du prix de vente, un revenu de plu sd'un million au trésor local.

Mayotte et dépendances, la Nouvelle-Galédonie, Tahiti, ont aussi envoyé à l'Exposition de 1867 quelques spécimens de leurs rhums et tafias. 


\section{COMPLÉMENT}

\section{Algérie.}

En 1867, un archevêché (Alger) et deux évêchés (Oran et Constantine) ont été érigés.

II. Importations et exportations en 1865.

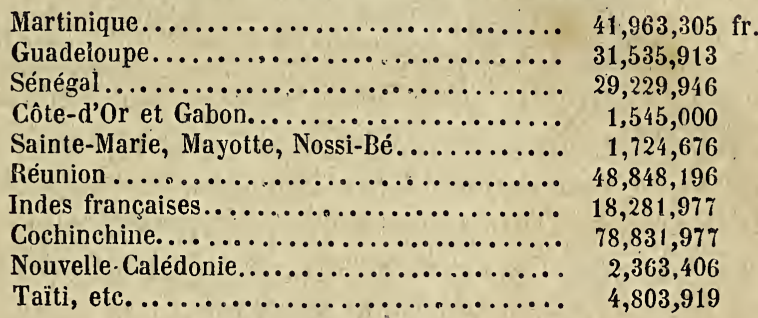

III. Houvement maritime (1865).

Martinique...................... 181,556 tonneaux.

Guadeloupe........................ 96,156

Guyane.......................... 27,235

Saint-Pierre et Miquelon . . . . . . . . . . . . 123,261

Sénégal ......................... 116,234

Côte-d'Or....................... 10,000

Réunion.......................... 181,071

Sainte-Marie, Mayotte, Nossi-Bé........... 16,117

Indes françaises.................... 73,864

Cochinchine ....................... 131,066

Nouvelle-Calédonie ................... 5,150

Taïti. etc....................... 16,234

Soit, ensemble, un mouvement de 977,000 tonneaux, qui alimentent 5,743 navires français, occupant 33,392 marins. Ce mouvement est à peu près la moitié du mouvement général de la marine française.

\section{Guyane.}

Nous extrayons de la Notice sur la transportation à la Guyane, les documents qui suivent : - De 1857 à 1862, la moyenne annuelle des décès avait été de 8,38 pour 100. - De 1863 à 1865, la moyenne annuelle s'est abaissée à 4,93 p. 100 .

Au 31 août 1866, le nombre des concessionnaires était de 102; celui des enfants nés dans la colonie, de 75; celui des enfants venus d'Europe, de 3ٌ. - A Saint-Laurent, sur 406 hectares concédés, 248 étaient en culture; 158 en défrichement. A SaintMaurice, sur 1,044 hectares concédés, 380 étaient cultivés. A 
Saint-Pierre, centre des libérés à résidence perpétuelle, sur 420 hectarcs concédés, 70 seulernent étaient cultivés. Aux Hattes, centre des repris de justice, sur 174 hectares concédés, 42 étaient cultivés. A Saint-Jean, centre des libérés à résịdence temporaire, 177 hectares concédés, 42 cultivés.

L'effectif des transportés, répartis sur les divers établissements, s'élevait à 7,466 .

Les valeurs mobilières et immobilières des pénitenciers présentaient un total de $5,555,760$ francs.

Vers la fin du premier semestre de cette année (1867), l'arrivée d'environ 800 travailleurs coolies à la Guyane semble avoir provoqué un mouvement considérable vers la production agricole. En un an, 800 travailleurs pouvant mettre en culture 400 hectares, il en résulte qu'au bout de deux ans, on aurait en sucre un produit de 1,600,000 kilog., ou 1,600 tonneaux.

On signalait, à la même date,-une certaine augmentation dans

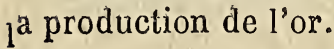

\section{Nouvelle-Calédonie.}

- Pour l'exercice 1867, le budget extraordinaire des recettes et le budget des dépenses du service local, s'élèvent en recettes à 94,300 francs, et en dépenses à la même somme (Arrêté du gouverneur, 27 juin 1867).

- Projet d'établissement d'une succursale du City Bank (Aus. tralie) à Noumea. Le Moniteur de la Nouvelle-Calédonie, du 30 juin 1867, renferme, sur ce sujet, une intéressante appréciation de M. Mage, avocat et secrétaire de la commission spéciale nommée pour examiner les propositions du City Bank.

\section{Cochinchine.}

Un fait de la plus haute importance s'est passé cette année (1867) en Cochinchine : notre colonie s'est augmentée de trois provinces nouvelles, et ce, sans effusion de sang. Les provinces conquises sont celles de Vinh-long, Chau-doc et Ha-tien (20 au 24 juin 1867). Toute la basse Gochinchine est donc entièrement française aujourd'hui. Ce résultat fait le plus grand honneur au vice-amiral de la Grandière, gouverneur, qui commandait en chef l'expédition. - Dès maintenant, on peut prévoir une partie des destinées de ce pays. La Cochinchine sera, en Orient, plus qu'une colonie française; ce sera presque une autre France. 


\section{TABLE DES MATIĖRES}

A M. le baron Oscar de Watteville.......................... 1

Un mot au lecteur.................................... v

\section{AFR IQUE}

\section{ALGÉRIE.}

Chapitre premier - Limites. - Superficie. - Sol. - Climat. - Zoologie. - Botanique. - Minéralogie. - Races algériennes. - Mœurs arabes

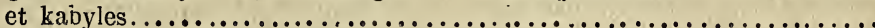

Chapitre II. - Rèsumé historique de l'Algérie...................

Ghaprtre III. - Population. - État civil. - Européens, Israélites, Indigènes ou Musulmans. - Opinions diverses touchant la population algérienne (Corps législatif, session de 1866). - Statistique officielle.......

Ghapitre IV. - Divisions administratives. - Territoire civil. - Territoire militaire. - Bureaux arabes. - Gouverneur général, etc............

Chaptrne V. - Désignation des principales localités algériennes. - Leur population. - Leur importance industrielle, commerciale, etc.........

Chapitne VI. - Organisation coloniale et agricole. - Villes, villages et périmètres de colonisation. - Routes. - Chemins de fer. - Population agricole. - Cultures diverses : tabac, coton, vigne, vins, céréales, lin, oranger, etc. - Mines. - Forêts. - Pépinières. - Jardin d'acclimatation de Hamma (commune d'Alger). - Forages artésiens. - Expositions

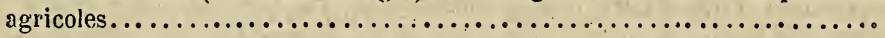

Chapitne VII. - Organisation financière. - Budget du gouvernement général. - Budgets provinciaux. - Budgets communaux. - Budgets locaux. Budgets des centimes additionnels à l'impôt arabe. - Services financiers. - Froduits réalisés au profit do Trésor, pendant les années 1860 à 1864 inclusivement. - Enregistrement et domaines. - Contributions diverses. - Télégraphie. - Postes. - Impôts au profit de l'État. - Impôts au profit des communes. - Impôts arabes. - Amendes. - Octroi de mer..

Ghapitre VIII. - Commerce. - Importations. - Exportations. - Mouvement de la navigation. - Cabotage. - Entrepôts réels et fictifs. - Pêches

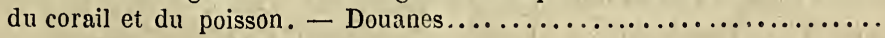

Chapitre IX. - Administration provinciale - Communes : leur nombre en 1864. - Assistance publique : hôpitaux et infirmeries; établissements d'eaux thermales; établissements d'aliénés ; orphelinats; bureaux de bien. faisance. - Mont-de-piété d'Alger. - Caisses d'épargne. - Sociétés de secours mutuels. - Prisons civiles, - Animaux nuisibles. ...........

Chapitre X. - Institutions de crédit. - Banque d'Algérie : ses opérations en 1863 et 1864. - Crédit foncier de France : ses opérations en 1864. Mont-de-piété d'Alger (renv oi au chap. IX): - Société Frémy et Talabor.. . 
Chapitre XI. - Instruction publique. - Enseignement supérieur. - Enseignement secondaire. - Enseignement primaire. - Renvoi au chap. XV relatif à l'instruction des indigènes..........................

Cha pitre XII. - Cultes. - Culte catliolique. - Culte protestant. - Culte hébraique. - Culte musulman (renvoi au chap. XV). - Situation en 1863

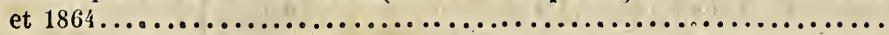

Chapitre XIII. - Justice. - Organisation judiciaire. - Statistique judiciaire. - Situation en 1863 et 1864. - Justice indigène (voir chap. XV). .

Chapitne XIV. - Armée et marine. - Effectif de l'armée. - Hôpitaux et ambulances militaires. - Justice militaire. - Établissements hippiques. - Fortifications. - Effectif de la marine.......................

Chapitre XV. - Situation des indigènes. - Sénatus-Consulte du 22 avril 1863 ; propriété du sol. - Réorganisation des tribus. - Terres domaniales, terres melks, etc. - Justice en pays arabe. - Justice en pays kabyle. - Djemaas. - Mehakmas. - Pénitenciers agricoles indigènes. - Instruction publique indigène. - École des douars, zaouias, médersas. Écoles arabes-françaises. - Collége impérial arabe-français. - Travaux publics en territoire militaire. - Productions agricoles. - Ferme-école

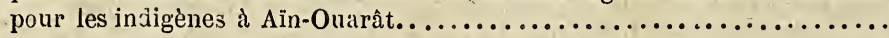

Chapitre XVI. - Renseignements utiles. - Distances et communications. - Acclimatement .................................

Chapitre XVII. - Appendice. - Rapport fait, au nom du jury spécial, par M. Jules Duval, membre du Conseil général de la province d'Oran, sur les produits exposés par l'Algérie au concours général et national d'agriculture de Paris, en 1860 (Extraits) : végétaux et produits végétaux; - textiles ; cotons; - matières oléagineuses et savons; - céréales, etc. - Extrait du discours de M. Lestiboudois, conseiller d'État, président du conseil général de Constantine, à l'ouverture de la session de 1861. Extraits de la brochure anonyme intitulée : " L'Algérie française - Indigènes et Inmmigrants, " publiée en 1863 à Paris. - Sénatus-Consulte du 5 juillet 1865. - Lettre de l'Empereur au maréchal de Mac-Mahon, duc de Magenta; résumé de cette lettre. - Appréciation de ladite lettre par le genéral Allárd (Corps législatif, 5 mars 1866). - Texte du décret du 21 avril 1866, portant règlement du Sénatus-Consulte sur la naturalisation en Algérie. - Coup d'œil sur les communications télégraphiques entre la

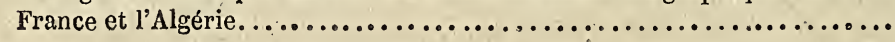

\section{LE SÉNE̊GAL}

Chapitre 1. - Histoire et éphémérides sénégalaises...............

Ghapitre II. - Possessions françaises. - Etats voisins. - Cercle d'action de la France..........................................

Chapitre III. - Fleuves et rivières. - Rades. - Lacs. - Etangs salins. - Température. - Saisons. - Opinion de Buffon sur le climat sénégalais. - Vents. - Ras de marée. - Marées. ....................

Chapitre IV. - Population. - Extrait de la notice du colonel (général) Faidherbe. - Blancs : race arabe et race berbère. - Noirs : race poul ou peul; race malinké ou bambara ; race wolof ou ouolof..............

Chapitre V. - Ancienne division administrative. - Nouvelle division en trois arrondissements. - Chiffre de la population. - Sa répartition. Gouvernement et administration. - Services divers...............

Сhapitre VI. - Armée et marine. - Effectif des troupes. - Flottille du Sénégal. - Effectif des équipages......................... 
Chapitre VII. - Justice françaíse : Cour impériale; - Tribunaux de première instance; - Cour d'assises ; - Conseils de conciliation. - Statistique judiciaire de 1861 . - Justice musulmane..................

ChapıTre VIII. - Instruction publique et cultes. - Écoles primaires. École primaire supérieure. - Inspection des écoles. - Culte musulman. - Prosélytisme de l'islamisme au Sénégal....................

Chapitre IX. - Agriculture et industrie. - Gomnie. - Arachide. - Béref. - Riz. - Mil. - Maïs. - Coton. - Indigofère. - Bœuf, âne, chameau. - Cheval. - Chèvros, moutons, cochons. - Essences forestières : Gonakié, etc. - Professions manuelles des indigènes. - Fer. - Or. - Peche. - Constructions maritimes. - Service du remorquage..............

Chapitre X. - Commerce. - Commerce de Saint-Louis. - Marchandises d'importation et d'exportation. - Commerce de Gorée. - Comptoir de Joal (Sine). - Comptoir de Kéolakh (Salaim). - Comptoir de Carabane (Casamance). - Rio-Nunez et Rio-Pongo. - Régime commercial du Sénégal. - Commerce spécial du Sénégal avec la France. - Commerce gé-

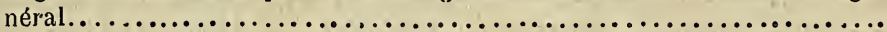

Chapitre XI. - Navigation. - Saint-Louis. - Gorée. - Joal. - Kaolakh. - Casamance. - Droits de tonnage, etc.....................

Chapitre XII. - Finances. - Budget de l'État. - Budget local. - Banque :

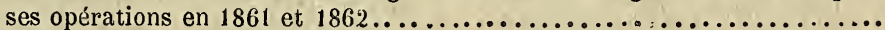

Chapitre XIII. - Service postal. - Bureaux de poste. - Correspondance avec l'Europe. - Frais de port. - Frais de traversée..............

\section{III. ÉTABLISSEMENTS FRANÇAIS DE LA COTE•D'OR}

(GRAND-BASSAM, ASSINIE, DABOU.)

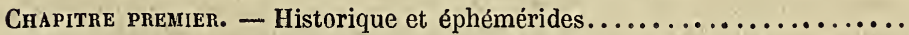

Chapitre II. - Le Grand-Bassam. - Assinie. - Dabou, - Saisons. - Ras de marée. - Climat. - Indigènes........................

Chapitre III. - Agriculture. - Huile de palme. - Or. - Ivoire. - Commerce. - Navigation intérieure. - Pecheries..................

Chapitre IV. - Administration. - Personnel administratif et judiciaire. Service des ports. - Forces militaires.......................

\section{GABON}

Chapitre premier. - Historique et éphémérides.................

Chapitre II. - Le Gabon. - Situation de notre établissement. - Géologie. - Forets. - Rivières. - La rivière Como. - L'île de Ningué-Ningué. L’Ogo-wai. - Caps. - Température. - Vents . - Marée. - Ras de marée. - Villages de la rive droite et de la rive gauche. - Indigènes : Ga-

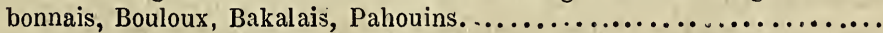

Chapıtre III. - Administration. - Forces militaires et maritimes. - Instruction publique. - Cultes. - Justice....................

Chapitre IV. - Agriculture. - Jardin d'essai fondé par M. Aubry-Lecomte. - Bœufs. - Chevaux. - Moutons. - Cabris. - Volaille. Cire. - Graines oléagineuses. - Ivoire. - Bois d'ébène. - Exportation et importation. - Objets d'échange. - Liberté commerciale. - Mouvement de la navigation à l'entrée...........................

Chapitre V. - Situation financière. - Budget de l'État. - Budget local ................................................ 


\section{APPENDICE}

1. Extrait du rapport de $M$. Jules Duval au concours général et national

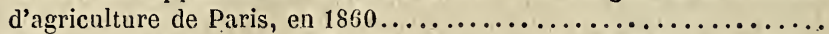

I1. Extrait du rapport présenté à l'Empereur le 4 août 1865 par la Com-

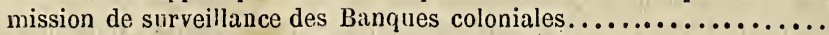

1II. Extrait de l'exposé de la situation de l'Empire................

IV. Service postal de la Côte-d'Or et du Gabon...................

V. Une station au Gabon, en $1864 \ldots \ldots \ldots \ldots \ldots \ldots \ldots \ldots \ldots \ldots \ldots$

\section{LA RÉUNION}

Chapitre premier. - Coup d'œil historique....................

Chapitre II. - La Réunion. - Superficie. - Côtes. - Le piton des neiges. - Le piton de la Fournaise. - Montagnes. - Partie du vent. - Partie sous le vent. - Plaines. - Forets. - Cours d'eau . - Rivières. - Eaux minérales. - Étangs. - Sol volcanique de l'île. - Éruption du GrandBrûlé (1860). - Ports et rades. - Projets de création de ports.........

Chapitre III. - Climat. - Température. - Moyenne barométrique. - Saisons. - Vents. - Cyclones. - Renvoi à la Science populaire (3e année). - Ras de marée. - État hygrométrique. - Moyenne de la quantité de pluie tombée par an. - Marée. - Durée du jour.................

Chaptrnes IV et V. - Division administrative. - Arrondissement du vent et arrondissement sous le vent. - Communes et districts. - Superficie de chaque commune ou district. - Villes, bourgs ou villages. - Gouvernement local. - Gouvernement colonial. - Services de l'ordonnateur. Hôpitaux. - Garde-magasin du matériel et des vivres. - Archives coloniales. - Service de santé. - Trésorerie. - Services des ports. Contrôle colonial. - Direction de l'intérieur. - Services financiers. Douanes. - Contributions. - Poste aux lettres. - Instruction publique. - Police. - Vaccine. - Ponts et chaussées. - Organisation munici-

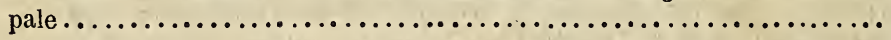

Chapıtre VI. - Population. - Population maritime. - Travailleurs indiens, chinois, etc. - Historique de l'immigration. - Intervention de la Société

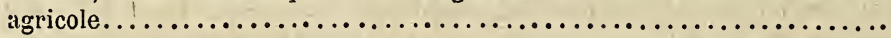

Chapitre VI bis. - Instruction publique. - Direction. - Surveillance. - Établissements d'instruction. - Lycée. - Colléges. - Écoles primaires. Ecoles particulières. - Cours publics et gratuits. - Bibliothèque publique. - Société des sciences et arts. - Presse et écrits périodiques. - Muséum

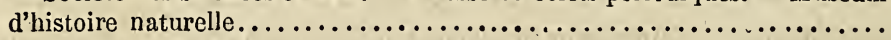

Chapitre VII. - Justice. - Cour impériale. - Tribunaux de première instance. - Justices de paix. - Cours d'assises. - Cour de cassation. Statistique judiciaire. - Ateliers de discipline. - Prison. - Maison de correction. - Etablissements pénitentiaires de la Guyane (condamnés aux

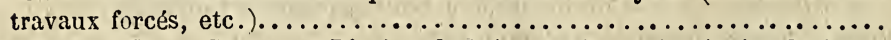

Chaprtre VIII. - Cultes. - Diocèse de Saint-Denis. - Séminaire du SaintEsprit (a Paris). - Mission de Zanzibar. - Mission de Madagascar. - Communautés religieuses. - Bureau de bienfaisance. - Société de Saint-Vincent de Paul. - Société de persévérance et de secours mutuels. - Autres sociétés chrétiennes et charitables. - Hôpitaux, léproserie,

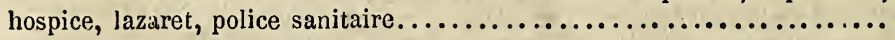

Chaprtre IX. - Finances. - Dépenses de l'État. - Dépenses locales. Recettes locales. - Budget des communes. - Banque de la Réunion. Crédit colonial. - Assurances coloniales. - Grédit colonial............. 
Chapitne X. - Industrie et commerce. - Fabrication du sucre. - Ver à soie. - Construction navale. - Pêche. - Imprimeries. - Commerce. Régime commercial de la Réunion. - Statistique commerciale de 1815 à 1861. - Importations. - Objets importés. - Exportations. - Réexpor-

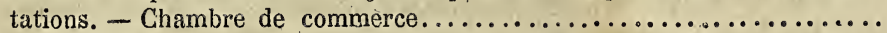

Chapitre XI. - Agriculture. - Sol cultivé. - Nombre d'hectares affectés à chaque culture. - Canne à sucre. - Café. - Coton. - Cacao. - Girofle. - Mûriers. - Épices. - Maĩs. - Manioc. - Patates. - Songes. - Riz. - Légumes secs. - Pommes de terre. - Tabac. - Blé. - Avoine. Embrevades. - Jardinage. - Vanille. - Savanes. - Volcans. - Produit brut et produit net. - Statistique des travailleurs. - Statistique des animaux de trait et bétail. - Capital engagé dans les cultures. - Exportations. - Sucre et sirop. - Café. - Girofle. - Cacao. - Muscades et macis. - Vanille. - Rhum. - Légumes secs, grains, pommes de terre. - Chambre d'agricul ure. - Expositions. - Courses. - Jardin botani-

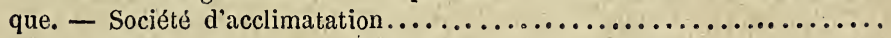

Chapitre XII. - Les produits de la Réunion. - Historique. - Canne à sucre. - Café. - Girofle. - Muscade. - Cacao. - Vanille. - Coton. Céréales. - Racines et tubercules. - Légumes. - Fruits. - Thé. -

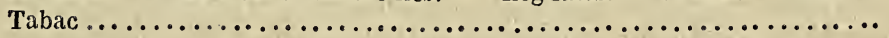

Chapıtre XIII, - Commerce maritime. - Entrées. - Sorties. - Mouvement de la navigation de 1846 à 1861. - Cabotage. - Son importance. - Effectif de la marine locale. - Législation relative à la navigation coloniale. - Recettes de la douane. - Octroi de mer. - Entrepôt de Saint-

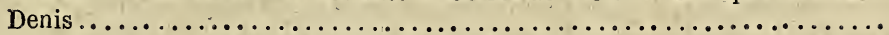

GirapITRe XIV. - Armée. - Effectif de la garnison. - Etat-major. - Génie. - Artillerie de marine. - Infanterie de marine. - Disciplinaires des colonies. - Gendarmerie coloniale. - Milice coloniale. - Station maritime............................................

Chapıtre XV. - Voies de communication. - Itinéraire des routes : partie du vent. - Partie sous le vent. - Points de lintérieur. - Route de ceinture. - Ponts. - Canaux. - Phare et feux de port..............

Chapitre XVI. - Service postal. - Personnel. - Transport des lettres à l'intérieur. - Ligne anglaise (voie de Suez). - Ligne française. - Prix du passage de France à la Réunion. - Taxe des lettres..............

\section{ILE MAYOTTE OU MAHORE}

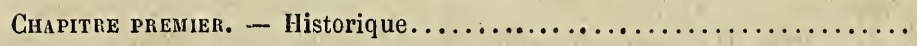

Chaprtre II. - Superficie. - Géologie. - Montagnes. - Ruisseaux. - Récifs. - Ilots voisins. - Baies. - Bois. - Villages. - Saisons. - Température. - Pluies. - Marées. - Courants. - Races. - Arabes. - Sakalaves. - Chiffre de la population.......................

Chapitre III. - Administration. - Cultes. - Instruction publique. - Jus-

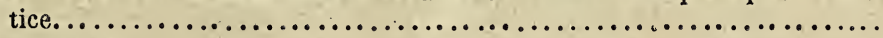

Chapitre IV. - Agriculture. - Productions naturelles. - Constitution de la propriété. - Exploitations de canne à sucre. - Industrie sucrière. Café. - Petite culture. - Mouvement commercial. - Articles d'importation:- Articles d'exportation. - Mouvement maritime. - Régime coin-

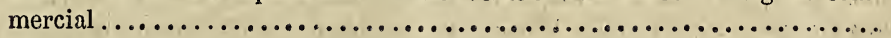

Chapitre V. - Armée. - Effectif. - Marine. - Finances : budget de l'État ; budget local................................. 
Chapitre VI. - Service postal. - Mode de transport. - Taxe des correspondances. - Ligne anglaise. - Ligne française..................

\section{ILE DE NOSSI-BE் OU NOS-BE்}

Chapitre premier. - Coup d'œil historique..................

Chapitre II - Configuration de Nossi-Bé. - Montagnes. - Sol. - Eaux. - Iles environnantes. - Anses. - Baies. - Climat. - Vents. - Pluies. - Marées. - Courants...............................

Chapitne IlI. - Population. - Administration. - Culte. - Instruction publique. - Justice..............................

ChapıTne IV. - Agriculture. - Fertilité du sol. - Répartition du sol entre les cultures suivantes : canne à sucre, café, plantes alimentaires. Savanes. - Forêts. - En friche. - Sucreries. - Fabrication du rhun. - Nombre des travailleurs. - Production en 1862. - Régime commercial. - Navigation. - Mouvement maritime...................

\section{ILE SAINTE-MARIE DE MADAGASCAR}

Chapitre premier. - Historique et éphémérides................

Chapitre II. - Configuration de Sainte-Marie. - Superficie. - Sol. Montagnes. - Port. - Cours d'eau. - Forets. - Température. Pluies. - Vents. - Ras de marée. - Marée...................

Chapitne IJI. - Population. - Villages. - Gouvernement et administration. - Justice. - Culte. - Instruction publique. - Force militaire....

Chaprtr e IV. - Agriculture. - Café, girofle, etc. - Cultures indigènes. Régime commercial. - Objets d'importation. - Objets d'exportation. -

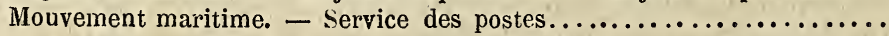

Chapitre V. - Revenus de Sainte-Marie, leur exiguité (10,000 fr.). - Budget de l'État. - Budget local............................

\section{APPENDICE}

1. Extrait du rapport de M. Jules Duval sur les produits de l'ile de la Réunion (concours général et national d'agriculture de Paris, 1860)..

II. Situation de la Banque de la Réunion au 30 juin $1864 \ldots \ldots \ldots \ldots \ldots$.

III. Les ouragans de la mer des Indes, leurs lois, moyens pour les navires d'en conjurer ou d'en atténuer les ravages. (Extrait de la Science

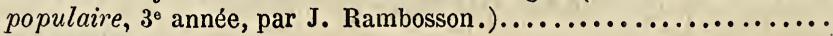
1V. Madagascar.

$1^{\circ}$ Extrait de l'Almanach religieux de la Réunion pour $1860 \ldots$.

$2^{\circ}$ Extrait du Discours de M. Achille Jubinal au Corps législatif,

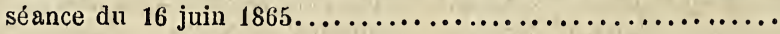

\section{AMÉRIQUE}

\section{ILES SAINT-PIERRE ET MIQUELON}

Ghapitre premier. - Coup d'œil historique.....................

Chapitre II. - Situation. - Saint-Pierre : sol, étangs, côtes, rade et port ; bourg de Saint-Pierre ; îlots voisins. - Miquelon : sol, rivière, étangs, baies; bourg de Miquelon. - Routes. - Canaux. - Quais, etc. - Température. - Climat. - Saisons. - Pluies. - Vents. - Marées. - Aurores boréales. - Phares. - Population............................ 
Chapitre III. - Gouvernement. - Administration. - Forces militaires. Forces maritimes. - Justice. - Tribunaux. - Statistique judiciaire. Culte. - Instruction publique. - Assistance publique. - Budget de l'É. tat. - Budget local...................................

Chapitre IV. - Culture. - Produits naturels. - Industrie : péche et préparation de la morue. - Armements depuis 1853. - Pêche locale. Importations. - Exportations. - Peche de la morue, du hareng, du capelan et de l'encornet. - Primes. - Grèves. - Régime commercial. Mouvement commercial de 1851 à 1862. - Objets d'importation. - Objets d'exportation. - Régime de la navigation. - Statistique. - Service

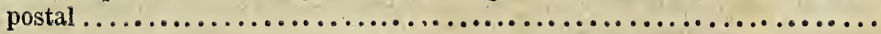

\section{LA MARTINIQUE}

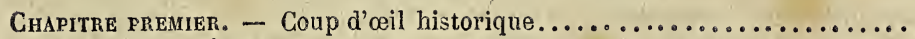

Chapirre II. - Etendue. - Sol. - Montagnes. - Cours d'eau. - Eaux minérales. - Forêts. - Côtes. - Rades et baies. - Routes. - Phares. -

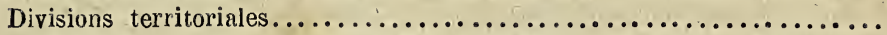

Chapitre III. - Température. - Hygrométrie. - Pluies. - Saisons. Vents. - Marées. - Ras de marée. - Ouragans. - Tremblement de terre. - Population. - Blancs et noirs. - Population maritime. - Immigration indienne. - Immigration africaine. - Immigration chinoise. .

Chapitre IV. - Gouvernement. - Administration. - Services de l'ordonnateur. - Services des ports. - Service de santé. - Trésor. - Direction de l'intérieur. - Enregistrement. - Hypothèques. - Service des douanes. - Contributions, etc. - Organisation municipale. - Effectif militaire. - Station locale. - Justice. - Statistique judiciaire... ....

Chapitre V. - Finances. - Budget de l'État. - Budget local. - Banque. - Crédit foncier colonial. .............................

Chapitre VI. - Culte. - Grand séminaire. - Clergé. - Comınunautés religieuses. - Bureaux de clıarité. - Ouvroir. - Hôpitaux militaires. Hospices civils. - Maison de santé. - Instruction publique. - Petit séminaire. - Institutions de Sainte-Marie. - Institut des sœurs de SaintJoseph de Cluny. - Écoles primaires. - Écoles particulières et laĩques. -

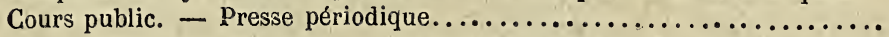

Chapitre VII. - Agriculture. - Situation agricole. - Genres de cul. ture. - Valeur des produits. - Habitations rurales. - Statistique des travailleurs. - Bétail et animaux de trait. - Canne à sucre. - Producduction annuelle. - Café. - Cacao. - Coton. - Tabac. - Épices. Vivres. - Bois. - Jardin botanique. - Chambre d'agriculture......... Chapitre VIII. - Industrie. - Sucres. - Rhums. - Tafias. - Poteries. Chaufourneries. - Peche. - Commerce. - Exportations. - Importa. tions. - Marchandises importées. - Marchandisés exportées. -- Entrepôts. - Navigation. - Douanes. - Communications ; durée du trajet entre la France et la colonie..............................

\section{LA GUADELOUPE ET DÉPENDANCES}

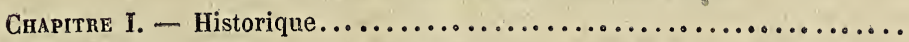
Ghapitre II. - Étendue. - Configuration. - Cours d'eau. - Montagnes. - Eaux thermales. - Sol. - Forêts. - Ports. - Caps. - Phares, feux. - Villes. - Division territoriale. - Dépendances : Marie-Galante, les

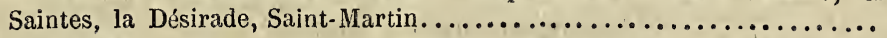

Chapitre III. - Températưre. - Climat. - Hygrométrie. - Pluies. - Saisons. - Vents. - Marées. - Tremblements de terre. - Population. - 
Statistique. - Population maritime. - Immigrants...............

Chapitre IV. - Gouvernement. - Administration. - Services divers. Contrôle colonial. - Effectif militaire. - Station locale. - Justice. Culte. - Assistance publique. - Instruction publique..............

Chapitre V. - Finances. - Budget de l'État. - Budget local. - Banque de la Guadeloupe. - Crédit foncior colonial....................

Chapitre VI. - Agriculture. - Nombre d'hectares affectés à chaque culture. - Sucre, café, cacao, etc. - Animaux de trait. - Bétail. - Statistique de la canne à sucre. - Caféier. - Coton. - Vivres. - Chambre

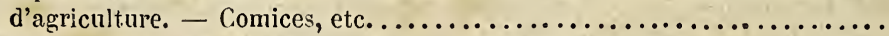

Chapitre VII. - Industrie. - Sucre. - Guildiveries (distilleries). - Liqueurs. - Alcools . - Confiseries. - Vins d'ananas, d'orangers. - Conserves d'ananas. - Tanneries. - Chaufourneries . - Poteries. - Salines. - Pêche. - Marine locale. - Commerce. - Régime commercial. - Importations. - Exportations. - Objets importés. - Objets exportés. Entrepôts. - Mouvement de la navigation. - Douanes. - Service postal et communications. .................................

\section{LA GUYANE}

Chaptrre premier. - Coup d'œil historique.................... Chapitre II. - Etendue. - Sol. - Montagnes. - Marais et savanes. - Forêts. - Cours d'eau. - Lacs. - Routes. - Callaux. - Circonscriptions

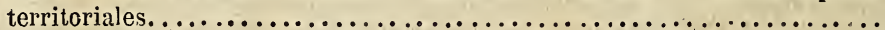

Chapitre III. - Climat. - Température. - Saisons. - Pluies. - Vents. Ouragans, etc. - Population. - Indigènes. - Nègres. - Immigrants indiens. - Transportés. - Pénitenciers...................... Chapitre IV. - Gouvernement. - Administration. - Services divers. Contrôle. - Organisation municipale. - Forces militaires. - Station lo-

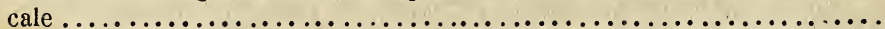

Chapitre V. - Justice. - Tribunaux de paix. - Tribunal de première instance. - Cour impériale. - Cour d'assises. - Statistique judiciaire. Culte. - Assistance publique. - Instruction publique.............

Chapitne VI. - Agriculture. - Hectares cultivés. - Quantités récoltées. - Valeur des produits. - Habitations rurales. - Statistique des travailleurs. - Animaux de trait. - Bétail. - Canne à sucre. - Cafe. Coton. - Rocon. - Gacao. - Girofle. - Vanille. - Tabac. - Vivres. - Fruits. - Pâturages. - Établissements domaniaux. - Comité d'ex-

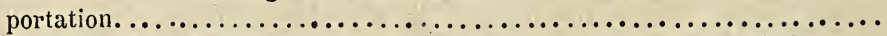

Chapitre VII. - Industrie. - Sucre. - Forets. - Gisements auriferes. Vers à soie. - Briqueteries. - Pêche. - Commerce. - Régime commercial. - Statistique commerciale (1855 à 1863). - Importations. - Exportations. - Objets importés - Objets exportés. - Réexportations. - En-

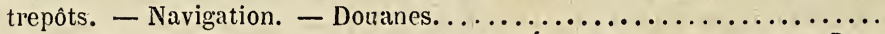

Chapitre VIII. - Finances. - Budget de l'État. - Budget local. - Banque de la Guyane. - Ses opérations. - Service postal et communications.............................................

\section{A SIE}

\section{1. ÉTABLISSEMENTS DE L'INDE}

Chapttre premer. - Coup d'œil historique................... Ghapitre Il. - Pondichéry. - Karikal. - Yanaon. - Mazulipatam. - 
Mahé. - Galicut. - Chandernagor. - Surate. - Loges............

Ghapitre III. - Climat. - Pluies. - Marées. - Ports. - Phares. -

Races. - Population (statistique). - Émigration..................

Chapitre IV. - Gouvernement colonial. - Administration. - Administration de la marine. - Contrôle. - Service des ports. - Administration

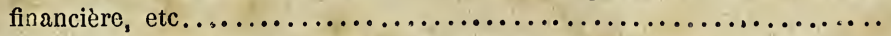

Chapıtre V. - Finances. - Budget de l'État. - Budget local. - Monnaies

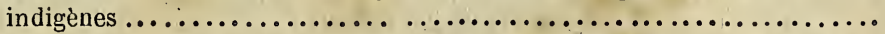

Chapitre VI. - Justice. - Cultes. - Instruction publique. - Assistance

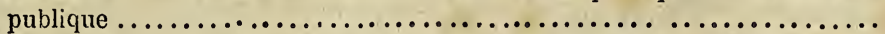

Chapıtre VII. - Agriculture. - Le sol réparti en cing classes. - Riz, canne à sucre, tabac, etc. - Valeur des produits. - Bétail..........

Chapitre VIII. - Industrie. - Filatures. - Tissage. - Teinture. - Sel. - Regime commercial. - Importations. - Exportations. - Articles d'importation. - Articles d'exportation........................

Chapitre IX. - Mouvement de la navigation. - Service postal..........

\section{COCHINCHINE}

Chapitre premier. - Coup d'œil historique.....................

Chaprtne II. - Superficie. - Cours d'eau. - Sol. - Forêts. - Les trois provinces de la Cochinchine française. - Saigon, Mitho, etc. - lle de

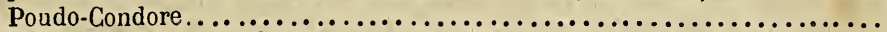

Chapıtre III. - Climat. - Température. - Pluies. - Vents. - Marées. -

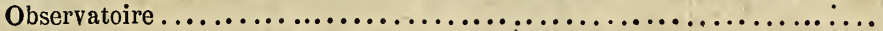

Chapitre IV. - Gouvernement. - Administration indigène. - Personnel européen et indigène. - Forces militaires. - Station locale. - Population indigène. - Mceurs des Annamites. - Chinois. - Européens. .........

Chapitre V. - Justice. - Décret organique du 25 juillet 1864. - Tribunaux indjgènes. - Tribunaux français. - Statistique judiciaire (1864). Culte indigène. - Culte catholique. - Assistance publique. - Hôpitaux.

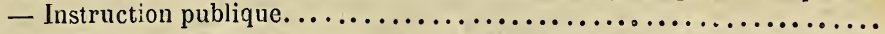

Chapitre VI. - Régime financier. - Budget local. - Recettes de 1860 à 1865. - Succursale du Comptoir d'escompte de Paris. - Monts-de-piété. - Impôts. - Monnaies, poids et mesures annamites...............

Cinapitre VII. - Agriculture. - Riz, coton, canne à sucre, tabac, maïs, etc. - Ventes et concessions de terre. - Industrie. - Pêche. - Vers à soie. - Bois. - Sel. - Carriere, etc. - Commerce. - Importations. Exportations. - Navigation. - Cabotage, etc....................

Chaptrne VIII. - Communication. - Service postal................

\section{OCE A NIE}

\section{1. ÉTABLISSEMENTS dE L'OCÉanie}

Chapitre premier. -- Historique..........................

Chapitre II. - Topographie. - Etendue du protectorat. - Iles de la Société : île Taüti ; îlots Trtiaroa ; îlot Meetia ; île Moorea. - Iles Basses ou Tuonıatu. - lles Tubuai. - Iles Marquises. - Météorologie.......... Cha Pitre HI. - Population. - Origine. - Mœurs. - Statistique. - Im-

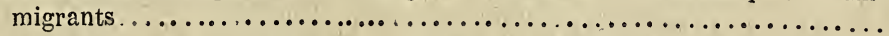

Chapitre IV. - Gouvernement. - Administration. - Forces militaires. - 
Forces maritimes. - Justice. - Cultes. - Assistance publique. - Instruction publique. - Finances............................

Chapitre V. - Agriculture. - Café. - Coton, canne à sucre, orangers. Essences diverses. - Bétail. - Poissons. - Huîtres. - Jardin botanique. - Industrie. - Charpenterie . - Briqueterie. - Régime commercial. Importations. - Exportations . - Objets d'exportation. - Navigation coloniale. - Mouvement de la navigation. - Service postal...........

\section{NOUVELLE-CALÉDONIE}

Chapitre premier. - Historique............................. Ghapitre II. - Glimat. - Température. - Saisons. - Vents. - Ouragans.

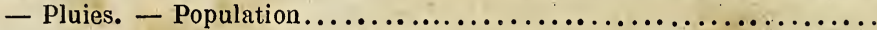

Chapitre III. - Étendıe. - Montagnes. - Sol. - Cours d'eau. - Caps. Côtes, forts, rades, baies. - Iles dépendant de la Nouvelle-Calédonie :

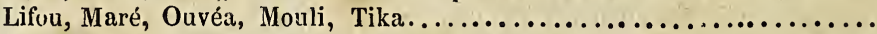

Chapitre IV. - Gouvernement. - Administration. - Personnel. - Forces militaires. - Services de santé..........................

Chapitre V. - Justice. - Cultes. - Instruction publique. - Finançes.... Chapıtre VI. - Agriculture. - Igname. - Patate douce. - Taro. - Canne à sucre. - Banane. - Coco. - Tabac. - Café. - Céréales. - Oléagineuses. - Bestiaux. - Concessions. - Marchés. - Ferme.modèle. Société agricole de Yaté. - Tères domaniales. - Impôl foncier....... Chapitre VIl. - Industrie. - Peche. - Constructions navales. - Mines. - Bois. - Commerce. - Importations et exportations (de 1861 à 1864). - Navigation. - Service postal............................

\section{APPENDICE}

Exposition de $186 \% \ldots \ldots \ldots \ldots \ldots \ldots \ldots \ldots \ldots \ldots \ldots \ldots \ldots \ldots \ldots \ldots \ldots$ Algérie.............................................

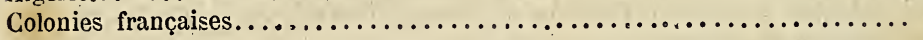

\section{COMPLÉMENT}

Algérie. ........................................ Importations, exportations, mouvement maritime $(1865) \ldots \ldots \ldots \ldots \ldots \ldots$

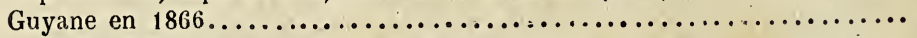
Nouvelle Galédonie en $1867 \ldots \ldots \ldots \ldots \ldots \ldots \ldots \ldots \ldots \ldots \ldots \ldots \ldots \ldots \ldots$

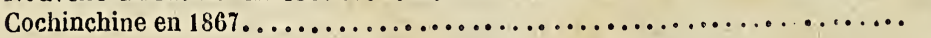





SMITHSONIAN INSTITUTION LIBAARIES

$\cos ^{2+2}$

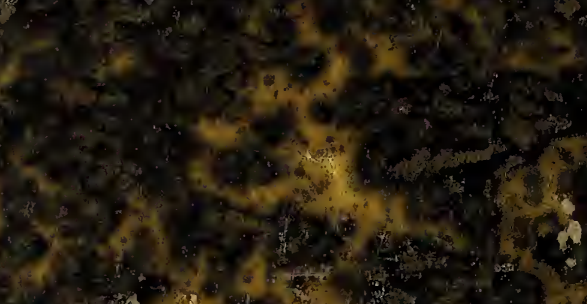

$\frac{5}{4}$

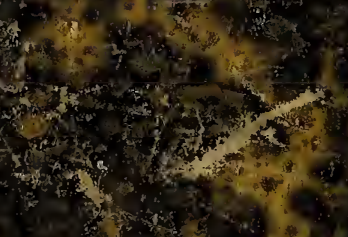

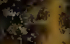
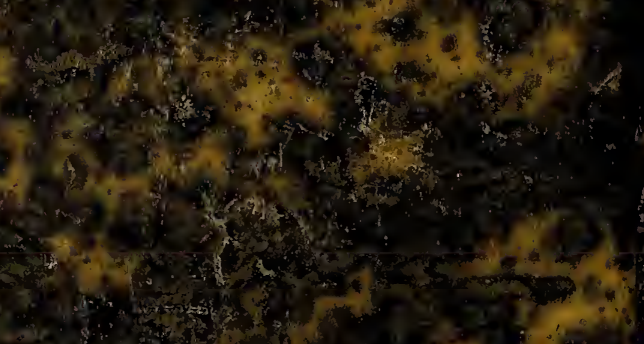

cor.

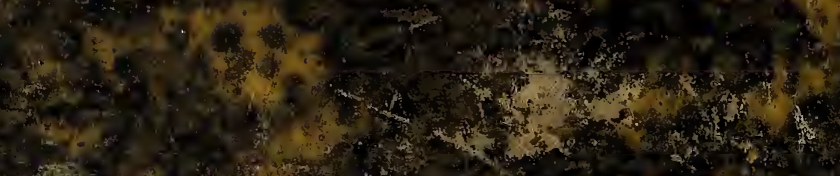

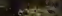

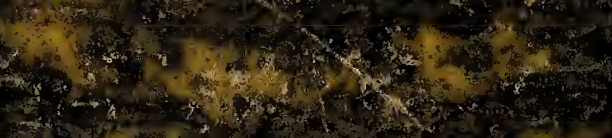

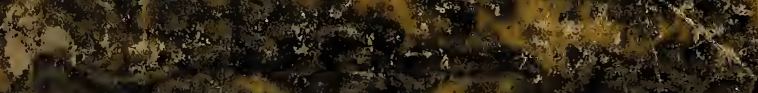

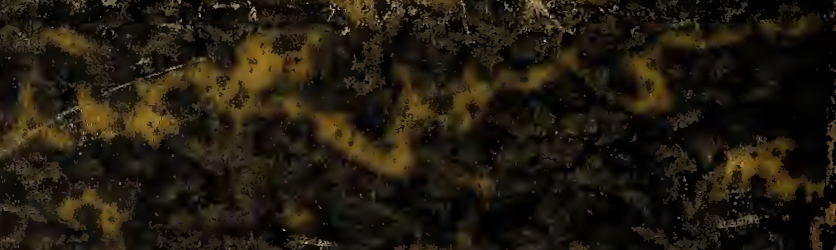

$+48$ 